\title{
Tratamiento térmico y manejo del fuego en sociedades cazadoras-recolectoras de la Meseta Central de Santa Cruz
}

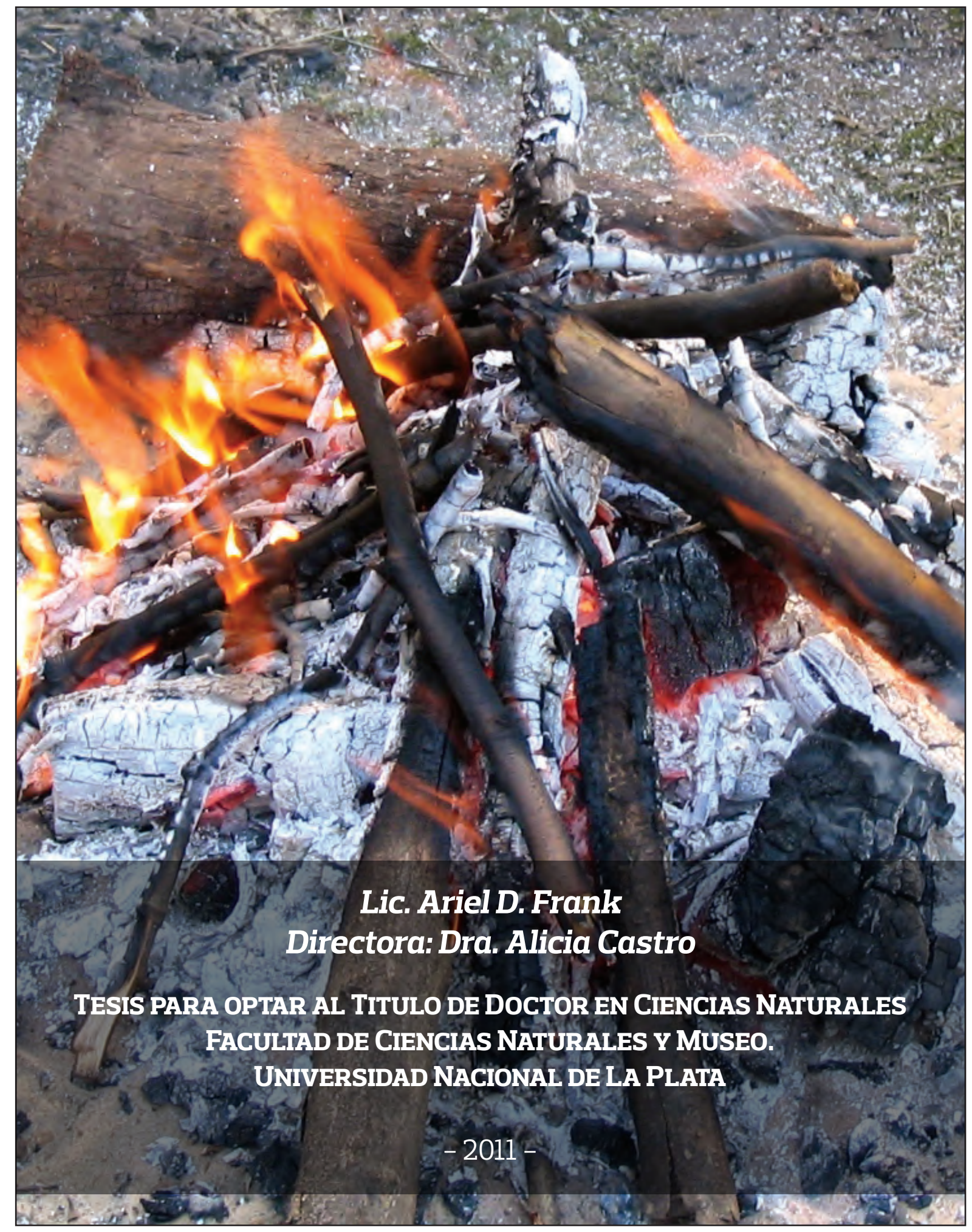


A mis viejos 


\section{AGRADECIMIENTOS}

Esta tesis es fruto de años de trabajo, de investigación y aprendizaje. Para poderla desarrollar y finalizar, he recibido la ayuda y colaboración de muchos seres queridos.

Le agradezco a Alicia Castro, por haber dirigido esta Tesis y por sus siempre oportunos comentarios. A Rafael Paunero, por abrirme las puertas de la arqueología de la Patagonia, dirigirme en las tareas de campo y laboratorio, por su afectuoso apoyo y constante enseñanza, entre muchas otras cosas.

A Fabiana Skarbun y Manuel Cueto, con quienes trabajo y aprendo constantemente. A Natalia Lunazzi quien me ayudó con el relevamiento etnohistórico. A mis compañeros de Laboratorio, pasados y presentes: Matías Paunero, Martín del Giorgio, Gabriela Rosales, Gonzalo Zapata, Darío Martínez, Diana Ramos, Juan Pifano, Gabriela Ghidini, con quienes compartimos experiencias y aventuras tanto en el campo como en gabinete. Ramiro López me ha ayudado con el reconocimiento de las materias primas líticas y Eugenia de Porras con la descripción paleoambiental de La María.

A Perla Imbellone, Julia Solari, Violeta Sbatella, Eliana Aguirre y Julieta Lynch, queridas colegas de la cátedra de Micromorfología de Suelos. A Florencia Gordón y Pablo Ambrústolo, compañeros de presentaciones, inquietudes y urgencias.

Quisiera agradecer a CONICET ya que gracias a su financiamiento he podido llevar a cabo esta Tesis. La FCNyM ha sido, no sólo el lugar donde desarrollé mis investigaciones, sino también el ámbito donde he interactuado con colegas y amigos quienes me han ayudado profundamente.

A Fernando Behm, Josefina Ortolá y toda su familia, por darnos su afecto y ofrecer todo su apoyo durante las campañas en la Meseta. La municipalidad y la comunidad de Puerto San Julián han estado siempre presentes, brindándonos su colaboración.

A mi familia, siempre pendiente, siempre dispuesta a ayudar, siempre afectuosa. A Vale por estar ahí. A Mari, por la confianza y la tapa! A Anne, por su amor, su paciencia y su comprensión. A mis padres, porque siempre confiaron en mí. 


\section{RESUMEN}

Esta tesis doctoral es un aporte al estudio de las sociedades cazadoras-recolectoras que ocuparon la Meseta Central de Santa Cruz. El objetivo general se orienta al estudio del manejo del fuego por parte de los grupos humanos que habitaron esta región durante el Pleistoceno final y el Holoceno temprano. Buscamos reconocer si los fogones funcionaron como estructuradores del espacio dentro de las cuevas y analizar si el fuego interviene como medio o instrumento dentro de sistemas tecnológicos de procesamiento de recursos, así como establecer conductas inducidas o accidentales a través de la alteración de los objetos.

Para poder abordar la problemática de investigación planteamos los siguientes objetivos específicos: realizar experimentaciones enfocadas en la alteración térmica de materiales líticos y óseos mediante fogones experimentales; estudiar aquellas variables y características que permitan identificar la aplicación del tratamiento térmico en estos; crear patrones experimentales de referencia que puedan ser utilizados para analizar el registro arqueológico y que nos permitan determinar las causas de las termoalteraciones; definir las características de las estructuras de combustión presentes en los componentes arqueológicos estudiados; evaluar la distribución de los conjuntos líticos y óseos de estos componentes analizando su vinculación con las estructuras de combustión y estudiar las características de estos conjuntos a fin de determinar si existieron eventos de tratamiento térmico, así como alteraciones no intencionales y postdepositacionales. Los sitios analizados se ubican en las Localidades Arqueológicas Cerro Tres Tetas y La María y corresponden en su totalidad a sitios reparados.

Los estudios experimentales en artefactos líticos fueron desarrollados con materias primas provenientes del área de estudio. Estos nos han permitido identificar los rasgos propios del tratamiento térmico así como aquellos atributos no específicos, que pueden ser generados por diversos procesos de termoalteración. Además, hemos corroborado la utilidad de este procedimiento en las materias primas de la región. Asimismo, hemos podido generar expectativas acerca de las características esperables de las piezas tratadas, en el marco de la secuencia de reducción.

En tanto, las experimentaciones con elementos óseos, llevadas a cabo con diáfisis de guanaco, nos han indicado que el tratamiento térmico aumenta las posibilidades de fractura, por lo que no sería apto para la confección de artefactos. También nos posibilitó la identificación de las características que toman los huesos al ser termoalterados en contextos subsuperficiales.

En relación al estudio de los contextos arqueológicos, los resultados indican una clara aplicación del tratamiento térmico en artefactos líticos durante el Pleistoceno final. Este se aplicaría en el marco de la formatización final de artefactos bifaciales, confeccionados con materias primas locales. En contraste, hay escasas evidencias de tratamiento térmico en los componentes del 
Holoceno temprano, probablemente por el carácter eventual de las ocupaciones. Por su parte, hemos podido descartar la hipótesis de aplicación de este mismo procedimiento en la producción de artefactos óseos e identificar otras formas de termoalteración de estos elementos, postdepositacionales y, probablemente también durante la cocción de alimentos.

La distribución de los restos arqueológicos, por su parte nos muestra, en la mayor parte de los componentes analizados, a los fogones como ejes sobre los que se organizaba el espacio, concentrando la mayor parte de las actividades a su alrededor. La evidencia de espículas de carbón y de restos termoalterados nos indica que en todos los contextos se encendieron fuegos, aún cuando estos no se hayan preservado en el registro arqueológico.

Para las ocupaciones del Pleistoceno final, tanto la distribución de los restos como las características de los fogones son coherentes con ocupaciones de baja intensidad, en las cuales se invierte escasa energía en el acondicionamiento de las estructuras de combustión y no se desarrollan importantes tareas del mantenimiento del espacio; durante el Holoceno temprano parecería que cambia la forma de organización del espacio, por un lado hay contextos en los cuales las actividades no se desarrollan en torno al fogón, mientras que en otros podría haberse realizado un mantenimiento del espacio ocupado. 


\section{ABSTRACT}

This doctoral thesis is a contribution to the study of the hunter-gatherer societies that inhabited the Central Plateau of Santa Cruz. Our aim is to study the way fire was managed among the human groups that lived in this region during the final Pleistocene and the early Holocene. Our goal is to recognize whether or not hearths structured the internal space in caves and to analyze if fire was used as a technology in the production processes of stone and bone artifacts. We also aim at identifying accidental or induced conducts through the recognition of the thermal alteration of archaeological remains.

In order to perform our research, we have defined several goals: to perform experimentations focused on the thermal alteration of lithics and bones using experimental hearths; to study the attributes and characteristics which make possible the identification of heat treatment in these kind of materials; to generate experimental reference patterns useful for the analysis of the archaeological record and the determination of the causes of thermal alterations; to define the characteristics of the hearths identified in our archaeological sites; to examine the distribution of lithic and bone assemblages in the archaeological units taking into consideration their relation with fire structures; to investigate the characteristics of these assemblages searching for heat treatment events as well as unintentional and postdepositional alterations. All the analyzed sites are sheltered spaces located at Cerro Tres Tetas and La María Archaeological Localities.

The experimental studies on lithic artifacts were developed using local raw materials. They have allowed us to identify the specific attributes of heat treatment on these rocks, as well as unspecific features which can be produced by several thermal alteration processes. We have also corroborated the usefulness of this procedure in local raw materials. Besides, we were able to generate expectations about the characteristics which should be present in heat treated remains regarding reduction sequences.

Regarding the experimentations with bones, they were performed with guanaco diaphysis. Results show that heat treatment increases fracture probabilities, which hints at the inefficiency of this technique for bone artifact production. Experimentation had also made possible to identify the characteristics of the thermal alteration of bones in subsurficial contexts.

As for the research of archaeological sites, results show clear evidence of the use of heat treatment in lithic artifacts during final Pleistocene, mainly during the final trimming of bifacial artifacts made on local raw materials. There is scarse evidence for the use of this technique during the early Holocene, probably due to the short time of the occupations.

He were also able to reject the hypothesis of the use of this procedure during the production of bone artifacts and to record different ways the bones were burnt, specially postdepositional events but also cooking episodes. 
The distribution of the archaeological remains shows us, in most of the analyzed units, that hearths were the axis along which space was organized, gathering most of the activities around them. The evidence of loose charcoal remains and of thermally altered materials indicates that in every unit at least a fire was lit, even if hearths were not preserved in the archaeological record. For final Pleistocene occupations, both the distribution of remains and the characteristics of hearths are coherent with low intensity occupations, in which scarse energy is invested in the building of combustion structures and where none or few space maintenance tasks are performed. On the other hand, during the early Holocene, it seems that the organization of internal space changed: there are contexts in which the activities where not performed around the hearth, while other present evidence that some maintenance of the occupied space may have been implemented. 


\section{ÍNDICE}

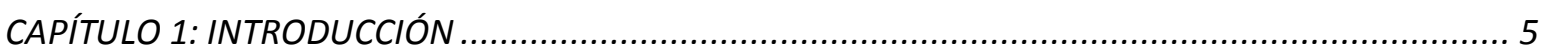

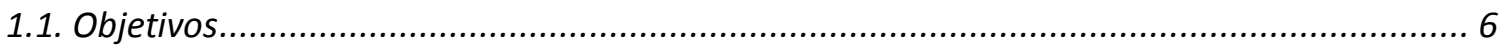

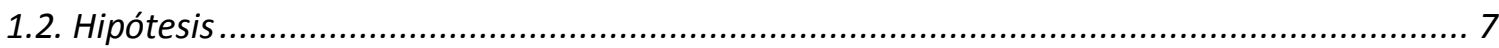

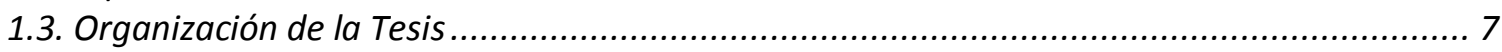

CAPITULO 2: MARCO TEÓRICO - METODOLÓGICO.................................................................... 9

2.1. El poblamiento de la Patagonia durante el Pleistoceno final y el Holoceno temprano .............. 9

2.2. El manejo del fuego ....................................................................................................... 10

2.2.1. Factores que afectan las características de las estructuras de combustión................... 11

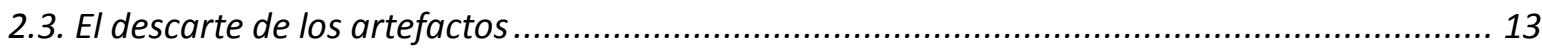

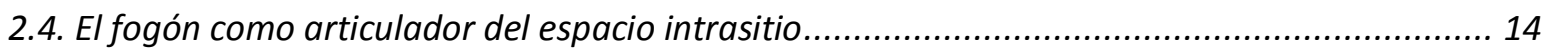

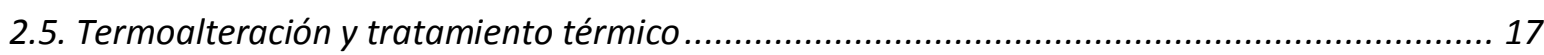

2.6. Aspectos de la tecnología lítica de una sociedad: La secuencia de reducción .......................... 19

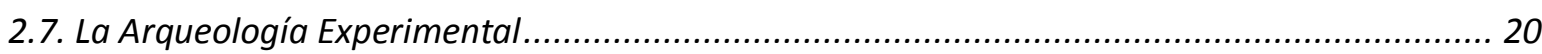

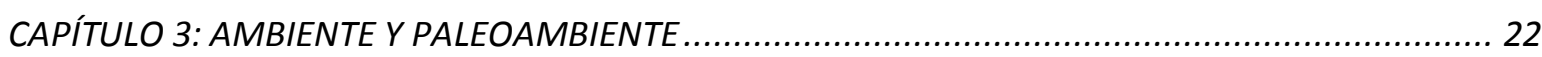

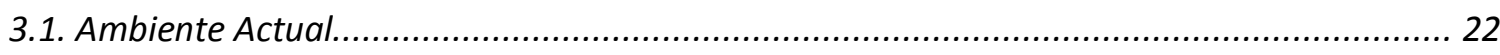

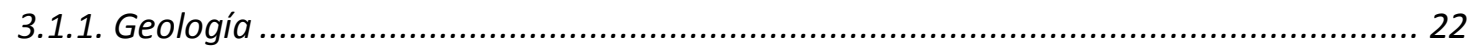

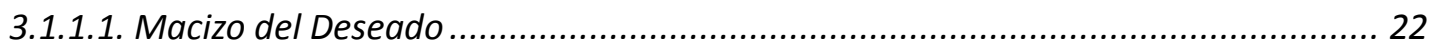

3.1.1.1.1. Localidades Arqueológicas La María y Cerro Tres Tetas ................................. 24

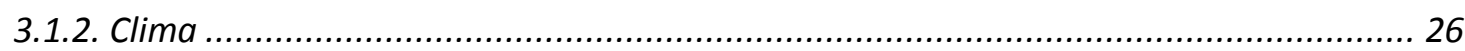

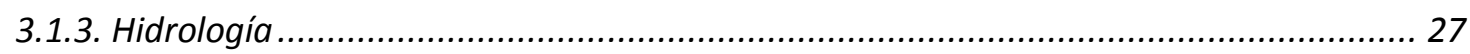

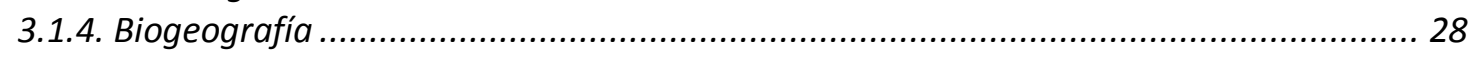

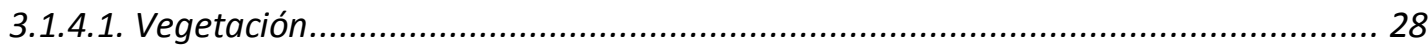

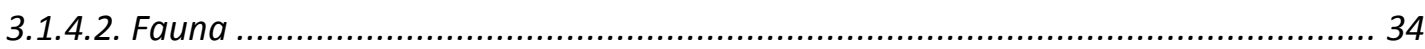

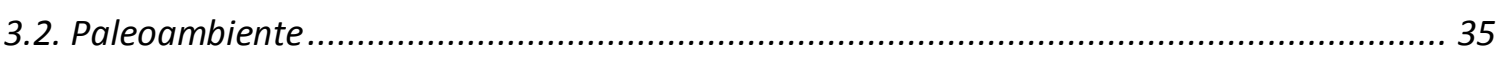

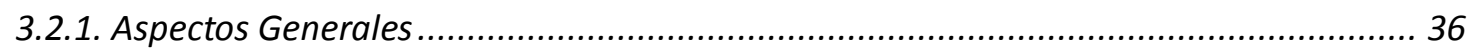

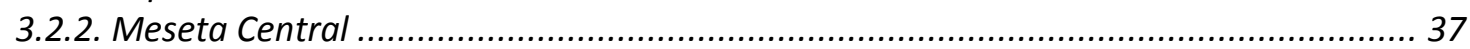

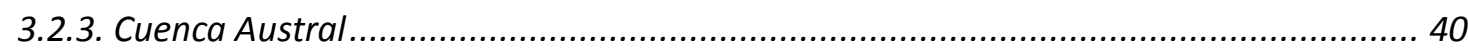

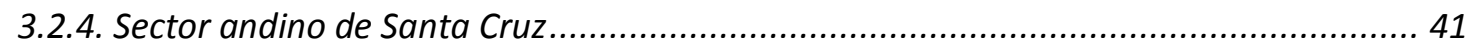

CAPÍTULO 4: EL MANEJO DEL FUEGO EN LA PATAGONIA SEGÚN LAS FUENTES ETNOHISTORICAS. 44

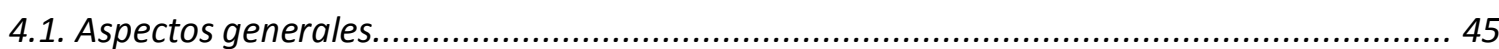

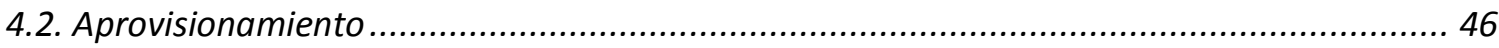

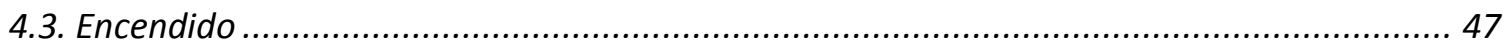

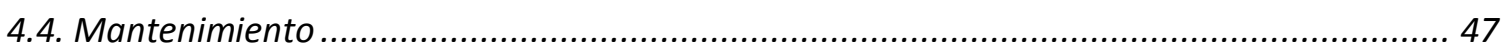

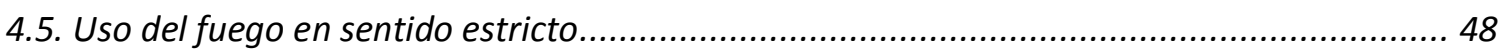

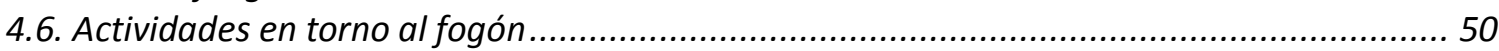

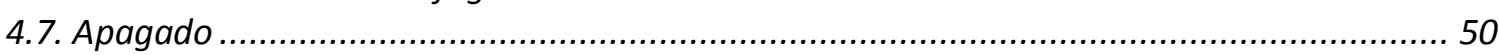

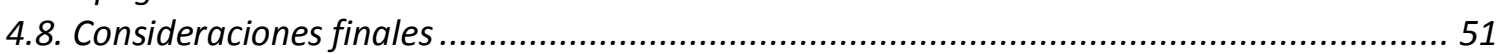

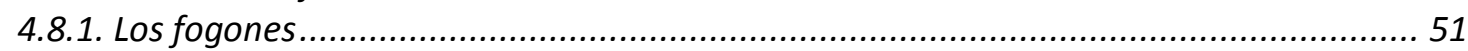

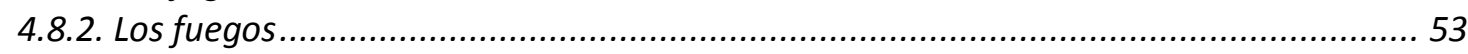

CAPÍTULO 5: CARACTERIZACIÓN DE LOS SITIOS ARQUEOLÓGICOS EN ESTUDIO ............................ 54

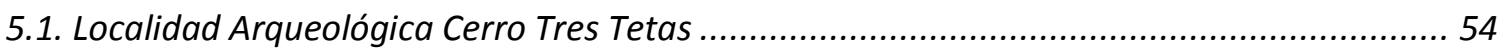

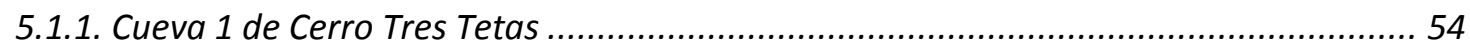

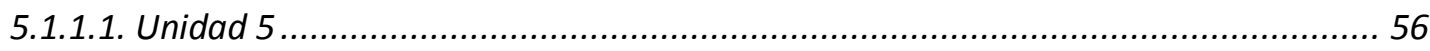

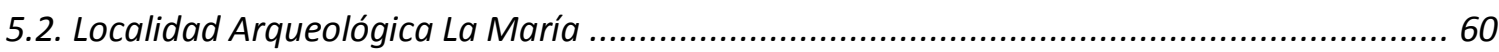

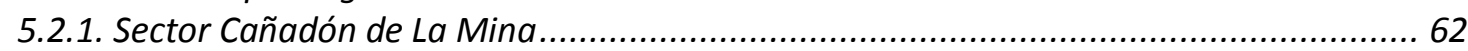

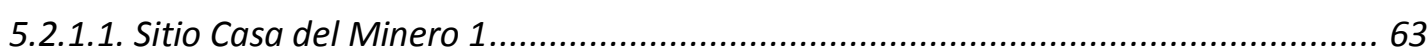

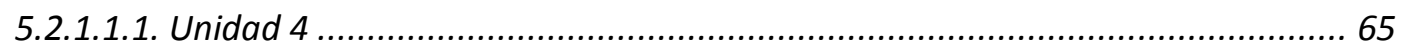




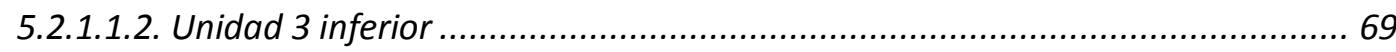

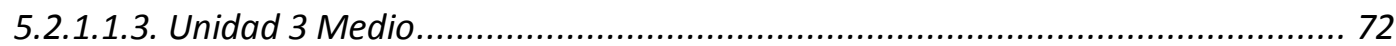

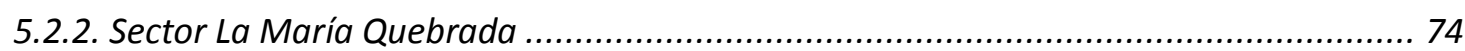

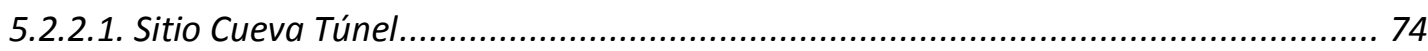

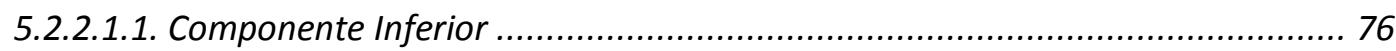

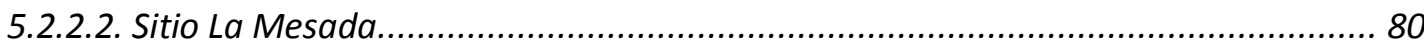

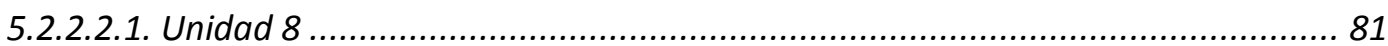

5.2.3. Sector Cañadón de la Cueva de La Ventana ..................................................... 83

5.2.3.1. Sitio Cueva de La Ventana ............................................................ 83

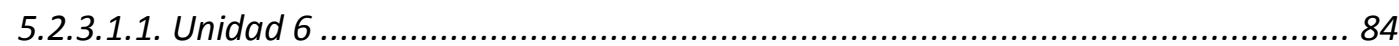

CAPÍTULO 6: EL TRATAMIENTO TÉRMICO DE ARTEFACTOS LÍTICOS: CARACTERÍSTICAS Y

ANTECEDENTES EN LA INVESTIGACIÓN .................................................................. 86

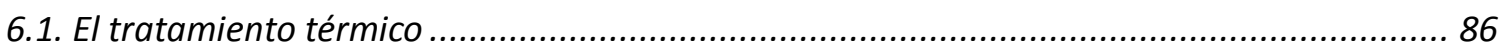

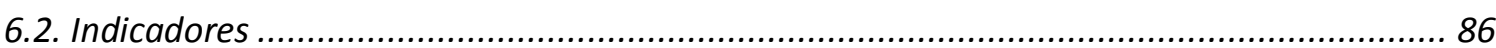

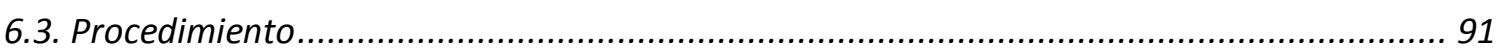

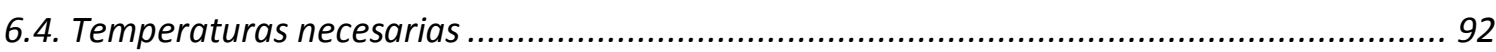

6.5. El tratamiento térmico en el marco de la secuencia de producción de artefactos líticos ..... 93

6.6. Alteración térmica e interacción con micropulidos..................................................... 94

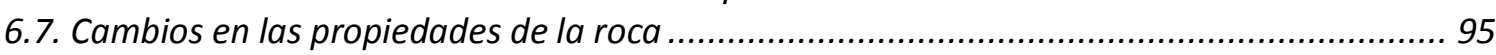

6.8. Antecedentes experimentales.................................................................. 97

6.8.1. Las investigaciones experimentales sobre tratamiento térmico en Argentina ........... 101

6.9. Antecedentes arqueológicos.......................................................................... 102

6.9.1. El tratamiento térmico en sitios arqueológicos de la Patagonia ............................. 104 CAPITULO 7: LA ALTERACIÓN TÉRMICA DE ELEMENTOS OSEOS: CARACTERÍSTICAS Y ANTECEDENTES EN LA INVESTIGACIÓN .................................................................. 106

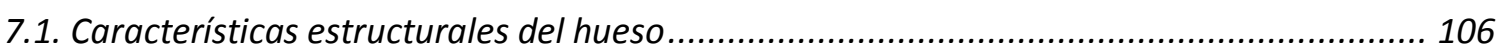

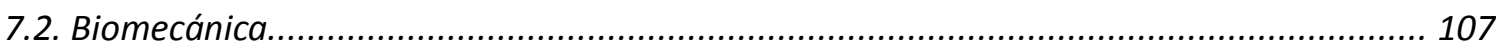

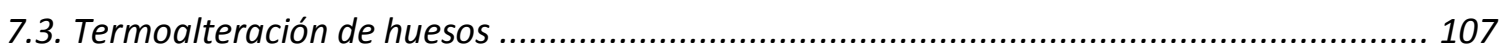

7.4. Formas de contacto del hueso con el fuego ............................................................. 112

CAPITULO 8: EXPERIMENTACIONES EN TRATAMIENTO TERMICO DE ARTEFACTOS LITICOS ........ 115

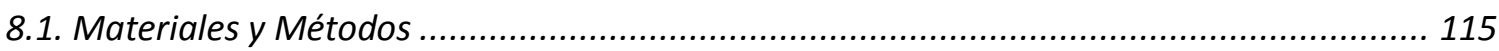

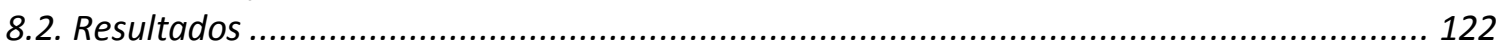

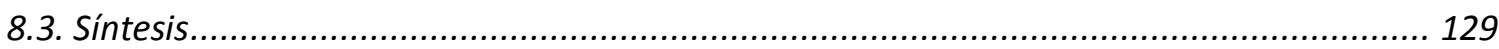

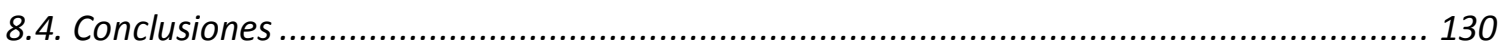

8.4.1. El uso de los fogones experimentales......................................................... 130

8.4.2. Indicadores macroscópicos de tratamiento térmico......................................... 131

8.4.3. Estadio de reducción ................................................................................ 132

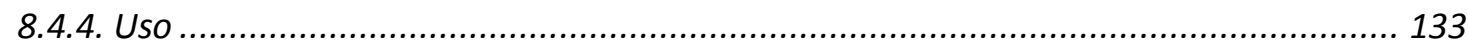

8.4.5. El daño térmico ....................................................................................... 134

CAPITULO 9: EXPERIMENTACIONES EN TRATAMIENTO TÉRMICO DE ARTEFACTOS ÓSEOS .......... 136

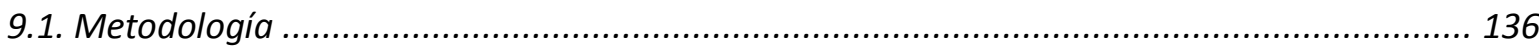

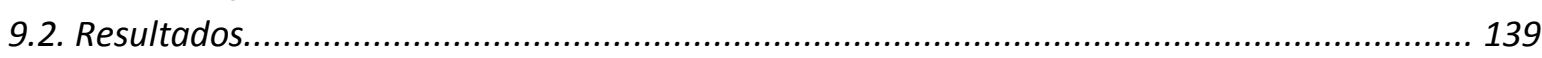

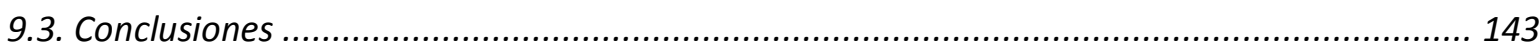

CAPITULO 10: ANALISIS DE LOS CONJUNTOS ARQUEOLÓGICOS ........................................... 146

10.1. Escala espacial y temporal de análisis ........................................................... 146

10.2. Metodología ........................................................................................ 146

10.2.1. El estudio de los fogones ....................................................................... 146

10.2.2. Análisis de los conjuntos arqueológicos .................................................. 147

10.2.2.1. Estudio de los restos líticos............................................................. 147

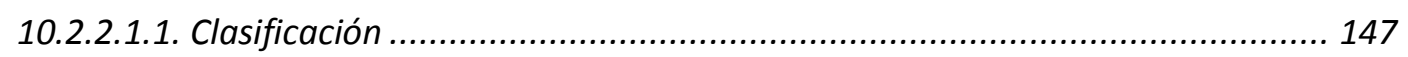




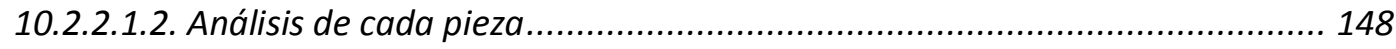

10.2.2.1.3. Análisis de distribución espacial intrasitio .............................................. 152

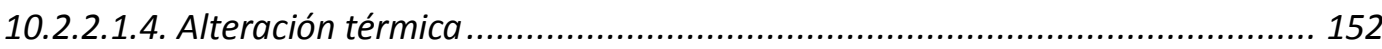

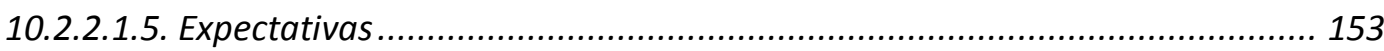

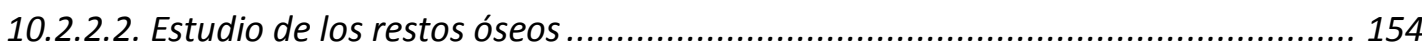

10.2.2.2.1. Análisis de distribución espacial intrasitio ............................................... 155

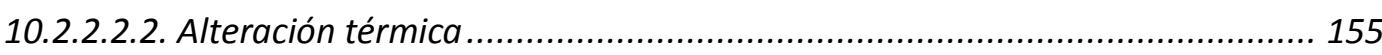

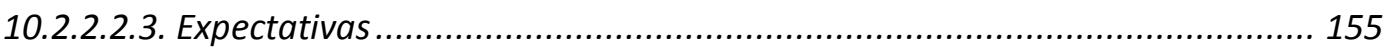

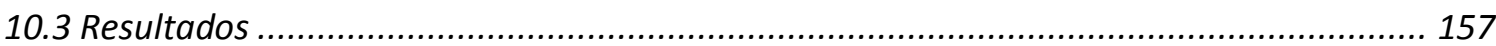

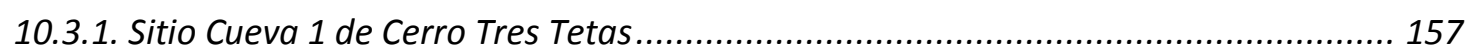

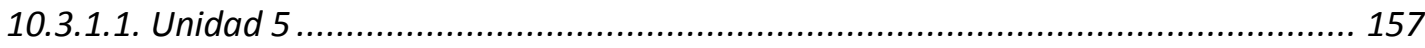

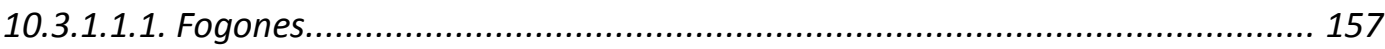

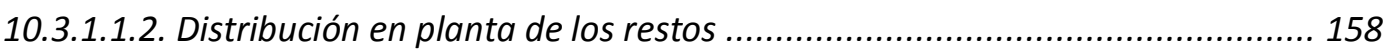

10.3.1.1.3. Material Lítico alterado térmicamente ..................................................... 160

10.3.1.1.4. Material óseo alterado térmicamente ...................................................... 166

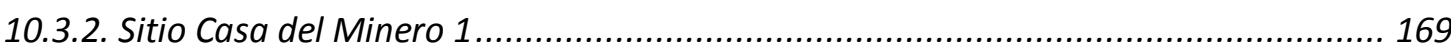

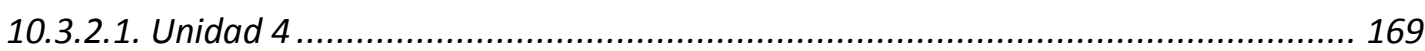

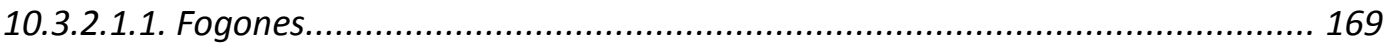

10.3.2.1.2. Distribución en planta de los restos ...................................................... 170

10.3.2.1.3. Material Lítico alterado térmicamente .................................................... 173

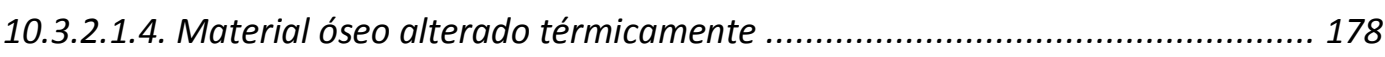

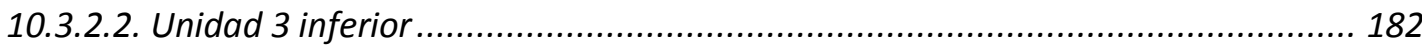

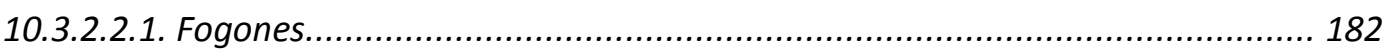

10.3.2.2.2. Distribución en planta de los restos ....................................................... 182

10.3.2.2.3. Material Lítico alterado térmicamente .................................................. 185

10.3.2.2.4. Material óseo alterado térmicamente .................................................... 189

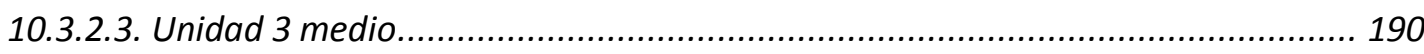

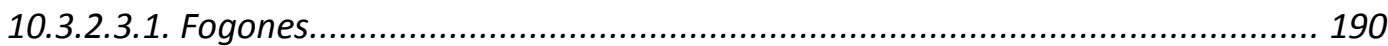

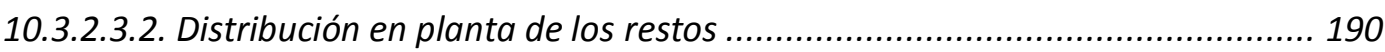

10.3.2.3.3. Material Lítico alterado térmicamente................................................. 193

10.3.2.3.4. Material óseo alterado térmicamente .................................................... 195

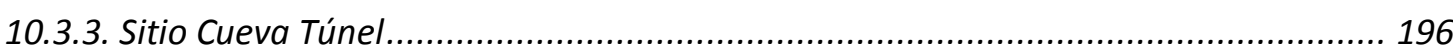

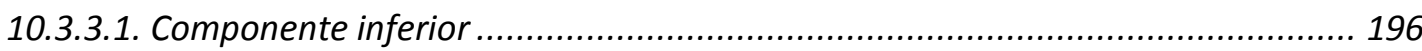

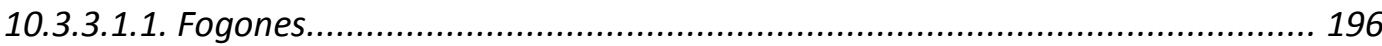

10.3.3.1.2. Distribución en planta de los restos ......................................................... 196

10.3.3.1.3. Material Lítico alterado térmicamente .................................................. 201

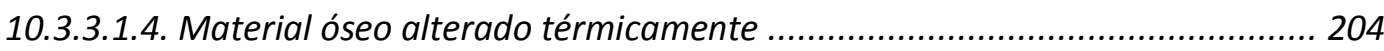

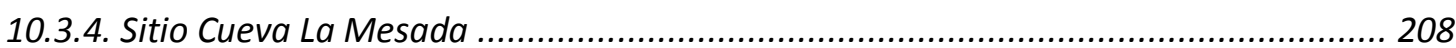

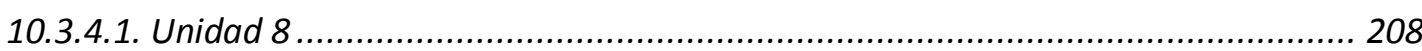

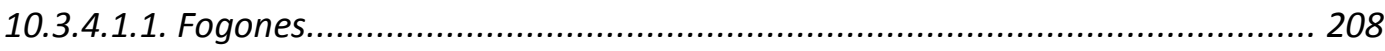

10.3.4.1.2. Distribución en planta de los restos ......................................................... 208

10.3.4.1.3. Material Lítico alterado térmicamente .................................................... 209

10.3.4.1.4. Material óseo alterado térmicamente ..................................................... 212

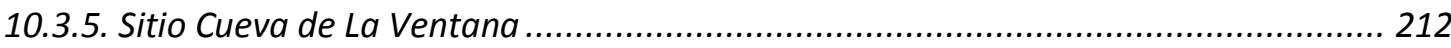

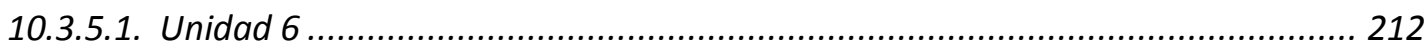

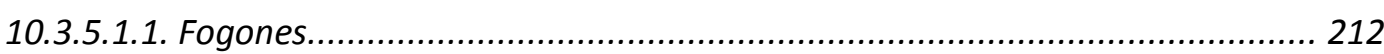

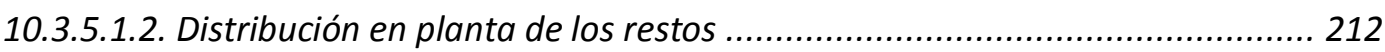


10.3.5.1.3. Material Lítico alterado térmicamente .................................................... 214

10.3.5.1.4. Material óseo alterado térmicamente .................................................. 217

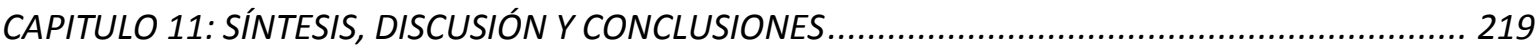

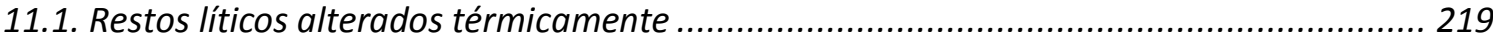

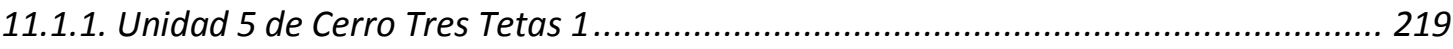

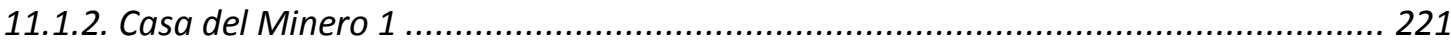

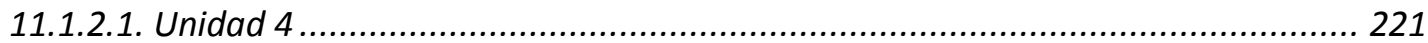

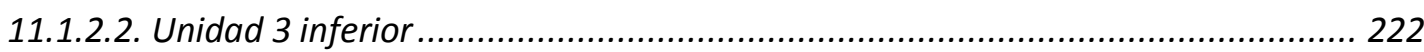

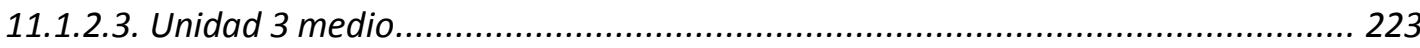

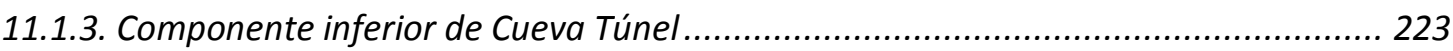

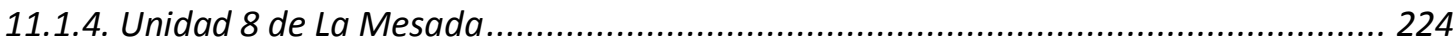

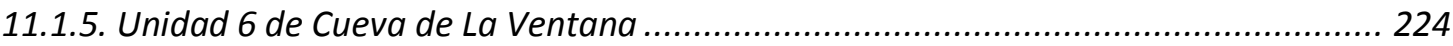

11.1.6. Tratamiento y daño térmico en los artefactos líticos de la Meseta Central............... 224

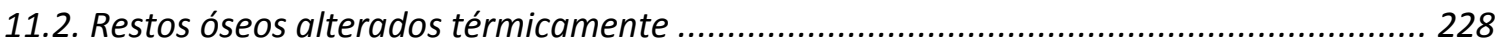

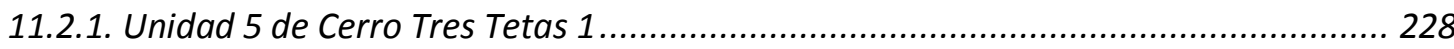

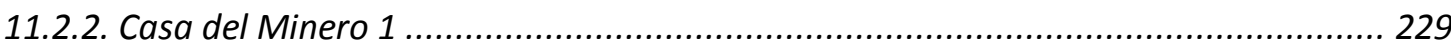

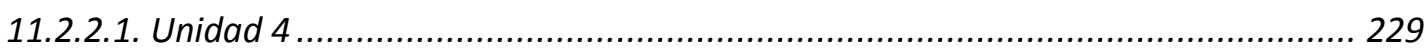

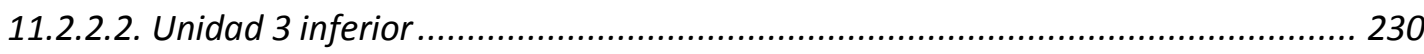

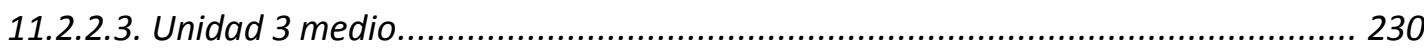

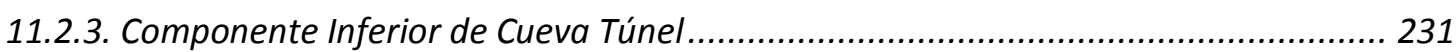

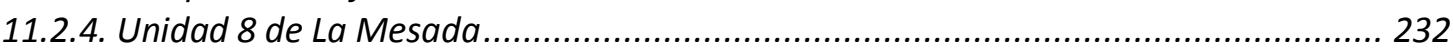

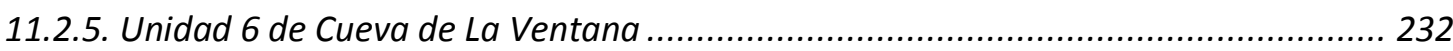

11.2.6. Alternativas para la alteración térmica de los restos óseos ................................... 232

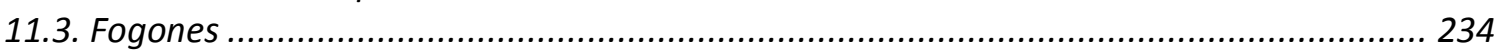

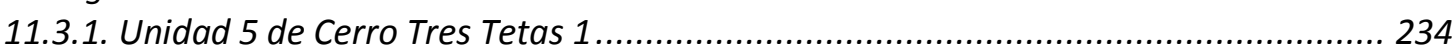

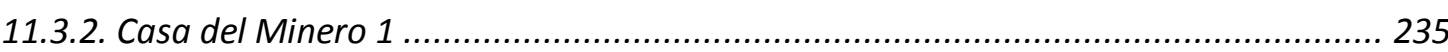

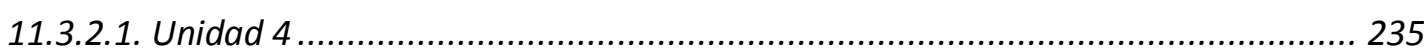

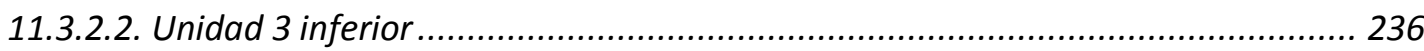

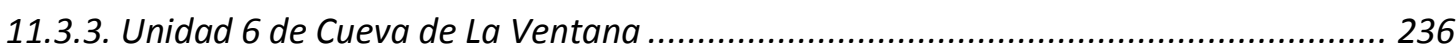

11.3.4. Características de las estructuras de combustión................................................. 236

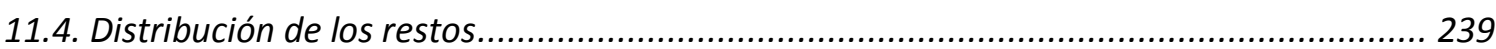

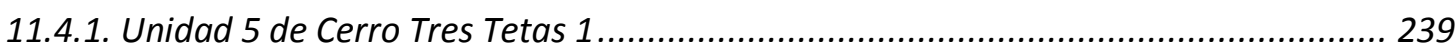

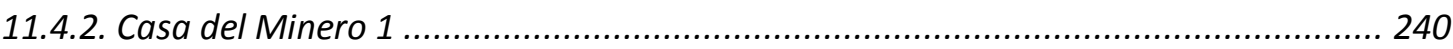

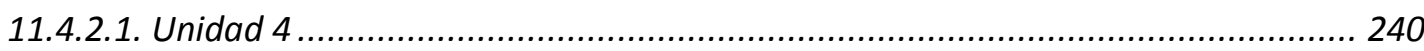

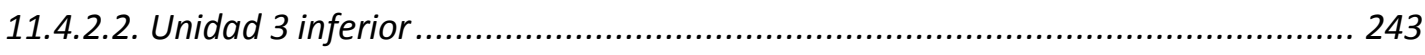

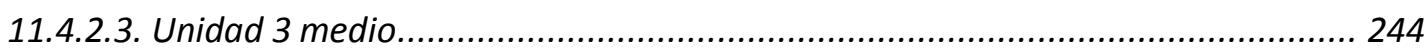

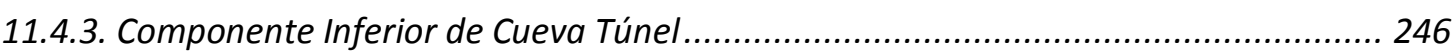

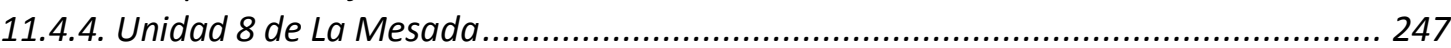

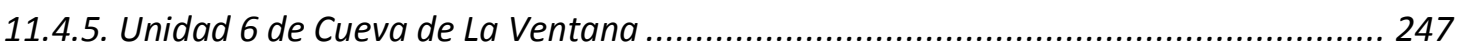

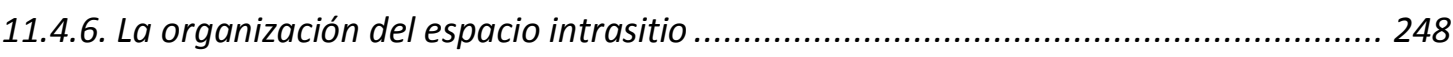

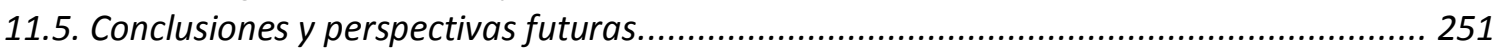

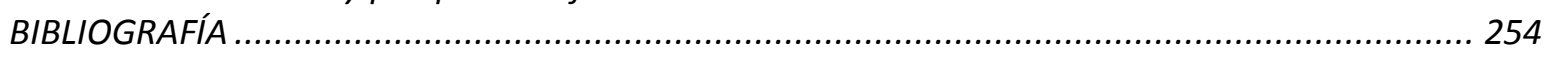

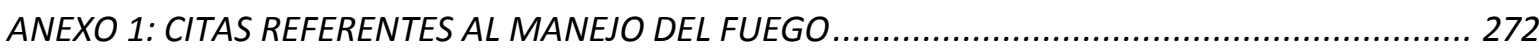

ANEXO 2: BASE DE DATOS DE PIEZAS LÍTICAS TRATADAS TÉRMICAMENTE DURANTE LAS

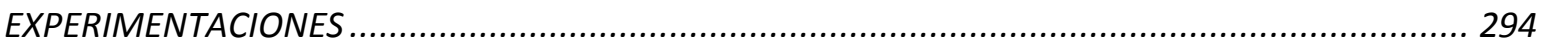




\section{CAPÍTULO 1: INTRODUCCIÓN}

En la presente Tesis buscamos analizar aspectos vinculados al uso del fuego por parte de las sociedades cazadoras-recolectoras que habitaron la Meseta Central de Santa Cruz durante el Pleistoceno final y el Holoceno temprano.

El fuego es $y$ ha sido una herramienta fundamental en la vida de las sociedades cazadoras recolectoras. Constituye una de las primeras adopciones humanas y ha tenido un fuerte valor adaptativo puesto que brinda calefacción e iluminación y permite la cocción de alimentos. Ha posibilitado la colonización de ambientes hostiles y constituido una forma de protección ante depredadores. Asimismo, ha sido utilizado como herramienta en el procesamiento de recursos.

El manejo del fuego, entendido como el conjunto de actividades relacionadas con la apropiación de los insumos, el encendido, el mantenimiento, el uso y el apagado del fuego, ha sido poco explorado en la arqueología patagónica a pesar de que es común hallar estructuras de combustión en los sitios de esta región.

Desde este punto de vista, nuestro enfoque pretende aportar al conocimiento del uso del fuego, entendido no solo como aquellas actividades en las cuales se aprovechan éste o sus derivados carbón, cenizas, humo, brasas-, sino también como aquellas que se realizan en su entorno, ya que concebimos al fogón como un elemento fundamental en la organización del espacio en las sociedades cazadoras - recolectoras.

Así, el análisis se estructura en dos partes. Por un lado, desarrollamos experimentaciones con material lítico y óseo, buscando evaluar diversas formas de termoalteración, especialmente el tratamiento térmico de estos materiales en el marco de la producción artefactual, y generando colecciones de referencia que nos permitieron investigar las características de los conjuntos arqueológicos. Por el otro, llevamos a cabo el análisis de los sitios arqueológicos, donde nos focalizamos en la evaluación de las características de los fogones, la distribución de los restos y las evidencias de termoalteración en ellos. Los conjuntos líticos y zooarqueológicos analizados corresponden a sitios ubicados en las localidades arqueológicas Cerro Tres Tetas y La María. Las evidencias registradas en algunos de estos sitios, para el contexto temporal considerado en esta Tesis presentan información inicial que nos permite generar hipótesis acerca de la importancia del fuego en la conformación de los conjuntos arqueológicos: presencia de estructuras de combustión, artefactos con atributos de alteración térmica y distribución particular de los restos arqueológicos recuperados. 
De esta manera, el objetivo es evaluar cómo el fuego actúa en la conformación de los sitios arqueológicos, por un lado, estructurando las actividades en torno a él, y por el otro, alterando los materiales, ya sea como consecuencia de procesos intencionales o accidentales.

El análisis se enmarca dentro de las investigaciones realizadas en la Meseta Central de Santa Cruz por el equipo que dirige el Lic. Rafael S. Paunero ${ }^{1}$. Este proyecto de investigación tiene como fin comprender cómo fueron los procesos de ocupación humana de los distintos ambientes a lo largo del tiempo, cuáles fueron las distintas estrategias de movilidad, subsistencia y uso del espacio implementadas, cómo fueron los patrones de asentamiento, qué expresiones artísticas y simbólicas realizaron estos grupos y cuál fue la organización tecnológica de los grupos cazadores recolectores que habitaron la región desde el Pleistoceno final.

\subsection{Objetivos}

El objetivo general de esta Tesis se orienta al estudio del manejo del fuego por parte de los grupos humanos que habitaron durante el Pleistoceno final y el Holoceno temprano, la Meseta Central de Santa Cruz. Buscamos reconocer si los fogones funcionaron como estructuradores del espacio dentro de las cuevas y analizar si el fuego interviene como medio o instrumento dentro de sistemas tecnológicos de procesamiento de recursos, así como establecer conductas inducidas o accidentales con relación al fuego a través de la identificación de restos arqueológicos termoalterados.

Los objetivos específicos de nuestro trabajo son:

1. Realizar experimentaciones enfocadas en la alteración térmica de materiales líticos y óseos mediante fogones experimentales.

2. Estudiar aquellos atributos que permitan identificar la aplicación del tratamiento térmico en estos elementos.

3. Crear patrones experimentales de referencia que puedan ser utilizados para analizar el registro arqueológico y que nos permitan determinar las causas de las termoalteraciones.

4. Definir las características de las estructuras de combustión presentes en los componentes arqueológicos estudiados.

5. Evaluar la distribución de los conjuntos líticos y óseos de estos componentes analizando su vinculación con las estructuras de combustión.

6. Estudiar las características de estos conjuntos a fin de determinar si existieron eventos de tratamiento térmico, así como alteraciones no intencionales y postdepositacionales.

\footnotetext{
${ }^{1}$ N429/N553 SeCyT. UNLP. 2004- 2007 y 2008-2011. Investigaciones arqueológicas en la Meseta Central de Santa Cruz: Pasado humano y comunicación.
} 


\subsection{Hipótesis}

1. Los pobladores de la Meseta Central de Santa Cruz durante el Pleistoceno final y el Holoceno utilizaban al fuego como medio en la confección de ciertos artefactos, aplicando la técnica conocida como tratamiento térmico.

1.a. En el caso de los artefactos líticos, el tratamiento térmico se realiza sobre formas base destinadas a producir artefactos bifaciales.

1.b. En el caso de los huesos, las alteraciones térmicas tienen fines tecnológicos.

- Se espera reconocer evidencias de producción de artefactos que muestren atributos de tratamiento térmico.

2. Estas sociedades dedicaron poca energía en el acondicionamiento de los fogones, debido a la baja intensidad de las ocupaciones.

- Se espera que éstos sean planos y que no estén limitados por estructuras de ningún tipo.

3. Estos grupos desarrollaban, durante las ocupaciones de sitios reparados, sus actividades domésticas principalmente en torno a las estructuras de combustión.

3.a. Se llevaron a cabo escasas tareas de limpieza y mantenimiento del espacio intrasitio debido a la baja intensidad de las ocupaciones.

- Se espera reconocer en todos los sitios evidencias del uso del fuego.

- Se espera que los restos materiales tiendan a encontrarse en las cercanías a las fuentes de calor.

- Se espera que una parte de los restos arqueológicos se encuentren termoalterados por causas accidentales, debido a la organización de las actividades en torno al fuego. Estas piezas se presentarán alrededor a las estructuras de combustión.

\subsection{Organización de la Tesis}

La Tesis consta de once capítulos. En el presente capítulo (Capítulo 1) exponemos el problema a estudiar, los objetivos y las hipótesis que se intentan contrastar en esta investigación. En el capítulo 2 presentamos nuestro marco teórico, delineando las herramientas conceptuales que permitirán abordarlo. En el capítulo 3 describimos las características ambientales y paleoambientales del área de estudio -rasgos geológicos, fitogeográficos y zoogeográficos-, que nos dan el marco necesario para comprender el contexto en el que se enmarcan los sitios estudiados. En el capítulo 4 presentamos los estudios realizados sobre relatos de cronistas que 
visitaron la Patagonia a lo largo de los últimos cinco siglos y que nos permiten aportar información para conocer de qué modo las sociedades patagónicas post-hispánicas manejaron el fuego. En el capítulo 5 presentamos los antecedentes de los estudios arqueológicos del área de estudio y en particular de los conjuntos que analizamos en esta Tesis, ubicando los componentes espacial, cronológica y estratigráficamente para dar una idea inicial de sus características y de las inquietudes que motivaron nuestro trabajo. En los capítulos 6 y 7 describimos los antecedentes de investigación referentes al tratamiento térmico y otras formas de termoalteración de los restos, líticos y óseos respectivamente. En los capítulos 8 y 9 desarrollamos nuestros estudios experimentales referidos al tratamiento térmico de artefactos líticos (8) y de elementos óseos (9). Presentamos los distintos análisis realizados a los conjuntos artefactuales de todas las unidades, y sus resultados en el Capítulo 10. Analizamos cinco sitios arqueológicos que presentan componentes asignables al Pleistoceno final y/o al Holoceno temprano. Corresponden en su totalidad a sitios reparados. Cerro Tres Tetas 1 cuenta con un componente fechado en el Pleistoceno final. Casa del Minero 1 posee tres componentes: dos corresponden al Pleistoceno final y uno al Holoceno temprano. Para el sitio Cueva Túnel analizamos el componente correspondiente al Pleistoceno final. Los sitios La Mesada y Cueva de La Ventana cuentan cada uno con un componente correspondiente al Holoceno temprano. En todos los casos seguimos tres lineamientos básicos en el estudio de los conjuntos: caracterizamos las estructuras de combustión, analizamos la distribución de los elementos líticos y óseos y evaluamos las evidencias de distintos tipos de termoalteración. Cabe aclarar que en los capítulos 8, 9 y 10 exponemos las estrategias metodológicas que guían cada una de estas etapas de la investigación. En el capítulo 11 sintetizamos los resultados y desarrollamos la discusión teniendo en cuenta los resultados experimentales y del análisis de los conjuntos arqueológicos, buscando evaluar si las actividades llevadas a cabo en los sitios se realizaban en torno a los fogones y si estos grupos trataban térmicamente los elementos líticos y óseos en el marco de la producción de artefactos o bien si se pueden distinguir otros procesos de termoalteración de los materiales. En dicho capítulo, además, presentamos las conclusiones desde la perspectiva de los objetivos e hipótesis propuestas y planteamos nuevas problemáticas que surgieron en el transcurso de esta investigación. 


\section{CAPITULO 2: MARCO TEÓRICO - METODOLÓGICO}

En este capítulo presentamos los lineamientos teóricos y las herramientas conceptuales tomadas como referencia para el desarrollo de esta tesis.

\subsection{El poblamiento de la Patagonia durante el Pleistoceno final y el Holoceno temprano}

La primera ocupación del territorio patagónico, ocurrida durante la transición Pleistoceno/Holoceno, en un marco de fluctuaciones ambientales, habría sido un proceso lento, caracterizado por una demografía muy baja (Borrero 1989-90, 1994-1995; Miotti y Salemme 2004; Paunero 2004b, 2009b), con ritmos no constantes, avances y retrocesos de las poblaciones y ocupaciones de corta duración (Borrero 1999; Paunero 2009b). Se considera que debió haber existido una jerarquización de los espacios ocupados; mientras que ciertos ámbitos debieron haber funcionado como barreras geográficas o no eran óptimos para su ocupación, otros resultaban más atractivos (Borrero 2001a; Miotti y Salemme 2004).

Miotti y Salemme (2004) proponen para el área de la Meseta Central un modelo de movilidad residencial restringida, debido a la existencia de áreas donde se concentran la mayoría de los recursos. Estas también reúnen condiciones estratégicas para la caza y el óptimo control de la región (Miotti y Salemme 2004; Paunero 2009b). Además, se postula que para el 11.000 AP la exploración en varias regiones de la Patagonia habría finalizado y que las poblaciones tenían ya un conocimiento acabado del espacio que ocupaban. Así, estas sociedades debían conocer las cualidades de los ambientes que habitaban y las propiedades de los recursos disponibles en ellos (Miotti y Salemme 2004; Paunero 2004b).

La retirada de los hielos durante el Holoceno temprano habría producido un aumento en las posibilidades de contacto y en las oportunidades de expansión territorial y de formación de redes sociales en un contexto de aumento poblacional (Borrero 1999, 2001a, b). Se ha postulado una estrategia de movilidad logística con una restructuración de los espacios, definición de áreas específicas de actividades, redundancia en el uso de lugares, un mejor conocimiento de los ambientes y de la distribución de los recursos (Borrero 1999, 2001a; Miotti y Salemme 2004). De acuerdo a Miotti y Salemme (2004) durante el Holoceno temprano se iniciaría una fase de consolidación territorial por parte de las sociedades que habitaron la Meseta Central, mientras que para Paunero (2009b), hay una probable disminución de la ocupación humana de esta región en los primeros 1000 años del Holoceno y un incremento a partir de los 9.000 AP, en base a las evidencias procedentes de cuevas y aleros. 
En este contexto, el fuego debe haber jugado un papel importante en la colonización de estos nuevos espacios, puesto que tiene un fuerte valor adaptativo en la colonización de ambientes fríos (Gamble 1990; Manzi y Spikins 2008; Odgaard 2003). Durante la colonización inicial, como la estadía en los sitios debió haber sido breve, y los grupos de pequeño tamaño, los fogones debieron haber tenido corta duración y haber sido encendidos para pocos individuos (Stadler 2002; Stadler et al. 2003). En contraste, durante etapas de ocupación efectiva del espacio, los fogones debieron haber tenido mayor duración y haber sido encendidos para más cantidad individuos (Stadler 2002; Stadler et al. 2003)

\subsection{El manejo del fuego}

El fuego es uno de los pocos rasgos que agrupan a todas las sociedades sin importar tiempo ni espacio. Interviene en diversos procesos de trabajo y actividades de la sociedad, resultando importante en distintos ámbitos -sociales, simbólicos, rituales, tecnológicos, fisiológicos-. De esta manera, el manejo del fuego puede ser considerado como una tecnología vinculada a diversos aspectos de la supervivencia y de la vida diaria de las poblaciones (Manzi y Spikins 2008). Se considera que encender un fuego es una acción social que resulta fundamental para conquistar un nicho natural como puede ser una cueva (Galanidou 2000); se puede afirmar que éste modifica las relaciones entre el hombre y el medio, dando la posibilidad de tener iluminación, abrigarse y luchar contra los predadores (Perles 1977 en Pérez de Micou 1991).

A partir de una serie de conceptos propuestos por Pérez de Micou (1991), entendemos como manejo del fuego al conjunto de actividades relacionadas con la apropiación de los insumos, su encendido, mantenimiento, uso y apagado. Dentro del uso se incluyen tanto las actividades en las cuales se aprovechan éste o sus derivados -carbón, cenizas, humo, brasas-, como las que se realizan en su entorno.

El fuego puede generarse por efectos no relacionados con la actividad humana, fenómenos naturales tales como tormentas eléctricas, erupciones volcánicas o incendios provocados por sequías. Así, se ha propuesto que el primer acercamiento del hombre, o de sus antepasados homínidos, con el fuego, no se habría producido como una invención sino como una apropiación de combustiones encendidas por alguno de estos efectos (Alperson-Afil 2008). La información arqueológica y ecológica de sitios del Pleistoceno Temprano y Medio de Asia, África y el Levante sugieren que Homo erectus habría sido la primer especie de homínido que logró dominar el fuego (Karkanas et al. 2007). Se ha planteado que el manejo del fuego se habría vuelto una actividad habitual hace aproximadamente 500 mil años, durante el Paleolítico Inferior, y que su uso se asociaría a un aumento de la complejidad social e intelectual de estos grupos humanos. Entre los 
sitios tempranos con posibles evidencias de fuego se puede mencionar a Chesowanja y Koobi Fora (Kenia), Qesem (Israel), Zhoukoudian y Xihoudu (China), Torralba y Ambrona (España) y Terra Amata (Francia), entre otros (Alperson-Afil 2008; Karkanas et al. 2007; Weiner et al. 1998). Sin embargo, para muchos investigadores, las pruebas aportadas para estos sitios son confusas 0 poco confiables (James 1989). El consenso generalizado es que existe evidencia inequívoca de uso del fuego para inicios del Paleolítico Medio, hacia 200 a 300 mil años (Karkanas et al. 2007; Weiner et al. 1998). Así, al momento del primer poblamiento americano, y durante la exploración y la colonización inicial de la Patagonia las poblaciones humanas contaban ya con conocimiento acerca del manejo del fuego y de diversos usos que se le podía dar a este.

\subsubsection{Factores que afectan las características de las estructuras de combustión}

Las estructuras de combustión son rasgos arqueológicos factibles de ser reconocidos por la concentración de restos de combustión (ceniza y carbones, entre otros) en un área restringida, asociados a superficies quemadas o rubificadas (Marconetto 2005). De acuerdo a su morfología y relación con la superficie de ocupación (Leroi-Gourhan 1979; Marconetto 2005), se pueden clasificar en:

- Planas o en plato: La combustión se da sobre una superficie plana, alcanzando temperaturas bajas y regulares.

- En cubeta: La combustión se produce dentro de un área excavada artificialmente o de origen natural. Se asocia a combustiones más largas.

- Sobre-elevadas: La combustión se produce en un área elevada con respecto al nivel del piso.

Las mencionadas estructuras pueden tener sus límites definidos de diversos modos, como por ejemplo, un cerco de piedras. Mientras que las estructuras de combustión sin límites definidos pueden transferir calor mediante radiación, aquellos que tienen paredes conformadas por piedras, o cuentan con piedras en su interior, también pueden hacerlo mediante convección, por lo que constituyen formas óptimas para ambientes muy fríos (Odgaard 2003).

Estas estructuras se asocian generalmente a actividades domésticas. Existen a su vez diferentes producciones artesanales que pueden necesitar estructuras de combustión específicas para poder ser desarrolladas, como por ejemplo la producción metalúrgica (Marconetto 2005).

Diversas variables afectan la forma en que cada sociedad maneja el fuego. Desde el punto de vista de los aspectos físico-químicos, son necesarios cuatro factores para que un fuego se inicie y tenga continuidad: combustible, comburente (el oxígeno del aire), temperatura o energía de activación y reacción en cadena (mediante la cual la combustión se mantiene sin necesidad de mantener la fuente principal de ignición). La coincidencia de estos cuatro factores da lugar a la combustión, 
liberando energía calórica. Cada combustible tiene una temperatura de ignición distinta, a la que es necesario llegar para encenderlo. En la mayoría de los casos, una vez que comienza la reacción de oxidación, el calor desprendido en el proceso sirve para mantenerlo (FAO 1993). Entre los aspectos que influyen en la forma en que un grupo maneja y gestiona un fuego se pueden mencionar la disponibilidad de material combustible, sus cualidades y abundancia, la proximidad al asentamiento y la funcionalidad e intensidad de la ocupación. Todos estos factores no son independientes, sino que interactúan (Allué Martí y Trassierra 2006). A estos se le suman rasgos socio-económicos y simbólicos propios de cada sociedad. El uso de las plantas, incluidas aquí las leñas, está condicionado culturalmente (Marconetto 2005, 2006).

Se ha propuesto que las estructuras de combustión tendrán diferente morfología de acuerdo a la intensidad de ocupación. Los fogones en cubeta permiten alcanzar mayores temperaturas y la combustión tiende a ser prolongada, mientras que en los fogones planos la temperatura suele ser más regular pero también más baja y el fuego tiene menor duración (Leroi-Gourhan 1979; Marconetto 2005; Nakazawa 2007). De esta manera, teniendo en cuenta que es necesario realizar una mayor inversión de energía para la formatización de las estructuras en cubeta, se espera que estas se asocien a ocupaciones más intensas, mientras que los fogones planos serían preponderantes en ocupaciones menos intensas (Nakazawa 2007; Pérez de Micou 1991). Asimismo, Pérez de Micou (1991), en base a estudios etnoarqueológicos considera que las estructuras en forma de cubeta no son esperables dentro de las cuevas y aleros, y que en caso de reconocerse, estas no serían producto de un cavado intencional sino como consecuencia de la limpieza y reactivación del fogón.

En contraste, de acuerdo a los estudios de Galanidou (2000) acerca del uso de los fogones dentro de cuevas, no existiría una correlación entre la duración de la ocupación y la energía invertida en el acondicionamiento de esta estructura. Por el contrario, observa que el tipo de fogón sería dependiente del grado de movilidad del grupo.

Por otro lado, también se ha propuesto que el tamaño de los fogones depende de la intensidad de la ocupación (Chatters 1987). De acuerdo a este autor, cuanto más larga sea una ocupación, más grandes serán éstos y más difusos sus límites. Una observación similar realizan Bartram y colaboradores (1991), quienes observan entre los Kua que los fogones utilizados de forma más intensa en un asentamiento -los usados durante todo el día- crecen en tamaño más rápidamente que aquellos empleados durante solo cierta parte del día o para actividades especiales. En consecuencia, los primeros deben ser limpiados más frecuentemente.

Sin embargo, una cuestión a tener en cuenta en vinculación al tamaño es que no siempre un grupo reutilizará las estructuras de combustión preexistentes en un asentamiento, sino que por el contrario en algunos casos se prefiere encender otro fuego, generándose, en consecuencia una 
multiplicidad de estructuras de combustión, que pueden o no estar funcionando en el mismo momento (Galanidou 2000).

Alternativamente, Pérez de Micou (1991) considera que existiría, en el caso de la Patagonia, una relación directa entre el tamaño del fogón y la cantidad de gente involucrada en su uso. De acuerdo a esta autora: "... los fogones grandes, cavados, sugieren un uso común en la cocción de alimentos principales mientras que los "fuegos" pequeños sugieren calentamiento individual o de pequeños grupos [...] Esta relación se comprueba sólo cuando en un mismo contexto se asocian ambos tipos de estructuras de combustión" (Pérez de Micou 1991, p. 138).

El desarrollo tecnológico es otro factor a tener en cuenta. Los diversos usos para los que se aprovecha el fuego implican también diferencias en sus características. De este modo, la forma en que se maneje y gestione un fuego en una determinada sociedad dependerá entre otras cosas de acuerdo a la función a la que este será destinado. Cada actividad para las que es empleado el fuego lleva implícita el conocimiento de los combustibles apropiados para ella; además sus diversos usos se relacionan con las necesidades de producción y reproducción de cada sociedad (Marconetto 2005, 2006). Por ejemplo, los pozos o "pits", cuando son hallados en cuevas, se asocian fundamentalmente con la cocción (Galanidou 2000).

Es probable, sin embargo, que un mismo fogón pueda ser utilizado para variadas actividades (Galanidou 2000). De acuerdo a esta autora, tanto los fogones planos, sin estructuras que limiten su tamaño, como aquellos que están rodeados por piedras o por troncos pueden ser utilizados para múltiples propósitos (Galanidou 2000). En esta misma línea de argumentación, Manzi y Spikins (2008) afirman que "[Las]... formas que asumieron las estructuras de combustión, tipificadas como fogones planos y en cubeta, no son por sí solas representativas de la alta variedad de funciones y de las actividades en las que pudieron haber sido utilizadas, ni de los múltiples usos en los que pudieron haber intervenido. Puede esperarse que una misma forma de estructura de combustión hubiera sido utilizada tanto con fines simbólicos [...], como para calentar, cocinar alimentos, preparar pigmentos y manufacturar astiles para puntas de proyectiles, entre otras posibilidades" (Manzi y Spikins 2008, p. 92). Esto es posible siempre que sus características cubran los requerimientos mínimos para cada una de ellas.

\subsection{El descarte de los artefactos}

Para analizar el comportamiento de los grupos cazadores recolectores en torno a las estructuras de combustión, es necesario primero introducir ciertos conceptos básicos referidos a diversas formas en que una sociedad maneja los desechos que produce y mantiene el espacio que ocupa. 
Existen diferentes formas en que los restos materiales son descartados por un grupo. Binford (1994), a partir de trabajos etnoarqueológicos realizados entre los Nunamiut, distingue entre zonas "drop" y "toss". Las primeras son aquellas donde se realizan las actividades, se usan los artefactos y donde caen la mayor parte de los desechos de una actividad. Por otra parte, las zonas "toss" son los puntos a donde se arrojan los elementos de mayor tamaño, alejados de las áreas donde se desarrolló la tarea.

También se puede diferenciar entre un descarte de tipo primario y otro secundario. El primero corresponde a aquellos restos que se desechan en el mismo lugar en el que fueron utilizados, mientras que en el segundo, el lugar de uso es diferente al de descarte final puesto que median tareas de limpieza (Schiffer 1972). Por lo general, se considera que cuanto mayor es la intensidad de ocupación, más probable es que se desarrollen espacios especializados donde concentrar los desechos, generando entonces áreas de descarte secundario (Schiffer 1972).

Una de las maneras en que es posible diferenciar estas áreas es a través de análisis del tamaño de los desechos y su distribución. En los casos de descarte secundario las actividades de limpieza y mantenimiento tenderán a focalizarse sobre los restos de mayor tamaño, que resultan más molestos y potencialmente peligrosos (Bamforth et al. 2005; O'Connell 1987; Schiffer 1972; Stevenson 1991). Parte de estos, además, habrán sido arrojados lejos del área de actividad, incorporándose a la zona "toss" (Binford 1994; Enloe et al. 1994; Schiffer 1972). Por otra parte, los artefactos pequeños tienen mayores posibilidades de introducirse en la matriz sedimentaria más rápidamente, por diversos procesos, como el pisoteo (Gifford 1980), mientras que los de mayor tamaño también pueden resultar desplazados horizontalmente por procesos tales como el "scuffage" (desplazamientos debidos al tráfico de personas o animales, Stevenson 1991).

Así, se espera que los elementos más pequeños tiendan a permanecer en el área de descarte primario mientras que, en el caso de los elementos de mayor tamaño, y dependiendo de la intensidad de ocupación, estos pueden ser removidos de dicho lugar y ser descartados en otros espacios (Bamforth et al. 2005; Bellomo 1994; Gifford 1980; O'Connell 1987; Stevenson 1991). En este sentido, diversos autores difieren acerca de cuál es el tamaño de los elementos pequeños, existiendo propuestas que fluctúan entre los $2 \mathrm{~cm}$ y los $9 \mathrm{~cm}$ (Alperson-Afil 2008; Bamforth et al. 2005; Bellomo 1994; Enloe et al. 1994; O'Connell 1987; Stevenson 1991).

\subsection{El fogón como articulador del espacio intrasitio}

Todas las sociedades han implantado en sus asentamientos algún nivel de estructuración espacial. En las disciplinas arquitectónicas se considera que existen ciertos principios ordenadores- 
jerarquizadores que modelan el espacio doméstico; estos generan una serie de relaciones espaciales y pautas de organización interna (Ayán Vila 2003).

En el caso de las sociedades cazadoras recolectoras, muchas de las actividades llevadas a cabo en un sitio determinado se desarrollan en torno a las estructuras de combustión, vinculándose así los fogones al diseño y organización del espacio. A partir de estudios etnoarqueológicos y de distribución espacial intrasitio, se ha planteado que es esperable encontrar una parte importante de los restos arqueológicos alrededor de las estructuras de combustión (lo que se conoce como "Hearth-associated artifact assemblages" en la literatura en inglés) (Alperson-Afil 2008; Bamforth et al. 2005; Bellomo 1994; Binford 1994; Enloe et al. 1994; Galanidou 2000; Gifford 1980; Massone 2004; Nakazawa 2007; O'Connell 1987; Paunero 2004b; Stevenson 1991; Vaquero et al. 2004). Se ha propuesto que esta agrupación en torno a los fogones constituye una estrategia de manejo del espacio universal y característica de los grupos cazadores recolectores (Vaquero y Pastó 2001).

De acuerdo a Paunero (2004b), el fuego en los cazadores recolectores organiza el espacio interior; lo asocia a lo endogámico, la familia, la vivienda y lo cotidiano en contraste con el agua que organizaría el espacio exterior, y que el autor asocia con lo diferente, cambiante, y exogámico. Los fogones dividen el espacio de manera física y también conceptualmente en unidades menores, de acuerdo a las necesidades y creencias de un grupo (Galanidou 2000). Al ser un punto que articula diversas actividades, en sociedades de cazadores recolectores el fogón es un espacio socializador, donde ocurren interacciones que posibilitan la reproducción de las relaciones sociales. Muchas de las actividades que se desarrollan en torno a él no requieren de su presencia. Así, la concentración de actividades a su alrededor puede explicarse por el valor social de este espacio (Vaquero et al. 2004). Entonces, se puede decir que la organización espacial refleja, refuerza y guía la comunicación entre los miembros de un grupo humano (Navarro 2007).

Entre los aspectos que inciden en el comportamiento de un grupo en torno al fuego están la intensidad y frecuencia de una ocupación determinada. La intensidad se define por la interacción entre el tamaño del grupo y la duración de la ocupación (Nakazawa 2007). Estos aspectos tienen implicaciones en la forma de descarte de los materiales, el tamaño del fogón y las prácticas de mantenimiento del espacio.

Existen diversos elementos que pueden ser tenidos en cuenta para evaluar las características de los fogones y la distribución de los materiales en torno a ellos, con relación a la intensidad de ocupación. Así, se espera que en ocupaciones cortas, de pocas personas, y con baja reutilización de los espacios, se invierta escasa energía en la preparación, encendido y mantenimiento de los fogones, que serán por lo general planos, de dimensiones acotadas y sin ningún tipo de preparación de su estructura (cubeta, piedras a su alrededor, etc.) (Nakazawa 2007; Pérez de Micou 1991) (aunque véase Galanidou (2000) para una posición contraria). La expectativa es que 
predomine un descarte de tipo primario, por lo cual los artefactos tenderán a ubicarse alrededor del fogón. Es posible, sin embargo, que los elementos de mayor tamaño sean arrojados a zonas más distantes o se realice una limpieza expeditiva. (Binford 1994; Gifford 1980; Nakazawa 2007; Schiffer 1972; Stevenson 1991).

Por otro lado, en ocupaciones largas y de muchas personas, con reutilización de los espacios, se invertirá mayor energía en la preparación de los fogones; estos serán de mayores dimensiones y/o serán más abundantes (Bartram et al. 1991; Chatters 1987; Galanidou 2000) y presentarán diversidad en su estructura (Nakazawa 2007; Pérez de Micou 1991). Se espera que los espacios reutilizados sean mantenidos libres de desechos molestos, por lo que predominará un descarte de tipo secundario, quedando como desechos primarios alrededor del fogón únicamente los elementos más pequeños (Bamforth et al. 2005; Binford 1994; Gifford 1980; Nakazawa 2007; O'Connell 1987; Schiffer 1972; Stevenson 1991).

Por otra parte, si bien es habitual encontrar fogones en sitios cazadores recolectores, no siempre esto ocurre. Diversos procesos, antrópicos o naturales, pueden eliminar este tipo de estructura. Se conoce como fogones "fantasma" a aquellas estructuras de combustión que, por diversas líneas de evidencia se sabe que estuvieron presentes en un sitio pero que no han podido reconocerse durante la excavación (Alperson-Afil 2008). Según Sergant et al. (2006) y a Backhouse y Johnson (2007) es posible identificar la ubicación de estos fogones si se evalúa la distribución de los artefactos y ecofactos termoalterados de los sitios. De acuerdo a sus experimentaciones, la mayor parte de los restos termoalterados deberían encontrarse dentro de una estructura de combustión, o bien a su alrededor. De esta manera, los huesos, líticos y otros restos fuertemente termoalterados son los mejores indicadores de la posición de los antiguos fogones (Alperson-Afil 2008; Sergant et al. 2006).

Para la identificación de estos fogones, además, es necesario considerar la intensidad de ocupación, puesto que en las ocasiones en las que estas estructuras son reutilizadas y en los que es necesario realizar una limpieza de dicha estructura, así como del área circundante, las piezas cambiarán de lugar, formándose basurales donde se encuentran asociados los productos del vaciado del fogón y otros desechos (Borrero y Yacobaccio 1989; Nakazawa 2007; Sergant et al. 2006). Además, se espera que sea más frecuente la presencia de piezas termoalteradas en ocupaciones más intensas que en aquellas de corta duración y pocas personas (Nakazawa 2007; Stadler et al. 2003). 


\subsection{Termoalteración y tratamiento térmico}

De acuerdo al Diccionario de la Lengua Española de la Real Academia (2001), el significado de la palabra alterar es el de "cambiar la esencia o forma de algo". Siguiendo esta definición, entendemos como alteración térmica a todo proceso por el cual un objeto ve modificadas sus características al exponerse a una fuente de calor. Existen diversos modos por los cuales los elementos líticos y óseos recuperados de los sitios arqueológicos pueden mostrar signos de termoalteración. Si bien estos se presentarán de manera más desarrollada en los capítulos 6 y 7 , nos interesa aquí delinear ciertos aspectos básicos.

El tratamiento térmico representa un modo de alteración térmica intencional mediante el cual se desea cambiar determinadas propiedades del material a tratar, ya sea por motivos funcionales, estéticos u otros, en el marco de diversos procesos productivos. Entre los materiales que pueden ser tratados térmicamente se encuentran los artefactos líticos, los elementos óseos, los pigmentos, el yeso y la madera (Aschero 1983-1985, 1985; Barbosa y Gradín 1987; Barbosa y Rial 1983 - 1985; Belardi et al. 2000; Bridges 2003; Bridges 1998; Cattáneo et al. 1997-98; Clemente Conte 1995, 1997; Flenniken y White 1983; Gibaja y Clemente 1997; Gusinde 1982; Iñíguez y Gradín 1977; Mandeville 1973; Mandeville y Flenniken 1974; Nami et al. 2000; Pasveer 2005; Pavlish y Sheppard 1983; Schindler et al. 1982; Sidéra 2000; Stadler et al. 2003, entre otros).

Las propiedades de los distintos materiales implican que el tratamiento térmico sea desarrollado de manera diferente para cada uno de ellos. Cada sustancia requiere temperaturas específicas así como tiempos y formas propias de calentamiento e incluso dentro de cada tipo de material existen particularidades que implican modificar la técnica de acuerdo a los objetivos deseados (Barbosa y Rial 1983 - 1985; Flenniken y Garrison 1975; Iñíguez y Gradín 1977; Mandeville 1973; Mercieca 2000; Mercieca y Hiscock 2008; Sidéra 2000).

Un manejo controlado del fuego, entonces, resulta imprescindible para el óptimo tratamiento térmico. El hecho de que existan diferencias en los procedimientos necesarios para aplicar esta técnica en distintos tipos de piezas y materias primas, implica que se debe tener una noción acerca de cuáles son las características necesarias del fuego y del fogón para realizar este procedimiento adecuadamente en los diversos casos (Cowan 1987; Mandeville 1973; Mercieca 2000; Mercieca y Hiscock 2008). Esto exige un conocimiento acerca de las posibilidades técnicas que brinda el fuego, del poder combustible de las distintas maderas, de qué combustibles utilizar y cuando utilizarlos (Allué Martí y Trassierra 2006; Manzi y Spikins 2008; Marconetto 2006; Pérez de Micou y Ratto 2004; Piqué 1999).

Por otra parte, el fuego también puede alterar los materiales por otros motivos no enmarcados en los procesos productivos de una sociedad. Estos pueden tratarse de efectos postdepositacionales 
tales como la acción de incendios naturales o de fuegos encendidos en ocupaciones posteriores, de contactos accidentales como pueden ser la caída de un elemento en el fogón durante el desarrollo de actividades en sus cercanías, o inclusive de acciones intencionales realizadas por el hombre: la cocción de alimentos o el descarte sistemático de restos dentro de estas estructuras por diversas causas (Bennett 1999; Clemente Conte 1995; Larsson 2000; Théry-Parisot 2002; Wandsnider 1997, entre otros).

En consecuencia, la sola identificación de restos termoalterados en un sitio no es evidencia suficiente para postular la aplicación del tratamiento térmico (Cattáneo et al. 1997-98; Clemente Conte 1995). Aunque las técnicas de tratamiento térmico pueden presentar en algunos casos indicadores diferentes de los producidos por otros procesos de termoalteración (Rick y Chappell 1983, ver capítulo 6), es necesario analizar esta problemática desde distintas perspectivas para poder determinar las causas del calentamiento de los restos. Entre los métodos factibles de ser utilizados podemos mencionar los estudios experimentales, que evalúan las diversas características que toman los materiales al estar sujetos a distintos tipos de termoalteración (Bennett 1999; Buikstra y Swegle 1989; Cattáneo et al. 1997-98; Domanski y Webb 2007; Mercieca 2000; Théry-Parisot 2002, entre otros); los análisis tecnológicos que evalúan al tratamiento térmico en el marco de la producción artefactual y no como técnica aislada (Gibaja 2002; Gregg y Grybush 1976; Rick y Chappell 1983; Schindler et al. 1982; Terradas y Gibaja 2001, entre otros) y las investigaciones distribucionales y contextuales que resultan útiles al momento de analizar posibles termoalteraciones postdepositacionales (Alperson-Afil 2008; Clemente Conte 1995; Massone 2004, entre otros).

Por otra parte, se ha propuesto para el caso de la Patagonia que existirían expectativas distintas con respecto a la ocurrencia de piezas alteradas y tratadas térmicamente ${ }^{2}$ para los distintos momentos del poblamiento de la región (Stadler 2002; Stadler et al. 2003). Para la etapa de exploración y colonización inicial de los territorios se espera una baja frecuencia de piezas termoalteradas, debido a la baja densidad poblacional y a la corta duración de las ocupaciones, mientras que la frecuencia de restos tratados estará en función de la procedencia de la materia prima. En contraste, para momentos de ocupación efectiva del espacio, se espera un aumento de la frecuencia de restos termoalterados, como consecuencia de la mayor duración de las ocupaciones, en tanto que la presencia de tratamiento térmico estará en función de la calidad, disponibilidad y abundancia de la materia prima (Stadler 2002; Stadler et al. 2003).

\footnotetext{
${ }^{2}$ Nótese que los autores utilizan el término alteración térmica de manera distinta a la empleada por nosotros, ya que diferencian tratamiento térmico de alteración térmica (Stadler et al. 2003, p. 20).
} 


\subsection{Aspectos de la tecnología lítica de una sociedad: La secuencia de reducción}

El tratamiento térmico, al ser una técnica implementada durante la confección de artefactos, está enmarcado dentro de los procesos productivos de una sociedad. Estos pueden entenderse analizando su secuencia de producción; esto es, las distintas etapas involucradas en la manufactura de un determinado producto. Los modelos secuenciales (Bleed 2001) han sido frecuentemente utilizados en la arqueología desde diversas tradiciones (Boëda et al. 1990; Collins 1989-90; Galarce 2004; Skarbun 2009b; Terradas y Gibaja 2001), en especial en lo referente a los estudios sobre material lítico, aunque es potencialmente aplicable a otros tipos de artefactos, como los óseos (Jurgens 2005; Smith y Poggenpoel 1988).

Al ser el proceso de producción de artefactos líticos, por la naturaleza de este material, un proceso básicamente reductivo, que implica una serie de pasos articulados (Bleed 2001), el análisis de la secuencia de producción es conocido frecuentemente como secuencia de reducción. La secuencia de reducción de artefactos líticos considera todo el proceso de producción, que se inicia en el momento de aprovisionamiento de la materia prima y termina con la formatización final de los instrumentos y las posibles actividades de reactivación o mantenimiento.

Collins (1989-90) divide el proceso de manufactura en pasos que son distintivos en términos de procedimientos y productos. Cada uno de estos está compuesto por uno o más conjuntos de actividades, que dan como resultado dos clases de materiales: elementos que serán descartados y objetos destinados a mayor formatización y/o uso.

Los pasos técnicos considerados, parcialmente modificados, son: a. obtención de la materia prima; b. preparación y reducción inicial del núcleo (descortezamiento), c. talla y extracción de formas bases, d. formatización final de los artefactos (d1. retalla, d2. retoque y d3. adelgazamiento bifacial); e. conservación/reactivación y f. descarte.

Si bien las etapas así planteadas aparecen como consecutivas y lineales, no necesariamente lo son. Es posible saltar alguna (por ejemplo la obtención de soportes a partir de material crudo) o bien retomar etapas que ya habían sido superadas (por ejemplo al reciclar núcleos). El modelo también considera la posibilidad de que entre los distintos pasos de la manufactura se lleven a cabo otras acciones sobre el material tales como el almacenamiento o el tratamiento térmico. 


\subsection{La Arqueología Experimental}

Al ser el tratamiento térmico un proceso en el cual se modifican las propiedades de los materiales, modificando sus características macro y microscópicas, es factible estudiarlo a partir del desarrollo de programas experimentales.

La arqueología experimental es una rama de la arqueología que incluye la replicación, el análisis y/o la interpretación de materiales arqueológicos por medio de la experimentación científica (Ascher 1961; Nami 1997-1998; Scarano et al. 1994). Desde hace varias décadas, la experimentación forma parte del bagaje de técnicas usadas por los arqueólogos para intentar resolver problemas relativos al pasado. Mediante la arqueología experimental se analizan los procesos que pueden estar vinculados con la formación y depositación de los restos arqueológicos. Se considera que las experimentaciones permiten comprender al comportamiento dinámico que subyace al registro arqueológico estático mediante la elaboración de teorías de rango medio (Binford 1981; Frere et al. 2004; García 1993; Johnson 1978; Nami 1997; Yacobaccio 1991).

La arqueología experimental busca brindar información acerca del pasado mediante el uso de analogías, basándose en el principio de uniformismo según el cual los mismos procesos naturales que actúan en la actualidad actuaron también en el pasado. La analogía sustancial (sensu Yacobaccio 1991) en los trabajos arqueológicos es factible de hacer cuando los patrones a interpretar pueden responder a conductas que tengan como consecuencia un efecto físico no ambiguo en el registro arqueológico (Yacobaccio 1991).

De acuerdo a Scarano et al. (1994) pueden diferenciarse distintos tipos de estudios que implican diferentes niveles de experimentación:

- Estudio observacional controlado: implica la búsqueda de variadas situaciones para definir si un fenómeno determinado se produce de la misma manera o de maneras distintas.

- Experiencia activa: son provocadas por el observador sin esperar a que sucedan los hechos. Implica un diseño rudimentario, selección deliberada de algunos factores y cierto grado de control, sin alcanzar a constituir un experimento. Al no informarse precisa y exhaustivamente el sistema o las condiciones mediante las cuales se obtuvieron los resultados, no está garantizada la replicación. Dentro de esta categoría existe una subcategoría que son los experimentos simulativos: estos implican realizar operaciones para modelar y usar un substrato material de manera similar al pasado.

- Experimento de campo: el sistema experimental aquí también es natural, pero conscientemente seleccionado por ser relativamente estable y controlable, se puede describir precisamente y variar dentro de cierta gama uno o varios factores. 
- Experimento en sentido estricto: el experimentador puede manipular ciertos aspectos de una situación (factores o variables) que supone que constituyen las condiciones para la aparición de los fenómenos estudiados. Al variar repetidamente algunos de ellos, pero conservando los otros constantes, el observador puede estudiar los efectos de tales cambios sobre dicho fenómeno y descubrir relaciones constantes de dependencia entre el fenómeno y las variables. El sistema en este caso es construido y por eso controlado en alto grado, garantizando la variación de un factor y el mantenimiento constante del resto. Todo experimento debe ser factible de ser reproducido.

A partir de lo antedicho, consideramos que esta metodología permitiría generar información valiosa para comprender la forma en que maneja el fuego una sociedad y, más específicamente, resulta útil para determinar si se aplicó la técnica del tratamiento térmico en los conjuntos arqueológicos de la región en estudio. 


\section{CAPÍTULO 3: AMBIENTE Y PALEOAMBIENTE}

En este capítulo describimos las características ambientales de la Patagonia, y más específicamente de la Meseta Central así como las evidencias paleoambientales disponibles para esta región para el Pleistoceno final y el Holoceno temprano. Esto nos permite dar el marco necesario para comprender el contexto en el que se enmarcan los conjuntos estudiados.

\subsection{Ambiente Actual}

\subsubsection{Geología}

La región patagónica se ubica al sur del río Colorado, desde los $39^{\circ} \mathrm{S}$ hasta los $55^{\circ} \mathrm{S}$, e incluye la Cordillera de los Andes y las mesetas, planicies y serranías ubicadas entre los Andes y el Océano Atlántico.

La zona cordillerana se encuentra dominada por la acción orogénica de los Andes, y se caracteriza por presentar un paisaje irregular, con alto relieve relativo, fuertes pendientes y marcados gradientes altitudinales, dominado por procesos erosivos (fundamentalmente hídricos) y de remoción en masa. Excluyendo a la Cordillera, los afloramientos patagónicos han sido agrupados en dos Macizos: Somún Cura (o Nordpatagónico) y del Deseado, que se encuentran rodeados por diversas cuencas Mesozoicas que los comunican entre sí. El Macizo de Somún Cura está limitado al norte por las Cuencas Neuquina y del Colorado, al sur por la Cuenca Cañadón Asfalto así como por la Cuenca de San Jorge. El Macizo del Deseado aflora al sur de la Cuenca de San Jorge y está limitado por la Cuenca Austral (o Magallanes) al sur (Figura 3.1) (Ramos 2008). El ambiente de mesetas se extiende desde la margen oriental de la cordillera hasta la costa. Existen distintos niveles mesetarios que se encuentran separados por fuertes escarpas conectadas por sistemas de cañadones. Sus cotas oscilan desde los 900 - 1.000 m.s.n.m. hasta los 150 m.s.n.m. aproximadamente. Frecuentemente, estas geoformas están coronadas por crestas o planchas basálticas (León et al. 1998).

\subsubsection{Macizo del Deseado}

La Meseta Central comprende geológicamente el Macizo del Deseado, el cual representa el producto de un vulcanismo continental masivo sucedido durante el Jurásico. Está compuesto principalmente por lavas riolíticas, tobas e ignimbritas, que forman una vasta meseta volcánica 
(Klohn et al. 2007). Sobre esta gran plataforma se asientan los sitios arqueológicos en estudio. Diversas formaciones están presentes en esta región:

- Pre Jurásico - Jurásico Inferior: Hay escasas rocas previas al Jurásico. Las más antiguas corresponden a la Formación La Modesta, consideradas del Precámbrico - Paleozoico Inferior (aproximadamente 540 m. a.). Consisten en esquistos, cuarcitas, anfíboles y gneises. Por sobre esta formación se reconocen secuencias sedimentarias continentales:

- Formación La Golondrina (Pérmico, 299-251 m. a.) compuesta por areniscas, limolitas y conglomerados.

- Formación El Tranquilo (Triásico, 251-200 m. a.), conformada por areniscas cuarzosas y pizarras.

○ Formación La Leona (Jurásico Inferior, 200-175 m. a.): cuerpos intrusivos graníticos calco-alcalinos.

- Formación Roca Blanca (Jurásico Inferior): se trata de lutitas y areniscas tanto fluviales como lacustres.

- Jurásico Medio a Superior: Las rocas volcánicas del Jurásico Medio- Superior del Macizo del Deseado presentan dos modas composicionales. Las rocas ácidas conforman el Grupo Bahía Laura y las intermedias a básicas se agrupan en la Formación Bajo Pobre. Los estudios regionales señalan una génesis conjunta para ambos conjuntos, considerando datos geoquímicos, isotópicos y geocronológicos (Guido et al. 2006).

- Formación Bajo Pobre (Jurásico Medio a Tardío, 177-151 m.a.): Sobreyace a la formación Roca Blanca y está presente de manera extensiva en el Macizo. Consiste en basaltos, andesitas y aglomerados volcánicos básicos que se intercalan con tobas máficas y conglomerados (Guido et al. 2006).

- Grupo Bahía Laura (Jurásico Medio a Tardío, 177-125 m.a.): Es la secuencia más importante y abundante del Macizo del Deseado cubriendo más de la mitad de su área. Se trata de volcanitas de composición riolítica, ricas en potasio y pobres en calcio y minerales ferromagnesianos (Guido et al. 2006). Este grupo está dividido en dos Formaciones:

- Formación Chon Aike: Compuesta principalmente de ignimbritas, aglomerados, brechas volcánicas y tobas. Son producto de numerosos ciclos de volcanismo intenso intercalado localmente con períodos erosivos y de sedimentación (Klohn et al. 2007; Panza 1994).

- Formación La Matilde: Incluye tobas, rocas sedimentarias volcanoclásticas y algunas capas de ignimbritas. Las tobas son compactas, por lo general de grano fino a arenosas. Se observan también sedimentos fluviales y lacustres que representan depósitos de cuencas calmas distantes de las áreas de volcanismo 
intenso. Estos sedimentos son fosilíferos y contienen habitualmente coníferas petrificadas así como otras evidencias paleontológicas (Klohn et al. 2007; Panza 1994).

- Cretácico y Cenozoico: Durante el Cretácico una importante tectónica de fallamiento produjo la evolución de pequeñas cuencas cerradas que facilitaron la depositación de sedimentos de origen continental, aflorando en las Formaciones Baqueró y Bajo Grande. Además desde fines del Cretácico, e intermitentemente hasta el Pleistoceno se produjeron efusiones basálticas que se depositan en forma de mantos (Marchionni et al. 1997). Finalmente, este marco estratigráfico se completa con los depósitos aluviales y coluviales cuaternarios.

\subsection{Localidades Arqueológicas La María y Cerro Tres Tetas}

Las localidades arqueológicas en estudio se localizan en el sector central del Macizo del Deseado. La ubicación geográfica de La María es $48^{\circ} 24^{\prime} 40^{\prime \prime} \mathrm{S}$ y $68^{\circ} 51^{\prime} 24^{\prime \prime} \mathrm{O}$ en el departamento de Magallanes, mientras que Cerro Tres Tetas se emplaza a los $48^{\circ} 08^{\prime} 58^{\prime \prime} \mathrm{S}$ y $68^{\circ} 56^{\prime} 00^{\prime \prime} \mathrm{O}$ en el departamento de Deseado, ambas en la provincia de Santa Cruz. Estas localidades distan a $55 \mathrm{~km}$ una de la otra (Fig. 3.2).

En ambas predominan las rocas del grupo Bahía Laura conformando un paisaje caracterizado por amplias mesetas basálticas, abundantes afloramientos minerales, bajos centrípetos y zanjones enmarcados en cañadones constituidos por altos paredones de ignimbritas ácidas de la formación Chon Aike que contienen numerosas cuevas y aleros que resultan aptos para la ocupación humana (Figura 3.3).

Un rasgo interesante, desde un punto de vista arqueológico, es que las formaciones Chon Aike, Baqueró y Bajo Pobre brindan importantes afloramientos de materias primas líticas de excelente calidad para ser usadas en la confección de artefactos. Es ubicua la presencia en las localidades en estudio de potenciales fuentes primarias de aprovisionamiento de sílex, xilópalo, toba silicificada y basalto, las cuales, de acuerdo a los estudios realizados, en muchos casos efectivamente han servido como canteras (ver capítulo 5) (Fig. 3.3). Estas materias primas también abundan en ciertos cursos de agua como zanjones y lagunas, donde se presentan como rodados. Además, estas formaciones presentan minerales tales como hematitas, goethitas, illitas, óxidos de manganeso y yeso que resultan aptos para ser utilizados como colorantes y fijadores en la confección de pinturas rupestres, abundantes en esta zona, así como en la decoración de otros elementos (Fig. 3.4). 


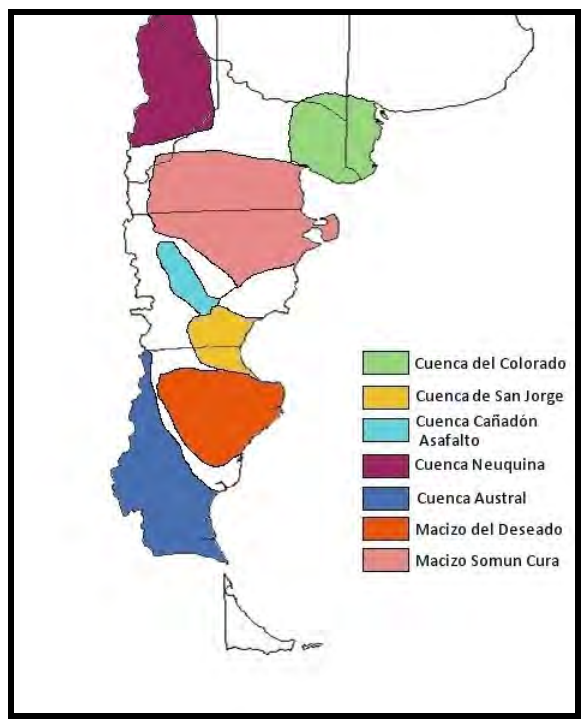

Figura 3.1. Principales rasgos geológicos de la Patagonia. Modificado de Ramos (2008).

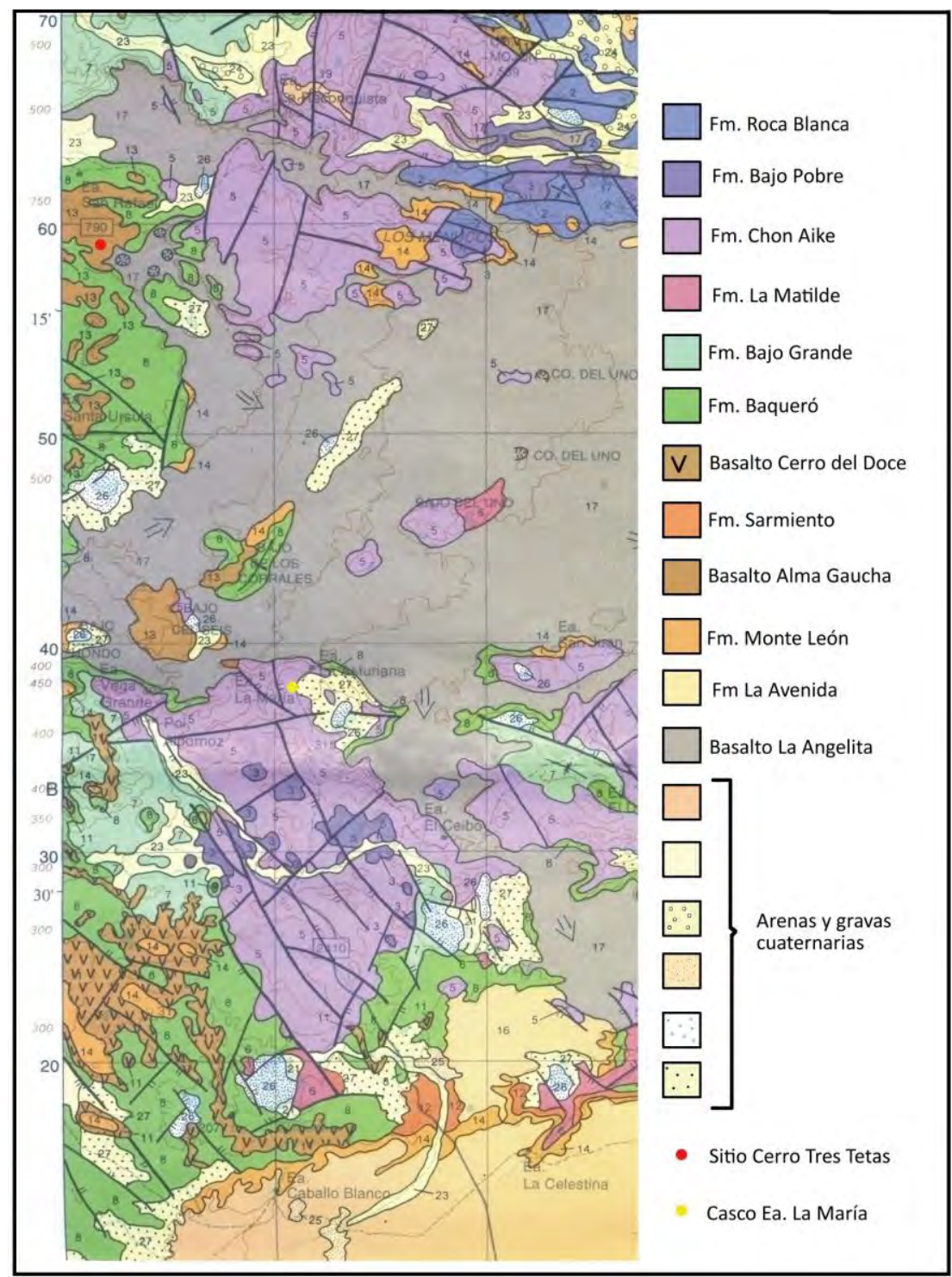

Fig. 3.2. Hoja geológica del área de estudio. Corresponde a un segmento de la Hoja Geológica 4969-II. Tres Cerros Escala 1:250.000 (Panza 1994). 


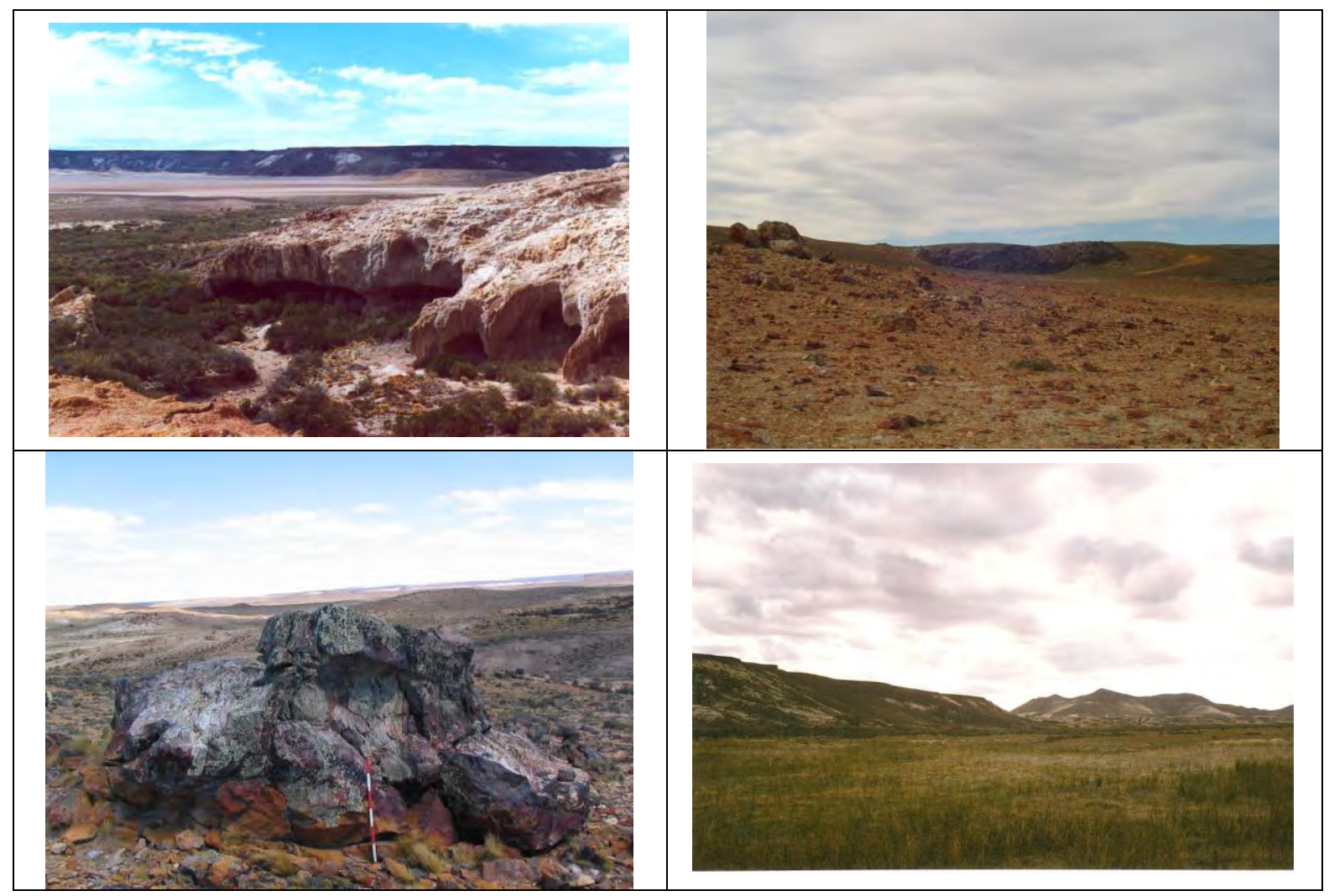

Fig. 3.3. De izq. a der y de arriba abajo. Cuevas y aleros en ignimbritas de la Formación Chon Aike, bajo centrípeto y de fondo manto de basalto cenozoico; Cantera de Sílex de CDM y Cantera Bosque Petrificado (Loc. Arq. La María). Localidad Arqueológica Cerro Tres Tetas (Foto R. Paunero).

\subsubsection{Clima}

El clima patagónico está influenciado principalmente por dos rasgos propios de esta región: la presencia de la Cordillera de los Andes que se orienta de norte a sur y el influjo predominante de vientos del oeste generados por el Anticiclón del Pacífico Sur. Mientras que el viento tiene un gran poder desecante y afecta a la génesis y erosión de los suelos, la Cordillera constituye una barrera para las masas de aire húmedo provenientes del Océano Pacífico. Las nubes descargan su humedad en la vertiente occidental de los Andes y, al descender del lado oriental, se calientan y se secan (Paruelo et al. 2005). De este modo se genera un importante gradiente de precipitaciones que decrece exponencialmente de oeste a este.

Si bien del lado occidental de los Andes las precipitaciones anuales exceden los $2000 \mathrm{~mm}$, las estepas y semidesiertos de la Patagonia oriental reciben entre 600 y $120 \mathrm{~mm}$ de precipitaciones anuales. En este sentido, en la mayor parte del territorio las precipitaciones no superan los 200 $\mathrm{mm}$ (Paruelo et al. 1998). Los vientos del oeste, predominantes en primavera y verano, hacen que la influencia atlántica sea escasa de manera que ni siquiera las zonas costeras reciben precipitaciones mayores. La escasa precipitación y la distribución invernal de ésta determinan un 
fuerte déficit hídrico estival. Más del $55 \%$ de la Patagonia es árida o hiperárida y sólo un 9\%, subhúmeda (Paruelo et al. 2005).

La Patagonia puede definirse como una región templada a templada fría. La distribución de las isotermas es de orientación NO-SE, y está determinada principalmente por la presencia de la cordillera. Las temperaturas medias anuales varían entre $12^{\circ} \mathrm{C}$ en el sector noreste y $3^{\circ} \mathrm{C}$ en el sur (Paruelo et al. 1998) Los valores mínimos de temperatura en invierno oscilan entre $-5^{\circ} \mathrm{C}$ en el sudoeste y $5^{\circ} \mathrm{C}$ en el noreste, y los máximos en verano entre 5 y $17^{\circ} \mathrm{C}$.

En la Meseta Central el clima es templado-frío árido, presenta una temperatura media anual que oscila entre 6 y $11^{\circ} \mathrm{C}$. Las isotermas siguen el gradiente de temperatura regional NO-SE. Las temperaturas mínimas varían entre $0^{\circ} \mathrm{C}$, en los ambientes serranos y de mesetas volcánicas (500 $1.000 \mathrm{~m}$ s.n.m.) y $5^{\circ} \mathrm{C}$ en los sectores de mesetas más bajas cercanos a la costa. Las temperaturas máximas fluctúan entre 13 y $17^{\circ} \mathrm{C}$ en uno y otro sector, respectivamente. Por otro lado, existen en esta región lugares reparados como fondo de valles, bajos sin salida y cañadones donde las temperaturas no siguen el patrón general. Las precipitaciones oscilan entre 150 y 200 mm al año.

\subsubsection{Hidrología}

La Cordillera de los Andes actúa como la principal divisoria de aguas entre el sector chileno, que vierte sus aguas hacia el Océano Pacífico, y el argentino, que lo hace hacia el Atlántico. Existen sin embargo ríos que tienen sus cabeceras en Argentina y descargan sus aguas en el Pacífico y otros que nacen en Chile y llevan sus aguas al Atlántico. La intensa acción de los glaciares durante el Pleistoceno ha causado estos desvíos en la dirección de los drenajes (Coronato et al. 2008).

La Patagonia argentina está surcada por 8 ríos principales que la atraviesan y descargan sus aguas en el Océano Atlántico. De N a S estos ríos son: Colorado, Negro, Chubut, Deseado, Chico, Santa Cruz, Coyle y Gallegos. Los Ríos Deseado y Chico delimitan a la Meseta Central de Santa Cruz al N y al $\mathrm{S}$ respectivamente. El área de drenaje de estos ocho ríos abarca el 30\% del total del territorio patagónico (Pasquini y Depetris 2007). Las cuencas endorreicas ocupan el 70\% restante, incluyendo la Meseta Central. Allí proliferan las cuencas sin desagües que cuentan en sus sectores más profundos con barreales o lagunas que por lo general son de carácter temporario (Fig. 3.4). Las cuencas cerradas muestran una red de drenaje tipo centrípeto, con colectores efímeros (Panza 1994). Los arroyos prácticamente no desarrollan planicies aluviales al labrar su cauce en las ignimbritas; por el contrario, los valles suelen ser muy angostos, llegándose a originar una estrecha garganta de paredes verticales abruptas y elevadas.

Finalmente, en la Patagonia continental existen dos grandes masas de hielo. El Hielo Patagónico Norte $\left(47^{\circ} 00^{\prime} \mathrm{S}, 73^{\circ} 39^{\prime}\right.$ O) tiene aproximadamente $120 \mathrm{~km}$ de largo y 40 a $60 \mathrm{~km}$ de ancho, y ocupa sectores de la Cordillera de los Andes a una altura de entre 700 y 2500 m.s.n.m., cubriendo 
una superficie aproximada de $4200 \mathrm{~km}^{2}$. El Hielo Patagónico Sur, de mayores dimensiones, tiene una longitud de aproximadamente $360 \mathrm{~km}$, entre los $48^{\circ} 50^{\prime} \mathrm{S}$ and $51^{\circ} 30^{\prime} \mathrm{S}$ y un ancho promedio de $40 \mathrm{~km}$. Cubre un área aproximada de $13.000 \mathrm{~km}^{2}$ (Glasser et al. 2004). De estos mantos de hielo se desprenden glaciares de grandes dimensiones que eran, sin embargo, de mayores dimensiones en el pasado. Al retroceder, quedaron formadas cuencas que fueron ocupadas por grandes lagos, cuyas aguas provienes en su mayoría del derretimiento de estos glaciares.

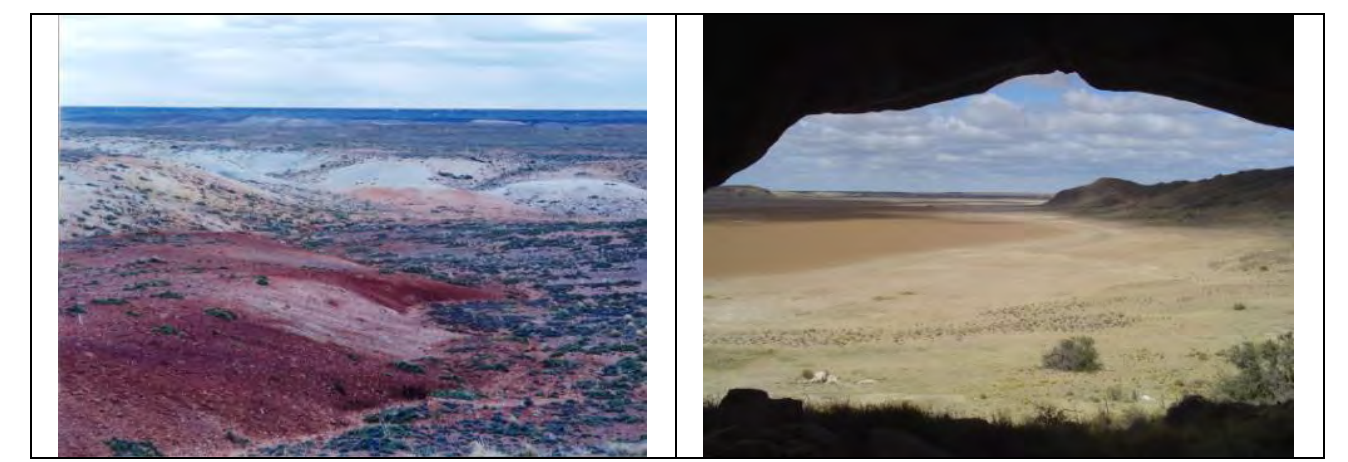

Fig. 3.4. Izq: Minerales útiles como colorantes. Localidad Arqueológica La María. Der: Cuenca endorreica con laguna de carácter alternante. Localidad Arqueológica El Ceibo (Foto: N. Lunazzi).

\subsubsection{Biogeografía}

\subsubsection{Vegetación}

La disminución de las precipitaciones de oeste a este determina un gradiente de tipos de vegetación: bosque, estepa graminosa, estepa arbustivo-graminosa, estepa arbustiva y erial. En la mayor parte del área extra andina la vegetación muestra caracteres adaptativos a condiciones de aridez (León et al. 1998): Arbustos áfilos o con hojas pequeñas o escamiformes, envoltura resinosa, pelos glandulares, cutícula engrosada, epidermis biestratificada, parénquima acuífero, estomas con amplio atrio externo o esclerénquima muy desarrollado; arbustos bajos hemisféricos en cojín o compactos con crecimiento heteroblástico; gramíneas cespitosas con porciones de la mata muerta en pie y con hojas plegadas o convolutas y con gruesa cutícula; hierbas perennes geólitas o hemicriptófitas y terófitas efímeras.

En la Patagonia están representadas 4 provincias fitogeográficas (Fig. 3.5) (Cabrera 1976; Cabrera y Willink 1980; León et al. 1998):

- 1) Altoandina: Abarca las altas montañas cordilleranas. La vegetación es pobre predominando gramíneas xerófilas y dicotiledóneas rastreras o en cojín.

- 2) Subantártica: Se trata de un bioma boscoso dominado por especies del género Nothofagus que ocupa una franja angosta de territorio a ambos lados de la cordillera desde el paralelo 38 hasta el estrecho de Magallanes. 
- 3) Del Monte: Conformada por estepas arbustivas donde son frecuentes las Zigofiláceas, en especial Larrea sp. Se extiende al oeste de los Andes desde el río Colorado hasta la costa atlántica de Chubut (León et al. 1998).

- 4) Patagónica: Abarca una amplia superficie, extendiéndose desde el sur de Mendoza hasta el norte de Tierra del Fuego. Los tipos de vegetación más representados son las estepas arbustivo - graminosas de mediana altura (de 20 a $80 \mathrm{~cm}$ ) y densidad (un arbusto cada $6 \mathrm{~m}^{2}$ ) y las caracterizadas por arbustos enanos (de 5 a $20 \mathrm{~cm}$ ) en cojín con escasos pastos y muy baja cobertura total (eriales) (León et al. 1998).

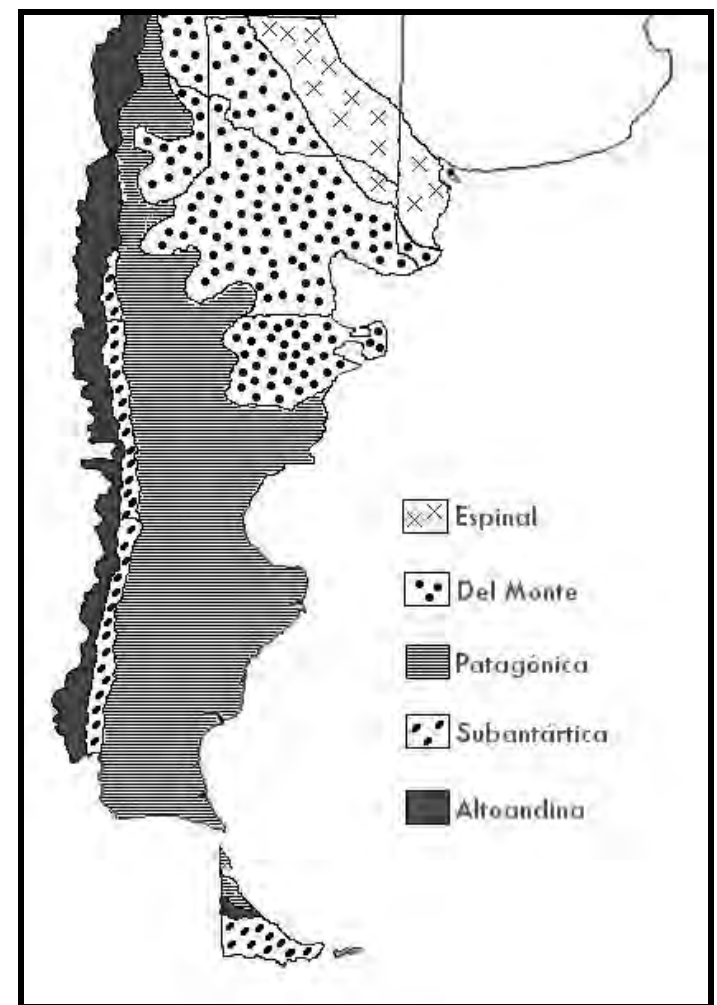

Fig. 3.5. Provincias fitogeográficas de la Patagonia. Adaptado de Ribichich (2002)

León et al. (1998) y Paruelo et al. (2005) subdividen esta provincia en 6 distritos que contienen diferentes unidades fisonómico florísticas:

- Distrito Occidental: Se ubica entre los distritos Subandino y Central, en sectores con precipitaciones menores a $250 \mathrm{~mm}$. Está caracterizado por una estepa arbustivo-graminosa de 60 a $180 \mathrm{~cm}$ de altura. Son predominantes los "coirones": Stipa speciosa (coirón amargo) y Stipa humilis (coirón llama). Adesmia campestris (mamuel choique), Berberis heterophylla (calafate) y Poa lanuginosa (pasto hilo) son frecuentes, así como también están presentes otros arbustos como: Senecio filaginoides (mata mora), Mulinum spinosum (neneo), Ephedra frustillata, Lycium chilense y Schinus polygamus (molle). Entre las hierbas se pueden mencionar Adesmia lotoides, Perezia recurvata, Oenothera contorta y Doniophyton patagonicum. 
- Distrito del Golfo de San Jorge: Es subdividida por León et al. (1998) en estepas arbustivas altas (donde abundan Stipa humilis, Stipa speciosa, y como leñosa dominante Colliguaya integerrima duraznillo) y estepas graminoso-arbustivas (dominadas por gramíneas cespitosas tales como Festuca pallescens y Festuca argentina, por los arbustos Senecio filaginoides, Nardophyllum obtusifolium, Mulinum spinosum, Adesmia campestris y por los subarbustos Verbena thymifolia y Acaena platyacantha).

- Distrito de la Payunia: Son estepas arbustivas que difieren en sus características en relación con la altura, el tipo de sustrato y la topografía. Cuando superan los 1800 están conformadas por Mulinum spinosum, y especies de Azorella, Adesmia y Maihuenia. Por debajo de los 1400 m.s.n.m. predominan Stillinga patagonica, Anarthrophyllum rigidum, Ephedra ochreata, Coliguaya integerrima, Berberis grevilleana, Astragalus pehuenches, Neosparton aphyllum y elementos del Monte como Larrea nitida.

- Distrito Subandino: Constituido por estepas graminosas con alta cobertura y pocos arbustos. Se ubican donde las precipitaciones son superiores a los $300 \mathrm{~mm}$ anuales e ingresan en el sector oriental de los bosques caducifolios de Nothofagus en un amplio ecotono en forma de parches o mosaicos. Son preponderantes Festuca pallescens (coirón blanco), Rhytidosperma picta y Lathyrus magellanicus.

- Distrito Magallánico: Junto con el Subandino son los distritos más húmedos de esta Provincia. Se relaciona a un clima frío y oceánico. Son frecuentes las estepas graminosas dominadas por Festuca gracillima (coirones). Otras fisonomías frecuentes son las estepas xéricas de Nardophyllum bryoides, los matorrales de Chiliotrichum diffusum (mata negra fueguina) y de Empetrum rubrum (murtilla).

- Distrito Central: Es el más extenso de la Patagonia y abarca la porción más árida de la región (Paruelo et al. 1992). Por ser el distrito en el que se enmarcan los sitios arqueológicos en estudio describiremos con mayor profundidad su características fitogeográficas. Se extiende desde el Noroeste Maquinchao en Río Negro hasta el río Coyle en Santa Cruz. Como las precipitaciones son escasas en todo el distrito, la vegetación varía en relación a la topografía, la temperatura y los tipos de suelos. León et al. (1998) subdividen este distrito en 5 subunidades:

- Estepa arbustiva con Chuquiraga avellaneda. Se presenta en el centro-sur de Río Negro y noreste de Chubut, limitando con la Provincia Del Monte. Además de Chuquiraga avellaneda, también cuentan con Lycium ameghinoi, L. chilense, Verbena ligustrina, Prosopis denudans, Schinus polygamus, Acantholippia serphiodes, Nassauvia ulicina, Pleurophora patagonica, Stipa humilis y Poa lanuginosa.

- Estepa arbustiva serrana con Colliguaya integerrima. Se la encuentra en el centro de Chubut. Son matorrales de hasta $170 \mathrm{~cm}$ de altura dominados por Colliguaya integerrima (duraznillo) asociados a Junellia tridens, Schinus polygamus (molle), Lycium chilense, Berberis heterophylla 
(calafate), Nardophyllum obtusifolium, Verbena ligustrina, Adesmia boroniodes (paramela), Anartrophyllum rigidum, A. desideratum y Neobaclea crispifolia.

- Estepa arbustiva baja con Junellia tridens. Se sitúan en las altiplanicies ubicadas al S y al N del valle del río Santa Cruz. Son matorrales de $70 \mathrm{~cm}$ de altura y $60 \%$ de cobertura con escaso estrato herbáceo, constituido por Stipa ibari, S. neaei, S. speciosa y Festuca pyrogea.

- Estepa arbustiva baja con Nardophyllum obtusifolium. Se ubican en las altiplanicies al oeste de los lagos Cardiel y Strobel y en mesetas cercanas a Puerto de San Julián. Además de la especie mencionada, son comunes Nardophyllum bryoides y Festuca pallescens.

- Erial. Es la unidad más ampliamente distribuida, abarcando desde la costa atlántica hasta altitudes cercanas a los 1000 metros, cubriendo planicies aluviales, mesetas, sierras, morenas y pendientes suaves. La María y Cerro Tres Tetas están emplazadas dentro de esta subunidad (Fig. 3.6). Se caracteriza por ser una estepa arbustiva muy baja (inferior a los $30 \mathrm{~cm}$ ), de muy escasa cobertura (menor al 30\%), con arbustos en cojín y escasas gramíneas (Paruelo et al. 2005). Estas comunidades están ubicadas, generalmente, sobre suelos muy arcillosos con un balance hídrico desfavorable. El erial es descripto como una fisonomía yerma y extremadamente xérica (León et al. 1998). En el caso del centro y oriente de Santa Cruz predominan Nassauvia glomerulosa (cola piche), Nassauvia ulicina y Chuquiraga aurea, a las que se suman Petunia patagonica, Poa dusenii y Azorella caespitosa, Ephedra frustillata, Acantholippia seriphioides, Mulinum microphyllum Chuquiraga kingii, Brachyclados caespitosus, Satureja darwinii y Nardophyllum obtusifolium achaparrado y Frankenia sp. Entre los arbustos enanos se intercalan gramíneas como Stipa speciosa y S. neanei en áreas poco degradadas; S. humilis y S. chrysophylla en zonas con acumulación de arena; y Festuca pallescens en mesetas sedimentarias y basálticas altas. En los paleodrenajes y depresiones secas se ubican poblaciones densas de Junellia tridens.

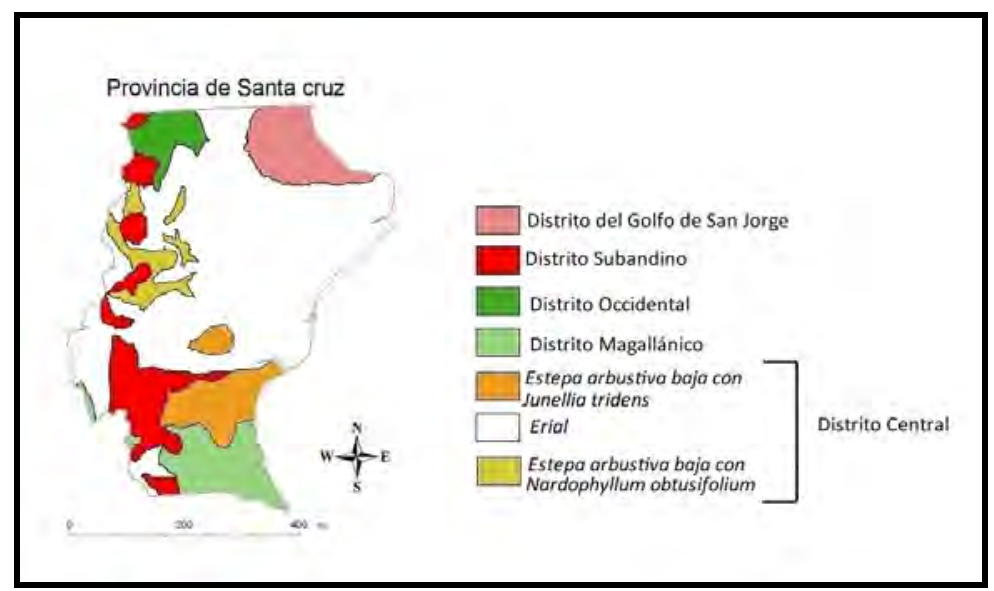

Fig. 3.6. Regiones fitogeográficas del área extraandina de Sta. Cruz, adaptado de León et al. (1998). 
La flora actual y pasada de la Localidad Arqueológica La María fue estudiada por la Dra. De Porras3, de manera que resulta interesante conocer la variabilidad interna dentro de una de las áreas donde desarrollamos nuestros estudios. Desde el punto de vista fitogeográfico, La María presenta una fisonomía de estepa arbustiva achaparrada y erial. La distribución de estas comunidades vegetales se relaciona principalmente con la topografía, la cual determina las características edáficas y las condiciones diferenciales de disponibilidad de agua, temperatura y viento (De Porras et al. 2009a). El factor más importante asociado a la topografía y que establece las diferencias de fisonomía y composición de las comunidades vegetales entre las mesetas y los cañadones es el reparo de la acción desecante y erosiva del viento. Como consecuencia se generan diferencias micro-ambientales importantes como por ejemplo, mayor temperatura dentro de los cañadones que en las mesetas circundantes. Además, los cursos temporarios por los cuales fluye el agua del derretimiento de la nieve en las mesetas más altas durante la primavera, son una fuente de agua adicional para las comunidades vegetales dentro de los cañadones. Estos se convierten así en refugios térmicos con mayor disponibilidad de agua en primavera permitiendo el desarrollo de comunidades vegetales fisonómica y composicionalmente diferentes a las de las mesetas (De Porras 2010).

En el manto de basalto (Fig. 3.7) se observa el desarrollo de una comunidad subarbustiva particular integrada por Azorella spp., Ephedra frustillata, Acantholippia seriphioides, Satureja darwinii, Senecio spp., Colliguaja integerrima (duraznillo), Junellia tridens (mata negra), Acaena magellanica, gramíneas, cariofiláceas, etc. (De Porras 2010). En cambio, en otros sectores de mesetas de la Localidad se detectan comunidades de erial con las características descriptas más arriba. La diferencia principal entre éstas y la meseta basáltica es la presencia de bloques de basalto que brindan protección a las plantas ante la acción del viento generando nichos ecológicos inexistentes en otras mesetas (De Porras 2010).

Los sectores con cañadones presentan comunidades arbustivas, con particularidades en cada uno. Por ejemplo, en el Sector Cañadón de la Mina (Fig. 3.7) se observa una comunidad arbustiva integrada por Nardophyllum obtusifolium, Lycium chilense, Anarthrophyllum rigidum (mata amarilla), Berberis heterophylla (calafate), Junellia ligustrina, Junellia tridens (Mata negra) y Senecio spp. En el Sector La María Quebrada (Fig. 3.7) la vegetación presente en la zona del bajo colector de aguas es una comunidad arbustiva integrada por arbustos altos y de altura media como Colliguaja integerrima (duraznillo), Anarthrophyllum rigidum, Anarthrophyllum strigulipetalum, Junellia tridens, Lycium chivense (yaoyín), Berberis heterophylla, Schinus

\footnotetext{
${ }^{3}$ Doctorado en Ciencias, área Biología. FCEyN, UNMDP. Tesis: Dinámica de la vegetación de la Meseta Central de Santa Cruz durante los últimos 11.000 años a partir del análisis polínico: forzantes bióticos y abióticos. Directora: María Virginia Mancini.
} 
polygamus (molle), Senecio spp., acompañados por coirones (Poaceae) y Acaena magellanica. Al ascender por la ladera oeste la vegetación se torna en comunidad subarbustiva integrada por Nassauvia glomerulosa, Nassauvia ulicina (manca perro), Chuquiraga avellanedae (quilembay) y Ephedra frustillata. En esta zona tanto el duraznillo como el molle están presentes pero en forma achaparrada.

Vale destacar que en todos los distritos de la Patagonia la vegetación muestra una mayor heterogeneidad que la descripta, asociada con la altura, la pendiente y la exposición. Por ejemplo, en la región se encuentran "mallines", praderas húmedas asociadas con los cursos de ríos o arroyos o con los fondos de los valles. En ellos, la alta disponibilidad de agua determina una fisonomía enteramente diferente. La cobertura a menudo supera el $100 \%$, y las dominan los pastos mesofíticos (Poa pratensis, Deschampsia flexuosa, etc.), los juncos (Juncus balticus) y las ciperáceas (Carex spp.). Si bien abarcan muy poca superficie, proveen un hábitat de crucial importancia para la fauna (Paruelo et al. 2005). Estos microambientes también se encuentran presentes en las localidades en estudio (Fig. 3.7).

Otro rasgo a resaltar es que las diferentes unidades de vegetación han resultado disturbadas desde el siglo XIX como consecuencia de diversas actividades humanas, como la cría de ovejas, que no sólo han generado una disminución de la diversidad de las comunidades sino también la introducción de especies exóticas como Rumex crispus, Taraxacum officinale, Plantago major, Carduus nutans, Lepidium sp., entre otras. (De Porras 2010). 


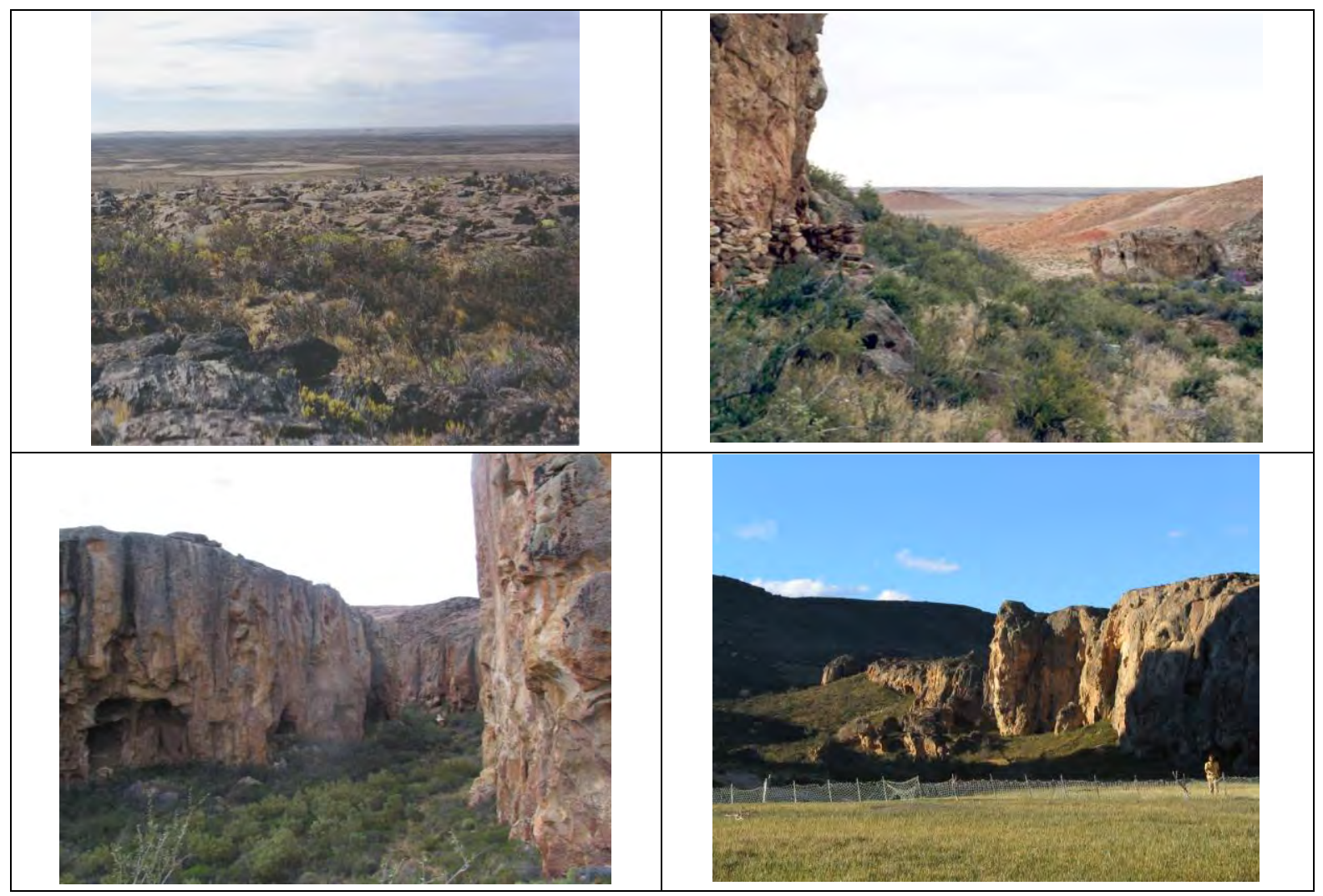

Fig. 3.7. Localidad Arqueológica La María. De Izq a Der y de arriba abajo. Manto de basalto. Sector Cañadón de la Mina. Cañadón La María Quebrada. Mallín en Sector La María Quebrada.

\subsubsection{Fauna}

Cabrera y Willink (1980) agrupan a la fauna siguiendo las provincias fitogeográficas mencionadas anteriormente, constituyendo, en consecuencia, provincias biogeográficas. A diferencia de lo que ocurre con la fitogeografía, no subdividen a estas provincias en distritos.

En la Provincia Patagónica encontramos diversos mamíferos: destaca el guanaco (Lama guanicoe), tanto por su número como por su importancia económica para las poblaciones que habitaron este territorio a lo largo de la historia. Hay carnívoros como los zorros gris (Pseudalopex griseus) y colorado (Pseudalopex culpaeus), el puma (Felis concolor), el zorrino (Conepatus humboldti) y el gato de los pajonales (Felis colocolo), el hurón menor (Galictis cuja), el huroncito (Lyncodon) y gato montés (Felis geoffroyi). Se observan roedores como la mara o liebre patagónica (Dolichotis patagonum), varias especies de tucu-tucu (Ctenomys sp.), numerosos ratones o ratas de la Familia Cricetidae y cuises de la Familia Caviidae. También se encuentran armadillos como el piche (Zaedyus pichiy) y el peludo (Chaetophractus sp.). Existen marsupiales como la marmosa (Marmosa), Lestodelphis, la comadreja overa (Didelphis) y murciélagos (Lasiurus, Tadarida, Histiotus). En la costa atlántica destaca el lobo marino (Otaria flavescens).

Se encuentran numerosas aves como el choique o ñandú petiso (Pteronemia pennata) que ha resultado de importancia para los antiguos habitantes de esta región. También pueden observarse diversos patos (Tachyeres, Anas, Oxyura, Merganeta), avutardas (Chloephaga), cisnes 
de cuello negro (Cygnus), gansos (Coscoroba), macás (Podiceps), gallinetas (Rallus), gallaretas (Fulica), gaviotas (Larus). Se observan Tinamiformes: las martinetas (Eudromia elegans) así como Nothura y Tinamotis; y rapaces: Buteo, Geranoaetus, Polyborus, Falco y Milvago. También hay palomas (Zenaida y Columbus), atajacaminos (Caprimulgus) y numerosos pájaros (Turdus, Mimus, Microsittace). En la costa están presentes los pingüinos (Spheniscus magellanicus).

Hay gran variedad de reptiles, muchos de los cuales son endémicos de esta provincia. Destacamos: yarará ñata (Bothops ammodytoides), víbora de la cruz (B. alternata) y coral (Micrurus). Culebras: Leimadophis, Tomodon, Chlorosoma. Geckonidos e iguánidos: Homdonta, Liolaemus, Phymaturus, Diplolaemus. Los géneros de iguánidos tuvieron una amplia dispersión pliocénica y posteriormente quedaron aislados en reductos de diferente extensión y separados por barreras naturales, lo que dio lugar a una notable diversidad de formas adaptadas a ambientes de condiciones extremas (Paruelo et al. 2005).

Entre los peces se pueden mencionar bagres (Hatcheria), otunos (Diplomystes), peladillas (Haplochiton), trucha criolla (Percichthys), pejerrey patagónico (Basilichthys), puyenes (Galaxias). Con excepción de los peces, algunas aves, reptiles (víboras y culebras) y carnívoros (el hurón menor, el huroncito y el gato montés), así como la fauna vinculada a la costa atlántica (pingüinos, lobos marinos, gaviotas, etc.), la mayor parte de la fauna aquí mencionada puede ser observada en las localidades arqueológicas en estudio. Cabe aclarar que la fauna nativa de la región fue severamente afectada por la introducción del ganado doméstico (principalmente ovino) y por las actividades relacionadas con la ganadería: cambios en la estructura y el funcionamiento de la vegetación, el pisoteo y la destrucción de cuevas, la caza irrestricta, etc. Además, la introducción de mamíferos exóticos como la liebre europea también modificaron las condiciones naturales y crearon situaciones de competencia con las especies nativas (Paruelo et al. 2005).

\subsection{Paleoambiente}

Los conjuntos arqueológicos en estudio cuentan con dataciones que los enmarcan dentro de lo que se conoce como Transición Pleistoceno - Holoceno, es decir, entre 13.000 y 8.000 años antes del presente de acuerdo al registro isotópico marino (Miotti y Salemme 2003). La transición Pleistoceno - Holoceno es el momento de finalización de la última era glacial, que tuvo su último máximo hace aproximadamente 18.000 años (Clapperton 1995). Durante este período se han registrado cambios en la vegetación, el volumen del hielo y condiciones de la superficie del mar para la Patagonia, así como la extinción de la megafauna Pleistocénica. Si bien la descripción ambiental dada anteriormente nos da un marco de referencia para conocer el paisaje en el que vivieron estas sociedades, resulta importante incluir, en la medida de lo posible, información 
paleoambiental referente a ese período, puesto que existen importantes diferencias entre el paisaje actual y el pasado.

En el siguiente apartado, presentamos la información paleoambiental disponible hasta el momento para la zona que nos interesa y áreas conexas, tomando diversos indicadores. Seguiremos un orden geográfico y cronológico.

\subsubsection{Aspectos Generales}

Durante el último máximo glacial el campo de hielo se extendía a lo largo de $1800 \mathrm{~km}$ en las crestas de los Andes, siendo sus límites norte y sur $41^{\circ} \mathrm{S}$ y $55^{\circ} \mathrm{S}$ respectivamente y constituyendo un reservorio de agua que equivalía a 1,2 $\mathrm{m}$ del nivel del mar (Hulton et al. 2002). De acuerdo a algunas simulaciones, una disminución en la temperatura de $6^{\circ} \mathrm{C}$ y un leve aumento en la sequedad podrían bastar para que existiera una masa de hielo del tamaño previamente expuesto. Además se ha propuesto que la Zona Frontal Antártica habría sufrido un movimiento en dirección norte, aproximadamente entre $3^{\circ}$ y $5^{\circ}$ con respecto a su situación actual (Kaplan et al. 2008).

Según Codignotto (1997), durante el Último Máximo Glaciar la costa marítima patagónica presentaba una fisonomía distinta, como consecuencia de las glaciaciones. Debido a estas, el nivel del mar se encontraba aproximadamente a $150 \mathrm{~m}$ por debajo del nivel actual, por lo que en aquel momento existía una porción de territorio libre que hoy se encuentra bajo las aguas.

El inicio de la desglaciación habría comenzado hace aproximadamente 17.500 años cal. AP, en respuesta a un calentamiento escalonado. Una vez iniciada, la desglaciación se dio rápidamente, especialmente en el sector norte de la Patagonia (Hulton et al. 2002). El registro paleoambiental patagónico parece indicar que el período 13.000 - 8.000 años AP habría tenido temperaturas relativamente cálidas (Glasser et al. 2004). La desglaciación fue interrumpida por reavances glaciales tardíos, particularmente en el sector sur, donde se observa un avance que abarca el Episodio Frío Reverso Antártico entre los 11.000 y 10.000 años AP (Hulton et al. 2002). Este episodio, (EFRA), sería equivalente al intervalo frío Younger Dryas sobre todo a partir de los análisis de polen (Heusser y Rabassa 1987; Rabassa y Clapperton 1990). Sin embargo, la correspondencia de fechados radiocarbónicos no es estricta (Lowell et al. 1995), y en muchos casos, este evento frío no se observa (Heusser 1995).

Durante el Tardiglacial, entre 16.000 y los 10.000 14C AP dominaron los ambientes esteparios, alternándose estepas herbáceas y arbustivas de acuerdo a las fluctuaciones en las temperaturas y precipitaciones, evolucionando paulatinamente a áreas boscosas en los sectores más cercanos a la cordillera de los Andes (Miotti y Salemme 2004). 
De acuerdo a Glasser et al. (2004), el período 10.000 - 8.000 años AP es un momento de mejoramiento climático para la Patagonia extraandina, en el cual suben las temperaturas estivales y disminuyen las precipitaciones.

El derretimiento de las grandes masas de hielo, en conjunto probablemente con otros factores como la actividad tectónica y la eustasia, generó la suba del nivel del mar, provocando así una disminución del territorio disponible, hecho que alcanzó su pico máximo durante la Transgresión Marina del Holoceno Medio (Coronato et al. 1999).

El fin del Pleistoceno marcó también la extinción de un gran conjunto de animales. La Patagonia contaba, antes de esta extinción con una mayor diversidad taxonómica que la actual que incluía ejemplares de caballos, camélidos, milodontinos, félidos y cánidos hoy ausentes (Martín 2007).

\subsubsection{Meseta Central}

Entre los 12.600 y ca. 11.000 años AP, de acuerdo a Páez et al. (1999), y basándose en datos palinológicos de la Localidad Arqueológica Los Toldos, existió en esta área una estepa de arbustiva con alta proporción de Ephedra. Este taxón se encontraría asociado con porcentajes bajos de Poaceae y Asteraceae y rastros de otros arbustos. De acuerdo a De Porras (2010), en cambio, entre ca. 12.000 y 10.250 años AP las asociaciones polínicas de Los Toldos representan una comunidad subarbustiva-graminosa de Ephedra frustillata y Nassauvia con Asteraceae subf. Asteroideae. Si bien en la actualidad no existen conjuntos modernos análogos a lo registrado en Los Toldos, la predominancia de Ephedra indicaría que las condiciones medioambientales durante este período eran más frías que las actuales y con precipitaciones menores a $200 \mathrm{~mm}$ anuales (De Porras 2010; Páez et al. 1999). Esta misma asociación polínica se observa en La María (De Porras 2010). De acuerdo a De Porras (2010), la historia de la vegetación de ambas localidades ha sido muy similar desde hace 12.000 años AP. Aunque los registros polínicos de La María son temporalmente fragmentarios, concuerdan y complementan la información registrada en Los Toldos.

Por su parte, en Piedra Museo los análisis polínicos del nivel inferior de AEP-1, datado en 12.890 10.470 años AP, indican un predominio de Asteraceae y Poaceae, con bajos valores de Nassauvia y Ephedra. Esta asociación indicaría una estepa arbustiva bajo condiciones de escasa disponibilidad hídrica (Borromei 2000). Aproximadamente a los ca. 11.000 años AP se evidencia una estepa de gramíneas, caracterizada por Poaceae, Asteraceae y Chenopodiineae, que indicarían condiciones de mayor humedad efectiva, quizás asociado con un incremento de las precipitaciones en condiciones frías (Borromei 2000). El registro polínico de Piedra Museo es contrastante con el de La María y el de Los Toldos. Esto podría deberse a las características 
topográficas y geomorfológicas de este sector, o bien a diferencias en la resolución temporal de la secuencia polínica (De Porras 2010).

En cuanto a la paleofauna, la Meseta Central posee evidencias que permiten inferir ambientes con una mayor capacidad de soporte y diversidad en los recursos faunísticos. Así, por ejemplo, se ha obtenido evidencia de Hippidion saldiasi, una especie de caballo americano, en diversos sitios de la región tales como Cuevas 2 y 3 (Los Toldos), Cueva 4 (El Ceibo), Alero El Puesto (Piedra Museo), Cueva Túnel (La María) y el sitio paleontológico Cerro Bombero (Alberdi et al. 2001; Miotti y Salemme 1999; Paunero et al. 2008b). Lama gracilis, un camélido de menor porte que el guanaco, ha sido identificado en Los Toldos, Piedra Museo, El Ceibo, Casa del Minero y Cueva Túnel (La María), mientras que Hemiauchenia Paradoxa, el camélido de mayor tamaño en la región, ha sido hallado únicamente en La María (sitios Casa del Minero y Cueva Túnel) dentro de la Meseta Central (Cardich 1987, Miotti 2000; Miotti y Salemme 1999, Paunero et al. 2007d, Ramos y Paunero 2009). Otras especies extintas o bien hoy ausentes en la zona, que han sido registrados para distintos sitios arqueológicos de la región, o regiones anexas son Rhea americana, Megatherium sp., Mylodon, un zorro: Dusicyon avus, un oso: Arctotherium tarijense y dos félidos: Smilodon sp. y Panthera onca mesembrina (Martín 2007; Miotti y Salemme 1999; Paunero et al. 2007d; Ramos y Paunero 2009).

Todas estas son evidencias de un ambiente con mayor diversidad faunística, lo que implica, desde el punto de vista de las primeras sociedades que colonizaron este espacio, un mayor abanico de recursos disponibles para su explotación. Hace aproximadamente 15.000 años AP comienza el proceso de extinción de estas poblaciones faunísticas, debido a los cambios climáticos que se venían produciendo. Además, la acumulación de cenizas volcánicas y el ascenso del nivel del mar disminuyeron la diversidad de hábitats para la fauna contribuyendo a la extinción de muchas de estas especies.

Entre 11.000 y 10.000 años AP la estepa arbustiva de Ephedra fue reemplazada en Los Toldos por una estepa de pastizal con altos valores de Poaceae y otros taxones herbáceos como Cyperaceae, Caryophyllaceae y Plantago. De acuerdo a Páez et al. (1999), esto sugiere que en este período ocurrió un aumento en la humedad efectiva relacionado a un aumento en las precipitaciones y las condiciones frías.

Además existe para este período evidencia de una mayor energía del régimen hídrico de ríos, arroyos, lagos y lagunas. Se produjo la progradación de la faja costera porque los ríos contaban con mayor carga, aportando sedimentos a la zona costera (Kokot 2004). Las evidencias sedimentológicas de la estratigrafía de Piedra Museo, Casa del Minero, Cueva Túnel, El Ceibo 7, La Mesada y Cerro Bombero, muestran para el EFRA un mayor caudal en los bajos próximos a los sitios (Paunero 2009b). En el arroyo del cañadón de Los Toldos la evidencia sedimentaria del sitio Cueva 2 muestra acción fluvial de alta energía para los primeros indicios de ocupación humana, 
evidenciada en la concentración de arena gruesa, gravas y arena intercalada en la secuencia (Paez et al. 1999; Paunero 2009b; Paunero y Blasi 2009).

Un fenómeno común en la Patagonia a partir de los ca. 10.000 años AP es el de derrumbes masivos de los techos de las cuevas, probablemente vinculados a actividad volcánica (Miotti y Salemme 2004). Ejemplos de estos derrumbes en cuevas en la provincia de Santa Cruz son los sitios Casa del Minero, Piedra Museo, Cueva 7 de El Ceibo, Arroyo Feo 1, Cueva de Las Manos y Las Buitreras (Cardich 1987; Miotti y Salemme 2004; Paunero et al. 2004b).

En Los Toldos, de acuerdo a los análisis sedimentológicos, a partir del Holoceno temprano las condiciones empiezan a semejarse a las actuales, con menor energía y régimen estacional del arroyo, y depósitos, principalmente, de arenas finas (Paunero 2009b). En Cerro Bombero, ubicado en un área intermedia entre la meseta y la costa atlántica, también se evidencian cambios en el régimen hídrico, presentando la unidad estratigráfica inferior rodados de tamaño mediano a grande (Paunero 2009b).

Entre los ca. 10.000 y los 8.750 años AP domina en Los Toldos una estepa arbustiva caracterizada por Asteraceae, Ephedra y Nassauvia, asociada con Verbena, Adesmia, Azorella, Chuquiraga, Colliguaja y algunos pastos. Esta comunidad también se presenta en el sitio Cueva Túnel de La María (De Porras 2010). La variación en las concentraciones de polen de algunos taxones sugeriría cambios en la disponibilidad del agua, lo que determinaría cambios a pequeña escala en la distribución de las plantas. Por otro lado, las fluctuaciones en los porcentajes y concentraciones de Chenopodiineae sugieren que los períodos húmedos y áridos ocurrieron intermitentemente, reflejando condiciones semiáridas (Páez et al. 1999). De acuerdo a los autores, la precipitación era similar a la del periodo anterior. El aumento de la cobertura arbustiva podría ser explicado por un aumento en la temperatura y una consiguiente disminución en la disponibilidad de agua (Páez et al. 1999).

También en La Martita se observan evidencias de estepas arbustivas hacia los 8.000 años AP, consistente en Asteraceae tubuliflorae, Solanaceae (Lycium), Fabaceae (Anarthrophyllum), Ephedra, Chenopodiineae y Empetrum, y Poaceae, Caryophyllaceae y Cyperaceae en el substrato herbáceo (Mancini 1998). Estas se relacionarían con un aumento en la temperatura con respecto al período anterior.

Por otra parte, los datos polínicos de Piedra Museo indican para el ca. 9.500 años AP un aumento en los pastizales y de la humedad efectiva del área (Miotti y Salemme 2004). Después de los 9.000 años AP el paleoambiente se volvió más seco y cálido que antes. Predominan Chenopodiineae y Asteraceae, lo que sugiere condiciones de disminución de la humedad disponible, relacionada a menores precipitaciones y/o más altas temperaturas (Coronato et al. 1999). 


\subsubsection{Cuenca Austral}

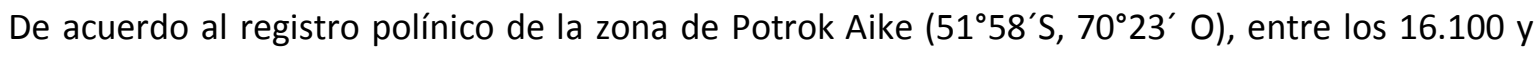
los 13.890 años cal. AP este sector estaba dominado por gramíneas, con un alto porcentaje de Poaceae que informa acerca de un alto nivel de humedad. Los elevados valores de Acaena, Ericaceae, Empetrum y Gunnera sugieren una cubierta vegetal relativamente abierta, probablemente debido a bajas temperaturas. Después de los 15.440 años cal. AP se observa un leve aumento de Nothofagus, debido probablemente al aumento en la temperatura, o bien al aumento de la velocidad del viento en la zona de estudio. Por otra parte, la presencia de la diatomea Aulacoseira granulata indica un calentamiento del agua de la laguna Potrok Aike (Wille et al. 2007).

En la zona del Estrecho de Magallanes, en Puerto del Hambre, de acuerdo a Heusser (1995) previo a los 15.800 años AP se observa la presencia de pequeñas comunidades abiertas de Nothofagus. Entre los 15.000 y los 14.000 años AP se desarrolla una estepa arbustiva dominada por Empetrum, que se encuentra asociada con Adesmia, por lo que se infieren condiciones más secas y frías que en los momentos previos (Heusser 1995).

Si bien después de los 13.890 años cal. AP en Potrok Aike la estepa sigue siendo dominada por gramíneas, aparece carbón y aumenta Asteraceae subf. Asteroideae, lo que sugiere ambientes más secos y mayores temperaturas. También se produce un aumento de Nothofagus. Información coherente con esta surge del análisis de los sedimentos y microfósiles de la laguna Potrok Aike, donde se observa que el nivel de la laguna disminuyó después de los 13.200 años cal. AP (Wille et al. 2007).

En Puerto del Hambre, Nothofagus no está bien representada después de los 13.190 años AP, siendo predominante una estepa arbustiva con altos valores de Acaena. Nothofagus sólo comienza a expandirse progresivamente a partir de los 10.940 años AP (Heusser 1995).

Entre los 12.520 y los 11.990 años cal. AP se observa en Potrok Aike una disminución de los elementos boscosos andinos, que indicarían un clima más seco o frío. Después de los 11.990 años cal. AP disminuye Poaceae en la vegetación y es reemplazada por arbustos de Asteraceae subf. Asteroideae, lo que sugiere una disminución en la humedad disponible (Wille et al. 2007).

Por otra parte, en el lago Cardiel se demostró la existencia de modificaciones en el nivel de agua entre el Pleistoceno final y el Holoceno temprano, provocándose un desecamiento completo aproximadamente sincrónico con el comienzo del Younger Dryas. Para los 10.230 años AP se observa un ascenso rápido del nivel del lago que se debería a un aumento de la humedad (Gilli et al. 2001).

Durante el Holoceno temprano, la retracción de los glaciares genera diversas consecuencias geográficas, como la disminución del tamaño de los campos de hielo continentales, la 
conformación total del estrecho de Magallanes, quedando delimitada la Isla Grande de Tierra del Fuego (Clapperton 1995; Rabassa et al. 2000); y la disminución de las características de continentalidad debido al incremento en el nivel del mar (Rabassa y Clapperton 1990). Debido a la intensa ablación producida por los glaciares se produjo la incisión de los sistemas fluviales y se constituyeron valles de grandes dimensiones. Esto generó que, al disminuir el caudal, los ríos configuraron un sistema hidráulico con muy baja capacidad de transporte (Kokot 2004).

Por otra parte, hacia inicios del Holoceno, la vegetación en el sitio Chorrillo Malo 2, al sur del Lago Argentino, es una estepa graminosa, con Cyperaceae y arbustos asociados; durante el Holoceno temprano comienzan a expandirse en zonas aledañas los bosques de Nothofagus (Mancini 2002). Esto podría relacionarse con un aumento en las precipitaciones. El intervalo de colonización y bosque abierto en esta zona perduró hasta los 8.000 años AP (Mancini 2002). Hacia los 8.500 años AP se observa un cambio de estepa graminosa a estepa arbustiva, lo que sugiere condiciones más secas (Mancini 2002).

Entre los 8.700 y 7.300 años cal. AP se infieren en Potrok Aike condiciones muy secas y un muy bajo nivel de la laguna de acuerdo a parámetros geoquímicos, estudios de diatomeas y análisis polínicos (Wille et al. 2007).

\subsubsection{Sector andino de Santa Cruz}

Durante el Último Máximo Glaciar, el paisaje de los Andes patagónicos estaba modificado por numerosos glaciares que se desprendían del Campo de Hielo. Estos glaciares de grandes dimensiones, se extendían a veces por cientos de kilómetros hasta llegar a sectores de planicies (Coronato et al. 1999). A partir de los 17.500 años cal. AP los glaciares comienzan a retroceder, y el espacio que estos abandonan es ocupado por grandes lagos que se nutren del derretimiento glacial.

Otro rasgo a tener en cuenta en este período es una marcada actividad volcánica. Por ejemplo el

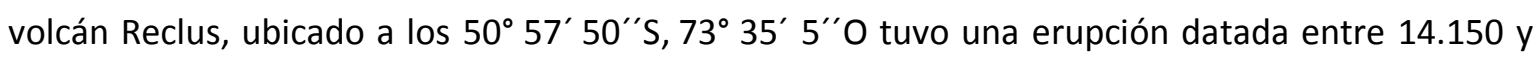
14.990 años AP en Represa Porvenir (Tierra del Fuego) (Miotti y Salemme 2004). Otra erupción del mismo volcán fue datada en 12.500 años AP (Heusser 1995; Miotti y Salemme 2004). Otras posibles fuentes de erupciones volcánicas durante la transición Pleistoceno - Holoceno habrían sido los volcanes Burney y Fueguino (Heusser 1995; Miotti y Salemme 2004). Si bien de manera aperiódica, las erupciones volcánicas fueron frecuentes durante este lapso.

Según Markgraf (1993) al este de los Andes, al sur de 50 S, los registros palinológicos anteriores a los 12.500 años AP señalan una vegetación de tundra árida caracterizada por Empetrum, indicando fuertes vientos y una precipitación anual menor a $300 \mathrm{~mm}$ con temperaturas muy frías durante todo el año. 
Después de los 12.500 años AP el bosque de Nothofagus comienza a expandirse dentro del ambiente de pastizales en el sector andino de Santa Cruz, sugiriendo un decrecimiento en la intensidad del viento (Coronato et al. 1999), un incremento en la humedad efectiva y en la temperatura (Glasser et al. 2004). Los cambios en las condiciones climáticas en este período se reflejan en la asociación predominante de Gramineae-Tubuliflorae Nothofagus (Heusser 1995), con una transición a condiciones de pastizal. Estas condiciones ambientales se mantuvieron hasta el Holoceno temprano.

De acuerdo a Clapperton (1995), entre los 12.400 y los 11.800 años AP los glaciares se encontraban en un período de estabilidad. El autor afirma que esto se vincularía con un giro hacia el sur de los vientos del oeste cargados de precipitaciones, vientos que previamente habría estado circulando más hacia el norte.

Luego de un corto período de aparente retroceso, una disminución progresiva de la temperatura a partir de los 11.400 años AP culmina en condiciones estadiales que duraron entre los $11.200 \mathrm{y}$ los 10.200 años AP y que llevaron al reavance de los glaciares.

En el área de Vega Ñandú, cercana a Torres del Paine (Chile), entre los 10.800 y los 9.500 años AP los análisis palinológicos indican la predominancia de arbustos (Ericaceae) y hierbas (Poaceae, Acaena, Asteraceae, Plantago, Valeriana y Phacelia), que revelan un paisaje abierto dominado por una vegetación arbustiva de tipo pre - andino bajo condiciones de relativa humedad y clima frío (Villa-Martínez y Moreno 2007).

En el sector andino a latitud $47^{\circ} \mathrm{S}$, con anterioridad a los ca. 9.000 años $\mathrm{AP}$, los conjuntos polínicos de Casa de Piedra 7 presentan altos valores de Poaceae que indican que la vegetación estuvo representada por una estepa graminosa, asociada a condiciones de mayor humedad que las actuales (Mancini 2007). Con posterioridad a ca. 9.000 años AP disminuyen las proporciones de pastos. El aumento de Nothofagus, de taxones arbustivos y de plantas de cojín (Empetrum, Azorella) sugiere una mayor heterogeneidad en la composición de la vegetación (Mancini 2007).

Entre los 10.000 y 8.000 años AP los glaciares en todo el globo habrían retrocedido rápidamente ya que el calentamiento global aceleró el derretimiento de grandes capas de hielo (Clapperton 1995). Como consecuencia, hace aproximadamente 10.000 años AP se desintegra el paleolago "Caldenius" formándose los lagos actuales Azara, Belgrano, Mogote, Nansen, Volcán y Burmeister en el Parque Nacional Perito Moreno (Tatur et al. 2002).

Las condiciones paleoambientales durante la deglaciación marcan la transición entre estepa/bosque y el bosque abierto con altos niveles de componentes no arbóreos. Las comunidades forestales comienzan a desarrollarse como grupos aislados en la estepa graminosa (Heusser 1989 en Coronato et al. 1999, p. 86).

En Vega Ñandú, a partir de los 9.500 años AP se observa un aumento abrupto de Nothofagus y Valeriana, disminuyendo Ericaceae, Poaceae, Liliflorae y Acaena. Esto indicaría una alta 
variabilidad en las precipitaciones y temperaturas más cálidas. A los ca. 8.500 años AP hubo un incremento en la humedad que alcanzó niveles máximos, evidenciado en Cueva del Mylodon por altos porcentajes de N. betuloides (Markgraf 1993). En el Parque Nacional Torres del Paine los vientos del oeste pudieron producir niveles más altos de los lagos y gran humedad para la expansión de Nothofagus (Heusser 1995). 


\section{CAPÍTULO 4: EL MANEJO DEL FUEGO EN LA PATAGONIA SEGÚN LAS FUENTES ETNOHISTORICAS}

En este capítulo estudiamos de qué modo manejaron el fuego las sociedades patagónicas posthispánicas. Para ello, realizamos una revisión de relatos escritos por diversos cronistas, viajeros y naturalistas que visitaron la Patagonia a lo largo de los últimos cinco siglos y analizamos las referencias vertidas en ellos, puesto que estos cronistas registraron ciertos aspectos de la vida de las sociedades que allí habitaban.

El estudio de las fuentes etnohistóricas resulta de utilidad como generador de referentes analógicos para la interpretación arqueológica y para la formulación de hipótesis acerca de cómo viven las sociedades. Es especialmente útil en casos en que, como en Pampa y Patagonia, las poblaciones autóctonas han quedado fuertemente disminuidas o han desaparecido, quedando imposibilitado el estudio etnoarqueológico de estas sociedades (Prates 2009). Cabe destacar que éstos son hoy en día una de las fuentes más importantes sobre las que se realizan analogías en arqueología (ver por ejemplo Politis 2002). Si bien en la Patagonia se han llevado a cabo este tipo de investigaciones para analizar el manejo del fuego (Pérez de Micou 1991), no es posible en la actualidad desarrollar estos estudios sobre cazadores-recolectores. De esta manera, una forma suplementaria de acceder a esta información es mediante la realización de análisis etnohistóricos (Cattáneo 2002; Manzi y Spikins 2008; Moreno 2008; Prates 2009).

En el caso que nos ocupa, existe poca información acerca del manejo y uso del fuego por parte de las primeras poblaciones que ocuparon la Patagonia en general y la Meseta Central en particular. Así, buscamos relevar información concerniente al aprovisionamiento de combustible, encendido, mantenimiento, uso y apagado del fuego, que resulte de utilidad como referente para los trabajos arqueológicos (Pérez de Micou 1991).

Nuestra búsqueda se realizó en publicaciones que refieren a un amplio marco geográfico, que excede a la Meseta Central y que podemos delimitar, en sentido Este-Oeste por el Océano Atlántico y la Cordillera de los Andes y en sentido Norte-Sur por el Río Negro y el Estrecho de Magallanes. Esto se debe fundamentalmente a dos motivos, por un lado, a la escasez de referencias vinculadas específicamente al área de estudio, por el otro, a la naturaleza móvil de parte de las sociedades que habitaron este territorio durante el período post-hispánico. Deseamos hacer hincapié en aquellas características que indican continuidades generales en distintos espacios y sociedades. Partimos de la premisa de que las sociedades que habitaron la Patagonia en el pasado, compartían un ambiente, explotaban recursos semejantes, contaban con una tecnología similar y tenían en común formas de pensamiento y una cosmovisión que vuelve posibles analizarlas en su conjunto. Esto no implica ignorar la diversidad existente, matices y 
variaciones que se dan por tratarse de sociedades diferentes que se desarrollaron en un espacio tan amplio (Prates 2009). De esta manera, resaltaremos también determinadas características que han sido expresadas para sociedades fuera del área de estudio (Tierra del Fuego), pero que son afines geográfica y culturalmente y que resultan de interés para el objetivo de esta Tesis.

El rango temporal en que se enmarcan estos relatos es amplio: se toman referencias desde principios del siglo XVI (Pigafetta 2004) hasta principios del siglo XX (Onelli 1904). También se incorporaron investigaciones etnográficas recientes (Aguerre 2000), puesto que brindan información relevante a la temática.

A medida que se realizó la lectura de las fuentes, todas las referencias vinculadas al fuego fueron volcadas en una base de datos en la que se registraba la cita, la información bibliográfica, el año de la observación, la página en la cual se encontraba la cita, las palabras clave y a qué etapa del manejo del fuego se refería, así como cualquier otra información que resultara de utilidad. Se registró un total de 219 citas en que se expresan diversos aspectos del manejo del fuego: aprovisionamiento de combustible, encendido del fuego, mantenimiento, uso y apagado abandono de la estructura de combustión. En relación al uso del fuego, se clasificaron las citas referentes a este acápite en dos grandes grupos, por un lado aquellas referencias que expresaban actividades en las cuales se aprovecha el fuego, el calor, el humo, el carbón, las brasas o las cenizas en algún tipo de actividad (por ejemplo la cocción) y por el otro las expresiones acerca de actividades que no necesitan del uso del fuego pero que igualmente se realizan cerca de él (por ejemplo comer).

Para facilitar la lectura, en el presente capítulo sólo pondremos las referencias bibliográficas, dejando las citas textuales en el ANEXO 1, donde pueden ser consultadas en su totalidad.

\subsection{Aspectos generales}

Relevamos un total de 25 fuentes. En 6 de ellas no registramos ninguna referencia. En las restantes 19, identificamos 219 citas vinculadas a alguna etapa del manejo del fuego De estas, 13 son mixtas, es decir, abordan más de una temática. Las restantes son citas simples (ver Cuadro 4.1).

La mayor parte de las expresiones se vinculan con aspectos relativos al uso del fuego $(64,7 \%)$. Le siguen las actividades realizadas en torno a estas estructuras de combustión con un 14,2\%. Las citas sobre las etapas de aprovisionamiento $(8,6 \%)$, encendido $(5,2 \%)$, mantenimiento $(4,3 \%)$ y apagado $(3,0 \%)$ presentan un bajo porcentaje en relación al total. Sin embargo, ofrecen elementos útiles a la hora de evaluar la forma en que se manejaba el fuego en épocas pasadas. 


\begin{tabular}{|c|c|}
\hline Etapa del manejo & Total \\
\hline Aprovisionamiento & 16 \\
\hline Aprovisionamiento - Encendido & 1 \\
\hline Aprovisionamiento - Uso & 3 \\
\hline Encendido & 10 \\
\hline Encendido - Uso & 1 \\
\hline Mantenimiento & 6 \\
\hline Mantenimiento - Actividades en torno al fogón & 2 \\
\hline Mantenimiento - Uso & 2 \\
\hline Actividades en torno al fogón & 28 \\
\hline Actividades en torno al fogón - Uso & 3 \\
\hline Uso del fuego & 140 \\
\hline Apagado - Uso & 1 \\
\hline Apagado & 6 \\
\hline Total & 216 \\
\hline
\end{tabular}

Cuadro 4.1. Cantidad de citas por etapa

\subsection{Aprovisionamiento}

Las expresiones en relación al aprovisionamiento de combustibles hacen referencia a los responsables de la recolección y las zonas con escasez o abundancia de insumos disponibles.

En cuanto a quién estaba a cargo del aprovisionamiento y acarreo de la leña al campamento, habitualmente se menciona a la mujer (Viedma 1783, p. 71 y 72; Larrain 1883, p. 39; Gonzalez 1965, p. 26; Claraz 1988, p. 66; Beerbohm 2004, p. 64), los niños (Larrain 1883, p.39) y los cautivos/esclavos (Cox 2006, p. 170). Un hombre sólo realizaba esta tarea si era soltero y no tenía cautivos (Claraz 1988, p. 79).

La abundancia o escasez también es una referencia muy presente en diversos autores, indicando la importancia que tenía este recurso en los grupos patagónicos. Se destaca cuando este se presenta de manera ubicua (Gonzalez 1965, p. 22; Musters 2005, p. 144 y 259) o bien cuando es particularmente exiguo (Claraz 1988, p. 88; Beerbohm 2004, p. 79 y 118; Cox 2006, p. 100; Musters 2005, p. 35). Inclusive se subraya que en los casos en que se iba a transitar por una zona sin leña disponible, los tehuelches acarreaban este combustible para tener suficiente durante el trayecto (Beerbohm 2004, p. 118). También se resalta que en áreas con poca leña los toldos se ubican de forma dispersa, modificando así la estructura del asentamiento (Cox 2006, p. 100). Se destaca asimismo la importancia de no malgastar la leña (Musters 2005, p. 35), hecho que se ve expresado en un relato mítico (Claraz 1988, p. 66).

También se ha mencionado en algunas ocasiones cual es la leña recolectada, como es el caso del coligüe (Nothofagus dombeyi), (Cox 2006, p. 127). En ciertas oportunidades se observa que determinada madera posee cualidades que la vuelven un muy buen combustible (Claraz 1988, p. 
45) o bien que ésta no es apta para ser usada como leña por diversos motivos (Musters 2005, p. 319).

\subsection{Encendido}

Las expresiones que se refieren al encendido del fuego expresan por un lado el método empleado y por el otro quien tenía el rol de hacer esta tarea.

En relación a la técnica utilizada para la ignición, lo predominante es la fricción entre dos maderas (Claraz 1988, p. 91 y 114; Pigafetta 2004, p. 51; Drake 1854, p. 50), aunque también se ha mencionado la percusión (Schmid 1964 en Pérez de Micou 1991). Se utilizaría como yesca hongos provenientes de la región cordillerana (Musters 2005, p. 238) o bien cera ótica (Claraz 1988, p. 114). Claraz (1988, p. 91) también postula la utilización de Baccharis salicifolia (Chilca) para el encendido. Cabe señalar al respecto que las técnicas de encendido deben haberse visto profundamente alteradas con la introducción de los fósforos; estos desplazaron totalmente a los métodos utilizados con anterioridad (Pérez de Micou 1991). Esto podría explicar en parte la escasez de referencias con respecto a esta temática.

En cuanto a quién era el responsable del encendido del fuego, se observa que habitualmente era la mujer la encargada de esta tarea (Cox 2006, p. 140; Claraz 1988, p. 73). También los cautivos tenían esta responsabilidad (Cox 2006, p. 94 y 185).

\subsection{Mantenimiento}

Son pocas las referencias que expresan elementos en cuanto al mantenimiento de los fogones. Estas se vinculan, entre otros aspectos, a las personas responsables de mantener el fuego encendido. Se expone que son los niños quienes en determinados casos se ocupan de ello (Onelli 1904, p. 143; Aguerre 2000, p. 64), estando a cargo también de la limpieza de estas estructuras (Aguerre 2000, p. 64). Los fogones se mantendrían encendidos todo el tiempo posible, inclusive durante la noche (Aguerre 2000, p. 30, 32 y 64). Existen diversas observaciones acerca de cuantos fogones podía contener un toldo, fluctuando entre uno y cuatro; estos se ubicaban en la parte delantera del toldo (Aguerre 2000, p. 64; Beerbohm 2004, p. 66; Musters 2005, p. 270). Sin embargo, en casos de escasez de leña se realizaban fogones comunales (Cox 2006, p. 155 y 169). En invierno, el fogón se ubicaba en el centro del toldo y era rodeado por piedras para que no se corrieran las brasas (Aguerre 2000, p. 30 y 31); además habitualmente el fogón se realizaba en un pozo (Aguerre 2000, p. 64). También se hacen expresiones relativas al mal cuidado del fuego, que pueden generar incendios (Claraz 1988, p. 106). 


\subsection{Uso del fuego en sentido estricto}

Se reconocieron 150 expresiones relativas a esta temática. Dentro de esta categoría, predominan las siguientes actividades:

1. Cocción de alimentos: Las observaciones preponderantes refieren a la cocción de carne, ya sea de guanaco, ñandú, piche o puma. Esta es habitualmente asada (Bove 1883, p. 154; Claraz 1988, p. 45, 59 y 61; Beerbohm 2004, p. 73; Moreno 1997, p. 247, 390 y 420; Lista 2006, p. 98; Cox 2006, p. 183 y 184; Musters 2005, p. 129; Drake 1854, p. 50), aunque también se han mencionado casos en los que es hervida (Beerbohm 2004, p. 73; Moreno 1997, p. 247; Cox 2006, p. 161) o en los que se usó piedras termóforas (Claraz 1988, p. 63; Moreno 1997, p. 271; Cox 2006, p. 184). También hay abundantes referencias en cuanto a la cocción de recursos vegetales. Las más comunes se refieren a tubérculos (Claraz 1988, p. 92; Lista 2006, p. 122; Musters 2005, p. 232), aunque también se registra esta acción sobre raíces (Claraz 1988, p. 132; Musters 2005, p. 88 y 143), semillas (Onelli 1904, p. 60; Claraz 1988, p. 140) y frutas (Aguerre 2000, p. 63; Musters 2005, p. 300). Las técnicas más habituales son el tostado y el hervido. En relación al hervido, resulta interesante destacar que todas las referencias identificadas con respecto a éste método de cocción, ya sea para carne o para vegetales, se observan a partir de 1863. Si bien en la mayor parte de las citas no se expresa qué tipo de contenedor es utilizado, en algunos se menciona el uso de ollas o tachos de pintura (Moreno 1997, p. 247; Cox 2006, p. 161; Musters 2005, p. 232). Finalmente, algunos cronistas mencionan la cocción de huevos (Moreno 1997, p. 374; Musters 2005, p. 127 y 128$)$.

2. Señales de humo: El uso del humo como forma de comunicación y visualización es una expresión recurrente en la bibliografía consultada (Onelli 1904, p. 158; Gonzalez 1965, p. 25 y 38 ; Claraz 1988, p. 70, 72, 112 y 122 entre otras; Moreno 1997, p. 237, 242 y 376; Musters 2005, p. 123 a 126, 130, entre otras; Villarino 2002, p. 14; Viedma 1783, p. 8 y 31). Estas señales podían verse a varias leguas de distancia. Para cumplir dicho propósito se encendían fuegos especiales, habitualmente en zonas altas donde podían ser detectados más rápidamente; quemándose arbustos (Moreno 1997, p. 414; Musters 2005, p. 40) o pasto seco (Musters 2005, p. 173).

3. Quema de objetos: Otro uso del fuego que es mencionado con frecuencia, como parte de ritos funerarios, es la destrucción de diferentes bienes del difunto o de sus deudos (Onelli 1904,p. 155; Claraz 1988, p. 139 y 141; Aguerre 2000, p. 169, 170 y 172; Beerbohm 2004, p. 63; Moreno 1997, p. 141; Cox 2006, p. 170; Musters 2005, p. 211, 212 y 294; Outes 1917, p. 213; Viedma 1783, p. 10 y 47; Martinic 2007, p. 162). Estos pueden ser, entre otros, lanzas, boleadoras, toldos, ropa y animales. 
4. Calefacción. El uso del fuego para calentarse también ha sido mencionado por diversos autores (Claraz 1988, p. 76, 111 y 125 entre otras; Musters 2005, p. 259, 265 y 283 entre otras; Drake 1854, p. 49; Schmid 1964 en Pérez de Micou 1991). Cabe destacar, sin embargo, que cualquier actividad que se desarrolle en las cercanías de un fuego encendido implica el acceso al calor. Así, consideramos que este ítem se ve subrepresentado en la bibliografía consultada.

5. Incendios. Se menciona en algunos casos el incendio intencional de campos, ya sea como método de caza (Bove 1883, p. 74; Beerbohm 2004, p. 120; Cox 2006, p. 143; Musters 2005, p. 141, 165 y 185 entre otras) o bien para facilitar la marcha (Claraz 1988, p. 103). En algunos casos se señala la quema del lugar donde se asentó el campamento una vez que este es abandonado (Moreno 1997, p. 256 y 420). También se ha notado que en algunas ocasiones se han generado incendios no intencionales a causa de descuidos en el manejo del fuego (Musters 2005, p. 133 y 165; Claraz 1988, p. 106).

6. Higiene personal: Existen abundantes referencias que destacan que los grupos patagónicos descartaban pelos, uñas, y otras excrecencias en el fuego (Claraz 1988, p. 43 y 69; Moreno 1997, p. 256; Musters 2005, p. 196)

7. Producción de medicamentos: Diferentes vegetales eran hervidos para la producción de infusiones y tópicos medicinales (Claraz 1988, p. 45 y 91; Aguerre 2000, p. 167; Musters 2005, p. 295).

8. Otros: Otras aplicaciones a las que era destinado el fuego según los cronistas eran, la iluminación (Moreno 1997, p. 21; Cox 2006, p. 127; Musters 2005, p. 313), la cremación de cuerpos (Onelli 1904, p. 157 y 207), el secado (Musters 2005, p. 122 y 170), el uso de ceniza para diversas actividades (Aguerre 2000, p. 96, 98 y 133 entre otras). Además, el fuego era importante en la visión del mundo por parte de estas sociedades, hecho que se ve expresado en diversos mitos y relatos (Moreno 1997, p. 97; Cox 2006, p. 169; Musters 2005, p. 119; Fernandez Garay y Hernandez 1999).

Estos diversos usos del fuego, registrados para las sociedades post-hispanicas que habitaron la Patagonia continental, son realizados también por las distintas sociedades que habitaron la Isla de Tierra del Fuego (Manzi y Spikins 2008). Sin embargo, resulta interesante destacar que la lectura de algunos cronistas que observaron a estas últimas sociedades de la isla nos permitió reconocer ciertas prácticas que no fueron registradas por los cronistas en el continente. Así, se ha observado que se utilizaba el fuego para el tratamiento térmico en el marco de la producción de artefactos óseos (Bridges 1998, p. 30). También se trataban térmicamente pigmentos, o bien se utilizaban carbón o ceniza como colorantes (Bridges 2003; Gusinde 1982, p. 358). Además, se utilizaba el fuego para facilitar la producción de astiles de madera (Bridges 2003, p. 368). 


\subsection{Actividades en torno al fogón}

Se encontraron 33 registros vinculados con diversas actividades desarrolladas alrededor de las estructuras de combustión. Las principales son:

1. Conversar, pasar el tiempo, estar sentado. Estas expresiones muestran como la mayor parte del tiempo que se pasa en el campamento transcurre en torno al fogón (Onelli 1904, p. 83 y 141; Wallis 2004, p. 98 y 102; Cox 2006, p. 155 y 186; Musters 2005, p. 263, 269 y 282, entre otras).

2. Comer, beber. Es común encontrar observaciones que resaltan que la alimentación se realiza cerca del fuego (Onelli 1904, p. 141; Claraz 1988, p. 130; Moreno 1997, p. 248; Musters 2005, p. 166, 277 y 316; Drake 1854, p. 50). También se aprovecha este espacio para tomar mate o bebidas alcohólicas (Beerbohm 2004, p. 66; Musters 2005, p. 250 y 316).

3. Bailar. En ocasiones festivas o rituales (por ej. un nacimiento o la primera menstruación de una joven) se bailaba alrededor del fuego (Aguerre 2000, p. 139 y 161; Moreno 1997, p. 22 y 130; Musters 2005, p. 224; Lista 2006, p. 71).

4. Fumar. Se observa también que es habitual fumar en torno al fuego. Seguramente esto se vincula al hecho de pasar el tiempo en ese espacio (Beerbohm 2004, p. 66; Cox 2006, p. 155; Musters 2005, p. 41, 246 y 282; Claraz 1988, p. 76).

5. Trabajar. Diversas tareas son realizadas cerca del fuego, como lo son el trabajo del cuero, tejer, empaquetar plumas y carnear animales (Onelli 1904, p. 141; Aguerre 2000, p. 64; Beerbohm 2004, p. 66; Musters 2005, p. 166).

Consideramos que estas tareas alrededor del fogón también implican un uso del fuego, puesto que si bien pueden realizarse en diferentes espacios, son desarrolladas habitualmente en torno a las estructuras de combustión. De esta manera, el fuego organiza y estructura el espacio a ser ocupado, concentrando gran parte de las actividades en sus cercanías (Paunero 2004b; Pérez de Micou 1991).

\subsection{Apagado}

Las referencias expresan elementos concernientes al apagado y abandono de los fogones. Estas muestran que una vez que se abandonaba el campamento no se tomaba ningún recaudo especial para con el fogón. Es decir, se dejaban los restos de madera y carbón en el punto donde se había encendido el fuego, de manera que se podían reconocer las estructuras de combustión (Bove 1883, p. 75; Byron 2004, p. 23; Cox 2006, p. 79; Fitz Roy 1837, p. 119) e inclusive en algunos casos aún se encontraban calientes, por lo que se infiere que no se apagaban completamente (Byron 2004$, p. 33 y 35$)$. 


\subsection{Consideraciones finales}

Como señaláramos al inicio de este capítulo nuestro objetivo es encontrar tendencias generales acerca del manejo del fuego por parte de las sociedades que habitaron la Patagonia durante los últimos 5 siglos. Estas nos permiten por un lado, generar hipótesis acerca de cómo era manejado éste en tiempos pretéritos y, por el otro, visualizar la importancia de considerar ciertas prácticas que no dejan rastros en el registro arqueológico, así como incluir en el relato actores que tradicionalmente no fueron considerados en las investigaciones arqueológicas, esto es, mujeres y niños.

Observamos que existían fundamentalmente dos tipos de estructuras de combustión. Por un lado los fogones, domésticos, habitualmente encendidos en el campamento para los que era necesario recolectar leña y acondicionar la estructura de combustión. Por el otro, los "fuegos", para los que se aprovechaban las matas y arbustos en pie. Ambos tipos de formas de combustión tenían diferentes funciones; como veremos a continuación, el fuego interviene en diversos aspectos de la supervivencia y de la vida diaria de las poblaciones patagónicas, incluidos aspectos socioeconómicos y simbólicos.

\subsubsection{Los fogones}

En relación al aprovisionamiento de combustibles se observa que son niños, mujeres y cautivos quienes desarrollaban esta tarea preferentemente. Existía una preocupación especial por la disponibilidad de este recurso: en casos de escasez se acarreaba leña de lugares lejanos, se preparaban fogones comunales o asentaban los toldos de forma dispersa. Además, se observa que no todas las maderas resultaban aptas como leñas: algunas presentaban características por las que se las evitaba si era posible, otras por el contrario, eran preferidas. De esta manera, la disponibilidad de material combustible, sus cualidades y abundancia, la proximidad al lugar de ocupación, son aspectos que no son independientes, sino que interactúan (Allué Martí y Trassierra 2006)

El encendido también era realizado habitualmente por mujeres y cautivos; la técnica más mencionada es la fricción entre dos maderas, aunque también se ha observado la percusión. Diversas sustancias podían utilizarse como yesca: por ejemplo hongos, maderas de ignición rápida y cera ótica. Es probable que la introducción de las cerillas europeas haya modificado rápidamente los hábitos de encendido del fuego. 
El mantenimiento y limpieza de las estructuras de combustión quedaba a cargo de los niños. Estos debían cuidarlo por la mañana y remover las cenizas cuando el fuego estaba apagado, antes de que se vuelva a encender. Por otra parte, vemos que los toldos podían tener entre uno y cuatro fogones, habitualmente ubicados en su parte delantera; sin embargo, en invierno ésta estructura de combustión cambiaba su ubicación original, estableciéndose en el centro del toldo. Para acondicionar el fogón en determinadas ocasiones era necesario cavar un pozo; estos tenían, en consecuencia, forma de cubeta. Además también podía estar rodeado por piedras.

El análisis de las fuentes indica que el fuego intervenía en diversos procesos de trabajo y actividades llevados a cabo por las sociedades. Resultaba importante en ámbitos sociales, funcionales, simbólicos, rituales, tecnológicos y fisiológicos.

El fogón claramente concentraba la mayor parte de la gente: además de diversas tareas para las que se destinaba el fogón, la gente se ubicaba en torno a él simplemente para descansar, pasar el tiempo y conversar; también se utilizaba este espacio para fumar y beber. Así, funcionaba como un elemento netamente socializador que organizaba el espacio del campamento.

Entre los usos más frecuentes se destacan la cocción de carne y vegetales, mayormente asados pero también hervidos o mediante el uso de piedras termóforas. El hervido de determinadas plantas les permitía producir ciertas medicinas. Del mismo modo, se registra la cocción de huevos. Una vez finalizada la cocción, los alimentos se comían alrededor del fogón. Estas estructuras de combustión posibilitaban además que las personas se iluminaran, se calefaccionen y se sequen, tanto sus cuerpos como sus ropas. En ellas, además se descartan pelos y otras excrecencias como parte de la higiene personal.

Los fogones destinados a la alimentación y calefacción podían encenderse tanto en el campamento como fuera de él. Por ejemplo, en las partidas de caza era común asar una parte de lo obtenido y comerlo inmediatamente.

En torno al fogón se desarrollaban igualmente diversos trabajos productivos, por lo general realizados por mujeres. Muchos de estos estaban vinculados con los recursos animales: el procesamiento de la carcasa, el trabajo del cuero y el empaquetamiento de plumas son algunos de los ejemplos. En el caso de las sociedades fueguinas, el fuego era también utilizado en diversas actividades tecnológicas, como son el tratamiento térmico de pigmentos y huesos y el calentamiento de maderas para la producción de astiles. En el caso de los grupos de la Patagonia continental, no se han registrado estas actividades, al menos en las fuentes consultadas, aunque sí se utilizaba la ceniza para diversos procedimientos.

Los fogones también eran utilizados para quemar los bienes de un difunto, y en algunos casos para una cremación. Desafortunadamente, no se ha explicitado si para ello si acondicionaban fogones especiales o bien si se utilizaban los fogones domésticos. Otra actividad que se desarrollaba en torno a los fogones era los bailes, particularmente en el marco de festejos o 
rituales. Estas actividades, sumado a la existencia de relatos míticos que explican el origen del fuego, o en los que se justifica la importancia de cuidar la leña, indican que el fuego jugó en estas sociedades también un rol simbólico que debe ser tenido en cuenta.

Teniendo en cuenta todo lo antedicho, consideramos que existía una tendencia a concentrar los elementos materiales alrededor de los fogones, tanto por las actividades desarrolladas a su alrededor como por el descarte de diversos elementos al fuego. Si bien hemos registrado referencias a la limpieza del fogón, no hemos identificado citas que hablen acerca de la limpieza del área alrededor del fuego. Esto nos lleva a considerar que es posible que al momento de abandonar el campamento, se dejaran los restos materiales en las cercanías del fogón.

En relación al apagado del fogón, se observa que éste era abandonado con los carbones recién apagados, o inclusive aún calientes, y no se tomaban recaudos en dispersar los fogones, hecho que volvería difícil el reconocimiento de estas fuentes de combustión.

\subsubsection{Los fuegos}

Los fuegos no exigían el acarreo de leña. Simplemente se utilizaban las matas o arbustos que estaban de pie. Si bien en la mayor parte de los casos en que las citas se referían a éste tipo de fuego no explicitaban quien era el responsable de su encendido, el hecho de que algunas de las actividades en las que se enmarcaban eran realizadas por hombres nos lleva a pensar que en estos casos eran ellos quienes se encargaban de su ignición. Por otra parte, estos fuegos tenían por lo general un carácter efímero, por lo cual no era necesario desarrollar técnicas de mantenimiento ni apagado.

El fuego, en estos contextos, era utilizado para la producción de señales de humo, que permitían la comunicación y la visualización. A diferencia de los fogones, estos eran encendidos preferentemente en zonas altas. En estos casos, se espera que una vez que el fuego se haya apagado, sólo quede la base del arbusto quemado, persistiendo de manera sobreelevada al piso. De esta manera, su morfología será inversa a la de un fogón (Pérez de Micou 1991).

Otros fuegos que se encendían fuera del campamento eran producto del incendio intencional de campos para la caza o por otros motivos. Al igual que los que eran destinados a señales, estos tendrían una morfología invertida, aunque en este caso, este rasgo estaría asociado con otros similares, mientras que los fuegos para señales estarían aislados.

Finalmente, en algunas oportunidades se incendiaban los campamentos luego de su abandono. De acuerdo a Moreno (1997), todo lo que quedaba tras estos incendios son matas quemadas, por lo tanto, estos tendrían también morfología inversa a los fogones. 


\section{CAPÍTULO 5: CARACTERIZACIÓN DE LOS SITIOS ARQUEOLÓGICOS EN ESTUDIO}

En este capítulo presentamos la información disponible hasta el momento para los sitios arqueológicos en estudio. Realizamos una descripción general de ellos y hacemos foco en los componentes sobre los que desarrollamos nuestras investigaciones, enmarcados temporalmente en el Pleistoceno final y el Holoceno temprano.

\subsection{Localidad Arqueológica Cerro Tres Tetas}

La localidad arqueológica Cerro Tres Tetas se encuentra ubicada en la estancia San Rafael, departamento Deseado de la provincia de Santa Cruz. Sus coordenadas geográficas son $48^{\circ} 08^{\prime}$ $58^{\prime \prime}$ S y $68^{\circ} 56^{\prime}$ O (Paunero 1994, 1996, 2000a, 2001, 2003a, 2004b, c; Paunero y Castro 2001; Paunero et al. 2007b).

\subsubsection{Cueva 1 de Cerro Tres Tetas}

La Cueva 1 de esta localidad (C3T1) está orientada hacia el oeste, a $110 \mathrm{~m}$ de distancia de una vertiente actual y a una altura sobre ésta de 9,13 m. Es una cueva oscura, cubierta en su techo por hollín y con manifestaciones rupestres en sus paredes, entre ellas una escena de caza mediante lazo cuya antigüedad correspondería al Pleistoceno final (Podestá et al. 2005). La profundidad máxima de la cueva es de $11 \mathrm{~m}$ entre la línea de reparo y el fondo. Su altura es de 1,50 m en el interior y de 2,60 m en la parte más externa. El ancho de la cueva propiamente dicha no excede los $11 \mathrm{~m}$, pero en la parte externa supera esta dimensión pues se continúa con un alero totalizando en este caso $21 \mathrm{~m}$ de entrada. Su excavación fue realizada en dos campañas durante los años 1994 y 1995. Se abrieron 9 cuadrículas con una superficie total de 12,25 $\mathrm{m}^{2}$, revelando una estratigrafía con evidencias de ocupaciones humanas desde el Pleistoceno Final hasta momentos posteriores a la llegada del hombre europeo a la región (Cuadro 5.1). 


\begin{tabular}{|c|c|c|}
\hline Época & Unidad & Edad Radiocarbónica \\
\hline \multirow{2}{*}{ Siglo $X X$} & Ceniza volcánica & - \\
\hline & 1 & - \\
\hline Tehuelche Histórico & 2 & - \\
\hline \multirow{4}{*}{ Holoceno Tardío } & 3 a. Superior & LP-770: $830+/-60$ años ${ }^{14} C$ AP \\
\hline & 3 a. Inferior & LP-1180: $1.340+/-50$ años ${ }^{14} \mathrm{C}$ AP \\
\hline & Camada de Paja & LP-1187: $1.740+/-60$ años ${ }^{14} \mathrm{C}$ AP \\
\hline & $3 \mathrm{~b}$ & LP-541: $2.190+/-70$ años ${ }^{14}$ C AP \\
\hline \multirow{2}{*}{ Holoceno Medio } & Ceniza Volcánica & - \\
\hline & 4 & LP-538: $5.220+/-70$ años ${ }^{14}$ C AP \\
\hline \multirow{8}{*}{ Pleistoceno Final } & Roca de Derrumbe & - \\
\hline & 5. Superior & LP- 800: $10.260+/-110$ años ${ }^{14} \mathrm{C}$ AP \\
\hline & \multirow{6}{*}{ 5. Inferior } & LP-781: $10.850+/-150$ años ${ }^{14} \mathrm{C}$ AP \\
\hline & & AA-39366: $10.853+/-70$ años ${ }^{14}$ C AP \\
\hline & & OxA-9244: $10.915+/-65$ años ${ }^{14} \mathrm{C}$ AP \\
\hline & & AA-39368: $11.015+/-66$ años ${ }^{14}$ C AP \\
\hline & & AA-22233: $11.100+/-150$ años ${ }^{14} C$ AP \\
\hline & & LP-525: $11.560+/-140$ años ${ }^{14} C$ AP \\
\hline
\end{tabular}

Cuadro 5.1. Fechados Radiocarbónicos. Cueva 1 de Cerro Tres Tetas.

Las unidades estratigráficas en el sitio presentan límites bien marcados, buena conservación de los elementos arqueológicos y una relativa horizontalidad (Fig. 5.1). La secuencia estratigráfica fue descripta por Paunero (2000a) de la siguiente manera:

De arriba hacia abajo,

0: Ceniza volcánica Hudson (agosto de 1991). Esta unidad es más espesa en las cuadrículas interiores. Espesor: 2-6 cm.

1: Capa arenosa color gris con guano de oveja. Espesor: 3-8 cm.

2: Capa arenosa oscura, sin guano. Con puntas de proyectil pedunculadas pequeñas y muy pequeñas. Restos de fogón y vidrio de botella. Esta unidad sólo está presente en las cuadrículas $A$ y B. Espesor: 6-12cm

3 a: Capa de sedimentos arenosa color gris claro, con fogón en la cuadrícula B, con puntas pequeñas similares a la capa 2 , pero sin vidrio ni material europeo. Restos óseos y líticos. Presencia de lana de guanaco y trozos de cuero. Espesor: 8-12 cm.

C.P: Camada de paja ubicada en forma de lente en las cuadrículas C, E1, D1 y D2. Espesor: 2-16 $\mathrm{cm}$.

E: Capa arenosa fina y clara, arqueológicamente estéril, ubicada en las cuadrículas G, H y parte de E1 y E2. Espesor: $11-20 \mathrm{~cm}$.

3 b: Unidad de arena fina, gris oscura, con fogones en las cuadrículas C, E y D. Con material arqueológico importante: lítico y óseo. Espesor: 12- $16 \mathrm{~cm}$.

C.V: Lentes de ceniza volcánica. Presente en las cuadrículas E, G, H, A y B. Descansa sobre la capa 4, salvo en el interior, E2, G1, G2 y H, donde sobreyace directamente sobre el techo de la unidad 5. Espesor: $2-5 \mathrm{~cm}$. 
4: Capa color castaño marrón areno-limosa, con contenido arqueológico, óseo y lítico. Presente en todas las cuadrículas salvo en G2, H1 y sectores internos de E2 y G1. Espesor: $10-14 \mathrm{~cm}$.

Discordancia erosiva: Separa la unidad 4 de la 5

Rocas de derrumbe: Excelente sello natural sobre la capa 5, de rocas de mediano y pequeño tamaño, caídas del techo de la cueva. Se encuentran en las cuadrículas E1, E2, G1, G2 y H1.

5: Estrato de color ocre muy claro, limo-arenoso separado de la capa 4 por una línea de discordancia. En las cuadrículas exteriores esta capa es delgada $(6 \mathrm{~cm})$ pero en el interior se hace más potente, hasta $38 \mathrm{~cm}$. En ella encontramos la primera presencia humana en este sitio.

6: Capa areno-arcillosa estéril muy clara.

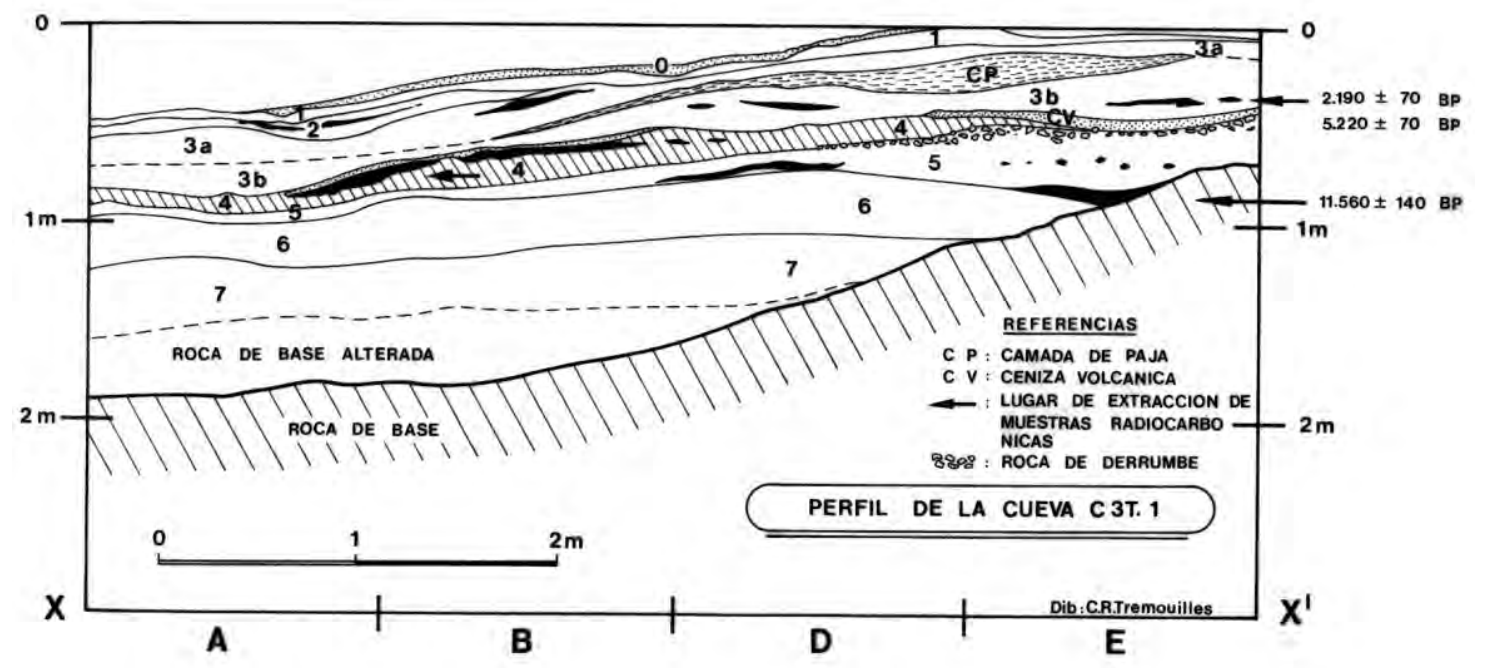

Fig. 5.1. Estratigrafía de C3T 1.

\subsubsection{Unidad 5}

Podemos describir la ocupación de la Unidad 5 por las siguientes características:

Se registraron cuatro fogones, localizados hacia el interior de la cueva, en la zona más oscura (Fig. 5.2). Tres de ellos fueron identificados en la base de la unidad, de donde procede la mayor parte de los elementos recuperados. El restante, ubicado en mayor proporción en la cuadricula G2 e inmediatamente debajo del nivel de rocas medianas y pequeñas de derrumbe, se superpone a otro fogón que ocupa las cuadrículas $\mathrm{G} 2$ y H1. Un análisis botánico realizado en una de las muestras de carbón para datación radiocarbónica, dio como resultado la pertenencia al género Schinus por lo que probablemente corresponda a Molle (Schinus polygamus) (Paunero y Castro 2001). 


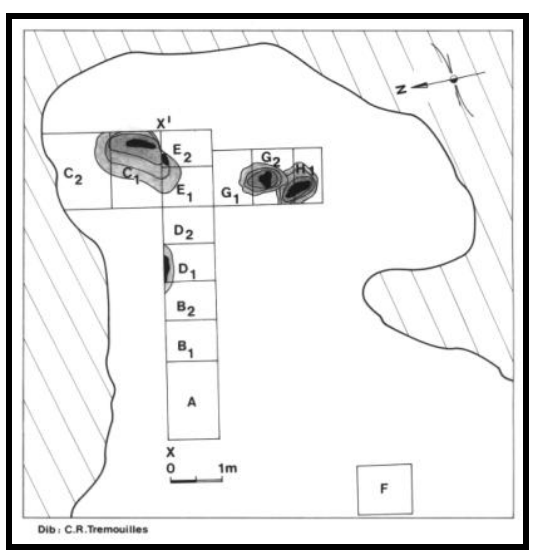

Fig. 5.2. Planta de excavación de C3T 1 con los fogones de la unidad 5.

Tanto los restos líticos como los fragmentos óseos fueron hallados por fuera de los fogones; no se encontraron restos dentro de estas estructuras. Los instrumentos, en tanto, se encontraban alrededor de estos, a una distancia de entre 20 y 75 cm (Paunero 2001; Paunero y Castro 2001). Debido a su ubicación estratigráfica, a su distribución, a las dataciones radiocarbónicas y a la proximidad registrada entre ellos, Paunero (2001) considera que estos fogones no representan eventos sincrónicos producto de una sola ocupación, sino que en sucesivas ocupaciones se habría seleccionado el mismo sector de la cueva para encender sus fogones.

Se recuperaron escasos restos óseos, que muestran un buen estado de conservación. Son en su mayoría fragmentos indeterminados. De los muy pocos casos en que pudo determinarse un taxón, éste correspondió a Lama guanicoe (Tabla 5.1). Esto llevó a Paunero (2001) a considerar que la fractura intencional de huesos largos y el consumo de médula ósea fueron realizados en el sitio solo circunstancialmente.

Se reconocieron dos instrumentos confeccionados sobre hueso: un punzón y una diáfisis retocada. El punzón fue elaborado sobre un fragmento de hueso largo, presenta brillo graso o lustre, en la zona potencialmente útil y de manera más intensa en el extremo apical, que enmascara las marcas de su fabricación. El otro artefacto corresponde a una diáfisis de tibia de guanaco con retoques marginales en uno de sus bordes, sobre la cara externa de la pieza, que presenta un color marrón oscuro y un brillo vítreo característico de los huesos termoalterados. Esta tibia también evidencia un brillo graso o lustre en el borde retocado que se concentra exclusivamente en el filo, por lo que se considera que estaría vinculado con su uso. Sus dimensiones son $20 \mathrm{~cm}$ de longitud, $2,7 \mathrm{~cm}$ de ancho y $5 \mathrm{~cm}$ de espesor máximo (en el extremo proximal), 0,7 cm de espesor mínimo (en el extremo distal). De acuerdo al análisis contextual, así como a las características de los artefactos, se ha postulado que éstos fueron utilizados para tareas de procesamiento secundario en cuero (Paunero et al. 2008a). Además se halló un pequeño fragmento de diáfisis indeterminada que también contaba con retoques en uno de sus bordes, así como signos de termoalteración. 


\begin{tabular}{|c|c|c|c|c|c|c|c|c|c|c|}
\hline & \multirow{2}{*}{$\begin{array}{l}\text { Indet. } \\
\text { Indet. }\end{array}$} & \multicolumn{7}{|c|}{ Lama guanicoe } & \multirow{2}{*}{$\begin{array}{l}\begin{array}{c}\text { Mamífero } \\
\text { pequeño }\end{array} \\
\text { Vértebra }\end{array}$} & \multirow{2}{*}{ Tot. } \\
\hline & & Molar & Vértebra & Cuneiforme & Fémur & Tibia & Metapodio & Falange & & \\
\hline A & 6 & 0 & 0 & 0 & 0 & 0 & 0 & 0 & 0 & 6 \\
\hline B1 & 4 & 0 & 0 & 0 & 1 & 0 & 1 & 0 & 0 & 6 \\
\hline B2 & 76 & 0 & 0 & 0 & 0 & 1 & 0 & 0 & 1 & 78 \\
\hline $\mathrm{C} 1$ & 1 & 0 & 0 & 0 & 0 & 0 & 0 & 0 & 0 & 1 \\
\hline $\mathrm{C} 2$ & 9 & 1 & 2 & 1 & 0 & 0 & 1 & 1 & 0 & 15 \\
\hline Total & 96 & 1 & 2 & 1 & 1 & 1 & 2 & 1 & 1 & 106 \\
\hline
\end{tabular}

Tabla 5.1. Restos faunísticos provenientes de la unidad 5 de C3T 1.

En relación a la estructura del conjunto lítico, se observa abundancia de productos de talla y escasos instrumentos y núcleos (Tabla 5.2). Se reconoció producción de artefactos, formatización y retoque, principalmente por percusión directa con percutores duros y circunstancialmente blandos, registrándose también evidencias del uso de la presión (Paunero 2001; Paunero y Castro 2001).

Entre los productos de talla identificados, $57,2 \%$ son lascas, $19,8 \%$ lascas anchas, $14,4 \%$ lascas muy anchas, 7,2 \% lascas largas y el 1,2\% láminas. Por otra parte, 27 son potenciales forma base $(5,7 \%)$ y 32 potenciales filos funcionales $(6,8 \%)$. Los tipos de talón registrados son: principalmente facetados $(30,1 \%)$ y lisos $(26,2 \%)$, también se observaron talones naturales, diedros, preparados y puntiformes (Paunero 2001; Paunero y Castro 2001).

La mayor parte de los instrumentos son unifaciales, salvo tres casos, una muesca y dos preformas con retoque bifacial (Tabla 5.3). Como evidencia de la bifacialidad también se reconocieron cinco lascas de adelgazamiento.

Existió un énfasis en la formatización de instrumentos confeccionados con materias primas locales, en especial sílex de una amplia gama de colores (Tablas 5.4 y 5.5). En la localidad las fuentes de esta materia prima se presentan, por un lado, en forma de rodados en un zanjón que la recorre, y por otro, como afloramientos en lugares próximos al sitio que habrían sido utilizados como canteras. También se registraron materias primas alóctonas, como la obsidiana con origen establecido en Pampa del Asador a 200 km de distancia (Paunero 2001; Paunero y Castro 2001; Stern 2004).

El análisis por estadios muestra una clara predominancia de las últimas etapas de la formatización de instrumentos, mientras que los estadios de descortezamiento y talla tienen valores similares (Tabla 5.6). Dentro del estadio de formatización final se observa un neto predominio de las piezas de retoque, aunque también está presente el adelgazamiento bifacial en el sílex, la calcedonia y el xilópalo (Tabla 5.7). 


\begin{tabular}{|c|c|c|}
\hline Grupo & Total & $\%$ \\
\hline Instrumentos & 31 & 6,08 \\
\hline Productos de talla & 474 & 92,94 \\
\hline Núcleos & 5 & 0,98 \\
\hline Total & 510 & 100 \\
\hline
\end{tabular}

Tabla 5.2. Estructura del conjunto lítico. C3T1. Unidad 5.

\begin{tabular}{|c|c|c|c|}
\hline Grupo & Clase & Cantidad & Total \\
\hline \multirow{4}{*}{1} & Lasca retocada & 9 & \\
\cline { 2 - 3 } & Raspador & 7 \\
\cline { 2 - 3 } & Raedera & 7 \\
\cline { 2 - 3 } 3 & Cuchillo & 3 & \multirow{4}{*}{31} \\
\cline { 2 - 3 } & Bifacial & 3 & \\
\cline { 2 - 3 } & Raspador/Raedera & 1 \\
\cline { 2 - 3 } & Percutor & 1 & \\
\hline
\end{tabular}

Tabla 5.3. Instrumentos. C3T1. Unidad 5.

\begin{tabular}{|c|c|c|c|c|}
\hline MP & $\mathbf{I}$ & $\mathbf{X T}$ & $\mathbf{N}$ & Total \\
\hline Sílex & 64,52 & 54,85 & 40 & 55,29 \\
\hline Xilópalo & 22,58 & 12,66 & 20 & 13,33 \\
\hline Calcedonia & 9,68 & 9,70 & 20 & 9,80 \\
\hline Toba sil. & 0 & 5,70 & 20 & 5,49 \\
\hline Obsidiana & 0 & 2,11 & 0 & 1,96 \\
\hline Indet. & 3,23 & 14,98 & 0 & 14,12 \\
\hline Total & 100 & 100 & 100 & 100 \\
\hline
\end{tabular}

Tabla 5.4. \% de Instrumentos, productos de talla y núcleos por materia prima. C3T1. U.5.

\begin{tabular}{|c|c|}
\hline Color & $\%$ \\
\hline Gris & 30 \\
\hline Marrón & 25,71 \\
\hline Rojo & 20,72 \\
\hline Verde & 6,07 \\
\hline Ocre & 4,64 \\
\hline Oscuro & 4,64 \\
\hline Otros & 8,22 \\
\hline Total & 100 \\
\hline
\end{tabular}

Tabla 5.5 Porcentaje de colores del sílex. C3T1. Unidad 5.

\begin{tabular}{|c|c|c|c|c|}
\hline Materia Prima & Descortezamiento & Talla & Formatización & Total \\
\hline Sílex & 15 & 9,17 & 75,83 & 100 \\
\hline Calcedonia & 13,33 & 3,33 & 83,33 & 100 \\
\hline Xilópalo & 15,38 & 15,38 & 69,23 & 100 \\
\hline Toba Sil. & 33,33 & 37,50 & 29,17 & 100 \\
\hline Obsidiana & 0 & 12,50 & 87,50 & 100 \\
\hline Indet. & 57,14 & 14,29 & 28,57 & 100 \\
\hline Total & 17,67 & 12,56 & 69,77 & 100 \\
\hline
\end{tabular}

Tabla 5.6. Estadios de reducción según materia prima. C3T1. Unidad 5

\begin{tabular}{|c|c|c|c|c|}
\hline Materia Prima & Adelgazamiento bifacial & Reactivación del filo & Retoque & Total \\
\hline Sílex & 7,89 & 5,26 & 86,84 & 100 \\
\hline Calcedonia & 25 & 8,33 & 66,67 & 100 \\
\hline Xilópalo & 33,33 & 11,11 & 55,56 & 100 \\
\hline Toba Silicificada & 0 & 0 & 100 & 100 \\
\hline Obsidiana & 0 & 0 & 100 & 100 \\
\hline Total & 14,29 & 6,35 & 79,37 & 100 \\
\hline
\end{tabular}

Tabla 5.7 \% de Estadio de Formatización del filo según materia prima. C3T1. Unidad 5

De acuerdo al análisis funcional de artefactos líticos, se identificaron dos actividades principales, una de raspado y otra de corte, ambas principalmente sobre cuero y en menor medida sobre hueso. Predominan los casos en que se realizó un mismo único movimiento sobre una única 
sustancia, solo dos casos se apartan de esto, el primero ha trabajado de la misma manera sobre dos sustancias, el segundo ha realizado una doble actividad o movimiento, funcionando como raspador y raedera, pero sobre la misma sustancia (Paunero y Castro 2001).

La distribución de los artefactos en el sitio llevó a afirmar que estas actividades se desarrollarían en sectores diferentes de la cueva, conformando áreas de actividad, principalmente alrededor de los fogones. Los artefactos fueron utilizados principalmente por prensión manual. Además, según el análisis funcional los artefactos no formatizados fueron escasamente usados (Paunero y Castro 2001).

Diversos tipos de evidencias apuntan a que en el sitio se desarrollaron procedimientos de tratamiento térmico. Por un lado, la presencia de un artefacto óseo termoalterado así como otro probable artefacto en hueso, también con evidencias de quemado. Por otro, se observaron evidencias de probable tratamiento térmico de artefactos líticos como forma de optimizar la materia prima: un núcleo sobre el que se logró remontar en laboratorio un conjunto de lascas con evidencias de cambio de color, mientras que el propio núcleo no presenta esta característica. Además, durante el análisis funcional se han registrado en las cercanías a los fogones 13 artefactos con terminación sedosa, por lo que se postuló que habrían sido sometidos a este procedimiento (Paunero 2001; Paunero y Castro 2001).

\subsection{Localidad Arqueológica La María}

La localidad arqueológica La María se encuentra ubicada a 150 kilómetros de la ciudad de Puerto San Julián, departamento de Magallanes, provincia de Santa Cruz. Su ubicación geográfica se define por la delimitación de un rectángulo ubicado entre los paralelos $48^{\circ} 24^{\prime} \mathrm{S}$ y $48^{\circ} 35^{\prime} \mathrm{S}$ y entre los meridianos $68^{\circ} 47^{\prime} \mathrm{O}$ y $68^{\circ} 56^{\prime} \mathrm{O}$ (Fig. 5.3).

A partir de 1982 esta localidad comenzó a ser investigada, primero bajo dirección del Ing. Augusto Cardich (Cardich 1987; Cardich et al. 1981-82) y posteriormente del Lic. Rafael Paunero (De Porras et al. 2009b; Franco et al. 2009; Frank et al. 2007; Paunero 2000b, 2003b, 2004a, b, c; Paunero et al. 2004a, b, 2005, 2007a, c, d, 2008a; Podestá et al. 2005; Ramos y Paunero 2009; Skarbun 2004, 2009a, b; Skarbun et al. 2007).

La María se caracteriza por su riqueza y alta visibilidad arqueológica. Presenta varios afloramientos de minerales para la talla ubicados en diversos sectores de la localidad, que muestran claros signos de aprovechamiento, por lo cual se infiere que muy probablemente hayan sido usados como canteras líticas en el pasado. De acuerdo a las evidencias registradas tanto en los afloramientos y en concordancia con lo observado en los sitios excavados, las primeras etapas de la producción de artefactos se producirían en las fuentes de aprovisionamiento. Los 
afloramientos de materias primas silíceas (sílex, tobas silicificadas y xilópalos) son por lo general de muy buena calidad para la talla (Frank et al. 2007; Paunero et al. 2004b; Skarbun 2009b).

La localidad resalta también por la gran cantidad y variedad de pinturas rupestres. Identificamos algunos motivos con estructuras de diseño reiteradas: negativos de manos, mano sobre guanaco, manos con puntos, guanacos tomando agua, circulares o con simetría radial, cortados por una o más líneas que los transforma en bilaterales, líneas paralelas, círculos concéntricos, bilaterales elípticos, escenas de caza, antropomorfos, guanacos solos y felinos. Estos diseños probablemente han sido confeccionados con los pigmentos disponibles en la localidad. Estas "tierras de color" se encuentran de manera abundante en distintos sectores, son de muy buena calidad para su utilización y presentan una amplia variedad de tonos, que se expresan en la policromía existente en algunas de las manifestaciones rupestres (Paunero 2000b, 2004a, 2009a; Paunero et al. 2005; Podestá et al. 2005).

Dentro de la localidad fueron delimitados 14 sectores, desde el punto de vista arqueológico, ambiental y paisajístico (Paunero 2000b; Paunero et al. 2004b, 2005; Skarbun 2009b); describiremos aquí tres, en los cuales se sitúan los sitios arqueológicos en estudio en la presente Tesis.

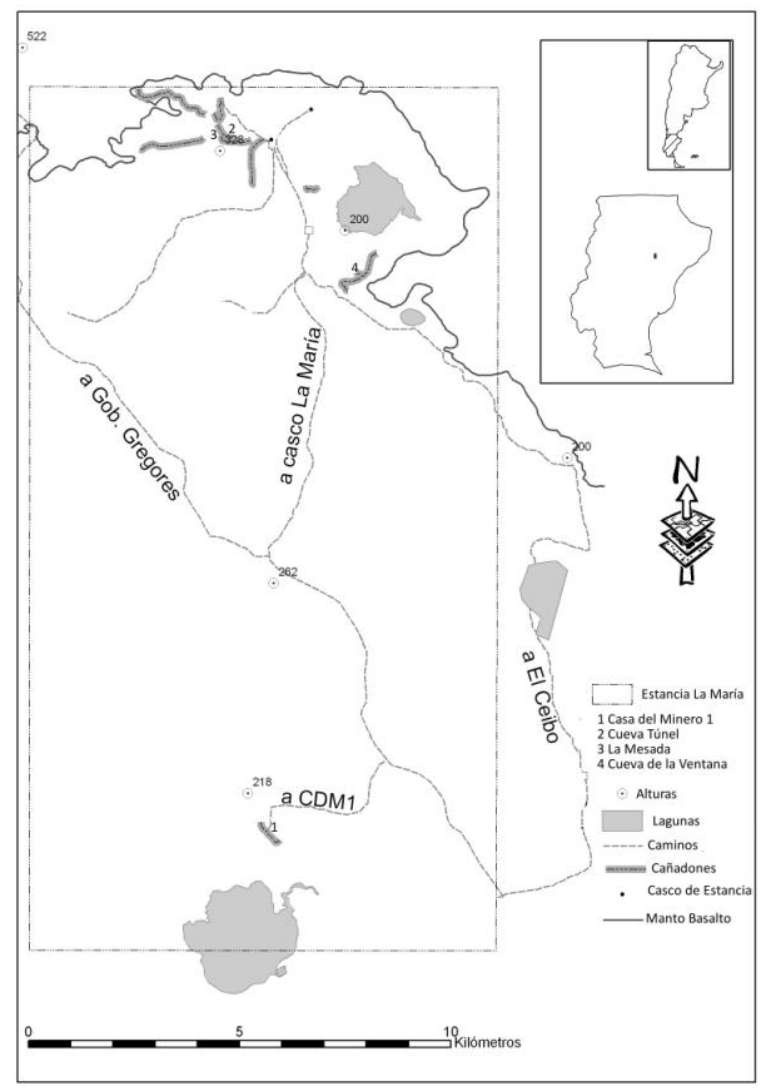

Fig. 5.3 Mapa de La María con ubicación de los sitios en estudio. Modificado de Frank et al. (2007) 


\subsubsection{Sector Cañadón de La Mina}

El Cañadón de La Mina se emplaza al sur de la localidad. En él se erige un farallón de 16 metros de altura compuesto por paredes de ignimbrita de la formación Chon Aike, orientado hacia el oeste y en el que se localizan dos cuevas que constituyen los sitios Casa del Minero 1 y 2 (CDM1 y 2) -el último con escasas pinturas rupestres: dos guanacos rojos, cuatro manos negras y tres manos rojas-. Otro alero, localizado en las cercanías del cañadón, constituye el sitio El Divisadero; su entrada cuenta con una acumulación de rocas en forma de parapeto (Paunero et al. 2004b).

Este sector presenta en la actualidad muy buenas condiciones en cuanto a recursos: leña, agua, fauna y materias primas. A lo largo del cañadón se extiende un zanjón que cuenta durante el año con agua de manera intermitente producto de las precipitaciones. Su base presenta dos vertientes que nutren a un cauce que desemboca en la Laguna Grande o Laguna de los Alzados. Esta ocupa la parte central de un gran bajo endorreico, se encuentra a 1360 metros de CDM1. Estas fuentes de agua atraen a la fauna, pudiéndose observar en la actualidad una gran cantidad de guanacos, zorros y aves. Además, las características topográficas y geológicas resultan excelentes para la caza, presentando oportunidades de ocultamiento y vistas globales y panorámicas.

En este sector se encuentra un afloramiento de caolín con importantes concentraciones de pigmentos rojos, ocres y amarillos en su alrededor (Frank et al. 2007; Paunero et al. 2004b, 2005). Además, dos afloramientos rocosos fueron utilizados como canteras: El Morro y la Cantera de Sílex CDM.

La cantera El Morro, es una cantera primaria, un cerro constituido en su mayor parte por toba silicificada ubicado a $800 \mathrm{~m}$ de la cantera de Sílex CDM y a $1400 \mathrm{~m}$ del sitio CDM1. Está compuesto por material tobáceo silicificado, de color predominantemente marrón y violáceo. Se presenta en forma de bloques de gran tamaño y nódulos menores. La calidad de la materia prima es por lo general buena a regular, dependiendo del grado de silicificación y de la homogeneidad de los nódulos.

Por otro lado, los estudios realizados en la Cantera de Sílex CDM, nos han permitido caracterizarla como una cantera primaria compuesta por abundante material suelto de color predominantemente rojo y amarillo producto principalmente del precipitado de un fluido (frío) sobresaturado en sílice (Frank et al. 2007; López 2004; Páez 2009; Skarbun 2009b). Las variedades litológicas presentes han sido definidas como ópalos que se encuentran fuertemente teñidos por óxidos de hierro, así como rocas piroclásticas retrabajadas posiblemente de la Fm. La Matilde y lavas e ignimbritas pertenecientes a la Fm. Chon Aike (Páez 2009; Skarbun 2009b). Macroscópicamente estas han sido definidas como sílex y tobas silicificadas (Frank et al. 2007; Skarbun 2009b). 
La zona de mayor concentración de material en esta cantera se encuentra a 620 m de CDM1. Los nódulos más abundantes presentan un diámetro menor a $20 \mathrm{~cm}$. La calidad de la materia prima es por lo general muy buena, aunque fluctúa dependiendo del grado de silicificación y de la homogeneidad de los nódulos. La corteza que recubre a los nódulos varía en grosor y calidad para la talla, presentándose material con corteza de poco espesor y de grano fino, como el sílex rojo y material con corteza de gran espesor y grano grueso como el sílex amarillo y las tobas (Frank et al. 2007; Paunero et al. 2004b).

El sílex está presente en el $75 \%$ de la muestra. Los colores más abundantes son el rojo y el amarillo (cada uno con un 25\% aproximadamente). El sílex marrón alcanza un 10\%. Las distintas variedades de tobas y tobas silicificadas no llegan al $15 \%$. Los demás tipos de materias primas en su conjunto no superan el 5\% (Frank et al. 2007).

La abundancia de núcleos y de lascas primarias, indican que la principal actividad llevada a cabo en la cantera fue el aprovisionamiento de nódulos para la talla así como las primeras etapas de reducción. También respalda esta afirmación el alto porcentaje de talones naturales (42\%) y lisos (36\%) que se reconocieron entre los productos de talla y la presencia de corteza en $15 \%$ de las piezas del estadio de talla. Las características de los núcleos (mayormente poliédricos) y de los productos de talla (bajo índice de laminaridad) indicaría que se le dio un uso expeditivo a la cantera (Frank et al. 2007).

A partir de estas características, teniendo en cuenta las particularidades de los conjuntos líticos de CDM1 (ver infra) y considerando que éste se encuentra en la misma unidad paisajística de la cantera, se ha propuesto que la mayor parte de los artefactos del sitio fueron confeccionados con materia prima proveniente de ésta. Sin embargo, habría existido selectividad en el transporte de materias primas desde el afloramiento hacia el sitio, ya que algunas se encuentran en él y no en CDM1 (toba, toba silicificada) o bien se presentan en menor proporción (sílex amarillo), mientras que algunas materias primas tienen una importancia relativamente mayor en el sitio (sílex rojo). Estos datos permitirían afirmar que la Cantera de Sílex jugó un papel importante en la configuración del conjunto lítico de CDM1 (Frank et al. 2007; Paunero et al. 2004b; Skarbun 2009b).

\subsubsection{Sitio Casa del Minero 1}

La cueva de CDM1 se encuentra orientada hacia el oeste, a $29 \mathrm{~m}$ del zanjón, a una altura de 5,83 $\mathrm{m}$ sobre el cauce del mismo. Sus coordenadas geográficas son $48^{\circ} 33^{\prime} 34^{\prime \prime} \mathrm{S}$ y $68^{\circ} 51^{\prime} 19^{\prime \prime} \mathrm{O}$. Las entradas naturales de la cueva actualmente están cerradas por un empircado realizado por mineros que ocuparon el lugar entre los años 1920 y 1960 (Paunero et al. 2007d). El largo máximo de la cueva es de $11,76 \mathrm{~m}$, medido de $\mathrm{N}$ a $\mathrm{S}$, el ancho máximo de $\mathrm{E}$ a $\mathrm{O}$ es de 5,80 m; la cueva 
abarca una superficie de $68,20 \mathrm{~m}^{2}$. La altura medida desde el piso actual al techo oscila entre 1,20 a 2,20 m. Se excavaron 15,32 $\mathrm{m}^{2}$, lo que representa el 22,5\% de la superficie total (Paunero et al. 2007d; Ramos y Paunero 2009).

Es un sitio multicomponente con evidencias de ocupaciones desde el Pleistoceno final hasta inicios del siglo XX (Cuadro 5.2). Su excavación se realizó entre los años 2000 y 2004. Los niveles estratigráficos presentan horizontalidad y buena conservación de los elementos. La estratigrafía definida para el sitio (Fig. 5.4) es la siguiente:

C. Cenizas del Volcán Hudson - agosto de 1991. Espesor: 1-2 cm.

1. Sedimento suelto gris claro de arenas medianas con restos culturales históricos de la ocupación de los mineros. Espesor: $6-8 \mathrm{~cm}$.

2. Arena compactada con tenues líneas de carbón en la base y restos arqueológicos holocénicos. Espesor: $5-10 \mathrm{~cm}$.

3. Sedimento ocre areno limoso fuertemente compactado y con piedras de tamaño mediano. Posee material arqueológico lítico y fragmentos óseos, ubicados en tres niveles de ocupación: Superior, Medio e Inferior. Este último descansa sobre rocas de derrumbe, sobre un lente estéril o sobre la unidad 4. Espesor: $10-16 \mathrm{~cm}$.

RD. Rocas de derrumbe

E. Lente estéril. Espesor: hasta $5 \mathrm{~cm}$.

4. Sedimento compactado areno limoso de color ocre claro. Con importante contenido cultural y fogones. Espesor: $8-20 \mathrm{~cm}$.

5. Sedimento limo arenoso claro que sobreyace a la roca de base, sin contenido arqueológico. Espesor: $8-14 \mathrm{~cm}$.

\begin{tabular}{|c|c|c|}
\hline Época & Unidad & Edad Radiocarbónica \\
\hline Siglo XX & 1 & - \\
\hline Holoceno Tardío & 2 & - \\
\hline Holoceno Medio & 3 Superior & LP-1552: 5.190 +/- 80 años 14C AP \\
\hline Holoceno Temprano & 3 Medio & - \\
\hline \multirow{2}{*}{ Pleistoceno Final } & 3 Inferior & AA 45705: 10.250+/- 110 años 14C AP \\
\cline { 2 - 3 } & 4 & $\begin{array}{c}\text { AA 37208: 10.967+/-55 años 14C AP } \\
\text { AA 37207: 10.999 +/-55 años 14C AP }\end{array}$ \\
\hline
\end{tabular}

Cuadro 5.2. Fechados Radiocarbónicos. Casa del Minero 1 


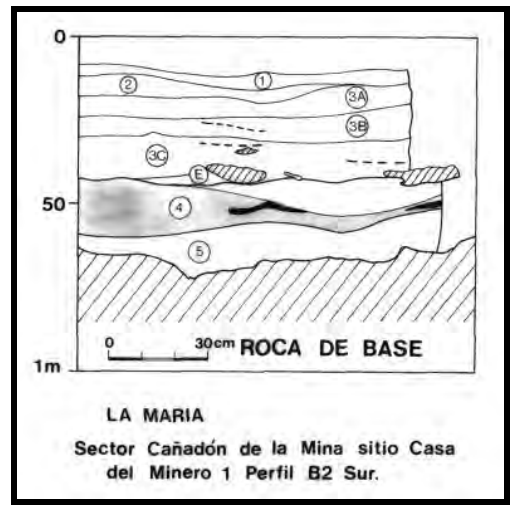

Fig. 5.4 Estratigrafía de CDM1. 3A=3 Superior. 3B= 3 Medio. 3C=Inferior. Dibujo de R. Paunero

\subsection{Unidad 4}

La unidad estratigráfica 4 está conformada por sedimentos areno-limosos de origen principalmente eólico, espélico y antrópico, con aporte de elementos de partículas en suspensión. Posee fechados de ca. 11.000 años 14C AP (Cuadro 5.2), y se encuentra sellado por una clara línea de rocas de derrumbe (Paunero et al. 2007d). Por encima de este derrumbe se encuentra la unidad 3 inferior. Las características de esta unidad remiten a ocupaciones tempranas en el poblamiento de la región, con características diagnósticas de fase colonizadora.

Se identificaron diez fogones que ocupan un sector restringido del espacio excavado (Fig. 5.5). Estas estructuras son planas y elípticas (Paunero et al. 2007d).

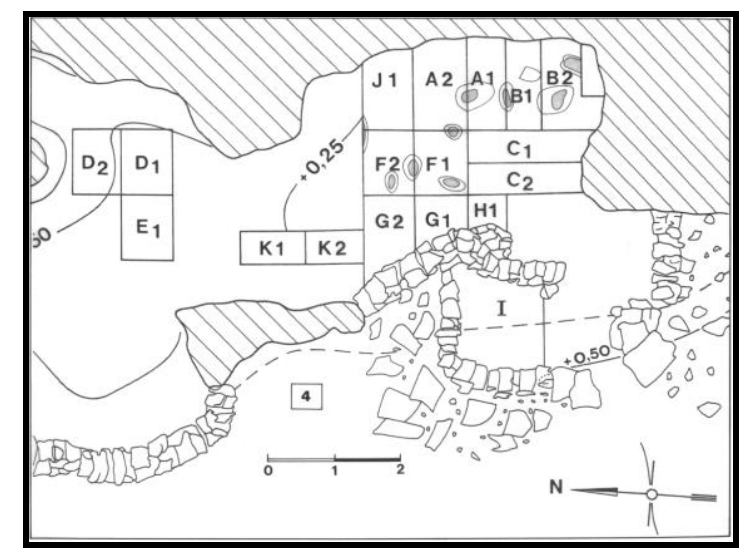

Fig. 5.5. Planta de excavación y ubicación de fogones. CDM1. U. 4. Dibujo por R. Paunero

El registro zooarqueológico incluye tres especies de camélidos: el guanaco y dos extintos (Hemiauchenia paradoxa y Lama gracilis), dos variedades de cánidos (Dusicyon griseus y Dusicyon $s p$. -éste último puede corresponder, a Dusicyon culpaeus ó a Dusicyon avus-) y Rhea sp. (Tabla 5.8) (Paunero et al. 2007a, d, 2008a). El estado de conservación de los restos es buena.

En cuanto a los camélidos, los análisis indican para este componente la presencia de elementos del zeugopodio y autopodio posterior de Hemiauchenia paradoxa; en Lama gracilis, si bien predominan elementos zeugopódicos y autopódicos posteriores, también están representados los 
autopodios anteriores. En el caso de Lama guanicoe además se identificaron otras partes esqueletarias como costillas y molares (Paunero et al. 2007d).

El análisis de los conjuntos óseos ha permitido inferir actividades de procesamiento primario y consumo, según las evidencias de fracturas helicoidales, longitudinales, lascados y marcas de corte (Tabla 5.9) (Paunero et al. 2008a). Además, en un análisis preliminar, algunos elementos de hueso mostraron evidencias de estar parcialmente quemados (Paunero et al. 2007d).

En este componente se registró la presencia de instrumental sobre hueso, se trata de 2 punzones y un retocador extremo lateral elaborados sobre diáfisis de camélido. Estos habrían sido confeccionados en el lugar de acuerdo con los remontajes de elementos realizados en el laboratorio. Uno de los punzones presenta brillo intenso en el extremo activo y posee finas marcas transversales, lo que indicaría utilización de pulido en la formatización previa al uso; el otro posee un lustre más parejo y estrías longitudinales. Con respecto al retocador extremo lateral, para su elaboración se utilizó como forma base un fragmento producto de fractura longitudinal. Posee sus dos extremos rebajados, uno de ellos en forma aguzada y el otro más redondeado o romo. El extremo agudo presenta mayor brillo; para su afinamiento probablemente se utilizó la técnica de lascados, complementada con un probable pulido, ya que se observaron tres negativos y marcas transversales. El otro extremo fue formatizado probablemente por lascados, en su borde distal presenta desgaste por probable presión sobre piedra y en el lateral lustre (Paunero et al. 2004b, 2008a).

Esta evidencia, sumada a la marcada presencia de elementos de zeugopodio y autopodio, señalan la posible elaboración de intermediarios para el procesamiento secundario de los productos derivados principalmente de los camélidos y cánidos (Cueto et al. 2009; Paunero et al. 2007d). En este contexto, los punzones fueron, muy probablemente, utilizados para perforar cuero (Paunero et al. 2008a).

Por otra parte, el retocador extremo lateral fue posiblemente utilizado en la confección de artefactos líticos bifaciales, mediante técnicas de presión (Paunero et al. 2008a). 


\begin{tabular}{|c|c|c|}
\hline Taxón & NISP & NISP\% \\
\hline Mamíferos indet. & 67 & 18,7 \\
\hline Dusicyon sp. & 12 & 2,1 \\
\hline Dusicyon griseus & 14 & 3,3 \\
\hline Camélidos indet. & 55 & 16,1 \\
\hline Hemiauchenia paradoxa & 11 & 2,5 \\
\hline Lama sp. & 128 & 32,7 \\
\hline Lama gracilis & 18 & 4,1 \\
\hline Lama guanicoe & 36 & 11 \\
\hline Roedores indet. & 8 & 1,8 \\
\hline Aves indet. & 14 & 4 \\
\hline Rheidos & 8 & 3,4 \\
\hline Total General & 371 & 100 \\
\hline
\end{tabular}

Tabla 5.8 Número y porcentaje de especímenes óseos identificados. CDM1 Unidad 4. Modificado de Paunero et al. (2007d)

\begin{tabular}{|c|c|}
\hline Marcas y fracturas & $\mathbf{n}$ \\
\hline Marcas de corte & 17 \\
\hline Lascados & 15 \\
\hline Marcas de golpe & 2 \\
\hline Fracturas helicoidales & 13 \\
\hline Fracturas longitudinales & 6 \\
\hline $\begin{array}{c}\text { Fracturas helicoidales y } \\
\text { lascados }\end{array}$ & 6 \\
\hline $\begin{array}{c}\text { Fracturas longitudinales } \\
\text { y lascados }\end{array}$ & 2 \\
\hline
\end{tabular}

Tabla 5.9. Marcas y fracturas identificadas para restos de camélidos. CDM1 Unidad 4.

El conjunto lítico de este componente, presenta gran cantidad de productos de talla, escasos instrumentos y ningún núcleo (Tabla 5.10). El conjunto muestra una buena integridad (Skarbun 2009b). Si bien permite inferir actividades de talla, muestra una importante actividad de formatización final (Tabla 5.11), observándose abundante cantidad de lascas de retalla, retoque y adelgazamiento bifacial (Tabla 5.12). Esto último además, se ve complementado por la presencia de una preforma bifacial y por el registro de filos bifaciales en dos instrumentos.

El porcentaje de lascas primarias es bajo. Esto indicaría que, en general, los primeros pasos de la secuencia de producción de artefactos - descortezamiento y preparación de los núcleos- debieron ser realizados en otros sectores del paisaje, mientras que la implementación los últimos pasos de la secuencia de reducción fue la actividad más frecuente en el sitio.

Entre los productos de talla identificados, $84,9 \%$ son lascas, 5,6\% laminillas, 4,6\% láminas, 3,4\% lascas largas y $1,5 \%$ lascas anchas. También se observa la existencia de técnicas de extracción de lascas triangulares, considerando que una lasca retocada fue confeccionada sobre este tipo de soporte.

Los tipos de talón registrados en los productos de talla son, al igual que en la unidad 5 de C3T1 principalmente lisos y facetados $(28,4 \%$ y $23,7 \%$ respectivamente), también se observaron talones lineales, preparados, naturales, puntiformes y diedros.

El conjunto muestra poca diversidad en el uso de la materia prima, predominando el sílex (Tabla 5.13), especialmente el rojo de probable procedencia de la Cantera de Sílex de CDM (Tabla 5.14). En cuanto a los instrumentos, se observa una alta predominancia de lascas retocadas de sílex, de escasa inversión de energía en su confección (Tabla 5.15). Teniendo en cuenta que las piezas más abundantes de esta materia prima fueron los productos de la formatización final pero que son 
pocos los instrumentos hallados en el sitio, se ha sugerido que no todos fueron descartados allí. Lo mismo sucede para la calcedonia. En cuanto al xilópalo, cambia la relación porcentual entre productos de talla y artefactos formatizados, aumentando la cantidad de artefactos en relación a los productos de talla. Esto podría evidenciar que los artefactos fueron ingresados al sitio en estados avanzados de formatización o que algunos de los artefactos formatizados hallados en el sitio no fueron confeccionados allí (Skarbun 2009b; Skarbun et al. 2007).

El conjunto de las evidencias registradas para este sitio ha llevado a proponer que en esta localización se realizaron múltiples actividades incluyendo la formatización de artefactos óseos y líticos, el procesamiento primario y secundario de las presas cazadas en las cercanías así como su consumo y el trabajo en cuero. En este contexto, los análisis preliminares del conjunto lítico del sitio indicaron que una porción de éste presentaba un lustre particular que podría indicar el uso del tratamiento térmico en la confección de artefactos.

\begin{tabular}{|c|c|c|}
\hline Grupo & Cant. & $\%$ \\
\hline Productos de talla & 1229 & 99,11 \\
\hline Instrumentos & 11 & 0,89 \\
\hline Núcleos & 0 & 0 \\
\hline Total & 1240 & 100 \\
\hline
\end{tabular}

Tabla 5.10. Estructura del conjunto. CDM1. U. 4

\begin{tabular}{|c|c|c|c|c|}
\hline & Descort. & Talla & $\begin{array}{c}\text { Formatización } \\
\text { final }\end{array}$ & Total \\
\hline Sílex & 3,94 & 26,54 & 69,52 & 100 \\
\hline Calcedonia & 4,12 & 62,94 & 32,94 & 100 \\
\hline Xilópalo & 3,12 & 46,88 & 50 & 100 \\
\hline Otras & - & 100 & - & 100 \\
\hline Indet. & - & 1,69 & 98,31 & 100 \\
\hline Total & 3,67 & 32,9 & 63,43 & 100 \\
\hline
\end{tabular}

Tabla 5.11 Estadios de producción según materia prima. CDM1. U. 4. Tomado de Skarbun (2009b). Descort. = Descortezamiento

\begin{tabular}{|c|c|c|c|c|c|c|}
\hline & Retoque & $\begin{array}{c}\text { Adelgazamiento } \\
\text { bifacial }\end{array}$ & Retalla & $\begin{array}{c}\text { Reactivación } \\
\text { del filo }\end{array}$ & Indet. & Total \\
\hline Sílex & 21,87 & 10,32 & 0,98 & 0,25 & 66,58 & 100 \\
\hline Calcedonia & 37,5 & 19,64 & 5,36 & 1,79 & 35,71 & 100 \\
\hline Xilópalo & 37,5 & 12,5 & - & - & 50 & 100 \\
\hline Indet. & - & - & - & - & 100 & 100 \\
\hline Total & 21,6 & 10,24 & 1,3 & 0,37 & 66,4 & 100 \\
\hline
\end{tabular}

Tabla 5.12 \% de Estadio de Formatización del filo según materia prima. CDM1. Unidad 4. Tomado de Skarbun (2009b) 


\begin{tabular}{|c|c|c|c|}
\hline Materia Prima & Productos de talla & Instrumentos & \% Total \\
\hline Sílex & 69,85 & 54,55 & 69,71 \\
\hline Calcedonia & 19,64 & 9,09 & 19,55 \\
\hline Indet. & 6,85 & - & 6,79 \\
\hline Xilópalo & 3,26 & 36,36 & 3,55 \\
\hline Toba & 0,24 & - & 0,24 \\
\hline Otras & 0,16 & - & 0,16 \\
\hline Total & 100 & 100 & 100 \\
\hline
\end{tabular}

\begin{tabular}{|c|c|}
\hline Color & \% \\
\hline Rojo & 70,69 \\
\hline Marrón & 20,1 \\
\hline Amarillo & 5,86 \\
\hline Otros & 3,34 \\
\hline Total & 100 \\
\hline
\end{tabular}

Tabla 5.13 Porcentaje de materias primas por grupo y en el

Tabla 5.14 Porcentaje de conjunto total. CDM 1. U. 4. Modificado de Skarbun (2009b) colores del sílex. CDM 1. U. 4 Tomado de Skarbun (2009b)

\begin{tabular}{|c|c|c|c|c|}
\hline & Sílex & Xilópalo & Calcedonia & Total \\
\hline Lasca retocada & 5 & 1 & - & 6 \\
\hline Fragmento de bifaz & - & 1 & - & 1 \\
\hline Raedera & - & 1 & - & 1 \\
\hline Raspador & - & - & 1 & 1 \\
\hline Cuchillo & 1 & - & - & 1 \\
\hline Raspador/raedera & - & 1 & - & 1 \\
\hline Total & 6 & 4 & 1 & 11 \\
\hline
\end{tabular}

Tabla 5.15 Materia prima de artefactos formatizados. CDM 1. U. 4. Tomado de Skarbun (2009b)

\subsection{Unidad 3 inferior}

Esta unidad está conformada por una matriz sedimentaria fuertemente compactada, con una granulometría areno limosa con clastos medianos. El origen de los sedimentos es eólico, sin evidencias de aporte de partículas en suspensión, el material de procedencia espélica es más importante que en la unidad inferior (Paunero 2009b). Posee un fechado de $10.250+/$ - 110 años 14C AP. La densidad de restos recuperados de este componente es menor a la de la unidad 4.

En este componente registramos evidencias de nueve fogones (Fig. 5.6). Presentan características similares a los del componente previamente descripto.

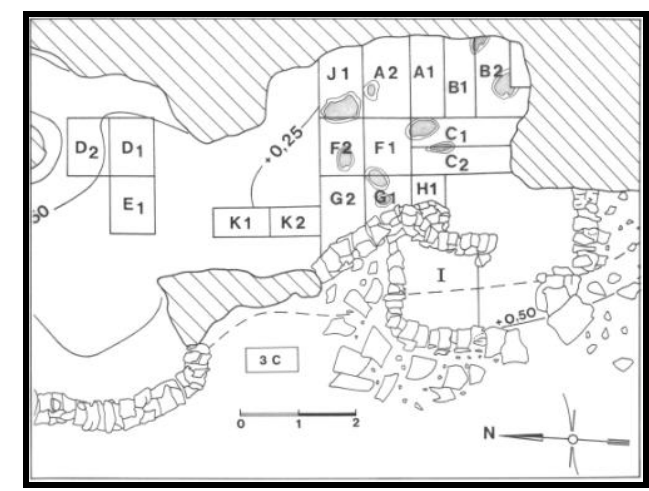

Fig. 5.6. Planta de excavación y ubicación de fogones. CDM1. U. 3 inf. Realizado por R. Paunero 
El conjunto faunístico es pequeño, presenta una disminución en el número de taxones en comparación con la unidad 4 y muestra un buen estado de conservación de los elementos. Identificamos principalmente Lama guanicoe (Tabla 5.16). Observamos una mayor presencia de fragmentos de huesos largos para las especies representadas, con escasas evidencias de acción humana. Es importante mencionar la presencia de un artefacto elaborado sobre diáfisis de Lama $s p$. Se trata de una porción con punta roma en un extremo que presenta desgaste por probable presión sobre piedra u otro elemento duro; fue elaborada sobre un fragmento producto de fractura helicoidal, registra negativos de lascados de formatización para achicar el extremo útil y marcas de golpes en la cara externa. En general los elementos del componente presentan un buen estado de conservación al igual que en el componente anterior (Paunero et al. 2007a, d, 2008a).

\begin{tabular}{|c|c|c|}
\hline Taxón & NISP & NISP\% \\
\hline Mamíferos indet. & 1 & 2,9 \\
\hline Lama sp. & 7 & 20 \\
\hline Lama guanicoe & 13 & 37,1 \\
\hline Roedor & 3 & 8,6 \\
\hline Aves indet. & 9 & 25,7 \\
\hline Rheidos & 2 & 5,7 \\
\hline Total & 35 & 100 \\
\hline
\end{tabular}

Tabla 5.16 Número y porcentaje de especimenes óseos identificados. CDM1 Unidad 3 inferior. Modificado de Paunero et al. (2007d)

En referencia al conjunto lítico, la estructura general muestra una alta cantidad de productos de talla en relación a los instrumentos (Tabla 5.17). La materia prima más utilizada fue el sílex (Tabla 5.18), en especial de color rojo (Tabla 5.19), existiendo menos diversidad de materias primas que en el componente inferior. La integridad del conjunto es media (Skarbun 2009b).

Se ha observado que las actividades están más centradas en la confección de soportes que en la regularización de los filos, evidenciado por porcentajes más altos de lascas de talla en relación a las de formatización final (Tabla 5.20). Al igual que en el componente inferior, no se presentan núcleos y son muy bajos los porcentajes de lascas de descortezamiento. Esto indicaría que, también para este componente, los primeros pasos de la secuencia de producción de artefactos debieron ser realizados en otros sectores del paisaje (Skarbun 2009b).

En cuanto a la formatización final, se observa predominancia de piezas de retoque, en especial en el sílex. Por otro lado, si bien hay abundantes piezas de adelgazamiento bifacial, no se evidencian artefactos bifaciales. De esta manera, parece probable que no todos los artefactos manufacturados en el sitio se hayan descartado allí. El resto de las materias primas presenta muy escasas piezas en este estadio (Tabla 5.21). 
Entre los productos de talla identificados, $90 \%$ son lascas, 4,3\% láminas, 3,9\% laminillas, 1,4\% lascas anchas y están presentes las lascas triangulares (0,36\%). Los tipos de talón registrados en los productos de talla son principalmente preparados $(41,4 \%)$ y lisos $(40 \%)$, también se observaron talones lineales, naturales, facetados y diedros.

En este componente se identificaron siete instrumentos, seis de sílex y uno de calcedonia (Tabla 5.22).

\begin{tabular}{|c|c|c|}
\hline Grupo & Cant. & $\%$ \\
\hline Productos de talla & 1191 & 99,42 \\
\hline Instrumentos & 7 & 0,58 \\
\hline Núcleos & 0 & 0 \\
\hline Total & 1198 & 100 \\
\hline
\end{tabular}

Tabla 5.17 Estructura del conjunto. CDM1. Unidad 3 inferior.

\begin{tabular}{|c|c|c|c|}
\hline & Productos de talla & Instrumentos & Total \% \\
\hline Sílex & 92,02 & 85,71 & 91,99 \\
\hline Calcedonia & 5,54 & 14,29 & 5,59 \\
\hline Indet. & 1,6 & - & 1,59 \\
\hline Otras & 0,5 & - & 0,5 \\
\hline Xilópalo & 0,34 & - & 0,33 \\
\hline Total & 100 & 100 & 100 \\
\hline
\end{tabular}

Tabla 5.18 Porcentaje de materias primas por grupo y en el conjunto total. CDM1. U. 3 inferior. Modificado de Skarbun (2009b)

\begin{tabular}{|c|c|}
\hline Color & $\%$ \\
\hline Rojo & 84,4 \\
\hline Marrón & 8,3 \\
\hline Amarillo & 4,5 \\
\hline Otros & 2,8 \\
\hline Total & 100 \\
\hline
\end{tabular}

Tabla 5.19 Porcentaje de colores del sílex. CDM1. U. 3 inferior. Modificado de Skarbun (2009b)

\begin{tabular}{|c|c|c|c|c|}
\hline & Descortezamiento & Talla & Formatización final & Total \\
\hline Sílex & 3,61 & 55,13 & 41,25 & 100 \\
\hline Calcedonia & - & 71,43 & 28,57 & 100 \\
\hline Xilópalo & - & 66,67 & 33,33 & 100 \\
\hline Indet. & - & 100 & - & 100 \\
\hline Total & 3,36 & 56,28 & 40,35 & 100 \\
\hline
\end{tabular}

Tabla 5.20 Estadios de reducción por materia prima. CDM1. U. 3 inf. Tomado de Skarbun (2009b)

\begin{tabular}{|c|c|c|c|c|c|c|}
\hline & Retoque & Adelgazamiento bifacial & Retalla & Reactivación del filo & Indet. & Total \\
\hline Sílex & 45,41 & 14,68 & 4,13 & 0,92 & 34,86 & 100 \\
\hline Calcedonia & 40 & 50 & - & - & 10 & 100 \\
\hline Xilópalo & - & 100 & - & - & - & 100 \\
\hline Total & 44,98 & 16,59 & 3,93 & 0,87 & 33,62 & 100 \\
\hline
\end{tabular}

Tabla 5.21 Estadio de Formatización del filo según materia prima. CDM1. Unidad 3 inferior. Tomado de Skarbun (2009b) 


\begin{tabular}{|c|c|c|c|}
\hline & Sílex & Calcedonia & Total \\
\hline Lasca retocada & 3 & - & 3 \\
\hline Raspador & 1 & 1 & 2 \\
\hline Cuchillo & 1 & - & 1 \\
\hline Raedera & 1 & - & 1 \\
\hline Total & 6 & 1 & 7 \\
\hline
\end{tabular}

Tabla 5.22 Materia prima de instrumentos. CDM1. Unidad 3 inferior. Tomado de Skarbun (2009b)

\subsection{Unidad 3 Medio}

El nivel de ocupación 3 Medio, al igual que el resto de la unidad 3 está compuesta por un sedimento ocre areno limoso fuertemente compactado. Si bien no cuenta hasta el momento con fechados radiocarbónicos, su ubicación estratigráfica y algunas de las características del conjunto artefactual han llevado a postular que este componente podría ser asignado al Holoceno temprano (Paunero et al. 2007d).

En este componente es notable la ausencia de fogones, así como la baja densidad de artefactos líticos y restos óseos, que indicaría una ocupación humana eventual del sitio para el Holoceno temprano (Paunero et al. 2007d; Paunero 2009b). Se ha propuesto que el espacio se estructuró de manera diferente a lo observado en las unidades inferiores (Paunero et al. 2007d).

Al igual que el componente anterior, la evidencia faunística es pequeña, continúa la disminución en el número de especies y se registra exclusivamente fauna actual (Tabla 5.23). Dentro de la muestra el $28,3 \%$ son camélidos. En este sentido cabe señalar que las únicas evidencias de corte, lascado y machacado corresponden a Lama guanicoe y Lama sp. También se observan roedores pequeños, aves y mamíferos indeterminados. No se identificaron artefactos óseos en este componente. El conjunto se presenta en un buen estado de conservación (Paunero et al. 2007d).

\begin{tabular}{|c|c|c|}
\hline Taxón & NISP & NISP\% \\
\hline Mamíferos indet. & 9 & 19,6 \\
\hline Lama sp. & 5 & 10,9 \\
\hline Lama guanicoe & 8 & 17,4 \\
\hline Roedores indet. & 13 & 28,2 \\
\hline Aves indet. & 11 & 23,9 \\
\hline Total & 46 & 100 \\
\hline
\end{tabular}

Tabla 5.23 Número y porcentaje de especimenes óseos identificados. CDM1 Unidad 3 medio. Modificado de Paunero et al. (2007d)

El conjunto lítico de este componente presenta 514 productos de talla, 5 artefactos formatizados y un núcleo (Tabla 5.24). El porcentaje de lascas de talla es alto (59\%) (Tabla 5.25). Se observaron muy pocas piezas producidas por el descortezamiento del núcleo. Esto indica que, al igual que en los componentes anteriores, los primeros pasos de la secuencia de producción de artefactos debieron ser realizados en otros sectores del paisaje. Dentro del estadio de formatización de filos 
los porcentajes de retoque son los más altos, aunque también se registran escasas lascas de adelgazamiento bifacial (Tabla 5.26). Sin embargo, no se hallaron artefactos bifaciales en el sitio, evidenciando esto que se produjeron artefactos que se descartaron en otro sector. Existen diferencias entre las diversas materias primas. Mientras que en el sílex predomina el estadio de talla, en la calcedonia son más abundantes las de formatización final (Skarbun 2009b; Skarbun et al. 2007).

Entre los productos de talla identificados, $82,3 \%$ son lascas, 12,3\% laminillas, 3,5\% láminas, 1,2\% lascas largas y 0,6\% lascas anchas. Los tipos de talón registrados en los productos de talla son, al igual que en la unidad 3 inferior, principalmente lisos y preparados (34,5\% y 32,4\% respectivamente), también se observaron talones lineales, diedros, facetados, naturales y puntiformes.

En el conjunto lítico de este componente predomina el sílex (Tabla 5.27), especialmente el rojo, de origen probablemente local (Tabla 5.28). También se registraron piezas de calcedonia, obsidiana y otras materias primas con porcentajes menores a $10 \%$. En cuanto a la obsidiana, se identificaron tres fragmentos indeterminados muy chicos que representan las evidencias más tempranas de esta materia prima en el sitio (Skarbun 2009b; Skarbun et al. 2007).

Se identificaron cinco instrumentos, de los cuales cuatro fueron confeccionados en sílex y uno en calcedonia. En sílex se identificó un cepillo, dos lascas retocadas y un raspador. En calcedonia se registró un fragmento chico de raspador distal.

\begin{tabular}{|c|c|c|}
\hline & Cant. & \% \\
\hline Productos de talla & 514 & 98,85 \\
\hline Instrumentos & 5 & 0,96 \\
\hline Núcleos & 1 & 0,19 \\
\hline Total & 520 & 100 \\
\hline
\end{tabular}

Tabla 5.24 Estructura del conjunto. CDM1. U. 3 Medio. Modificado de Skarbun (2009b)

\begin{tabular}{|c|c|c|c|c|}
\hline & Descort. & Talla & Formatización & Total \\
\hline Sílex & 1,58 & 61,08 & 37,34 & 100 \\
\hline Calcedonia & - & 30,77 & 69,23 & 100 \\
\hline Otras & 50 & 50 & - & 100 \\
\hline Total & 1,81 & 59,82 & 38,37 & 100 \\
\hline
\end{tabular}

Tabla 5.25 Estadios de reducción según materia prima. CDM1. Unidad 3 Medio. Tomado de Skarbun (2009b). Descort. $=$ Descortezamiento.

\begin{tabular}{|c|c|c|c|c|c|c|}
\hline & Retoque & Indet. & Adelg. bifacial & Reactivación del filo & Retalla & Total \\
\hline Sílex & 57,63 & 38,14 & 2,54 & 0,85 & 0,85 & 100 \\
\hline Calcedonia & 55,56 & 22,22 & 22,22 & - & - & 100 \\
\hline Total & 57,48 & 37,01 & 3,94 & 0,79 & 0,79 & 100 \\
\hline
\end{tabular}

Tabla 5.26 Estadio de Formatización del filo según materia prima. CDM1. Unidad 3 Medio. Tomado de Skarbun (2009b) 


\begin{tabular}{|c|c|c|c|c|}
\hline & Productos de talla & Instrumentos & Núcleos & Total \% \\
\hline Sílex & 90,27 & 80 & 100 & 90,19 \\
\hline Calcedonia & 7,59 & 20 & - & 7,69 \\
\hline Otras & 1,56 & - & - & 1,54 \\
\hline Obsidiana & 0,58 & - & - & 0,58 \\
\hline Total & 100 & 100 & 100 & 100 \\
\hline
\end{tabular}

Tabla 5.27 Porcentaje de materias primas por grupos. CDM1. Unidad 3 Medio. Modificado de Skarbun (2009b)

\begin{tabular}{|c|c|}
\hline Color & \% \\
\hline Rojo & 71,49 \\
\hline Marrón & 21,17 \\
\hline Otros & 7,34 \\
\hline Total & 100 \\
\hline
\end{tabular}

Tabla $5.28 \%$ de colores del sílex. CDM1. U. 3 Medio. Tomado de Skarbun (2009b)

\subsubsection{Sector La María Quebrada}

Se trata de un cañadón profundo, enmarcado por paredes verticales de ignimbrita de la formación Chon Aike, con desniveles de entre 15 y $35 \mathrm{~m}$. Se encuentra al norte de la localidad y a una altura aproximada de 300 a 400 m.s.n.m. Lo atraviesa un cauce temporario en forma de S que nace en un manto de basalto terciario que apoya sobre las ignimbritas a una altura de 400 metros y que luego, al dejar atrás al cañadón, desemboca en un bajo. Este bajo se constituye en un importante colector de aguas, puesto que, además del cauce previamente mencionado, desembocan en él otros cursos de agua provenientes de cañadones vecinos. Esto lo convierte en una vega que resulta en una fuente abundante de agua y también de vegetación apta para ser usada como pastura, por lo cual en la actualidad es utilizado para alimentar las ovejas de la estancia (Paunero 2000b; Paunero et al. 2005; Skarbun 2009b).

Este sector fue subdividido en Cañadón Principal en su parte más baja y Cañadón del Eco en su parte más alta hacia la meseta cubierta de basaltos. Se han relevado 28 sitios con pinturas rupestres. Se ha reconocido un afloramiento pequeño de sílex pardo-ocre dentro del mismo cañadón, en las cercanías del basalto y locus de yeso cristalino en el interior de las cuevas (Paunero 2000b; Paunero et al. 2005).

En este sector se encuentran los sitios Cueva Túnel y Cueva La Mesada cuyos componentes inferiores analizaremos en esta Tesis.

\subsubsection{Sitio Cueva Túnel}

El sitio Cueva Túnel (CT) se encuentra ubicado a la entrada de La María Quebrada, cercano al bajo colector de aguas. Sus coordenadas geográficas son $48^{\circ} 24^{\prime} 27^{\prime \prime} \mathrm{S} 68^{\circ} 52^{\prime} 21^{\prime \prime} \mathrm{O}$. Se trata de una cueva conformada por dos lóbulos que convergen en un umbral orientado mirando hacia el oeste. En el techo de éste registramos un conjunto de puntos pintados de rojo claro que forman una aparente figura de tamaño mayor a un metro y de difícil identificación. El ancho máximo, considerando toda la cueva, medido de norte a sur es de $6 \mathrm{~m}$; el lóbulo izquierdo mide 2,50 m de ancho y el derecho 4,30 m. El largo máximo medido de este a oeste desde línea de goteo al fondo es de 10,10 m. La superficie total de la cueva es de $60,6 \mathrm{~m}^{2}$. Al momento de la excavación inicial la 
cueva se encontraba prácticamente saturada por sedimentos; la altura del sector excavado medida desde el piso original al techo oscila entre 0,17 a 0,86 m. Hemos excavado en el umbral y parte exterior de los vestíbulos 16,12 $\mathrm{m}^{2}$, es decir el $27 \%$ de la superficie total de la cueva (Fig. 5.7) (De Porras et al. 2009b; Paunero 2009b; Paunero et al. 2005, 2007c, 2008a; Ramos y Paunero 2009; Skarbun 2009b).

Se identificaron 11 unidades estratigráficas (Fig. 5.8):

Unidad 1: Sedimento limo arenoso suelto gris claro con ceniza volcánica. Presencia de abundante guano de oveja, roca desprendida de la cueva, elementos óseos principalmente de oveja y escasos restos líticos. Espesor: $5,5-7 \mathrm{~cm}$.

Unidad 2: Sedimento pardo grisáceo limo arenoso compacto. Presencia de estructuras de fogones y algunos restos líticos. Espesor: $15-16,5 \mathrm{~cm}$.

Unidad 3: Sedimento gris oscuro de carácter limoso. Presencia de un importante fogón de amplias dimensiones, pero escasos restos culturales. Espesor: $7-8 \mathrm{~cm}$.

Unidad 4: Sedimento pardo oscuro limoso compacto. Con abundantes artefactos líticos y óseos. Espesor: 2,5-6,5 cm.

Unidad 5: Sedimento ocre limoso poco compacto. Sin evidencias de artefactos. Espesor: 2,5-7,5 $\mathrm{cm}$.

Unidad 6: Sedimento gris areno limoso muy compacto con escasos restos. Espesor: 25-26,5 cm.

Unidad 7: Lente de sedimento gris areno limoso compacto sin presencia de restos arqueológicos ni carbones, ubicado en la cuadrícula A1. Espesor: 2-5 cm.

Las unidades 6 y 7 representan una discontinuidad ocupacional con respecto al componente inferior (Paunero 2009b).

Unidad 8: Sedimento ocre limo arenoso compacto con presencia de escasos restos arqueológicos y carbones dispersos, se obtuvieron dos dataciones sobre huesos de $10.420 \pm 180$ años 14 C AP y $10.510 \pm 100$ años 14C AP (Cuadro 5.3). Espesor: 8,5-10 cm.

Unidad 9: Sedimento ocre limo-arenoso con líticos, óseos y carbones dispersos. Espesor: 4-6,5 cm. Unidad 10: Sedimento ocre limo-arenoso con pedregullo, restos líticos y óseos. Se obtuvieron dos fechados: $10.408 \pm 59$ años 14C AP (fechado sobre carbón) y $10.400 \pm 100$ años $14 C$ AP (sobre falange de Hippidion) (Cuadro 5.3). Espesor: 30-32,5 cm.

Las unidades 8, 9 y 10 corresponden al Pleistoceno final. El origen de los sedimentos es principalmente eólico, espélico y antrópico.

Unidad 11: capa areno-limosa muy clara, sin contenido arqueológico. 


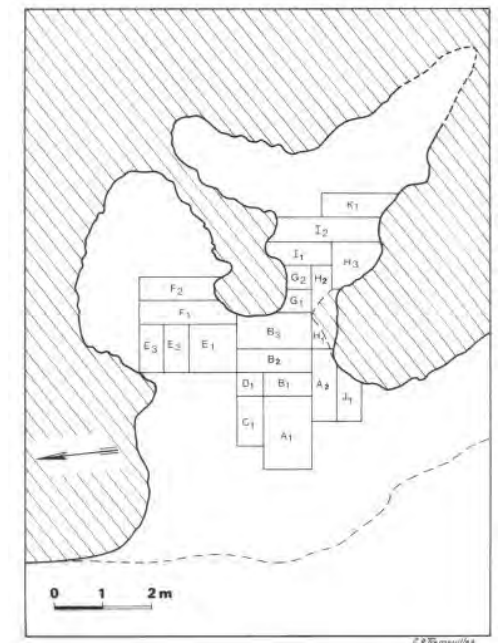

Fig. 5.7. Planta de excavación. CT.

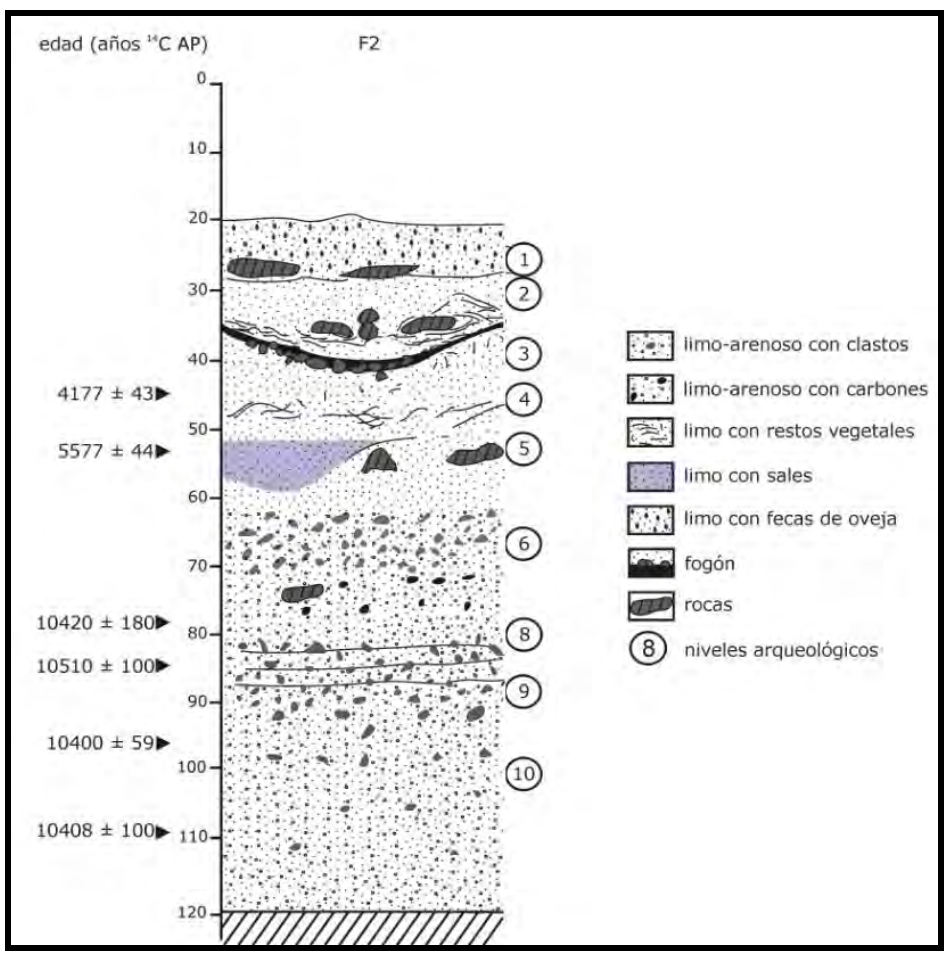

Fig. 5.8. Perfil estratigráfico. CT. Modificado de De Porras et al. (2009)

\begin{tabular}{|c|c|c|}
\hline Época & Unidad & Edad Radiocarbónica \\
\hline Siglo XX & 1 & - \\
\hline Holoceno Tardío & 2 y 3 & - \\
\hline \multirow{3}{*}{ Holoceno Medio } & 4 & AA $814174.177 \pm 43$ años ${ }^{14}$ C AP \\
\hline & 5 & AA $814235.577 \pm 44$ años ${ }^{14} C$ AP \\
\hline & 6 y 7 & - \\
\hline \multirow{3}{*}{ Pleistoceno Final } & 8 & $\begin{array}{l}\text { LP-1965 } 10.420 \pm 180 \text { años }{ }^{14} C \text { AP } \\
\text { AA82496: } 10.510 \pm 100 \text { años }{ }^{14} C \text { AP }\end{array}$ \\
\hline & 9 & - \\
\hline & 10 & $\begin{array}{l}\text { AA 71147: } 10.408 \pm 59 \text { años }{ }^{14}{ }^{14} \text { AP } \\
\text { AA 71148: } 10.400 \pm 100 \text { años }{ }^{14} C \text { AP }\end{array}$ \\
\hline
\end{tabular}

Cuadro 5.3. Fechados Radiocarbónicos. Cueva Túnel

\subsection{Componente Inferior}

Por las características sedimentarias similares, los fechados radiocarbónicos concordantes y la semejanza en los conjuntos arqueológicos, se ha considerado que los niveles 8,9 y 10 constituyen un único componente, denominado Componente Inferior. Está compuesto por sedimentos limoarenosos de color ocre, fuertemente compactado en algunos sectores y con presencias de clastos desprendidos del techo de la cueva. El origen de los sedimentos es principalmente eólico, espélico y antrópico. Arqueológicamente presenta restos de fauna actual y extinta en asociación con un escaso pero particular conjunto lítico. Está fechado entre 10.500 y 10.400 años $14 C$ AP aproximadamente. Este componente no presenta fogones, únicamente carbones dispersos. 
La fauna registrada muestra la presencia de especies extinguidas, como Hemiauchenia sp., Lama (Vicugna) gracilis, Panthera sp. e Hippidion saldiasi, además de Lama guanicoe, Rhea sp., Dusicyon sp., mamíferos y felinos indeterminados, aves y roedores (Tabla 5.29). Esto evidencia una gran diversidad a pesar de la cantidad de restos identificados. En este sentido, hay que destacar que el estado de conservación de los elementos óseos de este componente es malo, evidencian un alto grado de meteorización y fragmentación que dificulta una mayor precisión en la determinación de los taxones. En este componente identificamos fragmentos de huesos largos de camélidos con modificaciones producto de la acción humana: 13 con fractura longitudinal, 14 con fractura transversal y 11 con fractura helicoidal (Paunero et al. 2005, 2007c, 2008a; Ramos y Paunero 2009).

En cuanto a la formatización de elementos óseos, cabe señalar la presencia de tres artefactos. Dos fueron elaborados sobre diáfisis de camélido, se trata de un fragmento con punta roma en el extremo y de un punzón doble. La punta roma muestra un aspecto que indicaría pulido en su elaboración; no posee brillo y se observan rastros de probable presión sobre elementos más duros. Esta pieza presenta marcas de corte transversales previas a su formatización y su forma base ha sido un fragmento de hueso largo de fractura longitudinal. El punzón ha sido elaborado sobre un fragmento de hueso largo de fractura longitudinal y presenta los dos extremos rebajados y aguzados. Un extremo muestra marcas transversales en la cara externa y un brillo acotado a los últimos $4 \mathrm{~mm}$, en el otro se observan rastros de fabricación del aguzamiento, pero no así, brillo ni probables huellas de uso. Finalmente, se ha reconocido un machacador confeccionado sobre un fémur de Lama gracilis fracturado transversalmente, que muestra marcas de lascados en el borde activo (Paunero et al. 2008a, Paunero Com. Pers. 2010).

\begin{tabular}{|c|c|c|}
\hline Taxón & NISP & NISP\% \\
\hline Mamíferos Indet. & 986 & 64,74 \\
\hline Camélido & 9 & 0,59 \\
\hline Lama sp. & 212 & 13,92 \\
\hline Hemiauchenia paradoxa & 7 & 0,46 \\
\hline Lama gracilis & 7 & 0,46 \\
\hline Lama guanicoe & 24 & 1,58 \\
\hline Cánido & 8 & 0,53 \\
\hline Dusicyon sp. & 4 & 0,26 \\
\hline Félido & 4 & 0,26 \\
\hline Panthera sp. & 1 & 0,07 \\
\hline Hippidium saldiasi & 2 & 0,13 \\
\hline Zaedyus pichii & 2 & 0,13 \\
\hline Roedor & 173 & 11,36 \\
\hline Aves indet. & 47 & 3,09 \\
\hline Rhea sp. & 37 & 2,43 \\
\hline Total & 1523 & 100 \\
\hline
\end{tabular}

Tabla 5.29 Número y porcentaje de especímenes óseos identificados. CT. 
El conjunto lítico de este componente es escaso. Consiste en 90 productos de talla, 7 Instrumentos y 2 ecofactos (Tabla 5.30). La materia prima más frecuente en los instrumentos fue el ópalo translucido (Tabla 5.31). Resulta interesante destacar que no se conocen hasta el momento afloramientos de esta materia prima en la localidad ni en sus cercanías. En los productos de talla es el sílex el más abundante, sin embargo, no se encuentran instrumentos en esta roca. La mayoría de de las piezas de sílex son de color gris y marrón (Tabla 5.32). Los ecofactos son de basalto (Paunero et al. 2007c, 2005; Skarbun 2009b).

Al analizar los productos de talla se observa que son muy escasas las piezas de descortezamiento, la mayoría de las piezas se divide entre el estadio de talla y formatización del filo, siendo mayores los porcentajes del estadio de talla en el sílex y más altos los de formatización final en el ópalo translucido (Tabla 5.33).

No se identificaron artefactos formatizados de sílex. Esto indica que, si bien se debieron realizar actividades de manufactura de artefactos en el sitio, éstos no fueron descartados allí o fueron utilizados sin formatizar sus filos. Sin embargo, no se identificaron piezas con características de morfología y tamaño que indiquen que podrían haber sido instrumentos (Paunero et al. 2007c; Skarbun 2009b).

Las piezas de ópalo traslucido producidas por la formatización final de los artefactos fueron principalmente de retoque. También se reconocieron tres lascas de adelgazamiento bifacial (Tabla 5.34). Las piezas de sílex producidas durante la formatización final de los artefactos son, en un porcentaje alto, de retoque (Paunero et al. 2007c; Skarbun 2009b).

Entre los productos de talla identificados $80,7 \%$ son lascas, $12,9 \%$ laminillas y $6,4 \%$ lascas largas. Los tipos de talón registrados en los productos de talla son, principalmente lineales y puntiformes (cada uno $21,4 \%$ ), seguidos por los facetados, naturales, lisos, preparados y diedros.

Se identificaron siete instrumentos. La mayoría fueron confeccionados en ópalo traslúcido, mientras que uno fue realizado sobre basalto. Los artefactos de ópalo traslucido son tres lascas retocadas, una lámina retocada, un cuchillo y un cuchillo/raedera.

La baja cantidad de productos de talla con relación a los instrumentos, y la mayor cantidad de piezas de formatización final indicarían, en relación al ópalo traslúcido, que las actividades llevadas a cabo en el sitio consistieron en los últimos pasos de la secuencia de producción. De esta manera, para este componente se puede postular que se invirtió mayor energía en la conservación de las materias primas, las cuales fueron ingresadas al sitio preparadas de tal manera que solo fue necesario realizar los últimos pasos de la secuencia de manufactura (Skarbun 2009b). 
El instrumento de basalto se trata de un rodado con un filo destacado por lascados bilaterales, tipo chopper; mide 20,4 cm. x 5,8 cm. x $3 \mathrm{~cm}$. Remontado en laboratorio, consiste en dos fragmentos grandes y 3 piezas menores.

Se registraron dos ecofactos de basalto, uno de $22 \mathrm{~cm}$ de largo, 8,2 cm de ancho y 5,5 cm de espesor y otro de $25 \mathrm{~cm}$ de largo, $10 \mathrm{~cm}$ de ancho y $7 \mathrm{~cm}$ de espesor. Provienen, muy probablemente, del manto de basalto que corona al cañadón. Consideramos como hipótesis probable que se trataría de yunques utilizados como complemento del instrumento tipo chopper descripto anteriormente, para fracturar huesos en búsqueda de medula ósea o procurar soportes para la confección de artefactos óseos (Paunero et al. 2007c).

Según los indicadores del registro, se ha asignado a este componente inferior como un sitio de procesamiento primario de presas cazadas a poca distancia del lugar, principalmente en la vega próxima, en un contexto de etapa exploratoria en el proceso de colonización del área (Paunero 2009b; Paunero et al. 2007c).

\begin{tabular}{|c|c|c|}
\hline Grupo & Cant. & \% \\
\hline Productos de talla & 90 & 90,91 \\
\hline Instrumentos & 7 & 7,07 \\
\hline Ecofactos & 2 & 2,02 \\
\hline Núcleos & 0 & 0,00 \\
\hline Total & 99 & 100 \\
\hline
\end{tabular}

Tabla 5.30. Estructura del conjunto. CT. Componente inferior.

\begin{tabular}{|c|c|c|c|c|}
\hline & Instrumentos & Productos de talla & Ecofactos & Total\% \\
\hline Sílex & 0 & 55,56 & 0 & 50,51 \\
\hline Ópalo Translúcido & 85,71 & 36,67 & 0 & 39,39 \\
\hline Xilopalo & 0 & 1,11 & 0 & 1,01 \\
\hline Basalto & 14,29 & 0 & 100 & 3,03 \\
\hline Toba Silicificada & 0 & 5,56 & 0 & 5,05 \\
\hline Indet & 0 & 1,11 & 0 & 1,01 \\
\hline Total\% & 100 & 100 & 100 & 100 \\
\hline
\end{tabular}

Tabla 5.31 Porcentaje de materias primas por grupos. CT. Componente inferior. 


\begin{tabular}{|c|c|}
\hline Color & $\%$ \\
\hline Gris & 36 \\
\hline Marrón & 30 \\
\hline Rojo & 10 \\
\hline Blanco & 6 \\
\hline Crema & 6 \\
\hline Otros & 12 \\
\hline Total & 100 \\
\hline
\end{tabular}

Tabla $5.32 \%$ de colores del sílex. CT. C. I.

\begin{tabular}{|c|c|c|c|c|}
\hline Clase de MP & Descortezamiento & Talla & Formatización & Total \\
\hline Ópalo Translúcido & 3,85 & 30,77 & 65,38 & 100 \\
\hline Sílex & 11,54 & 53,85 & 34,62 & 100 \\
\hline Toba Silicificada & 0,00 & 100,00 & 0,00 & 100 \\
\hline Total & 7,55 & 43,40 & 49,06 & 100 \\
\hline
\end{tabular}

Tabla 5.33. Porcentaje de estadios de reducción según materia prima. CT. Componente inferior.

\begin{tabular}{|c|c|c|c|c|c|}
\hline & Adelgazamiento & Reactivación & Retoque & Indet. & Total \\
\hline Ópalo translucido & $17,65 \%$ & $0,00 \%$ & $58,82 \%$ & $23,53 \%$ & $100 \%$ \\
\hline Sílex & $0,00 \%$ & $11,11 \%$ & $55,56 \%$ & $33,33 \%$ & $100 \%$ \\
\hline Total & $11,54 \%$ & $3,85 \%$ & $57,69 \%$ & $26,92 \%$ & $100 \%$ \\
\hline
\end{tabular}

Tabla 5.34 Estadio de Formatización del filo. CT. Componente inferior.

\subsubsection{Sitio La Mesada}

El sitio La Mesada (LM) es una pequeña cueva ubicada a menos de 100 metros de CT. Está compuesta por dos oquedades, una superior, que cuenta con un panel de variadas manifestaciones rupestres, y la inferior en la cual se desarrollaron las excavaciones durante los años 1996, 1999 y 2000. Se realizaron 2 cuadrículas divididas en hemicuadrículas, lo que representó un área de 4,50 $\mathrm{m}^{2}$. La superficie total de la cueva, tomando como límite la línea de goteo, es de 12,50 $\mathrm{m}^{2}$ (Fig. 5.9). Esto implica que se excavó el 36\% (Paunero 2000b, 2009b; Paunero et al. 2005; Skarbun 2009a, b).

La estratigrafía registrada en esta cueva indica 9 unidades (Fig. 5.10):

1: Ceniza del Hudson de 1991, areno limosa. Espesor: $1-3 \mathrm{~cm}$.

2: Arena gris clara. Espesor: $2-4 \mathrm{~cm}$.

3: Capa areno limosa clara con pedregullo. Con huesillos de roedores en locus, productos de bolos de regurgitación de lechuza. Muy escasos materiales y líneas de carbón. Espesor: $14-23 \mathrm{~cm}$.

4: Areno limosa clara con rocas en su interior y sin material arqueológico. En su parte superior presenta piedras medianas de derrumbe de techo. Espesor: $15-19 \mathrm{~cm}$.

5: Arena fina de tamaño variable. En este nivel comienza a registrarse un aumento de la humedad. Dividida en $5 a$ y $5 b$. La $5 a$ es más clara y con escaso material arqueológico. La $5 b$ es castaño oscura y con variación según el sector. Posee lentes de fogón, elementos líticos y óseos presentando astillas y fragmentos quemados. Espesor: $13-23 \mathrm{~cm}$.

6: Capa Arenosa con pedregullo, marrón grisácea, un poco más clara y más húmeda. Con material arqueológico: lítico, óseo y restos de carbón. Espesor: 7-11 cm. 
7: Areno limosa clara. Con muy escaso material arqueológico. Espesor: 12- $16 \mathrm{~cm}$.

8: Limosa a arena fina, de color pardo y muy húmeda. Los sedimentos son de origen eólico y espélico. En esta unidad se registra el nivel de ocupación inicial de este sitio. Se encuentran materiales culturales en A1, B1 y B2. De la base de esta unidad, de un pequeño lente carbonoso se obtuvo un fechado de $9090+/-40$ años 14C AP (Cuadro 5.4).

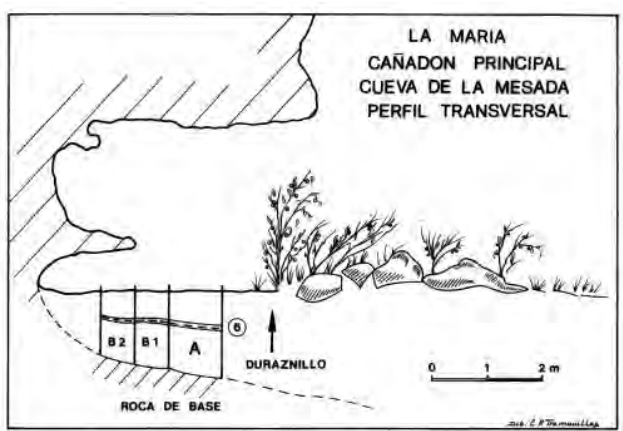

Fig. 5.9. Cueva de La Mesada. Perfil transversal. Tomado de Paunero (2000b)

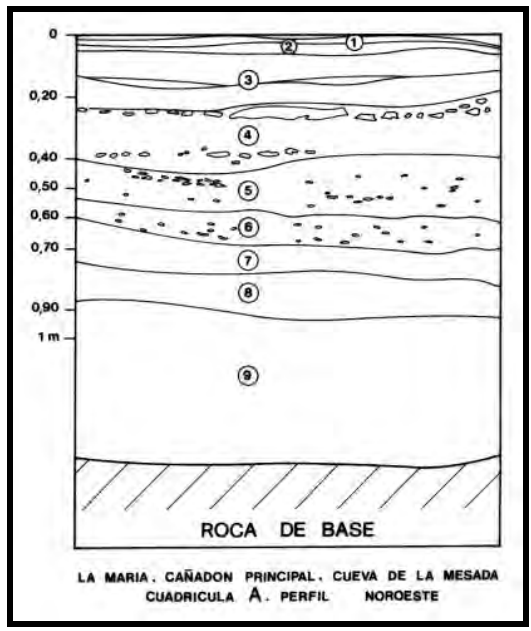

Fig. 5.10. Perfil estratigráfico. Cueva de La Mesada. Tomado de Paunero (2000b)

\begin{tabular}{|c|c|c|}
\hline & Unidad & Fechados \\
\hline Holoceno Tardío & $1,2,3$ y 4 & - \\
\hline & $5 a$ & \\
Holoceno Medio & $5 b$ & Beta - 135964: 4.500 +/- 40 años 14C AP \\
& 6 & \\
\hline Holoceno Temprano & 8 & Beta - 135963: 9.090 +/- 40 años 14C AP \\
\hline
\end{tabular}

Cuadro 5.4 Fechados Radiocarbónicos. La Mesada

\subsection{Unidad 8}

El componente no presenta fogones delimitados, pero si una pequeña mancha carbonosa en la cuadrícula B1. Los restos faunísticos correspondientes a este componente son muy exiguos. Únicamente un molar y una falange de Lama guanicoe y cuatro fragmentos indeterminados (Paunero 2000b, 2009b; Paunero et al. 2005).

El conjunto lítico posee 33 productos de talla y 6 instrumentos. No se hallaron ni núcleos ni nódulos (Paunero 2000b; Skarbun 2009b).

La materia prima más abundante, tanto para los productos de talla como para los artefactos formatizados, es el sílex (Tabla 5.35), las otras piezas son de calcedonia y solo se registró una pieza de obsidiana. La mayoría de los restos de sílex son de color marrón (Tabla 5.36) (Skarbun 2009b).

La cantidad de productos de talla identificados es muy baja como para sacar conclusiones definitivas (Tabla 5.37). Sin embargo, parecería que dentro de la cueva se procedió a realizar 
principalmente tareas de extracción de formas base de sílex. Cabe resaltar que el índice de cantidad de productos de talla por artefacto formatizado es muy bajo, lo cual evidencia que las actividades dedicadas a la producción de artefactos debieron haber sido pocas (Skarbun 2009b).

Entre los productos de talla identificados $83,3 \%$ son lascas, $11,1 \%$ laminillas y $5,6 \%$ lascas largas. Los tipos de talón registrados en los productos de talla son principalmente lisos (38,9\%), seguidos por los naturales, preparados y puntiformes, diedros y facetados.

Se identificaron seis artefactos formatizados. Los de sílex son dos raspadores, una punta de proyectil, una raedera y un cuchillo denticulado. También se confeccionó una raedera en calcedonia (Skarbun 2009b).

Las características de la ocupación indicarían que esta sería una ocupación eventual de probables características exploratorias. Sin embargo, se debe tener en cuenta que durante las sucesivas campañas de excavación del sitio se pudo comprobar una fluctuación en el régimen hídrico que afectaría los restos arqueológicos de esta unidad. Al excavar en el año 1999, se llegó al nivel de capa freática medio metro por debajo de esta ocupación. Al año siguiente se produjeron precipitaciones de más de $300 \mathrm{~mm}$ para la región, produciendo que el agua llegase a cubrir los niveles medios. Este tipo de fenómeno debe haber ocurrido varias veces a lo largo de la transición Pleistoceno-Holoceno. Al respecto, cabe señalar que un estudio funcional a altos aumentos, no pudo registrar microrrastros en ninguno de los artefactos lítico, por encontrarse sus superficies alteradas por un lustre que enmascaró las superficies de todas las piezas, hecho que se atribuye a un proceso de lixiviado. Se suma a esto, la ausencia de restos óseos en esta unidad (Paunero 2000b, 2009b).

\begin{tabular}{|c|c|c|c|}
\hline & Productos de talla & Instrumentos & Total\% \\
\hline Sílex & 81,82 & 83,33 & 82,05 \\
\hline Calcedonia & 15,15 & 16,67 & 15,38 \\
\hline Obsidiana & 3,03 & - & 2,56 \\
\hline Total\% & 100 & 100 & 100 \\
\hline
\end{tabular}

Tabla 5.35. Porcentaje de materias primas por grupos. LM. Unidad 8. Tomado de Skarbun (2009b)

\begin{tabular}{|c|c|}
\hline Color & $\mathbf{\%}$ \\
\hline Marrón & 46,67 \\
\hline Rojo & 26,67 \\
\hline Gris & 16,67 \\
\hline Otros & 10 \\
\hline Total & 100 \\
\hline
\end{tabular}

Tabla 5.36. Porcentaje de colores del sílex. LM. Unidad 8. Modificado de Skarbun (2009b)

\begin{tabular}{|c|c|c|c|c|}
\hline & Sílex & Calcedonia & Obsidiana & Total \\
\hline Descortezamiento & 2 & - & - & 2 \\
\hline Talla & 17 & - & - & 17 \\
\hline Formatización & 1 & 1 & 1 & 3 \\
\hline Total & 20 & 1 & 1 & 22 \\
\hline
\end{tabular}

Tabla 5.37. Estadios de reducción. LM. Unidad 8. Tomado de Skarbun (2009b) 


\subsubsection{Sector Cañadón de la Cueva de La Ventana}

Este sector se encuentra a una altura de 240 a 300 m.s.n.m. Está demarcado por un cañadón de ignimbritas correspondientes a la Fm. Chon Aike, el zanjón que lo atraviesa desemboca en la "Laguna de La María". En las partes altas que rodean al cañadón se registraron afloramientos de sílex y concentraciones de productos de talla de este material, delimitados en tres sectores con mayor densidad artefactual y reconocidos como probables sitios cantera-taller. Se relevaron tres sitios con pinturas rupestres, destacándose la cueva de La Ventana, en la cual también se han realizado excavaciones (Paunero 2000b, 2009b; Paunero et al. 2005).

\subsubsection{Sitio Cueva de La Ventana}

La Cueva de La Ventana (LV) presenta características particulares, es muy oscura y posee una "ventana" circular pintada con "rayos" a su alrededor de color rojo claro. Abarca una superficie de $76 \mathrm{~m}^{2}$, pudiéndose diferenciar dos sectores: un recinto interior oscuro de $36 \mathrm{~m} 2$ y un sector exterior hasta la línea de goteo de $40 \mathrm{~m}^{2}$. Se excavaron $6 \mathrm{~m}^{2}$ del sector interno (Fig. 5.11).

Se registró una estratigrafía con 7 unidades, que presentan buena horiontalidad (Fig. 5.12):

1: Guano suelto con ceniza del Hudson de 1991, areno limosa. Espesor: $4-7 \mathrm{~cm}$.

2: Guano muy compactado. Espesor: 7-10 cm.

3: Ceniza volcánica con algo de guano. Espesor: $5-9 \mathrm{~cm}$.

4: Limo color pardo obscuro suelto, con importantes fogones. Variando mucho el espesor en cada sector. Espesor: 3,5-14 cm

5: Limo ocre claro sin compactación. Con espesores variables según el sector. Sin restos de carbón. Espesor: $1-8 \mathrm{~cm}$.

6: Limo-arcilloso claro y sin compactar, oscurecido por una línea de fogones. El origen de los sedimentos, además del aporte antrópico, es casi exclusivamente eólico. En esta unidad registramos el nivel de ocupación inicial de este sitio. De un fogón de la base de esta unidad, en la cuadrícula B1 se obtuvieron los siguientes fechados: 7,970 \pm 40 14Caños AP y 7,665 \pm 75 14C años AP (Cuadro 5.5). Espesor: $3-9 \mathrm{~cm}$.

7: Limo- arcilloso muy claro sin compactar y sin restos culturales, también con espesores variables, descansa sobre la roca de base. Espesor: $2-6 \mathrm{~cm}$. 


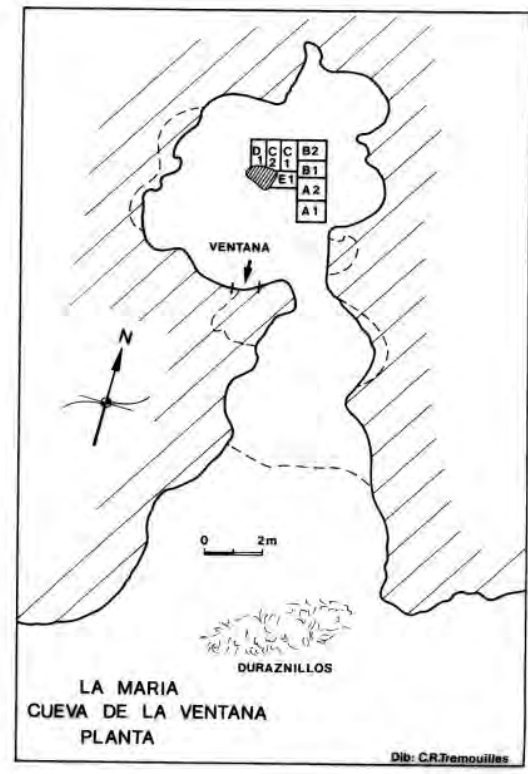

Fig. 5.11. Planta de excavación. LV. Tomado de Paunero (2000b)

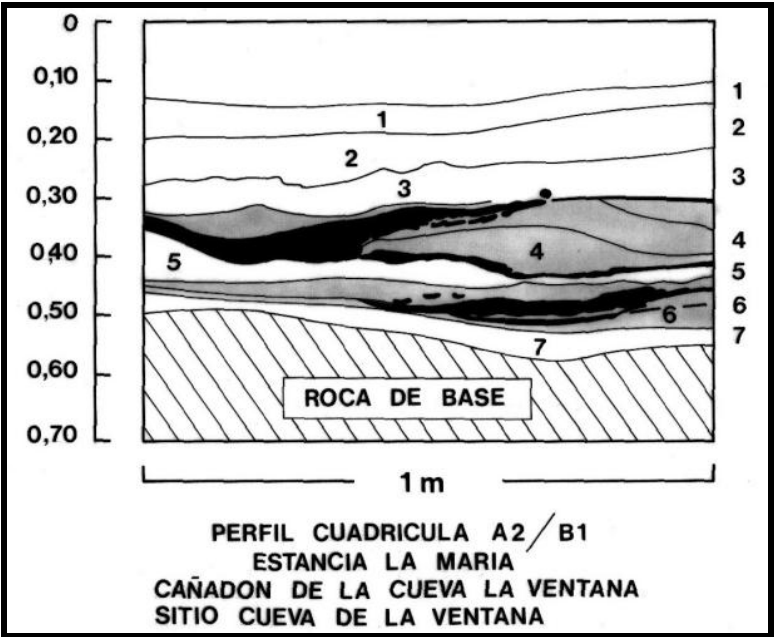

Fig. 5.12. Perfil estratigráfico. Tomado de Paunero (2000b)

\begin{tabular}{|c|c|c|}
\hline & Unidad & Fechados \\
\hline Siglo XX & 1 & - \\
\hline Holoceno Tardío & 2 & - \\
\hline Holoceno Medio & 4 & - \\
\hline Holoceno Temprano & 6 & $\begin{array}{c}\text { AA - 35237: 7.665 +/- 75 años }{ }^{14} \mathrm{C} \text { AP } \\
\text { Beta - 135965: 7.970 +/- 40 años }{ }^{14} \mathrm{C} \text { AP }\end{array}$ \\
\hline
\end{tabular}

Cuadro 5.5. Fechados radiocarbónicos. Cueva de La Ventana

\subsection{Unidad 6}

En este componente correspondiente al Holoceno temprano se reconoció un fogón, ubicado en las cuadrículas B1, B2 y A2. Se recuperaron muy escasos fragmentos óseos: 31 elementos de roedor y 24 fragmentos indeterminados.

En cuanto a los restos líticos recuperados, se registraron 3 instrumentos líticos y 39 productos de talla. La distribución por materias primas muestra una clara preponderancia del sílex, tanto en productos de talla como en instrumentos (Tabla 5.38). El color predominante en el que se presenta es el marrón, seguido por el rojo (Tabla 5.39). Estos son probablemente locales teniendo en cuenta que se han registrado afloramientos de sílex con esta gama de colores en los alrededores al sitio.

En todas las materias primas predominan los estadios de talla por sobre los de formatización final (Tabla 5.40). No se han registrado piezas de descortezamiento, ni núcleos.

Entre los productos de talla identificados, $76,5 \%$ son lascas y $23,5 \%$ láminas. Los tipos de talón registrados en los productos de talla son principalmente preparados $(45,5 \%)$, presentándose 
también lisos, facetados, lineales, naturales y puntiformes. Se han registrado sólo tres instrumentos, un raspador y dos lascas retocadas, ambos confeccionados en sílex.

La unidad 6 podría señalar un uso muy particular de este espacio; se trataría de funciones especificas fuera de las tipologías usuales, teniendo en cuenta los escasos indicadores de consumo, de procesamiento o de actividades de producción lítica y considerando también las características del arte rupestre de la cueva (Paunero 2000b; Paunero et al. 2005).

\begin{tabular}{|c|c|c|c|c|c|c|}
\hline & Calcedonia & Obsidiana & Sílex & Toba silicificada & Xilópalo & Total \\
\hline Productos de talla & 15,38 & 7,69 & 69,23 & 5,13 & 2,56 & 100 \\
\hline Instrumentos & 0 & 0 & 100 & 0 & 0,00 & 100 \\
\hline Total & 14,29 & 7,14 & 71,43 & 4,76 & 2,38 & 100 \\
\hline
\end{tabular}

Tabla 5.38 Porcentaje de materias primas por grupos. LV. Unidad 6

\begin{tabular}{|c|c|}
\hline Color & $\mathbf{\%}$ \\
\hline Marrón & $41,94 \%$ \\
\hline Rojo & $22,58 \%$ \\
\hline Gris & $19,35 \%$ \\
\hline Otros & $16,13 \%$ \\
\hline Total & $100 \%$ \\
\hline
\end{tabular}

Tabla 5.39 Porcentaje de colores del sílex. LV. U. 6.

\begin{tabular}{|c|c|c|c|c|}
\hline & Talla & Formatización Final & Indet. & Total \\
\hline Calcedonia & 66,67 & $16,67 \%$ & $16,67 \%$ & $100 \%$ \\
\hline Obsidiana & 100 & $0 \%$ & $0 \%$ & $100 \%$ \\
\hline Sílex & 58,33 & $4,17 \%$ & $37,50 \%$ & $100 \%$ \\
\hline Toba Silicificada & 100 & $0 \%$ & $0 \%$ & $100 \%$ \\
\hline Xilópalo & 100 & $0 \%$ & $0 \%$ & $100 \%$ \\
\hline Total & 66,67 & $5,56 \%$ & $27,78 \%$ & $100 \%$ \\
\hline
\end{tabular}

Tabla 5.40. Porcentaje de estadios de reducción. LV. Unidad 6. 


\section{CAPÍTULO 6: EL TRATAMIENTO TÉRMICO DE ARTEFACTOS LÍTICOS: CARACTERÍSTICAS Y ANTECEDENTES EN LA INVESTIGACIÓN}

En este capítulo presentamos las características y los antecedentes de investigación referentes al tratamiento térmico de artefactos líticos.

\subsection{El tratamiento térmico}

El tratamiento térmico consiste en exponer material lítico a la acción del calor controlado de fogones durante la confección de artefactos. Este proceso optimiza algunas de las cualidades de la roca importantes para la talla; esencialmente disminuye la dureza de las rocas, volviéndolas más frágiles y quebradizas (Nami et al. 2000). Al alterar algunas de las variables que se conjugan en el proceso de talla, este procedimiento pirotecnológico disminuye la fuerza necesaria para extraer lascas; permite generar productos más largos, con morfologías más controladas y filos más agudos; disminuye las probabilidades de ocasionar fracturas en charnela; además facilita la extracción de lascas por presión, por lo que es utilizado previo al adelgazamiento bifacial y la confección de láminas ya que permite una producción más estandarizada y de mejor calidad (Collins y Fenwick 1974; Domanski y Webb 2007; Flenniken y Garrison 1975; Gibaja y Clemente 1997; Inizan et al. 1999; Inizan y Tixier 2000; Mandeville 1973; Mandeville y Flenniken 1974; Nami 1992; Nami et al. 2000; Purdy y Brooks 1971; Terradas y Gibaja 2001; Webb y Domanski 2009). Por otra parte, existen testimonios según los cuales esta técnica es aplicada para fines estéticos, ya que el calor produce también cambios en el aspecto de las rocas (Inizan y Tixier 2000).

\subsection{Indicadores}

Los cambios en el color, lustre y brillo de las rocas generados por el tratamiento térmico resultan indicadores útiles a la hora de reconocer artefactos líticos expuestos a este procedimiento prirotecnológico en el registro arqueológico (Cattáneo et al. 1997-98; Clemente Conte 1995; Gibaja y Clemente 1997; Nami et al. 2000; Terradas y Gibaja 2001). Por lo general las piezas tratadas térmicamente toman una apariencia más sedosa y una textura más suave.

- Cambio de color: Los materiales líticos pueden cambiar su coloración cuando son expuestos a altas temperaturas (Fig. 6.1), tendiendo a tomar colores rojizos. Este cambio ocurrirá en materiales silíceos que contengan minerales que, como el hierro, reaccionen 
con una atmósfera oxidante al ser calentados (Ariet 1991; Flenniken y White 1983; Purdy y Brooks 1971; Schindler et al. 1982). El cambio de color comienza por la superficie externa de la pieza, y va penetrando en la roca a medida que la pieza es calentada por más tiempo o a mayor temperatura. Si la pieza no es calentada lo suficiente, el color original se mantendrá en su interior (Terradas y Gibaja 2001). Por otra parte, otras materias primas tienden a oscurecerse adquiriendo tonalidades negras, o a aclararse hacia tonos grisáceos. Estos procesos pueden ocurrir por la oxidación de materia orgánica presente en la roca, o por los cambios en las propiedades ópticas como resultado de la pérdida de agua (Luedtke 1992).

- Lustre: Es un brillo que se manifiesta de aspecto graso o sedoso. Constituye el rasgo distintivo de la aplicación del tratamiento térmico en aquellas materias primas en las que se desarrolla. Se observa en el interior de la pieza si ésta fue retocada con posterioridad al tratamiento térmico. Asimismo es identificable en planos de fractura generados por causas tecnológicas, accidentales o de uso, en la cara ventral de esquirlas producto del retoque y conos de desprendimiento térmico (ver infra). Si bien este lustre puede confundirse con otros de diverso origen (Cattáneo et al. 1997-98; Clemente Conte y López 2005), es posible diferenciarlo cuando la pieza no ha sido retocada en su totalidad, presentando los negativos del retoque lustrosos y la superficie natural más opaca (Fig. 6.2). Este lustre va acompañado de un cambio en la textura de la pieza; las superficies extraídas después del tratamiento se observan netamente más lisas (Bordes 1969; Crabtree y Butler 1964; Flenniken y White 1983; Gibaja 2002; Mandeville 1973; Nami et al. 2000; Rick y Chappell 1983; Terradas y Gibaja 2001).

- Brillo: Se trataría de un brillo vítreo que algunos autores lo diferencian del lustre aunque se produciría también en el interior de las piezas retocadas con posterioridad al tratamiento térmico (Stadler 2002). Si bien las piezas tratadas desarrollan un aspecto brilloso que se puede observar en su interior una vez retocadas, consideramos que éste es un modo en que se presenta el lustre térmico.

- Aparición de Ondas de percusión: Al tallar una pieza tratada térmicamente, puede observarse en la cara ventral de las lascas extraídas la presencia de las ondas de aplicación de fuerza, que se identifican con mayor nitidez que en las piezas no tratadas (Collins y Fenwick 1974; Nami et al. 2000; Terradas y Gibaja 2001). De acuerdo a Collins y Fenwick (1974) éstas se observan más grandes y ondulosas (Fig. 6.3). 


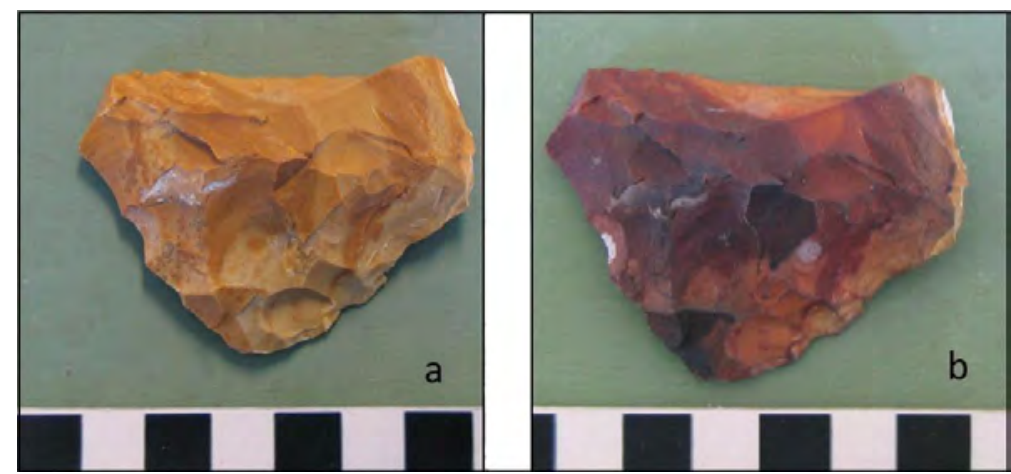

Fig. 6.1. Cambio de color. a: Materia prima original. b: Después del calentamiento. El material es producto de nuestra experimentación.

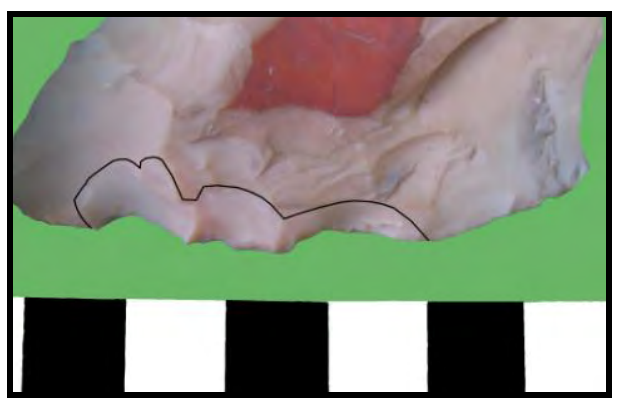

Fig. 6.2. Lustre térmico. Nótese el contraste entre los negativos lustrosos y los más opacos. El material es producto de nuestra experimentación.

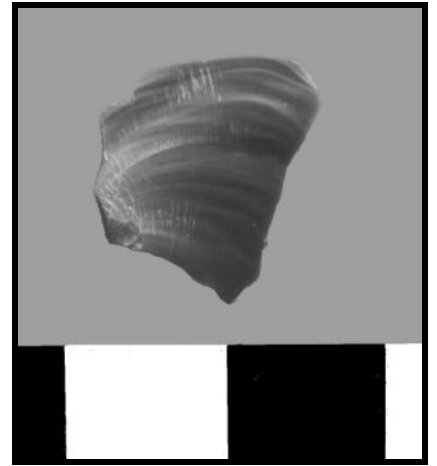

Fig. 6.3. Ondas de percusión en lasca tratada térmicamente. El material es producto de nuestra experimentación.

Es necesario destacar que no todas las materias primas al ser calentadas sufren estos cambios macroscópicos. Por el contrario, estos procesos dependen de las particularidades de los materiales y las temperaturas alcanzadas. Así, en algunas rocas no se observarán estos cambios en ninguna ocasión, mientras que en otras es necesario traspasar un determinado umbral térmico para que se observen. Además, no necesariamente todos estos indicadores se dan en cada materia prima, y si se dan, no siempre lo hacen de manera sincrónica.

Por ejemplo, los experimentos llevados a cabo por diversos investigadores indican que los resultados en cuanto a las características del lustre térmico no deben generalizarse a todas las materias primas. Cada litología puede responder frente al tratamiento térmico de manera desigual debido a su composición mineralógica, estructura, presencia de impurezas, etc. (Gibaja 2002; Rick y Chappell 1983). En cuanto al cambio de color, este no ocurrirá en ausencia de minerales adecuados o si las rocas son calentadas en un ambiente reductor (Ariet 1991; Flenniken y White 1983; Purdy y Brooks 1971; Schindler et al. 1982).

Por otra parte, hay que destacar que la identificación del tratamiento térmico a partir de los cambios en el color y de la observación de las ondas de percusión puede resultar problemática. Por un lado, reconocer que una materia prima cambió de color significa saber cuál era su color original; esto exige conocer la base regional de recursos líticos de la región y realizar 
experimentaciones con ella para observar de qué manera se modifican las rocas y qué colores toman. Por el otro, la identificación de ondas de percusión no significa que una pieza haya estado sujeta a este procedimiento ya que hay muchas materias primas de muy buena calidad para la talla a las que en determinados casos se les puede observar estas ondas. Sin embargo, la observación de éstas en una parte significativa del conjunto, sumado al conocimiento del investigador acerca de cómo reacciona esta materia prima en su forma natural, puede dar información positiva que lleve a la confirmación de la aplicación de este procedimiento.

Asimismo, también debemos resaltar que no todas las materias primas ven mejoradas sus propiedades para la talla luego del tratamiento térmico (Inizan et al. 1999). Por el contrario, en algunos casos su aplicación incide de manera negativa en las piezas, perdiendo estas su fractura concoidea (Cowan 1987). Lo mismo puede suceder cuando este procedimiento es realizado de manera defectuosa, por ejemplo elevando la temperatura muy rápidamente, sobrepasando la temperatura óptima o exponiendo las piezas al contacto con el fuego. En estos casos se produce daño térmico: fracturas características que permiten identificar la acción del fuego. Si bien en algunos casos éstas no impiden que se siga desarrollando posteriormente la talla, en otros la pieza puede llegar a destruirse completamente. Tales fracturas que en conjunto denominamos daño térmico son:

- Hoyuelos: También llamados levantamientos térmicos (Fig. 6.4). Son negativos de forma cónica que se producen en el cuerpo de la lasca. El desprendimiento que provoca este hoyuelo es denominado cono de desprendimiento (Fig. 6.5) (Cattáneo et al. 1997-98; Clemente Conte 1995, 1997; Terradas y Gibaja 2001).

- Escamaciones: Son fracturas en forma de medialuna, producto del desprendimiento incompleto de los conos. Puede hallárselas aisladas o en grupo (Fig. 6.6) (Cattáneo et al. 1997-98; Clemente Conte 1995, 1997; Terradas y Gibaja 2001).

- Rugosidad: Se caracteriza por ser una superficie sumamente irregular y áspera producto del desprendimiento de muy pequeños fragmentos de la pieza (Fig. 6.7).

- Agrietamientos: Son fisuras irregulares, de morfología variable, superficiales o profundas (Fig. 6.8). En algunos casos puede formar un reticulado superficial conocido como craquelado (Cattáneo et al. 1997-98; Clemente Conte 1995, 1997; Mandeville 1973; Terradas y Gibaja 2001).

El daño térmico por sí solo no es indicador de tratamiento térmico, sino del contacto del material lítico con el calor del fuego. Existen otras situaciones de alteración térmica involuntaria, accidental o no dirigida en que se dañan las piezas: la caída casual de una pieza en un fogón; el descarte de artefactos en estas estructuras de combustión como forma de mantenimiento del espacio o en el marco de rituales mortuorios; o la acción de incendios naturales o de fogones 
encendidos con posterioridad a la depositación de estos elementos (Bridges 2003; Buenger 2003; Clemente Conte 1995; Larsson 2000; Musters 2005; Stadler 2002).

Por otra parte, además de los desprendimientos que se producen en las piezas en formas de conos y microfragmentos y que dejan en la superficie hoyuelos y rugosidades, puede suceder que la pieza se fracture en grandes fragmentos. Estos presentan un alto grado de heterogeneidad, las fracturas pueden darse tanto en el planto transversal como longitudinal de la pieza.

Además de estos indicadores, en algunos casos puede observarse una pátina, que si bien no es habitual, es un claro indicador del contacto de la pieza con el fuego. Esta pátina es una cubierta blanquecina superficial (Fig. 6.9). En su estado inicial puede estar restringida a sectores acotados de la pieza, mientras que en casos extremos puede cubrirla completamente. Se asocia por lo general a temperaturas elevadas (Clemente Conte 1995, 1997; Terradas y Gibaja 2001).

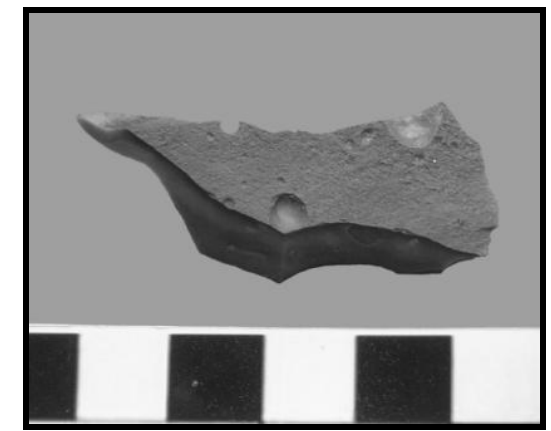

Fig. 6.4. Hoyuelos. El material es producto de nuestra experimentación.

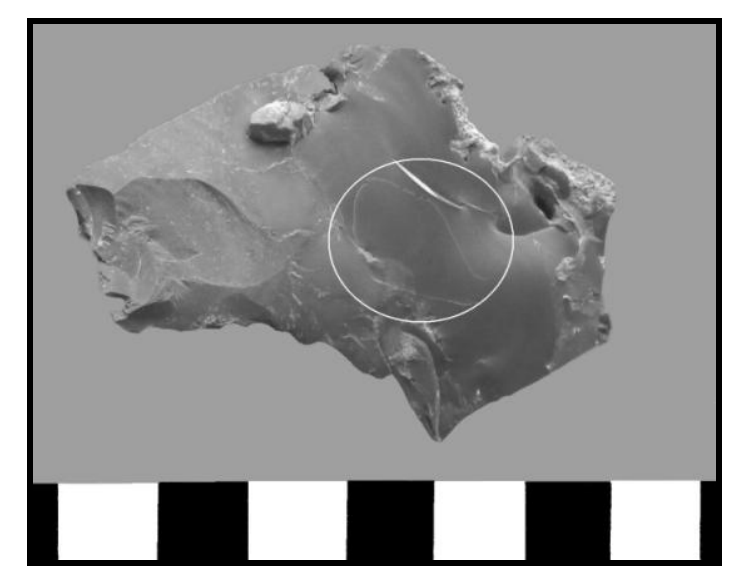

Fig. 6.6. Escamación. El material es producto de nuestra experimentación.

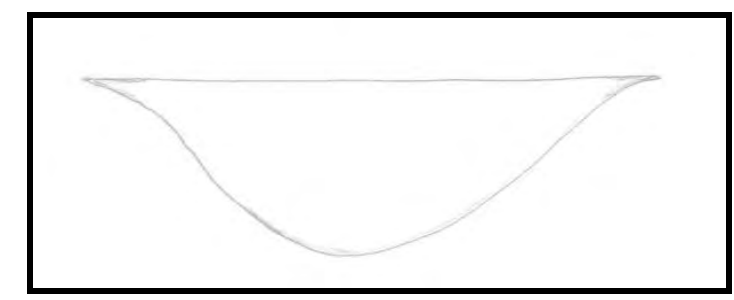

Fig. 6.5. Esquema típico de un cono de desprendimiento visto en sección transversal.

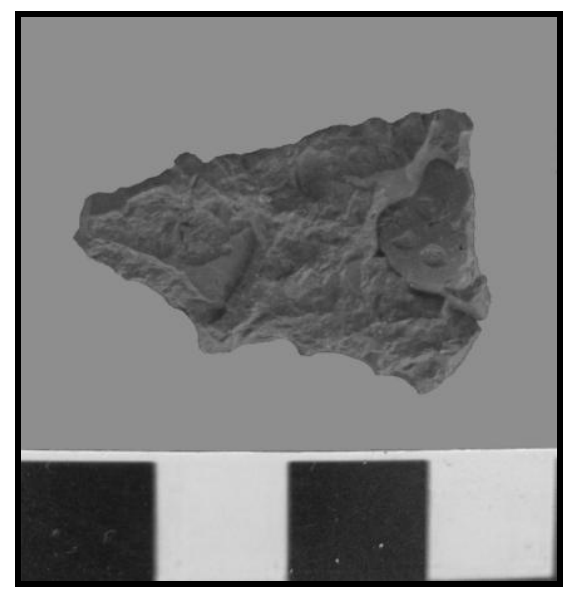

Fig. 6.7. Rugosidad. El material es producto de nuestra experimentación. 


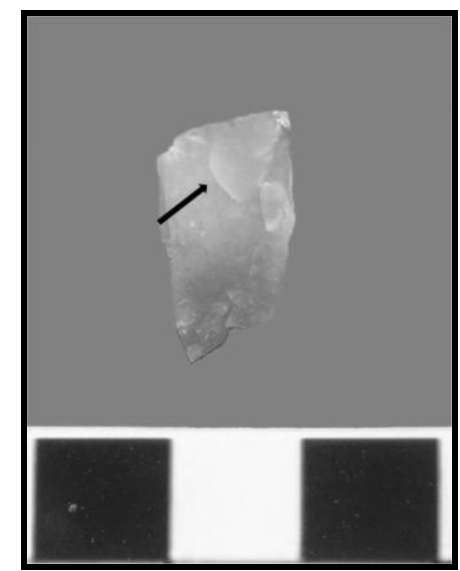

Fig. 6.8. Agrietamiento. El material es producto de nuestra experimentación.

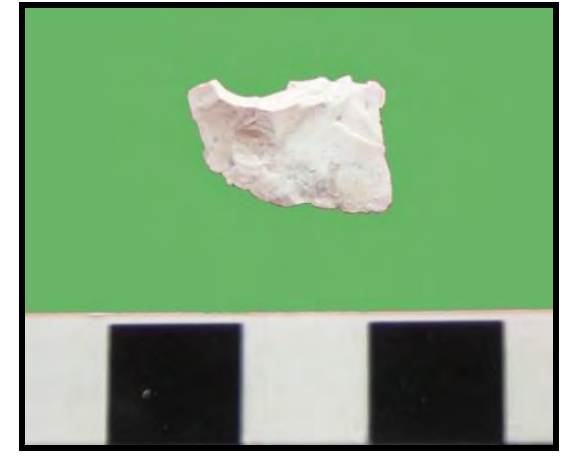

Fig. 6.9. Pátina. El material es producto de nuestra experimentación.

\subsection{Procedimiento}

En el caso del tratamiento térmico, es necesario que no exista un contacto directo entre el fuego y las piezas para evitar un shock térmico y que se dañen. Esto se logra enterrando las piezas, o bien cubriéndolas de sedimento, antes de encender el fogón. Las observaciones tanto experimentales como de sitios arqueológicos norteamericanos señalan la excavación de pozos relativamente profundos ("pits") donde se realizaría un calentamiento inicial del pozo, luego se colocarían las piezas dentro de una matriz de arena por encima de la cual se echaría nuevamente brasa (ver por ejemplo Mandeville y Flenniken 1974). Existen otros casos donde no hay evidencias de pozos (Inizan et al. 1999); además otros trabajos experimentales han demostrado que es suficiente con que las piezas no entren en contacto con el fuego (Clemente Conte 1995), por lo que un fogón en cubeta o plano también pueden ser útiles para llevar a cabo el procedimiento.

En cuanto a la duración del tratamiento térmico, existe un acuerdo generalizado en que cuanto más tiempo dure, mejor resultará el procedimiento. Si bien habitualmente los programas experimentales dejan a las piezas expuestas al calor varias horas (Flenniken y Garrison 1975; Mandeville 1973; Mandeville y Flenniken 1974; Nami et al. 2000; Schindler et al. 1982; Stadler 2002; Terradas y Gibaja 2001), no existe hasta el momento ninguna investigación que analice cuál es el tiempo óptimo de duración de este procedimiento. Sin embargo, hay que resaltar que es necesario que tanto el enfriamiento como el calentamiento de las piezas se realicen de manera lenta para evitar el shock térmico, por lo que estos requerimientos exigen que esta técnica sea prolongada (Cattáneo et al. 1997-98; Flenniken y Garrison 1975; Mandeville y Flenniken 1974; Nami et al. 2000; Schindler et al. 1982; Stadler 2002; Terradas y Gibaja 2001).

No obstante, recientes investigaciones han planteado que no existe una única forma para la realización del tratamiento térmico, sino que el modo en que se realice dependerá de las dimensiones de la pieza a tratar (Mercieca 2000; Mercieca y Hiscock 2008). De acuerdo a estos 
investigadores, las piezas más pequeñas son más resistentes al calor por lo que resistirían temperaturas más elevadas e incluso podrían ser tratadas térmicamente en contacto directo con el fuego (Mercieca 2000; Mercieca y Hiscock 2008). Es cierto que existen probablemente diversos métodos posibles que resultan útiles a la hora de llevar a cabo el calentamiento. Se han realizado numerosas observaciones experimentales que afirman que las dimensiones de la pieza juegan un papel importante en relación a la resistencia de una materia prima al calor (Ariet 1991; Clemente Conte 1997; Mandeville 1973). Hay por ejemplo diferencias entre el tratamiento térmico de núcleos y productos de talla. Se ha propuesto que el tratamiento de núcleos sería más dificultoso que el de piezas de poco espesor como las lascas, siendo necesario realizar el calentamiento de manera más lenta y por un mayor período de tiempo (Mandeville 1973). De esta manera se evitaría el stress térmico, que puede provocar la destrucción de la pieza. A pesar de esto, la propuesta de Mercieca (Mercieca 2000; Mercieca y Hiscock 2008) está basada en experimentaciones que no cumplen los objetivos propuestos ya que al evaluar la interacción entre el tamaño y el tiempo de calentamiento, sólo fija su atención en el momento de aparición de daño térmico, sin analizar cuáles son las consecuencias a nivel de las mejoras para la talla. Existen trabajos experimentales que demuestran que el calentamiento mal realizado puede llevar a la pérdida de la integridad estructural de la roca impidiendo la talla, sin así presentar evidencias de daño térmico (Collins y Fenwick 1974; Cowan 1987). Existen para cada caso un óptimo de temperatura y de duración del tratamiento térmico, más allá de los cuales se produce una recristalización que resulta negativa para la producción lítica (Terradas y Gibaja 2001).

\subsection{Temperaturas necesarias}

La duración del tratamiento, la gradualidad del calentamiento y del enfriamiento así como la temperatura máxima alcanzada, destacan como variables importantes a tener en cuenta para realizar un procedimiento efectivo. Podemos decir que cuanto más lento se realice el calentamiento y el enfriamiento de la pieza, mayor es la probabilidad de que tratamiento térmico sea efectivo. Si bien la temperatura óptima varía con las diversas materias primas, y probablemente influyan distintos factores tales como tamaño de grano, contenido de agua y de impurezas, existe un rango dentro del cual se debe realizar este procedimiento. Se considera que es necesario alcanzar al menos los $200^{\circ} \mathrm{C}$ para que la piedra se vea afectada por el calor, siendo en algunos casos imperante superar los $500^{\circ} \mathrm{C}$ (Mandeville 1973). Por lo general, las temperaturas propuestas como óptimas fluctúan entre los 250 y los $450^{\circ} \mathrm{C}$ (Tabla 6.1). Probablemente la temperatura máxima a la cuales se puede exponer las materias primas ronde en los $550^{\circ} \mathrm{C}$ al menos para el sílex. A los $573^{\circ} \mathrm{C}$ el cuarzo $\alpha$, del que se compone la mayor parte de 
los sílex, sufre una transición al cuarzo $\beta$ que implica un cambio en la estructura cristalina que daña a las materias primas volviéndolas inutilizables (Luedtke 1992).

Por otra parte, existen investigadores que afirman que existiría una relación inversa entre tiempo y temperatura requerida: se lograrían los mismos resultados exponiendo a las piezas por largos períodos a temperaturas relativamente bajas o por períodos más cortos a temperaturas más altas (Luedtke 1992; Terradas y Gibaja 2001).

\begin{tabular}{|c|c|c|c|}
\hline Materia prima & País & Rango T & Referencia \\
\hline Bald Eagle Jasper & EE.UU. & $200-300$ & Schindler et al. 1982 \\
\hline Calcedonia & Santa Cruz, Argentina & $200-300$ & Stadler 2002 \\
\hline Dacita & Santa Cruz, Argentina & $200-600$ & Stadler 2002 \\
\hline Sílex Sant Quintí & España & $250-300$ & Clemente Conte 1995 \\
\hline Ópalo La Liebre & Bs As, Argentina & $250-300$ & Ariet 1991 \\
\hline Sílex Teruel & España & $250-350$ & Gibaja y Clemente 1997 \\
\hline Sílex Río Don & Rusia & $250-350$ & Gibaja y Clemente 1997 \\
\hline Dolomía Silicificada La Liebre & Bs As, Argentina & $250-350$ & Nami et al. 2000 \\
\hline Toba Vítrea La Matilde & Santa Cruz, Argentina & $250-350$ & Nami et al. 2000 \\
\hline Sílice San Jorge & Santa Cruz, Argentina & $250-350$ & Nami et al. 2000 \\
\hline Xilópalo La Matilde & Santa Cruz, Argentina & $250-350$ & Nami et al. 2000 \\
\hline Riolita & Tierra del Fuego, Arg. & $250-350$ & Nami et al. 2000 \\
\hline Calcedonia La Matilde & Santa Cruz, Argentina & $250-450$ & Nami et al. 2000 \\
\hline Fort Payne Chert & EE.UU. & $250-450$ & Nami et al. 2000 \\
\hline Riolita & Santa Cruz, Argentina & $250-450$ & Nami et al. 2000 \\
\hline Ortocuarcita Sierras Bayas & Bs As, Argentina & $250-450$ & Nami et al. 2000 \\
\hline Nehawka Chert & EE.UU. & 325 & Mandeville y Flenniken 1974 \\
\hline Florida Chert & EE.UU. & $350-400$ & Purdy y Brooks 1971 \\
\hline Sílex Los Gallumbares & España & $350-400$ & Afonso Marrero 1997 \\
\hline Burlington Chert & EE.UU. & $370-410$ & Rick y Chappell 1983 \\
\hline Novaculita Arkansas & EE.UU. & 450 & Flenniken y Garrison 1975 \\
\hline Tabla 6.1. Temperas
\end{tabular}

Tabla 6.1. Temperaturas óptimas (en $\mathrm{C}^{\circ}$ ) propuestas para diversas materias primas.

\subsection{El tratamiento térmico en el marco de la secuencia de producción de artefactos líticos}

El tratamiento térmico constituye una técnica que puede ser incorporada al proceso de producción de artefactos líticos. Esto significa necesariamente que ocupará un lugar dentro de la secuencia de reducción (ver capítulo 2). Se ha observado el uso del fuego por parte de diversos grupos desde los primeros pasos de la producción lítica, esto es desde el aprovisionamiento de la materia prima (Binford y O’Connell 1984; Gregg y Grybush 1976). Específicamente el fuego sería usado en estos casos como medio para fracturar grandes bloques líticos. Creemos que este método consiste en una forma distinta de tratamiento térmico puesto que en este caso el fuego no se utiliza para mejorar las cualidades de talla de las rocas sino directamente para fracturarlas. 
Además las piezas son expuestas directamente a la fuente de calor; esto implica un manejo distinto del fuego, por lo que es considerada aquí como una técnica diferente.

Como observáramos más arriba, los estudios experimentales han demostrado que la forma de realizar el tratamiento térmico debe ser diferente si son núcleos o piezas más pequeñas como lascas o preformas.

En este sentido, se ha propuesto que esta técnica habría sido utilizada durante el Neolítico español y francés en los momentos finales de la formatización de núcleos a fin de extraer soportes laminares con morfologías controladas (Gassin et al. 2009; Gassin et al. 2006; Gibaja 2002; Terradas y Gibaja 2001). De acuerdo a Terradas y Gibaja (2001) el tratamiento térmico habría sido realizado una vez que se había llevado a cabo una configuración inicial del núcleo. Con posterioridad al tratamiento térmico comenzaría la fase de explotación del núcleo propiamente dicha en la cual se extraerían láminas por presión.

También se ha sugerido que este procedimiento se habría realizado sobre los soportes, previo a la formatización final de los instrumentos. Esta afirmación se presenta de manera general en los investigadores estadounidenses que publican sobre el tema (Collins y Fenwick 1974; Mandeville 1973; Schindler et al. 1982) así como en las publicaciones referidas al solutrense francés (Bordes 1969; Inizan y Tixier 2000; Mandeville 1973). En relación a esto, se ha afirmado que este tratamiento facilita el retoque por presión y el adelgazamiento bifacial; en consecuencia, es común reconocer este procedimiento en puntas de proyectil (Bordes 1969; Flenniken y Garrison 1975; Inizan y Tixier 2000; Mandeville y Flenniken 1974; Nami et al. 2000; Rick y Chappell 1983).

De esta manera se observan dos posibles caminos de aplicación del tratamiento térmico durante la producción de artefactos líticos; el primero sería durante la formatización de los núcleos con el objetivo de realizar extracciones de soportes, por lo general laminares, el segundo durante la formatización de preformas dirigidas a la producción de artefactos bifaciales, fundamentalmente puntas de proyectil. En ambos casos, la forma de extracción utilizada después del tratamiento sería primordialmente por presión.

\subsection{Alteración térmica e interacción con micropulidos}

Un aspecto que ha sido poco estudiado es la forma en que el tratamiento y el daño térmico inciden, durante el análisis funcional, en el reconocimiento de los micropulidos producidos durante del uso de los artefactos. Las superficies líticas se modifican de diversos modos por los procesos térmicos, y esto afecta la observación de los micropulidos (Clemente Conte 1997).

Por un lado, el daño térmico puede fragmentar la pieza; si éste se da en el filo del artefacto puede destruir todo o parte del micropulido. La pátina, en tanto, puede enmascarar ciertos tipos de 
micropulidos como los de la madera o los producidos por contacto del artefacto con tejidos blandos (Clemente Conte 1997).

Por otra parte, si bien el tratamiento térmico produce alteraciones morfológicas en los artefactos líticos como las indicadas previamente, aun no se sabe con certeza si produce modificaciones sobre los micropulidos generados posteriormente, al trabajar diferentes sustancias. Se han realizado escasos estudios en relación a este tema que sugieren que el lustre térmico podría enmascarar algunos tipos de micropulidos (Clemente Conte y López 2005; Gibaja 2002; Gibaja y Clemente 1997). De acuerdo a estos autores los micropulidos producto del trabajo sobre materias duras como el hueso son reconocibles en piezas expuestas a esta técnica, mientras que los micropulidos por trabajo sobre materias blandas como carne y piel fresca se enmascaran más fácilmente. Estos contrastes en la resistencia a las alteraciones térmicas se deberían a diferencias estructurales en los distintos tipos de micropulidos. De acuerdo a Gibaja y Clemente (1997):

"... en cuanto al micropulido, éste se genera y desarrolla como en cualquier tipo de sílex sin tratamiento térmico. Sin embargo, en estos últimos aun cuando el micropulido esté poco desarrollado o en el estadio de indiferenciado, (...) se pueden observar o distinguir con el brillo del resto de la superficie, cosa que no ocurre cuando el brillo del lustre térmico está presente. El micropulido debido al trabajo de materias blandas de origen animal no suele sobrepasar este estadio. Únicamente, cuando se combina con otras huellas o aparecen rastros más patentes (...) podemos discernir, con cierta probabilidad, la materia trabajada y/o la cinemática de utilización empleada." (Gibaja y Clemente 1997: 157).

Otros autores, por el contrario, plantean que sin importar sobre qué materia se haya trabajado, las características del micropulido no se ven afectadas por el tratamiento térmico, siendo así factibles de ser reconocidas (Binder y Gassin 1988, Gassin 1993 en Gibaja y Clemente 1997: 155). Finalmente, otro punto a destacar desde la óptica funcional es que en las piezas tratadas térmicamente se evidencia una menor resistencia de los filos ante el uso. Rick y Chappell (1983) consideran que la misma disminución de la fuerza de fractura que facilita la producción de instrumentos también disminuye la durabilidad del filo. De esta manera, muchos artefactos pueden dejar de ser utilizados, o necesitar de reacondicionamiento, antes que se hayan desarrollado micropulidos reconocibles.

\subsection{Cambios en las propiedades de la roca}

El primer cambio que ocurre en las rocas al ser calentadas es la pérdida del agua libre que se aloja en los poros y grietas presentes naturalmente en el material. Esto ocurre a partir de los $100^{\circ} \mathrm{C} y$ 
como consecuencia de ello se observa una reducción en el peso del material de entre un 0,4 y un $2 \%$. Por su parte, el agua ligada comienza a ser liberada a los $300^{\circ} \mathrm{C}$ aproximadamente (Luedtke 1992; Mandeville 1973).

Las impurezas en las materias primas también se ven alteradas a medida que aumenta la temperatura. Este proceso se inicia con la oxidación de los componentes orgánicos, formándose monóxido o dióxido de carbono. Posteriormente se oxidan los compuestos sulfurosos y ferrosos, lo que sucede a partir de los $225^{\circ} \mathrm{C}$ (Luedtke 1992).

Si bien parte del carbono, hidrógeno y oxígeno son liberados en forma de gases, la proporción del resto de los elementos se mantiene estable. Sin embargo, el tratamiento térmico puede cambiar la mineralogía de alguna de las impurezas, lo que resulta en cambios geoquímicos de manera indirecta. Esto también implica cambios en el volumen, solubilidad y susceptibilidad a la meteorización de la roca (Luedtke 1992).

Uno de los cambios más importantes que le ocurren a las piedras durante el tratamiento térmico es la alteración en sus propiedades de fractura: las fracturas se propagarán a través de los granos en vez de alrededor de ellos. De acuerdo a Luedtke (1992) existen dos modelos principales que buscan explicar este cambio: 1. El modelo de fusión de la sílice ("silica fusion model") plantea que los microcristales de cuarzo se conectan de manera más ajustada como consecuencia del tratamiento térmico. De acuerdo a Purdy y Brooks (1971) es probable que pequeñas cantidades de impurezas ubicadas en los espacios porales actúen como un flujo uniendo los granos cristalinos, mientras que las soluciones acuosas se convertirían en gel de sílice consolidado. Debido a esto, los espacios porales quedarían rellenados dándole a la superficie de la roca un aspecto más homogéneo y vítreo. 2. El modelo de grietas ("crack model") sugiere que el calentamiento aumenta el número de microfisuras en la roca y las distribuye de manera más homogénea. En consecuencia, las fracturas durante la talla se producirían más fácilmente. Se han propuesto diversas causas para la generación de estas grietas tales como la expansión de los granos de cuarzo o la transformación de la goethita en hematita (Luedtke 1992; Schindler et al. 1982).

Aún es necesario avanzar en las investigaciones para corroborar qué modelo explica mejor los cambios en las rocas, aunque hay investigadores que afirman que estos modelos no son mutuamente excluyentes (Domanski y Webb 2007; Luedtke 1992; Terradas y Gibaja 2001). Cualquiera sea el modelo adecuado, lo cierto es que el tratamiento térmico disminuye la dureza de las materias primas. Purdy y Brooks (1971) exponen que las piezas tratadas térmicamente tienen una menor resistencia a la tracción. Por su parte Schindler et al. (1982) al estudiar las propiedades del Bald Eagle Jasper tratado térmicamente han demostrado que la tenacidad disminuye significativamente en comparación con muestras no tratadas. 


\subsection{Antecedentes experimentales}

En este apartado buscamos describir brevemente la historia de las investigaciones experimentales referentes al tratamiento térmico. Si bien ha sido una búsqueda profunda, no agota el amplio conjunto de trabajos que se han publicado sobre el tema.

Las primeras sugerencias del uso del tratamiento térmico durante la confección de artefactos líticos fueron inicialmente realizadas por exploradores, en especial en Norteamérica (Holmes 1919; Nagle 1914). Estos relatos indicaban el uso combinado de fuego y agua en la confección de puntas de flecha. Nagle (1914), lo expresa de la siguiente manera:

"Cuando un Indio deseaba realizar una punta de flecha mantenía un pedazo de pedernal en el fuego hasta que estaba muy caliente, luego permitía que una gota de agua cayera desde el extremo de una varilla al punto que se deseaba tallar. El enfriamiento rápido hacía que el pedernal se fracture inmediatamente..." (Nagle 1914, p. 140; mi traducción).

Sin embargo, estas afirmaciones no fueron tenidas en cuenta desde un comienzo por los arqueólogos. La razón fundamental por la que en un primer momento no se consideraron estas explicaciones habría sido la incapacidad de los primeros arqueólogos experimentales en replicar esta técnica (Mandeville 1973). Esto llevó a que esta técnica sea vista como un mito.

De hecho, aún hoy aquellos relatos originales son puestos en duda. Existen dos causas principales por las cuales estas narraciones resultan dudosas. La primera es el calentamiento rápido. Hoy en día se sostiene que el calentamiento de la pieza debe ser lento y sostenido. De manera contraria, la pieza sufre de stress térmico y se quiebra de forma no deseada (Cattáneo et al. 1997-98). El segundo motivo es el uso del agua. Se han realizado numerosas experiencias y en ninguna de ellas se constató que el agua sea útil como agente para la talla. Por el contrario, el enfriamiento rápido de las piezas lleva, al igual que el calentamiento precipitado, al stress térmico. Los intentos de talla dejando caer agua en piezas calientes produjeron el craquelado de éstas (Purdy y Brooks 1971).

Si bien Shippee vuelve a mencionar la posibilidad del uso del fuego durante la confección de instrumentos (Shippee 1963), es a partir de las investigaciones de Crabtree y Butler (1964) que se comienza a tomar en consideración esta técnica. Uno de los aportes que realizan tiene que ver con la metodología experimental: demuestra que es necesario enterrar las piezas para que el calor se distribuya de manera pareja y que no ocurra stress térmico. Además, hacen notar que las características del procedimiento son diferentes para el tratamiento térmico de núcleos y de formas base, si bien es posible realizarlo en ambos tipos de artefactos. Finalmente, describe algunas de las consecuencias que tiene esta técnica en la producción de artefactos: las piezas se 
vuelven más elásticas y frágiles, permitiendo un mayor control de la talla, en especial la talla por presión (Crabtree y Butler 1964; Domanski y Webb 2007).

Desde ese momento y en adelante, se suceden numerosas investigaciones que, desde diversos enfoques, han aportado al conocimiento de este procedimiento pirotecnológico. En la década de 1970 y comienzos de la década de 1980 se llevaron a cabo abundantes investigaciones relativas a la temática, probablemente debido a que recién estaba comenzado a conocerse la técnica. Luego de una marcada disminución entre 1985 y 1995, comienza nuevamente a publicarse abundante información referida a este tema.

Así, ya desde los primeros experimentos se corrobora que para numerosas variedades de sílex, la acción térmica genera cambios de color en la superficie de las rocas con alto contenido en hierro, aunque solo en su porción más externa (Flenniken y White 1983; Mandeville 1973; Patterson 1984; Purdy y Brooks 1971; Schindler et al. 1982). Otra observación realizada por Purdy y Brooks (1971) fue que el desarrollo del lustre interno no era sincrónico con el cambio de color externo de las piezas.

Purdy y Brooks (1971) sugieren, a partir de la observación del aumento de la pérdida de agua, que la temperatura óptima para el tratamiento térmico estaría en el rango $350^{\circ}-400^{\circ} \mathrm{C}$. Sin embargo, ya hacia inicios de la década de 1970 quedaba claro que existe una interacción entre tres factores: temperatura, tiempo y tipo de roca. De acuerdo a Mandeville (1973) las piezas de grano fino sufren shock térmico a temperaturas más bajas que aquellas de grano más grueso. Este shock genera la fractura de piezas de una manera no deseada, hecho que ya había sido observado desde las primeras experimentaciones (Mandeville 1973). Esto llevó a los arqueólogos experimentales a buscar conocer a qué temperatura era tratada térmicamente de manera efectiva cada tipo de roca y a qué temperatura se fracturaba de forma no deseada; no todas las materias primas responden al tratamiento térmico de forma positiva, y aquellas que sí lo hacen, necesitan diferentes temperaturas y tiempos de exposición (Inizan et al. 1975-76 en Inizan et al. 1999).

En cuanto a la influencia que el tratamiento térmico puede tener sobre la talla, un trabajo experimental pionero es el de Mandeville y Flenniken (1974), quienes comprueban que este procedimiento permite realizar una talla más controlada, disminuye la probabilidad de producción de fracturas en charnela, facilita la talla por presión y el adelgazamiento bifacial, produciendo bifaces significativamente más delgados.

Otra observación realizada a partir de las primeras experiencias controladas mostró que las piezas tratadas térmicamente llegan a perder hasta 1,5\% de su peso como consecuencia de este proceso (Mandeville 1973; Purdy y Brooks 1971). Esto fue tenido en cuenta como factor que podría explicar el uso del tratamiento térmico por parte de las poblaciones prehistóricas.

A partir de las observaciones que las piezas podían fragmentarse de manera no deseada debido al calor, comenzó a resultar de importancia reconocer cuáles son las formas en que una pieza podía 
quedar expuesta al fuego y resultar termoalterada. Una de las causas posibles que inicialmente fue mencionada es el uso del fuego para el canteo de nódulos y bloques (Gregg y Grybush 1976). De acuerdo a las observaciones etnográficas, una vez que el bloque está caliente se podía esperar hasta que el fuego generase la fractura de la piedra a través de los planos de debilidad, o echarle agua para que se fragmente por shock térmico (Binford y O'Connell 1984; Gregg y Grybush 1976). Otra forma de termoalteración no intencional que se planteó fue el encendido de fogones de ocupaciones posteriores encima de los restos líticos. Esta propuesta es considerada, por ejemplo, para el caso del sitio Mediona 1 (Barcelona, España) (Clemente Conte 1995). El descarte intencional de piezas al fuego también puede fragmentarlas e incluso llegar a destruirlas totalmente. Larsson (2000) observa que durante el Neolítico en Suecia existía la costumbre de destruir durante actos rituales hachas líticas por medio del fuego.

Así, un aspecto que comienza a ser investigado es la búsqueda de criterios que permitan reconocer cuando una pieza fue tratada térmicamente y cuando estuvo expuesta al calor por otros motivos. Rick y Chapell (1983) proponen que la forma más efectiva de poder identificar este procedimiento en conjuntos arqueológicos es focalizarse en la observación del lustre. De acuerdo a estos autores, si se observan superficies contrastantes en cuanto a lustre en los negativos de lascado de las piezas, puede afirmarse con seguridad que estas fueron tratadas térmicamente. Por su parte, Clemente (1995) propone además del uso del lustre, la utilización del conjunto de evidencias de daño térmico y de pátina como forma de reconocer la causa de la termoalteración. Ambos trabajos plantean además que es vital evaluar en qué tipo de piezas la termoalteración está presente (Clemente Conte 1995; Rick y Chappell 1983).

Por otro lado, ya desde las primeras investigaciones se comienzan a realizar observaciones microscópicas que buscaban comprender cuáles son los efectos del tratamiento térmico en las rocas. Purdy y Brooks (1971) observan al microscopio petrográfico que la superficie fracturada de las piezas tratadas se presenta como muy lisa y que las fracturas pasan a través de los criptocristales más que alrededor de ellos como sucede en las piezas sin tratar. De acuerdo a estos autores los cambios que suceden debido al calentamiento son estructurales y no mineralógicos.

En este sentido, Mandeville (1973), utilizando el microscopio electrónico de barrido propone que durante el tratamiento térmico ocurre la fusión de la matriz intergranular en piezas de sílex calentadas a $400^{\circ} \mathrm{C}$. Por el contrario, Flenniken y Garrison (1975) consideran que el aumento en la facilidad para la talla ocurre como consecuencia del aumento de la cantidad de microfracturas debidas al calentamiento. De manera similar, Schindler y colaboradores (1982) observan para el jaspe un aumento de las microfracturas generadas por la descomposición de goethita en hematita y la consiguiente formación de vacíos que debilitan al material. Estos autores realizan también mediciones de tenacidad, comprobando su disminución en piezas termoalteradas (Schindler et al. 
1982). Borradaile y colaboradores (1993) realizan la observación de secciones delgadas de cherts tratados, observando que el carbono de las inclusiones orgánicas de sus muestras había migrado, pasando de estar disperso a concentrarse alrededor de granos y grietas. También notan la recristalización de la siderita en hematita y de la pirita en pirrotita.

Los estudios de altos aumentos también fueron utilizados para analizar la interacción entre el tratamiento térmico y los rastros de uso. En este sentido, los trabajos de Clemente y Gibaja (Clemente Conte 1997; Gibaja 2002; Gibaja y Clemente 1997) han sido de verdadera importancia, puesto que han evaluado diversos indicadores que podrían impedir el desarrollo de micropulidos o enmascararlos imposibilitando su reconocimiento, tales como el desarrollo de pátina o de lustre térmico.

Una vez que los efectos del tratamiento térmico fueron en cierta medida comprendidos de manera general, las investigaciones experimentales tendieron a focalizarse en analizar cómo reaccionan determinadas materias primas a esta técnica. Este tipo de investigaciones se dan fundamentalmente desde inicios de la década de 1980. Así, por ejemplo, Cowan (1987) analiza de qué modo el tratamiento térmico altera la calidad para la talla del chert de Onondaga mientras que Brown y colaboradores lo hacen con la silcreta de Sudáfrica (Brown et al. 2009).

La repetición en los experimentos llevó a reconocer diversas formas en que las piezas reaccionan al calor. En el trabajo de Cowan (1987) las temperaturas alcanzadas fueron bajas y se llegó a ellas de manera paulatina; las piezas una vez terminado el calentamiento, no exhibían ningún tipo de daño. Sin embargo, al intentar tallarlas estas habían perdido su integridad estructural, no se producía más fractura concoidea, y las superficies expuestas tenían textura rugosa, de manera que la materia prima ya no era apta para la talla. Otras observaciones interesantes relacionadas con el tema pueden tomarse del trabajo de Mercieca (Mercieca 2000; Mercieca y Hiscock 2008). De acuerdo a esta autora el tamaño de las piezas está inversamente relacionado con su resistencia al calor: cuanto más grandes menor la temperatura necesaria para que se fracturen durante el calentamiento (Mercieca 2000; Mercieca y Hiscock 2008).

Otros trabajos experimentales que comenzaron a practicarse fueron los tests que buscan cuantificar la disminución en la dureza que se produce en las piezas como consecuencia del tratamiento térmico

Si bien esto fue observado por los primeros experimentadores, siempre se trató de una aproximación cualitativa. En cambio, Bleed y Meier (1980), colocan piezas tratadas y sin tratar en un tambor mezclador de cemento, de manera que eso les permite comparar la cantidad y tamaño de los fragmentos generados en ambas categorías, sujetas a un proceso de agitación similar. Concluyen que las piezas tratadas generan estadísticamente mayor cantidad de fragmentos y de mayor longitud que las no tratadas. Otra observación interesante es que sus experimentos indican que en las piezas tratadas térmicamente ocurren mayor cantidad de fracturas en charnela, a 
diferencia de lo observado por otros investigadores que afirman que ocurre lo contrario (Bleed y Meier 1980). Por su parte, Afonso Marrero (1997) realiza tests de impacto dinámico con sílex de Málaga (España). Este método permite realizar golpes controlados y con la misma fuerza, lo que posibilita la comparación de los resultados entre muestras tratadas y sin tratar.

\subsubsection{Las investigaciones experimentales sobre tratamiento térmico en Argentina}

También se destacan en este contexto las primeras investigaciones realizadas en Argentina sobre el tema. Si bien Nami ya había publicado en algunas publicaciones comentarios con respecto a este procedimiento (Nami 1983), son los trabajos de Ariet (Ariet 1988, 1991) sobre ópalos de la región pampeana los primeros que abordan de una manera sistemática esta problemática. Por su parte Cattáneo y colaboradores (1997-98) estudian variedades de rocas silíceas de Pampa y Patagonia. En sus experimentaciones registran cambios de color, lustre, variaciones en el peso de las piezas así como el daño térmico presente. Además, realizan difracción de rayos $\mathrm{X}$ a las piezas con el objetivo de reconocer las causas del cambio de color en estas rocas. Nami y colaboradores (2000) también desarrollan experimentaciones con materias primas de Pampa y Patagonia analizando los cambios en las cualidades para la talla y las temperaturas óptimas, registrando cambios de color así como la aparición de lustre, daño térmico y ondas de percusión. Este trabajo resulta muy interesante puesto que analiza materias primas muy similares a las analizadas en el presente trabajo y provenientes de áreas cercanas. Así, observan que la calcedonia mejora sensiblemente su calidad a los $450^{\circ} \mathrm{C}$, observándose la aparición de ondas y lustre pero no así cambio de color ni daño térmico. En cuanto al xilópalo, la temperatura óptima para el tratamiento térmico serían los $350^{\circ} \mathrm{C}$, observándose a esta temperatura la aparición de lustre, pero no cambio de color ni ondas; el daño se observaría a partir de los $450^{\circ} \mathrm{C}$. En relación al sílice, los cambios óptimos estarían también en temperaturas cercanas a $350^{\circ} \mathrm{C}$ observándose lustre, ondas de aplicación de la fuerza y cambio de color; el daño térmico se observa a partir de los $450^{\circ} \mathrm{C}$ (Nami et al. 2000).

Finalmente Stadler (2002) realiza investigaciones con materias primas del área del Lago Argentino, provincia de Santa Cruz. Estas son dacitas, calcedonias y maderas silicificadas. Observa cambios a nivel macroscópico (lustre, brillo, cambio de color y daño térmico) y microscópico, utilizando tanto microscopio metalográfico como microscopio electrónico de barrido; en este último caso constata cambios estructurales en el material tratado. También realiza análisis paleomagnéticos pero los resultados le llevan a descartar este método como medio para identificar material termoalterado (Stadler 2002). 


\subsection{Antecedentes arqueológicos}

Es a partir de la publicación de los primeros trabajos experimentales que los arqueólogos empiezan a prestar atención a la presencia o no de rasgos de alteración térmica en los conjuntos líticos de los sitios. Así, comienzan a descubrirse evidencias de tratamiento térmico en sitios que abarcan un gran lapso temporal y que cubren prácticamente todo el planeta. Uno de los primeros en tomar nota de esta posibilidad fue Bordes, quien propone la aplicación de esta técnica para el Solutrense francés (Bordes 1969).

En Estados Unidos, Collins y Fenwick (1974) detectan evidencias de tratamiento térmico en sitios correspondientes a los períodos Arcaico y Woodland de Kentucky donde se observa abundancia de preformas bifaciales tratadas térmicamente. También se observa tratamiento térmico en lascas extraídas de núcleos sin tratar. La identificación del tratamiento térmico en las piezas se basó en el reconocimiento de cambios en su coloración y en la aparición de lustre. En Pennsylvania los arqueólogos norteamericanos reconocieron evidencias de tratamiento térmico, en el sitio Houserville correspondiente al período Arcaico. Se observaron abundantes preformas y lascas de adelgazamiento bifacial con evidencias de tratamiento térmico (Schindler et al. 1982). Su reconocimiento se basó en el contraste de color de las piezas correspondientes a distintas etapas de reducción.

En Australia, las investigaciones iniciales respecto a este tema fueron realizadas por Flenniken y White (1983) quienes observando cambios de color y lustre identifican la aplicación de esta técnica. Complementan la investigación realizando observaciones al SEM de piezas experimentales así como del conjunto arqueológico.

En España, se han publicado diversos artículos que hacen foco en la utilización de esta técnica en sitios arqueológicos. Por ejemplo en la Cueva del Toro (Málaga), se han observado evidencias de tratamiento térmico, fundamentalmente sobre láminas. La identificación positiva de este procedimiento se realizó por la presencia en la pieza de cambios de color, presencia de lustre y por el aumento en tamaño de las ondas de percusión (Afonso Marrero 1997). Por otra parte durante el Neolítico Medio se registra en Catalunya el tratamiento térmico de una materia prima particular, el sílex melado. Núcleos de este material se tratarían en el contexto de la producción de soportes laminares (Gibaja 2002; Terradas y Gibaja 2001) y circularían por un área geográficamente amplia que abarcaría sectores tanto de España como de Francia e Italia, siendo intercambiados por diversos grupos (Gassin et al. 2009; Gassin et al. 2006).

Como observáramos anteriormente, Bordes propone el tratamiento térmico en piezas del Solutrense francés. De acuerdo a Inizan y Tixier (2000) se puede considerar al tratamiento térmico 
sobre piezas bifaciales para su posterior retoque por presión como un excelente marcador de esta cultura.

Recientemente se ha reportado la presencia de artefactos tratados térmicamente en sitios sudafricanos para fechas tan tempranas como 70.000 años AP (Brown et al. 2009). Estas constituirían las evidencias más tempranas de aplicación de la técnica y reflejarían ya para estas épocas un buen manejo del fuego. De hecho, el tratamiento térmico aparecería en África sincrónicamente con otras evidencias de comportamiento simbólico, lo que señalaría el desarrollo creciente de las habilidades cognitivas complejas (Webb y Domanski 2009). Los artefactos tratados fueron confeccionados en silcreta, y si bien los autores no detallan de qué tipo de artefacto se trata, sí mencionan que un bifaz habría sido sujeto a esta técnica (Brown et al. 2009). Los autores utilizan tres métodos para determinar la presencia del tratamiento térmico: paleomagnetismo, termoluminiscencia y determinación de lustre (Brown et al. 2009).

En Asia, se han reconocido evidencias de tratamiento térmico en sitios neolíticos de Afganistán, Pakistán, India, Irak e Irán; aquí esta técnica fue utilizada principalmente durante la confección de núcleos para la extracción de laminillas por presión (Inizan y Tixier 2000). Por otra parte, resulta interesante señalar que el tratamiento térmico se utiliza hoy en día en esta región en la producción de cuentas de calcedonia (Possehl 1981). El uso, en este caso, tiene razones estéticas: se utiliza el fuego para cambiar intencionalmente el color a las rocas (Inizan y Tixier 2000). Otra observación que resulta interesante realizar aquí es que Flenniken (1987 en Inizan y Tixier 2000) reporta artefactos bifaciales retocados por presión tratados térmicamente en sitios de la cultura Dyuktai de Siberia. Esto es importante puesto que indica que probablemente los primeros pobladores de América ya contaran con esta técnica dentro de su repertorio tecnológico.

Rastros de este procedimiento se han reconocido en Perú en un sitio asignado al Formativo (Rick y Chappell 1983). De acuerdo a los autores, las clases de instrumentos que presentan mayor retoque son las que fueron más habitualmente tratadas térmicamente: puntas de proyectil, bifaces y raspadores con ángulos de aproximadamente $50^{\circ}$. Por el contrario, los raspadores con ángulos promedio de $75^{\circ}$ así como otros instrumentos para "tareas pesadas" cuentan con menores evidencias de tratamiento térmico. Esto tendría para los autores implicaciones funcionales: el tratamiento térmico haría más frágiles a los filos, de modo que no sería útil para aquellas clases de instrumentos utilizados en el trabajo sobre hueso o madera, puesto que se embotarían sus filos más fácilmente (Rick y Chappell 1983). El reconocimiento de la aplicación de la técnica de tratamiento térmico se realizó en este caso observando en los instrumentos zonas de contraste entre negativos de talla con y sin lustre térmico.

Por otra parte, se utilizaron otras técnicas más complejas con el propósito de corroborar si los elementos arqueológicos habían sido tratados térmicamente, ya que se consideraba que tanto los cambios de color como el lustre pueden deberse a más de una causa. Un ejemplo de ello es el uso 
de la termoluminiscencia (Brown et al. 2009; Melcher y Zimmerman 1977; Pavlish y Sheppard 1983). Un problema con esta técnica es que si bien puede identificar cuando una pieza fue calentada, no puede discernir las causas de este calentamiento, es decir, no puede diferenciar si fue producto de un proceso intencional o accidental. Además, tiene la dificultad de ser costosa y demandar mucho tiempo, por lo cual no puede ser aplicada a grandes conjuntos (Rick y Chappell 1983).

Problemas similares tienen los estudios de paleomagnetismo. Estos además exigen que la muestra utilizada sea de pequeño tamaño, en caso contrario debe ser fragmentada (Borradaile et al. 1993; Brown et al. 2009; Rowney y White 1997). Asimismo, otros autores han encontrado que no es posible diferenciar material termoalterado de no alterado (Stadler 2002).

La resonancia electrónica de spin ha sido utilizada con éxito para identificar piezas termoalteradas e inclusive determinar a qué temperatura fueron calentadas. Si bien es un método no destructivo, las piezas deben ser menores a $1 \mathrm{~cm}$ por lado (Inizan y Tixier 2000).

En cuanto al uso del SEM, aunque experimentalmente se han observado cambios en la microestructura (Flenniken y Garrison 1975; Mandeville 1973), se ha puesto en duda que las observaciones con microscopio electrónico sean útiles puesto que existiría gran heterogeneidad en la apariencia de las piezas (Rowney y White 1997). De acuerdo a las experimentaciones realizadas, existirían piezas sin tratar que tendrían la misma apariencia que las tratadas, por lo que sería imposible discernir ambos tipos de piezas a través de este método (Rowney y White 1997).

\subsubsection{El tratamiento térmico en sitios arqueológicos de la Patagonia}

En Argentina, si bien hay bastantes trabajos experimentales, existen menos investigaciones que hagan foco en la presencia de restos líticos tratados térmicamente en sitios arqueológicos. De acuerdo a nuestro conocimiento, los trabajos referidos a esta temática corresponden a sitios de la provincia de Santa Cruz.

Las investigaciones de Paunero acerca del sitio Cerro Tres Tetas si bien no se centran en esta técnica, la mencionan y son los fundamentos que dan origen a esta tesis (Paunero 2001, 2003a, 2004c; Paunero y Castro 2001). De acuerdo a estos trabajos, en el sitio se habría llevado a cabo la producción de artefactos líticos, para lo cual habría jugado un papel importante la aplicación del tratamiento térmico. En la presente tesis es analizado el conjunto lítico del componente más temprano del sitio.

Otro sector de Santa Cruz donde se ha propuesto la aplicación del tratamiento térmico y donde hay trabajos más específicos sobre la temática es el área de Lago Argentino (Stadler 2002; Stadler et al. 2003). En esta zona se ven claras evidencias sobre dacitas, donde se observa que los 
instrumentos y núcleos tratados son utilizados hasta el fin de su vida útil, a diferencia de aquellos artefactos que no han sido tratados (Stadler 2002). Las evidencias de este procedimiento proceden de contextos arqueológicos con cronologías a partir de los 6.100 años AP, mientras que los contextos más tempranos no presentarían piezas tratadas (Stadler 2002; Stadler et al. 2003). Más allá de estos dos ejemplos puntuales, no hay otros trabajos que se focalicen en la temática del tratamiento térmico en sitios arqueológicos de Argentina o de Patagonia en general. Sí existen, por el contrario, numerosas menciones en diversos artículos acerca de la observación de piezas probablemente tratadas térmicamente en sitios arqueológicos de la Patagonia, aunque por lo general no se brinda otra información relevante - como la materia prima en la que se reconoció, en qué tipo de artefacto u otros datos cuantitativos que serían útiles para comprender la importancia de esta técnica en la región-. Así, por ejemplo, Mena y colaboradores (2000) sugieren la presencia de artefactos tratados térmicamente en el componente temprano del sitio Cueva Baño Nuevo-1 (IX región de Aisén, Chile). En sectores superficiales cercanos al Lago Argentino algunas lascas angulares que presentan coloración rosada y cambios en textura insinúan la utilización de tratamiento térmico (Franco et al. 2007). En el sitio Tres Arroyos (sector chileno de Tierra del Fuego) también se cita el posible uso de esta técnica, aunque en este caso las características de los artefactos podrían referirse también a otras causas por las cuales los artefactos podrían haber quedado expuestos al calor (Massone 2004). En la Meseta Central se ha mencionado el uso del tratamiento térmico en el componente Toldense de la Cueva 2 de Los Toldos (Cardich y Paunero 1991-1992). Asimismo, se ha sugerido que las puntas de proyectil del Toldense de La Martita habrían sido sometidas a este procedimiento (Nami 1992). También se ha observado el uso del tratamiento térmico en una de las puntas cola de pescado de Piedra Museo (Hermo 2008); esta pieza fue confeccionada en ftanita roja cuya fuente se encuentra probablemente en las cercanías al sitio. Este procedimiento ha sido inferido también para preformas bifaciales en Piedra Museo (Hermo 2008).

Resulta interesante remarcar que, con excepción de los casos de sitios cercanos al Lago Argentino, las referencias a tratamiento térmico se dan en contextos con rangos temporales asignables a la transición Pleistoceno-Holoceno. Además, en los pocos casos en que se especifica el tipo de artefacto, este se refiere a puntas de proyectil. 


\section{CAPITULO 7: LA ALTERACIÓN TÉRMICA DE ELEMENTOS OSEOS: CARACTERÍSTICAS Y ANTECEDENTES EN LA INVESTIGACIÓN}

En este capítulo presentamos las características referentes a la alteración térmica de los restos óseos y los antecedentes experimentales y arqueológicos vinculados a los distintos tipos de contacto del hueso con el fuego.

\subsection{Características estructurales del hueso}

El hueso está compuesto por componentes orgánicos e inorgánicos. El componente inorgánico corresponde a cristales de hidroxiapatita de forma hexagonal elongada (Jurgens 2005). La matriz orgánica corresponde a alrededor del $35 \%$ del peso del hueso y se compone de largas fibras de colágeno. Mientras que las fibras de colágeno le confieren elasticidad al hueso, la hidroxiapatita le proporciona resistencia y dureza (Jurgens 2005; Lyman 1994; Miotti 1998). El eje mayor de los cristales de hidroxiapatita está alineado con las fibras de colágeno. En individuos juveniles las fracciones orgánicas e inorgánicas varían sus proporciones de manera inversa. En consecuencia, los huesos de individuos jóvenes son muchos más elásticos que los de individuos adultos.

El tejido óseo tiene una estructura compleja. A escala microscópica, presenta células que depositan material óseo (osteoblastos); estas se convierten en osteocitos cuando están incorporadas a la matriz ósea. Aquellas que remodelan al hueso una vez que se alcanza la adultez se denominan oseteoclastos. Una red dendrítica de canales que contienen vesículas de sangre y nervios se observa entre el hueso compacto; se denominan canales haversianos y están encargados de otorgar nutrientes. Alrededor de ellos se encuentran los osteones: capas cilíndricas de hueso compacto lamelar que se orientan paralelamente al eje longitudinal de los huesos largos; fibras de colágeno se agrupan por entre las lamelas (Jurgens 2005; Lyman 1994; Miotti 1998).

Las dos epífisis y la diáfisis de un hueso largo constituyen centros de osificación durante el desarrollo ontogenético y se desarrollan a partir de placas cartilaginosas. Estas tres zonas de crecimiento están separadas por cartílagos; su fusión marca el inicio de la adultez en los mamíferos. En corte longitudinal las epífisis están formadas por tejido esponjoso mientras que la diáfisis está compuesta principalmente por tejido compacto, cubierto al interior por el endosteo que es un tejido que rodea el canal medular; casi toda la superficie externa de los huesos, excepto las articulaciones, está recubierta por periosteo. Los huesos largos crecen tanto en longitud como en circunferencia, con sucesivas capas de hueso compacto que se depositan alrededor de la diáfisis. 


\subsection{Biomecánica}

La dureza de un hueso, y su capacidad de resistir a una fractura, dependen de su masa y su geometría, así como también de propiedades intrínsecas del tejido óseo (Burr 2002). La naturaleza compuesta del hueso lo vuelve más fuerte que si estuviese conformado por uno solo de los materiales (Lyman 1994). El hueso se quiebra cuando se le aplica una fuerza que excede su resistencia a la tracción. Esta es diferente cuando el animal está vivo de cuando este ha muerto, lo que se debe fundamentalmente a la pérdida de humedad. Cuando el animal está vivo e inmediatamente después de muerto, el hueso es dúctil y antes de fracturarse responde a las fuerzas mecánicas deformándose. Una vez que el animal muere el hueso pierde humedad lo que vuelve al hueso más quebradizo al ser menos elástico y con menor capacidad de absorber el stress.

El hueso en los animales vivos tiene una matriz estructural completamente hidratada que se deforma de manera plástica, lo que permite que se absorban grandes cantidades de stress sin que se fracture el hueso. La deformación microscópica irreversible sucede de manera acumulativa. Microfracturas comienzan a generarse en los sectores que cementan los osteones; luego grietas más profundas amplían el daño. El efecto producido en el cuerpo de un hueso ante una fuerza a la que es sometido será la separación total o parcial de los fragmentos, siguiendo diferentes direcciones acordes a la disposición de las fibras de colágeno y de los cristales de apatita. La fractura y la morfología de los fragmentos resultantes están determinadas por la interacción entre la fuerza aplicada, la dinámica de fractura y la estructura ósea (Jurgens 2005; Lyman 1994; Miotti 1998).

\subsection{Termoalteración de huesos}

De acuerdo a la investigaciones existentes hasta el momento, hay tres etapas básicas por las que pasa un hueso al ser calentado: primero se produce la evaporación del agua; luego entre los $200^{\circ}$ y los $450^{\circ} \mathrm{C}$ la materia orgánica se combustiona; y finalmente se modifica y descompone la materia mineral. En esta última etapa, a medida que aumenta la temperatura los cristales de hidroxiapatita se engrosan. Los cristales de mayores dimensiones tienden a crecer a expensas de los más chicos: este proceso es similar a lo que ocurre durante la diagénesis a bajas temperaturas. Por encima de los $650^{\circ} \mathrm{C}$ ocurre un proceso de recristalización y cerca de los $900^{\circ} \mathrm{C}$ la estructura cristalina de los huesos se desintegra (Hanson y Cain 2007; Hiller et al. 2003; Koon et al. 2003; McCutcheon 1992; Pijoan et al. 2007; Stiner et al. 1995). Estos procesos generan cambios en el 
hueso observables a nivel macroscópico, tales como variaciones en la coloración, textura, deformación ("warping") y fragmentación. También vuelven al hueso más liviano, producto de la pérdida de agua y lípidos durante la combustión (Hiller et al. 2003).

Estas transformaciones son diferentes de acuerdo a la interacción de distintos factores como la condición del hueso previo a la combustión, el tiempo de exposición de los huesos al fuego, la temperatura a la que están expuestos, a si el contacto con el fuego es directo o indirecto, entre otros (Bennett 1999; Buikstra y Swegle 1989; Nicholson 1993; Stiner et al. 1995; Théry-Parisot 2002). Sin embargo, se pueden delinear ciertos criterios que resultan confiables como indicadores relativos de termoalteración, en especial en relación al color y a la textura.

El color es el identificador más común de huesos quemados y de la intensidad de calor alcanzado por el hueso; indirectamente también se lo ha relacionado a la situación en que ocurrió el quemado (Cain 2005). A aproximadamente $200^{\circ} \mathrm{C}$ los huesos empiezan a tomar una coloración marrón oscuro mientras que cerca de los $300^{\circ} \mathrm{C}$ alcanzan un color negro (McCutcheon 1992; Nicholson 1993). Esto sucede por la carbonización de la matriz orgánica de hueso (Shahack-Gross et al. 1997). No existe un acuerdo generalizado acerca de en qué momento los huesos comienzan a tomar coloraciones blancas, grisáceas y azuladas. Si bien habitualmente se considera que son necesarias temperaturas de $500^{\circ} \mathrm{C}$ o más (Hanson y Cain 2007), existen estudios que demuestran que a menores temperaturas también se puede alcanzar este estadio, cuando la duración de la exposición es mayor (i.e. Bennett 1999; Buikstra y Swegle 1989). En todos estos casos los valores son aproximados y existe divergencia en las observaciones de distintos autores.

Las temperaturas a las que se alcanzan los diversos colores difieren por diversas causas. Una de ellas es el estado del hueso: secos, frescos y con carne (Buikstra y Swegle 1989). También, los huesos de diversas especies tienen características diferentes, con distinta proporción de componentes orgánicos, y esto incide en la velocidad y la temperatura necesaria para alcanzar cierto color (Nicholson 1993). Por otra parte, las diáfisis, las epífisis proximales y distales de los huesos largos mostrarán diferentes estadios de termoalteración cuando estén expuestos a las mismas temperaturas (Costamagno et al. 2002).

En cuanto a la clasificación de huesos por su color, Stiner y colaboradores (1995) y Cain (2005) han propuesto el uso de diversas escalas. Presentamos aquí una escala de 7 grados (Fig. 7.1) parcialmente modificada de ambos trabajos:

0 : Corresponde al hueso no quemado, que mantiene su color original, por lo general crema.

1: Parcialmente quemado, en parte color marrón, en parte mantiene el color original del hueso.

2: Totalmente quemado, todo el hueso es de color marrón.

3: Parcialmente carbonizado, el hueso es en parte color negro, y en parte marrón o bien del color original de la pieza.

4: Totalmente carbonizado, todo el hueso es de color negro. 
5: Parcialmente calcinado, el hueso muestra en un sector coloración gris, blanca o azulada, y en parte está carbonizado.

6: Totalmente calcinado: el hueso es en toda su superficie de color gris, blanco o azulado.

Otro indicador de termoalteración es la textura. A medida que el hueso se va calentando a mayores temperaturas se observan diversos cambios reconocibles tanto a ojo desnudo como a altos aumentos. Nicholson (1993) y Cain (2005) diferencian 4 estadios (Fig. 7.2):

1: Los huesos sin quemar o que no alcanzan más de $200^{\circ} \mathrm{C}$ presentan una superficie ondulante y continua; en las porciones articulares esta es grasosa, casi plástica.

2: Los huesos que llegan a $300^{\circ} \mathrm{C}$ presentan grandes áreas cubiertas por una capa "burbujosa" ("bubbly") o vítrea.

3: A los $400^{\circ} \mathrm{C}$ se observa una superficie granulosa y a menudo agrietada. A partir de los $500^{\circ} \mathrm{C}$ estos agrietamientos aumentan.

4: A medida que la temperatura se eleva, el hueso comienza a tener una textura similar a la tiza ("chalky") y progresivamente tienden a desaparecer los agrietamientos.

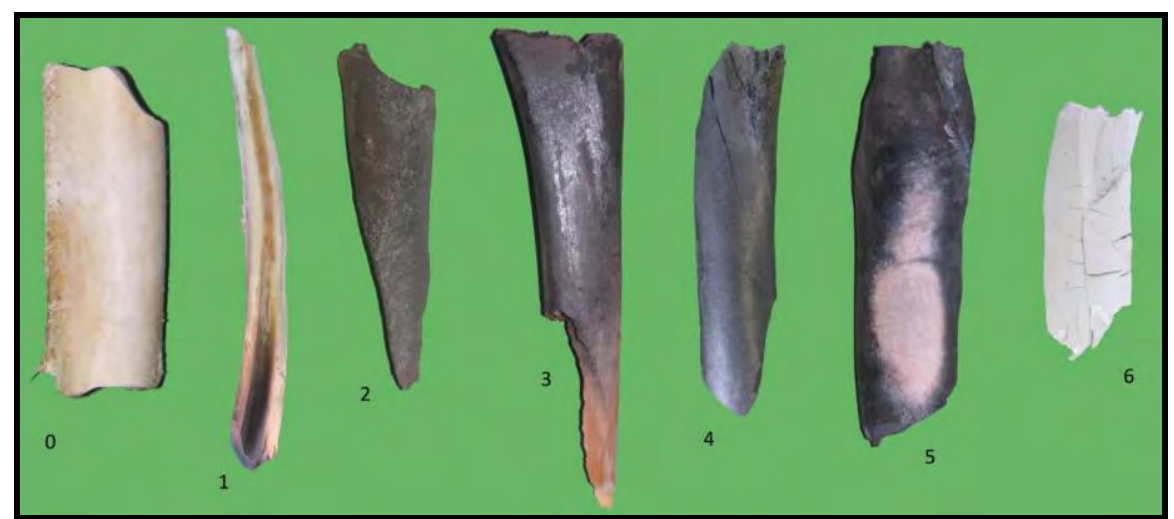

Fig. 7.1. Estadios de termoalteración por color. Los ejemplares son producto de nuestra experimentación.

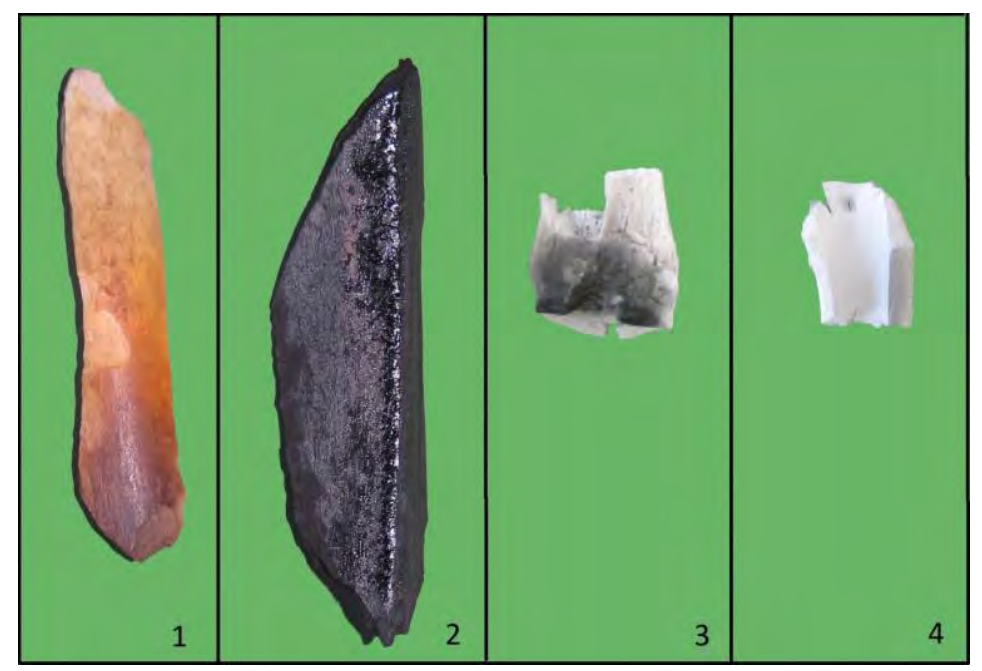

Fig. 7.2. Estadios de termoalteración por textura. Los ejemplares son producto de nuestra experimentación. 
La termoalteración vuelve más frágil a los huesos, puede fracturarlos o volverlos más susceptibles a la fragmentación por otros agentes como el pisoteo (Nicholson 1993; Stiner et al. 1995). A medida que aumenta la temperatura a la que está expuesto un hueso, aumenta su fragilidad. Esto lleva a que el hueso se fracture cada vez en mayor número de fragmentos más pequeños, disminuyendo su identificabilidad inicialmente con respecto al elemento y en un segundo momento con respecto al propio tejido óseo (Stiner et al. 1995). Existen diferentes tipos de fracturas producidas como consecuencia de la termoalteración (Whyte 2001). Entre las más típicas podemos mencionar grietas y fracturas trasversales y longitudinales, exfoliaciones, fisuras dendríticas y grietas reticulares (también llamadas cuarteaduras o "checking") (Fig. 7.3). Se ha propuesto que la superficie de fractura en los huesos termoalterados tiende a ser más rugosa que en huesos sin termoalteración (De Nigris 1999). El grado de fragmentación de los huesos como consecuencia de la termoalteración depende de diversos factores: la intensidad y duración del calentamiento, la completitud del elemento y su nivel de humedad. Así, por ejemplo, la termoalteración de elementos completos produce proporcionalmente más cantidad de fragmentos que cuando la exposición al fuego de sólo una porción del hueso. Esto se debería a la presión ejercida sobre el hueso por el agua y la médula cuando comienzan a evaporarse. Además, los huesos secos tienden a fragmentarse menos que aquellos en estado fresco (Costamagno et al. 2002).

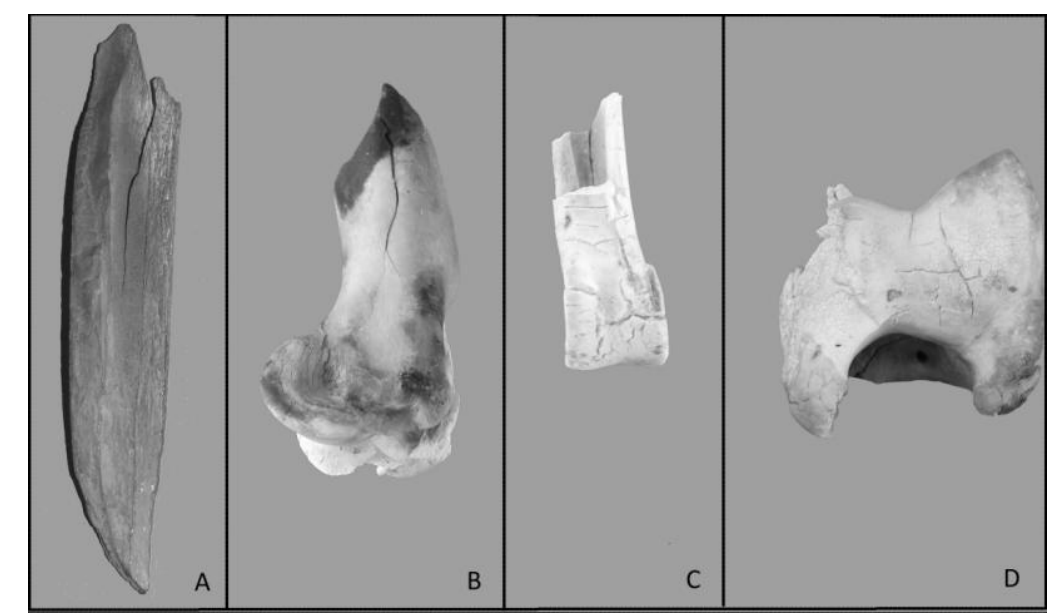

Fig. 7.3. Diferentes tipos de fracturas producto de la termoalteración. A: Grietas longitudinales; B: Fisuras dendríticas; C: Grietas transversales; D: Grietas reticulares. Los ejemplares son producto de nuestra experimentación.

Otro cambio que ocurre como consecuencia de la exposición del hueso al calor es el encogimiento de este. Buikstra y Swegle (1989) registran una reducción de hasta un 5,6\% en el tamaño de huesos largos quemados y calcinados. Si bien a bajas temperaturas se puede producir encogimiento, este será de mayor importancia a partir de los $700^{\circ}$ (Ubelaker 2009). En conjunto 
con el encogimiento puede ocurrir también la deformación de los elementos esqueléticos (Buikstra y Swegle 1989).

De acuerdo a las investigaciones realizadas, las evidencias de termoalteración diferirán de acuerdo al estado del hueso: con carne, frescos (recientemente descarnados) y secos; en consecuencia se podría identificar su estado al momento de la exposición al fuego. La apariencia de los huesos calcinados en estado seco sería distinta a la de los otros dos tipos de huesos: exhiben cuarteaduras, fisuras y fracturas longitudinales y ausencia de deformación. Además, los huesos secos muestran cambios hacia colores blancos o grisáceos sólo en sectores internos, teniendo en el exterior tonos marrones. Por el contrario los huesos frescos/con carne calcinados muestran deformación, grietas superficiales en las epífisis de los huesos largos, fracturas transversales y fracturas longitudinales de textura rugosa; así como colores blancos, grises y azulados en toda su superficie (Buikstra y Swegle 1989; Whyte 2001). También se podría diferenciar entre huesos calcinados con carne de aquellos que son descarnados previamente. Las fracturas transversales de textura rugosa acompañadas por agrietamientos diagonales $y$ deformación serían típicas de huesos con carne, mientras que fracturas dentadas cerca de las epífisis junto con fracturas rectas longitudinales y una deformación menos pronunciada serían características de los huesos calcinados sin carne. Además, habría más grietas en los huesos con carne que en los huesos sin este tejido (Buikstra y Swegle 1989; Whyte 2001).

A diferencia de lo que sucede con los huesos calcinados, la distribución de grietas y cuarteaduras no permiten diferenciar para los huesos quemados, el estado en que se encontraban antes de la combustión. En estos casos, el patrón de distribución de color sería un mejor indicador. En el caso de los huesos con carne, se observará calcinación en determinados sectores y quemado en otros, mientras que los huesos frescos se verán uniformemente quemados y lo huesos secos se observarán superficies heterogéneas con partes calcinadas y otras en la que no se distingue cambio de color (Buikstra y Swegle 1989).

Otra diferencia que se produce como consecuencia del distinto estado de los huesos previo a su contacto con el fuego es la diferencia en el tiempo requerido para alcanzar el estado de "quemado", esto es, coloraciones marrones en la superficie de hueso. Mientras que tanto los huesos secos como frescos pueden tardar unos 10 minutos en alcanzar esta condición, los elementos con carne pueden necesitar hasta una hora (Buikstra y Swegle 1989).

Sin embargo, los criterios establecidos para diferenciar huesos quemados frescos de secos son difíciles de aplicar a conjuntos arqueológicos ya que asumen que los elementos están completos. Se ha propuesto que es posible diferenciar si un hueso estaba entero o no al momento de entrar en contacto con el fuego. Cain (2005) considera que si se observan los contrastes de termoalteración en las diferentes partes de un hueso, entonces se puede determinar tanto el estado como la completitud de dicho elemento. Considera que: 1 . si el quemado es superficial, 
este sería incidental; 2. si es uniforme a través de las paredes del hueso, la fractura sería previa a la termoalteración y el hueso habría estado fresco cuando entró en contacto con el fuego; 3 . si el quemado se presenta bandeado y de forma más severa en la cara exterior, el elemento habría estado completo; 4. si la combustión es más severa en el interior, el elemento estaba fracturado; 5. si un hueso mayormente calcinado presenta un bandeado negro en sus paredes, este estaba seco y fracturado al momento de la termoalteración (Cain 2005).

Es cierto que estas modificaciones producidas por el fuego a nivel macroscópico pueden confundirse con otras producidas por distintos agentes. Por ejemplo los ácidos orgánicos pueden dar colores marrones al hueso, mientras que el óxido de manganeso los ennegrece, los óxidos de hierro le dan tonos rojizos y amarillentos; asimismo la meteorización y fosilización pueden generar cambios en la textura similares a los descriptos arriba (Hanson y Cain 2007; Nicholson 1993; Shahack-Gross et al. 1997). Esto ha llevado a generar una serie de investigaciones a fin de identificar con diversas metodologías cuándo un hueso fue quemado, entre ellas el uso del microscopio óptico y electrónico de barrido (McCutcheon 1992; Nicholson 1993), la observación de cortes histológicos (Hanson y Cain 2007), el estudio biogeoquímico de los huesos (Taylor et al. 1995), la difracción de rayos X (McCutcheon 1992) y la utilización de espectroscopia infrarroja (Shahack-Gross et al. 1997; Stiner et al. 1995). Sin embargo, aun hoy la determinación sigue siendo fundamentalmente a través de la observación macroscópica, y de hecho muchos de estos métodos presentan algunos de los mismos problemas que se marcan en los análisis macroscópicos (Asmussen 2009; Hanson y Cain 2007).

\subsection{Formas de contacto del hueso con el fuego}

Los estudios acerca de huesos con evidencias de termoalteración han demostrado que existen posibles causas por las cuales un hueso recuperado de un sitio arqueológico pudo haber estado expuesto al calor. Entre las causas más comunes, se mencionan en primer lugar la cocción de carne con hueso, y secundariamente otros motivos tales como el descarte intencional de huesos en el fogón, el uso de estos elementos como combustible, la cremación de cuerpos, las alteraciones postdepositacionales y el tratamiento térmico de artefactos óseos (Asmussen 2009; Bennett 1999; Buikstra y Swegle 1989; Cain 2005; Nicholson 1993; Sidéra 2000; Stiner et al. 1995; Théry-Parisot 2002; Whyte 2001).

Existen diversas propuestas para los casos en que se realiza cocción de carne con hueso. De acuerdo a algunos autores, las variaciones en el grosor del tejido blando influyen en el quemado diferencial de las distintas partes, por lo que en estos huesos ocurrirá la calcinación de algunas zonas antes de cualquier signo de combustión en otras (Buikstra y Swegle 1989). También se ha 
observado que durante la cocción sólo se quemarán los extremos articulares (Cain 2005); y se ha propuesto que la cocción de carne no dejaría evidencias notables a nivel macroscópico de termoalteración en los huesos, puesto que la carne actuaría como aislante (Koon et al. 2003). De este modo, la mayor parte de los huesos con rasgos de termoalteración en los sitios no serían resultado de procesos de cocción (De Nigris 1999). Además, la cocción facilita la separación de la carne del hueso, razón por la cual se reconocerán menos marcas de corte en estos casos que en aquellos en los que el descarne se realiza en crudo (De Nigris 1999).

En cuanto al descarte de huesos en los fogones, esta actividad tiende a mostrar todo el espectro de estadios de combustión, aunque es esperable que predominen las evidencias de calcinación (Cain 2005; Costamagno et al. 2002). Sería esperable también que los huesos quemados se encuentren principalmente dentro de los fogones o en su periferia. Existen diversas causas por las que se descartan huesos dentro de los fogones. Una de ellas es el uso de los huesos como combustible. Éste se asocia comúnmente con la escasez en un área determinada de leña. Se ha propuesto que una combinación entre leña y hueso permite que un fogón dure más que si usa únicamente leña; además, la combustión de hueso favorece la convección y la radiación del calor, siendo entonces apto para su uso en iluminación, cocción y secado (Théry-Parisot 2002; Yravedra et al. 2005). Los huesos también se pueden descartar en estructuras de combustión para evitar que se acerquen carroñeros, por cuestiones de higiene o inclusive por aspectos relacionados al mantenimiento del espacio (Yravedra et al. 2005).

Las cremaciones de cuerpos también dejan principalmente los huesos en estado de calcinación; presentado otras evidencias como deformación, fracturas transversas curvilíneas, fisuras dendríticas y grietas en reticulado (Whyte 2001).

En tanto, diveresos trabajos previos demuestran que la alteración térmica posterior al enterramiento es posible y sugieren que variables como la duración del calentamiento, la matriz sedimentaria, el estado de los huesos y la profundidad a la que están enterrados influyen en el grado de alteración (Bennett 1999; Stiner et al. 1995). Estas termoalteraciones se pueden dar tanto por la reocupación de los espacios y el encendido de nuevos fogones, o bien por incendios ocurridos en el sitio con posterioridad a su abandono. Para termoalteraciones en contextos subsuperficiales se espera que los huesos con evidencias de combustión presenten una coloración relativamente homogénea a lo largo de su superficie, en especial si la exposición al calor fue de larga duración y baja intensidad (Bennett 1999). Se ha observado que los elementos óseos enterrados hasta $10 \mathrm{~cm}$ por debajo de un fogón encendido pueden mostrar evidencias de termoalteración, mientras que huesos enterrados a mayor profundidad ya no presentarían rasgos macroscópicos observables de este proceso. Los huesos enterrados expuestos al calor llegarían al estado de calcinación sólo en los casos en que están muy cerca de la fuente de combustión, esto es a no más de $5 \mathrm{~cm}$ de profundidad (Bennett 1999; Stiner et al. 1995). Además de los cambios en 
la coloración, los huesos termoalterados en contextos subsuperficiales pueden mostrar fragmentación longitudinal y deformación estructural (Bennett 1999). Sin embargo, son necesarias más investigaciones para poder llegar a un conocimiento más profundo de este fenómeno, especialmente si tenemos en cuenta los resultados variables que han dado las experimentaciones con huesos provenientes de sitios arqueológicos. Por un lado Nicholson (1993) afirma que los huesos arqueológicos siguen las mismas etapas de termoalteración que los huesos frescos. Por el otro, Bennett (1999) observa discordancias en los resultados entre los huesos frescos y los huesos arqueológicos de una misma experimentación. Estos últimos evidencian mínimas alteraciones; por ejemplo, no registran fracturas ni deformación estructural, a pesar de haber sido expuestos al fuego en las mismas condiciones que los huesos frescos. Esto concuerda con lo propuesto por Buikstra y Swegle (1989) acerca de las evidencias de termoalteración para huesos secos.

En cuanto al tratamiento térmico de artefactos óseos, este ha sido poco mencionado en la literatura sobre termoalteraciones. Sidéra (2000) afirma que durante el Neolítico en el Cercano Oriente, y en el centro - sur europeo esta técnica habría sido común. Este procedimiento habría tenido como fin darle un brillo especial a las piezas, casi vítreo. Los artefactos también tomarían un color marrón oscuro o gris; pudiendo ser este uniforme o presentar una variedad de tonos en la misma pieza, aunque siempre de modo superficial. De acuerdo a este autor, la técnica era aplicada a un amplio abanico de artefactos óseos como punzones, elementos cortantes, mangos, cucharas, agujas y segmentos de útiles compuestos, entre otros. Teniendo en cuenta que su resistencia y otras propiedades funcionales parecen no quedar afectadas manteniéndose iguales a las de los objetos confeccionados en crudo, y que no se observan más fracturas ni daños en las piezas calentadas que en las producidas en el hueso sin termoalterar, el autor considera que la práctica se realiza por razones estéticas. Finalmente Sidéra (2000) sostiene que la forma en que se llevaba a cabo esta técnica era similar al tratamiento térmico en artefactos líticos, aunque también cree posible que las piezas hayan sido ahumadas. Por otra parte, en los sitios Liang Lemdubu y Liang Nabulei Lisa (Islas Aru, Indonesia) se observa que existe una preferencia en la selección de huesos quemados para la confección de puntas y espátulas óseas, aunque la autora no analiza si esta combustión fue realizada como un tratamiento térmico intencional con fines tecnológicos (Pasveer 2005). Hasta el momento no hemos encontrado referencias de tratamiento térmico de huesos con fines tecnológicos en Argentina, excepto la mención de Bridges acerca de su aplicación en la confección de puntas óseas (ver capítulo 4). También se ha propuesto el uso de esta técnica para el sitio Cerro Tres Tetas (Paunero 2001), que analizamos en la presente Tesis. 


\section{CAPITULO 8: EXPERIMENTACIONES EN TRATAMIENTO TERMICO DE ARTEFACTOS LITICOS}

En este capítulo presentamos las experimentaciones realizadas con artefactos líticos, las cuales tienen por objetivo identificar indicadores de aplicación del tratamiento térmico así como de otras formas de alteración térmica no intencionales. Es importante para reconocer si el tratamiento térmico fue una técnica utilizada por los antiguos habitantes de la Meseta Central o bien si los restos termoalterados hallados en los sitios arqueológicos son producto de otros procesos vinculados al fuego.

\subsection{Materiales y Métodos}

Esta etapa experimental del estudio contribuye sustancialmente al abordaje de la problemática de reconstrucción del registro material artefactual, generando evidencia muy rica para realizar inferencias durante la posterior etapa analítica (Schiffer 1988). La misma consiste en experiencias de simulación de alteración térmica, con control de variables y análisis de resultados. Deseamos estudiar aquellas variables y características que permitan identificar la aplicación del tratamiento térmico en artefactos líticos así como aquellas que hagan posible diferenciarlo de otras formas de alteración térmica. Para esto es necesario crear patrones experimentales de referencia propios, con materiales locales, que pueden ser utilizados para analizar el registro arqueológico y así determinar las causas de las termoalteraciones. Con estos objetivos, hemos realizado diez experimentaciones, con materias primas líticas de la Meseta Central de Santa Cruz (Tabla 8.1).

Asimismo, deseamos evaluar la incidencia que tienen ciertas características del tratamiento térmico al momento de aplicación de la metodología de análisis funcional de base microscópica: investigamos qué efecto tiene el lustre térmico sobre los micropulidos ya que ciertos autores han sugerido que en algunos casos éste podría enmascararlos (Gibaja 2002; Gibaja y Clemente 1997; ver capítulo 6). De esta manera tres de estas experimentaciones han incluido el uso de las piezas antes o después del tratamiento térmico. Estos últimos análisis fueron realizados en conjunto con el Lic. Manuel Cueto ${ }^{4}$, quien hizo las observaciones de los micropulidos en el marco de su tesis doctoral en curso. Finalmente a estas 10 experimentaciones agregamos 2 experiencias en las que

\footnotetext{
${ }^{4}$ Doctorado en Ciencias Antropológicas. FFyL. UBA. Tesis: El análisis funcional de bienes elaborados sobre material lítico y óseo, como medio para conocer la producción tecnológica de las sociedades de cazadoresrecolectores, que colonizaron la Meseta Central de Santa Cruz. Patagonia Argentina. Directora: Alicia Castro
} 
se descarta material lítico en el fogón, a fin de que nos permita comparar los resultados. Estas dos experiencias pueden ser consideradas como simulativas (Tabla 8.1).

Las experimentaciones sobre tratamiento térmico aquí desarrolladas cuentan con varias etapas, que describiremos paso a paso.

1. Selección de materia prima: Utilizamos nódulos de materias primas procedentes de la Localidad Arqueológica La María. Para su selección analizamos los conjuntos artefactuales del registro arqueológico de esta localidad. Escogimos 5 variedades de materias primas, altamente representadas y de las que las fuentes de aprovisionamiento están inmediatamente accesibles (Frank et al. 2007; Skarbun 2009b; Skarbun et al. 2007). Estos materiales corresponden fundamentalmente a dos tipos de materias primas: sílex y toba silicificada. La calcedonia, por su parte, si bien es una roca relativamente abundante en los sitios en estudio, no fue utilizada ya que se desconocen hasta el momento fuentes de aprovisionamiento locales. Las materias primas proceden de dos fuentes de aprovisionamiento localizadas en el Sector Cañadón de La Mina (Paunero et al. 2005):

- Sitio Cantera de Sílex (Frank et al. 2007): Es una cantera primaria compuesta por abundante material suelto de color predominantemente rojo y amarillo producto principalmente del precipitado de un fluido (frío) sobresaturado en sílice (López 2004) (para una descripción más detallada ver capítulo 5).

- Cantera El Morro: Se trata de un cerro constituido en su mayor parte por toba silicificada, ubicado a $800 \mathrm{~m}$ de la Cantera de Sílex. Es una cantera primaria, con material de color predominantemente marrón y violáceo. Se presenta en forma de bloques de gran tamaño y nódulos menores. La calidad de la materia prima es por lo general buena a regular, dependiendo del grado de silicificación y de la homogeneidad de los nódulos.

Específicamente, las materias primas utilizadas son:

Materia Prima 1. Fue determinada macroscópicamente como una roca piroclástica retrabajada de silicificación secundaria o por reemplazo (López 2004), color rojo amarillento (5 YR 5/8) proveniente del sitio Cantera de Sílex. No presenta inclusiones, vetas ni rajaduras observables a ojo desnudo. De calidad regular para la talla, fundamentalmente por no estar completamente silicificada (Fig. 8.1 A). El análisis de corte delgado de una muestra macroscópicamente similar y proveniente de la misma fuente, aunque correspondiente a un núcleo diferente (muestra 8 en Skarbun 2009b), es descripta como una roca posiblemente sedimentaria silicificada y cortada por vetillas finas de calcedonia. De origen posiblemente volcánico retrabajado y de grano fino que

\footnotetext{
${ }^{5}$ La determinación de los colores se realizó en base a la Munsell Soil Color Charts 1994.
} 
indicarían un ambiente sedimentario tranquilo, ya sea lacustre o fluvial de baja energía; correspondería a la Formación Chon Aike (Páez 2009; Skarbun 2009b).

Materia Prima 2. Es una roca piroclástica retrabajada de silicificación secundaria o por reemplazo (López 2004), de color rojo amarillento (5 YR 7/6), proveniente de la Cantera El Morro. No presenta inclusiones, vetas ni rajaduras; es de grano fino y resulta de buena calidad para la talla por percusión (Fig. 8.1 B).

Materia Prima 3. Sílex de precipitación primaria (López 2004), color marrón fuerte (7,5 YR 5/8) proveniente del sitio Cantera de Sílex. Si bien es de grano fino, presenta inclusiones que la vuelven de mala calidad para la talla. Es además extremadamente dura (Fig. 8.1 C).

Materia Prima 4. Roca piroclástica retrabajada de silicificación secundaria o por reemplazo (López 2004), color amarillo pálido (2,5 Y 7/4) proveniente del sitio Cantera de Sílex. No presenta a ojo desnudo inclusiones ni rajaduras, aunque sí algunas vetas que guían la dirección de fractura. Es de grano fino (Fig. 8.1 D). El análisis de corte delgado de una muestra macroscópicamente similar y proveniente de la misma fuente, aunque correspondiente a un núcleo diferente (muestra 7 en Skarbun 2009b) fue descripta como una roca sedimentaria de grano fino a muy fino, con fuerte silicificación y cortada por finas vetillas de sílice de grano fino, posiblemente calcedonia. Correspondería a un sedimento volcánico retrabajado que se depositó en un ambiente tranquilo, posiblemente lacustre; pertenecería a la Formación Chon Aike (Páez 2009; Skarbun 2009b).

Materia Prima 5. Fue determinada macroscópicamente como un sílex de precipitación primaria (López 2004) color marrón rojizo oscuro (2,5 YR 3/4) proveniente del sitio Cantera de Sílex. No presenta a ojo desnudo inclusiones, vetas ni rajaduras; es de grano fino y resulta de muy buena calidad para la talla por percusión (Fig. 8.1 E). El análisis de corte delgado de una muestra macroscópicamente similar y proveniente de la misma fuente, aunque correspondiente a un núcleo diferente (muestra 6 en Skarbun 2009b) ha sido descripta como un sílice criptocristalino de aspecto isótropo, posiblemente ópalo, con pequeños cristales de minerales opacos de hábito prismático. Presenta cavidades rellenas de calcedonia botroidal (Páez 2009; Skarbun 2009b). 


\begin{tabular}{|c|c|c|c|c|c|c|c|c|}
\hline $\begin{array}{l}\text { Exp } \\
N^{\circ}\end{array}$ & Lugar & Tipo de Exp. & MP & Piezas por MP & T Máx. & $\begin{array}{l}\text { cm de } \\
\text { arena }\end{array}$ & $\begin{array}{l}\text { Dimensión } \\
\text { fogón }\end{array}$ & $\begin{array}{l}\text { Actividad } \\
\text { realizada }\end{array}$ \\
\hline 1 & \begin{tabular}{|c|} 
La \\
María \\
\end{tabular} & TT & 5 & 5 & $333^{\circ}$ & 2 & $50 \times 50$ & - \\
\hline 2 & Bs As & $\pi T$ & 5 y s. gris & 3 & $303^{\circ}$ & 2 & $60 \times 50$ & - \\
\hline 3 & Bs As & TT + Uso & 5 & $\begin{array}{c}8 \text { lascas y } 1 \\
\text { núcleo }\end{array}$ & $413^{\circ}$ & 2 & $1 \mathrm{~m} \times 75$ & Raspar hueso \\
\hline 4 & Bs As & TT + Uso & 5 & $\begin{array}{c}8 \text { lascas y } 1 \\
\text { núcleo }\end{array}$ & $340^{\circ}$ & 2 & $60 \times 50$ & Raspar hueso \\
\hline 5 & Bs As & $\pi$ & $1,2,3$ y 4 & 3 & $444^{\circ}$ & 2 & $45 \times 55$ & - \\
\hline 6 & Bs As & $\begin{array}{c}\text { Tiras piezas } \\
\text { al fogón }\end{array}$ & $1,2,3$ y 4 & 4 & $\begin{array}{l}\text { No fue } \\
\text { medida }\end{array}$ & - & $45 \times 55$ & - \\
\hline 7 & Bs As & $T T$ & $1,2,3$ y 4 & 6 & $360^{\circ}$ & 5 & $60 \times 50$ & - \\
\hline 8 & Bs As & $T T$ & $1,2,4$ y 5 & 2, MP5:4 & $428^{\circ}$ & 5 & $50 \times 50$ & - \\
\hline 9 & Bs As & $\begin{array}{c}\text { Tiras piezas } \\
\text { al fogón }\end{array}$ & 1,2 y 4 & 4 & $670^{\circ}$ & - & $60 \times 50$ & - \\
\hline 10 & Bs As & $\mathrm{TT}$ & $1,2,4$ y 5 & 1, MP5: 2 & $274^{\circ}$ & 5 & $60 \times 50$ & - \\
\hline 11 & \begin{tabular}{|c|} 
La \\
María \\
\end{tabular} & TT & 3,4 y 5 & $\begin{array}{c}\text { MP } 4 \text { y } 5: 3 . \\
\text { MP 3: } 6\end{array}$ & $310^{\circ}$ & 5 & $80 \times 70$ & - \\
\hline 12 & Bs As & $\mathrm{TT}+$ Uso & 5 & 5 & $312^{\circ}$ & 5 & $60 \times 50$ & Cortar hueso \\
\hline
\end{tabular}

Tabla 8.1. Resumen de las experimentaciones. TT: Tratamiento térmico.

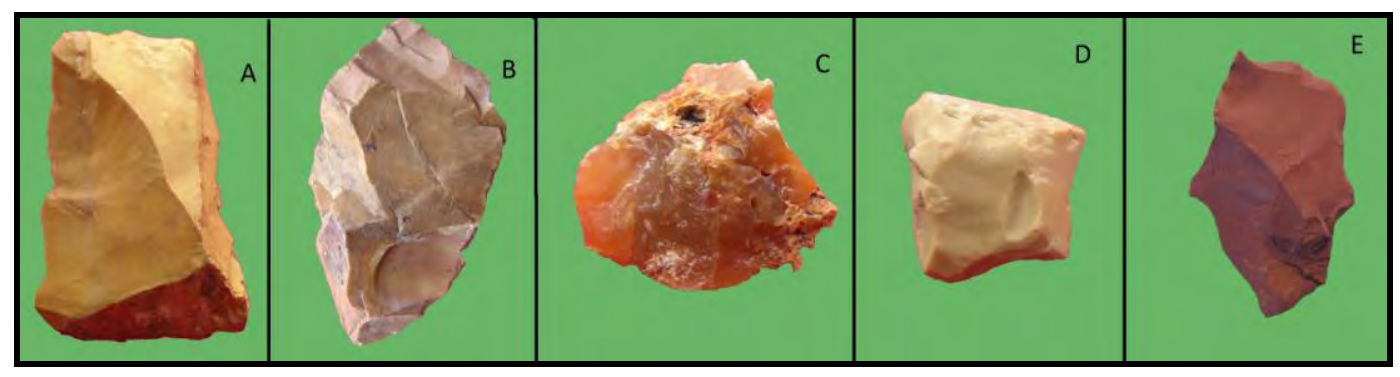

Fig. 8.1. Materias primas utilizadas en la experimentación. A. Materia prima 1; B. 2; C. 3; D. 4; E. 5.

2. Talla: Una vez seleccionadas las materias primas, procedimos a tallarlas por percusión directa. Utilizamos un percutor duro de piedra, obteniéndose gran cantidad de lascas, algunas de las cuales fueron tratadas térmicamente y otras reservadas como material de referencia. En el caso de la materia prima 5, también se reservaron dos núcleos para ser tratados térmicamente. Las piezas fueron fotografiadas, dibujadas y medidas.

3. Tratamiento térmico: Las piezas fueron tratadas térmicamente (Fig. 8.2); realizamos las experimentaciones en fogones buscando replicar las características y las dimensiones de estas estructuras de los sitios estudiados (ver capítulo 5). Los fogones experimentales fueron planos, con dimensiones aproximadas de $60 \mathrm{~cm}$ por $50 \mathrm{~cm}$, y una forma semicircular. En su base dispusimos una capa de arena en la que se ubicaron las piezas. Las lascas fueron ubicadas con la cara ventral mirando hacia abajo y cubiertas nuevamente con arena en cinco casos de un espesor de $2 \mathrm{~cm}$ y en otros cinco casos de $5 \mathrm{~cm}$. La arena permite una distribución homogénea de la temperatura e impide el contacto directo de las piezas con el fuego, disminuyendo las posibilidades de sufrir stress térmico. 
Una vez encendidos, alimentamos los fogones con leña, controlándose la cantidad y momento en que esta era utilizada. Los combustibles empleados fueron los disponibles en las madereras de Buenos Aires, esto es, mayormente quebracho colorado (Schinopsis balansae), eucaliptus (Eucalyptus camaldulensis) e itín (Prosopis kuntzei), con excepción de dos ocasiones en las cuales las experimentaciones se realizaron en la Localidad Arqueológica La María; allí se utilizó madera local: molle y calafate. Estas muy probablemente hayan sido las aprovechadas por los grupos cazadores recolectores que habitaron el área en el pasado, teniendo en cuenta las características fitogeográficas de la región, así como un análisis botánico realizado a una muestra de carbón vegetal, de la unidad 5 del sitio Cerro Tres Tetas 1 enviada al Dr. James Steele de la Universidad de Southampton, que arrojó la pertenencia al género Schinus, al que pertenece el molle (Paunero 2000a).

De acuerdo a las investigaciones realizadas por otros autores el calentamiento y el enfriamiento deben realizarse de manera lenta, a fin de evitar que la roca sufra stress térmico (Cattáneo et al. 1997-98; Mandeville 1973; Purdy y Brooks 1971, entre otros). Nuestros experimentos fueron realizados tomando como parámetro los rangos de temperaturas propuestos por diversos investigadores (Ariet 1991; Cattáneo et al. 1997-98; Clemente Conte 1995; Collins y Fenwick 1974; Flenniken y Garrison 1975; Flenniken y White 1983; Gibaja 2002; Mandeville 1973; Mandeville y Flenniken 1974; Stadler 2002, ver capítulo 6). En especial nos interesa lo propuesto por Nami et al. (2000) quienes consideran que los valores óptimos varían dentro del rango de $250^{\circ}$ y $450^{\circ} \mathrm{C}$ de acuerdo al tipo de roca. Cabe destacar que sus experimentaciones fueron realizadas con materias primas similares a las que nosotros hemos utilizado y también provienen de la Meseta Central de Santa Cruz.

El hecho de que para nuestras experimentaciones hayamos utilizado fogones vuelve imposible la "programación" de la temperatura, como podría hacerse en hornos de cocción de cerámica. Las variaciones de temperatura fueron medidas por medio de un Controlador de Temperatura6 anexado a una termocupla de tipo $\mathrm{K}$ que fue ubicada junto a las piezas. En los diversos experimentos determinamos a priori la temperatura que deseabamos alcanzar, y variamos la cantidad y momento de uso de la leña de acuerdo a los valores que nos brindaba el controlador y al ritmo con que cambiaba la temperatura.

Agregamos la leña paulatinamente, de manera que la temperatura máxima buscada se alcanzara lentamente. Habitualmente, dejamos de agregar combustible poco antes de llegar a la temperatura buscada, puesto que éste, al tardar en quemarse, no libera el calor inmediatamente después de ser agregado. A partir de ese momento no alimentamos más el fogón a menos que

\footnotetext{
${ }^{6}$ En los primeros cinco casos se utilizó un controlador OPR marca Metrovolt, en los restantes uno marca Caho.
} 
éste haya marcado una disminución en la temperatura muy repentina. Procuramos que, una vez alcanzada la temperatura máxima deseada, esta se mantenga por un período de al menos una hora, para luego permitir que se produzca un enfriamiento paulatino. Registramos la temperatura cada 15 minutos, hasta el momento en que se evidenció una tendencia hacia su disminución, lo que indica el comienzo de su extinción (Fig. 8.3). La experimentación duró en todos los casos de tratamiento térmico aproximadamente 24 horas. Una vez que el fogón se encontraba apagado y la arena a temperatura ambiente, retirabamos las piezas.

Solo en 2 oportunidades no seguimos este procedimiento. En ellos, la actividad consistió en replicar situaciones de calentamiento accidental, arrojando las piezas sobre un fuego encendido previamente. Registramos el momento en que estas eran echadas, y las retiramos una vez que el fogón estaba apagado. En los casos en que las piezas se fracturaban y salían desprendidas alejándose del fogón, medimos con cinta métrica a qué distancia de la estructura de combustión estas cayeron. Esto tuvo por objetivo entender cuáles son los rasgos que se generan en casos de contacto directo de piezas con el fuego, como pueden ser las caídas accidentales o el descarte intencional de estas piezas en un fogón, en comparación con los generados durante el tratamiento térmico. Asimismo, deseamos evaluar la forma en que se distribuyen los restos en los casos en que ocurre este tipo de proceso. Esta actividad se realizó con todas las materias primas excepto la 5.
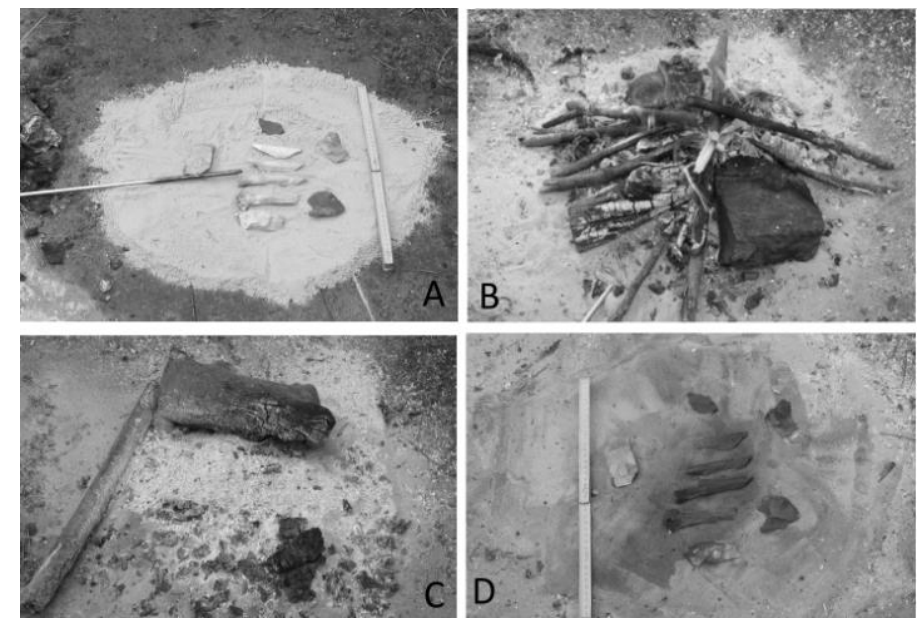

Fig. 8.2. Secuencia de la experimentación en tratamiento térmico. A: Se disponen las piezas sobre la base de arena. Nótese la ubicación de la termocupla. B: Luego de taparlas, se enciende el fuego.

C: El fogón, una vez finalizada la experimentación. D: Las piezas, una vez descubiertas. 


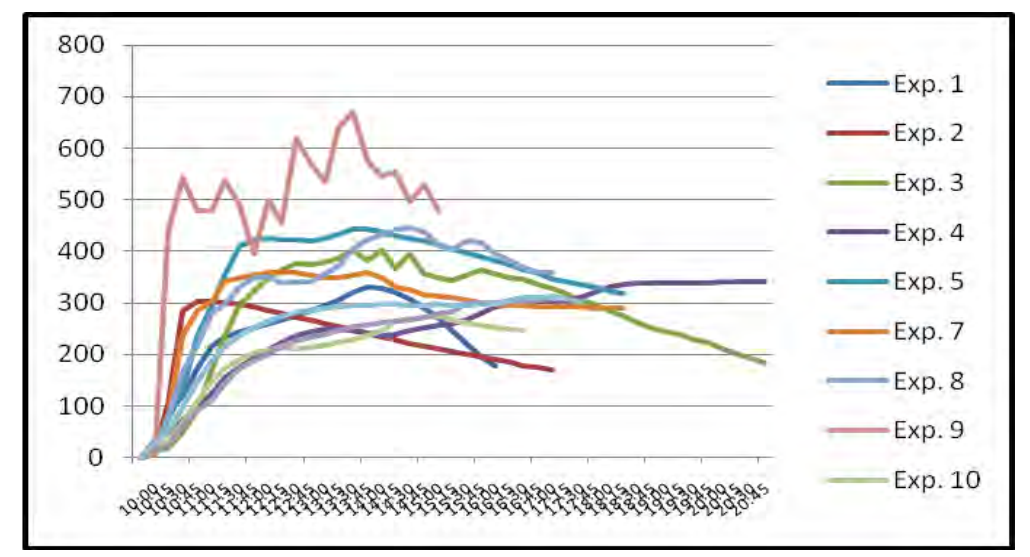

Fig. 8.3. Curva térmica de los diversos experimentos. El experimento 9 corresponde a una réplica de calentamiento accidental; el resto a tratamiento térmico.

4. Analizamos los resultados macroscópicos de la exposición térmica, buscando reconocer las alteraciones producidas. Los indicadores, observados a ojo desnudo y con lupa (10x), fueron los mencionados en el capítulo 6 es decir, cambio de color, lustre, hoyuelos, escamaciones, agrietamientos, rugosidad y pátina. Registramos en qué cara de las piezas se presentaban estos cambios. También se procuró identificar otros rasgos factibles de ser utilizados en el reconocimiento de las alteraciones térmicas en el registro arqueológico.

5. Retocamos las piezas con tres objetivos: observar si se formó lustre interno; registrar si las ondas de percusión se observaban más nítidamente que en las piezas no tratadas; y evaluar cualitativamente si este procedimiento mejoró la calidad para la talla. El retoque se realizó con un retocador lítico.

6. Uso: En tres de los experimentos utilizamos lascas de la materia prima 5 para el raspado y corte de hueso. Usamos estas piezas en algunos casos antes y en otros después de tratarlas térmicamente, puesto que se busca analizar de qué manera el calentamiento y determinados rasgos del tratamiento térmico como el lustre alteran o inciden en el reconocimiento de los micropulidos producto del uso.

Entre las tres experimentaciones (Tabla 8.1) donde se buscó evaluar esta problemática se trataron térmicamente seis piezas que ya habían sido utilizadas (dos para cortar y cuatro para raspar hueso); a su vez, trece piezas fueron utilizadas con posterioridad al tratamiento térmico (tres para cortar y diez para raspar hueso).

La acción de raspado implicó movimientos transversales al filo activo, en un ángulo de ataque de aproximadamente $45^{\circ}$. El corte de los huesos se realizó a través de movimientos longitudinales al filo, en un ángulo no menor a $75^{\circ}$ con respecto al hueso. El tiempo de trabajo fue de $30 \mathrm{~min}$ (Tabla 8.2).

La observación y análisis de los micropulidos fue realizada por el Lic. Manuel Cueto. Por un lado, se observó al microscopio qué efectos tenía el tratamiento térmico en rastros de uso que se habían generado previo a su exposición a temperaturas controladas. Por otro, se registró qué 
consecuencias tenía este procedimiento en la identificación de microrrastros generados posteriormente a la exposición de la pieza. La observación fue realizada con una Lupa triocular estereoscópica con aumentos de 80x, y un Microscopio metalográfico de luz incidental marca UNION ME-3206, con un aumento de 300x.

\begin{tabular}{|c|c|c|c|c|c|}
\hline & $\begin{array}{c}\text { Uso antes } \\
\text { de tratar }\end{array}$ & $\begin{array}{c}\text { Uso después } \\
\text { de tratar }\end{array}$ & Movimiento & Ángulo & $\begin{array}{c}\text { Tiempo } \\
\text { de uso }\end{array}$ \\
\hline Raspar hueso & 4 & 10 & Transversal al filo & $45^{\circ}$ & $30^{\prime}$ \\
\hline Cortar hueso & 2 & 3 & Longitudinal al filo & $75^{\circ}$ & $30^{\prime}$ \\
\hline
\end{tabular}

Tabla 8.2. Descripción de las experimentaciones de uso.

\subsection{Resultados}

Los resultados alcanzados aportaron una amplia y valiosa información respecto a la variabilidad en los referentes de termoalteración observables sobre las materias primas estudiadas. En el conjunto de las experimentaciones se han alterado térmicamente 125 piezas. En cuanto a las referidas al tratamiento térmico podemos ver dos grupos de resultados. En tres casos (experimentaciones 3, 4 y 5) gran cantidad de las piezas tratadas han sufrido un intenso daño, generándose múltiples fragmentos que no permitían reconocer la morfología original de cada pieza y que ya no podían ser tallados. Estos fragmentos, así como los generados en las otras experimentaciones, se clasificaron en cuatro rangos según su longitud máxima, sin tener en cuenta un eje técnico. Los rangos definidos fueron: 1 . entre 0 y $0,4 \mathrm{~cm} ; 2$. entre 0,5 y $1,9 \mathrm{~cm} ; 3$. entre 2 y $3,9 \mathrm{~cm} ; 4.4 \mathrm{~cm}$ o mayor. El rango número 1 , si bien se contabilizaron la cantidad de fragmentos generados, no será tenido en cuenta durante el análisis de los indicadores de daño y tratamiento térmico, ya que resulta dificultoso de reconocerlos.

En el resto de las experimentaciones, todas las piezas se mantuvieron enteras y sólo se produjeron escasos daños en algunas piezas que no implicaron una modificación en su morfología general ni un impedimento en su posterior talla. En estos casos, el daño térmico se dio de forma superficial. Si bien puede ubicarse tanto en la cara dorsal y ventral de la pieza tratada, se presentó de manera más habitual en la cara más cercana al fuego, que fue siempre la dorsal. En cuanto a las esquirlas de retoque extraídas con posterioridad al calentamiento, el daño térmico se presentó únicamente en la cara dorsal. Cabe aclarar que en todos los casos en que las piezas tratadas se fracturaron, los diversos fragmentos de cada pieza se encontraban asociados, permitiendo rescatar en consecuencia la totalidad de los segmentos en que se dividió cada una.

Presentaremos los resultados de las experimentaciones diferenciando por materia prima e indicando la temperatura a la cual aparece cada rasgo, pudiéndose consultar en el Anexo 2 los resultados para cada pieza. 
Materia Prima 1: En los experimentos de tratamiento térmico esta materia prima evidencia un cambio de color desde los $360^{\circ} \mathrm{C}$ donde comienza a tomar tonalidades rojizas (10 R 4/6 Rojo) (Cuadro 8.1). A partir de esa temperatura, todas las piezas tratadas han cambiado de color.

En cuanto al daño térmico, este empieza a observarse aproximadamente a los $428^{\circ} \mathrm{C}$ y se hace algo más intenso al alcanzar los $444^{\circ} \mathrm{C}$, momento en el cual una de las piezas se fragmentó en siete partes que se presentan principalmente en el rango 3 (Tabla 8.3). Los indicadores de daño presentes son, en primer lugar la rugosidad (en 37,5\% de los fragmentos) seguido por los hoyuelos y las escamaciones (Tabla 8.4). En cuanto a la forma, esta materia prima exhibe fragmentos mayormente angulosos, producto de fracturas tanto transversales como longitudinales. Cabe destacar que las piezas dañadas fueron las dos de mayores dimensiones de esta materia prima (Tabla 8.5).

Con posterioridad al retoque, no se observó el desarrollo de lustre en ningún caso; este tampoco se observó en los hoyuelos. En relación con las ondas de percusión, si bien en algunos casos estuvieron presentes, éstas nunca fueron más nítidas ni desarrolladas que en las piezas retocadas previo al tratamiento térmico. De manera cualitativa, evaluamos si este procedimiento mejoró la calidad para la talla de las rocas de esta materia prima. El retoque, realizado por percusión, fue equivalente al obtenido antes de tratar este material; el tratamiento térmico no permitió desarrollar retoques más profundos ni se mejoró la forma en que se fractura la pieza.

En los casos en que se arrojaron piezas al fogón, todas ellas cambiaron de color tomando también tonos rojizos (Cuadro 8.1). Las lascas se fracturaron extensivamente; se generaron 52 fragmentos, es decir, un promedio de 6,5 fragmentos por pieza. De estos, 35 son asignables al rango 2 de longitud máxima (67,3\%), 14 al $3(26,9 \%)$ y tres corresponden al $4(5,8 \%)$. En cuanto a los indicadores, 30 muestran rugosidad (57,7\%), 13 presentan hoyuelos (25\%), 12 tienen escamaciones $(23,1 \%)$ y ocho agrietamientos $(15,4 \%)$. No se desarrolló pátina ni lustre. Aunque las piezas se fracturaron extensivamente, estas permanecieron en su gran mayoría dentro de la estructura de combustión. Sólo dos fragmentos fueron recuperados por fuera de este a 30 y 38 $\mathrm{cm}$ de distancia de la fuente de calor. Cabe mencionar que las piezas se fragmentaron casi en el mismo momento en que tomaron contacto con el fuego. Si bien posteriormente se mantuvieron por un período prolongado dentro del fogón, no continuaron fracturándose.

Materia Prima 2: En los experimentos de tratamiento térmico esta materia prima evidencia un cambio de color desde los $360^{\circ} \mathrm{C}$, tomando un color Rojo Claro (2,5 YR 6/6) (Cuadro 8.1). A partir de esa temperatura, todas las piezas tratadas han cambiado de color.

El daño térmico se observa únicamente en las piezas expuestas a los $444^{\circ} \mathrm{C}$. A esta temperatura las lascas se fracturaron intensamente. Los fragmentos corresponden principalmente al rango 1 de longitud máxima (Tabla 8.3). Los indicadores de daño presentes son, en primer lugar los 
hoyuelos (en 37,5\% de los casos) seguido por las escamaciones y la rugosidad (Tabla 8.4). También se observan altos porcentajes de lustre, que se desarrolló en los hoyuelos. En cuanto a la forma que toman los fragmentos, esta materia prima muestra una fractura particular, ausente en las otras; ésta es una fractura longitudinal que genera piezas de plano rectangular a subrectangular, por lo general bastante delgadas. Si bien lascas originalmente expuestas correspondientes a los tres rangos de tamaño sufrieron daño, son los rangos 3 y 4 los que presentan valores más altos en este rubro (Tabla 8.5).

Con posterioridad al retoque, se observó el desarrollo de lustre en las piezas expuestas a más de $274^{\circ}$; mientras que las expuestas a $444^{\circ}$ no pudieron se retocadas por encontrarse extensamente dañadas. En éstas últimas, sin embargo, sí se observa lustre en los hoyuelos. En relación con las ondas de percusión, éstas nunca fueron más nítidas ni desarrolladas que en las piezas retocadas previo al tratamiento térmico. Al evaluar si este procedimiento mejoró la calidad para la talla, resgistramos un claro aumento en la fragilidad de la roca, aunque; el tratamiento térmico no permitió desarrollar retoques más profundos ni mejoró la forma en que se fractura la pieza.

En los casos en que replicamos calentamientos accidentales, arrojando piezas al fogón, todas ellas cambiaron de color tomando también tonos rojizos (Cuadro 8.1). Las lascas se fracturaron extensivamente; se generaron 101 fragmentos, es decir, un promedio de 12,6 fragmentos por pieza. De estos, 9 corresponden al rango 1 (8,9\%), 71 son asignables al rango 2 (70,3\%), 17 al rango $3(16,8 \%)$ y 4 pertenecen al rango $4(4 \%)$. En cuanto a los indicadores, 63 fragmentos presentan hoyuelos (25\%), 34 muestran rugosidad (37\%), 33 tienen escamaciones $(35,9 \%)$ y 20 agrietamientos (21,7\%). En 3 casos se observó lustre en los hoyuelos o en planos de fractura $(3,3 \%)$. No se desarrolló pátina. Las piezas permanecieron en su gran mayoría dentro de la estructura de combustión, sin embargo, 15 fragmentos fueron recuperados alejados de ésta. Si bien la mayor parte se alejó menos de $30 \mathrm{~cm}$, algunas piezas se encontraron más distantes, distanciadas hasta un metro del fogón. Las piezas se fragmentaron casi en el mismo momento en que tomaron contacto con el fuego. Aunque posteriormente se mantuvieron por un período prolongado dentro del fogón, no continuaron fragmentándose.

Materia Prima 3: En los experimentos de tratamiento térmico esta materia prima evidencia un cambio de color desde los $360^{\circ} \mathrm{C}$, momento en el cual toma un color rojo claro (2,5 YR 6/6) (Cuadro 8.1). A partir de esa temperatura, todas las piezas tratadas han cambiado de color.

En cuanto al daño, este se observa a partir de los $310^{\circ} \mathrm{C}$. Del total de piezas tratadas, el $23 \%$ muestra daño térmico, pero éste fue siempre poco intenso. Los fragmentos se presentan principalmente en tamaños del rango 3 (Tabla 8.3). Los indicadores de daño presentes son, en primer lugar la rugosidad (presente en $62,5 \%$ de los fragmentos) seguido por las escamaciones y los agrietamientos (Tabla 8.4). También se observan hoyuelos, lustre en los planos de fractura y 
pátina. La forma de los restos tiende a ser mayormente angulosa, producto de fracturas tanto transversales como longitudinales y oblicuas. Si bien las piezas originalmente expuestas correspondientes a los tres rangos de tamaño sufrieron daño térmico, son las correspondientes al rango 4 las más intensamente dañadas (Tabla 8.5).

Con respecto al retoque, si bien se observó el desarrollo de lustre en las piezas expuestas a partir de los $310^{\circ} \mathrm{C}$, estas no mejoraron su calidad para la talla después del tratamiento térmico. La materia prima continúa siendo muy dura, resultando muy difícil retocar la pieza. Las ondas de percusión no se observan en las lascas extraídas antes ni después del tratamiento térmico.

Todas las piezas termoalteradas por su descarte directo en el fogón cambiaron de color, tomando tonos naranjas. Sin embargo, en determinados casos se desarrolló una pátina blanca que cubrió la totalidad del artefacto, enmascarando otros cambios de color. Las lascas no se fracturaron y mostraron muy pocos rasgos de daño térmico. Sólo se observó un hoyuelo en una de ellas así como escamaciones y agrietamientos en otras tres. Las piezas permanecieron en su totalidad dentro de la estructura de combustión.

Materia Prima 4: En los experimentos de tratamiento térmico esta materia prima evidencia un cambio de color desde los $274^{\circ} \mathrm{C}$, tomando un color Marrón (7,5 YR 4/2) (Cuadro 8.1). A partir de esa temperatura, todas las piezas tratadas han cambiado de color.

El daño térmico se observa en las piezas expuestas a partir de los $310^{\circ} \mathrm{C}$, pero se hace notablemente más intenso al llegar a los $444^{\circ} \mathrm{C}$. Mientras que entre los $310^{\circ} \mathrm{C}$ y los $428^{\circ} \mathrm{C}$ sólo se quebraron dos piezas, a los $444^{\circ} \mathrm{C}$ todas las lascas tratadas se fracturaron extensivamente. Los fragmentos se presentan principalmente en el rango 1 (Tabla 8.3). Los indicadores de daño presentes son, en primer lugar la rugosidad (presente en $87,5 \%$ de los casos) seguido por los hoyuelos y los agrietamientos (Tabla 8.4). No se observa lustre ni pátina. En cuanto a la forma que toman los fragmentos, la materia prima 4 presenta principalmente fracturas transversales muy delgadas, como si se estuviera "descamando" la lasca. También presenta, en ciertos casos fracturas longitudinales y oblicuas rectas, por lo que las piezas se presentan angulosas y con una superficie irregular.

Si bien las piezas originalmente expuestas correspondientes a los tres rangos de tamaño sufrieron daño térmico, son los rangos 2 y 3 los más fuertemente dañados (Tabla 8.5). En este sentido, se diferencian de las otras materias primas que habitualmente resultaron más dañadas en las lascas correspondientes al rango mayor.

Con posterioridad al retoque, no se observó el desarrollo de lustre en los elementos tratados. En relación con las ondas de percusión, éstas fueron más nítidas que en las piezas retocadas previo al tratamiento térmico. Al evaluar si este procedimiento mejoró la calidad para la talla, observamos un claro aumento en la fragilidad de las rocas, que permitió desarrollar retoques más profundos. 
En los casos en que replicamos la caída accidental de lascas dentro del fogón, todas cambiaron de color. Mientras que la mayor parte tomaron tonos rojizos y anaranjados, algunas, en especial al alcanzar las temperaturas más altas, se volvieron grises (Cuadro 8.1). Las lascas se fracturaron extensivamente; se generaron 57 fragmentos, es decir, un promedio de 5,7 fragmentos por pieza. De estos, 45 son asignables al rango $2(78,9 \%)$ y 12 al rango $3(21,1 \%)$. No se registraron restos correspondientes al rango 4. En cuanto a los indicadores, 44 muestran rugosidad (77,2\%), 23 fragmentos presentan hoyuelos (40,3\%), 13 evidencian agrietamientos (22,8\%) y 10 tienen escamaciones (17,5\%). En sólo un caso se observó lustre en hoyuelos. No se desarrolló pátina. Las piezas permanecieron en su gran mayoría dentro de la estructura de combustión, sin embargo, dos fragmentos fueron recuperados alejados de ésta. Se encontraban a 26 y $80 \mathrm{~cm}$ de distancia del fogón respectivamente. Las lascas se quebraron casi en el mismo momento en que tomaron contacto con el fuego. Si bien posteriormente se mantuvieron por un período prolongado dentro del fogón, no continuaron fragmentándose.

Materia Prima 5: En los experimentos de tratamiento térmico esta materia prima evidencia un cambio de color desde los $274^{\circ} \mathrm{C}$ adquiriendo un color rojo oscuro (2,5 YR 3/2) (Cuadro 8.1). Mientras que a esa temperatura sólo una pieza ha cambiado de color, a partir de los $303^{\circ}$ todas lo hacen, al menos de manera superficial.

El daño térmico se observa en las piezas expuestas a partir de los $333^{\circ} \mathrm{C}$ (una lasca muestra agrietamientos), pero se hace notablemente más intenso al llegar a los $340^{\circ} \mathrm{C}$. Los fragmentos se presentan principalmente en el rango 2 (Tabla 8.3). Los indicadores de daño en estos son, en primer lugar la rugosidad (en $86,2 \%$ de los casos) seguido por los hoyuelos y las escamaciones (Tabla 8.4). Sólo en muy pocas ocasiones se observa lustre. La pátina está ausente. En cuanto a la forma que toman los fragmentos, esta materia prima se presenta mayormente angulosa, producto de fracturas tanto transversales como longitudinales irregulares. De las piezas originalmente expuestas, las del rango 2 no han sufrido daño; mientras que la mitad de las piezas del rango 4 muestran signos de daño térmico (Tabla 8.5).

Con posterioridad al retoque, observamos el desarrollo de lustre en las piezas tratadas. Este se desarrolló a partir de los $303^{\circ} \mathrm{C}$ pero fue más nítido desde los $333^{\circ} \mathrm{C}$. En relación con las ondas de percusión, éstas también fueron más claramente reconocibles, a partir de la misma temperatura. Al evaluar si este procedimiento mejoró la calidad para la talla, registramos un claro aumento en la fragilidad de la roca.

Por otra parte, hemos tratado térmicamente dos núcleos de esta materia prima. Uno fue calentado a $340^{\circ} \mathrm{C}$. Este no se fracturó durante su exposición en el fogón. Sin embargo al intentar tallar lascas, éstas no presentaban fractura concoide, sino que se quebraban irregularmente, exhibiend en su cara ventral rugosidades y otros indicadores de daño térmico. El segundo fue 
tratado a $413^{\circ} \mathrm{C}$. Éste resultó intensamente destruido por el fuego, generándose restos con característica análogas a las expuestas para los productos de talla. Sólo cuatro piezas, correspondientes al rango 4, presentan dimensiones y formas que nos permitirían considerarlas como potenciales formas base. Estas cuatro piezas no muestran indicadores de daño, cambiaron de color y, después de ser retocadas, desarrollaron lustre.

Finalmente, una etapa de las experimentaciones con esta materia prima consistió en evaluar de qué manera el calentamiento y determinados rasgos del tratamiento térmico, como el lustre, inciden en el reconocimiento de los micropulidos producto del uso. De acuerdo a lo observado por el Lic. Cueto (Cueto y Frank 2009a, b), los resultados parecen indicar que para esta materia prima, tratada térmicamente y utilizada para el corte y raspado en hueso, la exposición controlada al fuego no habría producido cambios significativos en las microalteraciones funcionales.

Por un lado, las piezas utilizadas antes del tratamiento térmico continuaban presentando micropulidos diagnósticos reconocibles una vez que fueron sometidas a este procedimiento. Por el otro, las piezas retocadas y utilizadas luego del tratamiento mostraban micropulidos que pudieron ser identificados a pesar del desarrollo de lustre térmico. El rastro formado no presenta diferencias reconocibles con el de las piezas no tratadas (Cueto y Frank 2009a, b).

Además, no existe diferencia en el tiempo de formación de los micropulidos entre las piezas usadas antes y después del tratamiento térmico. Estos se han desarrollado en ambos casos de manera diagnóstica luego de media hora de trabajo, sin manifestar diferencias aparentes en su aspecto (Cueto y Frank 2009a, b).

Las piezas utilizadas en la actividad de raspado para la formatización de superficies óseas presentan los rastros típicos de esta labor. En el trabajo de raspado con piezas tratadas térmicamente se producen mayor cantidad de daños morfológicos del filo que en piezas no tratadas, lo que sugiere un aumento en la fragilidad del filo en aquellas con tratamiento. El conjunto de piezas utilizadas en la actividad de corte también presenta los rastros típicos de esta labor (Cueto y Frank 2009a, b). 


\begin{tabular}{|c|c|c|c|c|c|}
\hline MP & 1 & 2 & 3 & 4 & 5 \\
\hline $\begin{array}{c}\mathrm{T}^{\circ} \\
\text { Amb. }\end{array}$ & $\begin{array}{c}5 \text { YR 5/8 Rojo } \\
\text { amarillento }\end{array}$ & $\begin{array}{c}5 \text { YR 7/6 Rojo } \\
\text { amarillento }\end{array}$ & $\begin{array}{c}7,5 \text { YR } 5 / 8 \\
\text { Marrón fuerte }\end{array}$ & $\begin{array}{c}2,5 \text { Y } 7 / 4 \\
\text { Amarillo pálido }\end{array}$ & $\begin{array}{c}2,5 \text { YR 3/4 Marrón } \\
\text { rojizo oscuro }\end{array}$ \\
\hline $274^{\circ}$ & $\begin{array}{c}5 \text { YR 5/8 Rojo } \\
\text { amarillento }\end{array}$ & $\begin{array}{c}5 \text { YR 7/6 Rojo } \\
\text { amarillento }\end{array}$ & - & $\begin{array}{c}\text { 7,5 YR 4/2 } \\
\text { Marrón }\end{array}$ & $\begin{array}{l}2,5 \text { YR } 3 / 2 \text { Rojo } \\
\text { oscuro }\end{array}$ \\
\hline $310^{\circ}$ & - & - & $\begin{array}{c}\text { 7,5 YR 5/8 } \\
\text { Marrón fuerte }\end{array}$ & $\begin{array}{c}7,5 \text { YR } 4 / 2 \\
\text { Marrón }\end{array}$ & $\begin{array}{c}\text { 2,5 YR 3/2 Rojo } \\
\text { oscuro }\end{array}$ \\
\hline $340^{\circ}$ & - & - & - & - & $\begin{array}{c}2,5 \text { YR } 3 / 6 \text { Rojo } \\
\text { oscuro }\end{array}$ \\
\hline $360^{\circ}$ & 10 R 4/6 Rojo & $\begin{array}{l}2,5 \text { YR 6/6 } \\
\text { Rojo Claro }\end{array}$ & $\begin{array}{c}\text { 2,5 YR 6/6 Rojo } \\
\text { Claro }\end{array}$ & 5 YR 8/4 Rosa & - \\
\hline $413^{\circ}$ & - & - & - & - & $\begin{array}{c}10 \text { R } 3 / 2 \text { Rojo } \\
\text { Oscuro }\end{array}$ \\
\hline $428^{\circ}$ & $\begin{array}{c}2,5 \text { YR } 4 / 4 \\
\text { Marrón rojizo }\end{array}$ & $\begin{array}{c}\text { 7,5 YR 6/6 } \\
\text { Amarillo rojizo }\end{array}$ & - & $\begin{array}{c}\text { 7,5 YR 6/6 } \\
\text { Amarillo rojizo }\end{array}$ & $\begin{array}{c}\text { 2,5 YR 4/4 Marrón } \\
\text { rojizo }\end{array}$ \\
\hline $444^{\circ}$ & $\begin{array}{c}2,5 \text { YR } 4 / 3 \\
\text { Marrón rojizo }\end{array}$ & $\begin{array}{c}10 \text { R 6/6 Rojo } \\
\text { Claro }\end{array}$ & $\begin{array}{c}\text { 2,5 YR 6/8 Rojo } \\
\text { Claro }\end{array}$ & $\begin{array}{l}5 \text { YR 7/4 Rosa; } \\
5 \text { Y 2,5/1 Negro }\end{array}$ & - \\
\hline $670^{\circ}$ & 10 R 4/6 Rojo & $\begin{array}{c}10 \text { R 5/4 Rojo } \\
\text { débil }\end{array}$ & - & $\begin{array}{c}\text { Chart } 1 \text { for Gley } \\
5 / \text { Gris }\end{array}$ & - \\
\hline
\end{tabular}

Cuadro 8.1. Colores adquiridos por las materias primas a distintas temperaturas

\begin{tabular}{|c|c|c|c|c|c|}
\hline Materia Prima & $\mathbf{1}$ & $\mathbf{2}$ & $\mathbf{3}$ & $\mathbf{4}$ & Total \\
\hline $\mathbf{1}$ & $0 \%$ & $25 \%$ & $62,5 \%$ & $12,5 \%$ & $100 \%$ \\
\hline $\mathbf{2}$ & $68,6 \%$ & $22,1 \%$ & $7,6 \%$ & $1,6 \%$ & $100 \%$ \\
\hline $\mathbf{3}$ & $0 \%$ & $25 \%$ & $50 \%$ & $25 \%$ & $100 \%$ \\
\hline $\mathbf{4}$ & $68 \%$ & $27,2 \%$ & $4 \%$ & $0,8 \% \%$ & $100 \%$ \\
\hline $\mathbf{5}$ & $32,6 \%$ & $61 \%$ & $5,8 \%$ & $0,6 \%$ & $100 \%$ \\
\hline Total & $42,3 \%$ & $50,4 \%$ & $6,3 \%$ & $0,9 \%$ & $100 \%$ \\
\hline
\end{tabular}

Tabla 8.3. Tamaño de los fragmentos recuperados de acuerdo al rango de longitud máxima.

\begin{tabular}{|c|c|c|c|c|c|c|}
\hline $\begin{array}{c}\text { Materia } \\
\text { Prima }\end{array}$ & Hoyuelos & Escamaciones & Rugosidad & Agrietamientos & Lustre & Pátina \\
\hline $\mathbf{1}$ & $37,5 \%$ & $25 \%$ & $25 \%$ & $0 \%$ & $0 \%$ & $0 \%$ \\
\hline $\mathbf{2}$ & $72,4 \%$ & $37,9 \%$ & $36,2 \%$ & $24,1 \%$ & $37,9 \%$ & $0 \%$ \\
\hline $\mathbf{3}$ & $25 \%$ & $37,5 \%$ & $62,5 \%$ & $37,5 \%$ & $25 \%$ & $25 \%$ \\
\hline $\mathbf{4}$ & $47,5 \%$ & $20 \%$ & $87,5 \%$ & $25 \%$ & $0 \%$ & $0 \%$ \\
\hline $\mathbf{5}$ & $80,6 \%$ & $8,3 \%$ & $86,2 \%$ & $6,5 \%$ & $0,4 \%$ & $0 \%$ \\
\hline Total & $77,3 \%$ & $11,5 \%$ & $49,54 \%$ & $81,7 \%$ & $3,4 \%$ & $0,25 \%$ \\
\hline
\end{tabular}

Tabla 8.4. \% de los diferentes indicadores en las materias primas tratadas térmicamente

\begin{tabular}{|c|c|c|c|c|c|c|}
\hline & \multicolumn{2}{|c|}{$\mathbf{2}$} & \multicolumn{2}{|c|}{$\mathbf{3}$} & \multicolumn{2}{c|}{$\mathbf{4}$} \\
\hline MP & Sin daño & Dañadas & Sin daño & Dañadas & Sin daño & Dañadas \\
\hline $\mathbf{1}$ & $100 \%$ & $0 \%$ & $100 \%$ & $0 \%$ & $60 \%$ & $40 \%$ \\
\hline $\mathbf{2}$ & $80 \%$ & $20 \%$ & $66,6 \%$ & $33,3 \%$ & $75 \%$ & $25 \%$ \\
\hline $\mathbf{3}$ & $75 \%$ & $25 \%$ & $75 \%$ & $25 \%$ & $28,6 \%$ & $71,4 \%$ \\
\hline $\mathbf{4}$ & $0 \%$ & $100 \%$ & $0 \%$ & $100 \%$ & $50 \%$ & $50 \%$ \\
\hline $\mathbf{5}$ & $100 \%$ & $0 \%$ & $83,3 \%$ & $16,6 \%$ & $50 \%$ & $50 \%$ \\
\hline Total & $68,4 \%$ & $31,6 \%$ & $65 \%$ & $35 \%$ & $50 \%$ & $50 \%$ \\
\hline
\end{tabular}

Tabla 8.5. \% de piezas dañadas y sin dañar durante el tratamiento térmico según rango de tamaño 


\subsection{Síntesis}

Los resultados muestran que las cinco materias primas con las que se experimentó cambiaron de color. Se dio una divergencia en la temperatura a la cual esto ocurre, mientras que las materias primas 4 y 5 muestran cambios ya desde los $274^{\circ} \mathrm{C}$, las materias primas 1,2 y 3 necesitan sobrepasar los $300^{\circ} \mathrm{C}$ para que se observen transformaciones en su tonalidad. Por lo general, los cambios se dieron hacia tonos más rojizos, aunque la materia prima 4 se volvió gris a altas temperaturas; $y$ en algunas piezas de la materia prima 3 una pátina blanca cubrió su superficie.

En relación a las piezas fracturadas, los fragmentos recuperados fueron en su gran mayoría pequeños, correspondientes a los rangos de tamaño 1 y 2 , es decir, no mayores a $2 \mathrm{~cm}$. Sin embargo, resulta interesante destacar que las lascas más pequeñas expuestas al fuego por lo general no se quebraron.

La aparición del daño, durante el tratamiento térmico, tiende a observarse a partir de los $310^{\circ} \mathrm{C}$, aunque se vuelve más habitual a medida que se va aumentando a temperatura. Así, las materias primas 3,4 y 5 muestran los primeros rasgos de daño a estas temperaturas pero al sobrepasar los $400^{\circ}$ se fragmentan más intensamente. Por otra parte, la materia prima 1 exhibe daños iniciales a los $360^{\circ} \mathrm{C}$ y la 2 a los $444^{\circ}$.

En cuanto al tipo de daño térmico factible de ocurrir vemos que la rugosidad y los hoyuelos son los indicadores más comunes. Existen, sin embargo, divergencias por materia prima. Mientras que en las materias 1 y 2 son más abundantes los hoyuelos y las escamaciones, en 3, 4 y 5 se observa predominancia de la rugosidad, seguido por los hoyuelos y los otros indicadores. Estas tendencias por materia prima se dan tanto para los experimentos de tratamiento térmico como para los casos de caída accidental dentro del fogón. En cuanto al lustre, se observa en los hoyuelos y planos de fracturas, sólo en las materias primas 2,3 y 5 . De éstas, solo en la materia prima 2 se ha presentado de manera abundante. No hemos reconocido piezas con craquelado en ninguna de nuestras experiencias.

Si bien existen características particulares para algunas materias primas $(2,4)$, la forma general que toman los fragmentos es de piezas angulosas, producto de fracturas tanto transversales como longitudinales. La rugosidad, por su parte, hace que la superficie de estos fragmentos sea sumamente irregular.

En relación con las variables consideradas con posterioridad al retoque, se puede decir que no existiría una correlación entre la presencia de lustre, la aparición más nítida de ondas y el aumento de la fragilidad para las piezas tratadas térmicamente. Así, el lustre se da en las materias primas 2, 3 y 5; las ondas se notan más nítidamente en 4 y en 5; mientras que aumenta la fragilidad en 2, 4 y 5 . En aquellas piezas en que se desarrolla, el lustre térmico aparece a los $310^{\circ} \mathrm{C}$ 
o por encima de esta temperatura. Por su parte, la materia prima 1 no desarrolla lustre ni ondas más nítidas y no aumenta su fragilidad con posterioridad al tratamiento.

En cuanto a las piezas arrojadas dentro del fogón, observamos que se concentran dentro de la estructura de combustión, aunque algunos pocos fragmentos podrán encontrarse en sus alrededores. La distancia máxima a la que hemos hallado restos es un metro.

\subsection{Conclusiones}

Las variables evaluadas aquí nos brindan información relacionada con el proceso de producción de artefactos líticos así como del manejo del fuego por parte de los grupos patagónicos. Es importante reconocer si el tratamiento térmico fue verdaderamente una técnica utilizada o bien si los restos termoalterados hallados en los sitios arqueológicos de la Meseta Central fueron producto de otras actividades (descarte en fogones, alteraciones postdepositacionales). En este sentido, nuestras experimentaciones aportan a la generación de un cuerpo de referencia que permite identificar de manera fiable la termoalteración de los restos líticos así como al conocimiento de las temperaturas y técnicas necesarias para un tratamiento térmico exitoso.

\subsubsection{El uso de los fogones experimentales}

Destacamos la importancia de realizar el tratamiento térmico mediante fogones experimentales, en un campo donde la mayoría de las experiencias se han realizado en hornos eléctricos. Estos últimos permiten precisar las temperaturas alcanzadas y definir los tiempos de ascenso, meseta y descenso de la curva térmica. Sin embargo la temperatura registrada no es la del sedimento circundante, sino la de la atmósfera del horno, que no necesariamente coinciden. En los fogones la temperatura se toma con termocupla en el sedimento en que se hallan las piezas. Este factor debe tenerse en cuenta a la hora de decidir cómo realizar las experimentaciones. Además, los experimentos en hornos eléctricos no permiten aprehender respecto del conjunto de procedimientos que constituyen al tratamiento térmico cómo técnica, puesto que esta requiere un conocimiento del combustible, de las características del fogón y del manejo del fuego. En este sentido, el empleo de fogones experimentales es una valiosa fuente de información.

Los experimentos aquí presentados se han realizado en diversos ámbitos y con diferentes maderas, inclusive aquellas disponibles en el área de estudio. Esto nos brinda un conocimiento más aproximado al manejo del fuego y de su aplicación en la técnica de tratamiento térmico.

Como observaran otros investigadores (Cattáneo et al. 1997-98; Gibaja 2002; Luedtke 1992; Mandeville 1973; Nami et al. 2000; Purdy y Brooks 1971; Schindler et al. 1982, entre otros), los resultados óptimos de este procedimiento dependen de una serie de factores. La temperatura máxima alcanzada es uno de ellos, pero también incide la velocidad con que se obtiene, durante 
cuánto tiempo esta se mantiene y cuán rápido se realiza el enfriamiento. Tiempos prolongados de cada una de estas fracciones del proceso permiten que se realice un tratamiento térmico exitoso. Por el contrario, en casos en los que se eleva la temperatura de manera muy rápida, o se disminuye de manera repentina, se genera stress térmico. Éste altera de manera sustancial la roca, siendo su destrucción proporcional al grado de stress al que fue expuesta.

En este sentido, un rasgo que permite realizar un calentamiento y enfriamiento paulatino es una apropiada capa de sedimento que recubra a las piezas, aislándolas del contacto con el fuego. Esto permite un mayor control y regularidad de la temperatura.

En cuanto a nuestra práctica con fogones, si tenemos en cuenta que durante la aplicación de la técnica de tratamiento térmico algunas piezas resultaron fragmentadas, es necesario evaluar cuales fueron las causas de este fenómeno, en especial en los casos en no se sobrepasaron los rangos propuestos por otros autores para el tratamiento térmico de materias primas silíceas de la región (Nami et al. 2000). En este contexto, observamos que existen divergencias en los resultados obtenidos cuando en las experimentaciones el sedimento aislante tenía un espesor de 2 y $5 \mathrm{~cm}$, siendo el daño térmico más frecuente en las primeras. Esto se debe fundamentalmente

a dos motivos, por un lado una mayor capa de sedimento permite un calentamiento y enfriamiento más paulatino dificultando alcanzar temperaturas excesivas, por el otro, una capa muy fina de sedimento puede ser removida accidentalmente durante el mantenimiento del fuego, generando así el contacto directo entre la madera encendida y las piezas.

\subsubsection{Indicadores macroscópicos de tratamiento térmico}

Distintos autores (Clemente Conte 1995; Gibaja y Clemente 1997; Nami et al. 2000; Purdy y Brooks 1971; Rick y Chappell 1983; Schindler et al. 1982, entre otros) coinciden en la existencia de una diferencia entre la superficie original de la roca, y la superficie interna de la misma tratada térmicamente. Esta modificación corresponde a un brillo de superficie muy específico, denominado "lustre térmico". En el caso de las materias primas utilizadas para este estudio, sólo en tres de ellas se identificó lustre, generado por el calentamiento a temperaturas mayores a los $300^{\circ} \mathrm{C}$. Este es en muchos casos sutil; se manifiesta de aspecto sedoso en las materias primas utilizadas en nuestras experimentaciones. El lustre térmico puede diferenciarse de otros tipos de lustre cuando la pieza no ha sido retocada en su totalidad, presentando los negativos del retoque lustrosos y la superficie natural más opaca. Asimismo es identificable en planos de fractura generados por causas tecnológicas, térmicas o de uso; en la cara ventral de esquirlas producto del retoque y conos de desprendimiento térmico. Constituye el rasgo distintivo de la aplicación del tratamiento térmico y es el parámetro que nos permitiría explorar la aplicación de esta técnica en conjuntos líticos de sitios de la Meseta Central de Santa Cruz. 
En relación a las ondas de percusión, sólo en dos materias primas (4 y 5) estas se volvieron más notables tras el tratamiento térmico, mientras que en las otras tres, o bien no se observaron ondas, o bien estas eran tan frecuentes e identificables como antes del calentamiento. De esto concluimos que estas no resultan por sí mismas un buen indicador del tratamiento térmico para nuestras materias primas, pero sí pueden considerarse cuando estas ocurren en conjunto con otros indicadores tales como el lustre o el cambio de color.

Por otra parte, tras el tratamiento térmico se modificó el aspecto de la superficie externa de todas las rocas, variando su color a tonalidades rojizas o anaranjadas. En muchos casos, el cambio de color es un cambio leve o sutil, factible de ser identificado sólo si se conoce la fuente de la cual proviene la materia prima. La temperatura a la cual se dieron estos cambios depende de la materia prima, en algunos casos desde las temperaturas más bajas y en otros recién al alcanzar los $360^{\circ}$. De cualquier manera, este indicador no puede ser usado aisladamente y debe ser complementado con otros criterios que permitan afirmar fehacientemente si se está en presencia de una alteración térmica o no.

Nuestras experimentaciones nos llevan a postular que para un tratamiento térmico efectivo los artefactos líticos deben exponerse a temperaturas menores a $400^{\circ} \mathrm{C}$. En estos casos, el índice de fragmentación disminuye notablemente, recuperándose por lo general piezas enteras, o bien con una o dos fracturas. Por lo tanto, los hoyuelos, la rugosidad, los agrietamientos, las escamaciones y la pátina en general estarán ausentes en piezas tratadas de manera precisa; sin embargo, pueden presentarse eventualmente. En aquellos casos en que se produzca daño durante el tratamiento térmico, éste se podrá ubicar en la cara dorsal y/o ventral de la pieza originalmente expuesta al fuego, pero sólo en la cara dorsal de las piezas extraídas posteriormente de ellas. Por lo tanto es fundamental registrar la ubicación del daño térmico en las piezas arqueológicas puesto que brinda información relevante a la hora de determinar la causa de la termoalteración.

\subsubsection{Estadio de reducción}

Nuestras experimentaciones muestran que el tratamiento térmico de formas base es factible. A temperaturas menores a $400^{\circ}$ las piezas resultaron enteras y pudieron ser subsecuentemente talladas. Desde una aproximación cualitativa-experimental evaluamos la fragilidad de las materias primas frente a los procedimientos técnicos correspondientes a la talla. En tres de las materias primas $(2,4$ y 5$)$ se requirió menor fuerza en la aplicación de las técnicas de talla, para la reducción y formatización lítica.

En el caso de la materia prima 5, nuestras observaciones parecen indicar que el tratamiento térmico de núcleos no era conveniente para esta variedad de sílex, puesto que estas piezas se ven intensamente fragmentadas o bien pierden su fractura concoidea, hecho que ya fuera observado 
por otros investigadores (Cowan 1987). Sin embargo, son necesarias más experimentaciones para poder corroborar esta idea, considerando que se han registrado arqueológicamente núcleos con evidencia de tratamiento térmico, en diferentes contextos, como por ejemplo sitios neolíticos (Terradas y Gibaja 2001), sitios de cazadores recolectores de Norteamérica (Schindler et al. 1982) e incluso de Patagonia (Stadler 2002).

Otra posibilidad que contemplamos, es que las características de los fogones para tratar los núcleos térmicamente difieran de las que son necesarias para tratar las formas base. Mandeville (Mandeville 1973), propone que este procedimiento es más factible de ser exitoso con una pieza fina de sílex que con todo un núcleo ya que en ellas la distribución homogénea del calor es más fácil de lograr. Afirma que los núcleos pueden ser tratados pero deben ser calentados más lentamente y por un mayor período de tiempo. Existen para cada caso un óptimo de temperatura y de duración del tratamiento térmico, más allá de los cuales se produce una recristalización que resulta negativa para la producción lítica (Terradas y Gibaja 2001).

\subsubsection{Uso}

En relación al desarrollo y reconocimiento de micropulidos producto del uso, las experimentaciones indican que en la materia prima 5 , tratada térmicamente y utilizada para el corte y raspado en hueso, la exposición controlada al fuego no habría producido cambios significativos en las microalteraciones funcionales.

En aquellas piezas que desarrollaron microhuellas diagnósticas previas al tratamiento, la aplicación del mismo no impactó de modo negativo alterando, transformando o encubriendo los rastros. En las que fueron utilizadas luego de recibir el tratamiento, los microrrastros se desarrollaron sin inconvenientes, alcanzando la apariencia estándar. Estas observaciones coinciden con lo propuesto por Clemente y Gibaja (Clemente Conte 1997; Gibaja 2002; Gibaja y Clemente 1997), quienes afirman que los micropulidos producto del trabajo sobre materias duras como el hueso, son reconocibles en piezas expuestas a esta técnica.

Asimismo desde la óptica funcional se evidencia una menor resistencia de los filos ante el uso, en la fragilidad de los mismos y la formación de microcicatrices, melladuras y retracción de la arista, con un mayor número en menor tiempo. Rick y Chappell (1983) coinciden con esta apreciación en relación a que la misma disminución de la fuerza de fractura, que facilita la producción de instrumentos, también disminuye la durabilidad del filo. Esto genera expectativas acerca del tipo de artefacto sobre el cual es esperable reconocer esta técnica. Así, no esperamos reconocer este procedimiento en instrumentos destinados a actividades que opongan mucha resistencia 0 desarrolladas sobre materias duras, o bien si se observase en este tipo de instrumentos, sería esperable que muestre mayor evidencia de reactivación. 


\subsubsection{El daño térmico}

En los casos en los que el tratamiento térmico ha resultado fallido, o bien cuando la termoalteración se dio por otras causas, tales como el descarte de piezas en fogones, su caída accidental en estas estructuras o la acción de fogones encendidos en ocupaciones posteriores, se espera que se produzcan más indicadores de daño térmico. La rugosidad y los hoyuelos, junto con el cambio de color serían los indicadores que se presentarían de forma más abundante en las piezas arqueológicas, mientras que las escamaciones, los agrietamientos, el lustre y la pátina serían secundarios. Sin embargo, debemos hacer hincapié en que todas las materias primas responden de manera diversa, presentándose los indicadores en distinta proporción en cada una, teniendo diferente resistencia al calor y fragmentándose de manera distinta.

Es interesante mencionar que no hemos reconocido piezas con craquelado en ninguna de nuestras experiencias. Esto resulta llamativo teniendo en cuenta que es constante su mención en la bibliografía sobre el tema y que inclusive es común reconocerlo en sitios de la región. Creemos que existen dos posibilidades para explicar esto, o bien el proceso para que se forme el craquelado es un proceso particular que no se dio en nuestras experimentaciones (i.e. calentamientos repetidos a bajas temperaturas de una pieza), o bien éste se presenta sólo en determinadas materias primas, no ocurriendo en las que hemos utilizado en esta ocasión. En línea con esta argumentación, observamos que en los conjuntos arqueológicos el craquelado se presenta de manera más habitual en piezas de sílex color blanco o crema.

En cuanto a la forma que toman las piezas fracturadas, hemos visto que estas son difícilmente sistematizables, respondiendo a la naturaleza propia de la materia prima. Son, sin embargo, principalmente fragmentos angulosos.

Respecto a los rangos de temperatura en los cuales comienza a generarse daño térmico observamos una discordancia con otros autores. Terradas y Gibaja (2001) observan los primeros conos de desprendimiento recién a los $350^{\circ} \mathrm{C}$ y la fractura total de la pieza a los 500 o C. Nami et al. (2000) observan daño macroscópico a los $450^{\circ} \mathrm{C}$. Nosotros observamos que algunas piezas han sufrido un daño a $310^{\circ} \mathrm{C}$, coincidiendo con los rangos propuestos por Ariet (1991) para minerales de Santa Cruz. Estas diferencias se pueden atribuir a diversas causas tales como una respuesta diferencial de cada materia prima al calor, distintos ritmos en los cambios de temperaturas y diferencias en los métodos experimentales aplicados, entre otros.

Las piezas más pequeñas de las experimentaciones (tanto las tratadas térmicamente como las descartadas dentro del fogón) exhiben escasas evidencias de daño térmico. Es decir que el tamaño incide en el grado de fractura que tendrá la pieza, hecho que ya fuera señalado por otros autores (Ariet 1991; Mandeville 1973). Por otra parte, si consideramos también que los 
fragmentos corresponden mayoritariamente a los rangos 1 y 2, podemos concluir que los restos líticos termoalterados formarán parte, en su mayoría, de la fracción más pequeña de las piezas recuperadas de los sitios. Allí deberíamos encontrar los restos fracturados por el calor, las esquirlas que estuvieron expuestas al fuego pero que se han mantenido enteras y aquellas que han sido talladas después del tratamiento térmico.

Destacamos estos indicadores se presentan tanto en los restos fragmentados durante el tratamiento térmico como para los que entraron en contacto directo con el fuego. En ambos conjuntos la divergencias en la predominancia de un determinado tipo de rasgo depende más del tipo de materia prima que del contexto de termoalteración. En consecuencia, la identificación de la causa que produjo estos restos dependerá de un análisis contextual del sitio, teniendo en consideración otras variables (i.e. presencia de huesos u otros restos termoalterados, posibilidad de remontaje, entre otras). 


\section{CAPITULO 9: EXPERIMENTACIONES EN TRATAMIENTO TÉRMICO DE ARTEFACTOS ÓSEOS}

En este capítulo presentamos las experimentaciones realizadas sobre tratamiento y alteración térmica de elementos óseos. Si bien no existen suficientes antecedentes referentes al tratamiento térmico de artefactos en hueso en la región patagónica (ver capítulo 7), se ha propuesto, para uno de los sitios en estudio (C3T1) la posibilidad de que esta técnica se hubiera aplicado a los huesos, considerando la presencia de un artefacto retocado con evidencias de termoalteración. Dicho artefacto corresponde a una diáfisis de tibia de guanaco con retoques marginales en uno de sus bordes, sobre la cara externa de la pieza, que presenta un color marrón oscuro y un brillo vítreo característico de los huesos termoalterados (ver capítulo 5). Además, T. Bridges (1998) relata acerca del uso del fuego en la formatización de puntas de proyectil óseas (ver capítulo 4).

De esta manera, hemos procurado, en el caso de los elementos óseos realizar experimentaciones para analizar si es factible su tratamiento térmico en el marco de la producción artefactual. Nos preguntamos si, al igual que con los artefactos líticos, el tratamiento térmico facilita la producción del instrumental.

Por otra parte, la propia metodología empleada nos brinda la oportunidad de aportar información relativa a la alteración térmica de materiales óseos por causas postdepositacionales, esto resulta interesante puesto que, si bien se ha demostrado que es posible, la termoalteración de huesos en contextos subsuperficiales o debajo de ocupaciones posteriores ha sido poco estudiada.

\subsection{Metodología}

En rasgos generales la metodología es similar a la utilizada en las experimentaciones de tratamiento térmico de artefactos líticos. Desarrollaremos aquí principalmente las diferencias en la metodología, remitiendo al lector al capítulo 8 para observar más detalladamente cómo se desarrollaron estos.

La selección de restos óseos se restringió a huesos de guanaco, puesto que este es el taxón más abundante en todos los sitios de la región (Paunero 2000b; Paunero et al. 2005). Recolectamos huesos largos de animales cazados por parte de los pobladores, es decir que para nuestras experimentaciones hemos usado huesos frescos. En un caso utilizamos restos arqueológicos: estos provienen del sitio Cueva del Nido, en la Localidad Arqueológica La María y son asignables al Holoceno Medio (Paunero, com. pers.). Los huesos frescos fueron descarnados y se removió todo el tejido blando que fue posible, quedando aun presente en algunas articulaciones e inserciones. 
Las colecciones experimentales constaron de fragmentos de diáfisis de huesos largos. Los huesos fueron fracturados utilizando un yunque de madera como elemento pasivo y un percutor lítico como elemento activo. Entre las variables de control experimental que registramos se encuentran: las dimensiones de la pieza, el estado (seco, fresco, con carne), el estadio de meteorización, el color, la presencia de agrietamientos y fisuras, la textura, entre otros.

Una vez obtenidos los elementos a utilizar procedimos a retocar parte de estos. El objetivo de esta acción es observar si el tratamiento térmico facilita la talla de los huesos y buscar referentes que permitan indicar en qué momento se realizó el retoque en artefactos termoalterados. Para esto es necesario contar con especímenes retocados antes y después de la exposición al fuego de modo que sea posible comparar los resultados en ambos subconjuntos. De los 28 elementos modernos utilizados, 13 fueron retocados previo a su termoalteración y en 15 esto se realizó $a$ posteriori. En el caso de la experimentación con huesos arqueológicos retocamos todos los huesos antes de su exposición al fuego. Esto se debe a que esperamos que los artefactos se realicen sobre huesos frescos; de esta manera, el objetivo de las experimentaciones con huesos arqueológicos es observar que características adquieren estos y aportar información relevante para reconocer termoalteraciones postdepositacionales. La acción se realizó con un percutor lítico cuyas dimensiones fueron $8,4 \mathrm{~cm} \times 4,8 \times 3,7$.

Tratamos térmicamente los elementos óseos. El procedimiento fue igual al utilizado en los experimentos de tratamiento térmico de artefactos líticos. Las piezas fueron ubicadas con su cara interna mirando hacia abajo y cubiertas por una capa de arena de $5 \mathrm{~cm}$ antes de encender sobre ellas el fuego. Realizamos un total de 6 experimentaciones, alterando un total de 32 elementos óseos, de los cuales 4 son restos arqueológicos asignables al Holoceno Medio (Exp. 3); el resto corresponde a huesos modernos frescos de guanaco (Tabla 9.1). Todos se presentaban en buen estado y con pocas evidencias de meteorización (estadios 0 y 1, Behrensmeyer 1978). El rango de temperaturas máximas (Fig. 9.1) a la que se expuso los materiales (entre $261^{\circ}$ y $312^{\circ} \mathrm{C}$ ) se enmarca dentro de las temperaturas en las cuales los artefactos toman coloraciones marrones y negras (estadios totalmente quemado y parcialmente carbonizado) puesto que estos son los colores que tomó el artefacto retocado del sitio C3T1 (ver capítulo 7). Al retirar las piezas estas se encontraban en la misma posición en que habían sido colocadas originalmente y todas estaban enteras. 


\begin{tabular}{|c|c|c|c|c|c|c|c|c|c|}
\hline Exp. & Fecha & $\mathrm{N}^{\circ}$ & Especie & Hueso & Porción & $\mathrm{L}$ & A & $E$ & Con retoque \\
\hline 1 & 09/08/2007 & 1 & Guanaco & Tibia & Diáfisis & 10 & 2,1 & 1,5 & posterior a To \\
\hline 1 & 09/08/2007 & 2 & Guanaco & Tibia & Diáfisis & 9,1 & 2,4 & 1 & anterior a To \\
\hline 1 & 09/08/2007 & 3 & Guanaco & Metapodio & $\begin{array}{l}\text { Epífisis } \\
\text { distal }\end{array}$ & 11,9 & 2,4 & 2,1 & posterior a To \\
\hline 1 & 09/08/2007 & 4 & Guanaco & Metapodio & $\begin{array}{l}\text { Epífisis } \\
\text { proximal }\end{array}$ & 10,8 & 3,5 & 2,2 & anterior \\
\hline 2 & 26/11/2007 & 5 & Gua & Fém & Epífisis & 10,3 & 3,5 & 1,5 & To \\
\hline 2 & $26 / 11 / 2007$ & 6 & Guanaco & Fémur & Epífisis & 8,3 & 3 & 1,6 & posterior a To \\
\hline 2 & $26 / 11 / 2007$ & 7 & Guanaco & Fémur & Epífisis & 8,2 & 2,8 & 1,1 & rior a To \\
\hline 2 & 26/11/2007 & 8 & Gua & Fémur & Epífisis & 13,2 & 2,9 & 1,3 & r a To \\
\hline 2 & $26 / 11 / 2007$ & 9 & Guanaco & Fémur & Epífisis & 9,9 & 2,8 & 1,2 & or a To \\
\hline 2 & 26/11/2007 & 10 & Guanaco & Fémur & Epífisis & 6,7 & 2,5 & 1 & a To \\
\hline 2 & $26 / 11 / 2007$ & 11 & Guanaco & Fémur & Epífisis & 7,5 & 1,9 & 0,8 & post \\
\hline 3 & $07 / 04 / 2008$ & 12 & Indet & Indet. & Diáfisis & 11 & 2,6 & 1 & G To \\
\hline 3 & 07/04/2008 & 13 & aco & Húmero & Diáfisis & 10,4 & 2,9 & 0,9 & a To \\
\hline 3 & $07 / 04 / 2008$ & 14 & Gua & Metapodio & Diáfisis & 10,3 & 1,7 & 0,9 & a To \\
\hline 3 & 07/04/2008 & 15 & Guanaco & Metapodio & Diáfisis & 8 & 2,3 & 1 & or a To \\
\hline 4 & $23 / 10 / 2008$ & 16 & Guanaco & Tibia & Diáfisis & 11 & 2 & 1,8 & posterior a To \\
\hline 4 & $23 / 10 / 2008$ & 17 & Guanaco & Tibia & Diáfisis & 12 & 2,1 & 1,6 & anterior a To \\
\hline 4 & $23 / 10 / 2008$ & 18 & Guanaco & Tibia & Diáfisis & 14,8 & 4 & 2 & posterior a To \\
\hline 4 & $23 / 10 / 2008$ & 19 & Guanaco & Tibia & Diáfisis & 12,9 & 2,1 & 1,4 & anterior a To \\
\hline 4 & $23 / 10 / 2008$ & 20 & Guanaco & Metapodio & Diafisis & 9,2 & 3 & 1,7 & posterior a To \\
\hline 5 & $30 / 10 / 2008$ & 21 & Guanaco & Fémur & Diáfisis & 6,4 & 2,1 & 0,5 & posterior a To \\
\hline 5 & $30 / 10 / 2008$ & 22 & Guanaco & Fémur & Diáfisis & 10,2 & 2,5 & 1,2 & posterior a To \\
\hline 5 & $30 / 10 / 2008$ & 23 & Guanaco & Fémur & Diáfisis & 11 & 2,9 & 1,7 & anterior a To \\
\hline 5 & $30 / 10 / 2008$ & 24 & Guanaco & Fémur & isis & 18,5 & 2,7 & 1,3 & anterior a To \\
\hline 5 & $30 / 10 / 2008$ & 25 & Guanaco & Fémur & Diáfisis & 7,4 & 3,4 & 1,4 & posterior a To \\
\hline 5 & $30 / 10 / 2008$ & 26 & Guanaco & Fémur & Diáfisis & 6,5 & 2 & 0,4 & anterior a To \\
\hline 6 & 23/01/2009 & 27 & Guanaco & Radioulna & Diáfisis & 15,5 & 1,7 & 1,6 & posterior a To \\
\hline 6 & $23 / 01 / 2009$ & 28 & Guanaco & Radioulna & Diáfisis & 12 & 1,6 & 1,2 & anterior a To \\
\hline 6 & $23 / 01 / 2009$ & 29 & Guanaco & Fémur & Diáfisis & 11 & 2,4 & 2,3 & anterior a To \\
\hline 6 & 23/01/2009 & 30 & Guanaco & Fémur & Diáfisis & 13,2 & 2,6 & 1,1 & posterior a To \\
\hline 6 & 23/01/2009 & 31 & Guanaco & Fémur & Diáfisis & 10,5 & 2,3 & 1 & anterior a To \\
\hline 6 & $23 / 01 / 2009$ & 32 & Guanaco & Fémur & Diáfisis & 8,7 & 2,1 & 0,8 & posterior a To \\
\hline
\end{tabular}

Tabla 9.1. Características de las piezas experimentales.

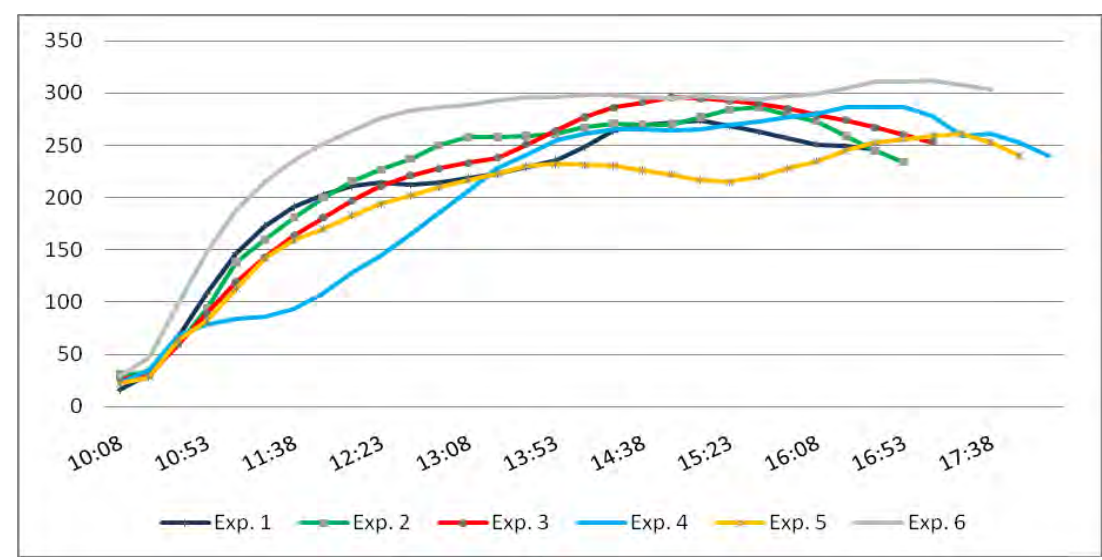

Fig. 9.1. Curvas térmicas de los diversos fogones experimentales.

Una vez retiradas las piezas, procedimos al registro fotográfico en laboratorio, así como a su clasificación siguiendo diversas variables observadas a ojo desnudo y con lupa (10x). Las variables 
consideradas fueron las expuestas en el capítulo 7. Se registró si la pieza se recuperó entera o fragmentada, sus dimensiones, si mostraba cambio de color y de textura, presencia de pátinas y brillos diferenciales, tipo de fracturas presentes, deformación y encogimiento.

Además procedimos a retocar aquellos elementos que no habían sido retocados previo al tratamiento térmico. Medimos la profundidad del retoque y la comparamos con el producido en los elementos sin tratar. También registramos el aspecto del retoque con el fin de observar diferencias entre elementos retocados antes y después del procedimiento pirotecnológico.

\subsection{Resultados}

La tabla 9.2 muestra los resultados para cada pieza. Como podemos observar, la mayor parte ha tomado colores correspondientes a estadios 2 y 3 , es decir, totalmente quemados, o bien parcialmente carbonizados (Tabla 9.3). Esto es consistente con lo esperado para huesos expuestos a temperaturas cercanas a 300 ․ C. También es interesante notar que, en muchas de las piezas, la cara externa del hueso, que había sido ubicada mirando hacia arriba, presenta estadios más avanzados de combustión que la cara interna. Inclusive, en muchas de aquellas piezas en que se consignó el mismo estadio para ambas caras, la cara interna es levemente más clara que la externa. Esto explica la inversión de los resultados entre la cara externa e interna para los estadios 2 y 3.

En cuanto a la textura, la mayor parte de las piezas se pueden agrupar en los estadios 1 y 2 , esto es, de textura ondulante y vítrea respectivamente (Tabla 9.4). Los valores para el estadio 2, que son en este caso mayoritarios, son los esperables para el rango de temperaturas a las que fueron expuestas las piezas. Sin embargo, sorprende el alto porcentaje de piezas correspondientes al estadio 1, puesto que éste es indicativo de temperaturas no mayores a $200^{\circ} \mathrm{C}$. Cabe aclarar que en varias ocasiones fue necesario optar por uno de los dos estadios, puesto que estas piezas mostraban en diferentes sectores diferentes texturas. En estos casos se seleccionó la textura que estaba presente en la mayor parte de la superficie.

Todas las piezas se encontraban enteras al momento de ser recuperadas del fogón. Además, sólo 11 piezas (34,37\%) mostraron fracturas producto de la termoalteración. Esto también es consistente con las temperaturas a las que fueron expuestas las piezas. Observamos grietas longitudinales $\mathrm{y}$, en menor medida, transversales y oblicuas. Estas son habitualmente superficiales, y curvas en mayor proporción, aunque también se han producido grietas rectas (Tabla 9.5). Esto produjo que, al retocar los huesos, aquellos que se partían presentaban planos de fractura principalmente curvos y en algunos casos rectos. Resulta interesante remarcar que una de las piezas arqueológicas provenientes de Cueva del Nido presentó un importante agrietamiento (Fig. 9.2), más ancho y profundo que las grietas que se generaron en los huesos 
frescos. Esta diferencia quizás se deba a que este hueso probablemente tuviera menos colágeno, y en consecuencia la formación de este tipo de agrietamientos anchos y profundos se habría producido con mayor facilidad. Este es, sin embargo, el único elemento arqueológico en el que se presentan fracturas. Por otra parte, no se han observado en la colección experimental otros tipos de fracturas tales como exfoliaciones, fisuras dendríticas ni grietas reticulares. Tampoco hemos observado en ningún caso evidencias de deformación ("warping") ni encogimiento. Ambos son indicadores de temperaturas mayores que a las que estuvieron expuestos nuestros elementos. De esta manera, los resultados están de acuerdo con las expectativas.

\begin{tabular}{|c|c|c|c|c|c|c|c|}
\hline Exp. & $\mathrm{N}^{\circ}$ & $\begin{array}{c}\text { Color Cara } \\
\text { Externa }\end{array}$ & $\begin{array}{c}\text { Color Cara } \\
\text { Interna }\end{array}$ & Borde retocado & Textura & Fracturas & Con retoque \\
\hline 1 & 1 & 2 & 2 & No contrasta & 2 & No & posterior a To \\
\hline 1 & 2 & 3 & 2 & No contrasta & 1 & No & anterior a To \\
\hline 1 & 3 & 3 & 1 & No contrasta & 2 & $\mathrm{Si}$ & posterior a To \\
\hline 1 & 4 & 3 & 1 & Contrasta color & 1 & No & anterior a To \\
\hline 2 & 5 & 3 & 3 & Contrasta color & 1 & No & anterior a To \\
\hline 2 & 6 & 4 & 4 & Contrasta brillo & 2 & $\mathrm{Si}$ & posterior a To \\
\hline 2 & 7 & 4 & 4 & Contrasta brillo & 2 & No & posterior a To \\
\hline 2 & 8 & 3 & 3 & No contrasta & 2 & No & anterior a To \\
\hline 2 & 9 & 5 & 4 & Contrasta brillo & 2 & $\mathrm{Si}$ & posterior a To \\
\hline 2 & 10 & 3 & 3 & No contrasta & 2 & No & anterior a To \\
\hline 2 & 11 & 1 & 1 & Contrasta brillo & 1 & No & posterior a To \\
\hline 3 & 12 & 2 & 1 & Contrasta color & 2 & No & anterior a To \\
\hline 3 & 13 & 2 & 2 & No contrasta & 2 & No & anterior a To \\
\hline 3 & 14 & 2 & 2 & No contrasta & 1 & $\mathrm{Si}$ & anterior a To \\
\hline 3 & 15 & 2 & 2 & Contrasta color & 1 & No & anterior a To \\
\hline 4 & 16 & 3 & 2 & No contrasta & 2 & $\mathrm{Si}$ & posterior a To \\
\hline 4 & 17 & 3 & 3 & Contrasta brillo & 3 & No & anterior a To \\
\hline 4 & 18 & 3 & 3 & Contrasta brillo & 2 & $\mathrm{Si}$ & posterior a To \\
\hline 4 & 19 & 2 & 2 & No contrasta & 2 & $\mathrm{Si}$ & anterior a To \\
\hline 4 & 20 & 2 & 2 & \begin{tabular}{|l|} 
Contrasta color \\
\end{tabular} & 2 & $\mathrm{Si}$ & posterior a To \\
\hline 5 & 21 & 2 & 2 & Contrasta Brillo & 1 & No & posterior a To \\
\hline 5 & 22 & 3 & 3 & Contrasta color & 2 & No & posterior a To \\
\hline 5 & 23 & 3 & 2 & No contrasta & 1 & No & anterior a To \\
\hline 5 & 24 & 3 & 2 & No contrasta & 1 & $\mathrm{Si}$ & anterior a To \\
\hline 5 & 25 & 3 & 3 & No contrasta & 2 & No & posterior a To \\
\hline 5 & 26 & 1 & 1 & No contrasta & 1 & No & anterior a To \\
\hline 6 & 27 & 1 & 1 & No contrasta & 1 & no & posterior a To \\
\hline 6 & 28 & 2 & 2 & Contrasta color & 1 & no & anterior a To \\
\hline 6 & 29 & 4 & 3 & Contrasta brillo & 3 & $\mathrm{Si}$ & anterior a To \\
\hline 6 & 30 & 4 & 3 & $\begin{array}{c}\text { Contrasta brillo } \\
\text { y color }\end{array}$ & 3 & $\mathrm{Si}$ & posterior a To \\
\hline 6 & 31 & 2 & 2 & Contrasta color & 1 & no & anterior a To \\
\hline 6 & 32 & 4 & 4 & Contrasta brillo & 3 & no & posterior a To \\
\hline
\end{tabular}

Tabla 9.2. Resultados observables en las piezas experimentales. 


\begin{tabular}{|c|c|c|}
\hline & Cara Externa & Cara Interna \\
\hline $\mathbf{0}$ & 0 & 0 \\
\hline $\mathbf{1}$ & 9,37 & 18,75 \\
\hline $\mathbf{2}$ & 31,25 & 40,62 \\
\hline $\mathbf{3}$ & 40,62 & 28,12 \\
\hline $\mathbf{4}$ & 15,62 & 12,5 \\
\hline $\mathbf{5}$ & 3,12 & 0 \\
\hline $\mathbf{6}$ & 0 & 0 \\
\hline Total & $100 \%$ & $100 \%$ \\
\hline
\end{tabular}

Tabla 9.3. Porcentaje de piezas según estadio de color para cada cara

\begin{tabular}{|c|c|}
\hline Textura & \% \\
\hline $\mathbf{1}$ & 40,62 \\
\hline $\mathbf{2}$ & 46,87 \\
\hline $\mathbf{3}$ & 12,5 \\
\hline
\end{tabular}

Tabla 9.4. Porcentaje de piezas según estadio de textura.

\begin{tabular}{|c|c|c|}
\hline & Curvas & Rectas \\
\hline Longitudinales & 4 & 4 \\
\hline Oblicuas & 2 & 1 \\
\hline Transversales & 1 & 0 \\
\hline Total & 7 & 5 \\
\hline
\end{tabular}

Tabla 9.5. Presencia de fracturas en elementos experimentales
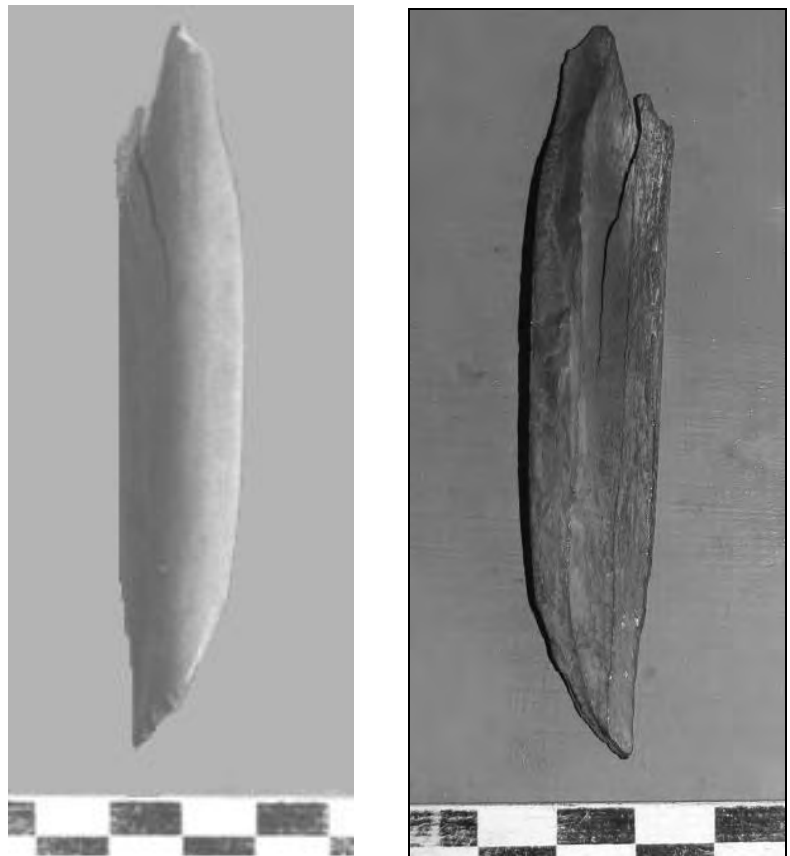

Fig. 9.2. Fogón 3. Pieza 14. Nótese el agrietamiento que va de cara a cara.

Para evaluar si el retoque se ve facilitado por la termoalteración y analizar si las experimentaciones pueden aportar referentes observables para determinar en qué momento fueron retocados los artefactos óseos con evidencias de termoalteración retocamos las piezas experimentales, algunas antes y otras después de exponerlas al calor. Observamos los cambios en color y brillo que se producen en la superficie del retoque, medimos la profundidad de los retoques producidos antes y después de la termoalteración y evaluamos la resistencia de los huesos a los golpes del percutor lítico antes y después de su exposición al fuego. 
Los bordes que habían sido retocados antes de la termoalteración en su mayoría exhiben un aspecto continuo con la superficie original de la pieza (Tabla 9.6). Esto es, no contrastan ni en el brillo ni en el color. Sin embargo, algunas piezas presentan el borde retocado de un color levemente más claro que el resto de la pieza. En dos casos se observan diferencias en brillo entre la zona retocada y sin retocar. En estos casos el área retocada es levemente más brillosa.

En cuanto a las piezas retocadas luego del fogón, un tercio de ellas no muestra diferencias entre la superficie original y la retocada. Por otra parte, algunas de las piezas talladas luego de la exposición al calor, (en particular piezas de los experimentos que obtuvieron los estadios más avanzados con respecto al color) muestran un contraste en el brillo entre ambas zonas. Más precisamente, la zona retocada es más opaca que la superficie original, y no se observa el brillo vítreo presente en el resto de la superficie ósea. En dos casos se observa que el área retocada presenta un color más claro que la superficie original y en un caso existe contraste tanto de color como de brillo.

Realizamos un test de Chi cuadrado para evaluar si existe dependencia entre el momento en que se produjo el retoque y la presencia o no de algún tipo de contraste en su superficie y este ha arrojado diferencias no significativas $\left(X^{2}=4,81 ; p=0,01 ; g . l .=2\right)$, aunque este test debe ser tomado con cuidado puesto que las frecuencias esperadas son bajas. Por otra parte, y si bien los valores son bajos, observamos que los casos de contraste por brillo son diferentes para las piezas con retoque anterior y posterior a la termoalteración. En las primeras, el contraste consiste en que el área retocada presente un brillo levemente más intenso, mientras que en las segundas esta área es más opaca y está acompañada de una textura más rugosa. En ambos casos, estos contrastes de brillo se dieron en piezas que obtuvieron los estadios más avanzados con respecto al color. En consecuencia, este podría ser un referente útil para los casos en que se observa piezas retocadas carbonizadas.

\begin{tabular}{|c|c|c|c|c|}
\hline Retoque & Sin Contraste & Contraste Brillo & Contraste Color & $\begin{array}{c}\text { Contraste } \\
\text { brillo y color }\end{array}$ \\
\hline Anterior a To & 9 & 2 & 6 & 0 \\
\hline Posterior a To & 5 & 7 & 2 & 1 \\
\hline
\end{tabular}

Tabla 9.6. Características del borde retocado.

En cuanto al retoque, los resultados indican que la termoalteración vuelve más frágiles a los huesos. Esto pudo concluirse a partir de las siguientes observaciones:

Menor fuerza necesaria para extraer lascas: De manera cualitativa observamos que la fuerza necesaria para poder tallar los huesos se ve reducida sensiblemente una vez que han estado expuestos al fuego. Esto significa que, para los huesos sin termoalterar, el retoque requería mayor fuerza en el golpe y en consecuencia, implicaba un menor control de los movimientos. 
Menor cantidad de intentos: En concordancia con lo arriba expuesto, los huesos retocados posteriormente a la termoalteración requirieron menor cantidad de golpes. Al retocar los huesos frescos fue necesario repetir la acción varias veces antes de lograr extraer lascas; en cambio en los huesos termoalterados por lo general las lascas se desprendían al primer golpe.

Profundidad: La profundidad promedio del retoque de los huesos retocados previamente a la termoalteración es de 3,74 mm, mientras que en los huesos tallados después del calentamiento es de 4,43 mm. La profundidad máxima de los huesos retocados previamente a la termoalteración es en promedio de 5,53 $\mathrm{mm}$, mientras que la de aquellos tallados después de ser expuestos a fuego es en promedio de $6,38 \mathrm{~mm}$. Si bien se observa que fueron más profundos los retoques en las piezas trabajadas después de ser sujetas a termoalteración, los análisis estadísticos no confirman esta aseveración. Hemos aplicado el test estadístico " $\mathrm{t}$ " de Student para cada caso y se observó que estas diferencias no son significativas ( $\mathrm{t}=1,38$ para la comparación de promedios, $\mathrm{t}=$ 1,16 para la comparación de máximas profundidades; $p=0,01$ y g.l. = 30 para ambos tests).

Fractura durante el retoque: Dos tercios de los huesos retocados después de la termoalteración, al momento del retoque se fracturaron de una manera no deseada, ya sea a lo largo de grietas provocadas por el fuego, ya sea a partir del lugar en que estaba siendo sujetada la pieza. Esto no sucedió en ninguna pieza retocada antes del fogón.

\subsection{Conclusiones}

Las piezas termoalteradas dentro de una matriz sedimentaria a $5 \mathrm{~cm}$ de profundidad muestran rasgos característicos de la exposición al fuego, indicando estadios iniciales de combustión. Nuestras experimentaciones demuestran que los huesos enterrados pueden ser quemados por un fuego encendido sobre ellos. Esto implica que la depositación del hueso y su termoalteración pueden representar eventos no contemporáneos en la formación del sitio arqueológico.

Podemos observar que los huesos termoalterados frescos y arqueológicos presentan características similares en cuanto a color y textura. La mayor parte de ellos mostraron colores asignables a los estadios 2 y 3 , aunque también registramos huesos con estadios 1,4 y 5 . Estos resultados son concordantes con lo propuesto por diversos investigadores para las temperaturas en torno a los $300^{\circ} \mathrm{C}$ que fueron las alcanzadas en estos experimentos (Cain 2005; McCutcheon 1992; Nicholson 1993). Retomando lo expuesto en el capítulo 7, se ha propuesto que en huesos arqueológicos con estos estadios de combustión, sería posible definir qué estado tenía el hueso al momento de la termoalteración. Tanto los huesos secos como aquellos quemados con carne presentarían bandeados de color con contrastes marcados entre distintas zonas del mismo elemento; mientras que los huesos frescos sin carne se verían uniformemente quemados (Buikstra y Swegle 1989). En nuestras experiencias no fue posible diferenciar los huesos 
arqueológicos de los frescos: en ambos se presentan casos con coloraciones homogéneas y otros en que existen leves diferencias de coloración en sectores de la superficie del hueso, no implicando lo dicho contrastes marcados sino que estas diferencias se dan de manera gradual. En síntesis, no observamos al color como un indicador que nos permita diferenciar huesos secos arqueológicos de frescos termoalterados en contextos subsuperficiales, lo cual es coincidente con lo propuesto por Bennett (1999).

Por otra parte, considerando lo propuesto por Cain (2005), observamos que efectivamente en casos en que el hueso se encuentra fracturado previo a la termoalteración el cambio de color se da de manera uniforme a través de las paredes del hueso, pero tal como expresáramos antes, esto no implica que el hueso se encuentre en estado fresco al momento de entrar en combustión. Otra observación relevante en cuanto a huesos fracturados quemados en contextos subsuperficiales es que es posible que se observe en una cara una termoalteración levemente más severa que en la otra. Esto es independiente de si es la cara externa o interna la más afectada y se relaciona con la cercanía a la fuente de calor: la cara más cercana al fuego estará algo más quemada, aunque la diferencia será como máximo entre estadios contiguos.

El estadio 2 de textura es el predominante. Habitualmente se considera que los huesos expuestos a $300^{\circ} \mathrm{C}$ presentarán texturas vítreas, de manera que los resultados concuerdan parcialmente con lo esperado. Sin embargo, existe una alta proporción de elementos que presentan estadio 1 de textura que es representativo de huesos sin quemar o expuestos a temperaturas menores a $200^{\circ} \mathrm{C}$. El problema reside en que los investigadores que han mencionado a la textura como indicador útil de termoalteración no han considerado el proceso de transición entre ambos estadios (Cain 2005; Nicholson 1993). Muchos de los elementos clasificados como Estadio 1 en nuestras experimentaciones en realidad constituyen ejemplos de ese proceso, puesto que presentan sectores localizados donde la textura es vítrea.

Las fracturas producto de la exposición al fuego se produjeron en un tercio del conjunto. Estas se presentan en forma principalmente de grietas longitudinales, seguidas por las oblicuas y las transversales. No se observan, en este sentido, diferencias en los resultados para huesos frescos y arqueológicos, en contraste con lo propuesto por Bennett (1999) quien afirma que no se producen fracturas en huesos arqueológicos producto de la termoalteración. Sin embargo, son aún muy pocas las publicaciones que tratan sobre la termoalteración experimental de huesos arqueológicos y en todos los casos las cantidades utilizadas son escasas, indudablemente debido a que éste es un proceso que afecta a las piezas de manera irreversible. Son sin embargo muy importantes estas experiencias, teniendo en cuenta que el conocimiento que se tiene en la actualidad sobre el tema muestra que los resultados no son necesariamente equiparables a los observados en huesos modernos en sus diversos estados. 
El retoque de los huesos nos permitió corroborar que la termoalteración vuelve más frágiles a los huesos. Esto se evidenció por la menor fuerza necesaria para aplicar el retoque, la menor cantidad de intentos necesarios para extraer lascas y las fracturas producidas por esta acción. Si bien los análisis estadísticos no lo confirman, a esto se podría agregar la mayor profundidad del retoque producido después de la experimentación.

Es decir que sería factible postular la termoalteración intencional de huesos con el fin de facilitar su retoque con fines tecnológicos. Sin embargo la alta tasa de fracturas generada al retocar las piezas termoalteradas nos lleva a pensar que esta técnica no es recomendable para la formatización de artefactos. Existe una alta probabilidad que los huesos con estadios iniciales de combustión se fracturen de manera no deseada durante la producción de instrumental.

Además, los resultados del análisis de las superficies de los negativos de retoque no son concluyentes como para poder diferenciar entre las piezas retocadas antes y después de la exposición al fuego. Aunque parece haber diferencias en las expectativas de contraste de color y brillo entre ambos tipos de piezas, los tests estadísticos indican lo contrario. Sin embargo, a nivel cualitativo observamos que en algunas piezas retocadas antes de su exposición al calor las superficies retocadas se vuelven más brillosas, mientras que en piezas carbonizadas retocadas después del fogón esta superficie es más opaca y de textura rugosa. 


\section{CAPITULO 10: ANALISIS DE LOS CONJUNTOS ARQUEOLÓGICOS}

En este capítulo presentamos los estudios desarrollados sobre los conjuntos arqueológicos; explicitamos la metodología implementada durante la investigación, la escala espacial y temporal de análisis que permite acotar el problema y los resultados obtenidos.

\subsection{Escala espacial y temporal de análisis}

La escala espacial de análisis sobre la que trabajamos es el sitio, considerando su ubicación en el paisaje local. El paisaje local en el cual se ubica el sitio se definió a partir de la delimitación de una unidad analítica basada en información geomorfológica, ambiental, paleoambiental, ecológica o de la estructuración de recursos (Paunero et al. 2005; Skarbun 2009b).

Tomamos en consideración dos rangos temporales: Pleistoceno final y Holoceno temprano. La asignación temporal de los sitios se realizó en base a indicadores cronológicos relativos estratigráficos, geomorfológicos, arqueológicos- y absolutos -fechados radiocarbónicos-. Para el Pleistoceno final los sitios estudiados son: Cerro Tres Tetas (C3T1, Unidad 5), Casa del Minero 1 (CDM1, Unidad 4 y 3 inferior) y Cueva Túnel (CT, Componente Inferior). Para el Holoceno Temprano se consideraron Casa del Minero 1 (CDM1, Unidad 3 medio), La Mesada (LM, Unidad 8) y Cueva de La Ventana (LV, Unidad 6) (Paunero 2000b, 2001, 2004a, 2009b; Paunero et al. 2007d, entre otros).

\subsection{Metodología}

\subsubsection{El estudio de los fogones}

Analizamos la presencia de fogones en los componentes estudiados, considerando su distribución espacial dentro del sitio. Registramos sus características, teniendo en cuenta su morfología, su relación con la superficie de ocupación y si se observan límites definidos en su estructura (LeroiGourhan 1979; Marconetto 2006). Asimismo, registramos sus dimensiones en planta, consideramos su largo máximo y el ancho medido perpendicularmente al largo en el centro de la estructura. Cabe aclarar que nuestro concepto de fogón se basa en lo que observamos en el análisis de fuentes etnohistóricas en el capítulo 4; en este sentido, entendemos al fogón como un área de combustión para la cual es necesario acarrear leña, en contraste con los "fuegos" encendidos directamente sobre matas en pie. No le damos, en este sentido, una connotación de 
funcionalidad, teniendo en cuenta que es probable que cada una de estas estructuras haya tenido más de un uso.

En consecuencia, al ser todos los sitios estudiados cuevas, en las cuales no hay evidencias de desarrollo de suelos, creemos que podemos definir a todas las estructuras de combustión reconocidas en el sitio como fogones.

\subsubsection{Análisis de los conjuntos arqueológicos}

Tanto en el caso de los restos líticos como de los óseos, los estudios se estructuran en base a dos ejes fundamentales, la distribución de las piezas dentro del sitio y su termoalteración. Consideramos ambos ítems de acuerdo a una serie de variables que permiten evaluar por una parte, si existe una distribución diferencial en torno a los fogones y por el otro lado, examinar la causa de la termoalteración.

\subsubsection{Estudio de los restos líticos}

Realizamos los estudios de distribución y alteración térmica segmentando los conjuntos a diferentes niveles. Esto nos permite, en primer lugar, estimar qué grado de alteración térmica tienen los conjuntos líticos estudiados y reconocer qué actividades del pasado, relativas al fuego, intencionales o no, han actuado en su configuración actual. Además, nos ayuda a identificar si se aplicó el tratamiento térmico en artefactos líticos y evaluar en qué etapa del proceso de producción lítica fue utilizada esta técnica. Finalmente, nos da la oportunidad de analizar cómo se distribuyen los restos en relación con las estructuras de combustión.

\subsection{Clasificación}

Realizamos una clasificación del material lítico procedente de estas unidades. Esta consistió en una clasificación tipológica basada en los criterios construidos por nuestro equipo (Frank et al. 2007; Paunero y Castro 2001; Skarbun 2009b; Skarbun et al. 2007), complementados con elementos de la bibliografía específica (Aschero 1975, 1983; Cardich y Flegenheimer 1978; Cardich et al. 1981-82; Orquera y Piana 1986; Paunero y Castro 2001). La tipología lítica, en sentido amplio, investiga los artefactos líticos como individualidades para clasificarlos luego por un sistema de tipos representativos de conjuntos; facilita su interpretación al establecer entre ellos relaciones según sus afinidades, en lo referente a su técnica de fabricación, su morfología y su función (Benito del Rey y Benito Álvarez 1998). Los análisis tecnotipológicos, al registrar variables tecnológicas, permiten el estudio de las distintas técnicas y estrategias que se utilizan durante las 
diversas etapas de la manufactura de los artefactos: la obtención de materia prima, el descortezamiento y la preparación de los núcleos, la talla y extracción de formas base, la formatización final de los artefactos y los filos, su mantenimiento y reactivación. De esta manera se dividen los productos de cada actividad, según criterios tecnomorfológicos. Diferenciamos los grupos en: 1-nódulos y litos no modificados, 2-núcleos, 3-productos de talla y 4- Instrumentos. La clasificación individual de cada pieza de los conjuntos fue volcada a fichas confeccionadas en el programa Excel. Los atributos considerados fueron:

Partes de una pieza (Aschero 1975, 1983)

Caras:

Ventral: o interior. Tiene el bulbo de percusión, el positivo en la separación producida por la fuerza que se transmite.

Dorsal: exterior

Sectores de la pieza:

Sector proximal: parte más cercana al talón,

Sector medio: entre sector proximal y distal

Sector distal: parte más alejada del talón

Sector lateral derecho/izquierdo: siguiendo el eje morfológico

\subsection{Análisis de cada pieza}

La primera diferenciación tipológica se refiere a la segmentación del conjunto en grupos. Se distinguieron en: litos no modificados/nódulos, núcleos, instrumentos y productos de talla.

1. Los nódulos y lascas nodulares son rocas transportables manualmente, que pueden ser rodados como los guijarros de diversas formas; o no rodados como las lajas, clastos o concreciones diversas; o también producto de la fractura intencional de una roca no transportable como un filón, un afloramiento o un bloque (Aschero 1975).

2. Los núcleos son nódulos de los que se han extraído lascas que por su tamaño, forma y técnica de extracción permiten inferir que han sido aprovechadas (Aschero 1975).

3. Los productos de talla son todos aquellos artefactos líticos originados antrópicamente y generados como consecuencia del proceso de reducción de núcleos y de la manufactura y mantenimiento de los instrumentos, mediante presión o percusión (Cardich et al. 1993-1994; Paunero y Castro 2001; Skarbun 2009b; Skarbun et al. 2007).

4. En relación a los instrumentos, en la presente Tesis utilizamos este término para referirnos a todo artefacto que ha sido subsecuentemente formatizado con posterioridad a su extracción 
inicial con el objetivo presunto de ser utilizado. Si bien es necesario desarrollar estudios funcionales de base microscópica para corroborar fehacientemente que un instrumento ha sido utilizado con algún fin, en el caso de los conjuntos líticos que hemos analizado estos sólo fueron realizados por otros investigadores en algunos de los sitios (Cueto et al. 2009; Paunero y Castro 2001). Mantenemos, sin embargo, esta denominación puesto que nos permite una diferenciación útil para los análisis que desarrollamos aquí.

Los instrumentos son segmentados, a su vez, en clase tipológica (Skarbun 2009b) que se refiere a lo que otros autores (Aschero 1975) denominan grupo tipológico y subgrupo tipológico.

Tipos

El tipo para los productos de talla se refiere a la distinción entre potencial forma base (PFB) y potencial filo funcional (PFF), lascas genéricas y fragmentos de talla (Skarbun 2009b).

$P F B$ : Son aquellos elementos con dimensiones suficientes y atributos tecnomorfológicos aptos para el soporte de un instrumento (Paunero y Castro 2001).

PFF: Son los productos de talla que presentan al menos un filo potencialmente funcional (Paunero y Castro 2001). Al caracterizar así estos tipos se plantea la hipótesis de su uso, que debe ser contrastada a través del análisis funcional.

Para todos los grupos, se consideraron en la clasificación determinados atributos comunes, útiles para reconocer la etapa de manufactura, siguiendo el criterio que se maneja en el proyecto marco de esta Tesis (Frank et al. 2007; Paunero y Castro 2001; Skarbun 2009a, b; Skarbun et al. 2007). Tanto a los productos de talla como a los instrumentos se agregó el estadio de reducción y el estado de fragmentación.

Tipo de materia prima: Se refiere a las diferentes materias primas que han sido aprovechadas en la confección de artefactos: sílex, calcedonia, ópalo translúcido, xilópalo, toba, toba silicificada, basalto, obsidiana, riolita e indeterminadas. Para el sílex, la calcedonia y el ópalo translúcido se analiza también la diversidad de colores en los que se ha recuperado cada materia prima.

Dimensiones: Para las medidas de longitud, anchura y espesor se siguieron los lineamientos de Orquera y Piana (1986). Realizamos las mediciones en cm; para la agrupación por tamaño, entendido como la longitud máxima de la pieza, utilizamos las siguientes categorías:

1. $0-0,5 \mathrm{~cm} ; 2.0,6-1,9 \mathrm{~cm} ; 3.2-3,9 \mathrm{~cm} ; 4.4-5,9 \mathrm{~cm} ; 5$. 6 - o más 
Productos de talla

Clase

Lasca (L): productos de talla cuya longitud máxima no supera el valor de dos anchos (Aschero 1975).

Lasca laminar o larga (LL, lamina según Aschero 1975): la longitud es igual o mayor que dos anchos (midiendo la longitud como un segmento de recta transversal al talón y la anchura como otro segmento transversal al de longitud).

Lasca ancha (LA): el ancho es igual o mayor que dos largos (midiendo la longitud como un segmento de recta transversal al talón y la anchura como otro segmento transversal al de longitud).

Microlasca o esquirla (ESQ): lascas con un largo y ancho igual o menor a 0,5 cm.

Lasca triangular (LT): posee talón facetado, negativos de lascados previos convergentes, ausencia de retoque salvo el producido por el uso. El largo de las piezas oscila entre 4 y $7 \mathrm{~cm}$ y su espesor es escaso (Cardich y Paunero 1991-1992).

Laminilla (LAS): Lascas largas de ancho menor a $1 \mathrm{~cm}$.

Lámina (LM, hoja según Aschero 1975): teóricamente son producto de una determinada técnica de talla y presentan longitud apreciable, bordes subparalelos y gran delgadez. En la práctica la longitud relativa y la delgadez no son tan definitorios para diferenciar hojas como lo son el paralelismo de los bordes y las aristas de lascado de la cara dorsal. En Orquera y Piana (1986) se agrega que sobre la cara dorsal muestra dos o más negativos correspondientes a hojas extraídas con anterioridad, con líneas de fuerza y ondas de compresión que indiquen que la percusión que las extrajo fue aplicada en la misma dirección que en el caso de la pieza que se tiene entre manos. Lamina corta (LC): láminas cuyo largo es menor a dos veces el ancho.

Otras características de los productos de talla considerados aquí, siguiendo los lineamientos de Aschero (1975) y Orquera y Piana (1986) son:

Forma del talón: naturales, lisos, lineales, puntiformes, diedros, facetados, preparados.

Bulbo: Difuso, Levemente Espeso, Espeso, Ausente por fractura, Indiferenciado

Ondas de percusión: Diferenciadas, no diferenciadas

Corteza: cantidad de corteza que presenta la pieza: Muy abundante -abarca la totalidad de la cara dorsal y el talón-, Abundante -abarca más del 75\% de la cara dorsal y/o dorso-, Parcial -abarca entre el 75 y $25 \%$ de la cara dorsal y/o dorso-, Escasa -abarca menos del $25 \%$ de la cara dorsal y/o dorso-, No posee. 
Estado de conservación: Entera, Fragmento proximal, Fragmento proximal medio, Fragmento medio, Fragmento medio distal, Fragmento distal, Fragmento lateral, Fragmentos indeterminados.

Otros rasgos considerados son la curvatura, la presencia de labio o estrías.

Estadio de reducción: pasos en la secuencia de producción en la que el elemento fue manufacturado:

- Primera lasca de descortezamiento (según Orquera y Piana 1986, lasca inicial): primera lasca en ser extraída del núcleo. Puede reconocerse en un núcleo más de una primera lasca de descortezamiento según donde se produzcan las extracciones. El talón es inexistente o natural y posee corteza sobre toda la cara dorsal.

- Piezas de descortezamiento: Son aquellas producidas por el descortezamiento del núcleo, presentan grandes placas de corteza conservadas sobre la cara dorsal (Orquera y Piana 1986). El talón puede ser natural, liso, diedro, facetado o preparado.

- Piezas de reactivación del núcleo (Aschero 1975, 1983).

- Piezas de talla y de extracción de formas base; denominadas también, según Orquera y Piana (1986), lascas secundarias o de desbastamiento.

- Piezas de formatización final y reactivación: Son aquellas producidas por el retallado primario, secundario, formatización, conservación y modificación de una pieza - lascas de retalla, de retoque, de adelgazamiento bifacial, de reactivación, indiferenciadas-.

La identificación de cada una de las piezas según el paso en la secuencia de producción se realiza en base a la conjunción de los diferentes atributos (cantidad de corteza, tamaño, talón, bulbo, curvatura, entre otros). La cantidad de corteza y la morfología de la cara dorsal son las características definitorias para distinguir entre piezas producto del descortezamiento, preparación y de la extracción de formas base. Las de formatización final se definen a partir de las características de los talones, bulbo, la presencia del labio y curvatura y el tamaño (Skarbun 2009b).

Además de los atributos arriba mencionados, analizamos los rasgos de alteración térmica presentes en las piezas. Las observaciones se realizaron a ojo desnudo y con lupa (10 x). Siguiendo a Luedtke (1992) y a Gibaja y Clemente (1997), consideramos que el conocimiento de las materias primas utilizadas por un grupo, sumado al desarrollo de programas experimentales y el análisis de los diversos indicadores de termoalteración en el marco de la secuencia de producción de artefactos puede permitirnos, en la mayoría de los casos, distinguir la aplicación del tratamiento térmico en los conjuntos líticos de los sitios. 
La identificación de los rasgos de alteración térmica se basó en la bibliografía existente para esta temática (ver capítulo 6), así como en los patrones experimentales de referencia construidos durante nuestra investigación (ver capítulo 8). Tales rasgos son: hoyuelos, conos de desprendimiento, escamaciones, rugosidad, agrietamientos, craquelado, cambio de color, lustre y pátina. Se registró si estos atributos se presentaban en la cara, la ventral, o en ambas.

Los hoyuelos, los conos de desprendimiento, las escamaciones, la rugosidad, los agrietamientos y el craquelado son considerados indicadores de daño térmico. Ocurren en la superficie externa de la pieza, aunque en algunos casos esta queda totalmente destruida y no se puede reconocer la superficie original. Si bien en algunas oportunidades estas fracturas no impiden que se siga desarrollando posteriormente la talla, en otras la roca se vuelve totalmente inutilizable. Pueden observarse en algunos casos de tratamiento térmico, aunque en baja proporción (ver capítulo 8), puesto que de ser predominantes, el tratamiento térmico habría resultado fallido. Por su parte, el cambio de color, el lustre y la pátina también son alteraciones térmicas pero no conjugan un cambio en las propiedades para la talla por sí mismas. De esta manera, se generan diferentes expectativas de acuerdo al hallazgo de los diversos indicadores en diferentes tipos de restos.

\subsection{Análisis de distribución espacial intrasitio}

A partir de los atributos arriba considerados, realizamos el estudio espacial intrasitio relacionando la distribución de artefactos con la ocurrencia de fogones. Tabulamos la información en relación con la distribución de las piezas en los distintos sectores. Tomamos en cuenta la cantidad de elementos líticos por cuadrícula y la presencia de fogones en cada sector, para analizar los porcentajes de piezas en cuadrículas con fogones y sin ellos, comparando la superficie ocupada por ambos grupos. Esto permite obtener una aproximación relativa de los restos hacia los mismos.

De esta manera, realizamos análisis de distribución por grupo, tamaño, materia prima y, para el caso de los productos de talla, también por estadio de reducción.

\subsection{Alteración térmica}

En relación a los productos alterados térmicamente, consideramos cuatro categorías: Piezas con daño en ambas caras, con daño en la cara dorsal únicamente, con daño en la cara ventral únicamente y sin daño pero con cambios de lustre, color o pátina.

Tabulamos la información y realizamos análisis de termoalteración por grupo, tamaño y materia prima. Para cada materia prima evaluamos, por componente, que porcentaje presentaba 
evidencias de alteración por calor. Para el caso de los productos de talla, también llevamos a cabo análisis por clase y estadio de reducción.

Estudiamos cómo estaban distribuidos los restos alterados térmicamente, según sector y cercanía a fogones. En los casos en que el componente inmediatamente superior al que estaba siendo analizado también presentara estructuras de combustión, cotejamos la distribución de las piezas en relación a dichas estructuras, para evaluar posibles alteraciones postdepositacionales (Unidad 5 de C3T1 y Unidad 4 de CDM1).

En los productos de talla sin daño térmico, también evaluamos, qué tipo de talón y bulbo presentaban $y$, dentro del estadio de formatización final, si correspondían a retoque, retalla, adelgazamiento bifacial o reactivación.

\subsection{Expectativas}

La combinación del estudio del tipo de resto con termoalteración, y la ubicación de estos rasgos en las piezas es relevante para asignar la causalidad de estas alteraciones, y en el caso del tratamiento térmico permite evaluar en qué momento del proceso de confección de los instrumentos este procedimiento pirotecnológico fue llevado a cabo. Para el caso de restos tratados térmicamente, podríamos resumir las expectativas de hallazgo de los diferentes rasgos de la siguiente manera:

Lustre: es esperable encontrar lustre en los negativos de lascado de la pieza tratada originalmente, y en la cara dorsal y ventral de los productos de talla extraídos de ella (con excepción de las primeras lascas extraídas que solo tendrán lustre en su cara ventral).

Color: es factible detectar cambio de color en la roca originalmente expuesta al calor, y en ambas caras de las primeras lascas extraídas de ella.

Pátina: es posible detectar pátina en la pieza originalmente expuesta al calor, y en ambas caras de aquellas inicialmente extraídas de ella.

Daño Térmico: sólo se hallará daño térmico en la cara dorsal en la pieza tratada térmicamente o en lascas extraídas de ella que contengan parte de la superficie original de ésta. No es esperable hallar daño térmico en la cara ventral de piezas tratadas térmicamente excepto si es el elemento originalmente expuesto al fuego (núcleo o forma base).

Por otra parte, cuando se produce daño térmico por causas no relacionadas al tratamiento térmico, las expectativas son distintas. En estos casos, se puede observar daño térmico y cambio de coloración en cualquiera de las dos caras, siendo predominante en la cara que estuvo más cercana a la fuente de calor. El lustre no es esperable excepto en los hoyuelos y en la cara ventral de los conos de desprendimiento. La pátina es posible que esté presente, pero siempre en baja proporción. 


\subsubsection{Estudio de los restos óseos}

Realizamos los estudios de distribución y termoalteración de los restos óseos segmentando los conjuntos a diferentes niveles, lo que permite analizar de qué manera se distribuyen dichos restos en torno a los fogones y evaluar si fueron tratados térmicamente. También nos permite estudiar la alteración térmica postdepositacional de los restos y aportar información relevante para analizar procesos de cocción de alimentos.

En el caso de los restos óseos, la clasificación taxonómica y de partes esqueletarias fue realizada por otros miembros del equipo (Paunero 2000b, 2001; Paunero et al. 2007d, 2008a; Ramos y Paunero 2009). Nuestra tarea en este caso consistió en revisar nuevamente los conjuntos, a fin de registrar las evidencias de alteración por calor, siguiendo los lineamientos propuestos por diversos autores (ver capítulo 7) en conjunción con lo observado por nuestras propias experimentaciones (ver capítulo 9). En unas pocas oportunidades, sin embargo, este nuevo análisis permitió una reclasificación taxonómica, de alguna parte esqueletaria o un reconocimiento de artefactos confeccionados sobre hueso así como la identificación de otras marcas antrópicas o naturales.

Al igual que con los restos líticos, volcamos la clasificación individual de cada pieza a fichas confeccionadas en Excel, registrando los rasgos de alteración térmica presentes en ellas. Esta alteración térmica puede producirse por diferentes procesos, como mencionamos en el capítulo 7. Las observaciones se realizaron a ojo desnudo y con lupa (10x). Siguiendo a Stiner y colaboradores (1995) consideramos que la observación macroscópica es apta para la identificación de los huesos quemados siempre que se realice un análisis contextual adecuado y se descarten otras posibles causas de alteración del hueso que puedan generar modificaciones similares. De esta manera, en los casos en que el análisis macroscópico no resultaba concluyente para considerar que un elemento había estado expuesto al fuego, este no era incluido dentro de dicha categoría.

Los rasgos de termoalteración considerados son: cambio de color, textura, y modificaciones de la superficie (grietas y fracturas trasversales y longitudinales, exfoliaciones, fisuras dendríticas y grietas reticulares, deformación, encogimiento) (Asmussen 2009; Bennett 1999; Buikstra y Swegle 1989; Cain 2005; Costamagno et al. 2002; Hanson y Cain 2007; Hiller et al. 2003; Koon et al. 2003; McCutcheon 1992; Nicholson 1993; Stiner et al. 1995; Théry-Parisot 2002; Ubelaker 2009; Whyte 2001). Registramos si estos atributos se presentaban en la cara externa del hueso; en los casos en que éste se encontraba fracturado se observó si también se veían en la cara interna. En el caso del cambio de coloración y la textura, inspeccionamos si estos cambios se daban de forma uniforme a lo largo de la pieza o bien si se presentaban restringidos en un sector de ella. 


\subsection{Análisis de distribución espacial intrasitio}

A partir de los atributos arriba considerados, junto con la información disponible en cuanto a la asignación taxonómica y de partes esqueletarias, tabulamos la información en relación con la distribución de los restos en los distintos sectores. Tomamos en cuenta la cantidad de piezas óseas por cuadrícula y la presencia de fogones en cada sector, para analizar los porcentajes de restos en cuadrículas con fogones y sin ellos, comparando la superficie ocupada por ambos grupos. Realizamos análisis de distribución por taxón. Para los camélidos, que son en todos los casos los más abundantes, analizamos también la distribución diferenciando entre esqueleto axial y apendicular. También llevamos a cabo análisis de distribución según tamaño.

\subsection{Alteración térmica}

En relación a los restos óseos alterados térmicamente, estudiamos la cantidad de elementos que presentaban estas evidencias, considerando la presencia de cambios de color, textura y fracturas. Tabulamos la información y se realizaron análisis de termoalteración por taxón.

Estudiamos como estaban distribuidos los restos modificados por el fuego, según sector y cercanía a fogones. En los casos en que el componente inmediatamente superior al que estaba siendo analizado también presentara estructuras de combustión, cotejamos la distribución de las piezas en relación a ellas, para evaluar posibles alteraciones postdepositacionales. También estudiamos el porcentaje de restos termoalterados por cuadrícula. Consideramos la presencia de artefactos y lascas óseas modificados por el calor.

\subsection{Expectativas}

La combinación del estudio del tipo de resto con termoalteración, sus características y la ubicación de alteraciones en las piezas es relevante para asignar la causalidad y el estado del hueso al momento de la termoalteración. Podríamos resumir las expectativas de hallazgo de rasgos de alteración térmica de la siguiente manera:

Los huesos con carne calcinados mostrarán deformación, grietas superficiales en las epífisis de los huesos largos, agrietamientos diagonales, fracturas transversales y fracturas longitudinales de textura rugosa; así como colores blancos, grises y azulados en toda su superficie. En aquellos que no estén totalmente calcinados, se observará diversidad de colores en diferentes sectores del hueso, indicando la aislación que produce la carne de ciertas porciones del hueso. 
Los huesos frescos calcinados muestran, grietas superficiales y fracturas dentadas en las epífisis de los huesos largos, fracturas rectas longitudinales y colores blancos, grises y azulados en toda su superficie. Menor cantidad de grietas y deformación menos marcada que en los huesos sin carne en estado calcinado.

Los huesos en estado seco que resulten calcinados exhibirán cuarteaduras, fisuras y fracturas longitudinales y ausencia de deformación. Además, los huesos secos muestran cambios hacia colores blancos o grisáceos sólo en sectores internos, teniendo en el exterior tonos marrones.

En cuanto a si el hueso se encontraba entero o fragmentado al momento de la termoalteración, se espera que para los elementos completos, el quemado se presente bandeado y de forma más severa en la cara exterior; mientras que para los huesos fracturados, se observará alteración térmica tanto en la cara externa como interna, pudiendo ésta presentar estadios mayores.

En relación a la causa por la que el hueso entro en contacto con el fuego, se espera que:

En casos de cocción de carne con hueso, se observa bajos valores de termoalteración. Esta se dará preferentemente en los extremos articulares, observándose calcinación de ciertas partes y ausencia de cualquier signo de combustión en otras.

En cuanto al descarte de huesos en los fogones, es esperable que al menos parte de la muestra presente evidencias de calcinación. Los huesos quemados deberían encontrarse principalmente dentro de los fogones o en su periferia.

Las cremaciones de cuerpos también dejan principalmente los huesos en estado de calcinación; presentado otras evidencias como deformación, fracturas transversas curvilíneas, fisuras dendríticas y grietas en reticulado.

Para termoalteraciones en contextos subsuperficiales se espera que los huesos con evidencias de combustión presenten una coloración relativamente homogénea a lo largo de su superficie. Los huesos enterrados expuestos al calor llegarían al estado de calcinación sólo en los casos en que estén muy cerca de la fuente de combustión, a no más de $5 \mathrm{~cm}$ de profundidad. Además de los cambios en la coloración, los huesos termoalterados en contextos subsuperficiales pueden mostrar fragmentación longitudinal y deformación estructural, aunque escasa.

En cuanto al tratamiento térmico de artefactos óseos, se espera que presenten textura ondulante o vítrea y color marrón oscuro o gris que se presentan de manera homogénea en toda la pieza. Como consecuencia del aumento de fragilidad del hueso producto de la termoalteración, los artefactos deberían encontrarse mayormente fracturados. 


\subsection{Resultados}

10.3.1. Sitio Cueva 1 de Cerro Tres Tetas

\subsubsection{Unidad 5}

\subsection{Fogones}

Se registraron 4 fogones hacia el interior de la cueva. Se ubican en las cuadrículas C1/E2, D1, G2/G1 y G2/H1 respectivamente (ver Fig. 5.2). Todos son de estructura plana. En cuanto a sus dimensiones, dos son de aproximadamente $60 \times 40 \mathrm{~cm}$, otro es mucho mayor y finalmente del cuarto se desconoce su dimensión total por no estar completamente excavado (Cuadro 10.1 y Fig. 10.1).

\begin{tabular}{|c|c|c|}
\hline Ubicación & Eje mayor & Eje menor \\
\hline C1 - E2 & 120 & 60 \\
\hline D1 & 60 & 8 \\
\hline G2 - G1 & 59 & 40 \\
\hline G2 - H1 & 65 & 40 \\
\hline
\end{tabular}

Cuadro 10.1. Dimensiones de los fogones en $\mathrm{cm}$. C3T1. Unidad 5

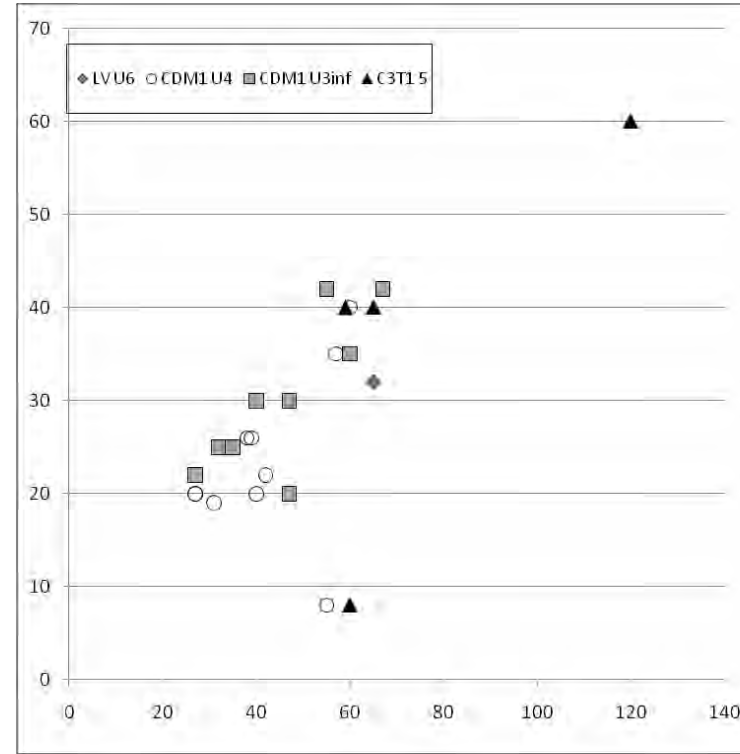

Fig. 10.1. Dimensiones de los fogones de todos los componentes considerados (en $\mathrm{cm}$ ). Referencias: triángulos: C3T1; círculos: CDM1 U4; cuadrados: CDM1 3inf.; rombo: LV U6. 


\subsection{Distribución en planta de los restos}

En referencia al conjunto lítico, el $42 \%$ de las piezas se encuentra en tres cuadrículas que no presentan fogones $\left(3 \mathrm{~m}^{2}\right)$, mientras que el $58 \%$ restante se ubica en ocho sectores que cuentan con evidencias de estas estructuras de combustión (6,7 $\mathrm{m}^{2}$ aproximadamente). Una cuadrícula (C2) presenta únicamente un resto. Cabe considerar que a las 510 piezas que fueron publicadas originalmente, se agregaron cuatro productos de talla, conformando un total de 514 .

Existen dos focos donde se concentran los restos. Uno está constituido por las cuadrículas A y B1, donde se presenta el $40,66 \%$ de los restos (Tabla 10.1). Este sector no cuenta con fogones. El otro foco está conformado por G2 y H1, que en conjunto agrupan el 30,35\% de los restos. Este sector cuenta con 2 fogones.

Son abundantes las piezas de diversos tamaños en ambos focos (Fig. 10.2), y en ambos son predominantes las mismas materias primas (sílex gris, marrón y rojo, calcedonia y xilópalo), aunque en el sector de G2 y H1 también se presentan abundantes elementos de toba silicificada (Tabla 10.2). Ambas zonas presentan además una marcada predominancia de productos de talla correspondientes al estadio 3 de formatización final (Fig. 10.3).

\begin{tabular}{|c|c|c|c|c|c|c|c|c|c|c|c|c|c|}
\hline Grupo & A & B1 & B2 & C2 & D1 & D2 & E1 & E2a & E2b & G1 & G2 & H1 & Total \\
\hline I & 5 & 6 & 3 & 1 & 2 & 1 & 2 & 1 & 1 & 4 & 3 & 2 & 31 \\
\hline Núcleo & 1 & 0 & 0 & 0 & 0 & 0 & 0 & 0 & 0 & 0 & 3 & 1 & 5 \\
\hline XT & 154 & 43 & 26 & 0 & 14 & 5 & 14 & 16 & 26 & 33 & 66 & 81 & 478 \\
\hline Total & 160 & 49 & 29 & 1 & 16 & 6 & 16 & 17 & 27 & 37 & 72 & 84 & 514 \\
\hline \% & 31,13 & 9,53 & 5,64 & 0,19 & 3,11 & 1,17 & 3,11 & 3,31 & 5,25 & 7,2 & 14,01 & 16,34 & 100 \\
\hline 1
\end{tabular}

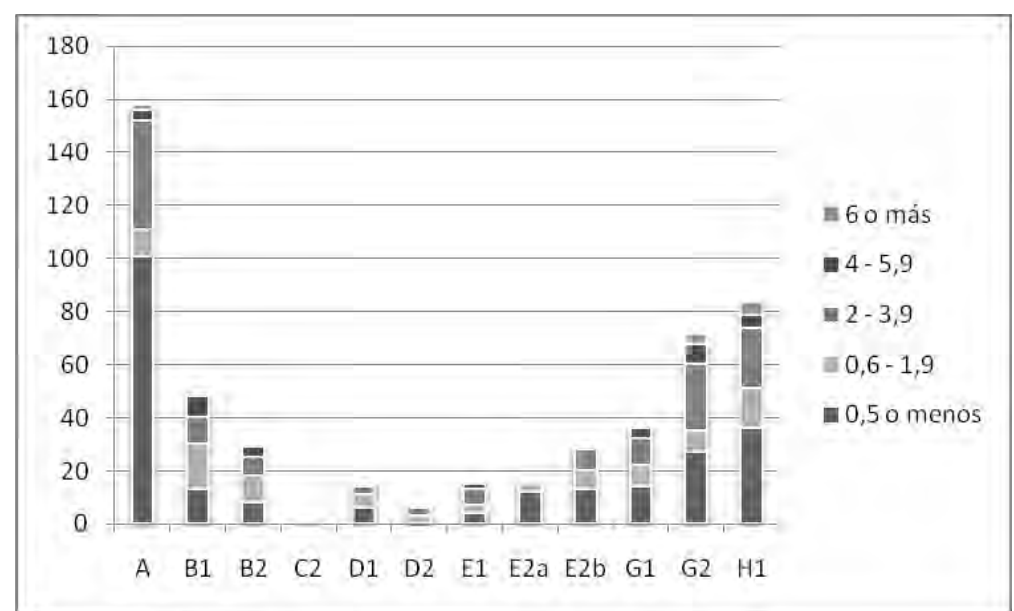

Fig. 10.2. Dimensión máxima en cm. de artefactos líticos por cuadrícula. C3T1. Unidad 5. 


\begin{tabular}{|c|c|c|c|c|c|c|c|c|c|c|c|c|c|c|}
\hline Materia Prima & Color & A & B1 & B2 & C2 & D1 & D2 & E1 & E2a & $E 2 b$ & G1 & G2 & H1 & Total \\
\hline Calcedonia & & 10 & 4 & \begin{tabular}{|l|}
2 \\
\end{tabular} & 0 & 2 & 0 & 1 & 1 & 2 & 3 & 15 & 12 & 52 \\
\hline Indet. & & 20 & 15 & 8 & 0 & 2 & 1 & 2 & 6 & 1 & 3 & 8 & 15 & 81 \\
\hline Obsidiana & & 6 & 1 & 3 & 0 & 0 & 0 & 0 & 0 & 0 & 0 & 0 & 0 & 10 \\
\hline Riolita & & 0 & 0 & 0 & 1 & 0 & 0 & 0 & 0 & 0 & 0 & 0 & 0 & 1 \\
\hline \multirow{9}{*}{ Sílex } & Amarillo & 5 & 0 & 0 & 0 & 0 & 0 & 5 & 0 & 1 & 0 & 1 & 0 & 12 \\
\hline & Gris & 27 & 8 & 7 & 0 & 1 & 2 & 3 & 3 & 5 & 5 & 18 & 8 & 87 \\
\hline & Otros & 1 & 2 & 3 & 0 & 4 & 2 & 2 & 0 & 0 & 1 & 3 & 1 & 19 \\
\hline & Marrón & 33 & 6 & 2 & 0 & 2 & 0 & 1 & 3 & 4 & 0 & 11 & 11 & 73 \\
\hline & Ocre & 9 & 0 & 0 & 0 & 0 & 0 & 0 & 0 & 0 & 0 & 4 & 0 & 13 \\
\hline & Oscuro & 10 & 0 & 0 & 0 & 0 & 0 & 0 & 0 & 0 & 3 & 1 & 0 & 14 \\
\hline & Rojo & 7 & 9 & 3 & 0 & 4 & 0 & 0 & 4 & 9 & 12 & 4 & 7 & 59 \\
\hline & Rosado & 6 & 1 & 0 & 0 & 0 & 0 & 0 & 0 & 1 & 1 & 0 & 2 & 11 \\
\hline & Verde & 9 & 1 & 1 & 0 & 1 & 0 & 0 & 0 & 4 & 0 & 1 & 0 & 17 \\
\hline Toba Silicificada & & 3 & 1 & 0 & 0 & 0 & 0 & 2 & 0 & 1 & 8 & 6 & 8 & 29 \\
\hline Xilópalo & & 12 & 1 & 0 & 0 & 0 & 1 & 0 & 0 & 0 & 1 & 1 & 20 & 36 \\
\hline Total & & 158 & 49 & 29 & 1 & 16 & 6 & 16 & 17 & 28 & 37 & 73 & 84 & 514 \\
\hline
\end{tabular}

Tabla 10.2. Materia prima de de artefactos líticos por cuadrícula. C3T1. Unidad 5.

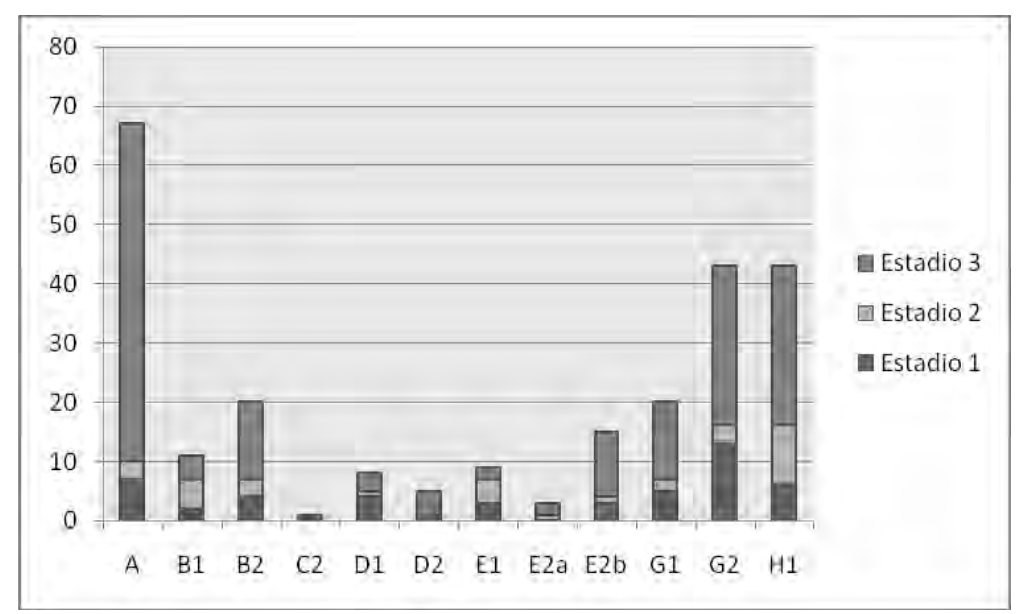

Fig. 10.3. Estadio de reducción de productos de talla por cuadrícula. С3T1. Unidad 5.

En referencia al conjunto óseo, el $11,3 \%$ de las piezas se encuentra en dos cuadrículas que no presentan fogones $\left(2,3 \mathrm{~m}^{2}\right)$, mientras que el $88,7 \%$ de las piezas se ubica en tres, que cuentan con evidencias de estas estructuras de combustión (3,9 $\mathrm{m}^{2}$ aproximadamente).

Si bien los restos óseos son escasos, la distribución difiere de la de los líticos, concentrándose en B2 (73,6\%) (ver Tabla 5.1). Estos corresponden principalmente a elementos indeterminados. En cuanto a los determinados, en B2 sólo se ha recuperado una tibia retocada de Lama guanicoe y una vértebra de mamífero, mientras que en $\mathrm{C} 2$, con un número mucho menor de huesos excavados (15) se ha registrado 6 restos de guanaco (un molar, dos vértebras, un cuneiforme, un metapodio y una falange).

La mayoría de los restos recuperados $(71,8 \%)$ es menor a dos cm (Fig. 10.4). Esto se ve determinado especialmente por el tamaño de los elementos de la cuadrícula B2, donde cinco de 
estos fragmentos, correspondientes a diáfisis indeterminadas pudieron ser remontados. Por el contrario, en $\mathrm{C} 2$ el $53,3 \%$ es mayor a dos $\mathrm{cm}$.

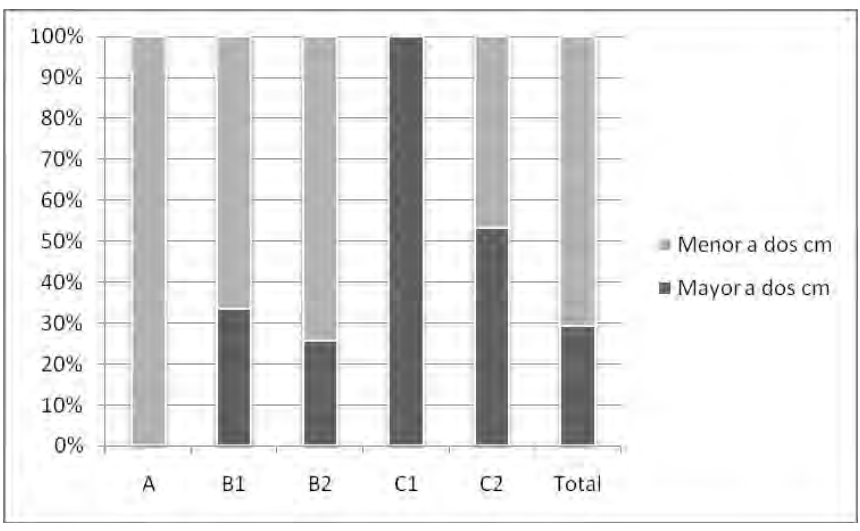

Fig. 10.4. Tamaño de los restos óseos por cuadrícula. C3T1. Unidad 5.

\section{$\underline{10.3 .1 .1 .3 . ~ M a t e r i a l ~ l i ́ t i c o ~ a l t e r a d o ~ t e ́ r m i c a m e n t e ~}$}

En cuanto a las piezas con alteración térmica (107), representan el 20,8\% del conjunto. De estas, 56 muestran evidencias de daño térmico y 51 tienen únicamente cambios de color, lustre o pátina. El 93,5\% de los elementos termoalterados son productos de talla, los restantes corresponden a instrumentos (Tabla 10.3).

Entre los productos de talla predominan las lascas (35\%), luego le siguen los fragmentos de talla, las esquirlas y las lascas anchas $(25 \%, 16 \%$ y $11 \%$ respectivamente) (Tabla 10.4$)$. De los productos de talla a los cuales se les pudo identificar un estadio dentro de la secuencia de producción, el $66,7 \%$ fueron generados durante la formatización final de artefactos, mientras que el 17,3\% por el descortezamiento y el $16 \%$ por la talla (Tabla 10.5 ).

El $84,1 \%$ de las piezas presentan una dimensión máxima de entre 0,1 y 3,9 cm (el 49,5\% entre 2 y $3,9 \mathrm{~cm}, 19,6 \%$ entre 0,6 y $2 \mathrm{~cm}$ y el $15 \%$ menor a $0,5 \mathrm{~cm}$ ) (Tabla 10.6).

Los restos con alteración térmica son principalmente de sílex $(72,9 \%)$, en especial de color gris y marrón. Se observan también piezas de calcedonia (10,3\%), toba silicificada $(9,3 \%)$ y xilópalo $(4,7 \%)$ (Tabla 10.7). La figura 10.5 muestra que son el sílex rosado y gris, junto con la toba silicificada las materias primas que presentan mayor índice de termoalteración. Se ubican en diversos sectores del espacio (Tabla 10.8), aunque predominantemente en A (25,5\%) y G2 (17\%). La figura 10.6 muestra que, mientras que las piezas dañadas, con pátina o cambio de color procedentes de $\mathrm{G} 2$ y cuadrículas circundantes se ubican en torno a estructuras de combustión, no sucede lo mismo con aquellas ubicadas en A y B1. Estas, sin embargo, sí cuentan con fogones en la unidad 4, inmediatamente sobreyacente. 


\begin{tabular}{|c|c|c|c|c|}
\hline Daño dorsal & Daño ventral & $\mathbf{I}$ & $\mathbf{X T}$ & Total \\
\hline \multirow{2}{*}{ No } & No & 3 & 48 & 51 \\
\cline { 2 - 5 } & Si & 0 & 10 & 10 \\
\hline \multirow{2}{*}{ Si } & No & 1 & 11 & 12 \\
\cline { 2 - 5 } & Si & 3 & 31 & 34 \\
\hline Total & & 7 & 100 & 107 \\
\hline
\end{tabular}

Tabla 10.3. Piezas con alteración térmica por grupo. C3T1. Unidad 5. No= Sin daño térmico pero con alteraciones del tipo lustre, color y pátina.

\begin{tabular}{|c|c|c|c|c|c|c|c|c|c|}
\hline $\begin{array}{c}\text { Daño } \\
\text { dorsal }\end{array}$ & $\begin{array}{c}\text { Daño } \\
\text { ventral }\end{array}$ & FT & ESQ & L & LA & LAM & LAS & LL & Tot. \\
\hline \multirow{2}{*}{ No } & No & 10 & 5 & 20 & 5 & 3 & 1 & 4 & 48 \\
\cline { 2 - 10 } & $\mathbf{S i}$ & 2 & 4 & 0 & 3 & 1 & 0 & 0 & 10 \\
\hline \multirow{2}{*}{$\mathrm{Si}$} & $\mathbf{N o}$ & 4 & 3 & 3 & 0 & 0 & 0 & 1 & 11 \\
\cline { 2 - 9 } & $\mathbf{S i}$ & 9 & 4 & 12 & 3 & 1 & 0 & 2 & 31 \\
\hline \multirow{2}{*}{ Total } & & 25 & 16 & 35 & 11 & 5 & 1 & 7 & 100 \\
\hline
\end{tabular}

Tabla 10.4. Productos de talla con alteración térmica por clase. С3T1. Unidad 5.

\begin{tabular}{|c|c|c|c|c|c|}
\hline $\begin{array}{c}\text { Daño } \\
\text { dorsal }\end{array}$ & $\begin{array}{c}\text { Daño } \\
\text { ventral }\end{array}$ & $\mathbf{1}$ & $\mathbf{2}$ & $\mathbf{3}$ & Tot. \\
\hline \multirow{2}{*}{ No } & No & 6 & 4 & 29 & 39 \\
\cline { 2 - 6 } & $\mathbf{S i}$ & 1 & 4 & 1 & 6 \\
\hline \multirow{2}{*}{$\mathrm{Si}$} & $\mathbf{N o}$ & 3 & 0 & 4 & 7 \\
\cline { 2 - 6 } & $\mathrm{Si}$ & 3 & 4 & 16 & 23 \\
\hline Total & & 13 & 12 & 50 & 75 \\
\hline
\end{tabular}

Tabla 10.5. Productos de talla con alteración térmica por estadio. С3T1. U. 5

\begin{tabular}{|c|c|c|c|c|c|c|c|}
\hline $\begin{array}{c}\text { Daño } \\
\text { dorsal }\end{array}$ & $\begin{array}{c}\text { Daño } \\
\text { ventral }\end{array}$ & $\begin{array}{c}\mathbf{0 , 5} \mathbf{0} \\
\text { menos }\end{array}$ & $\mathbf{0 , 6}-\mathbf{1 , 9}$ & $\mathbf{2}-\mathbf{3 , 9}$ & $\mathbf{4 - 5 , 9}$ & $\mathbf{6}$ o más & Total \\
\hline \multirow{2}{*}{ No } & $\mathbf{N o}$ & 5 & 9 & 27 & 8 & 2 & 51 \\
\cline { 2 - 8 } & $\mathbf{S i}$ & 4 & 1 & 5 & 0 & 0 & 10 \\
\hline \multirow{2}{*}{$\mathrm{Si}$} & $\mathbf{N o}$ & 3 & 3 & 6 & 0 & 0 & 12 \\
\cline { 2 - 8 } & $\mathbf{S i}$ & 4 & 8 & 15 & 5 & 2 & 34 \\
\hline Total & & 16 & 21 & 53 & 13 & 4 & 107 \\
\hline
\end{tabular}

Tabla 10.6. Piezas con alteración térmica por dimensión máxima. . C3T1. Unidad 5.

\begin{tabular}{|c|c|c|c|c|c|c|c|c|c|c|c|c|}
\hline \multirow{2}{*}{$\begin{array}{l}\text { Daño } \\
\text { dorsal }\end{array}$} & \multirow{2}{*}{$\begin{array}{c}\text { Daño } \\
\text { ventral }\end{array}$} & \multirow{2}{*}{ Calc. } & \multirow{2}{*}{ Indet. } & \multicolumn{6}{|c|}{ Sílex } & \multirow{2}{*}{$\begin{array}{c}\text { Toba } \\
\text { Sil. }\end{array}$} & \multirow{2}{*}{ Xil. } & \multirow{2}{*}{ Total } \\
\hline & & & & Gris & Marrón & Rojo & Rosado & Verde & Otros & & & \\
\hline \multirow{2}{*}{ No } & No & 9 & 0 & 13 & 6 & 4 & 1 & 4 & 7 & 4 & 3 & 50 \\
\hline & Si & 0 & 0 & 3 & 2 & 1 & 1 & 0 & 0 & 3 & 0 & 10 \\
\hline \multirow{2}{*}{ Si } & No & 0 & 1 & 2 & 1 & 3 & 3 & 0 & 1 & 1 & 0 & 12 \\
\hline & Si & 2 & 2 & 15 & 4 & 2 & 3 & 0 & 2 & 2 & 2 & 34 \\
\hline Total & & 11 & 3 & 33 & 13 & 10 & 8 & 4 & 10 & 10 & 5 & 107 \\
\hline
\end{tabular}

Tabla 10.7 Piezas con alteración térmica por materia prima. C3T1. Unidad 5. Calc. = Calcedonia. Sil. = Silicificada. Xil. $=$ Xilópalo 


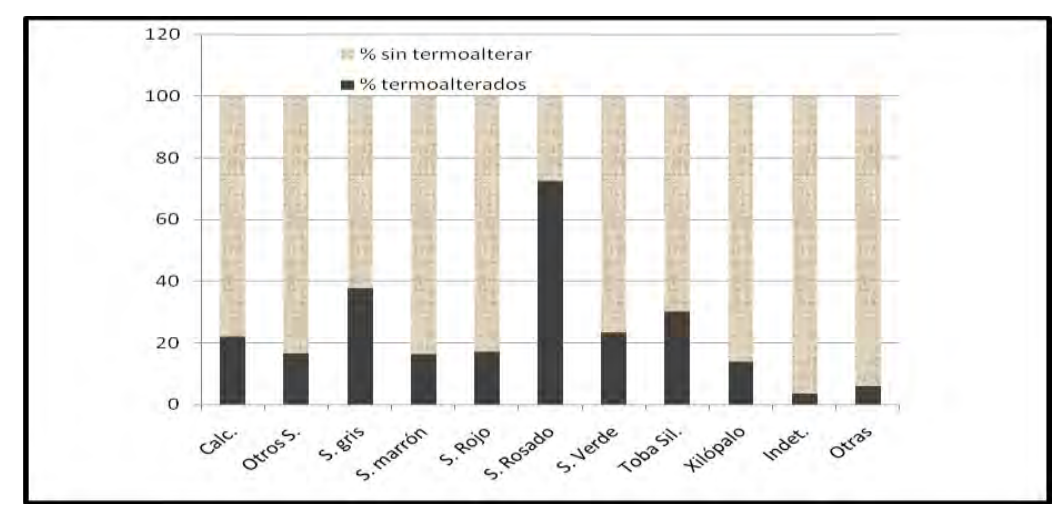

Fig. 10.5. \% de piezas termoalteradas por materia prima. C3T1. Unidad 5.

\begin{tabular}{|c|c|c|c|c|c|c|c|c|c|c|c|c|c|}
\hline $\begin{array}{l}\text { Daño } \\
\text { dorsal }\end{array}$ & $\begin{array}{l}\text { Daño } \\
\text { ventral }\end{array}$ & A & B1 & B2 & C2 & D1 & D2 & E1 & $E 2 b$ & G1 & G2 & H1 & Total \\
\hline \multirow{2}{*}{ No } & No & 17 & 2 & 4 & 1 & 1 & 1 & 2 & 4 & 2 & 10 & 7 & 51 \\
\hline & Si & 0 & 0 & 0 & 0 & 1 & 0 & 0 & 5 & 1 & 0 & 3 & 10 \\
\hline & No & 2 & 2 & 3 & 0 & 0 & 0 & 0 & 3 & 1 & 0 & 1 & 12 \\
\hline & Si & 8 & 8 & 0 & 0 & 1 & 0 & 0 & 1 & 4 & 8 & 4 & 34 \\
\hline Total & & 27 & 12 & 7 & 1 & 3 & 1 & 2 & 13 & 8 & 18 & 15 & 107 \\
\hline
\end{tabular}

Tabla 10.8. Piezas con alteración térmica por sector. C3T1. Unidad 5.

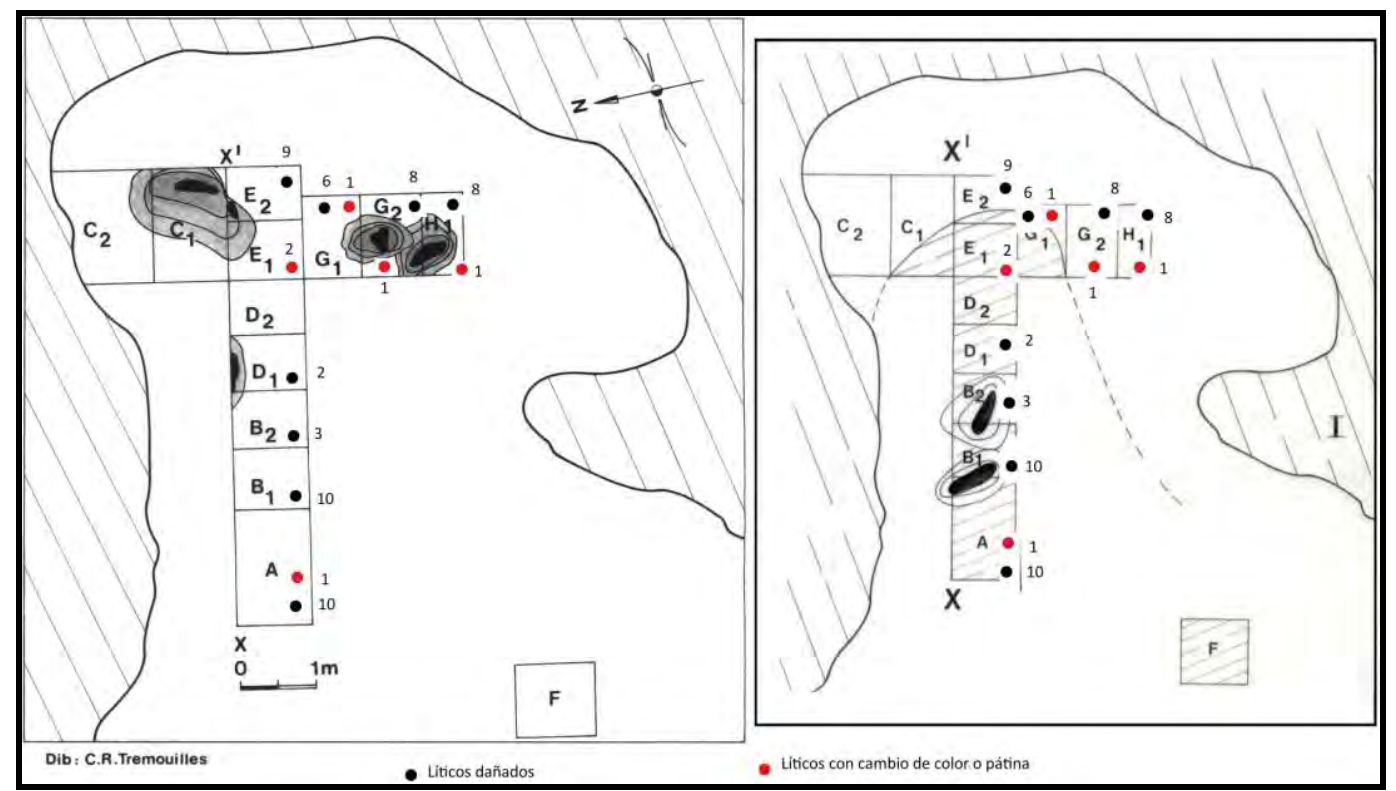

Fig. 10.6. Ubicación de los restos líticos dañados térmicamente, con cambio de color o pátina de la unidad 5 en relación a los fogones de esa unidad (izq.) y de la unidad 4 (der.). C3T1.

10.3.1.1.3.1. Piezas con daño térmico

Las piezas con daño térmico se distribuyen en los siguientes grupos: 12 con daño únicamente en la cara dorsal, 10 con daño únicamente en la cara ventral y 34 con daño en ambas caras. 
De las piezas con daño térmico en ambas caras, tres corresponden a instrumentos. De estos, dos (una raedera de sílex gris y un raspador de sílex marrón) presentan daño intenso, pátina y cambio de color. El otro instrumento es una preforma bifacial de sílex gris, con escamaciones y lustre. Los primeros dos instrumentos, proceden de B1 y presentan daño en los negativos de retoque. La preforma bifacial, procede de $\mathrm{A}$, y muestra escamaciones en sectores diferentes a los negativos lustrosos.

Las otras 31 piezas corresponden a productos de talla. De estas, el 41,9\% es de sílex gris, el 9,7\% es de sílex marrón y el $9,7 \%$ de sílex rosado (Tabla 10.7$)$. Son en su mayoría lascas (38,7\%) y hay una cantidad considerable de fragmentos de talla (29\%) (Tabla 10.4). Corresponden principalmente al estadio 3 (formatización final - 69,6\%), mientras que hay escasas piezas de los estadios 1 y 2 (descortezamiento - 13\% y talla - 17,4\% respectivamente) (Tabla 10.5).

El 79,4\% de estos elementos mide menos de $4 \mathrm{~cm}$ (Tabla 10.6). Se ubican predominantemente en A, B1 y G2 (cada una con el 23,5\%) (Tabla 10.8). Cabe destacar que A y B1 son adyacentes.

10.3.1.1.3.1.2. Piezas con daño en cara dorsal

Se trata de 11 productos de talla y un instrumento. Este último corresponde a una raedera de sílex rojo con hoyuelos en su cara dorsal y pátina en toda su superficie, recuperado de la cuadrícula A. $25 \%$ de los productos de talla es de sílex rojo, y otro $25 \%$ es de sílex rosado (Tabla 10.7). Son predominantemente fragmentos de talla (36,4\%) (Tabla 10.4). Corresponden principalmente al estadio $3(57,1 \%)$, presentándose también piezas del estadio 1 (42,9\%). No se observan piezas del estadio 2 (Tabla 10.5). Todas las piezas dañadas en la cara dorsal miden menos de $4 \mathrm{~cm}$ (Tabla 10.6). Se ubican predominantemente en B2 y E2b (cada una con el 25\%) (Tabla 10.8).

En cinco casos, además de daño térmico en la cara dorsal, se observa en la cara ventral cambio de color o lustre. Dos de estas lascas corresponden al estadio 3, y presentan lustre. Las otras tres muestran cambio de color en la cara ventral. Además, dos de los productos de talla presentan pátina en la cara ventral.

10.3.1.1.3.1.3. Piezas con daño en cara ventral

Se trata de 10 productos de talla, un 33,3\% es de sílex gris, y otro $33,3 \%$ de toba silicificada (Tabla 10.7). Son predominantemente esquirlas (40\%) (Tabla 10.4) que pertenecen en su mayoría al 
estadio 2 (66,6\%) (Tabla 10.5). Todas las piezas miden menos de $4 \mathrm{~cm}$ (Tabla 10.6). Se ubican principalmente en la cuadrícula E2b (50\%) (Tabla 10.8).

10.3.1.1.3.2. Piezas con alteración térmica pero sin daño

Hay 51 piezas que muestran evidencias de alteración térmica pero que no han sufrido daños. Es decir, solo presentan pátina, lustre o cambio de color. De estas, tres son instrumentos y 48 son productos de talla.

Los tres instrumentos son una preforma bifacial de sílex gris, un bifaz de sílex blanco, y una raedera de sílex marrón. En el caso de la raedera (Figura 10.7) resulta interesante observar que se trata de dos fragmentos, uno de los cuales presenta termoalteración y el otro no. Esto evidencia que el contacto con el fuego se produjo después de que se fracturó. Además, esta pieza solo cambió de color, y no fue tallada con posterioridad a su contacto con el fuego, hecho que sería notorio por el contraste de lustre entre ambos negativos de retoque. Los otros dos instrumentos son fragmentos de artefactos bifaciales de sílex, y ambos presentan únicamente lustre.

Las piezas con cambios en lustre, color o pátina corresponden principalmente a sílex gris (25,5\%), seguido por la calcedonia (17,6\%) (Tabla 10.7). En relación con los productos de talla, predominan ampliamente las lascas $(41,7 \%)$, seguidos por los fragmentos de talla $(20,8 \%)$ (Tabla 10.4$)$. Son mayormente pertenecientes al estadio $3(74,4 \%)$, presentándose escasos restos de los estadios 1 y $2(15,4 \%$ y $10,3 \%$ respectivamente) (Tabla 10.5$)$.

Al igual que en los otros subconjuntos, la mayor parte de las piezas miden menos de $4 \mathrm{~cm}(80,4 \%)$, ubicándose principalmente en dos cuadrículas: A (33,3\%) y G2 (19,6\%) (Tabla 10.8). La mayor parte muestra únicamente evidencias de lustre: $79,2 \%$ muestra lustre en ambas caras, el 4,2\% en la cara ventral y $2,1 \%$ sólo en la cara dorsal. Además, $10,4 \%$ ha cambiado de color en ambas caras; hay una pieza con cambio de color y lustre en ambas caras y otra presenta pátina (Tabla 10.9).

\begin{tabular}{|c|c|c|c|c|c|c|}
\hline & \multicolumn{7}{|c|}{ Cara dorsal } \\
\hline Cara ventral & Sin cambio & Color & color, lustre & Lustre & pátina & Total \\
\hline Sin cambio & 0 & 0 & 0 & 1 & 1 & 2 \\
\hline color, lustre & 0 & 0 & 1 & 0 & 0 & 1 \\
\hline Color & 0 & 5 & 0 & 0 & 0 & 5 \\
\hline Lustre & 2 & 0 & 0 & 38 & 0 & 40 \\
\hline Total & 2 & 5 & 1 & 39 & 1 & 48 \\
\hline
\end{tabular}

Tabla 10.9. Productos de talla con cambios de color, lustre o pátina. C3T1. Unidad 5.

En este sentido, resulta interesante destacar ciertos aspectos. Las piezas con lustre en la cara ventral muestran un marcado contraste en la textura entre ambas caras (Fig. 10.8). También en una de las lascas con lustre en las dos caras, se observa contraste en diversos sectores en cuanto a 
su textura y brillo. En cuanto a aquellas con cambio de color, tres de ellas remontan con un núcleo que no ha estado expuesto al calor (Fig. 10.9). Estas presentan dimensiones aptas para ser utilizadas como soportes (son PFF), y se han recuperado de 3 distintas cuadrículas.

De aquellas piezas a las que se pudieron asignar algún estadio de producción, 5 (13,2\%) corresponden al estadio 1 de descortezamiento, 4 (10,5\%) al estadio 2 de talla, y $29(76,3 \%)$ al estadio 3 de formatización final. Realizamos un test de Chi cuadrado para evaluar si existe dependencia entre el estadio de los productos de talla y la presencia o no de tratamiento térmico y este ha arrojado diferencias no significativas $\left(X^{2}=0,96 ; p=0,01 ; g . I .=2\right)$, lo que podría indicar que este procedimiento abarcaba toda la secuencia de producción, o bien que la muestra no es lo suficientemente grande como para que las diferencias resulten significativas. Dentro del estadio $3,11(73,3 \%)$ son de retoque, $3(20 \%)$ de adelgazamiento bifacial y $1(6,7 \%)$ de reactivación, siendo el resto indiferenciadas.

En relación al talón, en 21 casos está ausente. De aquellos restos en los que se pudo observar, predominan los facetados (40\%) y luego siguen los lisos (24\%) (Fig. 10.10). El test de Chi cuadrado que evalúa si existe dependencia entre el talón y la presencia o no de tratamiento térmico ha arrojado diferencias no significativas $\left(X^{2}=1,76 ; p=0,01 ; g . l\right.$. $\left.=2\right)$. Esto podría indicar que no existirían diferencias en la elección de plataformas de percusión entre los conjuntos tratados y sin tratar. 


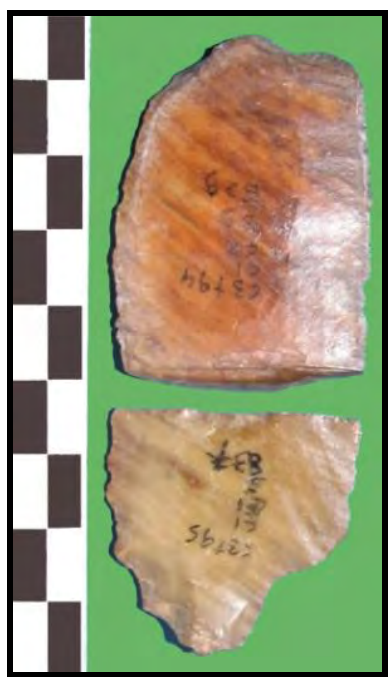

Figura 10.7. Piezas 529 y 837. Un fragmento de raedera termoalterada y otro sin termoalteración. C3T1. U. 5.

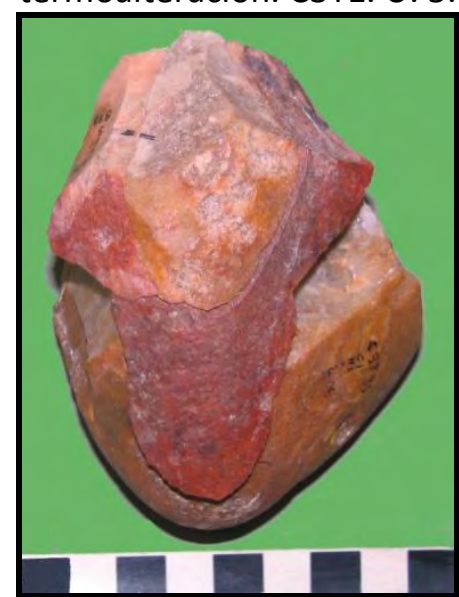

Fig. 10.9. Lascas $n^{\circ} 838$ y 910 (color rojizo) que remontan con núcleo $n^{\circ} 908$ y lasca $n^{\circ}$

812 (color naranja). C3T1. Unidad 5.

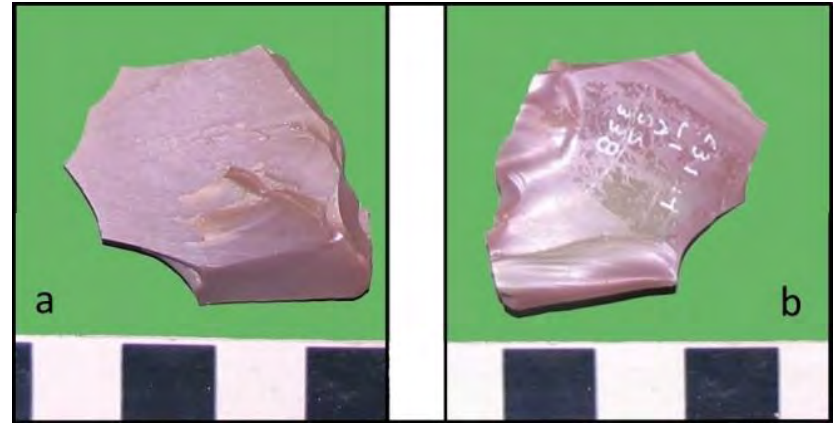

Fig. 10.8. Pieza 338. a. Cara dorsal sin lustre térmico. b. Cara ventral con lustre térmico. C3T1. Unidad 5

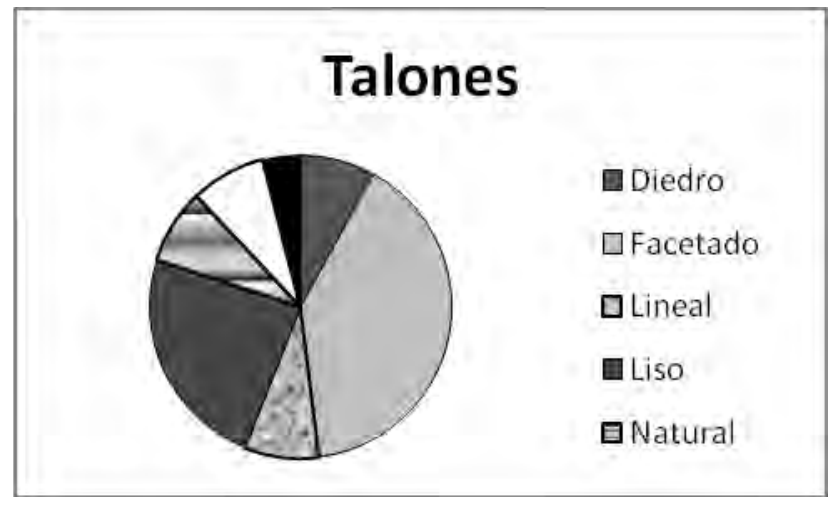

Fig. 10.10. Talones reconocidos en piezas tratadas térmicamente. C3T1. Unidad 5.

\subsection{Material óseo alterado térmicamente}

El 46,2\% de los restos (49 de 106 elementos) muestran evidencias de termoalteración. Estos están totalmente quemados $(69,4 \%)$ o bien totalmente carbonizados $(30,6 \%)$. No se han observado restos pertenecientes a los estadios intermedios (Tabla 10.10). En el análisis de la textura de los restos también destacan los estadios iniciales, siendo el estadio 1 (textura grasosa - ondulante) el más representado (60\%), seguido por el 2 (textura vítrea) con el 40\% (Fig. 10.11).

Al analizar la presencia de evidencias de termoalteración en la parte interna del hueso vemos que, en el $100 \%$ de los casos esta está presente tanto en la cara externa como en el interior del hueso (Fig. 10.12). En cuanto a las fracturas producidas por la acción térmica, hemos reconocido escasas piezas en las cuales esto se puede observar, predominando las longitudinales (Tabla 10.11).

Con respecto a la procedencia de los elementos termoalterados, estos proceden en su mayoría de B2 (85,7\%). Los elementos de ésta y de B1, inmediatamente adyacente, se encuentran 
termoalterados en elevadas proporciones (53,8\% en B2 y $100 \%$ en B1) (Tabla 10.12). En la unidad 5 estas cuadrículas no presentan fogones; sin embargo, como se observa en la figura 10.13, en la unidad 4 sí contienen estructuras de combustión.

En relación al tamaño, 65,3\% de los restos termoalterados es menor a dos cm (Tabla 10.13). En la mayor parte de los elementos no se ha podido reconocer el taxón (89,8\%). Cabe destacar que cuatro de los nueve elementos de guanaco $(44,4 \%)$ se encuentran alterados térmicamente (Tabla 10.14).

Por otra parte, como ya se mencionara en el capítulo 5, se han reconocido dos instrumentos óseos en el sitio, un punzón y una tibia retocada de guanaco. El punzón fue recuperado de la cuadrícula C1 y no muestra evidencias de termoalteración. La tibia retocada de guanaco, en tanto, se encuentra totalmente quemada, presentando un color marrón oscuro y un brillo vítreo (Fig. 10.14). A este instrumento se suma un pequeño fragmento de diáfisis indeterminada que también contaba con retoques en uno de sus bordes y que se encontraba totalmente carbonizado. Este fragmento pudo remontarse con otros dos que también se presentaban en el mismo estadio termoalteración (Fig. 10.15). Tanto la tibia retocada como los fragmentos carbonizados proceden de B2. No hemos identificado lascas óseas con evidencias de termoalteración.

\begin{tabular}{|c|c|c|c|}
\hline Cuadrícula & Totalmente carbonizado & Totalmente quemado & Total \\
\hline B1 & 0 & 6 & 6 \\
\hline B2 & 14 & 28 & 42 \\
\hline C2 & 1 & 0 & 1 \\
\hline Total & 15 & 34 & 49 \\
\hline
\end{tabular}

Tabla 10.10. Termoalteración de restos óseos por cuadrícula. C3T1. Unidad 5.

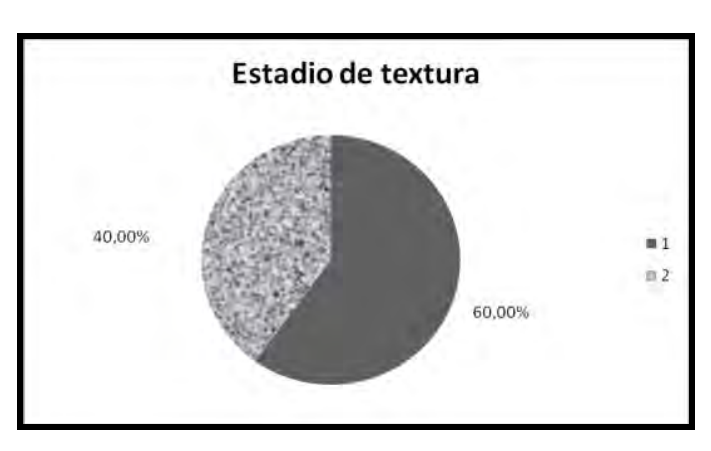

Fig. 10.11. Textura de los restos termoalterados por estadio. C3T1. Unidad 5.

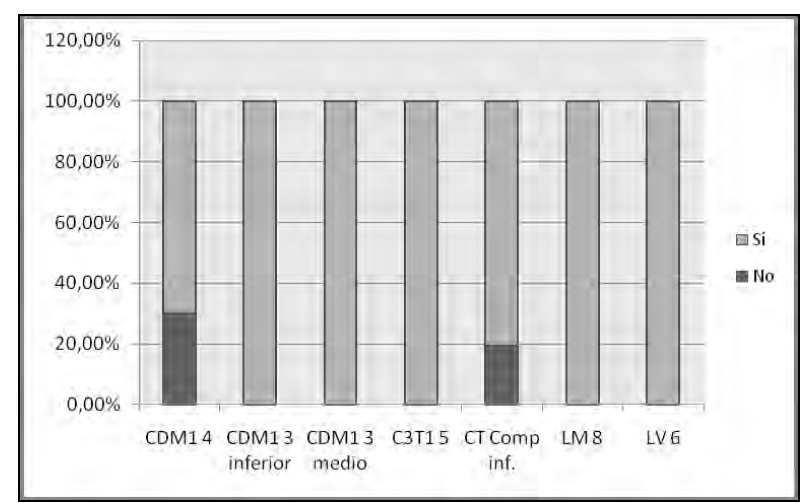

Fig. 10.12. Termoalteración en la cara interna de los restos. Todos los componentes estudiados. 


\begin{tabular}{|c|c|}
\hline Fracturas & $\%$ \\
\hline F. longitudinales & 10,2 \\
\hline F. transversales & 8,2 \\
\hline Sin F. por termoalteración & 81,6 \\
\hline Total & 100 \\
\hline
\end{tabular}

Tabla 10.11. Fracturas producidas por termoalteración. C3T1. U. 5. F. = Fracturas

\begin{tabular}{|c|c|c|c|}
\hline Sector & Termoalterados & Total & \% Termoalterados \\
\hline A & 0 & 6 & 0 \\
\hline B1 & 6 & 6 & 100 \\
\hline B2 & 42 & 78 & 53,8 \\
\hline C1 & 0 & 1 & 0 \\
\hline C2 & 1 & 15 & 6,7 \\
\hline Total & 49 & 106 & 46,2 \\
\hline
\end{tabular}

Tabla 10.12. \% de restos termoalterados por cuadrícula. C3T1. Unidad 5.

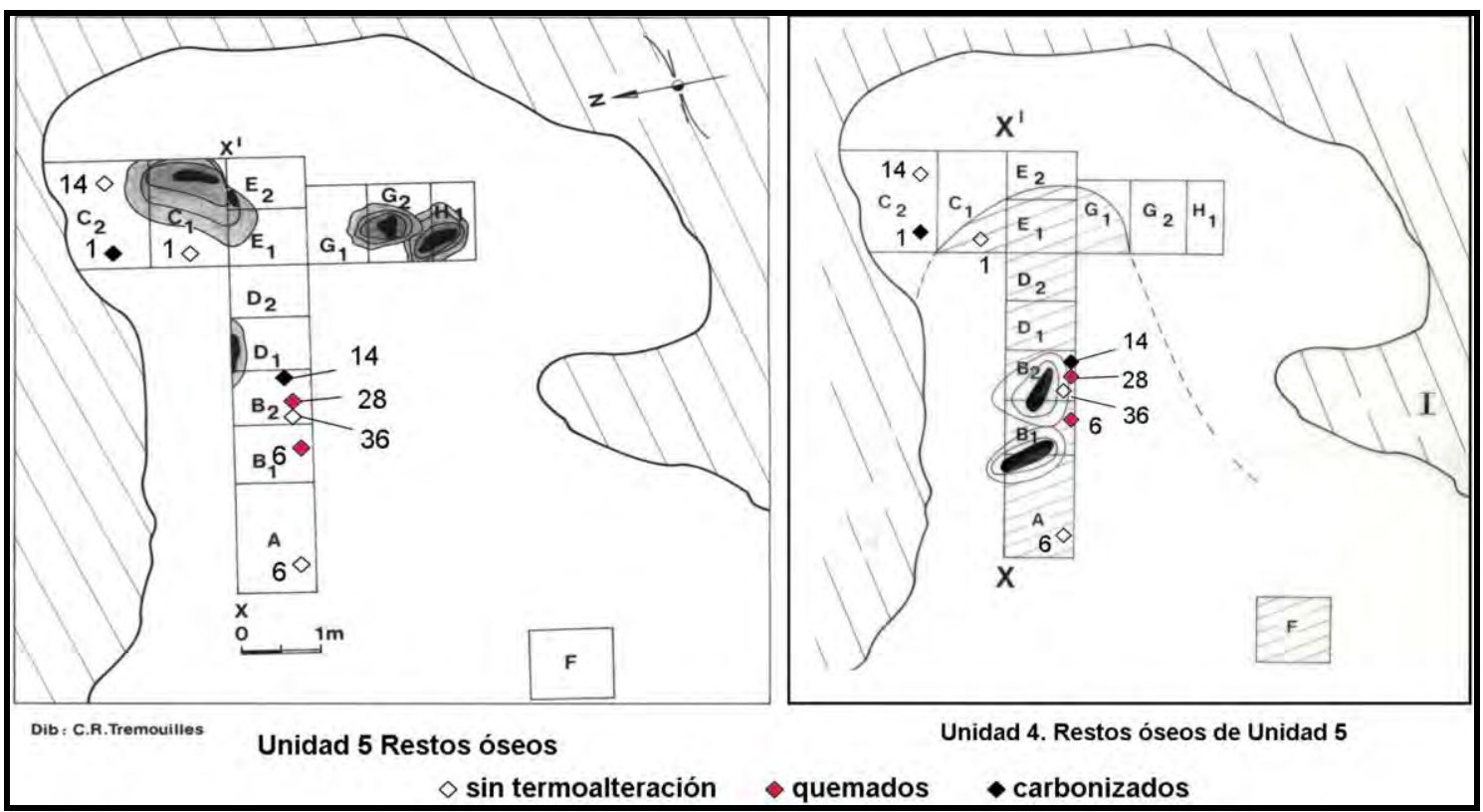

Fig. 10.13. Ubicación de los restos óseos termoalterados de la unidad 5 en relación a los fogones de esa unidad y de la unidad 4. C3T1.

\begin{tabular}{|c|c|c|c|}
\hline Tamaño & Totalmente carbonizado & Totalmente quemado & Total \\
\hline Mayor a dos $\mathbf{~ c m}$ & 6 & 11 & 17 \\
\hline Menor a dos $\mathbf{~ c m ~}$ & 9 & 23 & 32 \\
\hline Total & 15 & 34 & 49 \\
\hline
\end{tabular}

Tabla 10.13. Termoalteración de restos óseos por tamaño. C3T1. Unidad 5.

\begin{tabular}{|c|c|c|c|c|}
\hline Taxón & $\begin{array}{c}\text { Totalmente } \\
\text { carbonizado }\end{array}$ & $\begin{array}{c}\text { Totalmente } \\
\text { quemado }\end{array}$ & No alterado & Total \\
\hline Indet & 14 & 30 & 52 & 96 \\
\hline Lama guanicoe & 1 & 3 & 5 & 9 \\
\hline Mamífero pequeño & 0 & 1 & 0 & 1 \\
\hline Total & 15 & 34 & 57 & 106 \\
\hline
\end{tabular}

Tabla 10.14. Termoalteración de restos óseos por taxón. C3T1. Unidad 5. 


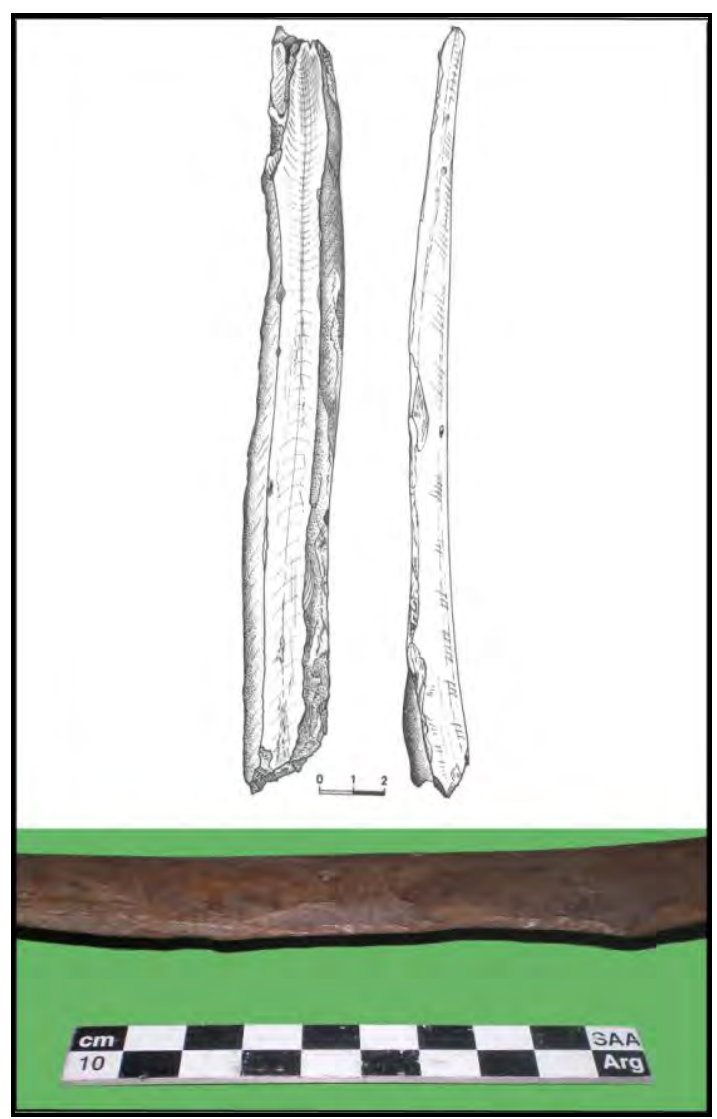

Fig. 10.14. Tibia de guanaco retocada termoalterada. C3T1. Unidad 5.

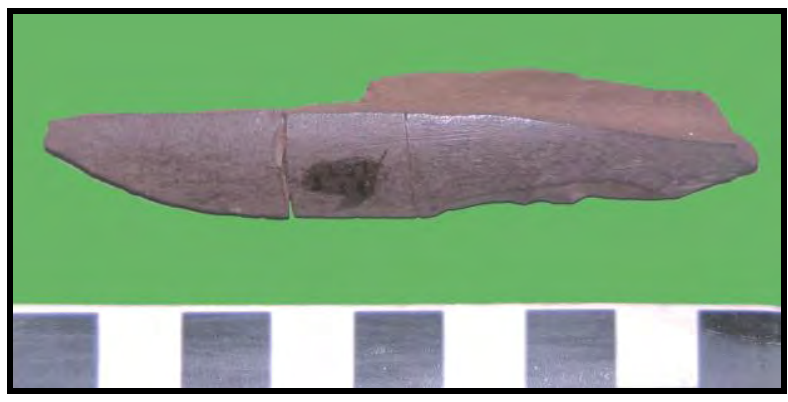

Fig. 10.15. Diáfisis retocada termoalterada. C3T1. U. 5.

10.3.2. Sitio Casa del Minero 1

\subsubsection{Unidad 4}

\subsection{Fogones}

Se identificaron diez fogones que ocupan un sector restringido del espacio excavado, en el sudeste de la cueva. Estos se concentran en siete de las diecisiete cuadrículas trabajadas (Cuadro 10.2 y Fig. 5.5), seis de las cuales presentan al menos dos cada una. Todos son de estructura plana lenticular. En cuanto a sus dimensiones, vemos que la mayor parte presentan dimensiones similares que rondan los $40 \times 20 \mathrm{~cm}$. Dos de ellos, sin embargo, son más grandes, y se aproximan a los $60 \times 40 \mathrm{~cm}$, mientras que uno ha sido parcialmente excavado por lo que no contamos con sus dimensiones totales (Cuadro 10.2 y Fig. 10.1). 


\begin{tabular}{|c|c|c|}
\hline Ubicación & Eje mayor & Eje menor \\
\hline A1-B1 & 42 & 22 \\
\hline B1 & 27 & 20 \\
\hline B1-B2 & 60 & 40 \\
\hline B2 & 39 & 26 \\
\hline A2-A1 & 57 & 35 \\
\hline F1-A2 & 27 & 20 \\
\hline F1 & 40 & 20 \\
\hline F2-F1 & 38 & 26 \\
\hline F2 & 31 & 19 \\
\hline J1-F2 & 55 & 8 \\
\hline
\end{tabular}

Cuadro 10.2 Longitud de los fogones. Las dimensiones del fogón J1-F2 son parciales dado que una parte de este penetra en el sector no excavado.CDM1. Unidad 4

\subsection{Distribución en planta de los restos}

En referencia al conjunto lítico, el $80,5 \%$ de las piezas se encuentra en siete cuadrículas que presentan evidencias de estructuras de combustión (6,3 $\mathrm{m}^{2}$ aproximadamente) mientras que el $19,5 \%$ restante se ubica en seis que no presentan fogones (alrededor de $\left.3,8 \mathrm{~m}^{2}\right)$. Cuatro $\left(2,6 \mathrm{~m}^{2}\right)$ no presentan restos líticos ni estructuras de combustión.

Observamos que las piezas se concentran preferentemente en el sector sudeste de la cueva, focalizándose en B1 que cuenta con casi el 30\% del conjunto (Tabla 10.15) y disminuyendo en las cuadrículas circundantes.

Los restos presentes en cada cuadrícula abarcan diversos tamaños, aunque predominan siempre los elementos más pequeños (Fig. 10.16). Tanto en B1 como en los sectores circundantes predomina ampliamente el sílex rojo, mientras que en F1 se observa una mayor proporción de sílex marrón. En relación a la calcedonia, se registra una relativa abundancia en todo el sector excavado (Tabla 10.16). Mientras que en el sector de mayor densidad de restos prevalecen ampliamente los elementos correspondientes al estadio 3 (Fig. 10.17), en los aquellos con menor cantidad de piezas hay cantidades similares de los estadios 2 y 3 .

\begin{tabular}{|c|c|c|c|c|c|c|c|c|c|c|c|c|c|c|}
\hline Grupo & A1 & A2 & B1 & B2 & C1 & C2 & E & F1 & F2 & G1 & J1 & K1 & K2 & Total \\
\hline $\mathbf{I}$ & 2 & 0 & 2 & 1 & 3 & 1 & 1 & 1 & 0 & 0 & 0 & 0 & 0 & 11 \\
\hline XT & 110 & 118 & 361 & 186 & 109 & 96 & 15 & 153 & 11 & 5 & 54 & 10 & 1 & 1229 \\
\hline Total & 112 & 118 & 363 & 187 & 112 & 97 & 16 & 154 & 11 & 5 & 54 & 10 & 1 & 1240 \\
\hline \% & 9,03 & 9,51 & 29,27 & 15,08 & 9,03 & 7,82 & 1,29 & 12,41 & 0,88 & 0,40 & 4,35 & 0,80 & 0,08 & 100 \\
\hline
\end{tabular}

Tabla 10.15. Artefactos líticos por cuadrícula. CDM1. Unidad 4. 


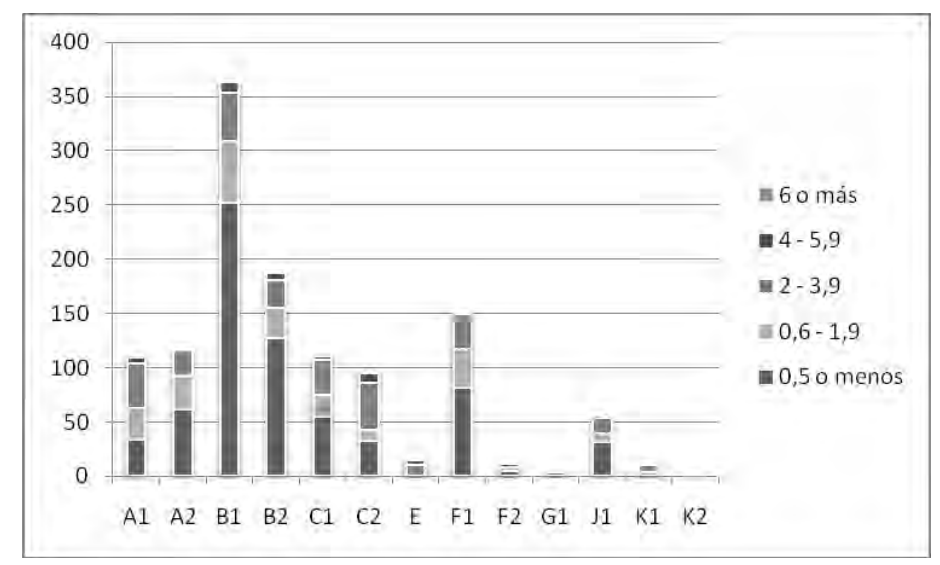

Fig. 10.16. Dimensión máxima en cm. de artefactos líticos por cuadrícula. CDM1. Unidad 4.

\begin{tabular}{|c|c|c|c|c|c|c|c|c|c|c|c|c|c|c|c|}
\hline $\begin{array}{c}\text { Materia } \\
\text { Prima }\end{array}$ & Color & A1 & $A 2$ & B1 & B2 & C1 & C2 & $E$ & F1 & F2 & G1 & J1 & K1 & K2 & Total \\
\hline Calcedonia & & 13 & 62 & 21 & 36 & 30 & 37 & 5 & 15 & 3 & 0 & 25 & 4 & 0 & 251 \\
\hline Indet. & & 2 & 1 & 41 & 20 & 0 & 0 & 0 & 7 & 0 & 0 & 0 & 1 & 0 & 72 \\
\hline \multirow{5}{*}{ Sílex } & Amarillo & 0 & 0 & 3 & 14 & 21 & 8 & 2 & 0 & 0 & 1 & 0 & 0 & 0 & 49 \\
\hline & Claro & 0 & 0 & 1 & 13 & 1 & 1 & 0 & 0 & 0 & 0 & 0 & 0 & 0 & 16 \\
\hline & Marrón & 4 & 19 & 0 & 4 & 7 & 21 & 0 & 104 & 2 & 1 & 7 & 1 & 0 & 170 \\
\hline & Otros & 6 & 1 & 6 & 14 & 0 & 0 & 0 & 2 & 0 & 1 & 2 & 1 & 0 & 33 \\
\hline & Rojo & 70 & 34 & 283 & 71 & 50 & 29 & 7 & 23 & 6 & 1 & 20 & 3 & 1 & 598 \\
\hline Xilópalo & & 16 & 0 & 8 & 15 & 2 & 1 & 1 & 1 & 0 & 0 & 0 & 0 & 0 & 44 \\
\hline Otras & & 1 & 1 & 0 & 0 & 1 & 0 & 1 & 2 & 0 & 1 & 0 & 0 & 0 & 7 \\
\hline Total & & 112 & 118 & 363 & 187 & 112 & 97 & 16 & 154 & 11 & 5 & 54 & 10 & 1 & 1240 \\
\hline
\end{tabular}

Tabla 10.16. Materia prima de de artefactos líticos por cuadrícula. CDM1. Unidad 4.

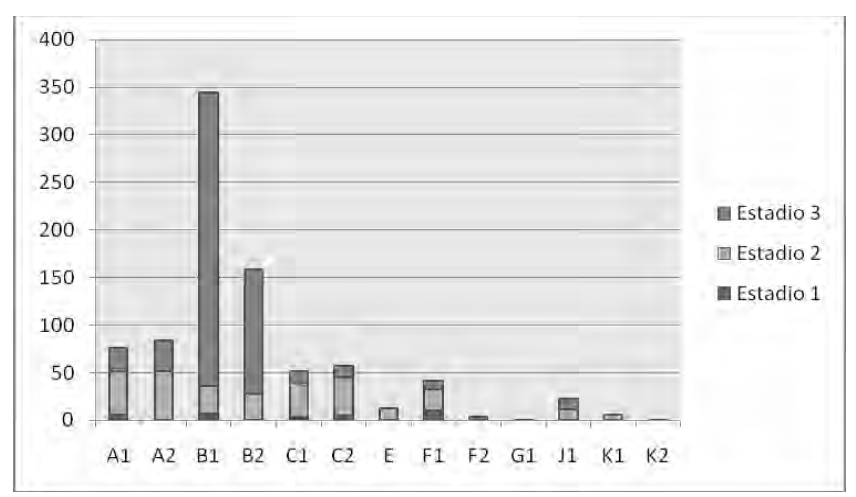

Fig. 10.17. Estadio de reducción de productos de talla por cuadrícula. CDM1. Unidad 4.

En relación con el conjunto óseo, podemos ver que la concentración de los restos coincide en términos generales con la de los artefactos líticos y que se ubica en los mismos sectores donde se presentan los fogones. En este sentido, el $80,71 \%$ de los elementos óseos se encuentra en siete cuadrículas que presentan evidencias de estructuras de combustión $\left(6,3 \mathrm{~m}^{2}\right.$ aproximadamente) mientras que el $19,29 \%$ restante se ubica en seis cuadrículas sin presencia de fogones $\left(3,6 \mathrm{~m}^{2}\right.$ aproximadamente). Cuatro $\left(2,8 \mathrm{~m}^{2}\right)$ no presentan restos óseos ni fogones.

Los restos se concentran principalmente en B1 $(29,6 \%)$ así como en B2 $(24,7 \%)$ inmediatamente adyacente. Son principalmente restos indeterminados (Tabla 10.17). En cuanto a los que se les 
pudo determinar taxón, en términos generales podríamos decir que no existe una distribución diferencial de acuerdo a la especie. Los restos de Dusicyon griseus, Hemiauchenia Paradoxa y Lama sp. son más abundantes en $\mathrm{B} 1$, los de Lama guanicoe en A1 y A2 y los de Lama gracilis en A2, B2 y C1. Sin embargo, se observa que los correspondientes a rheidos son más abundantes en K1, es decir un sector alejado de la zona de mayor concentración de restos.

Si consideramos los restos de camélidos, que constituyen la familia más abundante, observamos que mientras que los elementos del esqueleto apendicular se concentran en B1 y B2, los del esqueleto axial lo hacen en A2, A1 y B1 (Tabla 10.18).

Con relación al tamaño de los elementos, si bien a nivel general hay mayor cantidad de restos que superan los dos $\mathrm{cm}(56,2 \%)$, existen ciertas cuadrículas en las que se observa una relación inversa, siendo predominantes los elementos menores a dos $\mathrm{cm}$. Esto sucede en B1, la cuadrícula con mayor cantidad de restos, donde el $57,6 \%$ de las piezas son pequeñas. También se observa en aquellas ubicadas en el sector oeste de la cueva (Fig. 10.18).

\begin{tabular}{|c|c|c|c|c|c|c|c|c|c|c|c|c|c|c|}
\hline Taxón & A1 & A2 & B1 & B2 & C1 & C2 & E & F1 & F2 & H1 & J1 & K1 & K2 & Total \\
\hline Mamíferos indet. & 13 & 10 & 8 & 8 & 0 & 0 & 0 & 5 & 0 & 0 & 6 & 1 & 0 & 51 \\
\hline Dusicyon sp. & 1 & 4 & 1 & 2 & 0 & 0 & 0 & 0 & 0 & 0 & 0 & 3 & 0 & 11 \\
\hline Dusicyon griseus & 0 & 7 & 9 & 0 & 0 & 0 & 0 & 0 & 0 & 0 & 0 & 0 & 0 & 16 \\
\hline Camélidos indet. & 6 & 7 & 21 & 18 & 0 & 1 & 4 & 0 & 0 & 0 & 0 & 0 & 0 & 57 \\
\hline Hemiauchenia paradoxa & 2 & 2 & 7 & 1 & 1 & 0 & 0 & 0 & 0 & 0 & 0 & 0 & 0 & 13 \\
\hline Lama sp. & 22 & 12 & 46 & 31 & 19 & 4 & 5 & 0 & 0 & 0 & 2 & 0 & 0 & 141 \\
\hline Lama gracilis & 0 & 5 & 1 & 5 & 1 & 6 & 1 & 0 & 0 & 0 & 0 & 0 & 0 & 19 \\
\hline Lama guanicoe & 9 & 8 & 4 & 6 & 0 & 0 & 0 & 0 & 5 & 0 & 0 & 5 & 0 & 37 \\
\hline Roedores indet. & 0 & 0 & 39 & 1 & 0 & 0 & 3 & 0 & 0 & 1 & 0 & 0 & 0 & 44 \\
\hline Aves indet. & 1 & 4 & 4 & 4 & 1 & 0 & 0 & 0 & 1 & 0 & 0 & 0 & 0 & 15 \\
\hline Rheidos & 0 & 8 & 1 & 0 & 0 & 1 & 0 & 2 & 0 & 1 & 1 & 9 & 0 & 23 \\
\hline Indet. & 167 & 58 & 368 & 349 & 108 & 61 & 28 & 59 & 0 & 20 & 28 & 32 & 16 & 1294 \\
\hline Total & 221 & 125 & 509 & 425 & 130 & 73 & 41 & 66 & 6 & 22 & 37 & 50 & 16 & 1721 \\
\hline
\end{tabular}

Tabla 10.17. Restos óseos de cada taxón por cuadrícula. CDM1. Unidad 4.

\begin{tabular}{|c|c|c|c|c|c|c|c|c|c|c|}
\hline & A1 & A2 & B1 & B2 & C1 & C2 & E & J1 & K1 & Total \\
\hline Esqueleto Apendicular & 5 & 9 & 26 & 26 & 3 & 2 & 6 & 2 & 2 & 81 \\
\hline Esqueleto Axial & 16 & 19 & 16 & 10 & 5 & 0 & 1 & 0 & 1 & 68 \\
\hline Total & 21 & 28 & 42 & 36 & 8 & 2 & 7 & 2 & 3 & 149 \\
\hline
\end{tabular}

Tabla 10.18. Elementos del esqueleto apendicular y axial de camélidos por cuadrícula. CDM1. U. 4. 


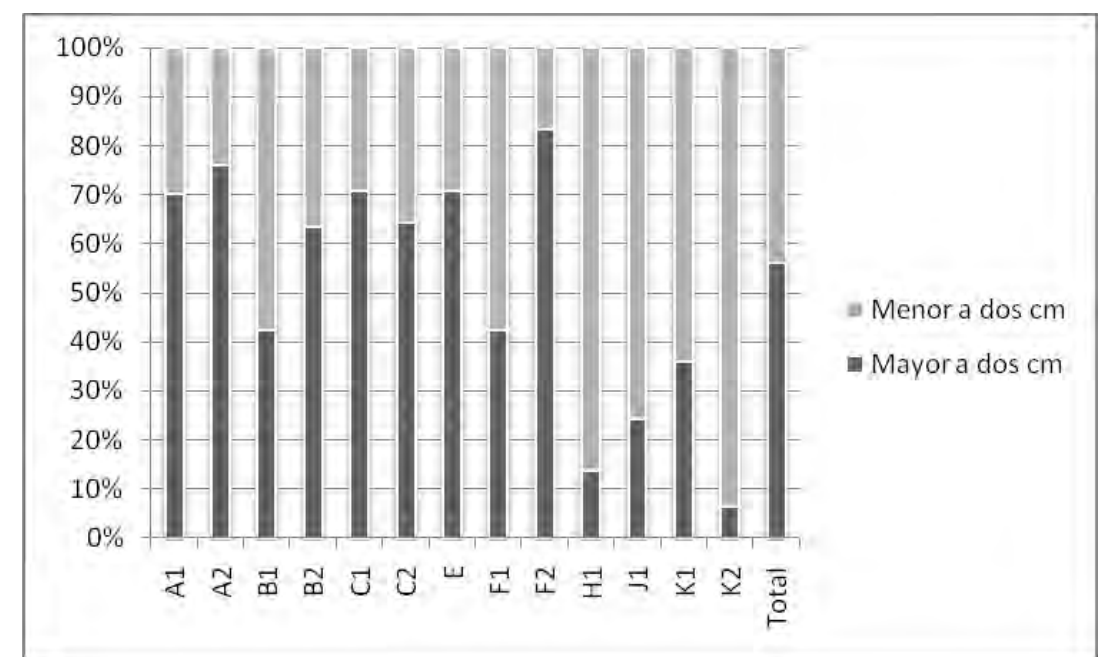

Fig. 10.18. Tamaño de los elementos óseos por cuadrícula. CDM1. Unidad 4.

\section{$\underline{10.3 .2 .1 .3 . ~ M a t e r i a l ~ l i ́ t i c o ~ a l t e r a d o ~ t e ́ r m i c a m e n t e ~}$}

En cuanto a las piezas con alteración térmica (453), constituyen el 36,5\% del conjunto. De estas, 44 presentan evidencias de daño térmico y 409 tienen únicamente cambios de color, lustre o pátina. El 99,6\% son productos de talla, las restantes corresponden a instrumentos (Tabla 10.19). Entre los productos de talla, predominan las esquirlas (57\%), luego le siguen las lascas y los fragmentos de talla (31,3\% y $7,1 \%$ respectivamente) (Tabla 10.20). De aquellos a los cuales se les pudo identificar un estadio dentro de la secuencia de producción, el 78,6\% corresponde al estadio de formatización final (3), mientras que dentro del estadio de descortezamiento (1) hay un 3,1\% y el $18,3 \%$ corresponde al estadio de talla (2) (Tabla 10.21). El 94,5\% de las piezas presentan una dimensión máxima de entre 0,1 y 3,9 cm (el 55,4\% es menor a 0,5 cm el $21,6 \%$ está entre 2 y 3,9 cm y el 19,4\% entre 0,6 y $2 \mathrm{~cm}$ ). Es decir, la gran mayoría son pequeñas (Tabla 10.22).

Estas piezas son principalmente de sílex (85,9\%), en especial rojo (Tabla 10.23). De acuerdo a la figura 10.20, más del $60 \%$ de las piezas de esta materia prima presentan evidencias de termoalteración. Se observan también restos de calcedonia (12,1\%). Se ubican concentrados en un sector acotado del espacio, predominantemente en B1 $(53,9 \%)$, B2 (15,7\%) y A1 $(10,8 \%)$ (Tabla 10.24). La figura 10.21 muestra que las piezas dañadas, o con cambio de color, tienden a concentrarse en las cercanías a las estructuras de combustión de esa unidad; por el contrario, no existiría una correlación entre su distribución y la ubicación de los fogones de la unidad 3 inferior, inmediatamente sobreyacente. 


\begin{tabular}{|c|c|c|c|c|}
\hline $\begin{array}{c}\text { Daño } \\
\text { dorsal }\end{array}$ & $\begin{array}{c}\text { Daño } \\
\text { ventral }\end{array}$ & $\mathbf{I}$ & $\mathbf{X T}$ & Total \\
\hline \multirow{2}{*}{ No } & No & 2 & 407 & 409 \\
\cline { 2 - 5 } & Si & 0 & 14 & 14 \\
\hline \multirow{2}{*}{ Si } & No & 0 & 6 & 6 \\
\cline { 2 - 5 } & Si & 0 & 24 & 24 \\
\hline Total & & 2 & 451 & 453 \\
\hline
\end{tabular}

Tabla 10.19. Piezas con alteración térmica por grupo. CDM1. U. 4. No= Sin daño pero con alteraciones del tipo lustre, color y pátina.

\begin{tabular}{|c|c|c|c|c|c|c|c|c|}
\hline $\begin{array}{c}\text { Daño } \\
\text { dorsal }\end{array}$ & $\begin{array}{c}\text { Daño } \\
\text { ventral }\end{array}$ & ESQ & FT & L & LAS & LL & LM & Tot. \\
\hline \multirow{2}{*}{ No } & No & 234 & 24 & 129 & 10 & 7 & 3 & 407 \\
\cline { 2 - 9 } & $\mathbf{S i}$ & 11 & 1 & 2 & 0 & 0 & 0 & 14 \\
\hline \multirow{2}{*}{ Si } & No & 1 & 1 & 4 & 0 & 0 & 0 & 6 \\
\cline { 2 - 9 } & $\mathbf{S i}$ & 11 & 6 & 6 & 1 & 0 & 0 & 24 \\
\hline Total & & 257 & 32 & 141 & 11 & 7 & 3 & 451 \\
\hline
\end{tabular}

Tabla 10.20. Productos de talla con alteración térmica por clase. CDM1. Unidad 4

\begin{tabular}{|c|c|c|c|c|c|}
\hline $\begin{array}{c}\text { Daño } \\
\text { dorsal }\end{array}$ & $\begin{array}{c}\text { Daño } \\
\text { ventral }\end{array}$ & $\mathbf{1}$ & $\mathbf{2}$ & $\mathbf{3}$ & Tot. \\
\hline \multirow{2}{*}{ No } & No & 11 & 62 & 286 & 359 \\
\cline { 2 - 6 } & $\mathbf{S i}$ & 0 & 2 & 9 & 11 \\
\hline \multirow{2}{*}{$\mathrm{Si}$} & No & 0 & 3 & 1 & 4 \\
\cline { 2 - 6 } & $\mathrm{Si}$ & 1 & 4 & 9 & 14 \\
\hline Total & & 12 & 71 & 305 & 388 \\
\hline
\end{tabular}

Tabla 10.21. Productos de talla con alteración térmica por estadio. CDM1. U. 4

\begin{tabular}{|c|c|c|c|c|c|c|c|}
\hline $\begin{array}{c}\text { Daño } \\
\text { dorsal }\end{array}$ & $\begin{array}{c}\text { Daño } \\
\text { ventral }\end{array}$ & $\begin{array}{c}\mathbf{0 , 5} \mathbf{0} \\
\text { menos }\end{array}$ & $\begin{array}{c}\mathbf{0 , 6}- \\
\mathbf{1 , 9}\end{array}$ & $\begin{array}{c}\mathbf{2}- \\
\mathbf{3 , 9}\end{array}$ & $\begin{array}{c}\mathbf{4}- \\
\mathbf{5 , 9}\end{array}$ & $\begin{array}{c}\mathbf{6} \mathbf{0} \\
\text { más }\end{array}$ & Total \\
\hline \multirow{2}{*}{ No } & $\mathbf{N o}$ & 229 & 79 & 85 & 14 & 2 & 409 \\
\cline { 2 - 8 } & $\mathbf{S i}$ & 10 & 2 & 2 & 0 & 0 & 14 \\
\hline \multirow{2}{*}{$\mathrm{Si}$} & $\mathbf{N o}$ & 1 & 1 & 4 & 0 & 0 & 6 \\
\cline { 2 - 8 } & $\mathbf{S i}$ & 11 & 6 & 7 & 0 & 0 & 24 \\
\hline \multirow{2}{*}{ Total } & & 251 & 88 & 98 & 14 & 2 & 453 \\
\hline
\end{tabular}

Tabla 10.22. Piezas con alteración térmica por dimensión máxima. CDM1. Unidad 4

\begin{tabular}{|c|c|c|c|c|c|c|c|c|}
\hline \multirow{2}{*}{ Daño dorsal } & \multirow{2}{*}{ Daño ventral } & \multirow{2}{*}{ Calcedonia } & \multirow{2}{*}{ Indet. } & \multicolumn{4}{|c|}{ Sílex } & \multirow{2}{*}{ Total } \\
\cline { 4 - 9 } & & & & Rojo & Marrón & Claro & Otros & \\
\hline \multirow{2}{*}{ No } & No & 48 & 7 & 337 & 0 & 4 & 13 & 409 \\
\cline { 2 - 9 } & $\mathbf{S i}$ & 0 & 1 & 11 & 1 & 0 & 1 & 14 \\
\hline \multirow{2}{*}{ Si } & No & 2 & 0 & 4 & 0 & 0 & 0 & 6 \\
\cline { 2 - 9 } & Si & 5 & 1 & 15 & 1 & 0 & 2 & 24 \\
\hline Total & & 55 & 9 & 367 & 2 & 4 & 16 & 453 \\
\hline
\end{tabular}

Tabla 10.23 Piezas con alteración térmica por materia prima. CDM1. Unidad 4

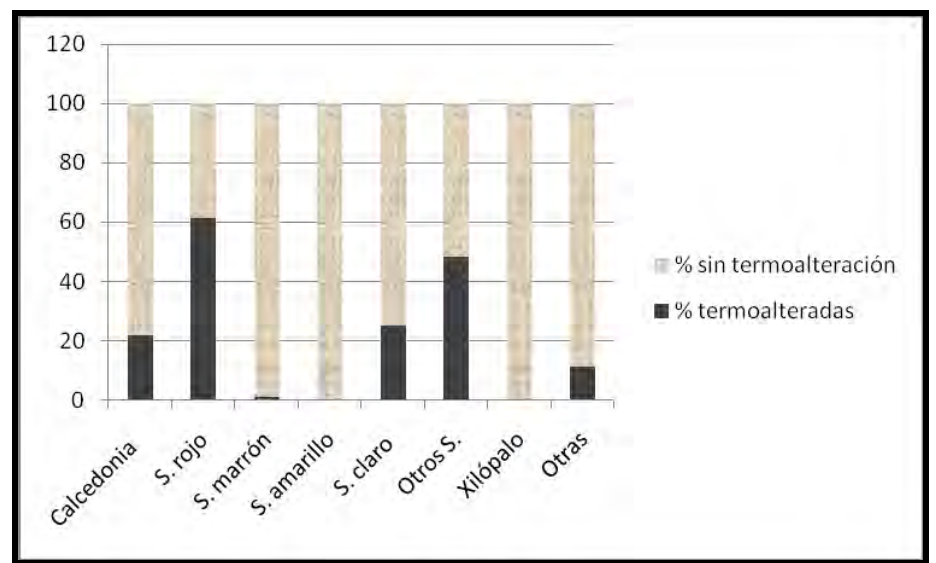

Fig. 10.19. \% de piezas termoalteradas por materia prima. CDM1. Unidad 4. 


\begin{tabular}{|c|c|c|c|c|c|c|c|c|c|c|c|c|c|c|}
\hline Daño dorsal & Daño ventral & A1 & A2 & B1 & B2 & C1 & C2 & $E$ & F1 & F2 & G1 & J1 & K1 & Total \\
\hline \multirow{2}{*}{ No } & No & 40 & 16 & 224 & 65 & 31 & 18 & 3 & 4 & 2 & 0 & 4 & 2 & 409 \\
\hline & Si & 0 & 0 & 10 & 2 & 0 & 1 & 0 & 0 & 0 & 0 & 0 & 1 & 14 \\
\hline \multirow{2}{*}{ Si } & No & 1 & 0 & 3 & 0 & 1 & 0 & 0 & 1 & 0 & 0 & 0 & 0 & 6 \\
\hline & Si & 8 & 1 & 7 & 4 & 0 & 1 & 1 & 1 & 0 & 1 & 0 & 0 & 24 \\
\hline Total & & 49 & 17 & 244 & 71 & 32 & 20 & 4 & 6 & 2 & 1 & 4 & 3 & 453 \\
\hline
\end{tabular}

Tabla 10.24. Piezas con alteración térmica por sector. CDM1. Unidad 4.

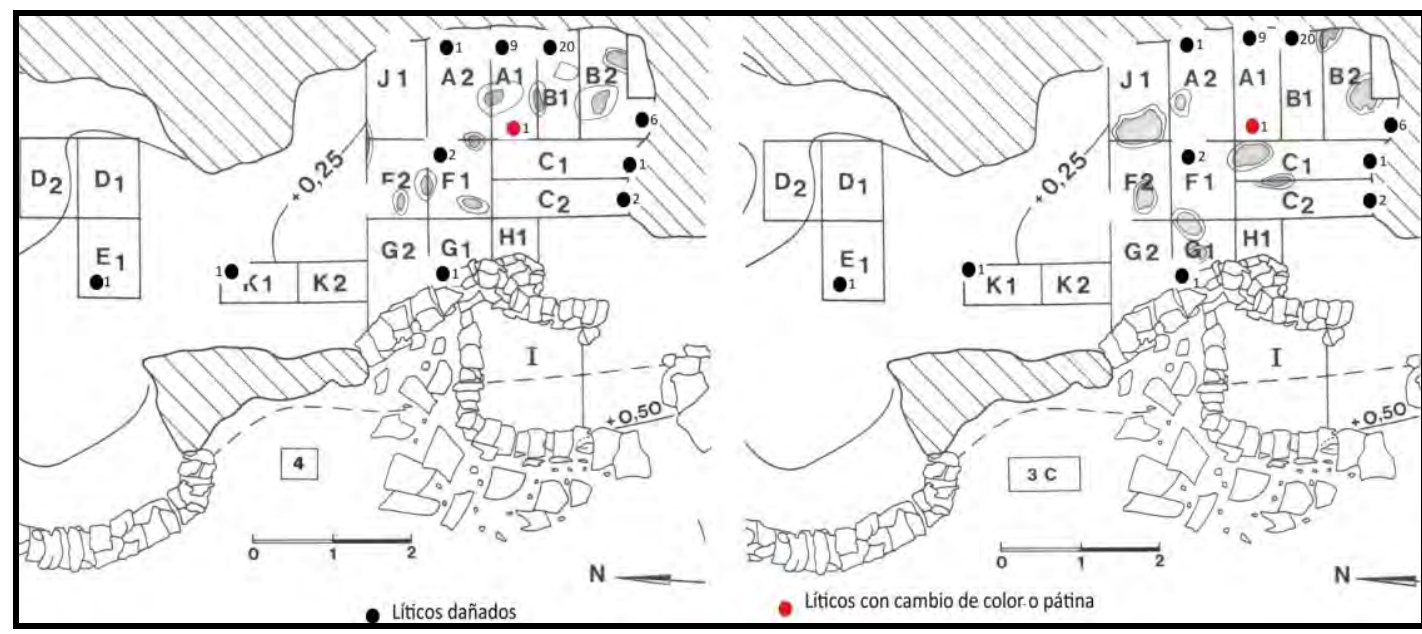

Fig. 10.20. Ubicación de los restos líticos dañados térmicamente, con pátina o cambio de color de la unidad 4 en relación a los fogones de esa unidad y de la unidad 3 inferior. CDM1.

10.3.2.1.3.1. Piezas con daño térmico

Las piezas con daño térmico se distribuyen en los siguientes grupos: seis con daño únicamente en la cara dorsal, 14 lo muestran únicamente en la ventral y 24 lo presentan en ambas caras.

10.3.2.1.3.1.1. Piezas con daño en ambas caras

Todas corresponden a productos de talla. De estas, el $62,5 \%$ son de sílex rojo y el $20,8 \%$ de calcedonia (Tabla 10.23). Son en su mayoría esquirlas $(45,8 \%)$ y se observan cantidades considerables de fragmentos de talla y lascas (25\% respectivamente) (Tabla 10.20). Pertenecen principalmente al estadio $3(64,3 \%)$, mientras que hay escasas piezas de los estadios 1 y $2(7,1 \%$ y $28,6 \%$ respectivamente) (Tabla 10.21 ).

Todos los restos miden menos de $4 \mathrm{~cm}$ (Tabla 10.22). Se ubican predominantemente en tres cuadrículas adyacentes: A1, B1 y B2 $(33,3 \%, 29,2 \%$ y $16,7 \%$ respectivamente) (Tabla 10.24). Ninguna de estas piezas presenta lustre térmico. 
10.3.2.1.3.1.2. Piezas con daño en cara dorsal

Se trata de seis productos de talla. El 66,6\% es de sílex rojo y el 33,3\% de calcedonia (Tabla 10.23). Son predominantemente lascas $(66,6 \%)$ (Tabla 10.20). Corresponden principalmente al estadio 2 (75\%), presentándose también piezas del estadio 3 (25\%). No se observan del estadio 1 (Tabla 10.21). Todas miden menos de $4 \mathrm{~cm}$ (Tabla 10.22). Se ubican mayormente en B1 (50\%) (Tabla 10.24). En dos casos, además de daño térmico en la cara dorsal, se observa lustre en la ventral. Ambas son de sílex rojo, una corresponde al estadio 2 y otra al 3.

10.3.2.1.3.1.3. Piezas con daño en cara ventral

Se trata de 14 productos de talla, corresponden principalmente a sílex rojo $(78,6 \%)$ (Tabla 10.23$)$. Son predominantemente esquirlas (78,6\%), asignadas en su mayoría al estadio 3 (81,8\%) (Tablas 10.20 y 10.21). Todas miden menos de $4 \mathrm{~cm}$ y se ubican preponderantemente en la cuadrícula B1 $(71,4 \%)$ (Tablas 10.22 y 10.24$)$.

Sólo un caso presenta dimensiones factibles de ser utilizada como forma base. Es una lasca de sílex rojo, posee un potencial filo funcional y fue encontrada en la cuadrícula C2 que no contiene fogones.

\subsection{Piezas con alteración térmica pero sin daño}

Hay 409 piezas que muestran evidencias de alteración térmica pero que no han sufrido daños. Es decir, solo presentan pátina, lustre o cambio de color. De estas, dos son instrumentos y 407 son productos de talla (Tabla 10.19).

Los instrumentos son un cuchillo confeccionado sobre lámina con retoque inverso lateral y bifacial distal y una lasca retocada de retoque inverso lateral. Ambos fueron formatizados por presión sobre sílex rojo y presentan únicamente lustre. La lasca retocada fue manufacturada con materia prima del mismo núcleo del que se reconocieron abundantes lascas de adelgazamiento bifacial con lustre térmico.

Las piezas con cambios en lustre, color o pátina corresponden principalmente a sílex rojo (82,3\%), seguido por la calcedonia (11,3\%) (Tabla 10.23 y Fig. 10.21). Si bien es cierto que existe una fuerte predominancia del sílex rojo en el conjunto lítico de esta unidad (48,2\%), ésta se acentúa al analizar los restos con posible tratamiento térmico. Hemos realizado un test de Chi cuadrado evaluando si existe dependencia entre el tipo de materia prima y la presencia o no de tratamiento térmico y este ha arrojado diferencias muy significativas $\left(X^{2}=298,08 ; p=0,01 ; g . I .=4\right)$. Esto podría indicar que existía una preferencia en el empleo de esta materia prima al momento de 
confeccionar instrumentos tratados térmicamente. Es decir que estos grupos conocían las propiedades de esta materia prima y de los óptimos resultados que su tratamiento térmico arrojaba.

En relación a los productos de talla, predominan las esquirlas (57,5\%), seguidas por las lascas $(31,7 \%)$ (Tabla 10.20). Son mayormente del estadio $3(79,6 \%)$, presentándose también piezas de los estadios 1 y 2 (3,1\% y 17,3\% respectivamente) (Tabla 10.21). Dentro del estadio 3, 73 (56,6\%) son de retoque, $51(39,5 \%)$ de adelgazamiento bifacial, 4 de retalla $(3,1 \%)$ y $1(0,8 \%)$ de reactivación. El resto son indiferenciadas. Es interesante la alta cantidad de elementos alterados que corresponden a adelgazamiento bifacial, teniendo en cuenta que de los escasos instrumentos hallados en este componente, solo dos tienen un muy leve y marginal retoque bifacial. Del total de piezas con adelgazamiento bifacial reconocidas en el conjunto (72), el 70,8\% habrían sido tratadas térmicamente. Realizamos un test de Chi cuadrado para evaluar si existe dependencia entre el tipo de producto de talla del estadio 3 y la presencia o no de tratamiento térmico y este ha arrojado diferencias muy significativas $\left(X^{2}=10,72 ; p=0,01 ;\right.$ g.l. $\left.=2\right)$, lo que podría indicar que en este caso la aplicación del tratamiento térmico se realizó como paso previo a el empleo de técnicas específicas de manufactura, lo que lleva a pensar en una correlación entre el calentamiento y ciertas cadenas operativas. En relación con lo anterior, la longitud promedio de las piezas de adelgazamiento bifacial con tratamiento $(1,98 \mathrm{~cm})$ es mayor que en las no tratadas $(1,66 \mathrm{~cm})$. Sin embargo, al aplicar el test estadístico " $\mathrm{t}$ " de Student se observó que estas diferencias no son significativas $(t=1,14, p=0,01 ;$ g.l. $=70)$. Con relación a este resultado, consideramos que esto podría interpretarse de distintas maneras. Una opción es que la aplicación del tratamiento térmico sobre artefactos bifaciales no genere restos más largos que los no tratados y que este procedimiento se realice con otros motivos que pueden estar vinculados a la optimización de la talla, a la reducción del riesgo o a cuestiones estilíticas. Otra posibilidad es que el test muestre algún tipo de sesgo, quizás por el tamaño de muestra, teniendo en cuenta hay en promedio más de $2,5 \mathrm{~mm}$ de diferencia entre la longitud de las piezas tratadas y las no tratadas.

Al igual que en los otros subconjuntos, la mayor parte mide menos de $4 \mathrm{~cm}(96,1 \%)$, ubicándose principalmente en B1 $(54,8 \%)$, B2 (16,1\%) y A1 (9,8\%) (Tablas 10.22 y 10.24$)$.

En relación con el talón, vemos que predominan los facetados $(24,7 \%)$ y lisos $(19,3 \%)$. También se observan lineales (15\%), preparados (14\%), puntiformes (11,8\%), diedros $(8,6 \%)$, naturales $(6,4 \%)$ (Fig. 10.22). Al realizar un test de Chi cuadrado para evaluar si existe dependencia entre el tipo de talón y la presencia o no de tratamiento térmico se observan diferencias no significativas $\left(X^{2}=\right.$ 12,$49 ; p=0,01 ;$ g.l. = 6). En cuanto al bulbo, son preponderantes los levemente espesos $(56,4 \%)$, seguidos por los difusos $(36,2 \%)$ y los espesos $(7,4 \%)$. Un test de Chi cuadrado para evaluar si las piezas con rasgos de tratamiento térmico diferían de aquellas que no lo presentan en relación al bulbo a dado diferencias no significativas $\left(X^{2}=4,5 ; p=0,01 ; g . l .=2\right)$. Al igual que lo que sucede en 
C3T1, esto podría indicar que no existirían diferencias en la elección de plataformas de percusión entre los conjuntos tratados y sin tratar.

En cuanto a los productos de talla, la mayor parte muestra únicamente evidencias de lustre: $97,8 \%$ exhibe lustre en ambas caras y $2 \%$ tiene lustre sólo en la ventral. Además, tres piezas han cambiado de color en su cara dorsal. De ellas, en su cara ventral una también cambió de color, una presenta lustre y una evidencia ambas alteraciones. Ninguna presenta pátina (Tabla 10.25).

\begin{tabular}{|c|c|c|c|c|}
\hline & \multicolumn{3}{|c|}{ Cara dorsal } & \\
\hline Cara ventral & Sin cambio & Color & Lustre & Total \\
\hline Color, lustre & 0 & 1 & 0 & 1 \\
\hline Color & 0 & 1 & 0 & 1 \\
\hline Lustre & 8 & 1 & 396 & 405 \\
\hline Total & 8 & 3 & 396 & 407 \\
\hline
\end{tabular}

Tabla 10.25. Productos de talla con cambios de color, lustre o pátina. CDM1. Unidad 4.

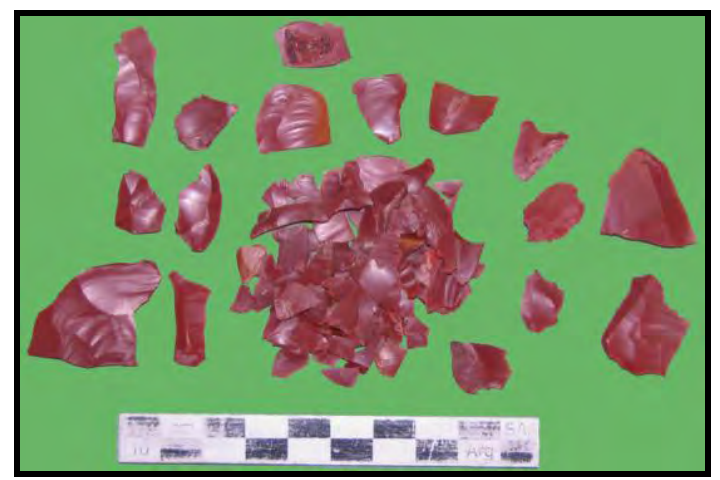

Fig. 10.21. Piezas de sílex rojo con lustre térmico. CDM1. Unidad 4.

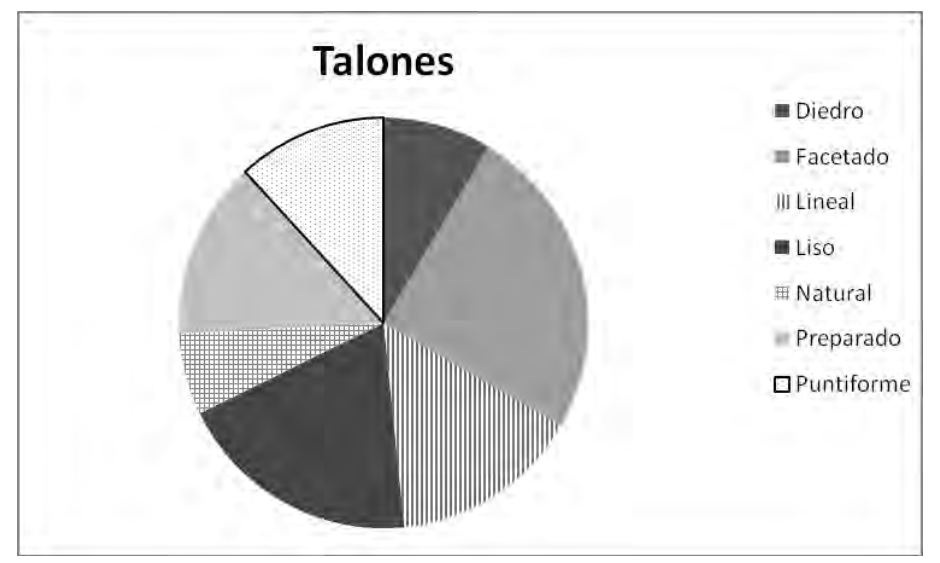

Fig. 10.22. Talones reconocidos en piezas tratadas térmicamente. CDM1. Unidad 4.

\subsection{Material óseo alterado térmicamente}

El 10,4\% de los restos muestran evidencias de termoalteración (Tabla 10.26). Estos están en su mayoría representando los estadios iniciales de combustión: parcialmente carbonizados (35,8\%), totalmente quemados $(20,1 \%)$, parcialmente quemados $(19 \%)$ o bien totalmente carbonizados 
$(15,6 \%)$. Los elementos termoalterados corresponden en su gran mayoría $(89,4 \%)$ a restos indeterminados. En el análisis de la textura también destacan los estadios iniciales, siendo el estadio 1 (textura grasosa - ondulante) el más representado $(65,6 \%)$, seguido por el estadio 2 (textura vítrea) con el 25,6\% (Fig. 10.23).

Al analizar la presencia de evidencias de termoalteración en la parte interna del hueso vemos que, en el $69,9 \%$ de los casos esta se presenta tanto en la cara externa como en el interior del hueso, mientras que en el 30,1\% restante no se observan evidencias de termoalteración interna (Fig. 10.12). En cuanto a las fracturas producidas por la termoalteración, estas se observan en escasas piezas (Tabla 10.27). Entre las fracturas y modificaciones de la superficie que se pudieron identificar predominan las fracturas longitudinales.

Con respecto a la procedencia de los elementos, estos provienen en su mayoría de B2 y B1 (27,4\% y $25,1 \%$ respectivamente) (Tabla 10.28). Por otra parte, al analizar los porcentajes de piezas termoalteradas en cada cuadrícula, se observa que el área con mayor cantidad de restos presenta porcentajes menores de restos termoalterados, mientras que las cuadrículas con menos cantidad de hallazgos presentan valores más altos de alteración térmica, en especial la cuadrícula H1 $(22,7 \%)$, que no presenta estructuras de combustión (Tabla 10.29). La figura 10.24 muestra que los restos termoalterados tienden concentrarse en las cercanías a las estructuras de combustión de esa unidad. No existiría, por el contrario, una correlación entre su distribución y la ubicación de los fogones de la unidad 3 inferior, inmediatamente sobreyacente. Con relación al tamaño, 66,5\% de los restos termoalterados es menor a dos cm (Tabla 10.30).

Por otra parte, como ya se mencionara en el capítulo 5, se han reconocido tres instrumentos óseos en el sitio. Se trata de 2 punzones y un retocador extremo lateral elaborados sobre diáfisis de camélido; en ninguno de ellos observamos evidencias de termoalteración. Tampoco identificamos lascas óseas termoalteradas. 


\begin{tabular}{|c|c|c|c|c|c|c|c|c|}
\hline Taxón & No alterado & P. quem. & T. quem. & P. carb. & T. carb. & P. calc. & T. calc. & Tot. \\
\hline $\begin{array}{c}\text { Mamíferos } \\
\text { indet. }\end{array}$ & 46 & 1 & 0 & 4 & 0 & 0 & 0 & 51 \\
\hline Dusicyon sp. & 10 & 0 & 0 & 1 & 0 & 0 & 0 & 11 \\
\hline $\begin{array}{c}\text { Dusicyon } \\
\text { griseus }\end{array}$ & 13 & 1 & 2 & 0 & 0 & 0 & 0 & 16 \\
\hline $\begin{array}{c}\text { Camélidos } \\
\text { indet. }\end{array}$ & 56 & 0 & 0 & 1 & 0 & 0 & 0 & 57 \\
\hline $\begin{array}{c}\text { Hemiauchenia } \\
\text { paradoxa }\end{array}$ & 13 & 0 & 0 & 0 & 0 & 0 & 0 & 13 \\
\hline Lama sp. & 137 & 2 & 0 & 1 & 0 & 0 & 1 & 141 \\
\hline Lama gracilis & 19 & 0 & 0 & 0 & 0 & 0 & 0 & 19 \\
\hline $\begin{array}{c}\text { Lama } \\
\text { guanicoe }\end{array}$ & 36 & 0 & 0 & 1 & 0 & 0 & 0 & 37 \\
\hline $\begin{array}{c}\text { Roedores } \\
\text { indet. }\end{array}$ & 44 & 0 & 0 & 0 & 0 & 0 & 0 & 44 \\
\hline Aves indet. & 15 & 0 & 0 & 0 & 0 & 0 & 0 & 15 \\
\hline Rheidos & 19 & 3 & 1 & 0 & 0 & 0 & 0 & 23 \\
\hline Indet. & 1134 & 27 & 33 & 56 & 28 & 5 & 11 & 1294 \\
\hline Total & 1542 & 34 & 36 & 64 & 28 & 5 & 12 & 1721 \\
\hline
\end{tabular}

Tabla 10.26. Termoalteración de restos óseos por taxón. CDM1. Unidad 4. P.: Parcialmente. T.: Totalmente. Quem.: Quemado. Carb.: Carbonizado. Calc.: calcinado.

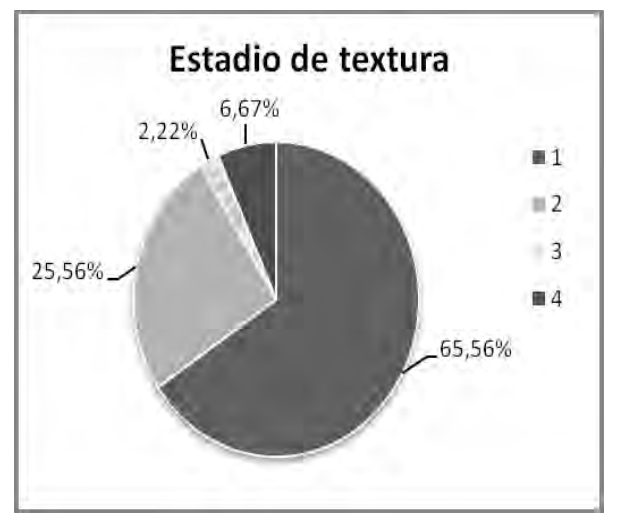

Fig. 10.23. Textura de los restos termoalterados por estadio. CDM1. Unidad 4.

\begin{tabular}{|c|c|}
\hline Fracturas & $\%$ \\
\hline Grietas longitudinales & 0,56 \\
\hline Deformación & 0,56 \\
\hline F. longitudinales & 8,89 \\
\hline F. transversales y longitudinales & 1,11 \\
\hline Sin F. por termoalteración & 88,89 \\
\hline Total & 100 \\
\hline
\end{tabular}

Tabla 10.27. Fracturas producidas por termoalteración. CDM1. Unidad 4. F. = Fracturas 


\begin{tabular}{|c|c|c|c|c|c|c|c|}
\hline & P. quem. & T. quem. & P. carb. & T. carb. & P. calc. & T. calc. & Total \\
\hline A1 & 3 & 5 & 7 & 5 & 0 & 0 & 20 \\
\hline A2 & 1 & 1 & 2 & 1 & 0 & 1 & 6 \\
\hline B1 & 8 & 12 & 14 & 6 & 0 & 5 & 45 \\
\hline B2 & 14 & 6 & 24 & 2 & 0 & 3 & 49 \\
\hline C1 & 2 & 1 & 6 & 1 & 1 & 0 & 11 \\
\hline C2 & 0 & 6 & 4 & 0 & 1 & 0 & 11 \\
\hline E & 0 & 0 & 0 & 0 & 1 & 0 & 1 \\
\hline F1 & 2 & 1 & 1 & 7 & 2 & 0 & 13 \\
\hline H1 & 3 & 2 & 0 & 0 & 0 & 0 & 5 \\
\hline J1 & 0 & 0 & 2 & 3 & 0 & 0 & 5 \\
\hline K1 & 1 & 2 & 4 & 2 & 0 & 2 & 11 \\
\hline K2 & 0 & 0 & 0 & 1 & 0 & 1 & 2 \\
\hline Total & 34 & 36 & 64 & 28 & 5 & 12 & 179 \\
\hline
\end{tabular}

Tabla 10.28. Termoalteración de restos óseos por cuadrícula. CDM1. Unidad 4.

\begin{tabular}{|c|c|c|c|}
\hline Sector & Termoalterados & Total & \% Termoalterados \\
\hline A1 & 20 & 221 & 9,0 \\
\hline A2 & 6 & 125 & 4,8 \\
\hline B1 & 45 & 509 & 8,8 \\
\hline B2 & 49 & 423 & 11,6 \\
\hline C1 & 11 & 130 & 8,4 \\
\hline C2 & 11 & 73 & 15,1 \\
\hline E & 1 & 41 & 2,4 \\
\hline F1 & 13 & 66 & 19,7 \\
\hline F2 & 0 & 6 & 0 \\
\hline H1 & 5 & 22 & 22,7 \\
\hline J1 & 5 & 37 & 13,5 \\
\hline K1 & 11 & 50 & 22 \\
\hline K2 & 2 & 16 & 12,5 \\
\hline Total & 179 & 1721 & 10,4 \\
\hline
\end{tabular}

Tabla 10.29. \% de restos óseos termoalterados por cuadrícula. CDM1. Unidad 4.

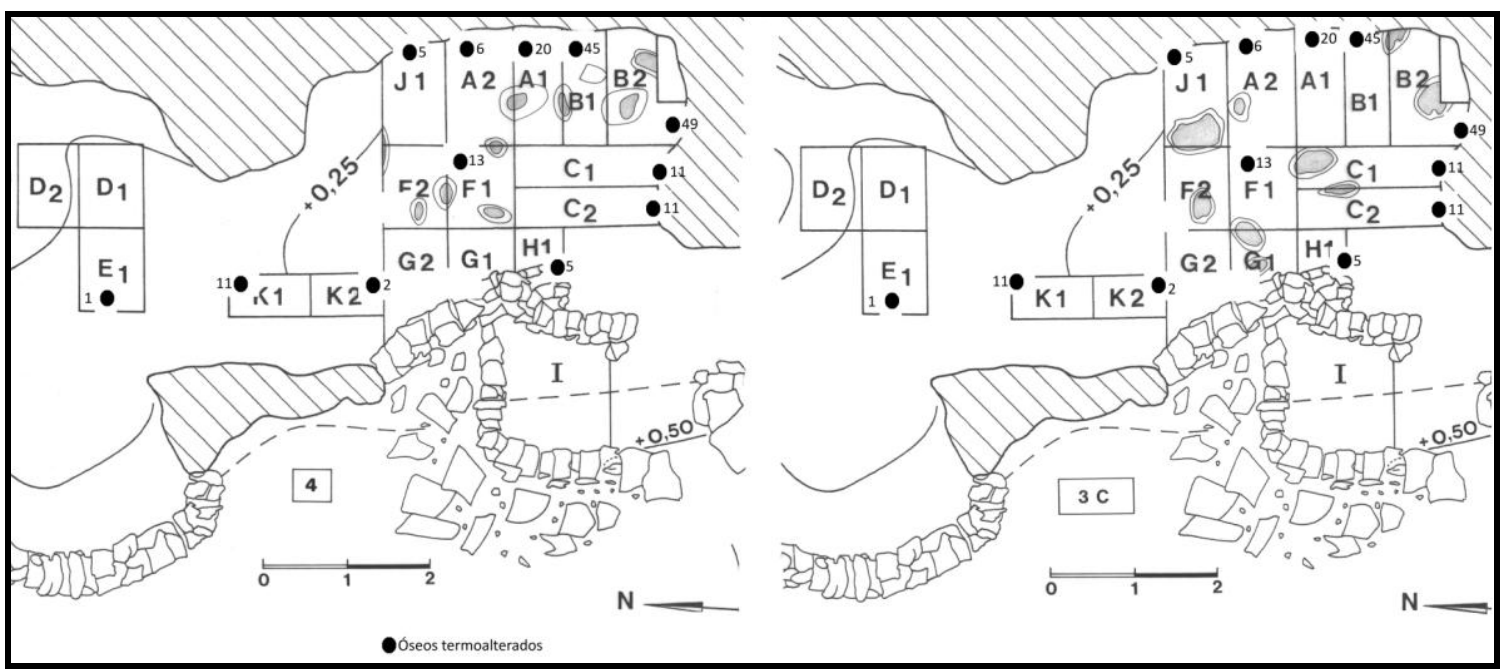

Fig. 10.24. Ubicación de los restos óseos termoalterados de la unidad 4 en relación a los fogones de esa unidad y de la unidad 3 inferior. CDM1. 


\begin{tabular}{|c|c|c|c|c|c|c|c|}
\hline & P. quem. & T. quem. & P. carb. & T. carb. & P. calc. & T. calc. & Total \\
\hline Mayor a dos cm & 16 & 9 & 29 & 2 & 3 & 1 & 60 \\
\hline Menor a dos cm & 18 & 27 & 35 & 26 & 2 & 11 & 119 \\
\hline Total & 34 & 36 & 64 & 28 & 5 & 12 & 179 \\
\hline
\end{tabular}

Tabla 10.30. Termoalteración de restos óseos por tamaño. CDM1. Unidad 4.

10.3.2.2. Unidad 3 inferior

\subsection{Fogones}

Se identificaron nueve fogones en este componente, que se encuentran algo más dispersos que en la unidad 4, ocupando un mayor espacio de la cueva, y abarcando diez de las diecisiete cuadrículas trabajadas (Cuadro 10.3 y Fig. 5.6), cuatro de las cuales presentan dos fogones cada una. Todos son de estructura plana lenticular, con formas levemente elípticas. En cuanto a sus dimensiones, vemos que la mayor parte presentan dimensiones similares, con un eje mayor que mide entre 27 y $47 \mathrm{~cm}$ y un eje menor que ronda entre los 20 y los $30 \mathrm{~cm}$. Tres de los fogones, sin embargo, son más grandes, con un eje mayor entre los 55 y los $67 \mathrm{~cm}$ y un eje menor que va entre los 35 y $42 \mathrm{~cm}$ (Cuadro 10.3 y Fig. 10.1).

\begin{tabular}{|c|c|c|}
\hline Ubicación & Eje mayor & Eje menor \\
\hline A1-A2 & 35 & 25 \\
\hline B1-B2 & 32 & 25 \\
\hline B2 & 55 & 42 \\
\hline C1-C2 & 47 & 20 \\
\hline C1-F1 & 60 & 35 \\
\hline F1-G1 & 47 & 30 \\
\hline G1 & 27 & 22 \\
\hline F2 & 40 & 30 \\
\hline F2-J1 & 67 & 42 \\
\hline
\end{tabular}

Cuadro 10.3. Longitud de los ejes mayor y menor de los fogones. CDM 1. Unidad 3 inferior.

\subsection{Distribución en planta de los restos}

En referencia al conjunto lítico, el 98,2\% de las piezas se encuentra en nueve cuadrículas que presentan evidencias de estructuras de combustión $\left(7,8 \mathrm{~m}^{2}\right.$ aproximadamente) mientras que el $1,8 \%$ restante se ubica en dos que no presentan fogones (alrededor de $1,1 \mathrm{~m}^{2}$ ). Seis $\left(3,8 \mathrm{~m}^{2}\right)$ no presentan restos líticos ni fogones.

Observamos que el conjunto se concentra en dos focos; uno en el sector este de la cueva, focalizándose en $A 2$, pero que incluye también a F1, F2 y J1 que cuenta con casi el $60 \%$ de las 
piezas, y otro ubicado al sudeste con B1, B2 y C1 reuniendo el 25\% del conjunto (Tabla 10.31). En el resto de las cuadrículas hay muy poco material lítico.

Las piezas de cada cuadrícula abarcan diversos tamaños, aunque predominan siempre los elementos más pequeños (Fig. 10.25). En todos los sectores, aunque especialmente en A2, prevalece ampliamente el sílex rojo. En B1 por su parte se observa una alta proporción de sílex marrón (Tabla 10.32). Son preponderantes los elementos correspondientes al estadio 2 (Fig. 10.26), en especial en los sectores con mayor cantidad de piezas.

\begin{tabular}{|c|c|c|c|c|c|c|c|c|c|c|c|c|}
\hline Grupo & A2 & B1 & B2 & C1 & C2 & E & F1 & F2 & G1 & K2 & J1 & Total \\
\hline I & 1 & 0 & 1 & 4 & 0 & 0 & 1 & 0 & 0 & 0 & 0 & 7 \\
\hline XT & 468 & 123 & 94 & 85 & 12 & 9 & 143 & 124 & 38 & 13 & 81 & 1190 \\
\hline Total & 469 & 123 & 95 & 89 & 12 & 9 & 144 & 124 & 38 & 13 & 81 & 1197 \\
\hline \% & 39,2 & 10,3 & 7,9 & 7,4 & 1,0 & 0,8 & 12,0 & 10,3 & 3,2 & 1,1 & 6,8 & 100 \\
\hline
\end{tabular}

Tabla 10.31. Artefactos líticos por cuadrícula. CDM1. Unidad 3 inferior.

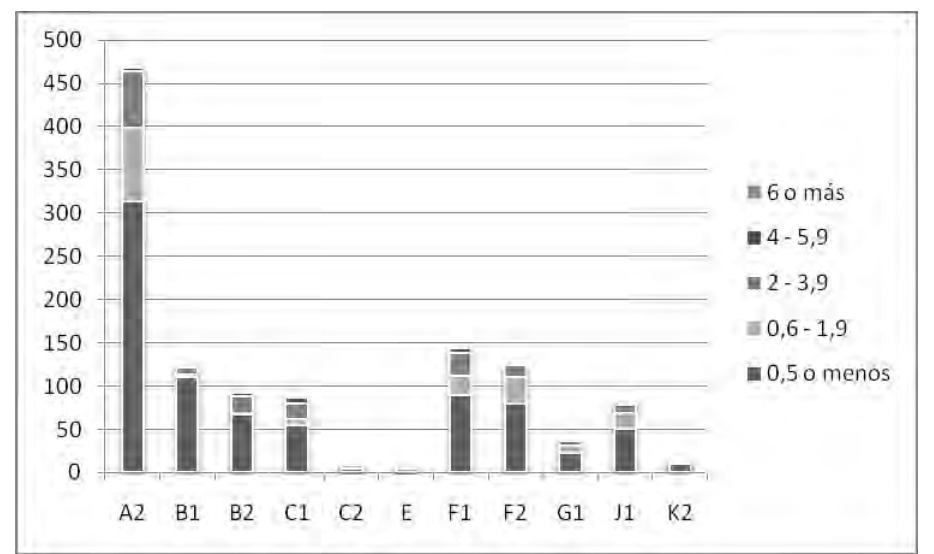

Fig. 10.25. Dimensión máxima en cm. de artefactos líticos por cuadrícula. CDM1. Unidad 3 inf.

\begin{tabular}{|c|c|c|c|c|c|c|c|c|c|c|c|c|c|}
\hline Materia Prima & Color & A2 & B1 & B2 & C1 & C2 & E & F1 & F2 & G1 & J1 & K2 & Total \\
\hline Calcedonia & & 11 & 2 & 6 & 12 & 1 & 3 & 16 & 3 & 4 & 5 & 6 & 69 \\
\hline \multirow{4}{*}{ Sílex } & Amarillo & 23 & 1 & 0 & 7 & 0 & 2 & 12 & 2 & 1 & 2 & 0 & 50 \\
\cline { 2 - 15 } & Gris & 3 & 8 & 1 & 0 & 0 & 0 & 2 & 0 & 0 & 1 & 1 & 16 \\
\cline { 2 - 15 } & Marrón & 4 & 57 & 10 & 2 & 5 & 0 & 8 & 1 & 2 & 4 & 0 & 93 \\
\cline { 2 - 14 } & Otros & 2 & 1 & 0 & 2 & 1 & 0 & 3 & 0 & 3 & 4 & 0 & 14 \\
\cline { 2 - 13 } & Rojo & 426 & 54 & 69 & 61 & 4 & 4 & 96 & 115 & 28 & 65 & 6 & 928 \\
\hline Otras & & 0 & 0 & 9 & 5 & 1 & 0 & 7 & 3 & 0 & 0 & 0 & 25 \\
\hline Total & & 469 & 123 & 95 & 89 & 12 & 9 & 144 & 124 & 38 & 81 & 13 & 1197 \\
\hline
\end{tabular}

Tabla 10.32. Materia prima de de artefactos líticos por cuadrícula. CDM1. Unidad 3 inferior. 


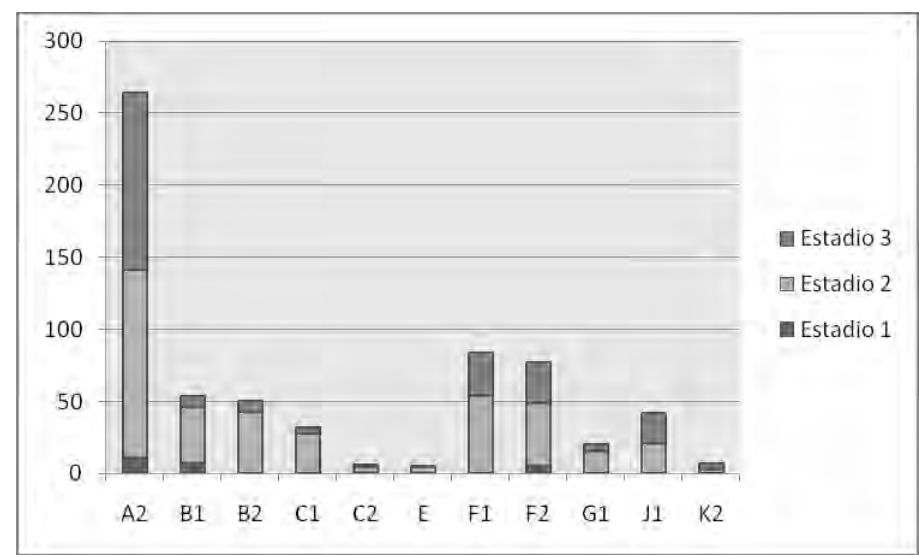

Fig. 10.26. Estadio de reducción de productos de talla por cuadrícula. CDM1. Unidad 3 inferior.

Con relación al conjunto óseo podemos ver que, al igual que con los líticos, la concentración de restos se da en el sector sudeste de la cueva. En este sentido, el 94,58\% se encuentra en nueve cuadrículas que presentan evidencias de estructuras de combustión (7,78 $\mathrm{m}^{2}$ aproximadamente) mientras que el 5,42\% restante se localiza en un sólo sector sin presencia de estructuras de combustión (0,4 $\mathrm{m}^{2}$ aproximadamente). Cuatro sectores $\left(3,8 \mathrm{~m}^{2}\right)$ no tienen elementos óseos ni fogones.

Los restos se concentran principalmente en la cuadrícula B2 $(27,4 \%)$ seguido por $F 1(16,2 \%)$ y A2 $(14,8 \%)$; estos son mayormente indeterminados (Tabla 10.33). En cuanto a aquellos a los que se les pudo determinar taxón, podríamos decir que están concentrados en B2. Cabe aclarar que el análisis llevó a reconsiderar la asignación taxonómica de algunos de los elementos clasificados.

Si consideramos los restos de camélidos, observamos que no existe una diferencia en la distribución del esqueleto apendicular en relación con el axial, ambos se concentran en B2 (Tabla 10.34). El 71,2\% de los restos miden más de $2 \mathrm{~cm}$ (Fig. 10.27). Estos se agrupan en B2 mientras que los elementos más pequeños, se distribuyen más uniformemente.

\begin{tabular}{|c|c|c|c|c|c|c|c|c|c|c|c|}
\hline Taxón & A2 & B1 & B2 & C1 & C2 & F1 & F2 & G1 & J1 & K2 & Total \\
\hline Mamíferos indet. & 0 & 1 & 0 & 0 & 0 & 0 & 0 & 0 & 0 & 0 & 1 \\
\hline Lama sp. & 0 & 0 & 4 & 3 & 0 & 0 & 0 & 0 & 0 & 0 & 7 \\
\hline Lama guanicoe & 0 & 1 & 11 & 0 & 0 & 0 & 1 & 0 & 0 & 0 & 13 \\
\hline Roedor & 0 & 0 & 2 & 0 & 0 & 0 & 0 & 1 & 0 & 0 & 3 \\
\hline Aves indet. & 0 & 1 & 8 & 0 & 0 & 0 & 0 & 0 & 0 & 0 & 9 \\
\hline Rheidos & 0 & 0 & 0 & 1 & 1 & 0 & 0 & 0 & 0 & 0 & 2 \\
\hline Indet. & 41 & 15 & 51 & 6 & 7 & 45 & 33 & 21 & 8 & 15 & 242 \\
\hline Total & 41 & 18 & 76 & 10 & 8 & 45 & 34 & 22 & 8 & 15 & 277 \\
\hline
\end{tabular}

Tabla 10.33. Restos óseos de cada taxón por cuadrícula. CDM1. Unidad 3 inferior.

\begin{tabular}{|c|c|c|c|c|c|}
\hline & B1 & B2 & C1 & F2 & Total \\
\hline Esqueleto apendicular & 1 & 9 & 2 & 1 & 13 \\
\hline Esqueleto axial & 0 & 3 & 0 & 0 & 3 \\
\hline Total & 1 & 12 & 2 & 1 & 16 \\
\hline
\end{tabular}

Tabla 10.34. Esqueleto apendicular y axial de camélidos por cuadrícula. CDM1. U. 3 inf. 


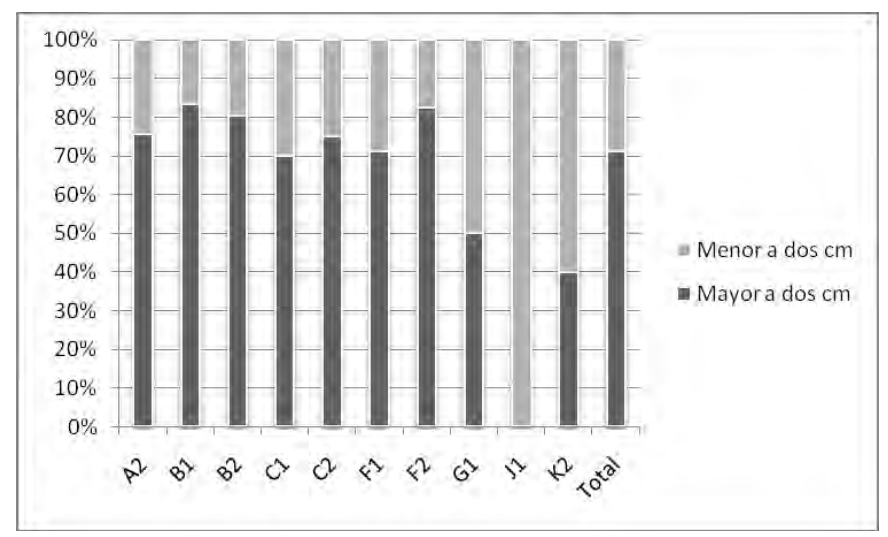

Fig. 10.27. Tamaño de los elementos óseos por cuadrícula. CDM1. Unidad 3 inferior.

\subsection{Material lítico alterado térmicamente}

En cuanto a las piezas con alteración térmica (61), constituyen el 5,1\% del conjunto. De estas, 34 presentan evidencias de daño térmico y 27 tienen únicamente cambios de color, lustre o pátina. Todas son productos de talla (Tabla 10.35$)$. Predominan las esquirlas $(49,2 \%)$, luego le siguen las lascas y los fragmentos de talla (26,2\% y $13,1 \%$ respectivamente) (Tabla 10.36$)$. De aquellos a los cuales se les pudo identificar un estadio dentro de la secuencia de producción, el 53,1\% corresponde al estadio 3 de formatización final, mientras que dentro del estadio 1 de descortezamiento hay un $6,25 \%$ y el $40,6 \%$ corresponde al estadio 2 de talla (Tabla 10.37).

El 96,7\% de las piezas presentan una dimensión máxima de entre 0,1 y 3,9 cm (el 60,7\% es menor a $0,5 \mathrm{~cm}$ el $23 \%$ está entre 0,6 y $2 \mathrm{~cm}$ y el $13,1 \%$ entre 2 y $3,9 \mathrm{~cm}$ ). Es decir, la gran mayoría posee dimensiones pequeñas (Tabla 10.38).

Son principalmente de sílex (82\%), en especial de color rojo. Se observan también restos de calcedonia (14,8\%) (Tabla 10.39). Al analizar la figura 10.28 notamos que en general las materias primas presentan muy bajos índices de termoalteración, con excepción del xilópalo y los otros sílex, aunque en ambos casos las cantidades totales son my exiguas. Se ubican dispersas en el espacio, presentándose en valores bajos en varias cuadrículas; las que más piezas tienen son A2 $(19,7 \%)$ y $C 1$ (18\%) (Tabla 10.40).

\begin{tabular}{|c|c|c|c|}
\hline Daño dorsal & Daño ventral & $\mathbf{X T}$ & Total \\
\hline \multirow{2}{*}{ No } & No & 27 & 27 \\
\cline { 2 - 4 } & $\mathbf{S i}$ & 6 & 6 \\
\hline \multirow{2}{*}{ Si } & No & 5 & 5 \\
\cline { 2 - 4 } & $\mathbf{S i}$ & 23 & 23 \\
\hline Total & & 61 & 61 \\
\hline
\end{tabular}

Tabla 10.35. Piezas con alteración térmica por grupo. CDM1. Unidad 3 inferior. No= Sin daño térmico pero con alteraciones del tipo lustre, color y pátina. 


\begin{tabular}{|c|c|c|c|c|c|c|}
\hline Daño dorsal & Daño ventral & ESQ & FT & L & MESQ & Total \\
\hline \multirow{2}{*}{ No } & No & 15 & 1 & 9 & 2 & 27 \\
\cline { 2 - 7 } & Si & 3 & 1 & 1 & 1 & 6 \\
\hline \multirow{2}{*}{ Si } & No & 4 & 0 & 1 & 0 & 5 \\
\cline { 2 - 7 } & Si & 8 & 6 & 5 & 4 & 23 \\
\hline Total & & 30 & 8 & 16 & 7 & 61 \\
\hline
\end{tabular}

Tabla 10.36. Productos de talla con alteración térmica por clase. CDM1. Unidad 3 inferior

\begin{tabular}{|c|c|c|c|c|c|}
\hline $\begin{array}{c}\text { Daño } \\
\text { dorsal }\end{array}$ & $\begin{array}{c}\text { Daño } \\
\text { ventral }\end{array}$ & $\mathbf{1}$ & $\mathbf{2}$ & $\mathbf{3}$ & Total \\
\hline \multirow{2}{*}{ No } & No & 1 & 4 & 15 & 20 \\
\cline { 2 - 6 } & $\mathbf{S i}$ & 0 & 3 & 0 & 3 \\
\hline \multirow{2}{*}{$\mathrm{Si}$} & $\mathbf{N o}$ & 1 & 2 & 0 & 3 \\
\cline { 2 - 6 } & $\mathbf{S i}$ & 0 & 4 & 2 & 6 \\
\hline Total & & 2 & 13 & 17 & 32 \\
\hline
\end{tabular}

Tabla 10.37. Productos de talla con alteración térmica por estadio. CDM1. Unidad 3 inferior

\begin{tabular}{|c|c|c|c|c|c|c|}
\hline $\begin{array}{c}\text { Daño } \\
\text { dorsal }\end{array}$ & $\begin{array}{c}\text { Daño } \\
\text { ventral }\end{array}$ & $\begin{array}{c}\mathbf{0 , 5} \mathbf{0} \\
\text { menos }\end{array}$ & $\begin{array}{c}\mathbf{0 , 6}- \\
\mathbf{1 , 9}\end{array}$ & $\mathbf{2}-\mathbf{3 , 9}$ & $\begin{array}{c}\mathbf{4}- \\
\mathbf{5 , 9}\end{array}$ & Total \\
\hline \multirow{2}{*}{ No } & No & 17 & 5 & 3 & 2 & 27 \\
\cline { 2 - 7 } & $\mathbf{S i}$ & 4 & 1 & 1 & 0 & 6 \\
\hline \multirow{2}{*}{$\mathrm{Si}$} & $\mathbf{N o}$ & 4 & 1 & 0 & 0 & 5 \\
\cline { 2 - 7 } & $\mathbf{S i}$ & 12 & 7 & 4 & 0 & 23 \\
\hline Total & & 37 & 14 & 8 & 2 & 61 \\
\hline
\end{tabular}

Tabla 10.38. Piezas con alteración térmica por dimensión máxima. CDM1. Unidad 3 inferior

\begin{tabular}{|c|c|c|c|c|c|c|c|}
\hline \multirow{2}{*}{ Daño dorsal } & \multirow{2}{*}{ Daño ventral } & \multirow{2}{*}{ Calcedonia } & \multicolumn{3}{|c|}{ Sílex } & \multirow{2}{*}{ Xilópalo } & \multirow{2}{*}{ Total } \\
\cline { 3 - 8 } & & & Rojo & Marrón & Otros & & \\
\hline \multirow{2}{*}{ No } & No & 6 & 12 & 4 & 3 & 2 & 27 \\
\cline { 2 - 8 } & Si & 0 & 5 & 0 & 1 & 0 & 6 \\
\hline \multirow{2}{*}{ Si } & No & 1 & 3 & 1 & 0 & 0 & 5 \\
\cline { 2 - 8 } & Si & 2 & 16 & 1 & 4 & 0 & 23 \\
\hline \multirow{2}{*}{ Total } & & 9 & 36 & 6 & 8 & 2 & 61 \\
\hline
\end{tabular}

Tabla 10.39 Piezas con alteración térmica por materia prima. CDM1. Unidad 3 inferior

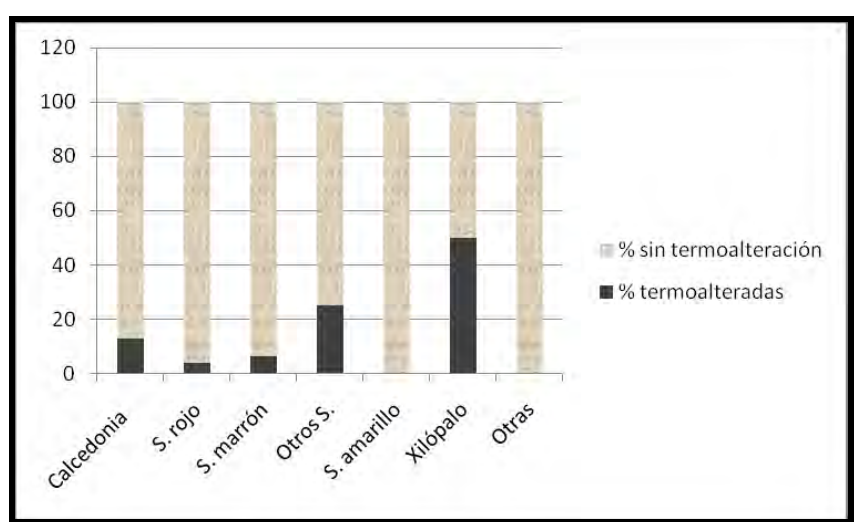

Fig. 10.28. \% de piezas termoalteradas por materia prima. CDM1. Unidad 3 inferior

\begin{tabular}{|c|c|c|c|c|c|c|c|c|c|c|c|c|}
\hline Daño dorsal & Daño ventral & A2 & B1 & B2 & C1 & C2 & F1 & F2 & G1 & J1 & K2 & Total \\
\hline \multirow{2}{*}{ No } & No & 5 & 2 & 4 & 4 & 1 & 3 & 3 & 1 & 3 & 1 & 27 \\
\cline { 2 - 14 } & Si & 1 & 0 & 0 & 2 & 0 & 2 & 0 & 0 & 1 & 0 & 6 \\
\hline \multirow{2}{*}{ Si } & No & 0 & 1 & 0 & 2 & 1 & 0 & 1 & 0 & 0 & 0 & 5 \\
\cline { 2 - 14 } & Si & 6 & 0 & 2 & 3 & 1 & 4 & 2 & 2 & 3 & 0 & 23 \\
\hline \multirow{2}{*}{ Total } & & 12 & 3 & 6 & 11 & 3 & 9 & 6 & 3 & 7 & 1 & 61 \\
\hline
\end{tabular}

Tabla 10.40. Piezas con alteración térmica por sector. CDM1. Unidad 3 inferior. 
10.3.2.2.3.1. Piezas con daño térmico

Las piezas con daño térmico se distribuyen en los siguientes grupos: cinco con daño únicamente en la cara dorsal, seis con daño únicamente en la ventral y 23 con daño en ambas caras.

10.3.2.2.3.1. Piezas con daño en ambas caras

Son principalmente de sílex rojo $(69,6 \%)$ (Tabla 10.39$)$. Son en su mayoría esquirlas $(34,8 \%$ ) y se observan cantidades considerables de fragmentos de talla y lascas $(26,1 \%$ y $21,7 \%$ respectivamente) (Tabla 10.36). Corresponden principalmente al estadio 2 (66,6\%) (Tabla 10.37). Todos miden menos de $4 \mathrm{~cm}$ (Tabla 10.38). Se ubican predominantemente en dos cuadrículas adyacentes: A2 y F1 (26,1\% y 17,4\% respectivamente) (Tabla 10.40). Estas piezas no fueron subsecuentemente retocadas ni evidencian lustre térmico.

10.3.2.2.3.1.2. Piezas con daño en cara dorsal

Se trata de cinco productos de talla. El 60\% corresponde a sílex rojo (Tabla 10.39). Son principalmente esquirlas (80\%) que corresponden mayormente al estadio 2 (66,6\%) (Tablas 10.36 y 10.37). Todas miden menos de $2 \mathrm{~cm}$ (Tabla 10.38). Se ubican dispersas en diferentes cuadrículas (Tabla 10.40). En una pieza de sílex rojo que corresponde al estadio 2, además de daño en la cara dorsal, se observa lustre en la cara ventral.

10.3.2.2.3.1.3. Piezas con daño en cara ventral

Se trata de seis productos de talla, corresponden principalmente a sílex rojo (83,3\%) (Tabla 10.39). Son predominantemente esquirlas (50\%) y pertenecen en su totalidad al estadio 2 (Tablas 10.36 y 10.37). Todas miden menos de $4 \mathrm{~cm}$ (Tabla 10.38). Se ubican dispersas en distintos sectores (Tabla 10.40).

Sólo una pieza presenta dimensiones factibles de ser posteriormente tallada. Es de sílex rojo, posee un potencial filo funcional y fue encontrada en la cuadrícula J1, que cuenta con un fogón de grandes dimensiones. 
10.3.2.2.3.2. Piezas con alteración térmica pero sin daño

Hay 27 piezas con evidencias de alteración térmica pero que no han sufrido daños. Es decir, solo presentan pátina, lustre o cambio de color. Son todos productos de talla, corresponden principalmente a sílex rojo (44,4\%), seguido por la calcedonia (22,2\%) (Tabla 10.39).

Predominan las esquirlas (55,5\%), seguidas por las lascas (33,3\%) (Tabla 10.36). Pertenecen mayormente al estadio 3 (75\%), presentándose también escasos restos de los estadios 1 y 2 (5\% y $20 \%$ respectivamente) (Tabla 10.37$)$. Dentro del estadio $3,8(72,2 \%)$ son de retoque y $3(27,8 \%)$ de adelgazamiento bifacial. El resto son indiferenciadas.

Al igual que en los otros subconjuntos, la mayor parte mide menos de $4 \mathrm{~cm}(92,6 \%)$ (Tabla 10.38). Están dispersas en diversas cuadrículas, aunque hay más presencia en A2 (18,5\%), B2 y C1 (14,8\% en cada una) (Tabla 10.40).

Con relación al talón, vemos que predominan los puntiformes (42,9\%) y preparados (28,6\%) (Fig. 10.29); mientras que al analizar los bulbos se observa la prevalencia de los difusos y levemente espesos (42,9\% respectivamente) reconociéndose sólo un producto de talla con bulbo espeso.

La mayor parte de este subconjunto muestra únicamente evidencias de lustre: 92,6\% en ambas caras y 7,4\% sólo lo tiene en la cara ventral. Únicamente dos piezas evidencian, además del lustre, cambio de color. Ninguna presenta pátina (Tabla 10.41). Las piezas con lustre en la cara ventral muestran un marcado contraste en la textura entre ambas caras.

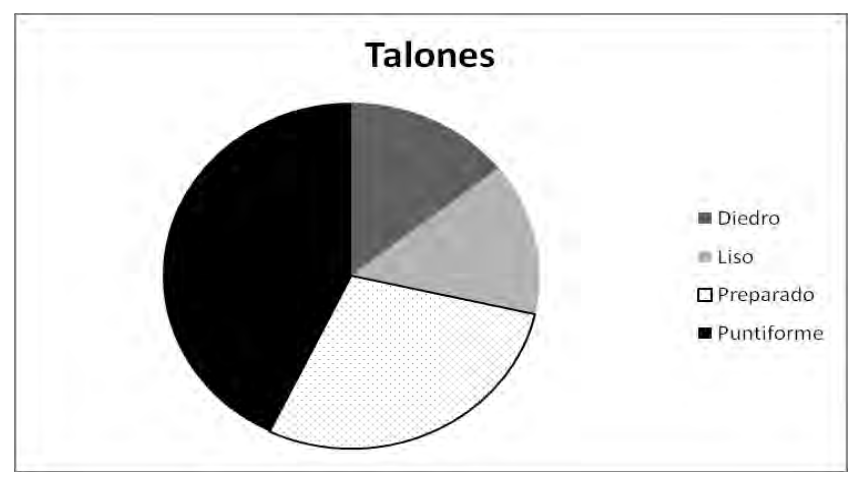

Fig. 10.29. Talones reconocidos en piezas tratadas térmicamente. CDM1. Unidad 3 inferior.

\begin{tabular}{|c|c|c|c|c|}
\hline & \multicolumn{3}{|c|}{ Cara dorsal } & \\
\hline Cara ventral & Sin cambio & Color, lustre & Lustre & Total \\
\hline Color, lustre & 0 & 1 & 0 & 1 \\
\hline Lustre & 2 & 1 & 23 & 26 \\
\hline Total & 2 & 2 & 23 & 27 \\
\hline
\end{tabular}

Tabla 10.41. Productos de talla con cambios de color, lustre o pátina. CDM1. Unidad 3 inferior. 


\subsection{Material óseo alterado térmicamente}

El 5,8\% de los restos están termoalterados (Tabla 10.42). Estos están en su mayoría representando los estadios iniciales de combustión: totalmente quemados $(56,3 \%)$ y parcialmente carbonizados (18,8\%). Los elementos alterados por el fuego corresponden en su gran mayoría $(93,8 \%)$ a restos indeterminados. En el análisis de la textura se nota que todas las piezas presentan un estadio inicial (textura ondulante).

Al analizar la presencia de evidencias de termoalteración en la parte interna del hueso vemos que, en el $100 \%$ de los casos está presente tanto en la cara externa como en el interior del hueso (Fig. 10.12). No se han reconocido fracturas producidas por la acción térmica.

Con respecto a la procedencia de los elementos, si bien se encuentran dispersos, estos tienden a concentrarse en el sector central de la cueva; proceden en su mayoría de A2 (25\%) (Tabla 10.43). Por otra parte, al analizar los porcentajes de piezas termoalteradas en cada cuadrícula, se observa que, con excepción de A2, el área con mayor cantidad de restos presenta porcentajes menores de restos con esta alteración, mientras que las cuadrículas con menos piezas presentan valores más altos, en especial J1 (25\%), que cuenta con una estructura de combustión (Tabla 10.44). En relación al tamaño, $87,5 \%$ de estos restos es menor a dos $\mathrm{cm}$ (Tabla 10.45).

Como ya se mencionara en el capítulo 5, se ha reconocido un instrumento óseo en esta unidad. Se trata de una punta roma elaborada sobre diáfisis de camélido, procede de $\mathrm{C} 1$ y no presenta evidencias de termoalteración. Por otra parte, durante la revisión del material identificamos otro instrumento, se trata de un punzón cuyas dimensiones son 3,1 cm de largo y 0,4 cm tanto de espesor como de ancho. Se confeccionó sobre un fragmento de diáfisis indeterminado. Este tampoco presenta evidencias acción del fuego. Reconocimos una sola lasca ósea termoalterada.

\begin{tabular}{|c|c|c|c|c|c|c|c|}
\hline Taxón & No alterado & P. quem. & T. quem. & P. carb. & T. carb. & T. calc. & Total \\
\hline Mamíferos indet. & 1 & 0 & 0 & 0 & 0 & 0 & 1 \\
\hline Lama sp. & 7 & 0 & 0 & 0 & 0 & 0 & 7 \\
\hline Lama guanicoe & 13 & 0 & 0 & 0 & 0 & 0 & 13 \\
\hline Roedores indet. & 2 & 0 & 1 & 0 & 0 & 0 & 3 \\
\hline Aves indet. & 9 & 0 & 0 & 0 & 0 & 0 & 9 \\
\hline Rheidos & 2 & 0 & 0 & 0 & 0 & 0 & 2 \\
\hline Indet. & 227 & 1 & 8 & 3 & 2 & 1 & 242 \\
\hline Total & 261 & 1 & 9 & 3 & 2 & 1 & 277 \\
\hline
\end{tabular}

Tabla 10.42. Termoalteración de restos óseos por taxón. CDM1. Unidad 3 inferior. P.: Parcialmente. T.: Totalmente. Quem.: Quemado. Carb.: Carbonizado. Calc.: calcinado. 


\begin{tabular}{|c|c|c|c|c|c|c|}
\hline & P. quem. & T. quem. & P. carb. & T. carb. & T. calc. & Total \\
\hline A2 & 0 & 3 & 1 & 0 & 0 & 4 \\
\hline B1 & 1 & 0 & 0 & 1 & 0 & 2 \\
\hline B2 & 0 & 0 & 1 & 0 & 0 & 1 \\
\hline F1 & 1 & 0 & 0 & 1 & 0 & 2 \\
\hline F2 & 0 & 1 & 0 & 0 & 0 & 1 \\
\hline G1 & 0 & 2 & 0 & 0 & 0 & 2 \\
\hline J1 & 0 & 1 & 0 & 0 & 1 & 2 \\
\hline K2 & 0 & 2 & 0 & 0 & 0 & 2 \\
\hline Total & 2 & 9 & 2 & 2 & 1 & 16 \\
\hline
\end{tabular}

Tabla 10.43. Termoalteración de restos óseos por cuadrícula. CDM1. Unidad 3 inferior.

\begin{tabular}{|c|c|c|c|}
\hline Sector & Termoalterados & Total & \% Termoalterados \\
\hline A2 & 4 & 41 & 9,8 \\
\hline B1 & 2 & 18 & 11,1 \\
\hline B2 & 1 & 76 & 1,3 \\
\hline C1 & 0 & 10 & 0 \\
\hline C2 & 0 & 8 & 0 \\
\hline F1 & 2 & 45 & 4,4 \\
\hline F2 & 1 & 34 & 2,9 \\
\hline G1 & 2 & 22 & 9,1 \\
\hline J1 & 2 & 8 & 25 \\
\hline K2 & 2 & 15 & 13,3 \\
\hline Total & 16 & 277 & 5,8 \\
\hline
\end{tabular}

Tabla 10.44. \% de restos óseos termoalterados por cuadrícula. CDM1. Unidad 3 inferior.

\begin{tabular}{|c|c|c|c|c|c|c|}
\hline Tamaño & P. quem. & T. quem. & P carb. & T. carb. & T. calc. & Total \\
\hline Mayor a dos cm & 0 & 0 & 2 & 0 & 0 & 2 \\
\hline Menor a dos cm & 1 & 9 & 1 & 2 & 1 & 14 \\
\hline Total & 1 & 9 & 3 & 2 & 1 & 16 \\
\hline
\end{tabular}

Tabla 10.45. Termoalteración de restos óseos por tamaño. CDM1. Unidad 3 inferior.

\subsubsection{Unidad 3 medio}

\subsection{Fogones}

No se identificaron fogones en este componente.

\subsection{Distribución en planta de los restos}

El conjunto lítico se concentra en dos cuadrículas, A2 (28,6\%) y K2 (19,6\%). Otro sector con gran cantidad de piezas es el área de B1 y B2. Ambas cuadrículas juntas abarcan el 24,9\% de los líticos (Tabla 10.46). En el resto hay muy poco material en piedra.

Las piezas presentes en cada cuadrícula abarcan diversos tamaños, aunque predominan siempre los elementos más pequeños (Fig. 10.30). En todos los sectores prevalece el sílex rojo. En A2 por 
su parte se observa una alta proporción de sílex marrón. La calcedonia se presenta principalmente en K2 (Tabla 10.47). Tanto los elementos correspondientes al estadio 2 de talla (los más abundantes) como los pertenecientes al estadio 3 de formatización final son más conspicuos en A2 (Fig. 10.31).

\begin{tabular}{|c|c|c|c|c|c|c|c|c|c|c|c|c|c|}
\hline Grupo & A2 & B1 & B2 & C1 & C2 & D1 & F1 & F2 & G1 & H1 & J1 & K2 & Total \\
\hline FI & 2 & 0 & 0 & 0 & 0 & 0 & 0 & 0 & 0 & 0 & 0 & 0 & 2 \\
\hline I & 1 & 0 & 0 & 0 & 0 & 0 & 1 & 2 & 1 & 0 & 0 & 0 & 5 \\
\hline XT & 146 & 72 & 58 & 4 & 10 & 25 & 20 & 34 & 12 & 2 & 29 & 102 & 514 \\
\hline Total & 149 & 72 & 58 & 4 & 10 & 25 & 21 & 36 & 13 & 2 & 29 & 102 & 521 \\
\hline \% & 28,6 & 13,8 & 11,1 & 0,8 & 1,9 & 4,8 & 4 & 6,9 & 2,5 & 0,4 & 5,6 & 19,6 & 100 \\
\hline
\end{tabular}

Tabla 10.46. Artefactos líticos por cuadrícula. CDM1. Unidad 3 medio.

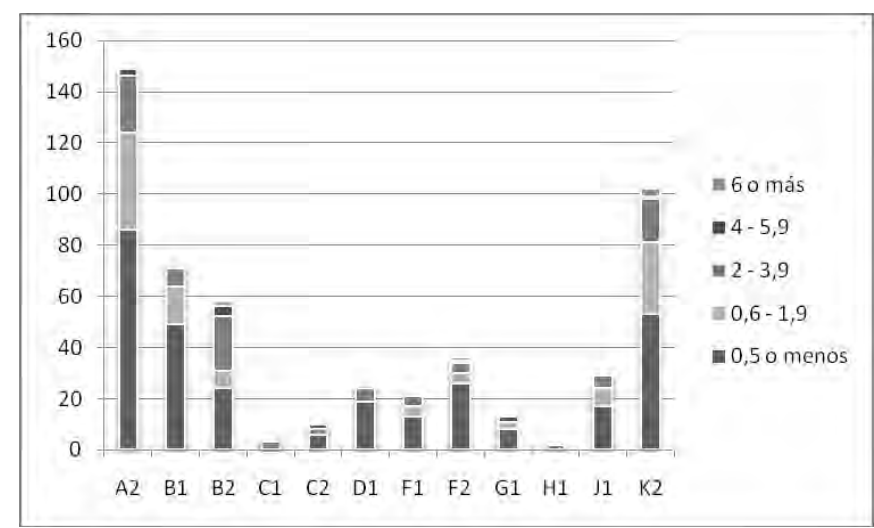

Fig. 10.30. Dimensión máxima en $\mathrm{cm}$. de artefactos líticos por cuadrícula. CDM1. Unidad 3 medio.

\begin{tabular}{|c|c|c|c|c|c|c|c|c|c|c|c|c|c|c|}
\hline Clase de MP & Color & A2 & B1 & B2 & C1 & $\mathrm{C2}$ & D1 & F1 & $\mathbf{F 2}$ & G1 & H1 & J1 & $\mathrm{K} 2$ & Tot. \\
\hline Calcedonia & & 5 & 2 & 0 & 0 & 0 & 3 & 2 & 4 & 2 & 1 & 1 & 20 & 40 \\
\hline Obsidiana & & 1 & 0 & 0 & 0 & 0 & 1 & 0 & 0 & 1 & 0 & 0 & 0 & 3 \\
\hline \multirow{4}{*}{ Sílex } & Amarillo & 0 & 0 & 1 & 0 & 0 & 1 & 1 & 1 & 0 & 0 & 1 & 5 & 10 \\
\hline & Marrón & 69 & 6 & 16 & 0 & 1 & 1 & 0 & 0 & 1 & 0 & 0 & 5 & 99 \\
\hline & Rojo & 67 & 61 & 39 & 3 & 7 & 14 & 17 & 29 & 6 & 1 & 26 & 63 & 333 \\
\hline & Otros & 6 & 3 & 2 & 1 & 0 & 1 & 1 & 2 & 2 & 0 & 1 & 8 & 27 \\
\hline Toba & & 1 & 0 & 0 & 0 & 0 & 0 & 0 & 0 & 0 & 0 & 0 & 0 & 1 \\
\hline Toba sil. & & 0 & 0 & 0 & 0 & 2 & 4 & 0 & 0 & 1 & 0 & 0 & 1 & 8 \\
\hline Total & & 149 & 72 & 58 & 4 & 10 & 25 & 21 & 36 & 13 & 2 & 29 & 102 & 521 \\
\hline
\end{tabular}

Tabla 10.47. Materia prima de de artefactos líticos por cuadrícula. CDM1. Unidad 3 medio. 


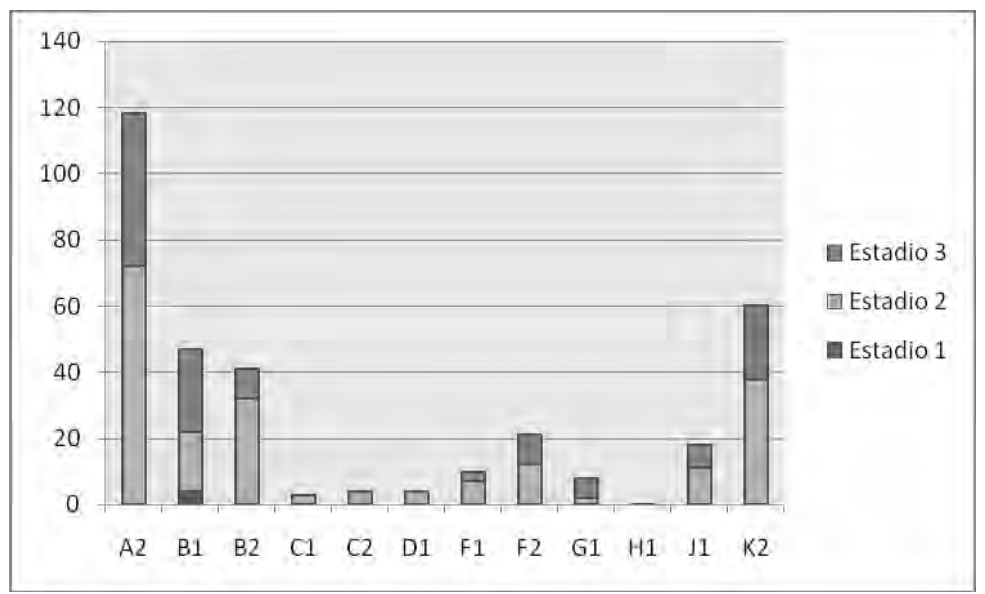

Fig. 10.31. Estadio de reducción de productos de talla por cuadrícula. CDM1. Unidad 3 medio.

Con relación al conjunto óseo, podemos ver que su concentración se da en el sector oeste de la cueva, en especial en K2 $(29,1 \%)$ y G1 $(20,3 \%)$. Corresponden principalmente a restos indeterminados, en tanto que los restos asignables a Lama guanicoe se encuentran en su totalidad en la cuadrícula B2 (Tabla 10.48 y 10.49).

Con relación al tamaño de los elementos, a nivel general hay mayor cantidad de restos que superan los dos cm (66,3\%); manteniéndose esta relación en las cuadrículas con mayor cantidad de restos excepto en F1 donde predominan los elementos menores a dos $\mathrm{cm}(93,1 \%)$ (Fig. 10.32).

\begin{tabular}{|c|c|c|c|c|c|c|c|c|c|c|c|c|}
\hline Taxón & A2 & B1 & B2 & C1 & C2 & D1 & F1 & F2 & G1 & J1 & K2 & Total \\
\hline Mamíferos indet. & 4 & 1 & 0 & 0 & 0 & 0 & 0 & 0 & 4 & 0 & 0 & 9 \\
\hline Lama sp. & 0 & 0 & 1 & 0 & 1 & 0 & 0 & 0 & 2 & 0 & 1 & 5 \\
\hline Lama guanicoe & 0 & 0 & 8 & 0 & 0 & 0 & 0 & 0 & 0 & 0 & 0 & 8 \\
\hline Roedores indet. & 0 & 0 & 2 & 0 & 0 & 0 & 6 & 5 & 0 & 0 & 0 & 13 \\
\hline Aves indet. & 1 & 0 & 1 & 0 & 0 & 0 & 0 & 4 & 4 & 1 & 0 & 11 \\
\hline Indet. & 4 & 10 & 20 & 6 & 4 & 25 & 23 & 2 & 43 & 3 & 75 & 215 \\
\hline Total & 9 & 11 & 32 & 6 & 5 & 25 & 29 & 11 & 53 & 4 & 76 & 261 \\
\hline
\end{tabular}

Tabla 10.48. Restos óseos de cada taxón por cuadrícula. CDM1. Unidad 3 medio.

\begin{tabular}{|c|c|c|c|c|c|}
\hline & B2 & C2 & G1 & K2 & Total \\
\hline Esqueleto apendicular & 4 & 0 & 2 & 1 & 7 \\
\hline Esqueleto axial & 5 & 1 & 0 & 0 & 6 \\
\hline Total & 9 & 1 & 2 & 1 & 13 \\
\hline
\end{tabular}

Tabla 10.49. Elementos del esqueleto apendicular y axial de camélidos por cuadrícula. CDM1. Unidad 3 medio. 


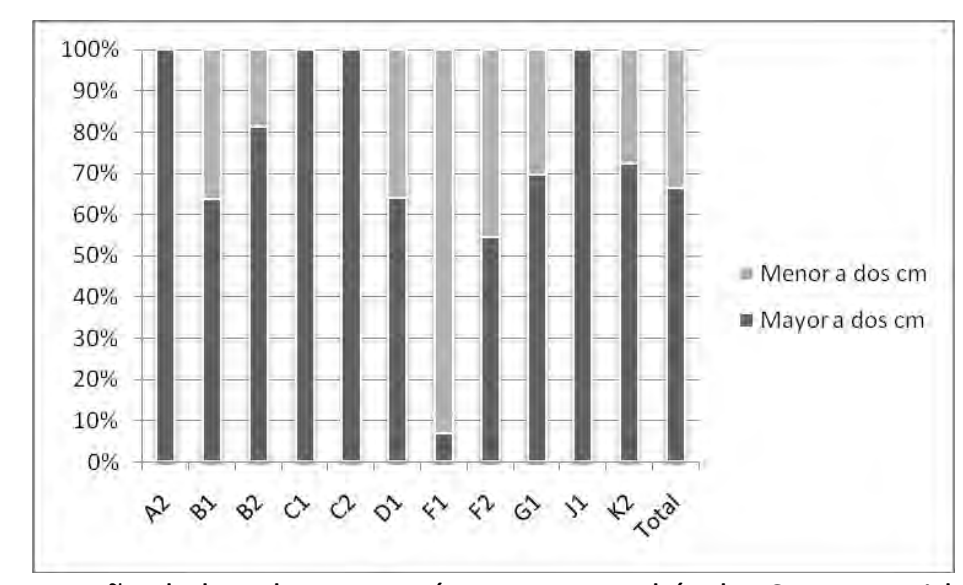

Fig. 10.32. Tamaño de los elementos óseos por cuadrícula. CDM1. Unidad 3 medio.

\subsection{Material lítico alterado térmicamente}

En cuanto a las piezas con alteración térmica (seis), representan el 1,1\% del conjunto. De estas, cinco están dañadas y una tiene únicamente rastros de lustre. Todas son productos de talla (Tabla 10.50), siendo principalmente lascas (50\%), correspondientes al estadio de talla (Tablas 10.51 y 10.52). El $83,3 \%$ presenta una dimensión máxima de entre 0,1 y $3,9 \mathrm{~cm}$. Sólo una pieza supera estas dimensiones, midiendo $6,2 \mathrm{~cm}$ de ancho (Tabla 10.53).

Las piezas son en su totalidad de sílex, de diversos colores (Tabla 10.54). En todos los casos los porcentajes de termoalteración por materia prima son muy bajos, y sólo se observan valores que superan el $10 \%$ en el caso de variedades de sílex con muy baja cantidad total de restos (Fig. 10.33) Se ubican principalmente en la cuadrícula K2 (66,6\%) (Tabla 10.55).

\begin{tabular}{|c|c|c|c|}
\hline Daño dorsal & Daño ventral & $\mathbf{X T}$ & Total \\
\hline No & No & 1 & 1 \\
\hline Si & Si & 5 & 5 \\
\hline Total & & 6 & 6 \\
\hline
\end{tabular}

Tabla 10.50. Piezas con alteración térmica por grupo. CDM1. U. 3 medio. No= Sin daño térmico pero con alteraciones del tipo lustre, color y pátina.

\begin{tabular}{|c|c|c|c|c|c|}
\hline Daño dorsal & Daño ventral & ESQ & FT & L & Tot. \\
\hline No & No & 0 & 0 & 1 & 1 \\
\hline Si & Si & 1 & 2 & 2 & 5 \\
\hline Total & & 1 & 2 & 3 & 6 \\
\hline
\end{tabular}

Tabla 10.51. Productos de talla con alteración térmica por clase. CDM1. Unidad 3 medio

\begin{tabular}{|c|c|c|c|}
\hline $\begin{array}{c}\text { Daño } \\
\text { dorsal }\end{array}$ & $\begin{array}{c}\text { Daño } \\
\text { ventral }\end{array}$ & $\mathbf{2}$ & Total \\
\hline No & No & 1 & 1 \\
\hline Si & Si & 2 & 2 \\
\hline Total & & 3 & 3 \\
\hline
\end{tabular}

Tabla 10.52. Productos de talla con alteración térmica por estadio. CDM1. U. 3 medio

\begin{tabular}{|c|c|c|c|c|c|c|}
\hline $\begin{array}{c}\text { Daño } \\
\text { dorsal }\end{array}$ & $\begin{array}{c}\text { Daño } \\
\text { ventral }\end{array}$ & $\begin{array}{c}\mathbf{0 , 5} \mathbf{0} \\
\text { menos }\end{array}$ & $\mathbf{0 , 6}-\mathbf{1 , 9}$ & $\mathbf{2}-\mathbf{3 , 9}$ & $\mathbf{6}$ o más & Total \\
\hline No & No & 0 & 0 & 1 & 0 & 1 \\
\hline Si & Si & 2 & 2 & 0 & 1 & 5 \\
\hline Total & & 2 & 2 & 1 & 1 & 6 \\
\hline
\end{tabular}

Tabla 10.53. Piezas con alteración térmica por dimensión máxima. CDM1. Unidad 3 medio 


\begin{tabular}{|c|c|c|c|c|c|c|c|}
\hline \multirow{2}{*}{ Daño dorsal } & \multirow{2}{*}{ Daño ventral } & \multicolumn{5}{|c|}{ Sílex } & \multirow{2}{*}{ Total } \\
\cline { 3 - 8 } & & Bordo & Marrón & Naranja & Rojo & Rosa & \\
\hline No & No & 0 & 0 & 0 & 1 & 0 & 1 \\
\hline Si & Si & 1 & 1 & 1 & 1 & 1 & 5 \\
\hline Total & & 1 & 1 & 1 & 2 & 1 & 6 \\
\hline
\end{tabular}

Tabla 10.54. Piezas con alteración térmica por materia prima. CDM1. Unidad 3 medio

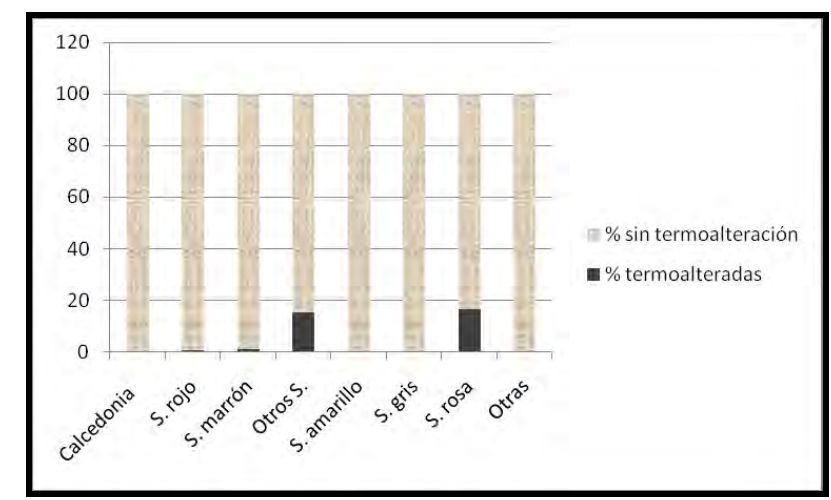

Fig. 10.33. \% de piezas termoalteradas por materia prima. CDM1. Unidad 3 medio

\begin{tabular}{|c|c|c|c|c|c|}
\hline Daño dorsal & Daño ventral & K2 & A2 & J1 & Total \\
\hline No & No & 1 & 0 & 0 & 1 \\
\hline Si & Si & 3 & 1 & 1 & 5 \\
\hline Total & & 4 & 1 & 1 & 6 \\
\hline
\end{tabular}

Tabla 10.55. Piezas con alteración térmica por sector. CDM1. Unidad 3 medio.

10.3.2.3.1. Piezas con daño térmico

Las cinco piezas dañadas térmicamente presentan este tipo de evidencias en ambas caras.

\subsection{Piezas con daño en ambas caras}

Los elementos con daño en ambas caras son de sílex de diversos colores (Tabla 10.54). Son principalmente fragmentos de talla y lascas ( $40 \%$ cada una), que corresponden al estadio 2 (Tablas 10.51 y 10.52). El $80 \%$ mide menos de $2 \mathrm{~cm}$ (Tabla 10.53). Se ubican predominantemente en K2 (60\%) (Tabla 10.55). No evidencian lustre. Sólo una de las piezas, una lasca de sílex marrón de grandes dimensiones y con un filo potencialmente funcional, podría haber sido tratada térmicamente. Sin embargo, no ha sido subsecuentemente retocada.

10.3.2.3.2. Piezas con alteración térmica pero sin daño

Sólo hay una pieza que presenta alteración térmica pero no daño. Se trata de una lasca de sílex rojo correspondiente al estadio dos. Mide 2,9 cm de largo, tiene un talón natural y un bulbo levemente espeso; procede de K2. Muestra lustre en ambas caras. 


\subsection{Material óseo alterado térmicamente}

El 2,7\% de los restos muestran evidencias de termoalteración (Tabla 10.56). Están en su mayoría representando los estadios finales de combustión: el 57,1\% está total o parcialmente calcinado. Los elementos modificados por el fuego corresponden a restos indeterminados. En el análisis de la textura de los restos también destacan los estadios finales de combustión, siendo el estadio 4 (textura tizosa) la más representada (71,4\%) (Fig. 10.34).

Al analizar la presencia de evidencias de termoalteración en la parte interna del hueso vemos que, en el $100 \%$ de los casos está presente tanto en la cara externa como en su interior (Fig. 10.12). No se han reconocido fracturas producidas por el fuego.

Con respecto a su procedencia, tienden a concentrarse en el sector central de la cueva; proceden en su mayoría de $\mathrm{F} 1(57,1 \%)$ (Tabla 10.57). Al analizar los porcentajes de piezas termoalteradas en cada cuadrícula, se observa que F1 muestra valores altos, teniendo en cuenta la escasa cantidad de restos (Tabla 10.58). Con relación al tamaño, $85,7 \%$ de los elementos modificados por el fuego es menor a dos cm (Tabla 10.59).

Hemos identificado una lasca ósea totalmente quemada. Por otra parte, no se han reconocido instrumentos óseos en esta unidad.

\begin{tabular}{|c|c|c|c|c|c|}
\hline Taxón & No alterado & T. quem. & P. calc. & T. calc. & Total \\
\hline Mamíferos indet. & 9 & 0 & 0 & 0 & 9 \\
\hline Lama sp. & 5 & 0 & 0 & 0 & 5 \\
\hline Lama guanicoe & 8 & 0 & 0 & 0 & 8 \\
\hline Roedores indet. & 13 & 0 & 0 & 0 & 13 \\
\hline Aves indet. & 11 & 0 & 0 & 0 & 11 \\
\hline Indet. & 208 & 3 & 1 & 3 & 215 \\
\hline Total & 254 & 3 & 1 & 3 & 261 \\
\hline
\end{tabular}

Tabla 10.56. Termoalteración de restos óseos por taxón. CDM1. Unidad 3 medio. P.: Parcialmente. T.: Totalmente. Quem.: Quemado. Carb.: Carbonizado. Calc.: calcinado.

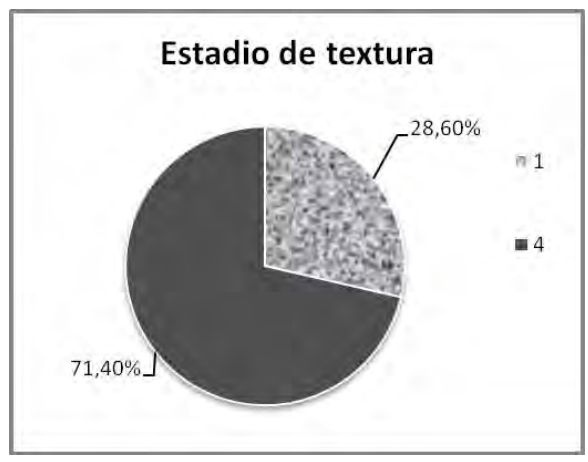

Fig. 10.34. Textura de los restos termoalterados por estadio. CDM1. Unidad 3 medio. 


\begin{tabular}{|c|c|c|c|c|}
\hline & T. quem. & P. calc. & T. calc. & Total \\
\hline B1 & 1 & 0 & 0 & 1 \\
\hline F1 & 1 & 1 & 2 & 4 \\
\hline G1 & 0 & 0 & 1 & 1 \\
\hline K2 & 1 & 0 & 0 & 1 \\
\hline Total & 3 & 1 & 3 & 7 \\
\hline
\end{tabular}

\begin{tabular}{|c|c|c|c|}
\hline Sector & Termoalt. & Total & \% Termoalt. \\
\hline A2 & 0 & 9 & 0 \\
\hline B1 & 1 & 11 & 9,1 \\
\hline B2 & 0 & 32 & 0 \\
\hline C1 & 0 & 6 & 0 \\
\hline C2 & 0 & 5 & 0 \\
\hline D1 & 0 & 25 & 0 \\
\hline F1 & 4 & 29 & 13,8 \\
\hline F2 & 0 & 11 & 0 \\
\hline G1 & 1 & 53 & 1,9 \\
\hline J1 & 0 & 4 & 0 \\
\hline K2 & 1 & 76 & 1,3 \\
\hline Total & 7 & 261 & 2,7 \\
\hline
\end{tabular}

Tabla 10.58. \% de restos óseos termoalterados por cuadrícula. CDM1. Unidad 3 medio.

Termoalt. $=$ Termoalterados

\begin{tabular}{|c|c|c|c|c|}
\hline & T. quem. & P. calc. & T. calc. & Total \\
\hline Mayor a dos cm & 0 & 0 & 1 & 1 \\
\hline Menor a dos cm & 3 & 1 & 2 & 6 \\
\hline Total & 3 & 1 & 3 & 7 \\
\hline
\end{tabular}

Tabla 10.59. Termoalteración de restos óseos por tamaño. CDM1. Unidad 3 medio.

\subsubsection{Sitio Cueva Túnel}

\subsubsection{Componente inferior}

\subsection{Fogones}

No se identificaron fogones en este componente.

\subsection{Distribución en planta de los restos}

Observamos que las escasas piezas líticas recuperadas se presentan dispersas en la totalidad del sector excavado, con porcentajes más altos en E1 (14,1\%) (Tabla 10.60). Los elementos presentes en cada cuadrícula abarcan diversos tamaños, aunque predominan siempre los más pequeños. Hay muy pocas piezas mayores a $4 \mathrm{~cm}$ y ninguna cuadrícula cuenta con más de dos de estos elementos (Fig. 10.35). En relación a las materias primas también se observa que estas están relativamente dispersas. Sin embargo, en el caso de las más abundantes, se puede observar una tendencia a concentrarse en cuadrículas determinadas. Así, por ejemplo, 22,2\% de los restos de sílex gris se registró en D1, y un porcentaje similar en J1. El 33,3\% de las piezas de sílex marrón 
proceden de 12. El 57,1\% de las de ópalo translúcido gris se ubican en F1 y el $41,7 \%$ de las de ópalo translúcido marrón de E1, de donde también proviene el $28,6 \%$ de las piezas de ópalo translúcido naranja (Tabla 10.61). Con relación al estadio de reducción, las lascas del estadio 3 tienden a concentrarse en E1 (32\%), mientras que las del estadio 2 se encuentran relativamente dispersas (Fig. 10.36).

\begin{tabular}{|c|c|c|c|c|c|c|c|c|c|c|c|c|c|c|c|c|c|c|c|c|}
\hline Grupo & A1 & A2 & B1 & B2 & B3 & C1 & D1 & E1 & E2 & F1 & F2 & G2 & H1 & H2 & H3 & I1 & I2 & J1 & K1 & Tot. \\
\hline I & 1 & 0 & 1 & 1 & 0 & 1 & 0 & 1 & 1 & 0 & 0 & 0 & 0 & 0 & 0 & 0 & 1 & 0 & 0 & 7 \\
\hline XT & 3 & 2 & 5 & 8 & 4 & 6 & 8 & 12 & 7 & 6 & 2 & 1 & 4 & 1 & 1 & 2 & 9 & 7 & 2 & 90 \\
\hline Ecofacto & 0 & 0 & 0 & 0 & 0 & 0 & 0 & 1 & 0 & 0 & 0 & 0 & 1 & 0 & 0 & 0 & 0 & 0 & 0 & 2 \\
\hline Total & 4 & 2 & 6 & 9 & 4 & 7 & 8 & 14 & 8 & 6 & 2 & 1 & 5 & 1 & 1 & 2 & 10 & 7 & 2 & 99 \\
\hline$\%$ & 4 & 2 & 6,1 & 9,1 & 4 & 7,1 & 8,1 & 14,1 & 8,1 & 6,1 & 2 & 1 & 5,1 & 1 & 1 & 2 & 10,1 & 7,1 & 2 & 100 \\
\hline
\end{tabular}

Tabla 10.60. Artefactos líticos por cuadrícula. CT. Componente inferior.

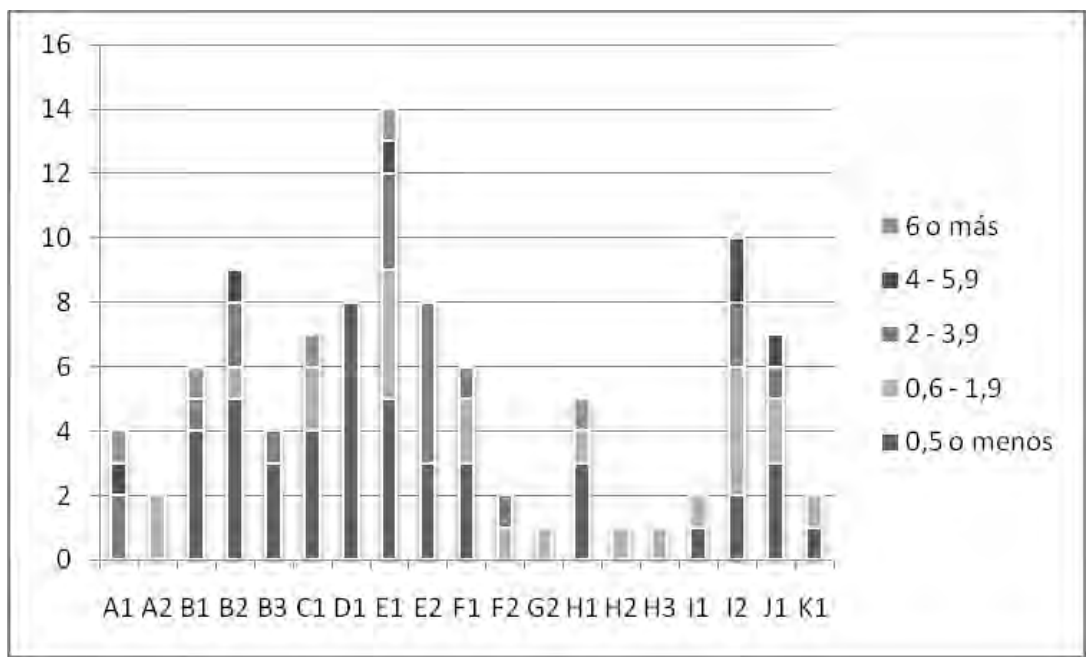

Fig. 10.35. Dimensión máxima en cm. de artefactos líticos por cuadrícula. CT. C.I. 


\begin{tabular}{|c|c|c|c|c|c|c|c|c|c|}
\hline MP & \multicolumn{3}{|c|}{ Sílex } & \multicolumn{4}{|c|}{ Ópalo trans. } & \multirow{2}{*}{ Otras } & \multirow{2}{*}{ Total } \\
\hline Color & Gris & Marrón & Otros & Gris & Marrón & Naranja & Otros & & \\
\hline A1 & 0 & 0 & 2 & 0 & 0 & 0 & 0 & 2 & 4 \\
\hline A2 & 2 & 0 & 0 & 0 & 0 & 0 & 0 & 0 & 2 \\
\hline B1 & 1 & 0 & 2 & 0 & 0 & 1 & 0 & 2 & 6 \\
\hline B2 & 0 & 2 & 3 & 0 & 1 & 3 & 0 & 0 & 9 \\
\hline B3 & 0 & 0 & 1 & 0 & 1 & 1 & 0 & 1 & 4 \\
\hline C1 & 1 & 0 & 2 & 0 & 1 & 0 & 1 & 2 & 7 \\
\hline D1 & 4 & 1 & 1 & 0 & 0 & 2 & 0 & 0 & 8 \\
\hline E1 & 0 & 1 & 0 & 1 & 5 & 4 & 1 & 2 & 14 \\
\hline E2 & 2 & 1 & 1 & 0 & 2 & 1 & 1 & 0 & 8 \\
\hline F1 & 1 & 0 & 0 & 4 & 0 & 1 & 0 & 0 & 6 \\
\hline F2 & 0 & 1 & 0 & 1 & 0 & 0 & 0 & 0 & 2 \\
\hline G2 & 1 & 0 & 0 & 0 & 0 & 0 & 0 & 0 & 1 \\
\hline H1 & 0 & 0 & 0 & 0 & 0 & 1 & 1 & 3 & 5 \\
\hline H2 & 0 & 0 & 0 & 1 & 0 & 0 & 0 & 0 & 1 \\
\hline H3 & 0 & 1 & 0 & 0 & 0 & 0 & 0 & 0 & 1 \\
\hline I1 & 1 & 0 & 1 & 0 & 0 & 0 & 0 & 0 & 2 \\
\hline 12 & 1 & 5 & 2 & 0 & 2 & 0 & 0 & 0 & 10 \\
\hline J1 & 4 & 1 & 2 & 0 & 0 & 0 & 0 & 0 & 7 \\
\hline K1 & 0 & 2 & 0 & 0 & 0 & 0 & 0 & 0 & 2 \\
\hline Tot. & 18 & 15 & 17 & 7 & 12 & 14 & 4 & 12 & 99 \\
\hline
\end{tabular}

Tabla 10.61. Materia prima de de artefactos líticos por cuadrícula. . CT. Componente inferior.

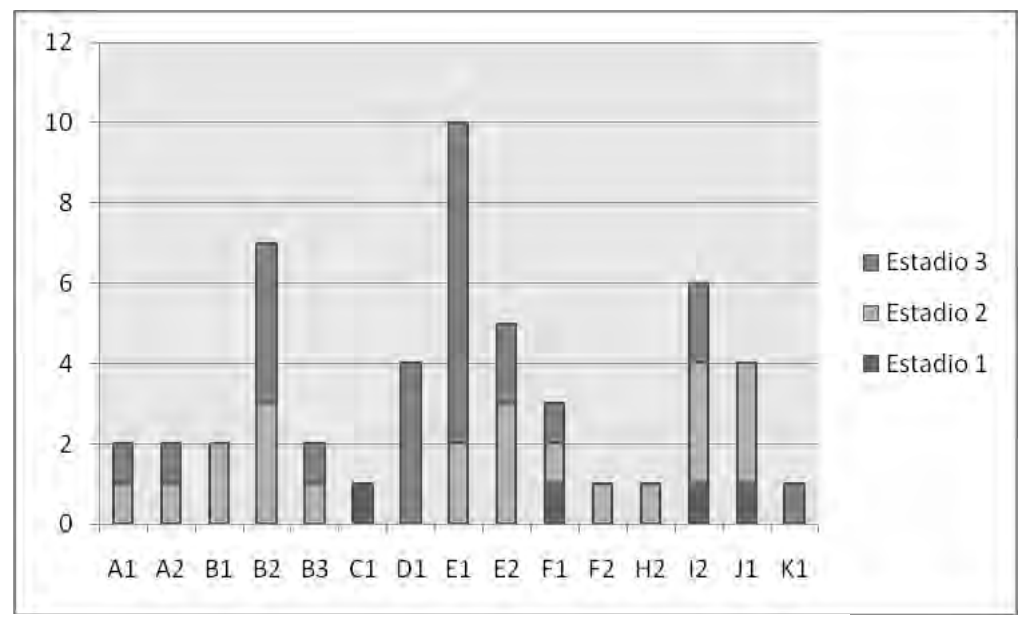

Fig. 10.36. Estadio de reducción de productos de talla por cuadrícula. CT. Componente inferior.

Con relación al conjunto óseo, podemos ver que si bien la mayor parte de las cuadrículas presentan abundantes restos, algunas muestran mayor cantidad de elementos, particularmente 12 donde se presenta el $21 \%$ de los huesos. En esta cuadrícula se observa gran cantidad de restos de roedores. En cuanto a los elementos a los que se les pudo determinar taxón, se puede observar que los restos de Lama sp. son más abundantes en B3 (14,6\%), los de Lama guanicoe en $12(37,5 \%)$ y los de Lama gracilis en $\mathrm{H} 1(57,1 \%)$, mientras que los de rheidos se hallan mayormente al este del sector excavado, principalmente en C1 (37,8\%) (Tabla 10.62).

Si consideramos los restos de camélidos, que constituyen la familia más abundante, observamos que mientras que los elementos del esqueleto apendicular se concentran en B3 $(11,4 \%)$, B2 
$(10,8 \%), A 2(10,1 \%)$ e $12(10,1 \%)$, los del esqueleto axial lo hacen en D1 $(17,2 \%)$, C1 e $12(10,3 \%$ cada una) (Tabla 10.63).

En relación con el tamaño de los elementos, en todas las cuadrículas hay mayor cantidad de restos que superan los dos $\mathrm{cm}(52,4 \%)$ (Fig. 10.37).

\begin{tabular}{|c|c|c|c|c|c|c|c|c|c|c|c|c|}
\hline Taxón & A1 & A2 & B1 & B2 & B3 & C1 & D1 & E1 & E2 & E3 & F1 & F2 \\
\hline $\begin{array}{c}\text { Mamíferos } \\
\text { indet. }\end{array}$ & 24 & 75 & 16 & 67 & 89 & 17 & 63 & 28 & 23 & 11 & 88 & 14 \\
\hline Camélido & 0 & 0 & 2 & 3 & 0 & 1 & 1 & 0 & 1 & 0 & 0 & 0 \\
\hline $\begin{array}{c}\text { Lama sp. } \\
\text { Hemiauchenia } \\
\text { paradoxa }\end{array}$ & 0 & 12 & 2 & 1 & 2 & 0 & 0 & 0 & 0 & 0 & 0 & 0 \\
\hline Lama gracilis & 0 & 0 & 0 & 0 & 1 & 0 & 0 & 1 & 0 & 0 & 0 & 0 \\
\hline $\begin{array}{c}\text { Lama } \\
\text { guanicoe }\end{array}$ & 0 & 0 & 1 & 0 & 1 & 4 & 0 & 3 & 2 & 0 & 0 & 0 \\
\hline Cánido & 0 & 0 & 0 & 1 & 1 & 0 & 0 & 0 & 2 & 0 & 2 & 1 \\
\hline Dusycion sp. & 0 & 0 & 0 & 1 & 0 & 0 & 0 & 1 & 0 & 0 & 0 & 0 \\
\hline Félido & 0 & 0 & 0 & 0 & 3 & 0 & 0 & 0 & 0 & 0 & 0 & 0 \\
\hline Panthera sp. & 0 & 0 & 0 & 0 & 0 & 0 & 0 & 0 & 1 & 0 & 0 & 0 \\
\hline $\begin{array}{c}\text { Hippidium } \\
\text { saldiasi }\end{array}$ & 0 & 1 & 0 & 0 & 1 & 0 & 0 & 0 & 0 & 0 & 0 & 0 \\
\hline Zaedyus pichii & 0 & 0 & 0 & 0 & 0 & 0 & 0 & 0 & 0 & 0 & 0 & 0 \\
\hline $\begin{array}{c}\text { Roedores } \\
\text { indet. }\end{array}$ & 0 & 1 & 3 & 1 & 5 & 5 & 8 & 1 & 0 & 0 & 6 & 0 \\
\hline Aves indet. & 0 & 1 & 5 & 6 & 8 & 5 & 5 & 2 & 1 & 1 & 2 & 0 \\
\hline Rhea sp. & 0 & 0 & 2 & 5 & 4 & 14 & 7 & 2 & 2 & 1 & 0 & 0 \\
\hline Indet. & 8 & 75 & 71 & 55 & 110 & 21 & 82 & 56 & 46 & 10 & 69 & 70 \\
\hline Total & 44 & 171 & 109 & 158 & 256 & 78 & 184 & 101 & 79 & 31 & 176 & 87 \\
\hline
\end{tabular}

Tabla 10.62. Restos óseos de cada taxón por cuadrícula. CT. Componente inferior. 


\begin{tabular}{|c|c|c|c|c|c|c|c|c|c|c|c|c|c|}
\hline Taxón & G1 & G2 & H1 & H2 & H3 & I1 & I2 & J1 & K1 & K2 & L1 & L2 & Total \\
\hline $\begin{array}{c}\text { Mamíferos } \\
\text { indet. }\end{array}$ & 12 & 2 & 82 & 28 & 36 & 5 & 137 & 30 & 50 & 29 & 34 & 26 & 986 \\
\hline Camélido & 0 & 0 & 0 & 0 & 0 & 0 & 0 & 1 & 0 & 0 & 0 & 0 & 9 \\
\hline Lama sp. & 5 & 2 & 9 & 4 & 2 & 2 & 16 & 5 & 4 & 3 & 6 & 11 & 212 \\
\hline $\begin{array}{c}\text { Hemiauchenia } \\
\text { paradoxa }\end{array}$ & 0 & 0 & 0 & 0 & 1 & 0 & 0 & 0 & 0 & 0 & 0 & 0 & 7 \\
\hline Lama gracilis & 0 & 0 & 4 & 0 & 0 & 0 & 0 & 0 & 0 & 1 & 0 & 0 & 7 \\
\hline $\begin{array}{c}\text { Lama } \\
\text { guanicoe }\end{array}$ & 0 & 0 & 1 & 1 & 0 & 0 & 9 & 0 & 2 & 0 & 0 & 0 & 24 \\
\hline Cánido & 0 & 0 & 0 & 0 & 0 & 0 & 1 & 0 & 0 & 0 & 0 & 0 & 8 \\
\hline Dusycion sp. & 0 & 0 & 0 & 0 & 0 & 0 & 1 & 0 & 1 & 0 & 0 & 0 & 4 \\
\hline Félido & 0 & 0 & 0 & 0 & 0 & 0 & 1 & 0 & 0 & 0 & 0 & 0 & 4 \\
\hline Panthera sp. & 0 & 0 & 0 & 0 & 0 & 0 & 0 & 0 & 0 & 0 & 0 & 0 & 1 \\
\hline $\begin{array}{c}\text { Hippidium } \\
\text { saldiasi }\end{array}$ & 0 & 0 & 0 & 0 & 0 & 0 & 0 & 0 & 0 & 0 & 0 & 0 & 2 \\
\hline Zaedyus pichii & 0 & 0 & 0 & 0 & 0 & 0 & 0 & 0 & 2 & 0 & 0 & 0 & 2 \\
\hline $\begin{array}{c}\text { Roedores } \\
\text { indet. }\end{array}$ & 0 & 0 & 14 & 7 & 3 & 5 & 73 & 7 & 8 & 19 & 4 & 3 & 173 \\
\hline Aves indet. & 0 & 0 & 3 & 0 & 1 & 0 & 2 & 1 & 1 & 1 & 1 & 1 & 47 \\
\hline Rhea sp. & 0 & 0 & 0 & 0 & 0 & 0 & 0 & 0 & 0 & 0 & 0 & 0 & 37 \\
\hline Indet. & 15 & 26 & 46 & 26 & 38 & 23 & 364 & 36 & 66 & 15 & 21 & 9 & 1357 \\
\hline Total & 32 & 30 & 159 & 66 & 81 & 35 & 604 & 80 & 134 & 68 & 66 & 50 & 2880 \\
\hline
\end{tabular}

Tabla 10.62. Continuación.

\begin{tabular}{|c|c|c|c|c|c|c|c|c|c|c|c|c|c|c|c|c|c|c|c|c|c|c|c|c|}
\hline Sector & A1 & A2 & B1 & B2 & B3 & C1 & D1 & E1 & E2 & E3 & F1 & F2 & G1 & G2 & H1 & H2 & H3 & I2 & J1 & K1 & K2 & L1 & L2 & Tot. \\
\hline $\begin{array}{c}\text { Esq. } \\
\text { apend. }\end{array}$ & 8 & 16 & 9 & 17 & 18 & 6 & 4 & 8 & 2 & 8 & 3 & 1 & 3 & 0 & 14 & 3 & 3 & 16 & 4 & 6 & 2 & 3 & 4 & 158 \\
\hline Esq.axial & 4 & 2 & 3 & 5 & 7 & 9 & 15 & 3 & 3 & 0 & 5 & 0 & 1 & 1 & 0 & 0 & 0 & 9 & 2 & 0 & 1 & 1 & 6 & 87 \\
\hline Total & 12 & 18 & 12 & 22 & 32 & 15 & 19 & 11 & 5 & 8 & 8 & 1 & 4 & 1 & 14 & 3 & 3 & 25 & 6 & 6 & 3 & 4 & 10 & 245 \\
\hline
\end{tabular}

Tabla 10.63. Elementos del esqueleto apendicular y axial de camélidos por cuadrícula. CT. C.I.

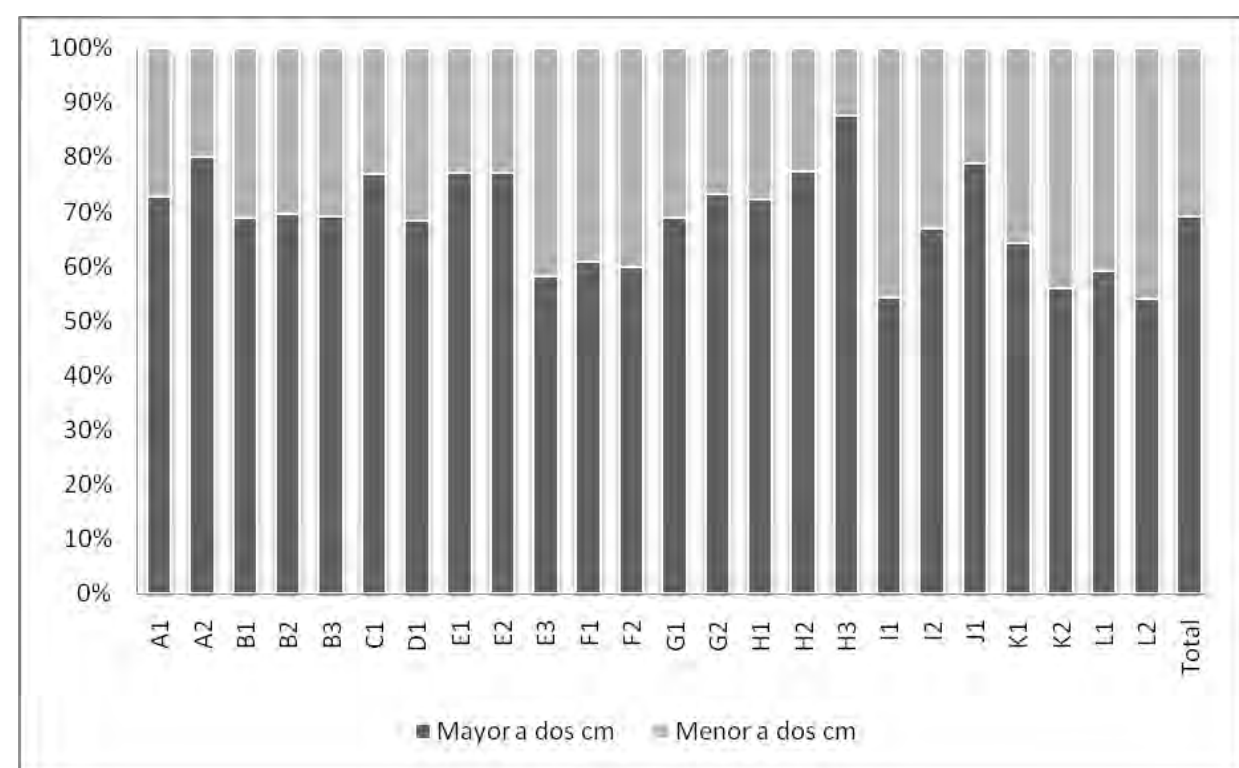

Fig. 10.37. Tamaño de los elementos óseos por cuadrícula. CT. Componente inferior. 


\subsection{Material lítico alterado térmicamente}

Las piezas con alteración térmica (13) representan el 13,1\% del conjunto. De estas, ocho muestran evidencias de daño térmico y cinco tienen únicamente cambios de color, lustre o pátina. El 92,3\% son productos de talla, habiendo tan sólo un instrumento termoalterado (Tabla 10.64).

Entre los productos de talla predominan las lascas (58,3\%), siguiendo luego los fragmentos de talla $(33,3 \%)$ (Tabla 10.65). De aquellos a los cuales se les pudo identificar un estadio dentro de la secuencia de producción, el 62,5\% corresponde al estadio 2 de talla, mientras que dentro del estadio 1 de descortezamiento hay un 12,5\% y el 25\% corresponde al estadio 3 de formatización final (Tabla 10.66).

El 92,3\% de las piezas tienen una dimensión máxima de entre 0,1 y 3,9 cm (el 23,1\% es menor a $0,5 \mathrm{~cm}$ el $38,5 \%$ está entre 0,6 y $2 \mathrm{~cm}$ y el $30,7 \%$ entre 2 y 3,9 cm). Es decir, la gran mayoría son de dimensiones pequeñas (Tabla 10.67).

Las piezas son principalmente de sílex, en especial de color gris $(53,8 \%)$, observándose también de sílex marrón (30,7\%) (Tabla 10.68). La figura 10.38 indica que las materias primas que presentan evidencias de termoalteración, tienen siempre altos porcentajes en dicho rubro. Se ubican principalmente en $12(38,5 \%)$ (Tabla 10.69).

\begin{tabular}{|c|c|c|c|c|}
\hline $\begin{array}{c}\text { Daño } \\
\text { dorsal }\end{array}$ & $\begin{array}{c}\text { Daño } \\
\text { ventral }\end{array}$ & $\mathbf{I}$ & $\mathbf{X T}$ & Total \\
\hline \multirow{2}{*}{ No } & No & 1 & 4 & 5 \\
\cline { 2 - 5 } & $\mathbf{S i}$ & 0 & 4 & 4 \\
\hline \multirow{2}{*}{ Si } & No & 0 & 1 & 1 \\
\cline { 2 - 5 } & $\mathbf{S i}$ & 0 & 3 & 3 \\
\hline Total & & 1 & 12 & 13 \\
\hline
\end{tabular}

Tabla 10.64. Piezas con alteración térmica por grupo. CT. C. I. No= Sin daño térmico pero con alteraciones del tipo lustre, color y pátina.

\begin{tabular}{|c|c|c|c|c|c|}
\hline $\begin{array}{c}\text { Daño } \\
\text { dorsal }\end{array}$ & $\begin{array}{c}\text { Daño } \\
\text { ventral }\end{array}$ & $\mathbf{1}$ & $\mathbf{2}$ & $\mathbf{3}$ & Total \\
\hline \multirow{2}{*}{ No } & No & 1 & 1 & 2 & 4 \\
\cline { 2 - 6 } & $\mathbf{S i}$ & 0 & 1 & 0 & 1 \\
\hline Si & $\mathbf{S i}$ & 0 & 3 & 0 & 3 \\
\hline Total & & 1 & 5 & 2 & 8 \\
\hline
\end{tabular}

Tabla 10.66. Productos de talla con alteración térmica por estadio. CT. C.I.

\begin{tabular}{|c|c|c|c|c|c|}
\hline Daño dorsal & Daño ventral & ESQ & FT & L & Total \\
\hline \multirow{2}{*}{ No } & No & 1 & 0 & 3 & 4 \\
\cline { 2 - 6 } & Si & 0 & 3 & 1 & 4 \\
\hline \multirow{2}{*}{ Si } & No & 0 & 1 & 0 & 1 \\
\cline { 2 - 6 } & Si & 0 & 0 & 3 & 3 \\
\hline \multirow{2}{*}{ Total } & & 1 & 4 & 7 & 12 \\
\hline
\end{tabular}

Tabla 10.65. Productos de talla con alteración térmica por clase. CT. Componente inferior.

\begin{tabular}{|c|c|c|c|c|c|c|}
\hline $\begin{array}{c}\text { Daño } \\
\text { dorsal }\end{array}$ & $\begin{array}{c}\text { Daño } \\
\text { ventral }\end{array}$ & $\begin{array}{c}\mathbf{0 , 5} \text { o } \\
\text { menos }\end{array}$ & $\begin{array}{c}\mathbf{0 , 6}-\mathbf{1 , 9} \\
\mathbf{2}\end{array}$ & $\mathbf{2}-\mathbf{3 , 9}$ & $\mathbf{4}$ - 5,9 & Total \\
\cline { 2 - 7 } & $\mathbf{S i}$ & 0 & 3 & 1 & 1 & 5 \\
\hline \multirow{2}{*}{ Si } & No & 1 & 0 & 0 & 0 & 1 \\
\cline { 2 - 7 } & $\mathbf{S i}$ & 0 & 0 & 3 & 0 & 3 \\
\hline \multirow{2}{*}{ Total } & & 3 & 5 & 4 & 1 & 13 \\
\hline
\end{tabular}

Tabla 10.67. Piezas con alteración térmica por dimensión máxima. CT. Componente inferior. 


\begin{tabular}{|c|c|c|c|c|c|c|}
\hline \multirow{2}{*}{ Daño dorsal } & \multirow{2}{*}{ Daño ventral } & \multicolumn{3}{|c|}{ Sílex } & \multirow{2}{*}{ Basalto } & \multirow{2}{*}{ Total } \\
\hline & & Gris & Marrón & Naranja & & \\
\hline \multirow{2}{*}{ No } & No & 2 & 2 & 0 & 1 & 5 \\
\hline & Si & 3 & 1 & 0 & 0 & 4 \\
\hline \multirow{2}{*}{ Si } & No & 0 & 0 & 1 & 0 & 1 \\
\hline & Si & 2 & 1 & 0 & 0 & 3 \\
\hline Total & & 7 & 4 & 1 & 1 & 13 \\
\hline
\end{tabular}

Tabla 10.68. Piezas con alteración térmica por materia prima. CT. Componente inferior.

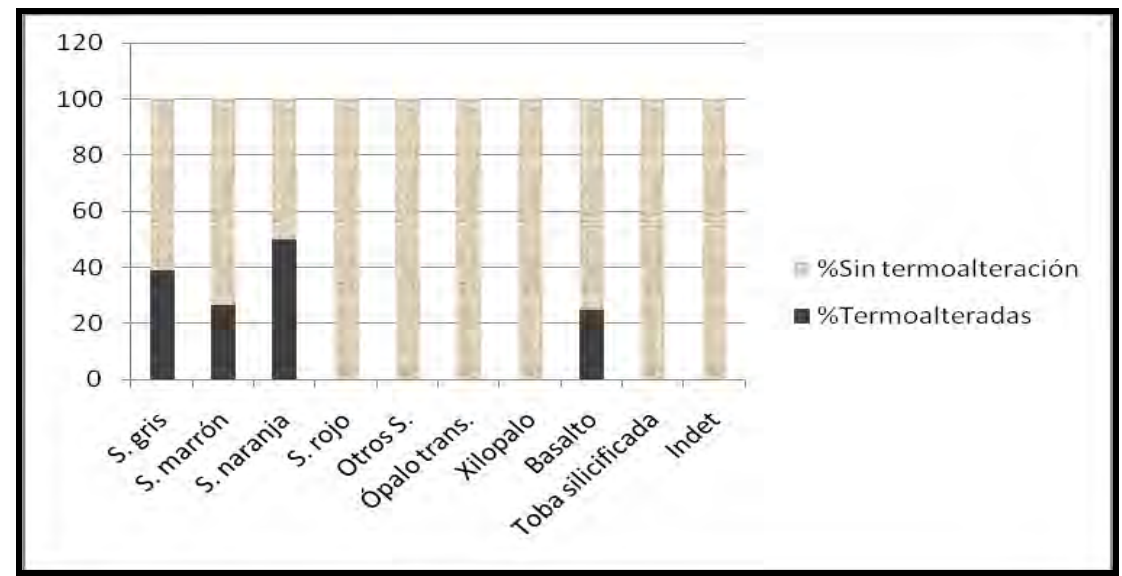

Fig. 10.38. \% de piezas termoalteradas por materia prima. CT. Componente inferior.

\begin{tabular}{|c|c|c|c|c|c|c|c|c|}
\hline Daño dorsal & Daño ventral & A2 & B1 & D1 & E2 & I2 & J1 & Total \\
\hline \multirow{2}{*}{ No } & No & 2 & 1 & 0 & 0 & 2 & 0 & 4 \\
\cline { 2 - 8 } & Si & 0 & 0 & 2 & 0 & 1 & 1 & 4 \\
\hline \multirow{2}{*}{ Si } & No & 0 & 0 & 0 & 0 & 1 & 0 & 1 \\
\cline { 2 - 8 } & Si & 0 & 0 & 0 & 1 & 1 & 1 & 4 \\
\hline Total & & 2 & 1 & 2 & 1 & 5 & 2 & 13 \\
\hline
\end{tabular}

Tabla 10.69. Piezas con alteración térmica por sector. CT. Componente inferior.

10.3.3.1.3.1. Piezas con daño térmico

Las piezas dañadas se distribuyen en los siguientes grupos: una con daño únicamente en la cara dorsal, cuatro con daño sólo en la ventral y tres con daño en ambas caras.

10.3.3.1.3.1. Piezas con daño en ambas caras

Las tres piezas corresponden a lascas (Tabla 10.65). Dos son de sílex gris y una de sílex marrón (Tabla 10.68). Pertenecen al estadio 2 de talla (Tabla 10.66) y miden entre 2 y 3,9 cm (Tabla 10.67). Se encuentran en tres cuadrículas distintas: E2, 12 y J1, que se ubican alejadas entre sí (Tabla 10.69). Ninguna de éstas presenta lustre térmico. 
10.3.3.1.3.1.2. Piezas con daño en cara dorsal

Se trata de un fragmento de talla de sílex naranja, que mide $0,5 \mathrm{~cm}$ de largo y procede de 12 (Tablas 10.67, 10.68 y 10.69).

10.3.3.1.3.1.3. Piezas con daño en cara ventral

Son cuatro productos de talla, corresponden principalmente a sílex gris (75\%) (Tabla 10.68). Son predominantemente fragmentos de talla (75\%) (Tabla 10.65), reconociéndose también una lasca que corresponde al estadio 2 (Tabla 10.66). Todas las piezas miden menos de dos cm (Tabla 10.67), dos proceden de D1, una de 12 y otra de J1 (Tabla 10.69).

10.3.3.1.3.2. Piezas con alteración térmica pero sin daño

Hay cinco piezas que muestran evidencias de alteración térmica pero que no han sufrido daños. De estas, una es un instrumento y cuatro son productos de talla (Tabla 10.64).

El instrumento es un rodado de basalto que presenta en un borde natural un filo destacado por lascados bilaterales, tipo chopper. Remontado en laboratorio, consiste en dos fragmentos grandes y 3 piezas menores, una de las cuales muestra evidencias de haber cambiado de color, mientras que el resto mantiene su coloración original de tonalidad bordó (Fig. 10.39).

En cuanto a los productos de talla, estos corresponden a tres lascas y una esquirla (Tabla 10.65). Son de sílex gris y marrón (50\% cada uno) (Tabla 10.68). Pertenecen en 2 casos al estadio 3, presentándose también una pieza de los estadios 1 y 2 (Tabla 10.66). Dentro del estadio 3, una de las lascas es de reactivación y la otra es indiferenciada.

Con excepción del fragmento de chopper, todas las piezas miden menos de $4 \mathrm{~cm}$ y se ubican en dos cuadrículas A2 e 12 (Tablas 10.67 y 10.69). Con relación al talón, una de las lascas tiene talón natural, una liso y una preparado; en una el talón está ausente.

De las piezas alteradas térmicamente pero sin daño, dos muestran únicamente lustre en ambas caras, una presenta lustre y cambio de color en ambas caras, una cambió de color en ambas caras, y una sólo en su cara dorsal. Ninguna presenta pátina (Tabla 10.70). 


\begin{tabular}{|c|c|c|c|c|}
\hline & \multicolumn{3}{|c|}{ Cara Dorsal } & \\
\hline Cara Ventral & Color & Color, lustre & Lustre & Total \\
\hline Sin cambio & 1 & 0 & 0 & 1 \\
\hline Color & 1 & 0 & 0 & 1 \\
\hline Color, Lustre & 0 & 1 & 0 & 1 \\
\hline Lustre & 0 & 0 & 2 & 2 \\
\hline Total & 2 & 1 & 2 & 5 \\
\hline
\end{tabular}

Tabla 10.70. Productos de talla con cambios de color, lustre o pátina. CT. Componente inferior.

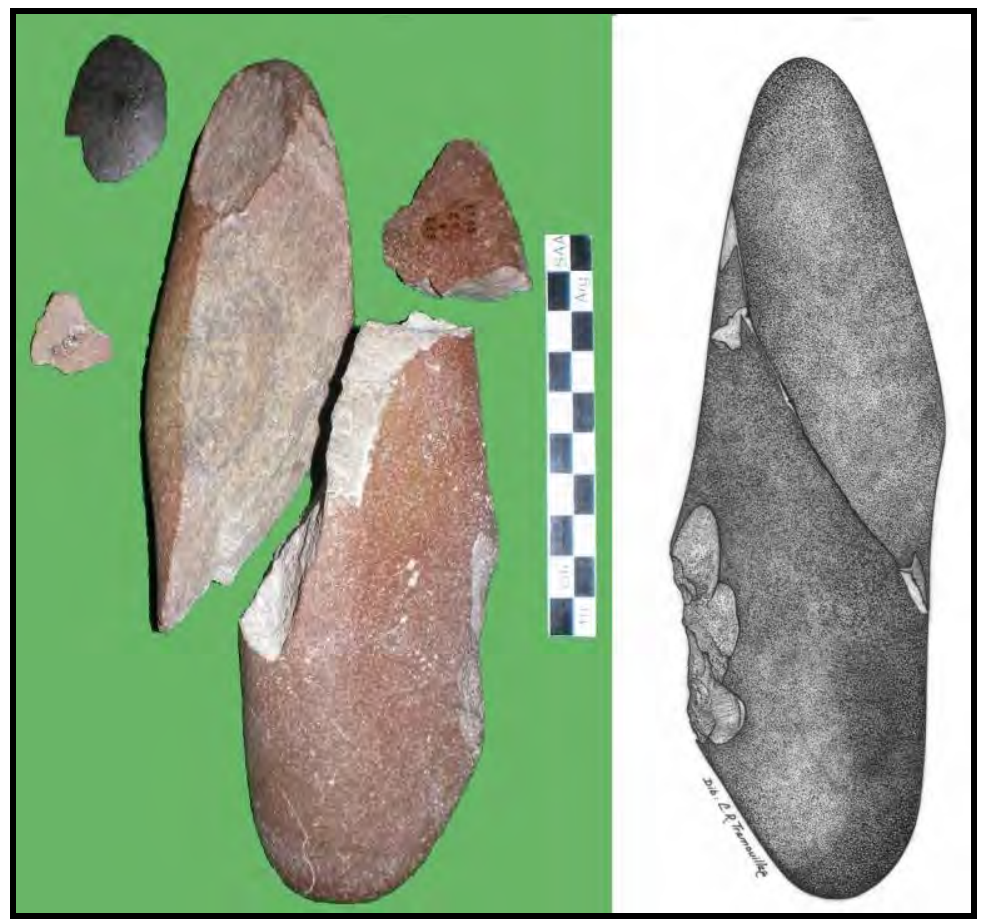

Fig. 10.39. Chopper. Piezas 144, 250, 255, 268 y 269. Nótese en el extremo superior izquierdo el fragmento termoalterado. CT. Componente inferior.

\subsection{Material óseo alterado térmicamente}

El 7\% de los restos está termoalterado (Tabla 10.71). Estos representan mayormente los estadios iniciales de combustión: parcialmente carbonizados $(36,8 \%)$, totalmente quemados $(19,9 \%)$ y parcialmente quemados $(19,4 \%)$ o bien totalmente carbonizados $(15,6 \%)$. Los elementos alterados por el fuego corresponden en su gran mayoría $(89,4 \%)$ a restos indeterminados. En el análisis de la textura también destacan los estadios iniciales de combustión, siendo el estadio 1 (textura grasosa - ondulante) la más representada (49\%), seguido por el estadio 2 (textura vítrea) con el 23\% (Fig. 10.40).

Al analizar la presencia de evidencias de termoalteración en la parte interna del hueso vemos que, en el $80,8 \%$ de los casos está presente tanto en la cara externa como en el interior del hueso, mientras que en el 19,2\% restante no se observan evidencias de combustión interna (Fig. 10.12). Un 22,89\% de los restos presentan fracturas o algún tipo de modificación de su superficie. Entre 
las modificaciones de la superficie que se pudieron reconocer, predominan las fracturas y grietas longitudinales (Tabla 10.72).

Los elementos con alteración térmica proceden en su mayoría de D1, que cuenta con el 25,9\% de los restos modificados por el calor (Tabla 10.73). Otras cuadrículas con abundantes restos de este tipo son $\mathrm{C} 1$, B2, B1 y A2 (12,4\%, 9,5\%, 8,5\% y $8 \%$ respectivamente). Todas éstas son adyacentes entre sí (Fig. 5.7). Por otra parte, estas cuadrículas también tienen el porcentaje más alto de restos termoalterados (Tabla 10.74). En relación al tamaño, 65,7\% de estos restos es mayor a dos cm (Tabla 10.75).

Por otra parte, como ya se mencionara en el capítulo 5, se han reconocido tres instrumentos óseos en el sitio. Se trata de un punzón doble, una punta roma y un machacador. En ninguno de ellos se observó evidencias de termoalteración. Identificamos dos lascas óseas totalmente quemadas.

Cabe destacar que durante el análisis de los restos hemos podido identificar diversas marcas que no habían sido registradas hasta ahora. Particularmente, se pudieron constatar abundantes marcas de corte, así como evidencias de carnívoros, lo que plantea la necesidad de desarrollar estudios tafonómicos detallados que permitan determinar qué medida rol jugaron estos animales en la conformación del conjunto.

\begin{tabular}{|c|c|c|c|c|c|c|c|}
\hline Taxón & P. quem. & T. quem. & P. carb. & T. carb. & P. calc. & T. calc. & Total \\
\hline Mamíferos indet. & 15 & 7 & 22 & 2 & 5 & 5 & 56 \\
\hline Camélido & 0 & 1 & 0 & 0 & 1 & 0 & 2 \\
\hline Lama sp. & 10 & 3 & 11 & 0 & 7 & 1 & 32 \\
\hline Lama gracilis & 0 & 0 & 0 & 0 & 4 & 0 & 4 \\
\hline Lama guanicoe & 0 & 2 & 0 & 0 & 0 & 0 & 2 \\
\hline Cánido & 0 & 1 & 1 & 0 & 0 & 0 & 2 \\
\hline Dusycion sp. & 0 & 0 & 0 & 0 & 1 & 0 & 1 \\
\hline Roedores indet. & 0 & 0 & 1 & 0 & 0 & 0 & 1 \\
\hline Aves indet. & 1 & 1 & 2 & 0 & 0 & 1 & 5 \\
\hline Rhea sp. & 0 & 2 & 0 & 0 & 1 & 2 & 5 \\
\hline Indet. & 13 & 23 & 37 & 7 & 4 & 7 & 91 \\
\hline Total & 39 & 40 & 74 & 9 & 23 & 16 & 201 \\
\hline
\end{tabular}

Tabla 10.71. Termoalteración de restos óseos por taxón. CT. Componente inferior. P.: Parcialmente. T.: Totalmente. Quem.: Quemado. Carb.: Carbonizado. Calc.: calcinado. 


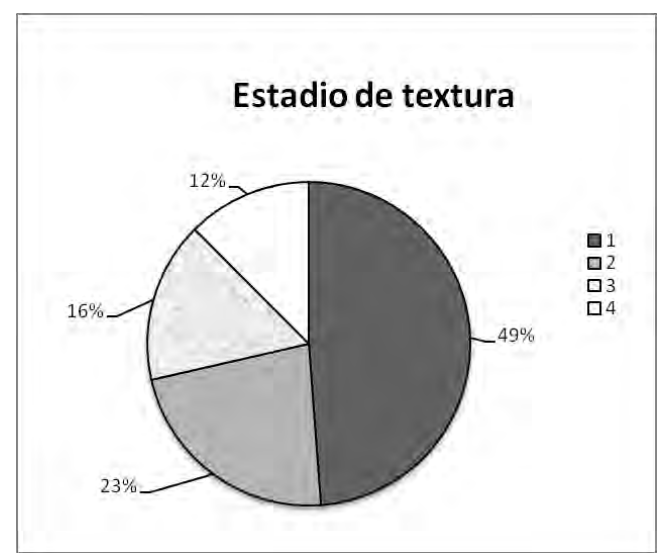

Fig. 10.40. Textura de los restos termoalterados por estadio. CT. Componente inferior.

\begin{tabular}{|c|c|}
\hline Fracturas & $\%$ \\
\hline Grietas longitudinales & 1,99 \\
\hline Grietas longitudinales y transversales & 0,50 \\
\hline Grietas longitudinales y oblicuos & 0,50 \\
\hline Grietas y F. longitudinales, deformación & 0,50 \\
\hline Grietas longitudinales y reticulares & 0,50 \\
\hline Grietas oblicuas, F. longitudinales & 0,50 \\
\hline Grietas oblicuas & 0,50 \\
\hline Grietas reticulares & 1,99 \\
\hline Deformación & 0,50 \\
\hline Exfoliaciones & 2,99 \\
\hline F. longitudinales & 6,97 \\
\hline F. longitudinales y transversales & 1,49 \\
\hline F. longitudinales y oblicuas & 1,00 \\
\hline F. longitudinales, deformación & 0,50 \\
\hline F. transversales & 1,99 \\
\hline F. oblicuas & 0,50 \\
\hline Sin F. por termoalteración & 77,11 \\
\hline
\end{tabular}

Tabla 10.72. Fracturas producidas por termoalteración. CT. Componente inferior. F. = Fracturas 


\begin{tabular}{|c|c|c|c|c|c|c|c|}
\hline & P. quem. & T. quem. & P. carb. & T. carb. & P. calc. & T. calc. & Total \\
\hline A1 & 2 & 0 & 0 & 0 & 0 & 0 & 2 \\
\hline A2 & 2 & 4 & 7 & 0 & 0 & 3 & 16 \\
\hline B1 & 5 & 5 & 3 & 2 & 1 & 1 & 17 \\
\hline B2 & 5 & 2 & 9 & 1 & 1 & 1 & 19 \\
\hline B3 & 3 & 2 & 2 & 0 & 0 & 1 & 8 \\
\hline C1 & 3 & 6 & 12 & 1 & 1 & 2 & 25 \\
\hline D1 & 14 & 7 & 16 & 1 & 8 & 6 & 52 \\
\hline E1 & 1 & 0 & 3 & 0 & 3 & 0 & 7 \\
\hline E2 & 1 & 2 & 5 & 0 & 1 & 0 & 9 \\
\hline E3 & 0 & 1 & 2 & 0 & 0 & 0 & 3 \\
\hline F1 & 0 & 8 & 2 & 2 & 0 & 0 & 12 \\
\hline F2 & 0 & 2 & 2 & 0 & 0 & 1 & 5 \\
\hline G2 & 0 & 0 & 0 & 1 & 0 & 1 & 2 \\
\hline H1 & 1 & 0 & 1 & 0 & 5 & 0 & 7 \\
\hline H3 & 0 & 0 & 2 & 0 & 0 & 0 & 2 \\
\hline I2 & 1 & 0 & 0 & 1 & 1 & 0 & 3 \\
\hline J1 & 0 & 0 & 2 & 0 & 0 & 0 & 2 \\
\hline K1 & 0 & 0 & 3 & 0 & 2 & 0 & 5 \\
\hline L1 & 1 & 1 & 2 & 0 & 0 & 0 & 4 \\
\hline L2 & 0 & 0 & 1 & 0 & 0 & 0 & 1 \\
\hline Total & 39 & 40 & 74 & 9 & 23 & 16 & 201 \\
\hline
\end{tabular}

Tabla 10.73. Termoalteración de restos óseos por cuadrícula. CT. Componente inferior.

\begin{tabular}{|c|c|c|c|}
\hline Sector & Termoalterados & Total & \%Termoalterados \\
\hline A1 & 2 & 44 & 4,5 \\
\hline A2 & 16 & 171 & 9,4 \\
\hline B1 & 17 & 109 & 15,6 \\
\hline B2 & 19 & 158 & 12 \\
\hline B3 & 8 & 256 & 3,1 \\
\hline C1 & 25 & 78 & 32,1 \\
\hline D1 & 52 & 184 & 28,2 \\
\hline E1 & 7 & 101 & 6,9 \\
\hline E2 & 9 & 79 & 11,4 \\
\hline E3 & 3 & 31 & 9,7 \\
\hline F1 & 12 & 176 & 6,8 \\
\hline F2 & 5 & 87 & 5,7 \\
\hline G1 & 0 & 32 & 0 \\
\hline G2 & 2 & 30 & 6,7 \\
\hline H1 & 7 & 159 & 4,4 \\
\hline H2 & 0 & 66 & 0 \\
\hline H3 & 2 & 81 & 2,5 \\
\hline I1 & 0 & 35 & 0 \\
\hline I2 & 3 & 604 & 0,5 \\
\hline J1 & 2 & 80 & 2,5 \\
\hline K1 & 5 & 134 & 3,7 \\
\hline K2 & 0 & 68 & 0 \\
\hline L1 & 4 & 66 & 6,1 \\
\hline L2 & 1 & 50 & 2 \\
\hline Total & 201 & 2880 & 7 \\
\hline r & & 50 & \\
\hline
\end{tabular}

Tabla 10.74. \% de restos óseos termoalterados por cuadrícula. CT. Componente inferior. 


\begin{tabular}{|c|c|c|c|c|c|c|c|}
\hline & P. quem. & T. quem. & P. carb. & T. carb. & P. calc. & T. calc. & Total \\
\hline Mayor a dos cm & 29 & 27 & 47 & 2 & 13 & 14 & 132 \\
\hline Menor a dos cm & 10 & 13 & 27 & 7 & 10 & 2 & 69 \\
\hline Total & 39 & 40 & 74 & 9 & 23 & 16 & 201 \\
\hline
\end{tabular}

Tabla 10.75. Termoalteración de restos óseos por tamaño. CT. Componente inferior.

\subsubsection{Sitio Cueva La Mesada}

\subsubsection{Unidad 8}

\subsection{Fogones}

Este componente no presenta fogones, únicamente se ha reconocido un pequeño lente carbonoso en la cuadrícula B1.

\subsection{Distribución en planta de los restos}

Los restos líticos se presentan en mayor proporción en B1 y B2, mientras que hay menor cantidad en A1 (Tabla 10.76). Las piezas presentes en cada cuadrícula abarcan diversos tamaños; si bien predominan los elementos más pequeños, hay un proporción considerable de elementos más grandes (28\% mayor a 4 cm) (Fig. 10.41). La materia prima más abundante es el sílex marrón, esta se concentra en B2 (58,3\%). El sílex rojo se presenta en valores similares en B1 y B2, mientras que la calcedonia se distribuye entre A1 y B1 (Tabla 10.77). En todos los sectores prevalecen las lascas del estadio 2, mientras que hay muy escasos elementos correspondientes a los estadios 1 y 3 (Fig. 10.42).

\begin{tabular}{|c|c|c|c|c|}
\hline Grupo & A1 & B1 & B2 & Total \\
\hline $\mathbf{I}$ & 0 & 4 & 2 & 6 \\
\hline $\mathbf{X T}$ & 7 & 13 & 13 & 33 \\
\hline Total & 7 & 17 & 15 & 39 \\
\hline$\%$ & 17,9 & 43,6 & 38,4 & 100 \\
\hline
\end{tabular}

Tabla 10.76. Artefactos líticos por cuadrícula. LM. Unidad 8. 


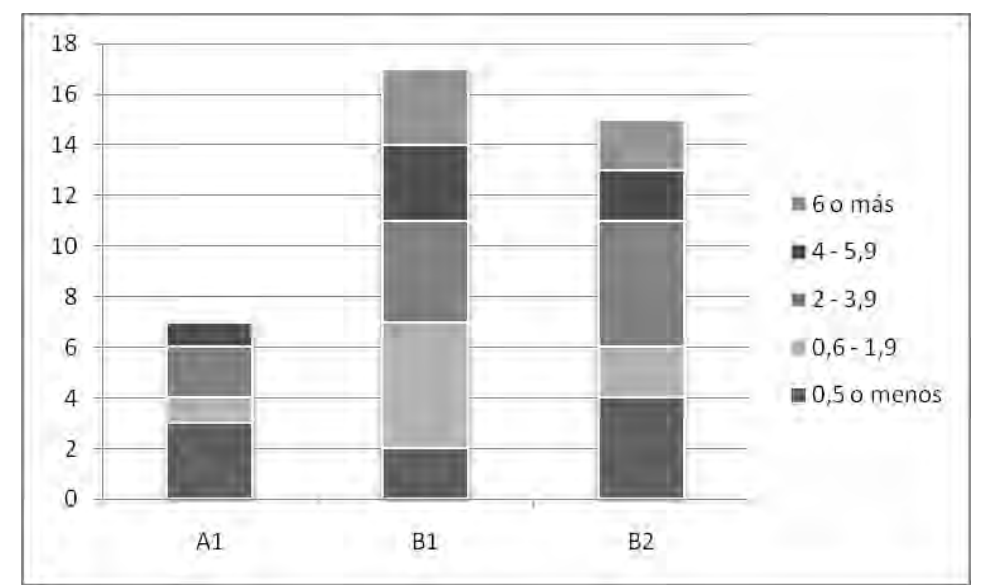

Fig. 10.41. Dimensión máxima (en cm) de artefactos líticos por cuadrícula. . LM. Unidad 8.

\begin{tabular}{|c|c|c|c|c|c|}
\hline Materia Prima & Color & A1 & B1 & B2 & Total \\
\hline Calcedonia & & 3 & 3 & 0 & 6 \\
\hline Obsidiana & & 0 & 1 & 0 & 1 \\
\hline \multirow{4}{*}{ Sílex } & Gris & 2 & 2 & 1 & 5 \\
\cline { 2 - 6 } & Marrón & 1 & 4 & 7 & 12 \\
\cline { 2 - 6 } & Rojo & 1 & 4 & 3 & 8 \\
\cline { 2 - 6 } & Otros & 0 & 3 & 4 & 7 \\
\hline Total & & 7 & 17 & 15 & 39 \\
\hline
\end{tabular}

Tabla 10.77. Materia prima de de artefactos líticos por cuadrícula. LM. Unidad 8.

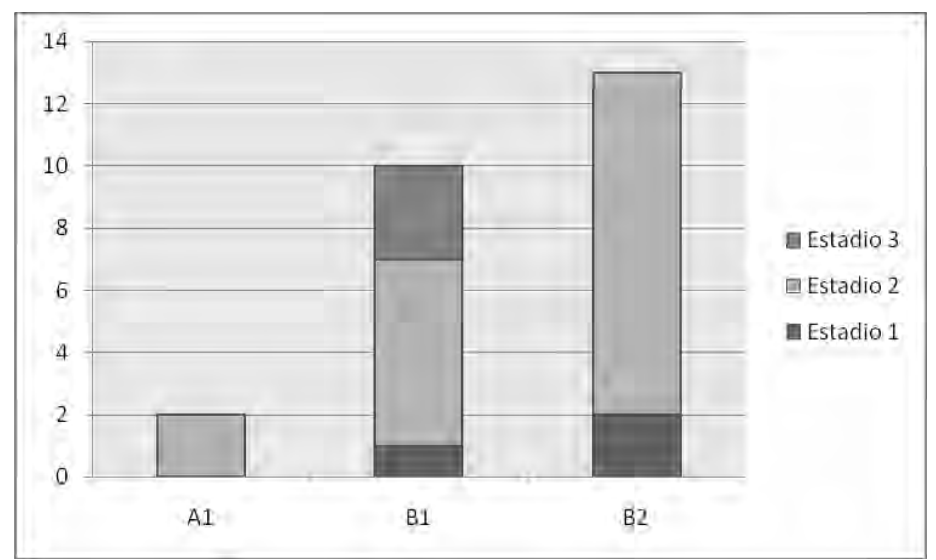

Fig. 10.42. Estadio de reducción de productos de talla por cuadrícula. LM. Unidad 8.

En relación al conjunto óseo, la totalidad de los escasos elementos recuperados se presentan en la cuadrícula A. Estos corresponden principalmente a restos indeterminados, observándose también un molar y una falange de Lama guanicoe. Todos son mayores a dos $\mathrm{cm}$.

\subsection{Material lítico alterado térmicamente}

Se han reconocido seis productos de talla con alteración térmica que representan el 15,4\% del conjunto. De estos, cuatro están dañados y dos tienen cambios de color, lustre o pátina (Tabla 10.78). Predominan las esquirlas (50\%), luego le siguen los fragmentos de talla y las lascas $(33,3 \%$ 
y 16,6\% respectivamente) (Tabla 10.79). El 83,3\% de los restos presenta una dimensión máxima de entre 0,1 y $3,9 \mathrm{~cm}$ (el $50 \%$ es menor a $0,5 \mathrm{~cm}$ el $16,6 \%$ está entre 0,6 y $2 \mathrm{~cm}$ y un porcentaje similar mide entre 2 y 3,9 cm). Es decir, la gran mayoría es de dimensiones pequeñas (Tabla 10.80).

Las piezas con alteración térmica son principalmente de sílex $(66,6 \%)$, de las cuales predominan las de color rojo; se observan también de calcedonia (33,3\%) (Tabla 10.81). La figura 10.43 indica que estas materias primas presentan porcentajes de termoalteración que van del 20 al 33\%. Se ubican principalmente en la cuadrícula A1 (66,6\%) (Tabla 10.82).

\begin{tabular}{|c|c|c|c|}
\hline $\begin{array}{c}\text { Daño } \\
\text { dorsal }\end{array}$ & $\begin{array}{c}\text { Daño } \\
\text { ventral }\end{array}$ & $\mathbf{X T}$ & Total \\
\hline \multirow{2}{*}{ No } & No & 2 & 2 \\
\cline { 2 - 4 } & $\mathbf{S i}$ & 1 & 1 \\
\hline Si & $\mathbf{S i}$ & 3 & 3 \\
\hline Total & & 6 & 6 \\
\hline
\end{tabular}

Tabla 10.78. Piezas con alteración térmica por grupo. LM. U. 8. No= Sin daño térmico pero con alteraciones del tipo lustre, color y pátina.

\begin{tabular}{|c|c|c|c|c|c|}
\hline $\begin{array}{c}\text { Daño } \\
\text { dorsal }\end{array}$ & $\begin{array}{c}\text { Daño } \\
\text { ventral }\end{array}$ & ESQ & FT & $\mathbf{L}$ & Total \\
\hline \multirow{2}{*}{ No } & No & 1 & 0 & 1 & 2 \\
\cline { 2 - 6 } & $\mathbf{S i}$ & 1 & 0 & 0 & 1 \\
\hline Si & Si & 1 & 2 & 0 & 3 \\
\hline Total & & 3 & 2 & 1 & 6 \\
\hline
\end{tabular}

Tabla 10.79. Productos de talla con alteración térmica por clase. LM. Unidad 8.

\begin{tabular}{|c|c|c|c|c|c|c|}
\hline Daño dorsal & Daño ventral & $\mathbf{0 , 5}$ o menos & $\mathbf{0 , 6}-\mathbf{1 , 9}$ & $\mathbf{2}-\mathbf{3 , 9}$ & $\mathbf{4 - 5 , 9}$ & Total \\
\hline \multirow{2}{*}{ No } & No & 1 & 1 & 0 & 0 & 2 \\
\cline { 2 - 7 } & $\mathbf{S i}$ & 1 & 0 & 0 & 0 & 1 \\
\hline Si & $\mathbf{S i}$ & 1 & 0 & 1 & 1 & 3 \\
\hline Total & & 3 & 1 & 1 & 1 & 6 \\
\hline
\end{tabular}

Tabla 10.80. Piezas con alteración térmica por dimensión máxima. LM. Unidad 8.

\begin{tabular}{|c|c|c|c|c|c|c|}
\hline \multirow{2}{*}{ Daño dorsal } & \multirow{2}{*}{ Daño ventral } & \multirow{2}{*}{ Calcedonia } & \multicolumn{3}{|c|}{ Sílex } & \multirow{2}{*}{ Total } \\
\cline { 4 - 7 } & & & Blanco & Gris & Rojo & \\
\hline \multirow{2}{*}{ No } & No & 1 & 0 & 1 & 0 & 2 \\
\cline { 2 - 6 } & $\mathbf{S i}$ & 0 & 0 & 0 & 1 & 1 \\
\hline Si & $\mathbf{S i}$ & 1 & 1 & 0 & 1 & 3 \\
\hline Total & & 2 & 1 & 1 & 2 & 6 \\
\hline
\end{tabular}

Tabla 10.81. Piezas con alteración térmica por materia prima. LM. Unidad 8.

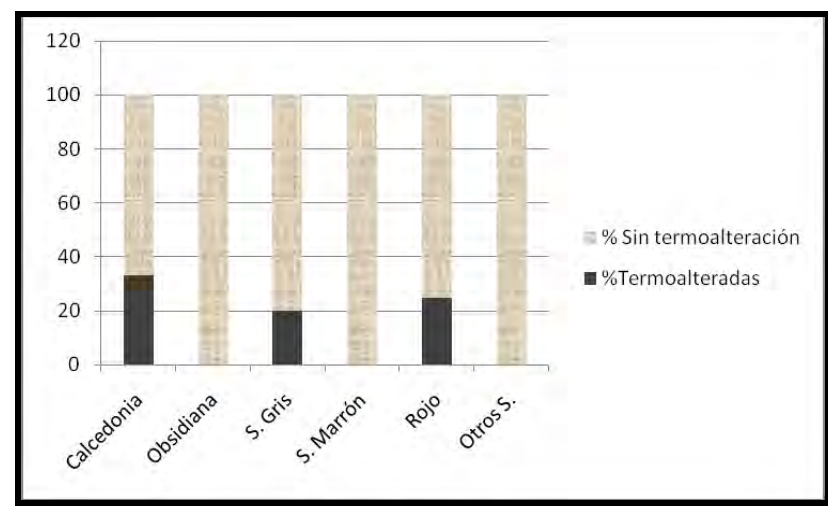

Fig. 10.43. \% de piezas termoalteradas por materia prima. LM. Unidad 8. 


\begin{tabular}{|c|c|c|c|c|}
\hline Daño dorsal & Daño ventral & A1 & B1 & Total \\
\hline \multirow{2}{*}{ No } & No & 2 & 0 & 2 \\
\cline { 2 - 5 } & Si & 1 & 0 & 1 \\
\hline Si & Si & 1 & 2 & 3 \\
\hline Total & & 4 & 2 & 6 \\
\hline
\end{tabular}

Tabla 10.82. Piezas con alteración térmica por sector. LM. Unidad 8.

10.3.4.1.3.1. Piezas con daño térmico

Las piezas dañadas se distribuyen en los siguientes grupos: una con daño únicamente en la cara ventral y tres con daño en ambas caras.

10.3.4.1.3.1.1. Piezas con daño en ambas caras

Todas corresponden a productos de talla. Una es de sílex rojo, otra de sílex blanco y otra de calcedonia (Tabla 10.81). Son dos fragmentos de talla y una esquirla (Tabla 10.79), a las que no se les pudo asignar un estadio de reducción. Presentan diferentes tamaños, que van de 0,5 a 5,1 cm de largo (Tabla 10.80). Sólo una lasca es potencial forma base. Dos provienen de B1, mientras que la restante procede de A1 (Tabla 10.82). No presentan lustre térmico.

10.3.4.1.3.1.2. Piezas con daño en cara ventral

Sólo un producto de talla muestra daño en la cara ventral. Se trata de una esquirla de sílex rojo que mide $0,5 \mathrm{~cm}$ de largo.

10.3.4.1.3.2. Piezas con alteración térmica pero sin daño

Hay dos productos de talla que muestran evidencias de alteración térmica pero que no han sufrido daños (Tabla 10.78). Corresponden a una lasca de sílex gris y a una esquirla de calcedonia. Ambas proceden de la cuadrícula $\mathrm{A} 1$ y miden menos de dos $\mathrm{cm}$ de largo. La primera muestra un talón preparado mientras que en la segunda está ausente.

La lasca de sílex gris corresponde al estadio 2 y presenta lustre únicamente en la cara ventral mientras que la esquirla de calcedonia tiene lustre en ambas caras; a esta no se le pudo determinar un estadio de reducción. 


\subsection{Material óseo alterado térmicamente}

Sólo un fragmento indeterminado muestra evidencias de termoalteración (16,6\% del conjunto). Presenta textura grasosa - ondulante, y se encuentra totalmente quemado tanto externamente como en su cara interna. Procede de la cuadrícula A1 y es mayor a dos $\mathrm{cm}$. No se han reconocido instrumentos óseos en el sitio.

\subsubsection{Sitio Cueva de La Ventana}

\subsubsection{Unidad 6}

\subsection{Fogones}

En este componente se ha registrado un fogón en las cuadrículas A2, B1 y B2. Es de estructura plana, y sus dimensiones son $65 \mathrm{~cm}$ de largo por $32 \mathrm{~cm}$ de ancho (Fig. 10.1)

\subsection{Distribución en planta de los restos}

En referencia al conjunto lítico, el $42,9 \%$ de las piezas se encuentra en dos cuadrículas que presentan evidencias de estructuras de combustión (1,3 $\mathrm{m}^{2}$ aproximadamente) mientras que el $57,1 \%$ restante se ubica en cuatro que no presentan fogones (alrededor de $2,1 \mathrm{~m}^{2}$ ). Una cuadrícula $\left(0,5 \mathrm{~m}^{2}\right)$ no presenta restos líticos ni fogones, mientras que en otra $\left(0,8 \mathrm{~m}^{2}\right)$, si bien se observa parte de un fogón, no ha arrojado ningún resto lítico.

Observamos que las piezas se concentran preferentemente en el sector noreste de la cueva, focalizándose en C1 y B1 (31\% y $26,2 \%$ del conjunto respectivamente) y disminuyendo en las cuadrículas circundantes (Tabla 10.83).

Si bien las piezas presentes en cada cuadrícula abarcan diversos tamaños, se observa una distribución diferencial, en tanto que el $46,2 \%$ de los elementos presentes en C1 es mayor a $4 \mathrm{~cm}$, mientras que en el resto es preponderante la presencia de elementos pequeños (Fig. 10.44). Se observa que las distintas materias primas se encuentran relativamente dispersas, con excepción del sílex marrón, que se concentra en C1 (46,2\%) (Tabla 10.84). Predominan ampliamente los elementos correspondientes al estadio 2 (Fig. 10.45), ubicado especialmente en C1 (38,5\%), seguido por B1 $(23,1 \%)$. 


\begin{tabular}{|c|c|c|c|c|c|c|c|}
\hline Grupo & A1 & B1 & B2 & C1 & D1 & E1 & Total \\
\hline XT & 5 & 11 & 6 & 12 & 2 & 3 & 39 \\
\hline I & 0 & 0 & 1 & 1 & 0 & 1 & 3 \\
\hline Total & 5 & 11 & 7 & 13 & 2 & 4 & 42 \\
\hline
\end{tabular}

Tabla 10.83. Artefactos líticos por cuadrícula. LV. Unidad 6.

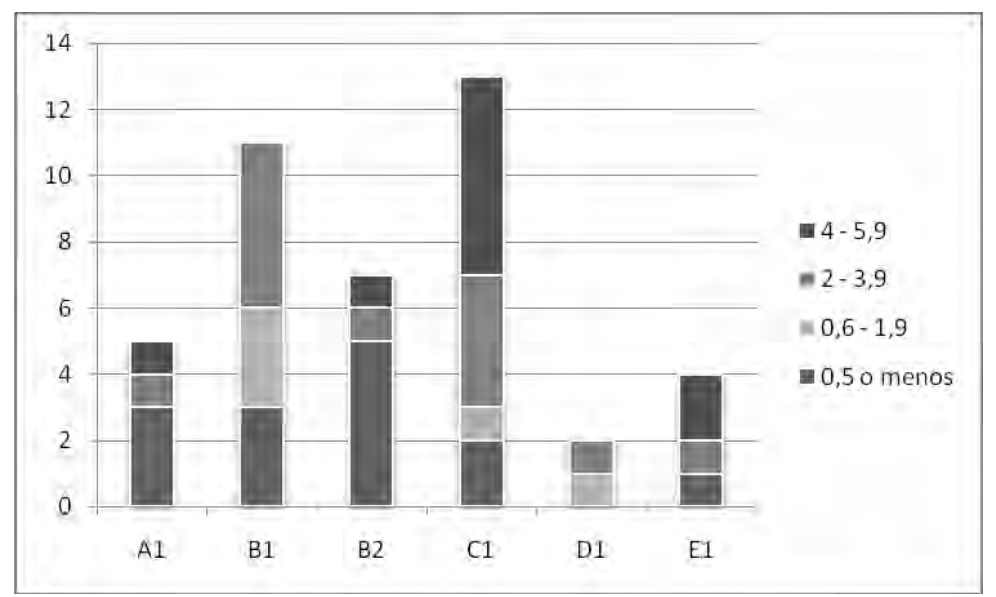

Fig. 10.44. Dimensión máxima en cm. de artefactos líticos por cuadrícula. LV. Unidad 6.

\begin{tabular}{|c|c|c|c|c|c|c|c|c|}
\hline Materia Prima & Color & A1 & B1 & B2 & C1 & D1 & E1 & Total \\
\hline Calcedonia & & 1 & 3 & 0 & 2 & 0 & 0 & 6 \\
\hline Obsidiana & & 2 & 0 & 0 & 0 & 1 & 0 & 3 \\
\hline \multirow{4}{*}{ Sílex } & Gris & 0 & 3 & 2 & 0 & 0 & 0 & 5 \\
\cline { 2 - 9 } & Marrón & 0 & 3 & 1 & 7 & 0 & 2 & 13 \\
\cline { 2 - 9 } & Otros & 0 & 1 & 1 & 2 & 0 & 0 & 5 \\
\cline { 2 - 8 } & Rojo & 1 & 0 & 3 & 0 & 1 & 2 & 7 \\
\hline Otras & & 1 & 1 & 0 & 1 & 0 & 0 & 3 \\
\hline Total & & 5 & 11 & 7 & 13 & 2 & 4 & 42 \\
\hline
\end{tabular}

Tabla 10.84. Materia prima de de artefactos líticos por cuadrícula. LV. Unidad 6.

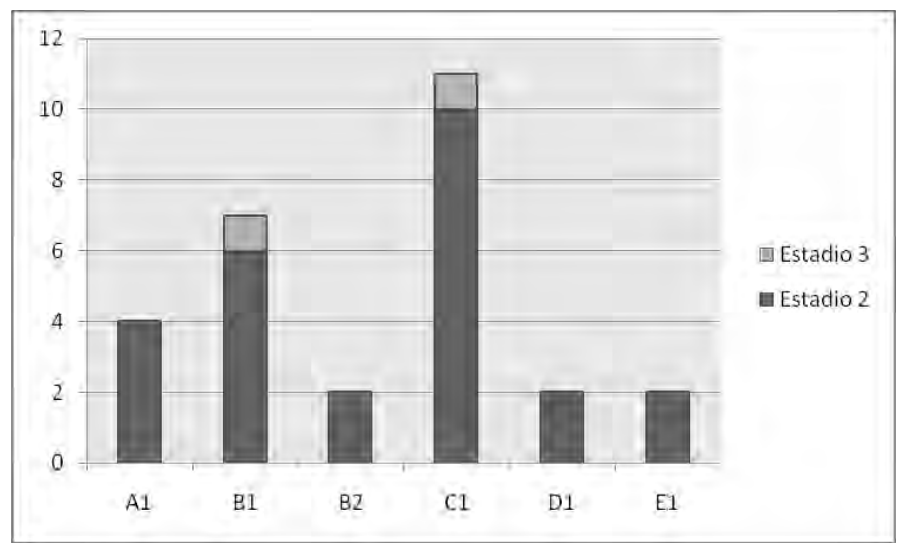

Fig. 10.45. Estadio de reducción de productos de talla por cuadrícula. LV. Unidad 6.

Con relación al conjunto óseo, podemos ver que la concentración de los restos coincide en términos generales con la de los artefactos líticos y que se ubica en el sector norte del área excavada. En este sentido, el 54,5\% de los elementos óseos se encuentra en dos cuadrículas que presentan evidencias de estructuras de combustión ( $1,3 \mathrm{~m}^{2}$ aproximadamente) mientras que el 
$45,4 \%$ se ubica en cinco sin presencia de fogones (2,6 $\mathrm{m}^{2}$ aproximadamente). Una cuadrícula (2,8 $\left.\mathrm{m}^{2}\right)$ no presenta restos óseos pero sí una porción de la estructura de combustión $\left(0,8 \mathrm{~m}^{2}\right)$.

Los restos se concentran principalmente en las cuadrículas B1 $(29,1 \%)$ así como en B2 $(25,57 \%)$ inmediatamente adyacente. Estos corresponden principalmente a indeterminados (Tabla 10.85). En relación al tamaño de los elementos, tanto las piezas que superan los dos $\mathrm{cm}$ como las de menores dimensiones tienden a concentrarse en B1 y B2 (Fig. 10.46)

\begin{tabular}{|c|c|c|c|c|c|c|c|c|}
\hline Taxón & A1 & B1 & B2 & C1 & C2 & D1 & E1 & Total \\
\hline Roedores indet. & 5 & 3 & 8 & 2 & 4 & 1 & 8 & 31 \\
\hline Indet. & 1 & 13 & 6 & 2 & 1 & 1 & 0 & 24 \\
\hline Total & 6 & 16 & 14 & 4 & 5 & 2 & 8 & 55 \\
\hline
\end{tabular}

Tabla 10.85. Restos óseos de cada taxón por cuadrícula. LV. Unidad 6.

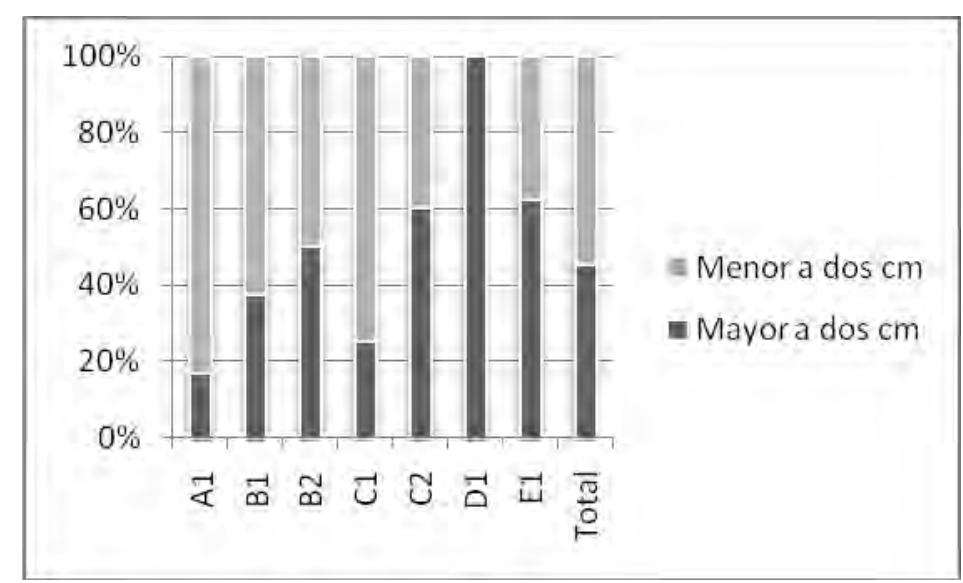

Fig. 10.46. Tamaño de los elementos óseos por cuadrícula. LV. Unidad 6.

\subsection{Material lítico alterado térmicamente}

Las piezas con alteración térmica (15) constituyen el 35,7\% del conjunto. De estas, 12 presentan evidencias de daño térmico y tres tienen únicamente cambios de color, lustre o pátina. El 86,7\% son productos de talla, las restantes corresponden a instrumentos (Tabla 10.86).

Entre los productos de talla, se observan lascas, esquirlas y fragmentos de talla en cantidades similares (Tabla 10.87). Todos aquellos a los cuales se les pudo identificar un estadio dentro de la secuencia de producción corresponden al estadio de talla (Tabla 10.88).

El $80 \%$ de las piezas presenta una dimensión máxima de entre 0,1 y 3,9 cm (el 26,7\% es menor a $0,5 \mathrm{~cm}$ y el $53,3 \%$ está entre 2 y 3,9 cm). Es decir, la mayoría es de dimensiones pequeñas (Tabla 10.89). Las piezas son principalmente de sílex $(93,3 \%)$, siendo éste de diversos colores (Tabla 10.90). La figura 10.47 muestra que todos los sílex poseen porcentajes altos de termoalteración. Las mismas están concentradas en el sector noreste de la cueva, predominantemente en las cuadrículas B1 y B2 (33,3\% cada una) (Tabla 10.91). 


\begin{tabular}{|c|c|c|c|c|}
\hline $\begin{array}{c}\text { Daño } \\
\text { dorsal }\end{array}$ & $\begin{array}{c}\text { Daño } \\
\text { ventral }\end{array}$ & $\mathbf{I}$ & $\mathbf{X T}$ & Total \\
\hline \multirow{2}{*}{ No } & No & 2 & 1 & 3 \\
\cline { 2 - 5 } & $\mathbf{S i}$ & 0 & 2 & 2 \\
\hline \multirow{2}{*}{ Si } & No & 0 & 3 & 3 \\
\cline { 2 - 5 } & Si & 0 & 7 & 7 \\
\hline Total & & 2 & 13 & 15 \\
\hline
\end{tabular}

Tabla 10.86. Piezas con alteración térmica por grupo. LV. Unidad 6 . No= Sin daño térmico pero con alteraciones del tipo lustre, color y pátina.

\begin{tabular}{|c|c|c|c|}
\hline Daño dorsal & Daño ventral & $\mathbf{2}$ & Total \\
\hline No & No & 1 & 1 \\
\hline \multirow{2}{*}{ Si } & No & 3 & 3 \\
\cline { 2 - 4 } & Si & 4 & 4 \\
\hline Total & & 8 & 8 \\
\hline
\end{tabular}

Tabla 10.88. Productos de talla con alteración térmica por estadio. LV. U. 6.

\begin{tabular}{|c|c|c|c|c|c|}
\hline Daño dorsal & Daño ventral & ESQ & FT & $\mathbf{L}$ & Total \\
\hline \multirow{2}{*}{ No } & No & 1 & 0 & 0 & 1 \\
\cline { 2 - 6 } & Si & 2 & 0 & 0 & 2 \\
\hline \multirow{2}{*}{ Si } & No & 0 & 1 & 2 & 3 \\
\cline { 2 - 6 } & Si & 1 & 3 & 3 & 7 \\
\hline \multirow{2}{*}{ Total } & & 4 & 4 & 5 & 13 \\
\hline
\end{tabular}

Tabla 10.87. Productos de talla con alteración térmica por clase. LV. Unidad 6.

\begin{tabular}{|c|c|c|c|c|c|c|c|}
\hline & & \multicolumn{4}{|c|}{ Sílex } & \multirow{2}{*}{ Toba sil. } & \multirow{2}{*}{ Total } \\
\hline Daño dorsal & Daño ventral & Gris & Marrón & Naranja & Rojo & & \\
\hline \multirow{2}{*}{ No } & No & 0 & 1 & 1 & 1 & 0 & 3 \\
\cline { 2 - 8 } & Si & 0 & 1 & 0 & 1 & 0 & 2 \\
\hline \multirow{2}{*}{ Si } & No & 1 & 2 & 0 & 0 & 0 & 3 \\
\cline { 2 - 8 } & Si & 3 & 1 & 0 & 2 & 1 & 7 \\
\hline \multirow{2}{*}{ Total } & & 4 & 5 & 1 & 4 & 1 & 15 \\
\hline
\end{tabular}

Tabla 10.90 Piezas con alteración térmica por materia prima. LV. Unidad 6.

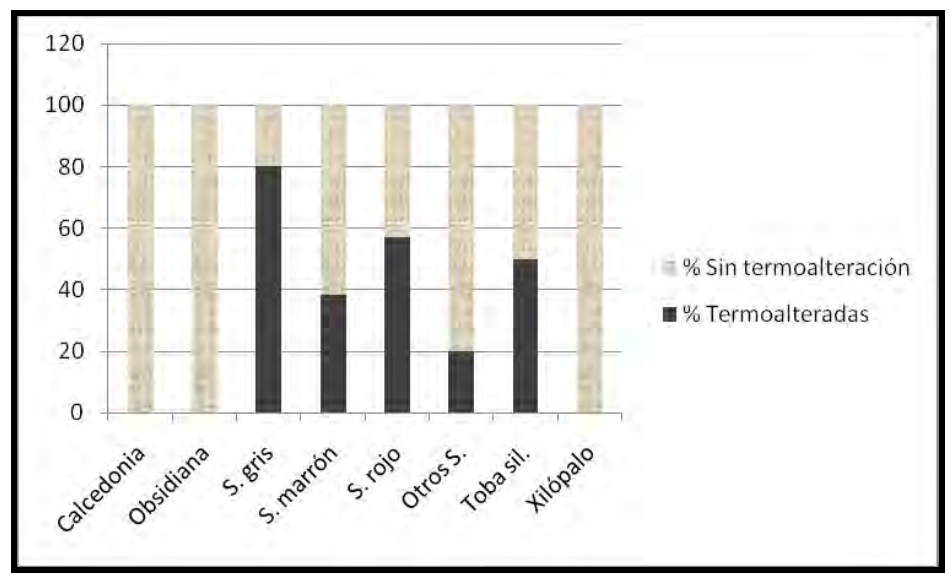

Fig. 10.47. \% de piezas termoalteradas por materia prima. LV. Unidad 6. 


\begin{tabular}{|c|c|c|c|c|c|c|}
\hline Daño dorsal & Daño ventral & B1 & B2 & C1 & E1 & Total \\
\hline \multirow{2}{*}{ No } & No & 0 & 2 & 0 & 1 & 3 \\
\cline { 2 - 7 } & Si & 1 & 1 & 0 & 0 & 2 \\
\hline \multirow{2}{*}{ Si } & No & 0 & 1 & 2 & 0 & 3 \\
\cline { 2 - 7 } & Si & 4 & 1 & 1 & 1 & 7 \\
\hline Total & & 5 & 5 & 3 & 2 & 15 \\
\hline
\end{tabular}

Tabla 10.91. Piezas con alteración térmica por sector. LV. Unidad 6.

10.3.5.1.3.1. Piezas con daño térmico

Las piezas dañadas se distribuyen en los siguientes grupos: tres con daño únicamente en la cara dorsal, dos sólo en la cara ventral y siete con daño en ambas caras.

10.3.5.1.3.1.1. Piezas con daño en ambas caras

Todas las piezas con daño en ambas caras corresponden a productos de talla. Son principalmente de sílex gris y rojo (Tablas 10.86 y 10.90); en su mayoría fragmentos de talla y lascas $(42,9 \%$ respectivamente) (Tabla 10.90). Pertenecen al estadio 2 de talla, no hay piezas de los estadios 1 y 3 (Tabla 10.88). Todas miden menos de $4 \mathrm{~cm}$ (Tabla 10.89) y se ubican predominantemente en B1 $(57,1 \%)$ (Tabla 10.91). Ninguna exhibe lustre térmico.

10.3.5.1.3.1.2. Piezas con daño en cara dorsal

Se trata de tres productos de talla. Dos corresponden a sílex marrón y uno es de sílex gris (Tabla 10.90). Son dos lascas que pertenecen al estadio 2 y un fragmento de talla (Tabla 10.87 y 10.88 ). Miden entre 2 y 5,9 cm (Tabla 10.89). Se ubican predominantemente en C1 (66,6\%) (Tabla 10.91). En dos casos, además de daño térmico en la cara dorsal, se observa en ambas caras lustre.

10.3.5.1.3.1.3. Piezas con daño en cara ventral

Se trata de dos esquirlas de sílex, una roja y la otra marrón (Tablas 10.87 y 10.90). Miden menos de $0,6 \mathrm{~cm}$ y proceden de las cuadrículas B1 y B2 (Tablas 10.89 y 10.91). Una de las piezas, además de daño térmico en la cara ventral, presenta pátina en su cara dorsal. 
10.3.5.1.3.2. Piezas con alteración térmica pero sin daño

Hay tres piezas que muestran evidencias de alteración térmica pero que no han sufrido daños. Dos son instrumentos y hay una esquirla (Tablas 10.86 y 10.87). Los instrumentos son lascas retocadas de retoque directo lateral. Ambos fueron confeccionados sobre sílex, uno de color rojo y el otro marrón. En un caso presenta únicamente lustre en ambas caras, procede de E1 y mide 4,4 cm de largo; tiene talón facetado y bulbo difuso. En el otro, se trata de un fragmento distal en el que sólo se observa un leve cambio de color en la cara dorsal, procede de B2 y mide $3,2 \mathrm{~cm}$ de largo. La esquirla es de sílex naranja, procede de B2, mide 0,5 cm de largo y presenta lustre en ambas caras; tiene talón puntiforme y bulbo difuso.

\subsection{Material óseo alterado térmicamente}

El 20\% de los restos muestran evidencias de termoalteración. Se trata de 11 astillas que presentan estadios iniciales de combustión: parcialmente carbonizados $(63,6 \%)$ y totalmente quemados $(36,4 \%)$ (Tabla 10.92). En el análisis de la textura de los restos también destacan los estadios iniciales, siendo el estadio 1 (textura grasosa - ondulante) el más representado $(72,7 \%)$, seguido por el estadio 2 (textura vítrea) con el 27,3\% (Fig. 10.48).

Al analizar la presencia de evidencias de termoalteración en la parte interna del hueso vemos que en el $100 \%$ de los casos éste se presenta en ambas caras (Fig. 10.12). No han podido reconocerse fracturas producidas por la acción del fuego.

Con respecto a la procedencia de los elementos con evidencias de alteración térmica, estos proceden de B1 y B2 (63,6\% y 36,4\% respectivamente) (Tabla 10.93). De hecho, estos fueron recuperados del interior de la estructura de combustión. Al analizar los porcentajes de piezas termoalteradas por cuadrícula, se observa que tanto B1 como B2 presenta porcentajes altos de alteración térmica (Tabla 10.94). En relación con el tamaño, hay cantidades similares de restos mayores y menores a dos $\mathrm{cm}$ (Tabla 10.95).

Por otra parte, no se han reconocido instrumentos óseos en el sitio.

\begin{tabular}{|c|c|c|c|c|}
\hline Taxón & No alterado & T. quem. & P. carb. & Total \\
\hline Roedores indet. & 31 & 0 & 0 & 31 \\
\hline Indet. & 13 & 4 & 7 & 1294 \\
\hline Total & 44 & 4 & 7 & 1721 \\
\hline
\end{tabular}

Tabla 10.92. Termoalteración de restos óseos por taxón. LV. Unidad 6.

P.: Parcialmente. T.: Totalmente. Quem.: Quemado. Carb.: Carbonizado. Calc.: calcinado. 


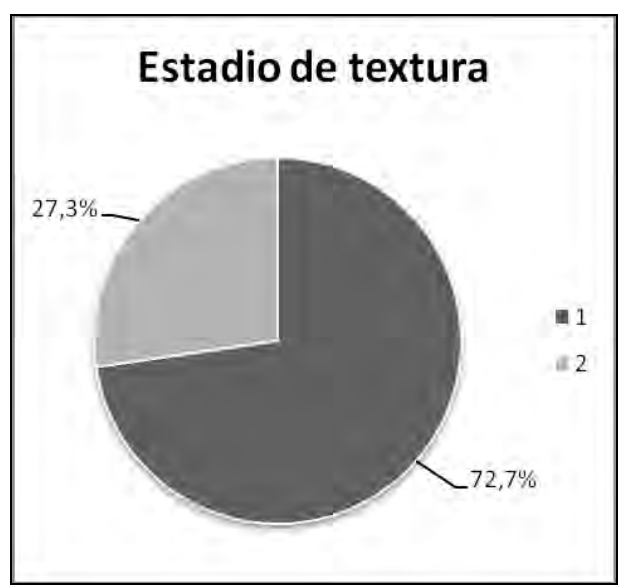

Fig. 10.48. Textura de los restos termoalterados por estadio. LV. Unidad 6.

\begin{tabular}{|c|c|c|c|}
\hline & T. quem. & P. carb. & Total \\
\hline B1 & 2 & 5 & 7 \\
\hline B2 & 2 & 2 & 4 \\
\hline Total & 4 & 7 & 11 \\
\hline
\end{tabular}

\begin{tabular}{|c|c|c|c|}
\hline Sector & Termoalterados & Total & \% Termoalterados \\
\hline A1 & 0 & 6 & 0 \\
\hline B1 & 7 & 16 & 43,7 \\
\hline B2 & 4 & 14 & 28,6 \\
\hline C1 & 0 & 4 & 0 \\
\hline C2 & 0 & 5 & 0 \\
\hline D1 & 0 & 2 & 0 \\
\hline E1 & 0 & 8 & 0 \\
\hline Total & 11 & 55 & 20 \\
\hline
\end{tabular}

Tabla 10.93. Termoalteración de restos óseos por cuadrícula. LV. U. 6.

Tabla 10.94. \% de restos óseos termoalterados por cuadrícula. LV. Unidad 6.

\begin{tabular}{|c|c|c|c|}
\hline & T. quem. & P. carb. & Total \\
\hline Mayor a dos cm & 3 & 3 & 6 \\
\hline Menor a dos cm & 1 & 4 & 5 \\
\hline Total & 4 & 7 & 11 \\
\hline
\end{tabular}

Tabla 10.95. Termoalteración de restos óseos por tamaño. LV. Unidad 6 


\section{CAPITULO 11: SÍNTESIS, DISCUSIÓN Y CONCLUSIONES}

En este capítulo sintetizamos y discutimos los resultados de los estudios realizados a los conjuntos arqueológicos en referencia a la distribución y termoalteración de los elementos, en el marco de los objetivos e hipótesis planteados. Finalmente, presentamos las conclusiones derivadas de nuestro trabajo.

\subsection{Restos líticos alterados térmicamente}

\subsubsection{Unidad 5 de Cerro Tres Tetas 1}

En esta unidad observamos claras evidencias de alteración térmica de artefactos líticos. De acuerdo a los remontajes, distribución e indicadores presentes en las piezas, podemos decir que existirían tanto eventos de tratamiento térmico intencional como sucesos accidentales en los cuales se dañaron o modificaron las piezas.

La mayor parte de las piezas dañadas se habrían termoalterado en eventos no relacionados con un tratamiento térmico intencional. Nuestra afirmación se basa en los criterios desarrollados durante nuestra investigación experimental (ver capítulo 8, p. 115), así como en lo propuesto por diversos investigadores (ver capítulo 6, p. 86). Esperamos que los restos tratados térmicamente tengan daño en su cara ventral sólo cuando la pieza analizada sea aquella que fue originalmente expuesta al fuego (la forma base o el núcleo tratado). Si es una lasca extraída de ella, no podrá contar con daño en su cara ventral, sólo en la dorsal. De esta manera, la mayor parte de las piezas dañadas en C3T1 presentan características que no son coherentes con eventos de tratamiento térmico: la ubicación del daño ocurre en la cara ventral o en ambas caras de piezas muy pequeñas o asignadas al estadio de formatización final. En otros casos observamos elementos que también desarrollaron pátina, que es indicador de temperaturas excesivas para tratamientos térmicos exitosos, a juzgar por los resultados de nuestras experimentaciones. Finalmente en los instrumentos el daño se pudo observar en los negativos de retoque, indicando que éste fue realizado antes de que sean expuestos al fuego (p. 162/3). Por otra parte, este calentamiento accidental ha modificado algunas piezas que no resultaron dañadas pero sí cambiaron de color. Es el caso de un fragmento de raedera que pudo ser remontado con otro que mantenía su color original lo cual nos lleva a considerar que la termoalteración fue posterior a su fragmentación. No muestra evidencias de reciclado ni reactivación, indicando que este calentamiento no fue realizado de manera intencional (p.164). 
Al analizar la distribución de las piezas dañadas y/o con cambio de color vemos que se concentran en dos sectores. En uno de ellos están presentes fogones, de modo que es muy probable que el daño térmico se haya producido por la caída accidental de las piezas en ellos. El otro es un sector en el que no hay fuentes de combustión; es decir que una parte del conjunto se presenta de manera acorde a las expectativas, mientras que otra parte no responde a ellas (p. 163/4). Esto puede deberse a diversas posibilidades:

En primer lugar, al evaluar su ubicación con respecto a las fuentes de combustión ubicadas en la unidad suprayacente, vemos que estas coinciden parcialmente, de modo que es factible que el daño se deba a la acción de fogones encendidos por ocupaciones posteriores. Sin embargo, teniendo en cuenta la distancia vertical a la que se ubican estos fogones (aproximadamente 10 $\mathrm{cm}$ ), no es esperable un daño térmico intenso, puesto que las temperaturas a las que podrían haber estado expuestas las piezas serían relativamente bajas - por ejemplo las experimentaciones realizadas por Bennett (1999) muestran que, en matrices arenosas, a $15 \mathrm{~cm}$ por debajo de la fuente de combustión las temperaturas no superan los $244^{\circ} \mathrm{C}$-. Muchas de estas piezas presentan daño en ambas caras, lo cual no sería posible en un contexto de termoalteración postdepositacional como éste, puesto que para ello son necesarias temperaturas más altas. Además, no hemos podido realizar remontajes entre piezas dañadas de este sector. Como observamos en el capítulo 8 (p. 122), esto es esperable en dichos procesos, al menos en aquellos casos en que las piezas no modificaron su posición original con posterioridad a su enterramiento. En segundo lugar, es factible que hayan existido actividades de limpieza y mantenimiento de los fogones y de su espacio circundante, y que en consecuencia estas piezas constituyan un descarte secundario. Sin embargo, las piezas son en su mayoría muy pequeñas, lo que contradice esta expectativa. Además, en los casos de limpieza de las estructuras de combustión, se espera que las piezas se encuentren asociadas a productos de combustión tales como carbones dispersos o cenizas, hecho que no sucede en este caso (Borrero y Yacobaccio 1989; Sergant et al. 2006).

También es posible que estén representando la ubicación de un fogón que no se ha conservado en el registro arqueológico (Backhouse y Johnson 2007; Sergant et al. 2006). Sin embargo, la conservación de estas estructuras en este componente es buena, muestran límites claros y siendo posible identificar carbones y tierra quemada. Además, la distribución de estas piezas no coincide con la de los elementos óseos termoalterados.

Una cuarta posibilidad es que la dispersión de estos materiales, alejados de las estructuras de combustión, se haya debido a la acción de procesos postdepositacionales. No tenemos hasta el momento elementos para descartar esta hipótesis, sin embargo las características estratigráficas y del resto del conjunto arqueológico nos llevan a considerarla como poco probable. 
Finalmente, es dable que exista una estructura de combustión en un sector no excavado de la cueva, en las cercanías a esta zona de concentración de piezas líticas dañadas, y que estas se estructuren en torno a ella.

Sólo en pocos casos el daño puede vincularse al procedimiento pirotecnológico. En primer lugar, lascas de toba silicificada constituyen potenciales formas base y que están dañadas en ambas caras o en la cara dorsal. También hay lascas de formatización final de distintos sílex con daño en la cara dorsal y lustre en la ventral. Finalmente, una preforma bifacial de sílex gris muestra daño y lustre térmico; el daño se ubica en puntos distintos al lustre, indicando que primero se trató térmicamente el artefacto y luego se lo talló (p. 163).

Hay otras evidencias que también indican que se aplicó este procedimiento (p. 164). Un bifaz y una preforma bifacial así como abundantes lascas muestran lustre térmico producto del tratamiento pirotecnológico. Estas últimas corresponden principalmente al estadio de formatización final; son en su mayor parte de retoque, pero también hay de adelgazamiento bifacial y de reactivación del filo con estas características. Finalmente tres potenciales formas base han cambiado de color. Estas han podido remontarse con un núcleo que no ha estado expuesto al calor. A diferencia de lo que ocurre con el fragmento de raedera, en este caso descartamos que el cambio se haya producido de manera postdepositacional, en primer lugar porque estas lascas proceden de diferentes sectores de la cueva, y en segundo lugar porque una de ellas se hallaba asociada al núcleo. Si la exposición al calor hubiese ocurrido de manera postdepositacional, el núcleo tendría que mostrar signos de termoalteración.

En síntesis, observamos que en este componente se presentan piezas termolateradas por diversos procesos. Por un lado, vemos piezas tratadas térmicamente en el marco de la formatización de artefactos - principalmente un instrumento, formas base, preformas y lascas de formatización final-. Por el otro, hemos reconocido piezas que resultaron expuestas al calor de manera accidental.

\subsubsection{Casa del Minero 1}

\subsubsection{Unidad 4}

En esta unidad se observan evidencias de alteración térmica de artefactos líticos que se refieren tanto al tratamiento térmico como a eventos accidentales en los cuales se dañaron las piezas.

Podemos decir que la mayor parte de las piezas se dañó en eventos no relacionados con un tratamiento intencional, puesto que presentan características que no son coherentes con ello: la ubicación del daño ocurre en la cara ventral o en ambas caras de lascas muy pequeñas o asignadas al estadio de formatización final (p. 175). Además, la mayor parte de estas son de sílex 
rojo, y en ellas no se observa lustre, que es un indicador que está presente en esta materia prima cuando se la trata térmicamente, como pudimos observar en nuestras experimentaciones (ver capítulo 8, p. 129).

Al analizar la distribución de las piezas dañadas vemos que se concentran en torno a los fogones (p. 175). En el caso del sílex rojo, que presenta la gran mayoría de los restos dañados, estas piezas se encuentran asociadas a otras de la misma materia prima, que conforman claros eventos de talla; de este modo es muy probable que el daño se haya producido por la caída accidental de algunas de estas piezas, durante la confección de artefactos, en las estructuras de combustión.

Sólo en unos pocos casos éste puede ser consecuencia del procedimiento pirotecnológico: se trata de lascas de sílex rojo con daño en la cara dorsal y lustre en la ventral (p. 176). Otras evidencias que también apuntan hacia el tratamiento térmico de artefactos son un cuchillo y una lasca retocada con lustre. Ambos fueron confeccionados por presión y sobre sílex rojo. También hay abundantes lascas con lustre, correspondientes principalmente al estadio de formatización final. Son por lo general lascas de retoque y adelgazamiento bifacial de la misma materia prima (p.176). El estudio de la longitud de las piezas de adelgazamiento muestra que si bien estas son más largas cuando son extraídas con posterioridad al tratamiento, la diferencia no es significativa estadísticamente (p. 177).

En resumen, podemos afirmar que este componente presenta claras evidencias de tratamiento térmico expresadas por la presencia de instrumentos y lascas de formatización final principalmente de sílex rojo- con lustre. Asimsmo, hemos podido reconocer procesos de termoalteración accidental producidos muy probablemente durante la manufactura de instrumental lítico alrededor de las fuentes de calor.

\subsubsection{Unidad 3 inferior}

En esta unidad hay pocas piezas termoalteradas. Los restos dañados presentan en su mayoría daño en la cara ventral, son muy pequeños, no fueron subsecuentemente retocados ni evidencian lustre. La mayor parte de ellos se ubican en cuadrículas que presentan fogones (p. 187). En consecuencia, sus características nos llevan a descartar que éste daño se deba al tratamiento térmico.

Sólo una lasca de talla de sílex rojo, además de daño en la cara dorsal, muestra lustre en la cara ventral por lo que probablemente haya sido tratada térmicamente (p. 187). Además de ésta, observamos pocos productos de talla con lustre o cambio de color. Corresponden principalmente a la formatización final de artefactos de sílex rojo; son piezas de retoque y adelgazamiento bifacial (p. 188). Éstas presentan características acordes al tratamiento térmico, aunque son escasas como para poder analizarlo más detalladamente. 


\subsubsection{Unidad 3 medio}

En este componente se reconocieron muy escasas piezas alteradas térmicamente. En cuanto a las dañadas, son muy pequeñas como para corresponder a formas base, no fueron subsecuentemente retocadas ni evidencian lustre (p. 194). Por lo tanto, en su mayoría descartamos que éste daño se haya generado durante la aplicación del tratamiento térmico. Sólo una lasca de sílex marrón con un filo potencialmente funcional podría haber sido tratada. Sin embargo, no ha sido subsecuentemente retocada. Las piezas dañadas provienen en su mayoría de la cuadrícula K2 (p. 194).

Por otra parte, sólo una lasca muestra lustre térmico (p. 194). En consecuencia, la evidencia es muy escasa como para afirmar el uso de este procedimiento.

\subsubsection{Componente inferior de Cueva Túnel}

En este componente hay muy escasas piezas termoalteradas. Las dañadas lo están en la cara ventral, son muy pequeñas como para corresponder a formas base, no fueron subsecuentemente retocadas ni evidencian lustre, razón por la cual descartamos que éste se deba al tratamiento térmico. Éstas se encuentran dispersas en varias cuadrículas (p. 202).

Por otra parte, sólo cinco piezas evidencian cambio de color o lustre. Una de ellas es un fragmento de instrumento que pudo ser remontado en laboratorio, donde se observó que el resto del artefacto mantenía su coloración original, lo que indicaría que el fragmento entró en contacto con el fuego con posterioridad a que ocurriera la fractura. Las cuatro piezas restantes presentan lustre y cambio de color. Se trata de productos de talla de sílex (p. 203). Si bien la evidencia es muy escasa, esta es coherente con la información contextual del sitio

En este sentido, se ha propuesto que los instrumentos presentes en el sitio habrían sido introducidos ya confeccionados y que allí no se habrían realizado eventos de talla, lo que podría estar relacionado con la funcionalidad propuesta para esta ocupación de la cueva -procesamiento primario de presas cazadas en las cercanías- y con la procedencia de los instrumentos formatizados con materias primas posiblemente no locales- (Paunero et al. 2007c; Skarbun 2009b). De esta manera, consideramos que las piezas analizadas podrían ser acordes con la aplicación del tratamiento térmico. Este, sin embargo, se habría realizado fuera del sitio, en otras locaciones y los artefactos se habrían introducido al sitio una vez tratados. Apoya esto además el hecho de que una de las piezas con lustre es una lasca de reactivación del filo. De cualquier manera, son insuficientes estas piezas como para poder desarrollar mayores interpretaciones. 


\subsubsection{Unidad 8 de La Mesada}

En este componente hay muy pocas piezas termoalteradas. La mayoría de las piezas dañadas son muy pequeñas como para corresponder a formas base y no evidencian lustre (p. 211). Consideramos en consecuencia que, en la mayoría de las lascas dañadas, ésta alteración no se produjo como consecuencia de un tratamiento térmico intencional. Una potencial forma base de sílex podría haber sido tratada térmicamente, aunque no ha sido subsecuentemente retocada ( $p$. 211).

Sólo dos lascas muestran características acordes a un posible tratamiento térmico. En consecuencia, la evidencia es muy escasa como para afirmar el uso de este procedimiento ( $p$. 211).

\subsubsection{Unidad 6 de Cueva de La Ventana}

En este componente hay muy escasas piezas alteradas térmicamente, aunque representan un porcentaje alto del conjunto lítico. Las dañadas, que constituyen más del $28 \%$ del total, muestran múltiples indicadores de daño, son muy pequeñas como para corresponder a formas base, no fueron subsecuentemente retocadas ni evidencian lustre. Una de ellas además presenta pátina. En consecuencia, probablemente su alteración no se deba al tratamiento térmico. Dos lascas de sílex marrón podrían haber sido tratadas ya que muestran lustre. La mayor parte de las piezas dañadas proviene del sector donde se ubicaba el fogón (p. 216).

Sólo dos restos han sido, posiblemente, tratados. En consecuencia, la evidencia es muy escasa como para afirmar el uso de este procedimiento (p. 217).

\subsubsection{Tratamiento y daño térmico en los artefactos líticos de la Meseta Central}

El análisis de los conjuntos líticos nos estaría indicando que los pobladores de la Meseta Central de Santa Cruz durante el Pleistoceno final y el Holoceno temprano practicaban el tratamiento térmico durante la producción artefactual. Es decir que como parte de las técnicas de confección de instrumental lítico, estos grupos contaban con alternativas que les permitían optimizar la calidad de las materias primas y reducir riesgos durante la talla, mediante el uso del fuego. Este tratamiento se observa especialmente en los componentes que presentan claros eventos de talla (Unidad 5 de C3T1, Unidad 4 de CDM1), mientras que en aquellos componentes en los que el conjunto lítico es escaso (Unidad 3 medio de CDM1, Componente Inferior de CT, Unidad 8 de LM, Unidad 6 de LV), las evidencias son exiguas. El único componente en el cual se presenta un 
conjunto lítico abundante y en el que hay pocas evidencias de tratamiento térmico es la Unidad 3 inferior de CDM1.

Si consideramos, de acuerdo a la cronología, a los componentes de C3T1 y CT y las unidades 4 y 3 inferior de CDM1 como representativos de la colonización inicial de la Meseta Central (Paunero 2009b), y al resto de los componentes analizados como correspondientes a una fase inicial de consolidación territorial (Miotti y Salemme 2004), lo observado plantea algunos interrogantes.

En este sentido, vemos que las evidencias más claras de este procedimiento proceden, en nuestro caso, de los componentes del Pleistoceno final, mientras que los sitios del Holoceno temprano muestran muy escasas piezas asignables a este tratamiento (Cuadro 11.1), lo cual llama la atención, puesto que es esperable que para estos momentos ya se conocieran bien las características y potencialidades de las materias primas disponibles en esta región (Paunero 2004b). En este sentido, creemos que hay que tener en cuenta algunos factores.

Por un lado, los conjuntos correspondientes a dos de los componentes asignados al Holoceno temprano muestran características acordes a ocupaciones eventuales y no redundantes (U. 3 medio de CDM1 y U.9 de LM: baja cantidad de restos líticos y óseos, ausencia de estructuras de combustión) (Paunero 2009b). La escasez de piezas tratadas térmicamente es, en este contexto, coherente con una ocupación eventual. La unidad 6 de LV, en tanto, presenta características particulares que analizaremos más adelante.

Por el otro, consideramos que la abundancia de restos tratados en los componentes finipleistocénicos tiene vinculación con determinadas actividades de talla desarrolladas es esos sitios, que están prácticamente ausentes en los contextos holocénicos estudiados, nos referimos al adelgazamiento bifacial.

En este sentido, nuestra primera observación es que este procedimiento pirotecnológico se realizaría como etapa previa a la formatización final de artefactos. Si bien los núcleos son escasos o están ausentes en los componentes analizados, no se han reconocido en ellos evidencias de tratamiento térmico y en un caso hemos podido remontar lascas tratadas con núcleos sin termoalterar (U. 5 de C3T1). Los estudios desarrollados en canteras (Frank et al. 2007; Paunero et al. 2004b), por su parte, no han arrojado evidencias de núcleos tratados. A esto se suman los resultados negativos obtenidos en nuestras experiencias con estos artefactos (ver capítulo 8, p. 132). Además, la mayor parte de las piezas tratadas corresponden a lascas extraídas durante la etapa de formatización final (U. 5 de C3T1, U. 4 y 3 inferior de CDM1, C.I. de CT). Al analizar estos productos de talla observamos que son fundamentalmente esquirlas de retoque $y$ adelgazamiento bifacial. Destaca, en este sentido lo observado en la Unidad 4 de CDM1 donde un alto porcentaje de las lascas de adelgazamiento se encuentran tratadas térmicamente, a pesar de que en el sitio sólo se recuperaron dos instrumentos con un retoque bifacial marginal. Es decir, en esta unidad se desarrollaron tareas de confección de artefactos bifaciales tratados térmicamente 
que no fueron descartados en el sitio. Por otra parte en la Unidad 5 de C3T1 los instrumentos y preformas tratadas son bifaciales.

Este conjunto de evidencias nos llevan a postular el tratamiento térmico de formas base para los sitios de la región en el marco de la formatización final de artefactos, particularmente durante la producción de instrumentos bifaciales, tales como bifaces y puntas de proyectil, lo que es coherente con lo observado para otros sitios de la región (Hermo 2008; Nami 1992) para contextos correspondientes al Pleistoceno final y el Holoceno temprano. Esto, asimismo es acorde a las observaciones experimentales realizadas por diversos investigadores, quienes afirman que este procedimiento pirotecnológico facilita las tareas de adelgazamiento, permitiendo desarrollar una tarea más controlada, tener menor probabilidad de fallas y extraer lascas más largas (Domanski y Webb 2007; Flenniken y Garrison 1975; Inizan et al. 1999; Luedtke 1992; Mandeville y Flenniken 1974; Nami et al. 2000, entre otros).

En el caso de la Unidad 4 de CDM1, que es el componente con mayor cantidad de piezas de adelgazamiento bifacial, las lascas de adelgazamiento tratadas son más largas que las no tratadas, aunque la diferencia no es estadísticamente significativa. Además, no se observan diferencias en los talones y bulbos de piezas con y sin tratamiento (p. 177). Esto nos indicaría que las técnicas de talla no variaban para las piezas tratadas y que el producto final buscado no era muy diferente, lo que nos lleva a pensar que las causas de aplicación de este procedimiento estarían en otros factores. Creemos, en este sentido, que pueden influir variables relacionadas con un aumento en la aptitud para la talla (mayor control de las extracciones, menor fuerza necesaria, menor probabilidad de falla) así como cuestiones estéticas (dadas por el cambio en lustre y color de las piezas). Consideramos que ambas alteraciones, a nivel de la talla y de la apariencia de la pieza, tienen influencia en la decisión de realizar o no esta técnica. Si bien entendemos que los beneficios que se dan a nivel de la facilidad de la talla son importantes, seguimos a Pfaffemberger (1988) al considerar que cualquier comportamiento tecnológico es al mismo tiempo, un comportamiento político, social y simbólico. De esta manera, determinadas modificaciones en la apariencia de un artefacto pueden jugar un papel importante en la decisión de realizar o no este procedimiento, en especial en contextos con abundantes materias primas de muy buena calidad para la talla como lo son las localidades arqueológicas estudiadas.

De acuerdo al análisis de los instrumentos óseos (Paunero et al. 2008a), en este componente el adelgazamiento bifacial se habría realizado utilizando un retocador extremo lateral confeccionado sobre diáfisis de camélido, mediante la técnica de presión. Esta técnica se habría implementado también en el retoque de los dos únicos instrumentos líticos tratados en este componente.

En contraste, los otros componentes finipleistocénicos (U. 3 inferior de CDM1, C.I. de CT) muestran muy escasas evidencias de bifacialidad, de manera que resulta coherente en este contexto no reconocer abundantes piezas tratadas. 
El tratamiento térmico se habría realizado con materias primas locales: en primer lugar sílex, y en menor medida toba silicificada y calcedonia. Todos los sitios estudiados cuentan con fuentes de aprovisionamiento de sílex y toba silicificada a menos de $5 \mathrm{Km}$ de distancia, mientras que para la calcedonia no se identificaron fuentes precisas, pero es común hallarla dispersa en el territorio (Frank et al. 2007; Paunero et al. 2005; Skarbun 2009b; Skarbun et al. 2007). En el caso del sílex rojo, que es el que más habitualmente se presenta tratado en CDM1, nuestras experimentaciones han demostrado que el tratamiento térmico es posible, que mejora sus propiedades para la talla y que puede ser identificable mediante el reconocimiento principalmente del lustre. El xilópalo, por su parte, muestra escasos restos tratados y, la obsidiana, en los casos en que está presente, no muestra ningún signo de alteración térmica.

\begin{tabular}{|c|c|c|c|}
\hline Componente & TT & Bifacialidad & Asignación Cronológica \\
\hline C3T1 U. 5 & $\mathrm{Si}$ & $\mathrm{Si}$ & Pleistoceno final \\
\hline CT C.I. & Muy escaso & Muy escasa & Pleistoceno final \\
\hline CDM U. $\mathbf{4}$ & $\mathrm{Si}$ & $\mathrm{Si}$ & Pleistoceno final \\
\hline CDM U. 3 inf. & Escaso & Escasa & Pleistoceno final \\
\hline CDM U. 3 med. & No & Muy escasa & Holoceno temprano \\
\hline LM U. 8 & No & Muy escasa & Holoceno temprano \\
\hline LV U. 6 & No & No & Holoceno temprano \\
\hline
\end{tabular}

Cuadro 11.1. Evidencias de tratamiento térmico (TT), bifacialidad y asignación cronológica de los componentes analizados.

Por otro lado, observamos que durante estos eventos de tratamiento térmico se han dañado muy escasas piezas. Si consideramos que esta técnica requiere distintas temperaturas y ritmos de calentamiento de acuerdo al tipo de pieza y a la materia prima a utilizar (Ariet 1991; Flenniken y Garrison 1975; Mandeville 1973; Mercieca 2000; Nami et al. 2000, entre otros), su implementación estaría evidenciando un manejo controlado del fuego y un conocimiento preciso de las temperaturas y técnicas necesarias para realizar este procedimiento de manera efectiva, de los combustibles potencialmente utilizables así como de las características de las materias primas líticas a emplear.

De acuerdo a nuestras experimentaciones, y teniendo en cuenta las temperaturas a las cuales comienza a generarse lustre y a las cuales las piezas ya sufren un intenso daño, consideramos que el tratamiento térmico habría sido realizado a temperaturas que van entre los $300^{\circ} \mathrm{C}$ y los $400^{\circ} \mathrm{C}$. Estos valores también han sido propuestos como óptimos para las materias primas de la región por otros investigadores (Nami et al. 2000).

En tanto, hay piezas dañadas que por sus características no fueron tratadas. En los componentes en los que se reconocieron fogones (U. 5 de C3T1, U. 4 y 3 inferior de CDM1, U. 6 de LV), la mayor parte de éstas proceden de su alrededor, lo cual responde a las expectativas planteadas 
(Alperson-Afil 2008; Backhouse y Johnson 2007; Nakazawa 2007; Sergant et al. 2006). Teniendo en cuenta su escasez y considerando su distribución, creemos que estas habrían entrado accidentalmente en contacto con el fuego como consecuencia del desarrollo de las diversas actividades en torno a él.

Sin embargo, una porción de las piezas dañadas en С 3 T1 no se presenta cerca de las estructuras de combustión. Como hemos mencionado arriba, descartamos que ésta alteración se deba a la acción de los fogones encendidos durante la ocupación de la Unidad 4. De esta manera, son necesarios otros enfoques para poder determinar la causa de su alteración térmica y de su ubicación final.

Finalmente, en los componentes en que no se han identificado estructuras de combustión (U. 3 medio de CDM1, C.I. de CT, U. 8 de LM) reconocimos siempre muy escasas piezas dañadas. Así, no tenemos suficientes elementos para evaluar detenidamente la causa de su termoalteración, aunque sus características apunten a contactos accidentales con el fuego.

\subsection{Restos óseos alterados térmicamente}

\subsubsection{Unidad 5 de Cerro Tres Tetas 1}

Las características de los restos termoalterados en C3T1 son muy particulares. En primer lugar, los huesos presentan siempre estadios iniciales de combustión, tanto en relación al color como a la textura. Además, la coloración se presenta homogénea en toda su superficie, sin grandes variaciones en los diversos sectores de la pieza (p. 166). Asimismo, en la totalidad de los elementos fracturados se observa que la termoalteración se ha dado también en la cara interna del hueso, indicando que estos se encontraban ya fragmentados al momento de resultar calentados (Asmussen 2009; Bennett 1999; Buikstra y Swegle 1989; Cain 2005; Nicholson 1993; Stiner et al. 1995, ver también capitulo 9). También observamos que los fragmentos que pudieron ser remontados en laboratorio presentaban coloración homogénea a través de la cara del hueso. Finalmente, si bien algunos de estos elementos se ubican en torno a una estructura de combustión, otros proceden de una cuadrícula más lejana, ubicada a $75 \mathrm{~cm}$ del fogón más cercano. Por el contrario, observamos que todos estos huesos se ubican inmediatamente por debajo de fogones de la unidad 4, encendidos aproximadamente $10 \mathrm{~cm}$ por encima de ellos, y que el porcentaje de restos termoalterados en estas cuadrículas es muy elevado (p. 166/7). En consecuencia, creemos que sus rasgos son acordes a situaciones donde dicha alteración se dio en contextos subsuperficiales. En este sentido sabemos que los huesos pueden resultar modificados por fogones encendidos en ocupaciones posteriores (Bennett 1999; Stiner et al. 1995), y que si 
esto sucede presentarán características similares a las observadas, debido a las propiedades de los huesos arqueológicos y a que la matriz sedimentaria circundante impediría que estos alcancen temperaturas elevadas. Esta temperatura, por el contrario, no resultaría suficiente para dañar a los artefactos líticos.

En consecuencia, consideramos que en esta unidad habrían existido múltiples causas por las que se termoalteraron los restos arqueológicos: tratamiento térmico de artefactos líticos, caída accidental o eventual de lascas e instrumentos de piedra en las estructuras de combustión y acción de los fogones encendidos durante la ocupación de la unidad 4 sobre los huesos depositados inmediatamente por debajo.

\subsubsection{Casa del Minero 1}

\subsubsection{Unidad 4}

Las características de los restos termoalterados en esta unidad difieren de lo expresado para C3T1. En primer lugar, observamos que si bien tanto la coloración como la textura indican estadios iniciales y medios de combustión, también se presentan, aunque en baja proporción, restos alterados de manera más intensa, representando los estadios superiores (p. 178/9). Además, observamos que alrededor del $30 \%$ de los restos muestra evidencias de calentamiento sólo en su cara externa (p. 179). Se reconocieron escasas fracturas generadas por termoalteración, siendo estas principalmente longitudinales. No se observaron artefactos con rastros de calentamiento. Los restos calentados tienden a concentrarse en las cercanías a las estructuras de combustión de esa unidad (p. 179).

A partir de las características enumeradas, consideramos que los restos se termoalteraron por diversas causas. El hecho de que una parte no muestre modificaciones en su cara interna evidenciaría que al menos una porción de ellos se encontraba entero al momento del contacto con el fuego (Cain 2005). La presencia de huesos en los que se observa una termoalteración irregular de la superficie (parcialmente quemado, carbonizado o calcinado) podría indicar que en parte estos huesos presentaban carne al momento de ser calentados (Asmussen 2009; Buikstra y Swegle 1989). Es decir que las características de parte del conjunto presentarían evidencias acordes a contextos de cocción de carne con hueso. Las evidencias de marcas de corte y fracturas helicoidales identificadas en este componente (Paunero et al. 2008a) apoyarían esta idea, ya que indican procesamiento y consumo. Sin embargo, al ser los restos indeterminables los predominantes en el conjunto, la cocción de carne con huesos se mantiene como hipótesis, ya que no ha sido posible analizar si hubo selección de especies o de partes entre los restos termoalterados. 
Por otra parte, también se presentan abundantes huesos que exhiben alteración térmica en su cara interna. En algunos casos, la combustión es en ésta más intensa que en la externa, lo que indicaría que el hueso se encontraba fragmentado y sin carne al momento del calentamiento (Asmussen 2009; Cain 2005). Consideramos que esto podría evidenciar un contacto accidental o eventual de estos elementos con el fuego, en el marco de las actividades desarrolladas en torno a los fogones, que es donde se concentran estas piezas. En este sentido, pensamos que esta termoalteración no es producto de un descarte intencional sistemático de las piezas en los fogones; en primer lugar porque sólo el $10 \%$ de la muestra está termoalterada (p. 178) y sería esperable que si existió una actividad habitual de descarte dentro de estas estructuras se hallen más restos con rasgos de combustión, en segundo lugar porque hay muy pocos elementos calcinados, mientras que en casos de descarte en fogones estos serían más comunes (Cain 2005; Costamagno et al. 2002; Théry-Parisot 2002; Yravedra et al. 2005).

En síntesis, cnsideramos que la termoalteración de los elementos óseos presentes en esta unidad se produjo como consecuencia de dos procesos: la cocción de carne y la caída accidental de huesos durante tareas de procesamiento.

\subsubsection{Unidad 3 inferior}

En esta unidad se observan muy escasos huesos termoalterados que, por coloración y textura, están en su mayoría representando los estadios iniciales de combustión. La totalidad de los restos muestran modificaciones tanto en la cara externa como en su interior. No se han reconocido fracturas producidas por el fuego. Los instrumentos no muestran evidencias de termoalteración. La mayor parte de estos restos están asociados a estructuras de combustión (p. 189).

Estas características nos llevan a considerar que su termoalteración se dio como consecuencia del contacto accidental de las piezas en los fogones. Esto es coherente si se considera que en las cuadrículas se observan bajos índices de restos con alteración por calor.

\subsubsection{Unidad 3 medio}

Son muy pocas las piezas alteradas térmicamente en este componente. A diferencia de las otras unidades estudiadas, en ésta se presentan principalmente restos en los estadios finales de combustión, tanto por color como por textura. Todas las piezas presentan modificaciones en ambas caras. No se han reconocido fracturas producidas por el calor ni se han recuperado instrumentos en esta unidad (p. 195). 
Al ser muy bajas las cantidades y carecer este componente de fogones, resulta muy dificultoso establecer las causas de su termoalteración. Las evidencias tienden a indicar, sin embargo, que los huesos habrían estado frescos o con carne y entrado en contacto directo con el fuego, alcanzando altas temperaturas (Buikstra y Swegle 1989; Whyte 2001). Los restos termoalterados provienen en su mayor parte de la cuadrícula F1 (p. 195), distribuyéndose de manera diferente a lo que sucede con los restos líticos dañados térmicamente.

\subsubsection{Componente Inferior de Cueva Túnel}

Las características de termoalteración de los restos de este componente son similares a las observadas en la unidad 4 de CDM1. Si bien tanto la coloración como la textura indican estadios iniciales y medios de combustión, también se presentan en baja proporción, restos termoalterados de manera más intensa, representando los estadios superiores. Observamos que cerca del 20\% muestra evidencias de calentamiento sólo en la cara externa del hueso (p. 204); esto sucede únicamente en estos dos componentes. El fuego generó principalmente fracturas y grietas longitudinales, pero también las hay oblicuas y transversales, así como deformación y exfoliaciones (p. 204/5). No se observaron artefactos óseos con evidencias de calentamiento. Las piezas termoalteradas se presentan en su mayor parte agrupadas al este del sector excavado, principalmente en la cuadrícula D1. Ésta y C1, inmediatamente adyacente, muestran porcentajes de restos termoalterados más altos que el resto de las cuadrículas (p. 205).

Los indicadores son coincidentes con lo esperable para contextos en los que los huesos presentan carne al momento de ser calentados, es decir que posiblemente habrían sido consecuencia de la cocción de carne con hueso (Asmussen 2009; Buikstra y Swegle 1989; Cain 2005). El conjunto óseo de este sitio ha arrojado evidencias de consumo, presentes en forma de fracturas helicoidales, transversales y longitudinales, así como lascados y marcas de corte, lo que resulta coherente con nuestra propuesta. Al igual que en la unidad 4 de CDM1, al ser los restos indeterminables los predominantes en el conjunto, no ha sido posible analizar si hubo selección de especies o de partes entre los restos termoalterados; en consecuencia, se mantiene com hipótesis la cocción de carne con hueso. Sin embargo, notamos que predominan los camélidos.

Por otra parte, también hay abundantes huesos con evidencias de termoalteración en su cara interna. En algunos casos, la combustión es en esta más intensa que en la externa, lo que indicaría que el hueso se encontraría fragmentado y sin carne al momento del calentamiento (Asmussen 2009; Cain 2005). Esto podría ser evidencia de un contacto accidental de estos elementos con el fuego, aunque al no haber reconocido fogones en este componente, resulta difícil evaluar esta propuesta más detenidamente. El hecho de que los restos termoalterados estén concentrados en un sector de la excavación podría estar indicando la cercanía de estos a una fuente de 
combustión, teniendo en cuenta que estas cuadrículas son adyacentes a un sector no excavado de la cueva. Sin embargo, como discutiremos más adelante, existen elementos que nos llevan a considerar que la distribución de los restos arqueológicos ha sufrido desplazamientos postdepositacionales, por lo cual su ubicación final no necesariamente estaría reflejando el lugar donde se ubicaba la estructura de combustión.

Es decir, en este componente habrían actuado al menos dos factores en la termoalteración de los restos óseos. Por un lado, las actividades de cocción, por el otro el contacto incidental de estos elementos durante el desarrollo de diversas tareas de procesamiento.

\subsubsection{Unidad 8 de La Mesada}

Sólo un fragmento indeterminado, totalmente quemado y con textura grasosa - ondulante, ha sido reconocido (p. 212). Esta evidencia es muy escasa como para poder sacar alguna conclusión.

\subsubsection{Unidad 6 de Cueva de La Ventana}

La cantidad de restos óseos de esta unidad es muy escasa. Sin embargo, el $20 \%$ se encuentra termoalterado. Se trata en todos los casos de astillas que, por su coloración y textura, presentan estadios iniciales y medios de combustión. En todos los casos muestran estos rasgos en ambas caras (p. 217). Los huesos alterados han sido recuperados del interior del único fogón identificado en el componente, lo que indicaría que su combustión habría sido causada por su caída dentro de éste.

\subsubsection{Alternativas para la alteración térmica de los restos óseos}

En términos generales observamos que la mayor parte de los conjuntos óseos de los sitios muestran bajos porcentajes de termoalteración, siendo predominantes los estadios iniciales de combustión. Sin embargo, el análisis de los conjuntos nos estaría indicando que estuvieron actuando diversos procesos relacionados con el fuego.

En primer lugar una parte de los restos termoalterados (U. 4 de CDM1, C.I. de CT) presenta evidencia acorde a contextos de cocción de carne con hueso: presencia de todos los estadios de combustión pero predominancia de los iniciales, heterogeneidad en la coloración de la superficie del hueso, ausencia de evidencias de termoalteración en su cara interna y diversidad de fracturas generadas por la acción térmica (Asmussen 2009; Buikstra y Swegle 1989; Cain 2005; Whyte 2001). La evidencia de marcas de corte y fracturas antrópicas en ambos sitios es coherente con 
esta propuesta, ya que esta indicando que allí se desarrollaron actividades de procesamiento y consumo. En el caso de la Unidad 4 de CDM1, estos restos se concentraron en sectores con fogones; mientras que CT no cuenta con estas estructuras. Son necesarios, sin embargo, más análisis para poder afirmar fehacientemente que estos huesos fueron termoalterados durante la cocción de alimentos, teniendo en cuenta que la mayor parte de ambos conjuntos es indeterminable en cuanto a taxón y parte esqueletaria. Si bien las marcas de corte y las fracturas pueden estar vinculadas a la cocción, también podrían estar relacionadas a otras actividades tales como la producción de artefactos óseos. Entonces, sería interesante analizar la vinculación y frecuencia de marcas de corte y de percusión en los restos óseos, ya que de acuerdo a De Nigris $(1999,2004)$, existen diferentes expectativas en cuanto a la frecuencia de estas marcas antrópicas en huesos cocidos con respecto a huesos frescos sin cocción. Esto requiere un estudio más exhaustivo de las evidencias antrópicas y naturales presentes en el conjunto, puesto que hasta el momento dichos análisis no se realizaron de manera sistemática.

Por otra parte, una porción de los conjuntos (U. 4 y 3 inferior de CDM1, C.I. de CT, U. 6 de LV) muestra características acordes a un contacto eventual con el fuego de huesos frescos ya fracturados (Buikstra y Swegle 1989; Cain 2005), probablemente generado de manera incidental. Estos huesos presentan termoalteración en ambas caras, bajos estadios de combustión y escasas fracturas generadas por la acción térmica. En el caso de las unidades de CDM1 estas piezas se recuperaron de los alrededores de los fogones, mientras que en LV se hallaron dentro de la estructura de combustión. En la Unidad 3 medio de CDM1, por su parte, las características de los escasos restos termoalterados indicarían un contacto directo con el fuego, probablemente a mayores temperaturas que en los casos anteriores.

Finalmente, para la Unidad 5 de C3T1, consideramos que muy probablemente la alteración térmica se deba a la acción de los fogones encendidos por las ocupaciones de la Unidad 4, durante el Holoceno medio. Estos se presentan inmediatamente por encima de los restos alterados, que muestran características acordes a la acción térmica en contextos subsuperficiales: estadios iniciales de combustión y coloración homogénea en toda la superficie del hueso, según lo observado en nuestras experimentaciones y lo propuesto por diversos investigadores (Asmussen 2009; Bennett 1999; Buikstra y Swegle 1989; Cain 2005; Nicholson 1993; Stiner et al. 1995).

En consecuencia, y teniendo en consideración la evidencia experimental, descartamos la hipótesis propuesta acerca de la aplicación del tratamiento térmico en el marco de la confección de instrumental óseo. Experimentalmente vimos que si bien el tratamiento térmico facilita el retoque durante la producción de artefactos, también aumenta las probabilidades de fracturas no deseadas, de modo que no sería útil, al menos desde la perspectiva funcional, para la producción de instrumentos óseos (ver capítulo 9, p. 143). En el caso de los conjuntos arqueológicos, sólo la tibia retocada de C3T1 muestra evidencias de termoalteración, mientras que el resto de los 
instrumentos no presentan signos de combustión. Esta tibia, como observamos arriba, probablemente sufrió alteraciones postdepositacionales. Además, sólo tres lascas óseas muestran evidencias de termoalteración, considerando todos los conjuntos analizados. Cabe destacar en este sentido que la percusión ha sido propuesta como una de las técnicas intervinientes en la confección de instrumental de hueso para la Meseta Central (Paunero et al. 2008a). Es decir que las evidencias nos llevan a considerar que el fuego no era utilizado durante la confección de instrumentos óseos.

Por otra parte, nos interesa analizar la distribución de los restos óseos alterados térmicamente en aquellos sitios en los que hemos postulado que esta modificación se produjo por fogones de la misma ocupación. El análisis de los componentes que presentan estructuras de combustión (U. 4 y 3 inferior de CDM1, U. 6 de LV) indica que estos huesos se ubican a su alrededor o bien en su interior. En cuanto a los sitios en los que no se observan fogones (C.I. de CT, U. 3 medio de CDM1), notamos que tienden a localizarse en sectores distintos de los de mayor cantidad de restos líticos dañados, por lo que es poco probable que los restos sean indicadores de fogones "fantasma" (Backhouse y Johnson 2007; Sergant et al. 2006). Esto podría estar indicando que diversos factores han jugado un papel en la distribución de los restos, lo cual será analizado más adelante, en conjunto con la distribución general observada en estos sitios.

\subsection{Fogones}

\subsubsection{Unidad 5 de Cerro Tres Tetas 1}

Todos los fogones de esta unidad tienen un eje mayor que mide al menos $60 \mathrm{~cm}$. Son de estructura plana y forma elíptica o subelíptica. Están distribuidos en diferentes puntos del sector excavado (p. 157). De acuerdo a su ubicación estratigráfica y horizontal, a las dataciones radiocarbónicas y a la proximidad registrada entre ellos, Paunero (2001) afirma que estos fogones no representan eventos sincrónicos producto de una sola ocupación. En este sentido, dos de ellos están parcialmente superpuestos por lo cual es esperable que se trate al menos de dos ocupaciones diferentes.

Sus características generales son acordes con ocupaciones poco intensas (Nakazawa 2007). Sin embargo, si analizamos su tamaño en comparación con el conjunto de las estructuras de combustión de todos los componentes estudiados (ver infra), vemos que los fogones de C3T1 se agrupan dentro de los más grandes (Fig 10.1, p. 157). A este respecto, una posibilidad es que su mayor tamaño relativo con respecto al resto esté indicando que más cantidad de gente ha utilizado estas estructuras o que permanecieron durante más tiempo en el sitio (Bartram et al. 
1991; Chatters 1987; Pérez de Micou 1991). Otra posibilidad es que el mayor tamaño de los fogones se deba a funciones específicas a las cuales fuesen destinados estos. En este sentido, cabe destacar que de acuerdo a Paunero (2001), este sitio cuenta con características particulares que lo llevan a considerar que estos fogones estaban destinados para actividades productivas tales como el tratamiento térmico de artefactos, el secado de pieles o el calentamiento para doblar maderas de enmangue. Sabemos que la forma y el tamaño de los fogones no son definitorios por sí mismos de las funciones que cumplieron (Manzi y Spikins 2008) sino que éstos pueden tener diversidad de usos, siempre y cuando satisfagan los requisitos mínimos necesarios para desarrollar cada actividad. Nuestras experimentaciones (ver capítulo 8, p. 131) indican que es posible desarrollar un tratamiento térmico exitoso utilizando fogones como los presentes en C3T1; y las evidencias líticas son acordes con la aplicación de este procedimiento. Por otra parte, no contamos con elementos hasta el momento para poder evaluar las otras posibilidades propuestas por Paunero (2001).

\subsubsection{Casa del Minero 1}

\subsubsection{Unidad 4}

Los diez fogones de esta unidad tienden a agruparse dentro de los más pequeños en cuanto a dimensiones del total de los estudiados. Sólo dos de ellos son más grandes, con ejes mayores de entre 57 y $60 \mathrm{~cm}$, mientras que un tercer fogón, si bien no ha sido excavado en su totalidad, cuenta con un eje de al menos $55 \mathrm{~cm}$. Todos son de estructura plana y forma circular, elíptica o subelíptica (p. 169).

Todas las estructuras de combustión tienden a estar agrupadas, principalmente en el sector sudeste del área excavada. Se observa habitualmente más de un fogón en una misma cuadrícula, indicando que éstos no representarían eventos sincrónicos producto de una sola ocupación de la cueva (Paunero et al. 2007d). Se ha registrado etnográficamente que existe diversidad en la cantidad de fogones que son encendidos dentro de una cueva al mismo tiempo, dependiendo, entre otros factores, de la cantidad de gente presente y las funciones destinadas a ellos (Galanidou 2000). Sin embargo, en este caso la cercanía entre ellos no dejaría espacio disponible para ser utilizado, de modo que es esperable que los fogones correspondan a repetidas ocupaciones, más que corresponder a eventos sincrónicos, hecho que se observa en otros sitios patagónicos tempranos con abundantes estructuras de combustión (Massone 2004).

De esta manera, sus características generales son acordes con ocupaciones reiteradas pero poco intensas, donde se encienden fuegos que requieren poca inversión de energía en su acondicionamiento (Nakazawa 2007; Pérez de Micou 1991). Dado que no es probable que estas 
estructuras de combustión hayan estado activas al mismo tiempo, posiblemente el sitio haya sido reocupado con una redundancia en la elección del espacio donde encender las estructuras de combustión (Paunero et al. 2007d).

\subsubsection{Unidad 3 inferior}

Al igual que en la unidad 4, los fogones de esta unidad tienden a ser pequeños. Sólo tres tienen ejes mayores, de entre 55 y $67 \mathrm{~cm}$. Todos son de estructura plana, forma elíptica o subelíptica y tienden a estar agrupados. A diferencia de lo que observamos en la unidad 4, se concentran en el sector central del área excavada. Se observa habitualmente más de un fogón en una misma cuadrícula, o bien en cuadrículas adyacentes pero ubicados de manera muy cercana (p. 182). Esto indicaría, al igual que en la unidad 4, que estos fogones no representan eventos sincrónicos producto de una sola ocupación. En consecuencia, sus características generales serían acordes con ocupaciones reiteradas pero poco intensas (Nakazawa 2007; Pérez de Micou 1991).

\subsubsection{Unidad 6 de Cueva de La Ventana}

En esta unidad hay un solo fogón cuyo eje mayor mide $65 \mathrm{~cm}$. Es plano, de forma elíptica y no presenta límites de ningún tipo. Está ubicado en el sector central del lóbulo interno de la cueva (p. 212). Sus características generales, junto con la escasez de material arqueológico recuperado, resultan acordes con una ocupación eventual de la cueva (Nakazawa 2007; Pérez de Micou 1991).

\subsubsection{Características de las estructuras de combustión}

En síntesis, observamos que la totalidad de los fogones estudiados son de tipo plano, y de forma elíptica o subelíptica. En ningún caso se presentan limitados por estructuras. Sin embargo, se pueden reconocer dos grandes grupos en relación con sus dimensiones (Fig. 10.1, p. 157). Por un lado fogones con un diámetro máximo que fluctúa entre los 27 y los $47 \mathrm{~cm}$ y un eje menor, perpendicular al anterior, con dimensiones que están entre los 19 y los $30 \mathrm{~cm}$ (U. 4 y 3 inferior de CDM1). Por el otro, fogones de mayor tamaño con un diámetro máximo que va entre 57 y $67 \mathrm{~cm}$ de largo y un eje menor con dimensiones que están entre los 32 y los 42 cm (U. 5 de C3T1, U. 4 y 3 inferior de CDM1, U. 6 de LV). Por fuera de estos dos grupos sólo quedan tres fogones, dos de los cuales no han sido completamente excavados, razón por la cual no se cuenta con sus dimensiones totales. El restante, uno de los fogones de la unidad 5 de C3T1, presenta dimensiones mucho mayores a todos $(120 \mathrm{~cm}$ por $60 \mathrm{~cm})$. 
En este sentido, los fogones planos de la Meseta Central que hemos estudiado son acordes a lo que se espera para contextos de ocupaciones poco intensas o de corta duración, donde se destina poca energía en la formatización de los fogones (Nakazawa 2007; Pérez de Micou 1991). Cabe considerar que los fogones planos tienden a alcanzar temperaturas menores que los que tienen forma de cubeta, y a tener menor duración, razón por la cual no resultan morfologías óptimas para ocupaciones prolongadas (Leroi-Gourhan 1979; Marconetto 2005; Nakazawa 2007).

Por su parte, la abundancia de estructuras de combustión en tres de los cuatro componentes analizados donde están presentes este tipo de rasgos (U. 5 de C3T1, U. 4 y 3 inferior de CDM1), muchas veces ubicados de manera cercana entre ellos o inclusive superpuestos podrían estar evidenciando una sucesión de ocupaciones en estas cuevas, así como una redundancia en la elección de los espacios utilizados para encender fogones. Si bien es posible que más de un fuego haya sido iniciado al mismo tiempo (Galanidou 2000), resulta poco factible que fogones ubicados a muy poca distancia entre ellos hayan sido contemporáneos, ya que esto implicaría la disminución del espacio disponible en torno a la estructura de combustión y una consecuente pérdida del poder calórico generado, teniendo en cuenta que este disminuye a medida que uno se aleja de la fuente de calor (Massone 2004; Nakazawa 2007).

La fluctuación en el tamaño, por otro lado, podría estar vinculada con la variación en la cantidad de personas utilizando el fogón, el tiempo que se permaneció en el asentamiento, o bien con la práctica de ciertas actividades que requieran fogones más grandes (Bartram et al. 1991; Chatters 1987; Nakazawa 2007; Pérez de Micou 1991).

Las actividades que implican la utilización del fuego -sin considerar en este caso su función probable como eje de la organización espacial intrasitio- para las que hasta el momento tenemos evidencias en los sitios son el tratamiento térmico y posiblemente la cocción de alimentos. $\mathrm{Si}$ analizamos el Cuadro 11.2 observamos que no existiría una correlación entre el tamaño de las estructuras de combustión (grandes o chicas de acuerdo a los dos rangos mencionados arriba) y las actividades desarrolladas en el sitio. Por lo tanto, estas tareas no estarían determinando el tamaño de los fogones. En consecuencia, postulamos como hipótesis que sus dimensiones estarían variando en función de la intensidad de la ocupación, es decir que podría haber fluctuado la cantidad de personas que ocuparon el sitio en el momento de encendido el fogón, o bien el tiempo que permanecieron en el sitio. En este sentido, consideramos más probable que se deba al primero de estos enunciados, puesto que, como veremos más adelante, estos sitios presentan la mayor parte de los restos alrededor de las estructuras de combustión, evidenciando escasas actividades de mantenimiento del espacio, las cuales serían esperables en contextos en los que se ocupó un lugar de manera prolongada (Gifford 1980; O'Connell 1987; Schiffer 1972; Stevenson 1991). 
Resultan necesarios más estudios para corroborar dicha hipótesis, ya que existen otros posibles usos del fuego que no dejan un correlato material (como por ejemplo la calefacción) o bien que estos elementos no hayan perdurado en el registro arqueológico (por ejemplo el uso del fuego en el tratamiento térmico de pigmentos) (Aschero 1983-1985, 1985; Barbosa y Gradín 1987; Barbosa y Rial 1983 - 1985). Además, también es posible que otros factores no considerados aquí hayan jugado un papel en el tamaño del fogón.

\begin{tabular}{|c|c|c|c|}
\hline & TT & COCCIÓN & FOGONES \\
\hline C3T1 U. 5 & Si & No & G \\
\hline CDM1 U. 4 & Si & Si & G y C \\
\hline CDM1 U. 3 inf. & Si & No & G y C \\
\hline LV U. 6 & No & No & G \\
\hline
\end{tabular}

Cuadro 11.2. Evidencias de tratamiento térmico (TT), probable cocción y tamaño de fogones por componente (G: Grandes, C: Chicos).

Por otra parte, es escasa la información sistemática concerniente a formas y dimensiones de fogones en la literatura arqueológica de la Patagonia. Una excepción es el caso de los fogones relevados y descriptos por Massone correspondientes a lo que él denomina modalidad Fell (Massone 2002, 2004; Massone et al. 1998) y que son parcialmente contemporáneos a los que estamos estudiando. Si realizamos una comparación con ellos vemos que estos son planos, mientras que aquellos pueden ser planos, pero también los hay en cubeta, así como grandes manchas carbonosas. Los fogones Fell pueden ser circulares, subcirculares o de forma irregular mientras que en la Meseta Central tienden a ser elípticos o subelípticos. En dos de los fogones de los sitios adscribibles a la modalidad Fell, además, se presentan grandes bloques líticos que podrían ser interpretados como límites a las estructuras de combustión (Massone 2002, 2004). En cuanto a sus dimensiones, Massone $(2002,2004)$ marca que la mayor parte de ellos presenta un diámetro máximo de entre 31 y $55 \mathrm{~cm}$ y sólo un fogón tiene un diámetro mayor a los $55 \mathrm{~cm}$. Este último presenta un diámetro de $107 \mathrm{~cm}$ y sus límites no son definidos (Massone 2002, 2004).

De esta manera, observamos que mientras que los fogones Fell presentan una mayor diversidad de formas que los de la Meseta Central, éstos últimos muestran un rango mayor de tamaños. Esto podría estar indicando que para dos regiones vecinas de la Patagonia meridional, se estarían implementando, para fines del Pleistoceno e inicios del Holoceno, estrategias diferentes con respecto al diseño de los fogones. Si bien son necesarios mayor número de estudios, existen diversos factores que podrían estar influyendo en la forma en que se diseñan estas estructuras de combustión. Por un lado, es posible que diferencias climáticas estén actuando. En este sentido, los fogones en cubeta permiten alcanzar temperaturas mayores (Leroi-Gourhan 1979; Marconetto 2005), por lo que resulta más óptimos que los planos para ambientes fríos. Por el otro, los fogones en cubeta tienden a perdurar más tiempo, y podrían haber sido preferidos en los 
casos en que se pretendía ocupar un sitio de forma más prolongada. Finalmente, es factible que las diferencias puedan deberse a usos distintos de las estructuras de combustión, aunque la evidencia contextual indica actividades similares en ambas regiones (Massone 2004; Mena et al. 2000; Paunero 2009b). Esto resalta la importancia de implementar estudios comparativos entre los conjuntos arqueológicos de regiones vecinas, generando enfoques más abarcativos y superadores que nos permitan identificar los factores que inciden en el diseño y funcionalidad de un fogón en un momento dado.

Por otra parte, cabe destacar que en algunos de los componentes estudiados no se han reconocido estructuras de combustión (C.I. de CT, U. 3 medio de CDM, U. 8 de LM). Sin embargo, la presencia de espículas de carbón, junto con el reconocimiento de huesos y líticos termoalterados, nos indica que en todos ellos hubo al menos un fogón encendido. Teniendo en cuenta que en dos de estos componentes la distribución de los restos líticos y óseos alterados por el fuego no se superponen o lo hacen sólo parcialmente (C.I. de CT, U. 3 medio de CDM), consideramos probable que los fogones se hayan ubicado fuera del área excavada, aunque no descartamos que diversos procesos postdepositacionales hayan destruido estas estructuras.

\subsection{Distribución de los restos}

\subsubsection{Unidad 5 de Cerro Tres Tetas 1}

En relación con el conjunto lítico vemos que la mayor parte de los restos se ubican en cuadrículas con estructuras de combustión. Sin embargo, un porcentaje importante se encuentra alejado de ellos. En ambos sectores predominan los restos menores a dos $\mathrm{cm}$, correspondientes a los estadios de formatización final. Hay, además, aproximadamente un $10 \%$ de piezas mayores a $4 \mathrm{~cm}$ (p. 158).

En cuanto al conjunto óseo, si bien la cantidad de restos es muy baja, estos también se concentran en las cercanías de las fuentes de calor. Los huesos tienden a ser menores a dos $\mathrm{cm}$ y a ubicarse en espacios separados de aquellos de mayor densidad de restos líticos. Por otra parte, en los espacios cercanos a los fogones los huesos se encuentran más fragmentados, razón por la cual hay menor cantidad de restos a los cuales se les ha asignado un taxón (p. 159).

Las características generales del sitio (ver capítulo 5, p. 56), la presencia de fogones claramente estructurados junto con los diversos remontajes que hemos podido realizar, indicarían que los procesos postdepositacionales no han alterado significativamente la distribución horizontal de los elementos. Además, los restos líticos dañados térmicamente se presentan, en un porcentaje importante, en torno a los fogones. 
De esta manera, las distribuciones de artefactos líticos, teniendo en cuenta su tamaño y estadio de formatización, podrían estar indicando áreas de descarte primario (Schiffer 1972). Estas concentraciones podrían evidenciar que allí se desarrollaron actividades de talla, particularmente la formatización final de instrumentos. Estas tareas se estarían llevando a cabo, por un lado, en torno a un sector de fogones, por el otro en un área alejada a ellos. En ambos sectores, se tallaron tanto piezas tratadas como no tratadas.

Por otra parte, la distribución de los huesos también estaría evidenciando principalmente áreas de descarte primario, considerando la predominancia de restos menores a dos $\mathrm{cm}$ en torno al fogón. Esto podría indicar que en estos sectores se han llevado a cabo tareas de procesamiento que han implicado la fragmentación de los restos, lo cual es coherente con la información disponible acerca de la funcionalidad de los instrumentos líticos del sitio. De acuerdo al estudio de los micropulidos (Paunero y Castro 2001), los instrumentos líticos cumplieron funciones de raspado y corte de cuero y hueso. Estas actividades se habrían desarrollado en sectores diferentes de la cueva, conformando áreas de actividad, principalmente alrededor de los fogones (Paunero y Castro 2001).

Las características de los conjuntos, en consecuencia, resultan coherentes con las expectativas para sitios con ocupaciones de baja intensidad, donde se espera que predomine el descarte primario y que se realicen escasas tareas de mantenimiento del espacio (Binford 1994; Gifford 1980; Nakazawa 2007; Schiffer 1972; Stevenson 1991). Diversas actividades que incluyen la talla lítica, tanto de piezas tratadas térmicamente y no tratadas, y el uso de instrumentos líticos y óseos en el procesamiento de materias primas animales habrían sido realizadas mayormente en torno a las estructuras de combustión. Sin embargo, una parte de las actividades de talla lítica debió haberse realizado en un sector alejado a los fogones presentes en el sector excavado.

\subsubsection{Casa del Minero 1}

\subsubsection{Unidad 4}

En relación con el conjunto lítico vemos que, la mayor parte de los restos se encuentran en cuadrículas con estructuras de combustión. Las piezas se concentran preferentemente en el sector sudeste de la cueva, que es el mismo donde están la mayor parte de los fogones (p. 170). La distribución de los restos líticos dañados, además, también es coincidente con la ubicación de estas estructuras.

La mayor parte de los instrumentos se han encontrado en cuadrículas con fogones. En este sentido, cabe considerar que éstos han cumplido funciones de cortar hueso y raspar cuero, de acuerdo a los análisis funcionales realizados (Cueto et al. 2009). 
En este componente predominan los restos líticos menores a dos $\mathrm{cm}$. El porcentaje de piezas mayores a $4 \mathrm{~cm}$, por su parte, es baja. Existen divergencias en la distribución de determinadas materias primas, que tienden a concentrarse en sectores diferenciados, tal es el caso del sílex rojo, el marrón y el amarillo (p. 170).

Los restos óseos también se concentran en los alrededores de las estructuras de combustión, coincidiendo su distribución, en términos generales, con la correspondiente a la de los elementos líticos (p. 171). Se observa una alta proporción de desechos menores a dos $\mathrm{cm}$, en especial en el sector de mayor densidad de restos, lo cual es coherente con la información acerca del conjunto lítico. La distribución por taxón no muestra tendencias marcadas, la mayor parte de las especies reconocidas han sido identificadas en los mismos sectores o en sectores aledaños (p. 172). Lo mismo puede afirmarse para las diferentes porciones de los camélidos: el esqueleto apendicular y axial tienden a concentrarse en los mismos puntos o puntos adyacentes. La excepción a esta afirmación podría ser el caso de los rheidos, que se encuentran alejados de los sectores de mayor densidad y que no están asociados a estructuras de combustión. Sin embargo, estas consideraciones deben ser tomadas con cuidado, dado el alto índice de restos indeterminables presentes en el sitio.

Las características de esta unidad nos llevan a considerar que los diversos procesos postdepositacionales no han jugado un papel significativo en la distribución de los artefactos (ver capítulo 5, p. 65). La distribución de los restos líticos dañados y de los huesos termoalterados en torno a los fogones, así como la integridad e identificabilidad de estas estructuras también apunta en esta dirección.

En consecuencia, las distribuciones de artefactos líticos, teniendo en cuenta su tamaño y estadio de formatización, podrían estar indicando, al igual que en el caso de la Unidad 5 de C3T1, áreas de descarte primario (Schiffer 1972) y que probablemente allí se desarrollaron actividades de talla, particularmente la formatización final de instrumentos. Las divergencias en la distribución de algunas de las materias primas podrían indicar eventos de talla discretos que se realizaron separados espacialmente el uno del otro, y quizás también temporalmente, si los fogones fueron encendidos durante distintas ocupaciones del lugar. Estas actividades se habrían realizado en torno a estructuras de combustión, aunque no es factible realizar una vinculación directa entre un determinado fogón y un evento de talla, puesto que se observa una redundancia en la localización de muchas de las estructuras.

A partir de la escasez de restos líticos mayores a $4 \mathrm{~cm}$, podría postularse que los elementos de mayor tamaño no fueron descartados en ese sector, o bien que se realizó una limpieza de la superficie ocupada. Si bien es probable que ambos factores hayan jugado un papel en la ausencia de estos restos, observamos que sí se presentan elementos óseos de grandes dimensiones en este mismo espacio; de esta manera, si hubo algún proceso de limpieza y mantenimiento del 
espacio, este debe haber sido eventual y expeditivo. En este sentido, resulta interesante subrayar que la cuadrícula I, ubicada en el umbral de la cueva y no considerada en esta Tesis por presentar dificultades en su asignación estratigráfica, muestra una predominancia de elementos líticos de mayor tamaño que los presentes en el resto del sector excavado, así como mayor cantidad de instrumentos. Consideramos que son necesarios estudios más detallados para poder determinar si existe una vinculación cronológica entre este sector y el resto del componente, aunque de hacerlo, estos restos podrían estar representando un descarte preferencial de los restos líticos de mayor tamaño en un sector del sitio.

Asimismo, los análisis de los conjuntos líticos (Skarbun 2009b; Skarbun et al. 2007) indican que una parte de los instrumentos confeccionados en el sitio no fueron descartados allí; entre ellos los artefactos bifaciales tratados térmicamente de los cuales sólo hemos encontrado las piezas de adelgazamiento. Estos instrumentos conservados habrían requerido mayor inversión de energía y formarían parte del equipo trasladado del grupo (Skarbun 2009b). En consecuencia, al menos algunos de los artefactos mayores a $4 \mathrm{~cm}$ están ausentes del sitio a causa de las estrategias tecnológicas implementadas y no por las actividades de mantenimiento del espacio llevadas a cabo.

Por otro lado, la distribución de los huesos también estaría indicando áreas de descarte primario, considerando la abundancia de restos menores a dos $\mathrm{cm}$ en torno al fogón y la vinculación entre restos óseos termoalterados y estructuras de combustión. Esto podría indicar que se seleccionó el mismo sector de la cueva, en torno a los fogones, para el procesamiento faunístico teniendo en cuenta la evidencia de fracturas helicoidales, marcas de corte, huesos lascados y lascas óseas.

En consecuencia, al igual que en C3T1, las características de los conjuntos resultan coherentes con las expectativas para sitios con ocupaciones de baja intensidad donde se espera que predomine el descarte primario y que se realicen escasas tareas de mantenimiento del espacio (Binford 1994; Gifford 1980; Nakazawa 2007; Schiffer 1972; Stevenson 1991). En síntesis, observamos que en esta unidad los restos tienden en su mayoría a ubicarse en las cercanías a las fuentes de calor, lo que indicaría que las actividades fueron realizadas, por lo general en torno a él. A lo largo de las sucesivas ocupaciones que constituyen esta unidad, la gente habría seleccionado el mismo sector de la cueva para desarrollar las actividades de formatización final de artefactos líticos tratados térmicamente y sin tratar, el procesamiento de carcasas, y, probablemente la cocción de alimentos y su consumo. El procesamiento de rheidos, por su parte, debió haberse realizado en un sector alejado a los fogones. 


\subsubsection{Unidad 3 inferior}

La mayor parte de los restos líticos se encuentran en cuadrículas con estructuras de combustión. Las piezas se concentran preferentemente en el sector este de la cueva, en torno a ellas, mientras que otros fogones muestran un bajo porcentaje de elementos líticos en sus cercanías (p. 182). Predominan los restos menores a dos $\mathrm{cm}$, correspondientes a los estadios de talla y hay pocas piezas mayores a cuatro $\mathrm{cm}$ (p. 183). Todos los instrumentos se han encontrado en cuadrículas con fogones.

Existen, por otra parte divergencias en la distribución de determinadas materias primas, que tienden a concentrarse en sectores diferenciados, como por ejemplo el sílex marrón. En el caso del sílex rojo, por su parte, si bien se observa en mayor proporción en determinados sectores, es preponderante en todas las cuadrículas (p. 183).

Los huesos también tienden a concentrarse en los alrededores de las estructuras de combustión, coincidiendo parcialmente su distribución con la de los elementos líticos (p. 184). En particular, los restos de guanaco están concentrados en una cuadrícula, siendo muy escasos o ausentes en el resto. Se observa una alta proporción de elementos mayores a dos $\mathrm{cm}$, en la mayor parte del sector excavado, sólo observándose mayores proporciones de elementos pequeños en cuadrículas con muy escasos restos. Sin embargo, observamos que en todos los sectores hay al menos un $15 \%$ de restos que miden menos de dos $\mathrm{cm}$.

Las características de esta unidad nos llevan a considerar que la distribución de los artefactos ha sido poco modificada como consecuencia de los diversos procesos postdepositacionales actuantes (ver capítulo 5). La distribución de los restos líticos dañados y de los huesos termoalterados en torno a los fogones, así como la integridad e identificabilidad de estas estructuras también apunta en esta dirección. La abundancia de piezas tanto líticas como óseas de menos de dos cm nos lleva a considerar que muy posiblemente su distribución corresponda a contextos de depositación primaria.

De esta manera, si bien existen ciertas diferencias tanto en la tecnología lítica como en las características del conjunto zooarqueológico de esta unidad con respecto a la unidad 4 (Paunero et al. 2007d; Skarbun 2009b; Skarbun et al. 2007), observamos que existen recurrencias y similitudes entre ambos componentes en cuanto al tratamiento del espacio:

- Redundancia en los espacios elegidos para el encendido de las estructuras de combustión.

- Predominio de desechos líticos muy pequeños en torno a ellos y escasa presencia de piezas mayores.

- Ubicación de los instrumentos líticos en las cercanías a los fogones.

- Distribución diferencial de determinadas materias primas. 
- Presencia de restos óseos menores y mayores a dos $\mathrm{cm}$ alrededor de las estructuras de combustión.

- Restos termoalterados, líticos y óseos, ubicados alrededor de estas estructuras.

Las características de los conjuntos, en consecuencia, resultan coherentes con las expectativas para sitios con ocupaciones de baja intensidad, donde se espera que predomine el descarte primario y que se realicen escasas tareas de mantenimiento del espacio (Binford 1994; Gifford 1980; Nakazawa 2007; Schiffer 1972; Stevenson 1991). En síntesis, observamos que en esta unidad los restos tienden en su mayoría a ubicarse en las cercanías a las fuentes de calor, lo que indicaría que las actividades fueron realizadas, por lo general en torno a él. A lo largo de las sucesivas ocupaciones que constituyen esta unidad, la gente habría seleccionado el mismo sector de la cueva para desarrollar las actividades de talla lítica y el procesamiento de carcasas.

\subsubsection{Unidad 3 medio}

En esta unidad no se han reconocido fogones. Las piezas líticas se concentran en tres sectores separados. La predominancia en todos ellos es de elementos menores a dos cm (p. 190). Si bien en ellos prevalece el sílex rojo, observamos que otras materias primas como el sílex marrón y la calcedonia se encuentran concentradas en determinados puntos del espacio. Las piezas corresponden principalmente a los estadios de talla y formatización final (p. 191). Los escasos restos líticos dañados térmicamente provienen en su mayoría de un solo sector.

En relación con el conjunto óseo, éste se concentra en el sector oeste de la cueva, coincidiendo parcialmente con un área de alta densidad de restos líticos. Estos corresponden principalmente a fragmentos indeterminados, en tanto que los asignables a Lama guanicoe se encuentran en su totalidad en una sola cuadrícula alejada del sector de mayor concentración. Por otra parte, observamos discrepancias en la distribución por tamaños; mientras que las cuadrículas con menos restos sólo muestran piezas mayores a dos $\mathrm{cm}$, el resto presenta porcentajes de piezas pequeñas que van del $19 \%$ al $45 \%$. Finalmente, una cuadrícula cuenta casi exclusivamente con elementos pequeños (p. 192). Los restos óseos termoalterados provienen en su mayor parte de un sector diferente de aquel del cual provienen las piezas líticas dañadas.

A partir de esta evidencia, observamos ciertas divergencias con respecto a los componentes descritos previamente. En primer lugar, no se han reconocido fogones, y la distribución de los elementos termoalterados óseos y líticos, aunque escasos, no se superpone. Además, ciertas cuadrículas solo muestran restos óseos de más de dos $\mathrm{cm}$, mientras que una presenta un valor elevado de restos muy pequeños, y escasos elementos mayores. 
Por el contrario, los restos líticos sí muestran un patrón similar al de los componentes previos, con sectores de alta concentración de restos de pequeñas dimensiones y distribución acotada de ciertas materias primas.

En consecuencia, consideramos que probablemente los restos líticos estén correspondiendo a zonas de descarte primario. La ausencia de fogones estaría indicando que en esta oportunidad, las actividades de talla no se realizaron en torno a las estructuras de combustión. En el caso de los restos óseos, su distribución podría indicar que existieron actividades relativas al mantenimiento del espacio ocupado.

Por otro lado, la presencia y dispersión de los conjuntos líticos y óseos termoalterados, nos dan algunos elementos para analizar. Su presencia nos indicaría que efectivamente se encendieron fuegos en el sitio, lo que estaría implicando que los fogones han desaparecido, o bien que estos se ubicaban en un sector no excavado del sitio. Aunque es posible que estas estructuras hayan resultado desintegradas por la acción de diversos procesos de formación de sitio, en dichos casos se esperaría encontrar diferentes tipos de materiales termoalterados de forma asociada (Alperson-Afil 2008; Backhouse y Johnson 2007; Sergant et al. 2006). Sin embargo, la distribución de los escasos restos óseos termoalterados es diferente a la de los artefactos líticos dañados, de manera que esta opción nos parece poco probable. Además se observa una buena conservación de los fogones en otros componentes de CDM1, ubicados tanto por encima como por debajo de esta unidad. En consecuencia, éstos productos procederían de sectores no excavados y podrían haber alcanzado la ubicación donde fueron recuperados por diversos motivos: por un lado es factible que las escasas lascas dañadas hayan salido despedidas del fogón al entrar en contacto con el fuego, por el otro, es probable que hayan actuado diversos procesos postdepositacionales en la distribución de parte del conjunto. Resta analizar qué factores actuaron y con qué intensidad, en especial si consideramos que los restos líticos parecen estar representando principalmente desechos primarios. Así, son necesarios otros enfoques que permitan evaluar esta situación.

En síntesis, observamos que en este componente del sitio hubo al menos un fogón encendido, que probablemente se ubicó por fuera del sector excavado. Los eventos de talla reconocidos, en consecuencia, estarían desarrollándose alejados de la fuente de calor, a diferencia de lo observado en los componentes previos. En tanto, la distribución particular de los restos óseos estaría indicando un comportamiento especial con respecto al tratamiento de este tipo de desechos, probablemente vinculado a actividades de mantenimiento del espacio ocupado. 


\subsubsection{Componente Inferior de Cueva Túnel}

En este componente no se han reconocido fogones. Las escasas piezas líticas se encuentran muy dispersas. La predominancia en la mayor parte de los sectores es de elementos menores a dos $\mathrm{cm}$ (p. 196). Si bien observamos que ciertas materias primas se encuentran concentradas en determinados puntos del espacio, las cantidades son en todos los casos muy bajas. Las piezas corresponden principalmente a los estadios de talla y formatización final, en ambos casos se encuentran mayormente dispersas (p. 197). Lo mismo sucede con los escasos restos líticos dañados térmicamente.

En relación con el conjunto óseo, éste se concentra en dos sectores, uno al oeste de la cueva, cerca de su entrada, y el otro en el interior de uno de sus dos lóbulos internos. Son principalmente restos indeterminables, aunque se observa una alta diversidad en las especies faunísticas representadas (p. 198). En cuanto al tamaño, si bien en todos los sectores predominan restos mayores a dos $\mathrm{cm}$, observamos que en todos hay porcentajes considerables de elementos menores (entre el $10 \%$ y el $45 \%$ ) (p. 199). Los restos óseos termoalterados provienen en su mayor parte de un sector particular de la cueva, localizado al oeste.

A diferencia de lo que ocurre con los componentes de CDM1 y C3T1, la evidencia contextual disponible muestra que diversos procesos postdepositacionales habrían alterado, en alguna medida, la distribución de los restos líticos y óseos, así como la preservación de las estructuras de combustión. En primer lugar, este componente está agrupando tres niveles estratigráficos, abarcando una potencia que en determinados sectores supera los $40 \mathrm{~cm}$; se han podido remontar fragmentos de instrumentos líticos dispersos por diferentes cuadrículas y procedentes de los niveles estratigráficos 8,9 y 10 . Esto, sumado a los fechados de los distintos niveles de este componente (p. 75) nos indicarían que la sedimentación no habría sido un proceso paulatino, sino, por el contrario, repentino e intenso, probablemente producto de la repetida disgregación de roca del techo de la cueva, teniendo en cuenta que en este componente se observa abundante material espélico. En segundo lugar, en la cuadrícula 12 hemos identificado improntas de una cueva de roedor que invade parcialmente la unidad 8 , y se han podido recuperar abundantes huesos de estos animales, lo que lleva a considerar la posibilidad de que ellos hayan actuado en la dispersión de parte del material. A esto se suma que, durante la inspección de los restos óseos, que cuentan en general con un mal estado de conservación, hemos podido reconocer algunos elementos que presentaban claras marcas de carnívoros. La confluencia de estos procesos muy probablemente haya actuado en la disgregación de las estructuras de combustión y en la dispersión del material arqueológico, así como en la incorporación de material faunístico no vinculado con la ocupación humana. En consecuencia, consideramos que el análisis distribucional puede resultar sesgado por estos diversos factores. 
En este sentido, si bien determinados rasgos con respecto a la distribución de los restos óseos quemados pueden estar marcando el consumo de algunos taxones en un determinado sector de la cueva, consideramos que son necesarios estudios tafonómicos más profundos que nos permitan reconocer con que intensidad estos diversos factores han actuado. Por lo tanto, no contamos con elementos positivos que permitan evaluar si las actividades se desarrollaron, en este sitio, en torno a estructuras de combustión.

\subsubsection{Unidad 8 de La Mesada}

Este componente no cuenta con fogones. La distribución de los restos líticos no muestra un claro patrón. Las cantidades de piezas son similares en todas las cuadrículas; aunque esto se debe probablemente a su escasez (p. 208). Cabe considerar, por otra parte, que se ha observado que en este componente la acción del agua pudo haber jugado un papel en la conformación del registro arqueológico, ya que existen evidencias que indican que la napa freática podría haber fluctuado a lo largo del tiempo, invadiendo intermitentemente estos niveles (Paunero 2000b). Así, este agente pudo haber destruido los huesos, que están prácticamente ausentes en el sitio, removido los elementos líticos más pequeños, que se presentan en forma escasa y, posiblemente también afectado las estructuras de combustión. Si bien son necesarios más estudios para poder evaluar de manera más fehaciente si éste factor, u otros, han actuado en la conformación del registro arqueológico de $\mathrm{LM}$, consideramos que los análisis distribucionales resultan difícilmente aplicables para este componente. En consecuencia, no contamos con elementos positivos suficientes que permitan evaluar si las actividades se desarrollaron en torno a estructuras de combustión.

\subsubsection{Unidad 6 de Cueva de La Ventana}

En este componente, se observa un alto porcentaje de restos líticos en las cercanías del único fogón presente. Aunque las materias primas se encuentran relativamente dispersas, en el caso del sílex marrón este se concentra principalmente en una cuadrícula. Los instrumentos líticos provienen en su mayoría de las cercanías del fogón. Los restos miden en su mayor parte menos de dos $\mathrm{cm}$ (p. 212).

El conjunto óseo, si bien es muy escaso, se presenta mayormente en las cercanías o dentro de la estructura de combustión. Se trata principalmente de restos menores a dos cm (p. 213/4). Las evidencias, en consecuencia, indican que los restos tienden a concentrarse en las cercanías al fogón. Sin embargo, ciertas características del conjunto lo diferencian de los otros componentes en los cuales se reconocen estas estructuras. 
Por un lado, las cantidades de restos óseos y líticos son muy bajas, por el otro, ambos conjuntos muestran un alto porcentaje de piezas termoalteradas ( $28 \%$ y $20 \%$ respectivamente). Además, este es el único componente en el cual se reconoció sólo un fogón, que puede ser considerado de gran tamaño según lo observado más arriba. Estos rasgos le brindan a LV un patrón propio, ante lo cual se presentan una serie de alternativas. Es dable que el conjunto corresponda a una serie de ocupaciones eventuales que dejaron muy escasos restos. También es factible, de acuerdo a las características arriba mencionadas, que se hayan llevado a cabo tareas de limpieza y mantenimiento del espacio y que sólo se estén recuperando aquellos restos que no han sido removidos de los alrededores del fogón. En relación con lo dicho, cabe considerar que este componente es el más tardío de todos los analizados, su asignación cronológica lo sitúa en el límite entre el Holoceno temprano y medio. El análisis de otros componentes arqueológicos asignables al Holoceno medio también evidencia una mayor proporción de restos dañados térmicamente, es el caso por ejemplo de la unidad 4 de C3T1, de acuerdo a lo observado por Paunero (com. pers. 2010). Esto es coherente con lo propuesto por Stadler (Stadler 2002; Stadler et al. 2003) para momentos de ocupación efectiva del espacio.

Una tercera posibilidad es que en este sitio se hayan desarrollado actividades que no dejaron restos. De acuerdo a Paunero et al. (2005) esta cueva presenta características particulares: es muy oscura, tiene una "ventana" casi exactamente circular y pintada con "rayos" rojo claro que podrían estar representando un sol, está ubicada hacia el naciente de verano. Esto, sumado a los escasos indicadores de consumo, de procesamiento de derivados animales o vegetales o de actividades de producción lítica, podrían señalar un empleo particular de esta cueva, como por ejemplo su uso ceremonial (Paunero et al. 2005).

Mantenemos estas posibilidades como hipótesis, considerando que para poder dilucidar cuál de estas, $\mathrm{u}$ otras posibilidades ha influido en la conformación del registro arqueológico se necesita contar con más información: en primer lugar, creemos que sería oportuno extender la excavación de esta cueva, para poder determinar si existen áreas de mayor concentración o de descarte secundario ubicadas en un sector no excavado. Por otra parte, serían útiles estudios de las características sedimentológicas para evaluar si existieron procesos que hayan afectado la conservación de los huesos y análisis comparativos detallados de las características de este sitio en comparación con componentes asignados al Holoceno medio.

\subsubsection{La organización del espacio intrasitio}

El análisis de la distribución de los distintos conjuntos, nos indica que muchas de las actividades llevadas a cabo en los sitios se habrían desarrollado en torno a los fogones. En aquellos componentes en que se hallaron estructuras de combustión (U. 5 de C3T1, U. 4 y 3 inferior de 
CDM1, U. 6 de LV), la mayor parte de los restos, tanto líticos como óseos se encontraron rodeando estas estructuras.

En el caso de los componentes finipleistocénicos (U. 5 de C3T1, U. 4 y 3 inferior de CDM1), los restos se distribuyen de manera acorde a lo esperado para ocupaciones cortas y de baja intensidad, en las cuales se espera que predomine un descarte primario (Binford 1994; Gifford 1980; Nakazawa 2007; Schiffer 1972; Stevenson 1991). Las evidencias en estos contextos parecen indicar que no se habrían desarrollado importantes tareas de mantenimiento del espacio cercano al fogón.

Las características de los conjuntos líticos, en cuanto a estadio de producción y materia prima, indicaría que se realizaron actividades de talla y formatización final de instrumentos en torno a estas estructuras. La distribución de determinadas materias primas, que se concentran en cuadrículas acotadas (sílex rojo, marrón y amarillo en U. 4, sílex marrón en U. 3 inferior de CDM1) indicaría que estas actividades se habrían desarrollado en sectores limitados del espacio.

En cuanto a la distribución de los restos óseos, la evidencia podría estar indicando que alrededor del fogón se realizaron distintas actividades. Por un lado el procesamiento (U. 5 de C3T1, U. 4 y 3 inferior de CDM1), por el otro cocción y consumo (U. 4 de CDM1).

En este contexto, parte de las evidencias de termoalteración presentes en algunos de estos sitios se habría producido como consecuencia del contacto incidental de estos elementos con el fuego: es factible que algunos elementos hayan caído accidentalmente en el fuego, o bien que estos hayan sido descartados intencionalmente pero de manera muy eventual, considerando las características y proporciones de los restos termoalterados, lo cual resulta coherente con lo esperado para ocupaciones de baja intensidad (Nakazawa 2007; Stadler 2002; Stadler et al. 2003). Esto puede observarse tanto en los restos líticos (U.5 de C3T1, U. 4 y 3 inferior de CDM1) como óseos (U. 4 y 3 inferior de CDM1) de estos componentes.

Entonces, si consideramos al fogón como un eje articulador del espacio, podemos plantear que éste tuvo también otras funciones que van más allá de su utilización en tareas domésticas; el fogón pudo tener valor simbólico y social. Si bien las metodologías implementadas en esta Tesis no permiten avanzar más sobre estas cuestiones, pensamos que las observaciones registradas por los cronistas, volcadas en el capítulo 4 (p. 44) pueden darnos una imagen acerca de la variabilidad de tareas desarrolladas alrededor del fogón, muchas de ellas no se vinculan con tareas productivas o de consumo. Así, en torno al fuego los grupos patagónicos realizaban bailes, reuniones y despedían a los difuntos, entre otras actividades. De manera similar al de otras sociedades cazadoras recolectoras, el fogón se constituía en el ámbito en torno al cual se producía la interacción social entre los grupos patagónicos, posibilitando así su reproducción. En consecuencia el fogón, al organizar el espacio intrasitio, se vuelve a la vez un reflejo de y un medio 
para la comunicación entre los miembros de un grupo (Manzi y Spikins 2008; Navarro 2007; Vaquero et al. 2004).

Por otra parte, en algunas de estas unidades (U. 5 de C3T1, U. 4 de CDM1) existirían evidencias de que ciertas tareas se desarrollaron alejadas de las fuentes de combustión: por ejemplo algunas actividades de talla en C3T1 y el procesamiento de rheidos en CDM1. De esta manera, aunque resulta aparente que en estos componentes los fogones habrían servido como organizadores del espacio doméstico, concentrando en su alrededor diversas actividades cotidianas, parte de estas se habrían desarrollado alejadas de las fuentes de calor, lo cual nos estaría indicando una estructuración del espacio más compleja, que no respondería únicamente a la localización de los fuegos sino también a otros factores que no son analizados en esta Tesis.

Asimismo, en los contextos del Holoceno temprano para los cuales fue factible realizar un análisis distribucional, las evidencias podrían estar indicando diferencias con respecto a lo que sucede durante el Pleistoceno final. Así, en el componente 3 medio de CDM1 se evidenciaría que las actividades de talla no se realizaron cerca del fuego, mientras que los conjuntos óseos parecerían mostrar un tratamiento especial, de acuerdo a los patrones de distribución por tamaño. En tanto, la Unidad 6 de LV, aunque también presenta sus restos en torno al fogón, no muestra tendencias tan nítidas como en los componentes pleistocénicos. Su conjunto lítico es escaso y no muestra claras evidencias de eventos de talla in situ; el conjunto óseo también es muy exiguo, presentándose únicamente astillas; ambos muestran altos porcentajes de termoalteración. En consecuencia, consideramos posible que LV esté representando un patrón distinto. En este sentido, cabe considerar que éste es el único componente del Holoceno temprano en el que hemos reconocido un fogón y, asimismo, es el más tardío de todos los sitios analizados. De esta manera, la evidencia podría estar indicando un cambio en los comportamientos referidos al mantenimiento del espacio en torno a las estructuras de combustión y la superficie ocupacional en general, o bien, un uso particular de esta cueva. En esta línea de argumentación, resulta interesante lo observado por Miotti (2006) quien afirma que durante el Holoceno medio se dan en la Meseta Central condiciones de territorialidad y estructuración de las actividades de forma más marcada que en el Holoceno temprano. Sería de esperar que estos cambios en la forma en que se utiliza el espacio a nivel regional se vean reflejados también en la forma en que se utilizan los espacios reparados. Restan realizar más cantidad de estudios, en sitios contemporáneos a este que cuenten con estructuras de combustión para poder investigar más detenidamente estas propuestas.

Finalmente, los componentes de Cueva Túnel y La Mesada presentan evidencias de que determinados procesos de formación de sitio estuvieron actuando en forma significativa, lo que vuelve difícilmente aplicables los análisis distribucionales. 


\subsection{Conclusiones y perspectivas futuras}

Esta Tesis representa una aproximación al manejo del fuego por parte de las sociedades cazadoras-recolectoras que ocuparon la Meseta Central de Santa Cruz, durante el Pleistoceno final y el Holoceno temprano.

Las características particulares de la región estudiada, los estudios experimentales y etnohistóricos desarrollados, junto con los análisis realizados en los conjuntos arqueológicos, nos han permitido contribuir al conocimiento acerca de la importancia del fuego en estas sociedades. Además, hemos desarrollado metodologías útiles para ser aplicadas en otros contextos arqueológicos y hemos construido referentes empíricos que enriquecen los procesos de análisis vinculados a la acción del fuego.

Los resultados obtenidos son valiosos para comprender las diversas formas en que los materiales arqueológicos pueden resultar termoalterados y las distintas estrategias implementadas por estos grupos en relación al uso del fuego.

Considerando las hipótesis propuestas en el capítulo 1, nuestras investigaciones han arrojado información sustancial que nos permitiría llegar a las siguientes conclusiones:

Con respecto al uso del fuego en el marco de los procesos productivos, consideramos que existe evidencia suficiente para postular la aplicación del tratamiento térmico en los artefactos líticos. Este se observa claramente en los conjuntos del Pleistoceno final mientras que la evidencia no es tan clara para los componentes correspondientes al Holoceno temprano. Se aplicaría fundamentalmente durante la formatización final de artefactos bifaciales, confeccionados con materias primas locales, las cuales ya de por sí son de muy buena calidad, pero que ven mejoradas sus cualidades para la talla luego de la aplicación de dicho procedimiento. La implementación de esta técnica nos indica que estas sociedades contaban con un conocimiento de las materias primas líticas y de sus propiedades; de los combustibles disponibles en el área, y de las posibilidades técnicas que brinda el fuego, por lo que se puede afirmar que contaban con un manejo controlado de este recurso.

Esto contrasta con lo observado para la confección de artefactos óseos. Nuestros análisis nos han llevado a considerar que el tratamiento térmico no era aplicado durante la confección de instrumental. Las pruebas experimentales han arrojado resultados negativos en este sentido y hemos aportado pruebas que nos permiten plantear que el único artefacto óseo termoalterado sufrió modificaciones postdepositacionales.

En relación con las características de los fogones, observamos que son acordes a lo esperado para ocupaciones de baja intensidad en las cuales se dedica baja energía en el acondicionamiento de estas estructuras. Los fogones presentan estructura plana, son de forma elíptica o subelíptica y no 
tienen ningún tipo de elemento que demarque sus límites. Sin embargo, registramos que existen al menos dos tipos de fogones en relación a su tamaño, lo cual podría deberse a fluctuaciones en la intensidad de ocupación. En aquellos contextos en los que no se reconocieron fogones, por otra parte, existe evidencia que demuestra que estos sí se han encendido.

En cuanto al rol del fogón como organizador del espacio intrasitio, podemos decir que en aquellos componentes donde se reconocieron estructuras de combustión, diversas actividades se habrían desarrollado por lo general en torno a ellas, tales como la talla de artefactos líticos tratados térmicamente y sin tratar, el uso de instrumentos líticos en el procesamiento faunístico, la cocción y la alimentación. Sin embargo, determinadas concentraciones alejadas de estas fuentes de calor indicarían que algunas de las tareas realizadas se llevaron a cabo en áreas separadas, en las cuales no se encontraba un fuego encendido. En tanto, de aquellos componentes donde no se reconocieron estas estructuras, sólo en uno la evidencia indicaría que las actividades no se llevaron a cabo cerca del fuego, mientras que en el resto, diversos procesos de formación de sitios podrían haber afectado la distribución de los restos y la conservación de los fogones.

Por otra parte, observamos que en los contextos correspondientes al Holoceno temprano la distribución de los restos difiere a lo identificado para los componentes pleistocénicos, evidenciando que probablemente las formas de ocupar los espacios de las cuevas sean diferentes, siendo posible que las actividades ya no se realizaran en torno a fogones o bien que se desarrollaran ciertas actividades de mantenimiento del espacio a ocupar.

Consideramos que estas conclusiones aportan información relevante para conocer el modo de vida de las sociedades aquí estudiadas. Sin embargo, creemos que son necesarios llevar a cabo otros estudios que permitan evaluar con mayor profundidad nuestros resultados, tales como estudios tafonómicos y microestratigráficos detallados, así como análisis más minuciosos de la distribución de los restos en torno a los fogones, utilizando nuevas tecnologías.

Finalmente, de este trabajo surgen problemáticas y líneas de investigación que requieren ser abordadas a fin de avanzar en la comprensión del manejo del fuego por parte de las sociedades que habitaron esta región. En este sentido, sería necesario implementar un estudio de las características de las estructuras de combustión a nivel regional, puesto que hasta el momento es escasa la información disponible al respecto. Además, sería relevante intentar implementar estudios antracológicos y de fitolitos que nos permitan conocer qué combustibles se estaban utilizando y evaluar si estos podrían indicar diferencias en los usos dados; también sería importante llevar a cabo estudios micromorfológicos de los fogones, a fin de determinar si estas estructuras estaban siendo reutilizadas. Asimismo, pensamos que resultaría interesante explorar metodologías que nos permitan acercarnos al conocimiento de los diversos usos del fuego que no dejan correlatos materiales. Por último, consideramos necesario desarrollar estudios comparativos de los componentes analizados con unidades del Holoceno medio y tardío, a fin de 
comprender de qué manera ciertos aspectos de estas sociedades -por ejemplo cambios en la tecnología y en las materias primas utilizadas, aumento demográfico- han influido en la forma en que se manejó el fuego en el pasado. 


\section{BIBLIOGRAFÍA}

Real Academia Española. 2001. Diccionario de la Lengua Española. Espasa-Calpe

Afonso Marrero, J. 1997. Tratamiento térmico: método para la cuantificación de su efecto sobre la materia prima y para la explicación de su selección. Arqueología 7: 77 - 100.

Aguerre, A. 2000. Las vidas de Pati en la toldería Tehuelche del Río Pinturas y el después. Facultad de Filosofía y Letras, UBA Buenos Aires.

Alberdi, M., L. Miotti y J. Prado. 2001. Hippidion saldiasi Roth, 1899 (Equidae, Perissodactyla), at the Piedra Museo Site (Santa Cruz, Argentina): Its Implication for the Regional Economy and Environmental Reconstruction. Journal of Archaeological Science 28: 411-419.

Alperson-Afil, N. 2008. Continual fire-making by Hominins at Gesher Benot Ya'aqov, Israel. Quaternary Science Reviews 27: 1733-1739.

Allué Martí, E. y M. D. García-Antón Trassierra. 2006. La transformación de un recurso biótico en abiótico: aspectos teóricos sobre la explotación del combustible leñoso en la prehistoria. Sociedades prehistóricas, recursos abióticos y territorio. 19 - 31. G. Martínez Fernández, A. Morgado Rodriguez y J. A. Afonso Marrero (coords). Fundación Ibn Al-Jatib de Estudios de Cooperación Cultural.

Ariet, I. 1988. Empleo de tratamiento térmico en sociedades tempranas de la región pampeana: un estudio experimental. Resúmenes de las ponencias científicas presentadas para el IX Congreso Nacional de Arqueología Argentina: 105. Buenos Aires

1991. Tratamiento térmico en grupos tempranos de la región pampeana. Shincal 3 (3): 140-144.

Ascher, R. 1961. Experimental Archaeology. American Anthropologist 63 (4): 793-816.

Aschero, C. 1975. Ensayo para una clasificación morfológica de artefactos líticos aplicada a estudios tipológicos comparativos. Informe al CONICET MS. Buenos Aires

1983. Ensayo para una clasificación morfológica de artefactos líticos aplicada a estudios tipológicos comparativos. Apéndices A - C. Revisión. MS. Buenos Aires

1983-1985. Pinturas rupestres en asentantamientos cazadores-recolectores: dos casos de aanálisis aplicando difracción de trayos X. Cuadernos del Instituto Nacional de Antropología XXX: 291-306.

1985. Notas sobre el uso de pigmentos minerales en el sitio CCP-5, provincia de Santa Cruz, Argentina. Primeras Jornadas de Arte y Arqueología: Santiago de Chile

Asmussen, B. 2009. Intentional or incidental thermal modification? Analysing site occupation via burned bone. Journal of Archaeological Science 36 528-536. 
Ayán Vila, M. 2003. Arquitectura como tecnología de construcción de la realidad social. Arqueología de la arquitectura 2: 17-24.

Backhouse, P. y E. Johnson. 2007. Where were the hearths: an experimental investigation of the archaeological signature of prehistoric fire technology in the alluvial gravels of the Southern Plains. Journal of Archaeological Science 34: 1367 - 1378.

Bamforth, D. B, M. Becker y J. Hudson. 2005. Intrasite Spatial Analysis, Ethnoarchaeology, and Paleoindian Land-Use on the Great Plains: The Allen Site. American Antiquity 70 (3): 561-580.

Barbosa, C. y C. Gradín. 1987. Estudio composicional por difracción de rayos X de los pigmentos provenientes de la excavación del Alero Cárdenas (provincia de Santa Cruz). Relaciones de la S.A.A Nueva Serie XVII (1): 143-171.

Barbosa, C. y G. Rial. 1983 - 1985. Análisis mineralógico por difracción de Rayos X de muestras de pinturas del Cerro Casa de Piedra, Sitio CCP5 (Provincia de Santa Cruz, Argentina). Cuadernos del INAPL 10: 307 - 311. 248

Bartram, L., E. Kroll y H. Bunn. 1991. Variability in camp structure and bone food refuse patterning at Kua San hunter-gatherer camps. The interpretation of archaeological spatial patterning. 77148. E. Kroll y T. Price. Plenum Press. New York.

Beerbohm, J. 2004. Vagando por la Patagonia. Zagier y Urruty.

Behrensmeyer, A. 1978. Taphonomic and ecologic information from bone weathering. Paleobiology 4: 150-62.

Belardi, J. B., A. Súnico y D. Puebla. 2000. Análisis de Pigmentos minerales y sus fuentes potenciles de aprovisionamiento en el área de Lago Roca (Sector Chorrillo Malo), Provincia de Santa Cruz (Argentina). Anales del Instituto de la Patagonia (Serie Ciencias Sociales) 28: 291 - 304.

Bellomo, R. 1994. Methods of determining early hominid behavioral activities associated with the controlled use of fire at FxJj 20 Main, Koobi Fora, Kenya. Journal of Human Evolution 27 (1-3): 173195.

Benito del Rey, L. y J. M. Benito Álvarez. 1998. Métodos y materias instrumentales en Prehistoria y Arqueología (La Edad de la Piedra tallada más antigua). Gráficas Cervantes, Salamanca

Bennett, J. 1999. Thermal alteration of buried bone. Journal of Archaeological Science 26: 1-8.

Binford, L. 1981. Bones: Ancient men and modern myths. Academic Press, New York.

1994. En busca del pasado. Descifrando el registro arqueológico. Crítica, Barcelona.

Binford, L. y J. O'Connell. 1984. An Alyawara day: The stone quarry. Journal of Anthropological Research 40 (3): 406 - 432.

Bleed, P. 2001. Trees or Chains, Links or Branches: Conceptual Alternatives for Consideration of Stone Tool Production and Other Sequential Activities. Journal of Archaeological Method and Theory 8 (1): $101-127$. 
Bleed, P. y M. Meier. 1980. An Objective Test of the Effects of Heat Treatment of Flakeable Stone. American Antiquity 45 (3): 502-507.

Boëda, E., J. Geneste y L. Meignen. 1990. Identification de chaines operatoires lithiques du Paleolithique Ancient et Moyen. Paleo 2: 43 - 80.

Bordes, F. 1969. Traitement thermique du silex au Solutréen. Bulletin de la Société Préhistorique Française 66 (7): 197.

Borradaile, G, S. Kissin, J. Stewart, W. Ross y T. Werner. 1993. Magnetic and Optical Methods for Detecting the Heat Treatment of Chert. Journal of Archaeological Science 20: 57 - 66.

Borrero, L. 1989-90. Evolucion cultural divergente en la Patagonia Austral. Anales del Instituto de la Patagonia (Serie Ciencias Sociales) 19: 133 - 140.

1994-1995. Arqueología de la Patagonia. Palimpsesto. Revista de Arqueología 4: 9-69.

1999. The Prehistoric Exploration and Colonization of Fuego-Patagonia. Journal of World Prehistory 13 (3): 321-355.

2001a. Cambios, continuidades, discontinuidades: Discusiones sobre arqueología Fuegopatagónica. Historia Argentina Prehispánica. Tomo II: 815-838. E. Berberián y A. Nielsen. Editorial Brujas. Córdoba.

2001b. El poblamiento de la Patagonia. Toldos, milodones y volcanes. Emecé, Buenos Aires.

Borrero, L. y H. Yacobaccio. 1989. Etnoarqueología de Asentamientos Aché. Journal De La Societé Des Américanistes LXXV: 7-33.

Borromei, A. 2000. Análisis polínico de la Localidad Arqueológica Piedra Museo. Guía de Campo de la Visita a las Localidades Arqueológicas: La Colonización del Sur de América Durante la Transición Pleistoceno/Holoceno. 65-67. L. Miotti, R.S. Paunero, M. Salemme y G. Cattáneo. UNLP. La Plata. Bove, G. 1883. pedición ustral rgen na nformes preliminares presentados a los Ministros del nterior y de uerra y Marina de la ep blica rgen na. Instituto Geográfico Argentino, Buenos Aires.

Bridges, L. 2003. El último confín de la tierra. Sudamericana, Buenos Aires.

Bridges, T. 1998. Los indios del último confín. Zagier y Urruty.

Brown, K., C. Marean, A. Herries, Z. Jacobs, C. Tribolo, D. Braun, D. Roberts, M. Meyer y J. Bernatchez. 2009. Fire as an Engineering Tool of Early Modern Humans. Science 325: 859 - 862.

Buenger, B. 2003. The impact of wildland and prescribed fire on archaeological resources. Department of Anthropology. University of Kansas. Doctor of Philosophy.

Buikstra, J. y M. Swegle. 1989. Bone modification due to burning: Experimental evidence. Bone Modification. Center for the study of the first Americans. University of Maine.

Burr, D. 2002. The Contribution of the Organic Matrix to Bone's Material Properties. Bone 31 (1): 8-11. 
Byron, Lord. 2004. An Account of Commodore Byron's Voyage, in 1764, 5, and 6 in His Majesty's ship the Dolphin. A General History and Collection of Voyages and Travels. 12. R. Kerr. William Blackwood y Cadell. Edinburgh y London.

Cabrera, A. 1976. Regiones fitogeográficas argentinas. Enciclopedia Argentina de Agricultura y Jardinería (2da ed.) Tomo II, Fase 1 ACME. 85 p. Buenos Aires.

Cabrera, A. y A. Willink. 1980. Biogeografía de América Latina. Monografía - OEA. Serie de Biología 13. OEA, Washington.

Cain, C. 2005. Using burned animal bone to look at the Middle Stone Age occupation and behavior. Journal of Archaeological Science 32: 873 - 884.

Cardich, A. 1987. Arqueología de Los Toldos y El Ceibo (Provincia de Santa Cruz, Argentina). Investigaciones Paleoindias al sur de la línea ecuatorial. Estudios Atacameños 8: 98-117.

Cardich, A. y N. Flegenheimer. 1978. Descripción y tipología de las industrias más antiguas de Los Toldos. Relaciones de la S.A.A XII: 225-242.

Cardich, A., M. Mansur-Franchomme, V. Durán y M. Giesso. 1981-82. Arqueología de las cuevas de El Ceibo, Provincia de Santa Cruz, Argentina. Relaciones de la S.A.A. XIV (2): 241-267.

Cardich, A. y R.S. Paunero. 1991-1992. Arqueología de la Cueva 2 de Los Toldos (Santa Cruz, Argentina). Anales de Arqueología y Etnología 46/47: 49-97.

Cardich, A., R.S. Paunero y A. S.Castro. 1993-1994. Análisis de los conjuntos líticos de la cueva 2 de Los Toldos (Santa Cruz, Argentina). Anales del Instituto de la Patagonia. Serie Ciencias Humanas 22: 149 - 173.

Cattáneo, G. 2002. Una Aproximación a la Organización de la Tecnología Lítica entre los Cazadores-Recolectores del Holoceno Medio/Pleistoceno Final en la Patagonia Austral (Argentina). FCNyM. UNLP. Doctorado en Ciencias Naturales. La Plata. Tesis Doctoral MS

Cattáneo, R., A. Pupio, M. Valente y A. Barna. 1997-98. Alteración térmica en dos tipos de rocas silíceas: resultados experimentales y aporte de datos para el análisis arqueológico. Relaciones SAA XXII-XXIII: 343-361.

Clapperton, C. 1995. Fluctuations of Local Glaciers at the Termination of the Pleistocene: 18-8 Ka BP. Quaternary International 28: 41 - 50.

Claraz, J. 1988. Diario de viaje de exploración al Chubut, 1865-1866. Marymar, Buenos Aires.

Clemente Conte, I. 1995. Sílex y lustre térmico en el Paleolítico Medio ¿Alteración o técnica de talla? El ejemplo de Mediona 1. (Alt. Penedes Barcelona). Actas de Trabalhos de Antropologia y Etnologia 35 (3): 37-43.

1997. Thermal Alteration of Flint Implements and the Conservation of Microwear Polish: Preliminary Experimental Observations. Siliceous Rocks and Culture. A. Ramos-Millán y M. A. Bustillo. Universidad de Granada. 
Clemente Conte, I. y J. Pijoan López. 2005. Estudio Funcional de los instrumentos de trabajo líticos en el embarcadero del Río Palmones. Excavación en el asentamiento prehistórico del embarcadero del Río Palmones. (Algeciras, Cádiz): una nueva contribución al estudio de las últimas comunidades cazadoras y recolectoras. 252-282. J. Ramos y V. Castañeda. Universidad de Cádiz.

Codignotto, J. 1997. Geomorfología y dinámica costera. El mar argentino y sus recursos pesqueros 1: 89 - 105.

Collins, M. y J. Fenwick. 1974. Heat Treating of chert: Methods of Interpretations and their Application. Plains Anthropologist 19 (64): 134-145.

Collins, S. 1989-90. Una propuesta conductual para el estudio de la arqueología lítica. Etnía 34-35: 47-65.

Coronato, A., F. Coronato, E. Mazzoni y M. Vázquez. 2008. The physical geography of Patagonia and Tierra del Fuego. The Late Cenozoic of Patagonia and Tierra del Fuego. J. Rabassa. Elsevier.

Coronato, A., M. Salemme y J. Rabassa. 1999. Palaeoenvironmental conditions during the early peopling of Southernmost South America (Late Glacial-Early Holocene, 14-8 ka B.P.). Quaternary International 53/54: 77- 92.

Costamagno, S., I. Théry-Parisot, J. Brugal y R. Guibert. 2002. 6. Taphonomic consequences of the use of bones as fuel. Experimental data and archaeological applications. Biosphere to Litosphere. 9th ICAZ Conference: 51 - 62. T. O'Connor Durham.

Cowan, F. 1987. Heat-Treating Experiments With Onondaga Chert: Preliminary Results. http://www.wings.buffalo.edu/anthropology/Lithics/Files/thermal.pdf.

Cox, G. 2006. Exploración de la Patagonia norte. Un viajero en el Nahuel Huapi (1862-1863). Ediciones Continente, Buenos Aires.

Crabtree, D. y B. Butler. 1964. Notes on experiments in flintknapping: 1. Heat treatment of silica minerals. Tebiwa 7: $1-6$.

Cueto, M. y A. Frank. 2009a. La Interacción entre el Estudio de los Micropulidos y el Análisis de la Alteración Térmica en Artefactos Líticos. 3er. Congreso Argentino de Arqueometría y 2 das. Jornadas Nacionales para el estudio de Bienes Culturales, En Prensa.

2009b. Prueba experimental del trabajo del hueso con herramientas líticas. Tratamiento térmico y manifestación de trazas de uso. Patagonia, Argentina. Boletín de Arqueología Experimental Enviado.

Cueto, M., R.S. Paunero y A. Castro 2009. La aplicación del análisis funcional sobre el conjunto artefactual lítico del componente temprano del sitio Casa del Minero 1 para la determinación de operaciones técnicas. XVIII Congreso Nacional de Arqueología Chilena: Valparaíso, Chile

Chatters, J. 1987. Hunter-Gatherer Adaptations and Assemblage Structure. Journal of Anthropological Archaeology 6: 336-375. 
De Nigris, M. 1999. Lo crudo y lo cocido: sobre los efectos de la cocción en la modificación ósea. Arqueología 9: 239 - 264.

2004. El consumo en grupos cazadores recolectores: un ejemplo zooarqueológico de Patagonia Meridional. Sociedad Argentina de Antropología, Buenos Aires.

De Porras, M. E. 2010. Dinámica de la vegetación de la Meseta Central de Santa Cruz durante los últimos 11.000 años a partir del análisis polínico: forzantes bióticos y abióticos. FCEyN. UNMDP. Mar del Plata. Tesis Doctoral

De Porras, M. E., M. V. Mancini y A. Prieto. 2009a. Vegetation changes and human occupation in the Patagonian steppe, Argentina, during the late Holocene. Veget Hist Archaeobot 18 (3): 235244.

De Porras, M. E., M. Mancini, A. Prieto y R.S. Paunero 2009b. Arqueopalinología de la Cueva Túnel (Santa Cruz): una de las piezas del estudio multidisciplinario. . IV Congreso Argentino de Cuaternario y Geomorfología. XII Congresso da Assoçiacão Brasileira de Estudos do Quaternário. II Reunión sobre el Cuaternario de América del Sur: La Plata

Domanski, M. y J. Webb. 2007. A Review of Heat Treatment Research. Lithic Technology 32 (2): 153 - 194.

Drake, F. 1854. The world encompassed by Sir Francis Drake, being his next Voyage to that to Nombre de Dios. Collated with an unpublished manuscript of Francis Fletcher, Chaplain to the expedition. The Hakluyt Society, London.

Enloe, J., F. David y T. Hare. 1994. Patterns of Faunal Processing at Section 27 of Pincevent: the Use of Spatial Analysis and Ethnoarchaeological Data in the Interpretation of Archaeological Site Structure. Journal of Anthropological Archaeology 13: 105 - 124.

FAO. 1993. Improved Solid Biomass Burning Cookstoves: A development Manual. FAO, Bangkok. Fernandez Garay, A. y A. Hernandez. 1999. Origen y uso del fuego. Mito recogido entre los tehuelches araucanizados de la patagonia argentina. Amerindia 24: 73 - 90.

Fitz Roy, R. 1837. Extracts from the Diary of an Attempt to Ascend the River Santa Cruz, in Patagonia, with the Boats of His Majesty's Sloop Beagle. Journal of the Royal Geographical Society of London 7: 114-126.

Flenniken, J. y E. Garrison. 1975. Thermally altered novaculite and stone tool manufacturing techniques. Journal of Field Archaeology 2: 125-131.

Flenniken, J. y J. White. 1983. Heat treatment of siliceous rocks and its implications for Australian prehistory. Australian Aboriginal Studies 1: 43-47.

Franco, N., P. Ambrústolo, F. Skarbun, N. Cirigliano y M. Martucci 2009. La evaluación de la circulación de recursos líticos a grandes escalas: algunos ejemplos entre los ríos Deseado y Santa Cruz (Patagonia argentina). XVIII Congreso Nacional de Arqueología Chilena: Valparaiso Chile 
Franco, N., M. Cardillo, C. Otaola, N. Arregui y E. Gaal. 2007 Tendencias preliminares en el registro arqueológico del curso medio y superior del arroyo El Lechuza, provincia de Santa Cruz, Argentina. Intersecciones en Antropología 8: 271 - 285.

Frank, A. D., F. Skarbun y M. F. Paunero. 2007. Hacia una aproximación de las primeras etapas de reducción lítica en el Cañadón de la Mina, Localidad Arqueológica La María, Meseta Central de Santa Cruz Argentina. Magallania 35 (2): 133-144.

Frere, M., M. I. González, A. Guráieb y A. Muñoz. 2004. Etnoarqueología, arqueología experimental y tafonomía. Explorando algunos temas de arqueología. A. Aguerre y J. L. Lanata. Gedisa. Buenos Aires y Barcelona.

Galanidou, N. 2000. Patterns in Caves: Foragers, Horticulturists, and the Use of Space. Journal of Anthropological Archaeology 19: 243-275.

Galarce, P. 2004. Variabilidad interlocal en secuencias de reducción lítica: conjuntos cordilleranos de Chile Central. Chungará (Arica) 36: 77-87.

Gamble, C. 1990. El poblamiento paleolítico de Europa. Crítica, Barcelona.

García, L. 1993. Experimentaciones en Inca Cueva: arcillas, fogones y combustibles. Arqueología 3: 69-91.

Gassin, B., V. Léa, L. Astruc y J. Linton. 2009 Lithic management in the Chassey Culture Neolithic. Human Evolution s.p. disponible en http://halshs.archives-ouvertes.fr/halshs-00379277/

Gassin, B., V. Léa, J. Linton y L. Astruc. 2006. Production, gestion et utilisation des outillages lithiques du Chasséen méridional. Normes Techniques et Pratiques Sociales de la Simplicité des Outillages Pré- et Protohistoriques. XXVIe rencontres internationales d'archéologie et d'histoire $d^{\prime}$ ntibes. L. Astruc, F. Bon, V. Léa, P. Milcent y S. Philibert. Éditions APDCA. Antibes.

Gibaja, J. 2002. La función de los instrumentos líticos como medio de aproximación socioeconómica. Comunidades neolíticas V-IV milenio cal BC en el noreste de la Península Ibérica. Facultat de Lletres. Universitat Autònoma de Barcelona. Tesis doctoral. Barcelona.

Gibaja, J. y I. Clemente. 1997. El tratamiento térmico del sílex y sus repercusiones en la determinación de los rastros de uso. Algunos ejemplos del neolítico en Cataluña. Revista d'Arqueologia de Ponent 7: 153-160. 252

Gifford, D. 1980. Ethnoarchaeological contributions to the taphonomy oh human sites. Fossils in the Making, Vertebrate Taphonomy and Paleoecology. 93 - 106. A. Behrensmeyer y A. Hill. University of Chicago Press. Chicago.

Gilli, A., F. Anselmetti, D. Ariztegui, J. Bradbury, K. Kelts, V. Markgraf y J. McKenzie. 2001. Tracking abrupt climate change in the Southern Hemisphere: a seismic stratigraphic study of Lago Cardiel, Argentina (49 degrees S). Terra Nova 13: 443-448.

Glasser, N., S. Harrison, V. Winchester y M. Aniya. 2004. Late Pleistocene and Holocene palaeoclimate and glacier fluctuations in Patagonia. Global and Planetary Change 43: 79-101. 
Gonzalez, F. 1965. Diario del viaje que hizo por tierra del Puerto Deseado al Río Negro.1798. Acad. Nac. Hist., Biblioteca XXIII.

Gregg, M. y R. Grybush. 1976. Thermally altered siliceous stone from prehistoric contexts: Intentional versus unintentional alteration. American Antiquity 41 (2): 189-192.

Guido, D., M. Escayola, D. Barrio, I. Schalamuk y G. Franz. 2006. La Formación Bajo Pobre (Jurásico) en el este del Macizo del Deseado, Patagonia: vinculación con el Grupo Bahía Laura. Revista de la Asociación Geológica Argentina 61 (2): 187-196.

Gusinde, M. 1982. Los Selk'nam. Los indios de la Tierra del Fuego. Vol.1. Tomo I y II. CAEA. Bs As. Hanson, M. y C. Cain. 2007. Examining histology to identify burned bone. Journal of Archaeological Science 34 (11): 1902-1913.

Hermo, D. 2008. Rocas como símbolos: la selección de materias primas para puntas de proyectil en ambientes mesetarios de Patagonia. Intersecciones en Antropología 9: 319 - 324.

Heusser, C. 1995. Three Late Quaternary pollen diagrams from Southern Patagonia and their palaeoecological implications. . Palaeogeography, Palaeoclimatology, Palaeoecology 118 1-24.

Heusser, C. y J. Rabassa. 1987. Cold climatic episode of Younger Dryas age in Tierra del Fuego. Nature 328: 609-611.

Hiller, J., T. Thompson, M. Evison, A. Chamberlain y T. Wess. 2003. Bone mineral change during experimental heating: an X-ray scattering investigation. Biomaterials 24 5091-5097.

Holmes, W. 1919. Part 1. Lithic Industries. XXXV. Fire fracture processes. Handbook of Aboriginal Antiquities. Bulletin 60: 364-365. Bureau of American Ethnology. Smithsonian Institution. Washington D.C.

Hulton, N., R. Purves, R. Mcculloch, D. Sugden y M. Bentley. 2002. The Last Glacial Maximum and deglaciation in southern South America. Quaternary Science Reviews 21 233-241.

Inizan, M. L. y J. Tixier. 2000. L'émergence des arts du feu : le traitement thermique des roches siliceuses. Paléorient 26 ( 2 La pyrotechnologie à ses débuts. Evolution des premières industries faisant usage du feu): 23-36.

Inizan, M., M. Reduron-Ballinger, H. Roche y J. Tixier. 1999. Cap. 1. Raw Materials. Technology and Terminology of Knapped Stone. Préhistoire de la Pierre Taillée. Tomo 5. Nanterre. CREP.

Iñíguez, A. y C. Gradín. 1977. Análisis mineralógico por difracciones de raxos X de muestras de pinturas de la cueva de las manos, estancia Alto Río Pinturas (Provincia de Santa Cruz). Relaciones de la SAA XI: 121 - 128.

James, S. 1989. Hominid Use of Fire in the Lower and Middle Pleistocene. A Review of the Evidence. Current Anthropology 30 (I): 1 - 26.

Johnson, L. 1978. A history of flint-knapping experimentation, 1838-1976. Current Anthopology 19 (2): $337-359$. 
Jurgens, C. 2005. Zooarcheology and Bone Technology From Arenosa Shelter (41vv99), Lower Pecos Region, Texas. University of Texas. Austin. Tesis Doctoral. MS.

Kaplan, M., C. Fogwill, D. Sugden, N. Hulton, P. Kubik y S. Freeman. 2008. Southern Patagonian glacial chronology for the Last Glacial period and implications for Southern Ocean climate. Quaternary Science Reviews 27: 284-294.

Karkanas, P., R. Shahack-Gross, A. Ayalon, M. Bar-Matthews, R. Barkai, A. Frumkin, A. Gopher y M. C. Stiner. 2007. Evidence for habitual use of fire at the end of the Lower Paleolithic: Site-formation processes at Qesem Cave, Israel. Journal of Human Evolution 53: 197 - 212.

Klohn, M., C. Broili y D. Silva 2007. Technical Report. La Josefina Project. Santa Cruz Province, Argentina for HuntMountain Resources Inc.

Kokot, R. 2004. Erosión en la costa patagónica por cambio climático. Revista de la Asociación Geológica Argentina 59 (4): 715-726.

Koon, H., R. Nicholson y M. Collins. 2003. A practical approach to the identification of low temperature heated bone using TEM. Journal of Archaeological Science 30: 1393-1399.

Larrain, N. 1883. Viajes en el "Villarino" a la costa ud de la epublica rgentina Imprenta de Juan Alsina.

Larsson, L. 2000. The passage of axes: fire transformation of flint objects in the Neolithic of southern Sweden. Antiquity 74 (285): 602-610.

León, R., D. Bran, M. Collantes, J. Paruelo y A. Soriano. 1998. Grandes unidades de vegetación de la Patagonia extra andina. Ecología Austral 8: 125-144.

Leroi-Gourhan, A. 1979. Structures de combustion et strucdures d'excavation. Revista do Museu Paulista XXVI: 9 - 10

Lista, R. 2006. Viaje a la Patagonia Austral. Ediciones Continente.

López, R. 2004. Informe sobre afloramientos rocosos de interés arqueológico en Ea. La María, Sta Cruz.

Lowell, T., C. Heusser, B. Andersen, P. Moreno, A. Hauser, L. Heusser, C. Schluchter, D. Marchant y G. Denton. 1995. Interhemispheric correlation of Late Pleistocene glacial events. Science 269: 1541-1549.

Luedtke, B. 1992. An archaeologist's guide to chert and flint. Archaeological Research Tools Institute of Archaeology. UCLA.

Lyman, R. 1994. Vertebrate taphonomy. Cambridge Manuals in Archaeology. Cambridge University, Cambridge.

Mancini, M. 1998. Vegetational changes during the Holocene in Extra-Andean Patagonia, Santa Cruz Province, Argentina. Palaeogeography, Palaeoclimatology, Palaeoecology 138207 - 219.

2002. Vegetation and climate during the Holocene in Southwest Patagonia, Argentina. Review of Palaeobotanyand Palynology 122: $101-115$. 
2007. Cambios ambientales en el ecotono bosque-estepa: análisis polínico del sitios Cerro Casa de Piedra 7, Santa Cruz Argentina. Arqueología de Fuego-Patagonia. Levantando piedras, desenterrando huesos... y develando arcanos. 89-93. Ed. Cequa. Punta Arenas.

Mandeville, M. 1973. A consideration of the thermal pretreatment of chert. Plains Anthropologist 18: 177 - 202.

Mandeville, M. y J. Flenniken. 1974. A comparison of the flaking qualities of Nehawka chert before and after thermal pretreatment. Plains Anthropologist 19 (64): 146 - 148.

Manzi, L. y P. Spikins. 2008. El fuego en las altas latitudes: Los Selk'nam de Tierra del Fuego como referente etnográfico para el Mesolítico europeo. Complutum 19 (1): 79 - 96.

Marconetto, M. B. 2005. Recursos forestales y el proceso de diferenciación social en tiempos prehispánicos en el valle de Ambato, Catamarca. FCNyM. UNLP. La Plata. Tesis Doctoral MS

2006. La gente, la leña, el monte. El modo de hacer las cosas. C. Pérez de Micou. FFyL. UBA. Bs As. Marchionni, D., R. de Barrio, M. Tessone y H. Karszenbaum. 1997. Aportes de la información de ERS-1 en el reconocimiento de rasgos estructurales del sector central del Macizo del Deseado, Provincia de Santa Cruz, Argentina. Su implicancia metalogénica. The Use and Applications of ERS in Latin America. 133 - 141. T. Guyenne. European Space Agency. Paris.

Markgraf, V. 1993. Paleoenvironments and paleoclimates in Tierra del Fuego and southernmost Patagonia, South America. Paleogeography, Paleoclimatology, Paleoecology 102: 53-68.

Martín, F. 2007. Tafonomía y paleoecología de la transición Pleistoceno-Holoceno en FuegoPatagonia: Interacción entre poblaciones humanas y de carnívoros y su importancia como agentes en la formación del registro fósil. FCNyM. UNLP. Tesis Doctoral. La Plata.

Martinic, M. 2007. Documentos inéditos para la historia de Magallanes "Memorándum referido a los patagones". Magallania 35 (2): 159 - 164.

Massone, M. 2002. El fuego de los cazadores Fell 1 a fines del Pleistoceno. Anales del Instituto de la Patagonia 30: 117 - 131.

2004. Los cazadores después del hielo. Colección de Antropología. Centro de Investigaciones Diego Barros Arana, Dirección de Bibliotecas, Archivos y Museos, Santiago de Chile.

Massone, M., A. Prieto, D. Jackson, G. Cárdenas, M. Arroyo y P. Cárdenas. 1998. Los cazadores tempranos y sus fogatas: una nueva historia para la Cueva Tres Arroyos 1, Tierra del Fuego. Boletín de la Sociedad Chilena de Arqueología 26: 11-18.

McCutcheon, P. 1992. Burned archaeological bone. Deciphering a shell midden. J. Stein. Academic Press.

Melcher, C. y D. Zimmerman. 1977. Thermoluminiscent Determination of Prehistoric Heat Treatment of Chert Artifacts. Science 197: 1359-1362. 
Mena, F., V. Lucero, O. Reyes, V. Trejo y H. Velasquez. 2000. Cazadores tempranos y tardíos en la cueva Baño Nuevo-1, margen occidental de la estepa centropatagónica (XI Región de Aisen, Chile). Anales del Instituto de la Patagonia 28: 173-195.

Mercieca, A. 2000. Burnt and broken: An experimental study of heat fracturing in silcrete. Australian Archaeology 51: 40 - 47.

Mercieca, A. y P. Hiscock. 2008. Experimental insights into alternative strategies of lithic heat treatment. Journal of Archaeological Science 35 2634-2639.

Miotti, L. 1998 Zooarqueologia de la meseta central y costa de la provincia de Santa Cruz: Un enfoque de las estrategias adaptativas aborígenes y los paleoambientes. Tesis Doctoral. Facultad de Ciencias Naturales y Museo. Universidad Nacional de La Plata. Imprenta del Museo Municipal de Historia Natural de San Rafael, San Rafael.

2000. Localidad Arqueológica Piedra Museo. Guía de campo de la visita a las Localidades Arqueológicas: La colonización del Sur de América durante la Transición Pleistoceno/Holoceno. L. Miotti, R.S. Paunero, M. Salemme y R. Cattáneo. Universidad Nacional de La Plata. La Plata.

2006. Paisajes domésticos y sagrados desde la arqueología de los cazadores-recolectores en el Macizo del Deseado, Provincia de Santa Cruz. Cazadores Recolectores del cono sur. Revista de Arqueología: 11-40.

Miotti, L. y M. Salemme. 1999. Biodiversity, Taxonomic Richness and Generalist-Specialists economical systems in Pampa and Patagonia (Argentina, Southern South America). Quaternary International 53/54: 53-68.

2003. When Patagonia was colonized: people mobility at high latitudes during PleistoceneHolocene transition. Quaternary International 109-110: 95-111.

2004. Poblamiento, movilidad y territorios entre las sociedades cazadoras-recolectoras de Patagonia. Complutum 15: 177-206.

Moreno, F. P. 1997. Viaje a la Patagonia Austral. Ed. El Elefante Blanco, Buenos Aires.

Moreno, J. E. 2008. Arqueología y etnohistoria de la Costa Patagónica Central en el Holoceno Tardío. Fondo Editorial Provincial. Secretaría de Cultura del Chubut, Rawson.

Musters, G. 2005. Vida entre los Patagones. Ed. El Elefante Blanco, Buenos Aires.

Nagle, E. 1914. Arrow-chipping by means of fire and water. American Anthropologist 16 (1): 140.

Nakazawa, Y. 2007. Hearth-centered spatial organization: a comparative approach to the study of palimpsests in late upper paleolithic sites in Hokkaido (Japan) and Cantabria (Spain). University of New Mexico. Doctor of Philosophy. Albuquerque, New Mexico.

Nami, H. 1983. La experimentación aplicada a la interpretación de artefactos bifaciales. Un modelo de manufacura de las puntas de proyectil de los niveles inferiores del Alero Cárdenas, Provincia de Santa Cruz. FFyL. UBA. Tesis de Licenciatura MS. Buenos Aires. 
1992. El subsistema tecnológico de la confección de instrumentos líticos y la explotación de los recursos del ambiente: una nueva vía de aproximación. Shincal 2 13-53.

1997. Investigaciones actualísticas para discutir aspectos técnicos de los cazadores-recolectores del tardiglacial: el problema de Clovis-Cueva Fell. Anales del Instituto de la Patagonia 25: 151-181. 1997-1998. Arqueología experimental, talla de piedra contemporánea, arte moderno y técnicas tradicionales: observaciones actualísticas para discutir estilo en tecnología lítica. Revista Relaciones de la Sociedad Argentina de Antropología XXII-XXIII: 363-388.

Nami, H., G. Cattáneo y M. Pupio. 2000. Investigaciones experimentales sobre el tratamiento térmico en algunas materias primas de Pampa y Patagonia. Anales del Instituto de la Patagonia (Serie Ciencias Sociales) 28: 315-329.

Navarro, A. 2007. Sobre el concepto de espacio. Revista do Museu de Arquelogia e Etnologia 17: 3-21.

Nicholson, R. 1993. A morphological investigation of burnt animal bone and an evaluation of its utility in archaeology. Journal of Archaeological Science 20: 411-428.

O'Connell, J. 1987. Alyawara Site Structure and Its Archaeological Implications. American Antiquity 52 (1): 74-108.

Odgaard, U. 2003. Hearth and home of the Palaeo-Eskimos. Études/Inuit/Studies 27 (1-2): 349374.

Onelli, C. 1904. Trepando los Andes. Compañía Sud-Americana de Billetes de Banco.

Orquera, L. y E. Piana. 1986. Normas para la descripción de objetos arqueológicos de piedra tallada. CADIC. Contribución Científica № 1 (Publicación Especial).

Outes, F. 1917. Observaciones etnográficas de Francisco Javier Muñiz. Physis III: 197-215.

Páez, G. 2009. Estudio Petrográfico, Material Arqueológico Zona Ea. La María, Provincia de Santa Cruz. La Plata. M.S.

Páez, M., A. Prieto y M. Mancini. 1999. Fossil pollen from Los Toldos locality: A record of the Lateglacial transition in the Extra-Andean Patagonia. Quaternary International 53: 69-75.

Panza, J. 1994. Hoja Geológica 4969-II. Tres Cerros Escala 1:250.000. Provincia de Santa Cruz. Servicio Geológico Nacional Boletin 213.

Paruelo, J., M. Aguiar, R. Golluscio y R. León. 1992. La Patagonia extrandina: análisis de la estructura y el funcionamiento de la vegetación a distintas escalas. Ecología Austral 2: 123 - 136.

Paruelo, J., A. Beltrán, E. Jobbágy, O. Sala y R. Golluscio. 1998. The climate of Patagonia: general patterns and controls on biotic processes. Ecología Austral 8: 85-101.

Paruelo, J., R. Golluscio, E. Jobbágy, M. Canevarki y M. Aguiar. 2005. Situación ambiental en la estepa patagónica. La Situación Ambiental Argentina. 303 - 313. A. Brown, U. Martinez Ortiz, M. Acerbi y J. Corcuera (eds.). Fundación Vida Silvestre Argentina. Buenos Aires. 
Pasquini, A. y P. Depetris. 2007. Discharge trends and flow dynamics of South American rivers draining the southern Atlantic seaboard: An overview. Journal of Hydrology 333: 385- 399.

Pasveer, J. 2005. Bone Artefacts from Liang Lemdubu and Liang Nabulei Lisa, Aru Islands. The Archaeology of Aru Islands, Eastern Indonesia. Terra Australis 22: 235-254. Pandanus Books. Canberra.

Patterson, L. 1984. Comments on Studies of thermal alteration of Central Pennsylvania Jasper. American Antiquity 49 (1): 168 - 173.

Paunero, R.S. 1994. El sitio Cueva 1 de la Localidad Arqueológica Cerro Tres Tetas (Estancia San Rafael, provincia de Santa Cruz, Argentina). Anales de Arqueología y Etnología 48/48: 73-90.

1996. Noticia sobre nuevas fechas radiocarbónicas del sitio Cueva 1, C3T, Santa Cruz, Argentina. Anales de Arqueología y Etnología 50-51: 189-199.

2000a. Localidad Arqueológica Cerro Tres Tetas. Guía de campo de la visita a Las Localidades Arqueológicas. 89 - 100. L. Miotti, R.S. Paunero, M. Salemme y G. Cattáneo. UNLP. La Plata.

2000b. Localidad Arqueológica La María. Guía de campo de la visita a las Localidades Arqueológicas: La colonización del Sur de América durante la Transición Pleistoceno/Holoceno. L. Miotti; R. Paunero; M. Salemme y R. Cattáneo

2001. Fogones, conjuntos líticos y funcionalidad en el componente pleistocénico del sitio Cueva 1 de Cerro Tres Tetas, provincia de Santa Cruz. Actas XIV CNAA: Facultad de Humanidades y Artes. UNR. Rosario

2003a. The Cerro Tres Tetas (C3T) locality in the Central Plateau of Santa Cruz, Argentina. Where the South Winds Blow: Ancient Evidence of Paleo South Americans. 33-140. L. Miotti, M. Salemme y N. Flegenheimer (Editor in Chief R. Bonnichsen). Center for the Studies of the First Americans (CSFA) and Texas A \& M University Press.

2003b. The presence of a Pleistocene Colonizing Culture in La Maria archaeological locality, Casa del Minero 1. Where the South Winds Blow: Ancient Evidence of Paleo South Americans. 127-132. Editor R. Bonnichsen. Center for the Study of the First Americans and Texas A\&M University Press. 2004a. Arte Rupestre en contextos arqueológicos de Estancia La Maria, Santa Cruz: análisis, tecnologías y experimentación. XV Congreso Nacional de Arqueología Argentina, Río Cuarto, Cba. 2004b. Las cuevas como sitios arqueológicos y los diferentes usos del espacio en sociedades colonizadoras de la Meseta Central de Santa Cruz. 51ํ Congreso Internacional de Americanistas: Santiago de Chile

2004c. Localidades La María y Cerro Tres Tetas (Santa Cruz, Argentina): Aportes al poblamiento humano temprano del Cono Sur de América. X Congreso Uruguayo de Arqueología: Versión digital.

2009a. El Arte Rupestre Milenario de Estancia La María, Meseta Central de Santa Cruz. Municipalidad de Puerto San Julián, Puerto San Julián. 
2009b. La colonización humana de la meseta central de Santa Cruz durante el pleistoceno final: indicadores arqueológicos, referentes estratigráficos y nuevas evidencias. Arqueología de la Patagonia - Una mirada desde el último confín. M. Salemme, F. Santiago, M. Álvarez, E. Piana, M. Vazquez y M. Mansur. Editorial Utopias. Ushuaia.

Paunero, R.S., P. Albertengo, M. Cueto, A. Dávila, A. Frank, A. Olivera y C. Piva. 2007a. Sitio Casa del Minero 1, localidad arqueológica La María: nuevas evidencias sobre ocupación humana pleistocénica en Santa Cruz. Arqueología Argentina en los inicios de un nuevo siglo. 337-344. N. de Grandis y J. Rodríguez Comp.: F. Oliva. Laborde Editor.

Paunero, R. S. y A. Blasi. 2009. Geoarqueología de la Cueva 2 Los Toldos, Santa Cruz, Argentina. IV Congreso de Geomorfología y Geología del Cuaternario. La Plata.

Paunero, R.S. y A. Castro. 2001. Análisis lítico y funcionalidad del componente inferior del sitio Cueva 1, localidad arqueológica Cerro Tres Tetas, provincia de Santa Cruz, Argentina. Anales del Instituto de la Patagonia (Serie Ciencias Sociales) 29: 189-206.

Paunero, R.S., A. Castro y M. Reyes. 2007b. Estudios Líticos del componente medio del sitio Cueva 1 de Cerro Tres Tetas, Santa Cruz, Argentina: Implicaciones para construir patrones de distribución artefactual y uso del microespacio. Arqueología de Fuego Patagonia. Levantando piedras, desenterrando huesos... y develando arcanos. 613-622. Ed: CEQUA. Punta Arenas.

Paunero, R.S., M. E. Cueto, A. Frank, G. Rosales, F. Skarbun, M. F. Paunero y G. Zapata 2004a. Localidad Arqueológica La María en la Meseta Central de Santa Cruz: estado actual de nuestra investigación. XV Congreso Nacional de Arqueología Argentina: Río Cuarto, Córdoba

Paunero, R.S., M. Cueto, A. Frank, G. Ghidini, G. Rosales y F. Skarbun. 2004b. Comunicación sobre campaña arqueológica 2002 en Localidad La María, Santa Cruz. Contra Viento y Marea. Arqueología de Patagonia. 797-808. INAPL. Bs.As.

Paunero, R.S., A. D. Frank, F. Skarbun, M. F. Paunero, M. Cueto, G. Rosales, N. Lunazzi y D. Martínez 2007c. Componente pleistocénico del sitio Cueva Túnel de la Maria Quebrada: fauna extinta y artefactos asociados. XVII CNAA: Jujuy

Paunero, R.S., A. D. Frank, F. Skarbun, G. Rosales, M. E. Cueto, G. Zapata, M. F. Paunero, N. Lunazzi y M. Del Giorgio. 2007d. Investigaciones Arqueológicas en el Sitio Casa del Minero 1, Estancia La María, Meseta Central de Santa Cruz. Arqueología de Fuego Patagonia. Levantando piedras, desenterrando huesos...y develando arcanos. 577-588. Ed: CEQUA. Punta Arenas.

Paunero, R.S., A. D. Frank, F. Skarbun, G. Rosales, G. Zapata, M. Cueto, M. F. Paunero, D. G. Martínez, R. López, N. Lunazzi y M. Del Giorgio. 2005. Arte rupestre en Estancia La María, Meseta Central de Santa Cruz: sectorización y contextos arqueológicos. Relaciones de la SAA XXX: 147168. 
Paunero, R.S., M. F. Paunero y D. Ramos 2008a. Artefactos óseos en componentes del Pleistoceno final de las Localidades La María y Cerro Tres Tetas, Santa Cruz, Argentina. Primer Congreso Nacional de Zooarqueologia Argentina: Malargüe

Paunero, R.S., G. Rosales y M. Alberdi. 2008b. Cerro Bombero: registro de Hippidion saldiasi Roth, 1899 (Equidae, Perissodactyla) en el Holoceno temprano de Patagonia (Santa Cruz, Argentina). Revista Estudios Geológicos 64 (1): 89-98.

Pavlish, L. y P. Sheppard. 1983. Thermoluminiscent Determination of Paleoindian Heat Treatment in Ontario, Canada. American Antiquity 48 (4): 793-799.

Pérez de Micou, C. 1991. Fuegos, fogones y señales. Una aproximación etnoarqueológica a las estructuras de combustión en el Chubut medio. Arqueología 1: 125-150.

Pérez de Micou, C. y N. Ratto. 2004. Las plantas silvestres como recurso en regiones áridas (Patagonia y Puna). Contra viento y marea. Arqueología de Patagonia. 295 - 310 . INAPL. Bs As.

Pfaffenberger, B. 1988. Fetishised Objects and Humanised Nature: Towards an Anthropology of Technology. Man (New Series) 23 (2): 236-252

Pigafetta, A. 2004. Primer Viaje alrededor del mundo. El Elefante Blanco, Buenos Aires.

Pijoan, C., J. Mansilla, I. Leboreiro, V. Lara y P. Bosch. 2007. Thermal alterations in archaeological bones. Archaeometry 49 (4): 713-727.

Piqué, R. 1999. Producción y uso del combustible vegetal: una evaluación arqueológica. CSIC, Madrid.

Podestá, M., R.S. Paunero y D. Rolandi. 2005. El Arte Rupestre de Argentina Indígena: Patagonia. Corpus Antiquitatum Americanensium. Argentina V Academia Nacional de La Histora. Unión Académique Internationale.

Politis, G. 2002. Acerca de la etnoarqueología en America del Sur. Horizontes Antropológicos 8 (18): $61-91$.

Possehl, G. 1981. Cambay beadmaking. An ancient craft in Modern India. Expedition 23: 39 - 47.

Prates, L. 2009. El uso de los recursos por los cazadores - recolectores posthispánicos de Patagonia contnental y su importancia arqueológica. Relaciones de la S.A.A XXXIV: 201 - 229.

Purdy, B. y H. Brooks. 1971. Thermal alteration of silica minerals: an archaeological approach. Science 173: 322-325.

Rabassa, J. y C. Clapperton. 1990. Quaternary Glaciations of the Southern Andes. Quaterny Science Rewiew 9 (153-174).

Rabassa, J., A. Coronato, G. Bujalesky, M. Salemme, C. Roig, A. Meglioli, C. Heusser, S. Gordillo, F. Roig, A. Borromei y M. Quattrocchio. 2000. Quaternary of Tierra del Fuego, Southernmost South America: an updated review. Quaternary International 68/71: 217 - 240. 
Ramos, D. y M. F. Paunero. 2009. Estudio preliminar de los elementos óseos de un sitio componente pleistocénico: sitio Cueva Túnel, localidad La María, Provincia de Santa Cruz. VIII Jornadas de Jóvenes Investigadores en Ciencias Antropológicas, Buenos Aires.

Ramos, V. 2008. Patagonia: A paleozoic continent adrift? Journal of South American Earth Sciences 26 235-251.

Ribichich, A. 2002. El modelo clásico de la fitogeografía de argentina: un análisis crítico. INCI 27 (12): 669-675.

Rick, J. y S. Chappell. 1983. Thermal alteration of silica materials in technological and functional perspective. Lithic Technology 12 (3): 69-80.

Rowney, M. y J. White. 1997. Detecting heat treatment on silcrete: experiments with methods. Journal of Archaeological Science 24: 649-657.

Scarano, E., H. Pucciarelli, M. Crivos y M. Prati. 1994. Estado actual de la Experimentación Antropológica en Argentina. Interciencia 19 (4): 191-195.

Schiffer, M. 1972. Archaeological Context and Systemic Context. American Antiquity 37 (2): 156165.

1988. The Structure of Archaeological Theory Source. American Antiquity 53 (3): 461-485.

Schindler, D., J. Hatch, C. Hay y R. Bradt. 1982. Aboriginal thermal alteration of a Central Pennsylvania jasper: analytical and behavioral implications. American Antiquity 47 (3): 526-544.

Sergant, J., P. Crombe y Y. Perdaen. 2006. The 'invisible' hearths: a contribution to the discernment of Mesolithic non-structured surface hearths. Journal of Archaeological Science 33: 999 - 1007.

Shahack-Gross, R., O. Bar-Yosef y S. Weiner. 1997. Black-coloured bones in Hayonim Cave, Israel: differentiating between burning and oxide staining. Journal of Archaeological Science 24 (5): 439446.

Shippee, J. 1963. Was flint annealed before flaking? Plains Anthropologist 8 (22): 271-272.

Sidéra, I. 2000. Feu et industrie osseuse. Un marqueur d'identité culturelle. Paléorient 26 (2. La pyrotechnologie à ses débuts. Evolution des premières industries faisant usage du feu): 51-59.

Skarbun, F. 2004. Explorando la variación de los conjuntos artefactuales de la meseta central de santa cruz: el análisis de diversidad y su medición según diferentes atributos tecnológicos. $X V$ Congreso Nacional de Arqueología Argentina, Río Cuarto, Córdoba.

2009a. Análisis de los conjuntos líticos del sitio La Mesada, Localidad Arqueológica La María, Meseta central de Santa Cruz. Arqueología de Patagonia: una mirada desde el último confín. Editorial Utopías. Ushuaia.

2009b. La organización tecnológica en grupos cazadores recolectores desde las ocupaciones del Pleistoceno final al Holoceno tardío, en la Meseta Central de Santa Cruz. FCNyM. UNLP. La Plata. Tesis doctoral MS 
Skarbun, F., A. Frank, M. Paunero, M. Cueto y G. Rosales. 2007. Análisis de la tecnología lítica del Sitio Casa del Minero 1, Meseta Central de Santa Cruz. Arqueología de Fuego-Patagonia. Levantando piedras, desenterrando huesos..y develando arcanos. 589-600. Ed: CEQUA Pta. Arenas.

Smith, A. y C. Poggenpoel. 1988. The Technology of Bone Tool Fabrication in the South-Western Cape, South Africa. World Archaeology 20 (1): 103-115.

Stadler, N. 2002. El uso del tratamiento térmico sobre las materias primas líticas en el área de Lago Argentino. Facultad de Filosofía y Letras. UBA. Tesis de Licenciatura. Buenos Aires.

Stadler, N., N. Franco y L. Borrero. 2003. El tratamiento térmico y la ocupación de las cabeceras del Río Santa Cruz. Análisis, interpretación y gestión en la arqueología de Sudamérica. R. Curtoni y M. Endere. INCUAPA - UNICEN.

Stern, R. C. 2004. Obsidian in Southern Patagonian: Review of the Current Information. Contra viento y marea. Arqueología de Patagonia. 167-176. Instituto Nacional de Antropología y Pensamiento Latinoamericano. Buenos Aires.

Stevenson, M. 1991. Beyond the formation of hearth-associated artifact assemblages. The intepretation of archarological spatial patterning. E Kroll y D. Price. Plenum Press. New York.

Stiner, M., S. Kuhn, S. Weiner y O. Bar-Yosef. 1995. Differential burning, recrystallization and fragmentation of archaeological bone. Journal of Archaeological Science 22 (2): 223-237.

Tatur, A., M. Bianchi, V. Outes, G. Villarosa, J. Niegodzisz y G. Debaene. 2002. Late Pleistocene palaeolakes in the Andean and Extra-Andean Patagonia at mid-latitudes of South America. Quaternary International 89: 135 - 150.

Taylor, R., P. Hare y T. White. 1995. Geochimical criteria for thermal alteration of bone. Journal of Archaeological Science 22 (1): 115-119.

Terradas, X. y J. Gibaja. 2001. El tratamiento térmico en la producción lítica: el ejemplo del Neolítico Medio catalán. Cypsela 13: 31-56.

Théry-Parisot, I. 2002. Fuel Management (Bone and Wood) During the Lower Aurignacian in the Pataud Rock Shelter (Lower Palaeolithic, Les Eyzies de Tayac, Dordogne, France). Contribution of experimentation. Journal of Archaeological Science 29: 1415 - 1421.

Ubelaker, D. 2009. The forensic evaluation of burned skeletal remains: A synthesis. Forensic Science International 183: 1-5.

Vaquero, M. y I. Pastó. 2001. The Definition of Spatial Units in Middle Palaeolithic Sites: The Hearth-Related Assemblages. Journal of Archaeological Science 28: 1209-1220.

Vaquero, M., J. Rando y M. Chacón. 2004. Neanderthal spatial behaviour and social structure: hearth-related assemblages from the Abric Romaní Middle Palaeolithic site. Settlement Dynamics of the Middle Palaeolithic and Middle Stone Age I/ 367-392. N. Conard. Kerns Verlag. Tübingen. 
Viedma, A. 1783. Descripcion de la Costa meridional del sur, llamada vulgarmente Patagónica. http://www.cervantesvirtual.com/servlet/SirveObras/49250514294669165350046/p000004.htm. Villa-Martínez, R. y P. Moreno. 2007. Pollen evidence for variations in the southern margin of the westerly winds in SW Patagonia over the last 12,600 years. Quaternary Research 68: 400 - 409.

Villarino, B. 2002. Diario del Piloto de la Real Armada Dn. Basilio Villarino del reconocimiento que hizo del Río Negro en la Costa Oriental de Patagonia el año 1782. Alicante: Biblioteca Virtual Miguel de Cervantes, <http://www.cervantesvirtual.com/FichaObra.html?Ref=8669\&portal=0>.

Wallis, C. 2004. An Account of Captain Wallis's Voyage in 1766, 7, and 8, in his Majesty's ship the Dolphin. A General History and Collection of Voyages and Travels. 2. R. Kerr. Blackwood y Cadell. Edinburgh y London.

Wandsnider, L. 1997. The roasted and the boiled: Food composition and heat treatment with special emphasis on pit-hearth cooking. Journal of anthropological archaeology 16: 1-48.

Webb, J. y M Domanski. 2009. Fire and Stone. Science 325: 820 - 821.

Weiner, S., Q. Xu, P. Goldberg, J. Liu y O. Bar-Yosef. 1998. Evidence for the Use of Fire at Zhoukoudian, China. Science 281: 251 - 253.

Whyte, T. 2001. Distinguishing Remains of Human Cremations from Burned Animal Bones. Journal of Field Archaeology 28 (3/4): 437 - 448.

Wille, M., N. Maidana, F. Schäbitz, M. Fey, T. Haberzettl, S. Janssen, A. Lücke, C. Mayr, C. Ohlendorf, G. Schleser y B. Zolitschka. 2007. Vegetation and climate dynamics in southern South America: The microfossil record of Laguna Potrok Aike, Santa Cruz, Argentina. Review of Palaeobotany and Palynology 146: 234-246.

Yacobaccio, H. 1991. Información actual, analogía e interpretación del registro arqueológico. Shincal 3 (1): 185-194.

Yravedra, J., J. Baena, Á. Arrizabalaga y M. Iriarte. 2005. El empleo de material óseo como combustible durante el Paleolítico Medio y Superior en el Cantábrico. Observaciones experimentales. Museo de Altamira. Monografías 20: 369-383. 


\section{ANEXO 1: CITAS REFERENTES AL MANEJO DEL FUEGO}

Aprovisionamiento: Se reconocieron 20 expresiones en relación al aprovisionamiento de combustibles:

"La mujer i los chicos hacen los trabajos domèsticos, acarrean la leña, el agua, confeccionan la comida..." (Larrain 1883, p. 39)

"...tiene fruta blanca y mucha leña de salinas..." (Gonzalez 1965, p. 22)

"Este día las chinas fueron en busca de leña para guisar otro caballo..." (Gonzalez 1965, p. 26)

"Allí encontré por primera vez un arbusto que parece segregar por sus ramas una materia cerosa. Los indios, es decir los pampas, la llaman "gitscha". Les gusta encontrarlo, pues aunque esté verde, arde bien. Lo usan para hacer "itschó", queman las ramas y ponen debajo una bandeja con agua. Las gotas de cera caen dentro, pero están tiznadas y negras." (Claraz 1988, p. 45)

"En la orilla occidental de la pequeña laguna se ve un montón de leña seca. Los indios dicen que debajo de él yace una piedra, que esa piedra es una vieja (Yahmoc) y que esa vieja, es sin duda, una diosa. Ella es la dueña de estos campos y de los animales que viven en ellos. Antes de llegar a dicho punto, cada uno arranca una rama seca, la lleva consigo y la coloca en el montón como una ofrenda. Dicen que como es una vieja que ya no puede juntar leña (entre los indios, juntar leña es tarea de las mujeres; sólo cuando son viejas, no salen más a juntar), éste es el regalo que mas aprecia. Se acercan al montón con respeto, no cabalgan frente a él, sino que lo rodean en un semicírculo dirigiendo una oración a la vieja. Le ruegan que los proteja cuando están a caballo y que les dé carne gorda de sus campos. Llenos de indignación cuentan que un tehuelche que no quiso ofrendar nada y se burlaba de la vieja, cayó del caballo, rompiéndose casi el pescuezo. En otra ocasión, los tehuelches llevaron el sacrilegio a un extremo tal que sacaron leña del montón, arrojándola luego. En castigo, casi murieron de hambre..." (Claraz 1988, p. 66)

"Los solteros son raros entre los indios, pues la mujer les es necesaria. Los solteros tienen que armar su toldo, cocinar, buscar agua y leña, etc. Por eso dicen que no sirve que un hombre esté solo." (Claraz 1988, p. 79)

"La noche había sido extremadamente fría. Los indios se levantaron para calentarse y quemaron la provisión de leña. Manzana se levantó muy temprano, pues no podía soportar más el frío. Fue en busca de leña, eran peines, pues la otra leña andaba muy escasa." (Claraz 1988, p. 88)

"Las indígenas por el contrario, están ocupadas de la mañana a la noche. Son las encargadas de cortar la leña y traer el agua." (Beerbohm 2004, p. 64)

"Gallegos es el lugar favorito de los indios para acampar durante varios meses al año, y por lo tanto, cualquier arbusto que alguna vez hubiese existido en los alrededores del valle, había sido extraído por las indias para utilizarlo como combustible para el fuego..." (Beerbohm 2004, p. 79) 
"...luego los tres salimos en busca de madera para el fuego, lo que nos llevó un largo rato pues el terreno entero parecía estar desnudo a causa de las indias." (Beerbohm 2004, p. 79)

"En esta región los arbustos, que habían venido disminuyendo gradualmente, desaparecieron por completo. En el tramo que estábamos por recorrer, uno podía cabalgar por leguas sin encontrar un solo pedazo de madera lo suficientemente grande como para hacer un simple palillo. Cuando los indios atraviesan esta zona siempre traen bastante madera en sus caballos de carga para que les alcance durante el trayecto. No podría explicar de ningún modo la falta de arbustos en aquella región en particular a diferencia del resto, pues tanto el suelo, como la formación y las condiciones atmosféricas, eran las mismas allí que en el resto de la Patagonia." (Beerbohm 2004, p. 118)

"La leña es escasa; en unas 15 leguas apenas hemos encontrado uno que otro arbusto; por eso, como también por el poco pasto, no están juntos los toldos, sino desparramados a lo largo del valle." (Cox 2006, p. 100)

[Acerca del coligüe] "Seco, arde chisporroteando y da una viva luz; los indios lo usan como antorcha para alumbrarse." (Cox 2006, p. 127)

"A su servicio [de las viudas] se agregan, generalmente, los cautivos, que deben buscarles leña y agua. Ignacio Argomedo, que encontramos cautivo en los toldos de Paillacán, tenía por obligación buscar leña para dos o tres viudas [...] Nunca en mi vida olvidaré las eternas frases de: "Ignaciomamuln, Ignacio-ovijias" (en castellano: "Ignacio, andá por la leña; Ignacio, andá por las ovejas")..." (Cox 2006, p. 170)

"...Aquí - dijo Jaria - no hay con qué hacer fuego, y esas estúpidas indias, se llevan cargas enteras de leña de la primera parada..." (Musters 2005, p. 35)

“Ese paraje se llamaba Chiriq, por una especie de arbusto cuya hoja se parece un poco a la del endrino, y que crece abundantemente en las orillas de la corriente. La madera de este arbusto es blanda y de poco mérito, pero arde bien cuando está seca." (Musters 2005, p. 144)

"Después de juntar un poco de leña, de encender fuego y de despachar el armadillo y un pedacito de carne cada cual, nos envolvimos en nuestras mantas y nos acostamos a dormir..." (Musters 2005, p. 308)

"Al otro día seguimos por el mismo desierto interminable de piedras y de breñas de las siguientes especies: el chañar o espino blanco, el picayun, que suministra la mejor leña; la clase mimbrera ya descrita, la zarza negra, inadecuada para leña a causa del olor pestilante que despide; el algarrobo y el incienso, muy escasos sin embargo, y varias otras cuyos nombres no pude conseguir. " (Musters 2005, p. 319)

"Las mugeres tienen obligación de guisar la comida, traer el agua y la leña, armar y desarmar el toldo..." (Viedma 1783, p. 71) 
"En llegando al destino que está asignado, arman las mugeres los toldos, recogen leña, y lo tienen todo pronto para cuando los hombres vengan..." (Viedma 1783, p. 72)

Encendido: Se han reconocido doce expresiones que se refieren al encendido del fuego:

"The makeing of their fyers is strange; for they have two peeces, the one as hard as holly, the other soft as firr, the one flatt, the other round. They lay the flatt peece ipon their knees, and set the hard peece upon the other, and drill it between their heads, the motion wherof doth sodainly engender such a heat that it breaketh out immediately into flame, where with some dry rushes or ther matter they receave fyer at their pleasure." (Drake 1854, p. 50)

"Los indios duermen bastante. Primero se levantan las mujeres, que van al río para lavarse y gargarizar; luego encienden fuego y preparan algo para comer." (Claraz 1988, p. 73)

"...otro árbol se presenta a menudo; los araucanos lo llaman "kemel" y los pampa "selau", luego la chilca, el yacnaiotr de los pampas o sasinn de los chilenos (Baccharis salicifolia, los indios la usan para producir fuego frotándola, pues su madera es muy porosa)..." (Claraz 1988, p. 91)

"Vera insistió en encender un fuego en el campo seco. Yo lo prohibí y le dije que lo hiciera cerca del río. Como no tenían cerillas, frotaron un pedazo de chilca con otro. Hacen girar un trozo entre las manos, contra otro pedazo horizontal que sostienen con los pies. Generalmente agregan un poco de cera de la oreja. Tardaron mucho. Les di una cerilla y con ella hicieron fuego. Soplaba un viento fresco del SE, que había quebrado el calor, y algunas chispas saltaron a la paja. Estalló un incendio que no pudimos apagar y con toda premura debimos llevar nuestras cosas junto al río y ahuyentar los caballos." (Claraz 1988, p. 114)

“... entre otras cosas me enseñó el medio de que se valen ellos para hacer fuego; frotan dos trozos de madera, uno contra otro, hasta que arde la médula de cierto árbol que ponen entre ambos..." (Pigafetta 2004, p. 51)

[acerca del rol del esclavo] "...aunque el servicio no era mucho; consistía sólo en el cuidado de las ovejas, en ensillar al caballo del cacique y encender el fuego para cocinar..." (Cox 2006, p. 94)

"Las mujeres volvieron con sus cántaros de agua, encendieron el fuego y pusieron a calentar las ollas, porque la primera cosa en que piensan los indios al levantarse es en comer." (Cox 2006, p. 140)

"Su mujer o mujeres han encendido el fuego, le traen un plato de comida..." (Cox 2006, p. 166)

"A la mañana siguiente, cuando despertamos, ya el fiel Dionisio había encendido el fuego..." (Cox 2006, p. 185)

"...con su ayuda encendí fuego, pero con gran dificultad a causa de la escasez de leña..." (Cox 2006, p. 186)

"Después de prestar mi ayuda en eso, me interné con un compañero en la espesura en busca de hongos para hacer yesca. Encontramos pocos..." (Musters 2005, p. 238) 
"Después de juntar un poco de leña, de encender fuego y de despachar el armadillo y un pedacito de carne cada cual, nos envolvimos en nuestras mantas y nos acostamos a dormir..." (Musters 2005, p. 308).

Mantenimiento: Sólo 10 referencias se hallaron que expresan elementos en cuanto al mantenimiento de los fogones:

"... los chicuelos iban ya tironeando, con sus dientes blanquísimos, pedazos de carne que habían cocido al contacto de las brasas y desde ángulos de la boca corrían dos surcos de grasa y ceniza; entonces el fogón queda a discreción de los someros desayunos de los niños..." (Onelli 1904, p. 143)

"Vera, según su costumbre había prendido fuego al campo. Pero el viento era fuerte, y soplaba siempre del Oeste. Nuestro asado todavía no estaba a punto, cuando casi fuimos alcanzados por el fuego, que venía saltando de cortadera en cortadera con gran velocidad." (Claraz 1988, p. 106)

"...en invierno las dos medias lunas se juntaban y el fogón iba al medio adentro con piedras para que no se corrieran las brasas puesto con piedras...así lajas para que no corrieran...los fogones se limpiaban. [...] Todo el tiempo estaba prendido el fogón...se limpiaba... [...] la ceniza se tiraba afuera en los basurales..." (Aguerre 2000, p. 30)

"...el fogón al medio del toldo, adentro del toldo. Todos los días se limpiaban. [...] siempre quedaba prendido el fogón todo el tiempo [...].el fogón de verano, toldo grande, dependía de cada familia cuántos iban a vivir. Cuando empezaba el frío tenían la tapa para cerrarlos...cada familia tenía su fogón...nosotros vivíamos cuando quedamos solos con la abuela...un toldito afuera...era la tapa del toldo para el invierno...había varios fogones...cada toldo tenía un fogón...en invierno el fogón estaba adentro, en verano el fogón se sacaba afuera..." (Aguerre 2000, p. 31)

"...las camas se armaban de noche con cueros de guanaco abajo y mantas de arriba y se armaban de noche; el fogón siempre prendido..." (Aguerre 2000, p. 32)

"A: ¿el fogón se limpiaba, no?; P: sí, se iba sacando las cenizas; A: ¿lo hacían con el pozo?; P: claro, el pozo ahí; A: ¿y había algún encargado de mantenerlo siempre, alguna persona?; P: no, no, no. Era trabajo para los hijos en general. Antes de hacer el fuego a la mañana tenía que quedar limpito, se levantaba uno y tenía que limpiarlo sacando toda la ceniza; A: ¿y con qué lo limpiaba?¿con una pala?; P: claro, se sacaba con una pala hecha de palo de molle; A: ¿y dónde se tiraba la ceniza?; P: la ceniza se tiraba en el mismo basurero; A: ¿pero se iba hasta allá lejos?; P: sí, si; A: ¿no había un lugar mas cerca?; P: no, no, porque no dejaban juntar ni cenizas ni nada cerca de los toldos, por el asuntos de los bichos; P: así que el primero que se levantaba hacía la limpieza del fogón...; A: y después a mediodía se volvía a limpiar...; P: si, se dejaba limpito; A: ¿no se dejaba la brasa?; P: no, no, se saca todo, todo, todo...; A: osea dos veces al día se limpiaba...; P: claro, a la 
mañana, después del almuerzo ya se volvía a limpiar. A la noche se dejaba, para calor del toldo...; A: un solo fogón tenían...; P: si, un solo fogón...; A: estaban cerca un toldo del otro...; P: claro, cada cual tenía su propio fogón, porque era para ir costurando el quillango, o sobando cueros..." (Aguerre 2000, p. 64)

"Entré en una de esas carpas y miré a mi alrededor. En la parte de adelante había tres o cuatro pequeñas fogatas, cada cual circundada por un grupo de indígenas calentándose los pies, fumando o tomando mate. Las mujeres estaban todas trabajando duramente, cosiendo capas, tejiendo fajas o empaquetando plumas de avestruz." (Beerbohm 2004, p. 66)

"El toldo Cheoeque, tenía precisamente dieciséis pies de altura y podía alojar cuarenta hombres, mientras que en su parte delantera ardían tres fogatas de enormes leños." (Musters 2005, p. 270) "En la mañana, todas las mujeres se hallaban sentadas alrededor de los fuegos, que eran dos, porque, siendo muy escasa la leña, no se encendían sino dos para toda la toldería." (Cox 2006, p. 155)

"En la toldería de Caleufú no había más que dos fuegos para todos" (Cox 2006, p. 169)

Uso del fuego en sentido estricto: 150 expresiones relativas a esta temática:

"Los indios Tehuelches los cazan atacándolos por diversos lados, rodeándolos y lanzando contra ellos sus perros esprofesamente amaestrados, asustándolos con fuego y gritos." (Bove 1883, p. 74)

"...mientras que el buen Hallen, que casi nunca decia palabra, asó y comió un zorrino (mephites patagonicus) que él habia muerto con las bolas en el camino." (Bove 1883, p. 154)

"Me aseguran personas prácticas en estas cosas que el Zorrino muerto y preparado por un indio es un riquísimo plato. El indio lo desuella, le saca los huesos, con pacienda admirable, saca la vejiga miasmática, y después pone al fuego la carne desinfectada del más mínimo olor." (Bove 1883, p. 154)

[la piña de la araucaria] "...los indígenas lo comen crudo y tostado; para sus provisiones invernales, lo cuecen en agua y lo entierran en paraje húmedo..." (Onelli 1904, p. 60)

"El tehuelche al enterrar con sus muertos las armas que usó, al sacrificar sus caballos y al quemar al día siguiente los objetos de su propiedad, lo hace porque cree en una vida futura..." (Onelli 1904, p. 155)

"...en los numerosos kairns prehistóricos que he registrado, he encontrado siempre, antes de llegar al esqueleto principal, mucha cantidad de huesos carbonizados de pequeñas criaturas." (Onelli 1904, p. 157)

"...empezaron a divisarse del lado Este, grandes humaredas que denunciaban que los indios habían terminado la caza y marchaban hacia su toldos; á medio día los fuegos ya estaban más próximos, y cerca de la una de la tarde ya estaban más próximos..." (Onelli 1904, p. 158) 
"...los indios podían ya poner al fuego al sacramental y jugoso matambre..." (Onelli 1904, p. 191)

"Juntaron leña sobre su cuerpo é intentaron quemarlo para borrar el rastro; no obtuvieron su propósito y el cuerpo carbonizado á medias fue echado bajo un arbusto." (Onelli 1904, p. 207)

"A las 11 del día salieron a carnear y saber que indios eran los que hicieron ayer el humo [...] Hoy no caminamos por saber qué indios son..." (Gonzalez 1965, p. 25)

"Por la mañana fueron los indios a campear la caballada y a las 8 del día se ha visto una humada de otros y a las 10 del día salieron cuatro indios en busca de ellos, a saber que indios son." (Gonzalez 1965, p. 38)

"Los indios echan cuidadosamente al fuego, para que no haga daño a otro, el pus de un abseso" (Claraz 1988, p. 43)

"Allí asamos charqui y lo comimos con grasa, lo que tiene un gusto muy agradable..." (Claraz 1988, p. 45)

"Allí encontré por primera vez un arbusto que parece segregar por sus ramas una materia cerosa. Los indios, es decir los pampas, la llaman "gitscha". Les gusta encontrarlo, pues aunque esté verde, arde bien. Lo usan para hacer "itschó", queman las ramas y ponen debajo una bandeja con agua. Las gotas de cera caen dentro, pero están tiznadas y negras." (Claraz 1988, p. 45)

[la zarzaparrilla]"Los indios la conocen y la usan como remedio. Los pampas la llaman "tschicaipa", y los chilenos, "kenéo". Hierven sus ramas como té. Usan la cocción como refrigerante y, por vía interna, contra la viruela y ataques febriles." (Claraz 1988, p. 45)

"...rompen los huesos ahí mismo y comen el caracú crudo o lo llevan para tostarlo ligeramente y comer la carne medio chamuscada, y luego el caracú..." (Claraz 1988, p. 59)

"Vera y el peón comieron, sin embargo, charqui de caballo; naturalmente por pereza, porque se asa mas rápidamente." (Claraz 1988, p. 61)

"...muslos del avestruz...Calientan piedras al rojo y las ponen adentro y luego asan todo al fuego." (Claraz 1988, p. 63)

"Hernández me pidió un cuchillo para "desvasarse". Esta operación la hacen con todo cuidado, para que el viento no se lleve ningún pedacito de uña. Los juntan todos y los ocultan en la tierra. Lo mismo hacen con el cabello, o lo queman... Vera quemó la crin de su yegua." (Claraz 1988, p. 69)

"Habíamos incendiado el bajo de Yamnago y nos contestaron desde el norte. Se notaba que la gente de Chagallo se aproximaba hacia nosotros y que hacían humo para contestar al nuestro." Claraz 1988, p. 70)

"Cuando los indios vieron que bajaba, prendieron fuego al campo y salieron cabalgando. Pronto los alcancé. En dirección sur vimos humo que parecía estar cerca. Era evidentemente la gente de Antonio." (Claraz 1988, p. 72) 
"Allí había un poco de monte. Prendieron fuego en varias partes. Todos se aparearon y se calentaron. Algunas mujeres vinieron con nosotros para buscar pintura. Fumaron allí y se calentaron...En diversos lugares los indios prendieron fuego al monte, es decir, al matorral para calentarse, lo que también hicieron en las faldas del valle." (Claraz 1988, p. 76)

“...el paico (de hojas grandes), aiha-tschagepenn de los pampas, que usan como remedio contra los resfríos (Chenopodium ambrosioides). Araucanos y españoles la llaman paico macho para distinguirla de la variedad de hojas angostas que denominan paico hembra. Es una planta aromática, muy difundida en toda la América del Sur y Centro. Se tomaba en infusión o de cocción como sudorífero contra los resfríos..." (Claraz 1988, p. 91)

[Acerca de un tubérculo] "Crudas tienen un sabor algo amargo; comida así, se dice que causan dolores de vientre. Pero tostadas en ceniza caliente tienen el mismo gusto que las papas dulces y casi el de las castañas. Hervidas en agua, igualmente." (Claraz 1988, p. 92)

"En nuestro campamento y un poco antes, vimos árboles quemados y señales (carbonización de hierba y árboles) de que el incendio se había producido en invierno" (Claraz 1988, p. 97)

"En todas partes los indios prendían fuego para hacer humo, en parte para que la espesa paja (cortadera) nos permitiera un pasaje más fácil a la vuelta, pero principalmente en la creencia de que los ingleses les iban a contestar. En vano les dije que los ingleses no entienden este modo de telegrafiar. Opinaban, sin embargo, que podría haber alguien para contestarles. Les dije que era más probable que con ello los ingleses se asusten, lo que no podían comprender." (Claraz 1988, p. 103)

"Vera había hecho esta mañana un ancho tajo en el hígado del caballo, llenándolo con grasa de caballo cortada en tajadas; luego lo había asado. Es esta la manera con que los indios preparan su guisado." (Claraz 1988, p. 110)

"Los indios estaban ocupados en derretir grasa. Son muy ingeniosos para ellos. Cerca del fuego cavan en la tierra un agujero en forma de olla. Dentro del agujero colocan un pedazo de cuero de caballo que todavía tiene que ser blanco y fresco, o humedecido. Este cuero se coloca con el lado del pelo contra la tierra, se ajusta al hoyo y en su borde se hacen agujeros para estacarlo. En esta olla ponen una gruesa capa de grasa aplastada, encima de ella piedras calentadas al rojo, luego alternativamente grasa, piedras y nuevamente grasa, hasta que, por fin, cubren todo con otro cuero. La grasa derretida se saca a cucharadas y se pone en la vejiga del caballo o en una bota de piel de guanaco; luego se sacan las piedras, se las calienta nuevamente al rojo, hasta que todo queda derretido." (Claraz 1988, p. 110)

"Tuvimos que calentarnos, envueltos en los ponchos, junto al fuego, y nos fuimos a dormir temprano...pero como la noche fue muy fría, se convirtió en escarcha. Nos calentamos junto al fuego con los ponchos puestos, comimos algo y partimos." (Claraz 1988, p. 111) 
"...esperaba ver a los otros. Por fin ví humo y ensillé para cabalgar en su dirección pues distaba media legua del lugar donde había acampado. Durante la bajada y subida se apagó el fuego y desapareció todo vestigio de humo un poco más lejos. Pero después de unas dos leguas, no veía nada todavía....Antes de seguir adelante, prendí fuego y lo mantuve una hora entera. No hubo contestación...Creí oir gritos al subir la montaña, y me pareció ver humo. Grité y pronto ví a Hernández. Todos los indios me habían campeado y cuando vieron mi fuego, Hernández cabalgó en su dirección para cortar el rastro, y así me encontró." (Claraz 1988, p. 112)

"En todas partes prendimos fuego, pero no obtuvimos ninguna respuesta de Antonio. El 24 se vió humo a lo lejos en dirección a Gitschacal" (Claraz 1988, p. 122)

"... la noche muy fría, había caído escarcha. Vera no aguantó más e hizo fuego." (Claraz 1988, p. 125)

"Habíamos prendido fuego en varios lugares. Pero como el tiempo era nublado y gris, no tuvimos ninguna respuesta." (Claraz 1988, p. 129)

"Comimos y nos calentamos junto al fuego, y cabalgamos hacia la cueva..." (Claraz 1988, p. 130)

"En una planta pequeña; tenían semillas y con dificultad encontré algunas flores marchitas. Tiene raicillas blancas y delgadas que crudas tienen un gusto agradable, pero hervidas en caldo o fritas en grasa son más sabrosas" (Claraz 1988, p. 132)

"...todos los indios viejos se quejan del frío en las rodillas y en la cintura, y se sientan con la espalda contra el fuego." (Claraz 1988, p. 133)

"Ayer prendieron fuego. A la tarde se vió humo en dirección norte. Hoy volvimos a prender fuego." (Claraz 1988, p. 135)

"...restos de un toldo quemado. La mujer de un indio murió aquí hace dos años y quemaron todo; los restos parecían extrañamente recientes porque llueve poco." (Claraz 1988, p. 139)

"...los indios se hicieron una fiesta con piquillines y algarrobas (tolu); estas últimas las comen ya sea crudas, ya un poco tostadas en ceniza caliente [...] Se tuestan en un instante, luego se machacan entre piedras, y la sustancia alveolar es la que proporciona la harina. [...] Las vainas y las semillas se hierven en agua y lo ingieren..." (Claraz 1988, p. 140)

"Si un indio muere durante el viaje, se quema todo y los deudos desparraman perlas en el lugar donde tenía su cama..." (Claraz 1988, p. 141)

"...se buscaban mucho frutas como calafate, era lo único o el macachin en tiempo de verano era lindo...se hacía dulce, se molía en un recipiente de barro y se hacía hervir." (Aguerre 2000, p. 63) "Se ponía un palo, uno de cada lado, para afirmarlo en el palo ahora se usa poxipol; y se pegaba con resina de molle, se preparaba y se mascaba bien, como si fuera un chicle y se hacía como una pasta, "se misturaba" con ceniza y se hacía una masa y se le ponía al palo, en una canaleta que se le hacía al palo y se ponía la piedra, y después con otra piedra se trabajaba el raspador, [...] éste va atado...éste es un tronco de molle,[...]acá le hacemos una horqueta, éste se pone la piedra ahí 
y se le pone la resina de molle con la ceniza y se aprieta bien...bueno se deja que se seque...cuando ya se gastaba había que romper esa capa de ceniza con la resina del molle..." (Aguerre 2000, p. 96)

"Los palos altos eran los de molle, hay algunos que son derechos, altos, el molle en los faldeos o los cañadones, para alisarlo bien y dejarlo bien pulido, le ponían la ceniza del fogón para que la madera quedara bien y lo iban raspando. Al cepillo se le tiraba ceniza y era para alisarlo bien al cuero..." (Aguerre 2000, p. 98)

"El macachín se juntaba en verano, era lindo...se molía en un recipiente de barro y se hacía hervir hasta que quedaba espeso [...]. No, no precisa azúcar, uno lo cocina, lo hace hervir y se espesa. El otro es un macachín chiquitito, redondito, parecido a una cebolla." (Aguerre 2000, p. 102)

"...con ceniza y grasa de piche hacían una crema para la cara y las manos. No llevaban pinturas y era para la cara, sol, viento, tierra...eso era distinto al lápiz." (Aguerre 2000, p. 133)

"...y también las cenizas del fogón, tibia para frotar las piernas como talco, el calor que agarra...le fortalece los huesos y le saca el frío de los huesos...volvíamos y nos lavaban bien los pies con agua de alfilerillo, bien calentita y nos secaban bien y nos pasaban la ceniza los pies las rodillas...da fuerza y la calor que agarra...la ceniza tibia de la orilla al lado del fogón sin brasa, nada, los huesos agarran calor, parece que se calientan...lo mismo en el pecho y en la espalda para que agarre calor..." (Aguerre 2000, p. 165)

"P: Hay una planta que ahora que me acordé el nombre, Cosuhaiquen.; A: ¿qué era?; P: es una planta que da una flor amarilla, como esa que le dicén el botón de oro. [...], esa es la planta para curar el hígado.; A: ¿tipo cataplasma?; P: no, agua caliente, todo lo mas caliente que se pueda, para lavar las heridas...; A: ¿̇ y esa planta se recogía en la época que florece?; P: claro, en el tiempo que florece, y se guarda para después hacerla hervir, lavar heridas...; A: ¿̇y que otras cosas usaban?; P: se manejaba...no me voy a acordar cómo se llama la otra planta. También era para cataplasma de las heridas. Es una plantita verde, es hedionda la planta, parece chinchimolle. Se hacía hervir y se sacaba toda la planta para hacer la cataplasma.; A: ¿y la cataplasma cómo se hacía?; P: se ponía la planta a hervirla..." (Aguerre 2000, p. 167)

"...cuando se moría alguien de los familiares de la tribu, no se dejaba el toldo...se desarmaba...ahí no quedaba nada...el toldo se quemaba, todo se quemaba...si había algún sillero y se enterraba cerca de la tumba...todas las cosas de plata que tuviera, eso se enterraba...el sillero no lo usaba nadie, no quedaba para nadie, ni para el hijo, ni para el hermano. Antes nadie se peleaba por las cosas...Antes se decía "murió fulana"; las prendas se enterraban y el toldo listo se desarmaba y se quemaba...si del toldo grande moría un chico o alguno de los grandes, se desarmaba y se quemaba. No se dejaba continuar en él..." (Aguerre 2000, p. 169)

"...cuando se quemaba el toldo, se hacía una ceremonia, cuando se quemaba la ropa y se mataba el animal se sacrificaba una ternera, un ternero, lo que fuera se carneaba, se sacaban los 
costillares y el resto del animal se dejaba para que el espíritu del finado tuviera para seguir viviendo..." (Aguerre 2000, p. 170)

"A: antes se hacía la ceremonia de quemar el caballo cundo moría alguien...; P: ah sí, si, cuando moría una mujer era lo mismo. Lo mismo. Porque si ella tenía un sillero, se mataba y se cuereaba. Claro. Se quemaba la ropa de ella, las alhajas no las usaba nadie. No, se quemaba. El sillero se quemaba con todo. A mi papá le mataron los caballos en el cementerio con todas las prendas, con todo. En el momento del entierro. $\mathrm{Y}$ al finado Agustín el chapiado que tenían lo quemaron también, y el toldo igual. Se levantaba y ya no existía más después. No quedaba para nadie más.; A: ¿y en la casa de uds., cuando murió el papá, que pasó?; P: le terminaron todo, le quemaron el toldo todo, y la abuela, la mamá...pasó a estar en el toldo de la abuela. Claro, murió mi papá, ella quedó sola, pasó a estar en el toldo de la abuela. Claro. El toldo que tenía papá con ella se levantó.; A: se levanta y se quema...; P: claro.; A: es una ceremonia que dura dos días...; P: sí, eso dura varios días, es como que están velándolo hasta que llegan los parientes..." (Aguerre 2000, p. 172)

"El dolor por la muerte de un hijo único suele manifestarse de la manera más exagerada. No es inusual que en estos casos los padres quemen todas sus pertenencias..." (Beerbohm 2004, p. 63) "Como es costumbre en tales ocasiones, varias yeguas habían sido sacrificadas y estaban hirviéndose y asándose sobre numerosas fogatas." (Beerbohm 2004, p. 73)

"Mientras mirábamos la primera columna de humo con ojos ansiosos, emergió otra no muy lejos de la primera, y luego otra mas y entonces supimos que el fuego estaba siendo producido por indios que estaban cazando en las Ilanuras. Un poco hacia la izquierda del humo había un sitio llamado 'Campo de Batalla', donde se asientan los indios cuando se encuentran por estos alrededores, y hacia él nos dirigimos." (Beerbohm 2004, p. 120)

"I therefore stood along the shore to the southward, the wind blowing off the land very hard, and saw several large columns of smoke rising in many places, but no tree or bush, the country resembling in appearance the barren downs of England" (Byron 2004, p. 20)

"Cientos de perros salieron a recibirnos en el camino que alumbraban los fogones de los guerreros pehuenches..." (Moreno 1997, p. 21)

"Sus restos reposan allí y uno de mis acompañantes dijo que las ramas que los cubrían estaban desinadas a suministrarles fuego en la otra vida." (Moreno 1997, p. 95)

"... sus compañeros que lo creían muerto no hablaban más de él y habían quemado cuanto le había pertenecido para olvidarlo." (Moreno 1997, p. 141)

"Allí, a la lumbre de hogueras siniestras que desde su centro alumbraban el gran toldo, convertido en infierno, y donde se quemaban repugnantes desperdicios, las armas, escondidas momentos antes, relucían por salvajes de melenas sueltas..." (Moreno 1997, p. 234) 
"Habiéndose señalado humos al oeste, enviamos a Isidoro al encuentro de los indígenas, que emplean este telégrafo primitivo para anunciar su aproximación a las habitaciones de los cristianos." (Moreno 1997, p. 237)

"A mediodía distinguimos humos en el horizonte, y a poca distancia de una angostura, donde se acercan dos barrancas de la meseta, divisamos grandes hogueras sobre las cuales se elevan densas espirales de humo negro: es la señal que hemos convenido con los indios para indicarnos sus tolderías" (Moreno 1997, p. 242)

"Chora, otra hija de María, colocó delante del toldo, sobre las brasas del fuego, que se alimenta casi perpetuamente, un asador conteniendo un gran trozo de carne de caballo de apariencia espléndida y cuya vista era un deleite para indios y cristianos. María se encargó de hacer un puchero de avestruz en un tarro de pintura vacío que había destinado para olla." (Moreno 1997, p. 247)

"Sólo los pelados, esos perros de aspecto repulsivo que conocemos, fueron admitidos y se encargaron de "espumar" el puchero, con sus lenguas, lamiendo de cuando en cuando el asado, que en las brasas concluía de condimentarse..." (Moreno 1997, p. 248)

"Los tehuelches, lo mismo que los mapuches, al cambiar de toldería queman cuanto objeto inservible no pueden llevar consigo. Creen que basta que un brujo enemigo encuentre uno de ellos para que pueda dañar al indio a quien haya pertenecido; según ello, el pelo es uno de los objetos que más prefieren los brujos para sus maldades." (Moreno 1997, p. 256)

"En muchas ocasiones he visto quemar los cabellos que se han caído al peinarse o espulgarse más de una vez, cuando viajaba entre los mapuches, vi a Shaihueque que entregaba a alguno de sus hijos, hebras sueltas para que las quemara o arrojara al río, de donde el espíritu de las Aguas no permitiría que los brujos las consiguieran nuevamente." (Moreno 1997, p. 256)

"Basta calentar algunas piedras rodadas (planas y ovaladas son las preferidas), colocarlas dentro de piche, y coser con el mismo cuero o con una ramita la abertura del vientre por donde se han extraído los intestinos, para conseguir un manjar delicioso. Esto, en menos tiempo del que se emplearía haciéndolo directamente en el fuego. El medio entre asado y cocido que producen las piedras es excelente, y el jugo de la carne y la gordura deja un caldo sustancioso que no se desperdicia jamás. Este mismo procedimiento se emplea en otros muchos animales, avestruces, guanacos pequeños, etc." (Moreno 1997, p. 271)

"La manera patagónica como se los prepara permite que no quede ningún desperdicio y que el feliz descubridor los aproveche enteramente. Se les hace un pequeño agujero de una pulgada de diámetro en un extremo y, después de sacarle una parte de la clara, se los coloca entre la ceniza cuidando de revolver su contenido y mantenerlos verticales; así a fuego lento se asan sin que la cáscara se quiebre." (Moreno 1997, p. 374) 
"Desde temprano hemos distinguido humos sobre las montañas del noreste al pie del Cerro Inclinado, que me anuncian la llegada de los indios a nuestro paradero en busca de los víveres que les prometí..." (Moreno 1997, p. 376)

"... para no dejar de aprovechar nada, hago repartir por Jonjonia (la insectívora) un espléndido asado que se condimenta desde largo rato sobre las brasas..." (Moreno 1997, p. 390)

"...en las alturas, la oscura verbenácea negrea grandes extensiones de planicie; esta planta sirve a los indios de pila eléctrica para su primitivo telégrafo; Chersco la aprovecha y, en un instante, nuestro trayecto se señala por densas columnas de humo que pronto después son contestadas desde los lejanos cerros del SE por los indios boleadores de baguales. Es un consuelo para el viajero, que siente dominado su ánimo por la soledad y el triste aspecto del paisaje al atravesar las mesetas patagónicas, ver el horizonte empañado por el humo que denuncia la presencia de hombres: el país está habitado, hay seres humanos que lo frecuentan, no se siente solo, aun cuando esos humos se distinguen algunas veces tan lejanos y tan tenues que indican una distancia de varias decenas de leguas entre quienes los han encendido y quien los divisa." (Moreno 1997, p. 414)

"El incendio, que sucede al abandono de un campamento, ha dejado el terreno sin un arbusto verde; sólo troncos y ramas carbonizadas se reflejan en las aguas..." (Moreno 1997, p. 420)

"...asamos el apetitoso avestruz, lo devoramos, y luego..." (Moreno 1997, p. 420)

"A ellos se les debe seguramente el gran incendio de los bosques de los cerros inmediatos que nos han ocultado la Cordillera a nuestra llegada al lago." (Moreno 1997, p 441)

"...y más allá, de color rosa pálido, envueltas en la bruma y en el humo de los incendios, característico de la índole salvaje de sus habitantes..." (Moreno 1997, p 471)

"... todos los amigos van a reunirse a alguna distancia de los toldos; a caballo, muñidos de asadores y haces de leña...Se encienden los fogones, se clavan los asadores con los trozos más suculentos y las piltrafas mas inmundas, y el sacrificio o mas bien el festín desenfrenado toca a su término." (Lista 2006, p. 98)

"... a veces echan mano de las hojas y pecíolos del taraxacum o achicoria silvestre, y extraen de los parajes húmedos, unas raíces o tubérculos azucarados y blancos que ellos llaman jaye o péchoro, según sean cortos o largos, prefiriendo los primeros, que indistintamente comen crudos o ligeramente tostados al rescoldo." (Lista 2006, p. 122)

"Quemaron y saquearon dos veces la ciudad de Osorno..." (Cox 2006, p.111)

[el coligüe] "Seco, arde chisporroteando y da una viva luz; los indios lo usan como antorcha para alumbrarse." (Cox 2006, p. 127)

"Pero no se veían los toldos; nuestro amigo Hueupán no los veía tampoco, porque se puso a encender fuego para que la gente de los toldos nos percibiese y viniese a nuestro encuentro; o 
quién sabe si él los había divisado, y encendía fuego para avisar a los toldos que llegaban extranjeros." (Cox 2006, p. 138)

"La noche era magnífica, el horizonte relucía con los fuegos encendidos por los indios que andaban boleando guanacos en las lomas lejanas." (Cox 2006, p. 143)

"En la tarde quise aumentar el ordinario de nuestra comida con un plato más: hice freir en una sartén las yahu-yehuines; tenían un gusto azucarado muy agradable, pero se escondía el veneno bajo las flores; en la noche Lenglier y yo tuvimos grandes dolores de estómago..." (Cox 2006, p. 152)

"Después se encendieron los fuegos, el cordero fue despedazado y puesto en las ollas..." (Cox 2006, p. 161)

"Inacayal me dijo que los malos serían castigados por el fuego en el infierno que el llamaba "quetral-mapu" ("tierra del fuego")..." (Cox 2006, p. 169)

"Encima de la sepultura se queman su lanza y sus boleadoras..." (Cox 2006, p. 170)

"Un indio había ya destripado un choique y arrojado los intestinos a los perros; en el fondo del esqueleto entreabierto se derramó la sangre en abundancia; echó sal para sazonar la salsa, cortó en trozos las partes comibles de las entrañas, el hígado, el corazón, etc., y sacó el estómago, bocado delicado, para ser asado en la noche." (Cox 2006, p. 183)

"...encendió Dionisio el fuego del vivaque de Inacayal, en donde yo estaba; los demás indios se habían reunido en tres grupos y habían también hecho sus fuegos. Me preguntaba yo, mirando alrededor, en donde estaban los árboles que iban a proporcionar los asadores; no teníamos a la manos más que tres o cuatro arbustillos que nos proveían de chamiza para el fuego, pero que no contenían rama alguna a propósito para ese fin; pero yo no contaba con la industria de los indios; cuando no hay asadores, suplen las piedras, y éstas no faltan en la Pampa; se las enrojece al fuego, se abre con el cuchillo el pedazo de carne que se quiere asar; se introducen las piedras y enseguida se pone todo al fuego; así se cuecen el interior y el exterior bien que mal, y así satisfacen la primera hambre." (Cox 2006, p. 184)

"...había introducido en el esqueleto de un choique piedras enrojecidas, grasa del animal y, habiéndolo atado, lo puso sobre otras piedras candentes." (Cox 2006, p. 184)

"Mientras tanto, se asaban, con concha y todo, unos cuantos quirquinchos, que debían servir de postres; la carne de quirquincho se parece a la de puerco lechón; ella terminó dignamente el sháscutun, así llaman los indios a esta manera de cocinar." (Cox 2006, p. 184)

“...vimos subir hacia el cielo, en la dirección noreste, grandes columnas de humo que respondían al fuego de señal que habíamos dejado a nuestras espaldas...Entonces, Jaria pegó otro fuego a un arbusto cercano, que soltó densas nubes de humo negro, y a los pocos minutos respondieron a esta señal en la misma dirección que habíamos observado antes. Se avistó al fin un jinete que venía galopando hacia nosotros y que resultó ser un indio llamado Sam..." (Musters 2005, p. 40) 
“...vivaqueamos a la sombra de un enorme matorral de incienso, soltando a los caballos y haciendo una fogata, en la que en breve empezaron a cocinarse los restos del avestruz bajo la mano maestra de Casimiro..." (Musters 2005, p. 68)

"Cavando en el montón se encuentra una raíz tuberosa grande y varias chicas, que asadas al rescoldo resultan bastante sabrosas para el que tiene hambre." (Musters 2005, p. 88)

"A propósito de esos fuego de señal, Casimiro me contó una historia curiosa. Hela aquí: "... La partida acampó junto a una gran laguna... Durante varios días seguidos estuvimos observando humo en diferentes direcciones y estas señales se acercaban cada vez más. Se supuso, naturalmente, que la causaban los indios; se respondió a ellas, y al fin se enviaron exploradores que averiguaran la cosa, porque no aparecía enviado alguno. Pero los exploradores volvieron diciendo que no habían podido descubrir nada. A los cuatro días sin embargo, llegó al campamento, preguntando por un jefe de nombre desconocido un indio alto, flaco, consumido, montando una mula trasijada... Al cabo de tres días el forastero montó en su mula, que parecía tan fresca como a la llegada, y partió en dirección norte. Al día siguiente durante la cacería, se declaro una enfermedad entre los indios..." (Musters 2005, p. 119)

"Pero la lluvia no hacía mucho daño a nuestras ropas, porque es fácil secar al fuego una manta de guanaco, para lo cual hay que tener la precaución de exponer al calor sólo el lado del pelo, porque de otra manera el cuero se resecaría y podría rasgarse fácilmente." (Musters 2005, p. 122) "En ese campamento se destacaron vigías, y uno de ellos volvió declarando que había visto humo en dirección al norte." (Musters 2005, p. 123)

"El nombre indio de ese lugar es Yaiken- Kaimak, y significa que esa es la colina desde donde se atisban las señales de humo reveladoras de la aproximación de indios del norte." (Musters 2005, p. 124)

"De suerte que pasamos el 16 a una pampa rasa; durante la travesía se vio humo al este y se respondió a él debidamente." (Musters 2005, p. 125)

"Al día siguiente el humo de este apareció muy cerca, y a poco de estar marchando, se despachó a dos jóvenes en dirección a él con instrucciones privadas de Orkeke." (Musters 2005, p. 126)

"...me uní a Orkeke y dos mas, junto al fuego, con el propósito de cocer unos huevos de avestruz..."(Musters 2005, p. 127)

"Al volver junto al fuego debajo del matorral, desmonté, y, mientras cocía otro huevo participé a Orkeke algunos de mis pensamientos..."(Musters 2005, p. 128)

"Afortunadamente, ese día dos de nosotros matamos pumas gordos, y algunas tajadas de esta carne, asadas para variar..."(Musters 2005, p. 129)

"El día era caluroso, y Orkeke me invitó a que fuéramos a la cima de una de las colinas para ver si desde allí se descubría humo o alguna otra señal de indios." (Musters 2005, p. 130) 
"Ese día se había visto claramente humo hacia el norte y se había enviado a Hummuns para que averiguara si eso era una señal de los tan esperados indios norteños...cuando Orkeke me despertó con la noticia de que se veían fogatas al norte, causadas indudablemente por el chasque que se había despachado." (Musters 2005, p. 131)

"Permanecimos allí tres días; y como se observara al este señales de humo que no se habían visto hasta entonces, se enviaron dos exploradores para averiguar la cusa de ellas; pero éstos regresaron sin noticias." (Musters 2005, p. 132)

"Como dos días antes había visto humo de algún campamento del cual estaba cerca entonces...se separó de su compañero chileno y subió a una altura para reconocer el terreno. Durante su ausencia, el chileno se entregó al sueño; la hierba se incendió y el fuego rodeó al dormido. Los indios, gente de Hinchel, atraídos por el humo, bajaron y salvaron al imprudente; se le había quemado toda la ropa y tenía el cuerpo seriamente chamuscado." (Musters 2005, p. 133)

"Pero con gran desilusión nuestra, no se vio señal alguna de los indios, de modo que bajamos, y, después de bañarnos en un charco, mientras se acababa de plantar los toldos, encendimos una gran fogata de señal, a la que en breve respondieron el oeste." (Musters 2005, p. 134)

"...se vió humo en varios puntos al oeste, y como a las dos de la tarde apareció en la parte norte del valle la cabeza de una pesada columna de mujeres, criaturas e innumerables caballos." (Musters 2005, p. 135)

"Al nornoroeste de nuestro campamento...podíamos ver el humo de las cacerías de los indios araucanos, que, sin embargo, estaban a muchas leguas de distancia. En toda la Patagonia el humo se ve siempre desde muy lejos, y los ojos ejercitados de los indios alcanzan a distinguirlo de las nubes cuando el común de las personas no podrían descubrirlo a menos que se les señalase." (Musters 2005, p. 141)

"...hicimos una expedición para extraer una especie de raíz un poco parecida a la chirivía, pero aunque estuvimos escarbando durante una hora, nuestros esfuerzos fueron recompensados apenas por unas cuantas raicecitas que se dieron a las criaturas. Invitado por la señora de Orkeke, probé una que había sido asada al rescoldo, y me pareció insípida e insulsa." (Musters 2005, p. 143)

"Se arrearon inmensas manadas de guanacos, y una vez cercadas de hombres y fogatas comenzó el deporte. Por alguna razón los tehuelches habían incendiado la hierba en todo lugar disponible, y como el viento se convirtiera en un vendaval furioso, el fuego se esparció en breve y empezó a avanzar en línea. Jakechan, yo y varios otros indios estábamos en el centro del círculo, ocupados todos en desollar al guanaco que habíamos muerto, ando de pronto nos encontramos rodeados de llamas y de humo, a tal punto que, si no queríamos chamuscarnos, debíamos buscar una vía de escape..." (Musters 2005, p. 165) 
"Cruzando luego el río hicimos alto debajo de los árboles, y en breve empezó a arder un fuego rugiente, junto al cual nos secamos y cocinamos nuestra comida." (Musters 2005, p. 170)

"...como al ponerse el sol no hubiera aparecido aún, se incendió un poco de hierba seca con el objeto de darle la dirección de nuestro campamento." (Musters 2005, p. 173)

"En los toldos encontramos al chileno perdido, que acababa de llegar; persiguiendo hasta una distancia a una manada se había extraviado, pero nuestras fogatas de señal lo habían dirigido bien." (Musters 2005, p. 174)

"Ese día vimos humo al norte, causado por las partidas de caza de los demás indios, y también otras a mayor distancia, que Orkeke atribuyo a los indios araucanos..." (Musters 2005, p. 185)

"La pintura para la cara se compone de ocre rojo, o tierra negra, mezclada con grasa sacada de los huesos medulares de los animales muertos en la caza; huesos que las mujeres reservan celosamente y que, cuando llega la oportunidad muelen y cuecen en grandes ollas..." (Musters 2005, p. 196)

"...las esposas, hijas, o novias peinan a los hombres, teniendo el mayor cuidado de quemar todas las hebras que les saquen, porque los indios creen firmemente que las personas malintencionadas que puedan obtener un pelo de ellos estarán habilitadas para hacerles sortilegios. Por esta misma razón cuando se cortan las uñas entregan cuidadosamente a las llamas las raeduras." (Musters 2005, p. 196)

"Cuando muere un tehuelche, matan todos sus caballos, perros y demás animales, y queman en pila sus ponchos, adornos, boleadoras y demás pertenencias personales..." (Musters 2005, p. 211) "La muerte de una criatura da lugar a una demostración de pesar sincero de parte de sus padres. Se va a buscar el caballo en que la criatura acostumbraba viajar durante las marchas, se le colocan los arreos y también la cuna, y luego se estrangula al animal así enjaezado, por medio de lazos... Se quema después los arreos, la cuna y todas las pertenencias de la criatura, en tanto que las mujeres lloran y cantan. Los padres arrojan además al fuego sus prendas de valor para expresar su pena. (Musters 2005, p. 212)

"Cuando dos partidas de indios se aproximan una a la otra, y están ya lo bastante cerca para percibir el humo de sus fogatas de cacería, se enciende un fuego de señal, y de uno y otro lado parte un chasque, llamado por los tehuelches coeto..." (Musters 2005, p. 218)

"...entramos en un llano a nivel, en cuyo extremo opuesto notamos con gran contento las humaredas de respuesta de los toldos araucanos." (Musters 2005, p. 226)

"Los tubérculos eran los mas grandes que había visto yo entonces, y se parecían mucho, por su aroma a la batata. La manera corriente de cocinarlos era hervirlos en una olla, colocándose encima de todo un terrón de arcilla para que el vapor no saliera." (Musters 2005, p. 232) 
"El 18 de febrero se vió humo al norte, no muy lejos, y al caer la tarde llegó un chasque trayendo consigo un par de botellas de aguardiente para Quintuhual, así como la noticia de que las cosas marchaban bien en el campamento de Foyel..." (Musters 2005, p. 242)

"...íbamos a hacer un alto allí para encender fuego cuando vimos surgir de pronto del lado opuesto una nube de humo que indicaba la aproximación del chasque enviado a Las manzanas." (Musters 2005, p. 245)

"...y a cierta distancia al noreste, en los llanos superiores, se veían los fuegos de caza de los propietarios de esos toldos." (Musters 2005, p. 249)

"La leña abundaba, la suministraban montones de maderas arrastradas por las inundaciones del invierno o de la primavera; de modo que, al calor de chispeantes fogatas y al abrigo de la hierba pampa, dormimos bastante cómodos." (Musters 2005, p. 259)

"Después de haberme bañado en el río, estaba sentado junto al fuego, viendo como se cocinaba nuestra comida, cuando recibí el recado de que me necesitaban en uno de los toldos." (Musters 2005, p. 262)

"Allí, al abrigo de unos árboles, hicimos alto y encendimos fuego para calentarnos, porque la fuerte lluvia había calado ya por completo nuestras mantas." (Musters 2005, p. 265)

"...pasamos la noche tiritando alrededor de los fuegos y haciendo bolas perdidas." (Musters 2005, p. 266)

"Encendí fuego, porque el tiempo se había depejado ya, y en breve todos los de la partida estaban apiñados en torno de él, calentando sus miembros medio ateridos para volver luego a acostarse." (Musters 2005, p. 283)

"...varias criaturas murieron, por lo que los padres, en su aflicción, sacrificaron una cantidad de yeguas y caballo y quemaron ponchos, atavíos y otros objetos." (Musters 2005, p. 294)

"...al sonar un grito, todos los fuegos se apagaron inmediatamente y empezó el disparo de los fusiles...a una señal que se dio, todos pararon simultáneamente y por dos o tres minutos el campamento quedó completamente envuelto en las tinieblas, después de lo cual volvieron a encenderse las fogatas y las cosas recobraron su ordinario aspecto." (Musters 2005, p. 295)

"...Casimiro y yo convinimos en probar si las hojas eran medicinales, para lo cual se hizo machacar y cocer una cantidad de ellas..." (Musters 2005, p. 295)

"Se llegó a la conclusión de que la señal de humo distante indicaba la presencia de Jackechan y de los indios pampas al mando de Teneforo..." (Musters 2005, p. 298)

"...el humo había sido causado por una partida de indios pampas que iban a unirse con Quintuhual, o, en todo caso que viajaban en esa dirección..." (Musters 2005, p. 299)

"...estaba cubierto de bayas que aun cuando no son comestibles, los indios las echan en agua para preparar una bebida; esta infusión tienen un gusto muy dulce..." (Musters 2005, p. 300) 
"Después de encender fuego para calentarnos el cuerpo, mojados como estábamos y helados por el viento..." (Musters 2005, p. 302)

"...vimos con alegría el humo de unas partidas cazadoras, que, al parecer, no estaban lejos." (Musters 2005, p. 311)

"La carta [...] me fue entregada ceremoniosamente a la luz de una llamarada producida por un poco de grasa echada al fuego." (Musters 2005, p. 313)

"Supe por los indios, que los fuegos o incendios del campo eran señal de reunión entre ellos, y seña de venir algún enemigo de aquella nación, a los cuales sus aliados y parientes le hacían esta seña." (Villarino 2002, p. 14)

"Si muere un indio, todo lo que posee perece: matan sus yeguas y caballos, queman sus ponchos, xergas, y aun hechan a la hoguera los recados y frenos [...] Si alguno quiere tomar alguna prenda de las que se deben quemar, se saca un poco de sangre de un braso con la punta de un cuchillo la derrama sobre el fuego, y queda dueño de la prenda" (Outes 1917, p. 213)

"...como cada cacique tiene señalado el terreno de su jurisdicción, no puede ninguno de sus indios entrar en el terreno de otro sin pedirle licencia para ello. El indio que vá a pedirla ha de hacer tres humaradas, y hasta que le correspondan con otras tres no puede llegar a los toldos..." (Viedma 1783, p. 8)

"Si el enfermo muere.... Tienen ya prevenida una hoguera, donde van arrojando á quemar el aparejo y alhajas que lleva el caballo; y la persona que hace cabeza de duelo se va quitando el vestido y cuanto tiene puesto, y lo va arrojando tambien al fuego; como tambien todos los parientes y amigos echan una prenda cada uno, que al efecto traen de sus toldos ó se quitan de su vestidura, compitíendose en entregar al fuego las mejores, en que denotan mas obligaciones al muerto, ó mas amistad, amor, \&c. Luego desuellan al caballo ahogado, y se reparte su carne entre todos los que echaron prendas al fuego." (Viedma 1783, p. 10)

"Vimos fuego en los mas $S$ de ella, y registrando como desagüe o entrada de puerto, juzgamos que éste sería el Río de Santa Cruz, y el fuego la señal ofrecida por los indios." (Viedma 1783, p. 31)

"...murió de sobreparto, e inmediatamente ensillaron su caballo, pusieron encima de él toda la ropa y alhajuelas de la difunta [...]. Concluido, le despojaron del aparejo, ropa y demás que le habían cargado; todo lo cual dieron al fuego en una hoguera que tenían preparada, añadiendo cada pariente y amigo alguna otra alhajilla, que de sus toldos traían para quemar con las de la difunta. Mataron luego una yegua, y haciendo de ella y del caballo trozos, se fueron repartiendo entre cuantos al fuego echaron algo. El marido, presente a todo este funeral, fue el primero que arrojó a las Ilamas cuanto tenía..." (Viedma 1783, p. 47) 
Actividades en torno al fogón: Se encontraron 33 registros vinculados con actividades desarrolladas alrededor de las estructuras de combustión:

"... no sooner are their children brought into the world, but hte mother bringeth them betweene two or more fyers made of purpose, in the midest whereof between them, haveing layed a padd of rushes, she layeth the child, and basteth the body with the oyle of ostrigges, mixed with som chawke or oare of sulphur, or som other such matter, which being rubbed one in the heat of the fier, entereth in the pores of the skinn and stoppeth them." (Drake 1854, p. 49)

"Wheresoever they take their victuall there they feede, amd making a fier, cast it by bitts of six pounds weight into the flames till it be a little scorched, and, takeing out, tare it in peeces like lyons..." (Drake 1854, p. 50)

"...llegué una tarde á su ranchito hecho con barro; me acerqué a la rueda de indias acurrucadas alrededor del fogón, buscando lugar para sentarme sobre una piel tendida en el suelo..." (Onelli 1904, p. 83)

"...las encontré humeantes alrededor del fuego, tranquilamente esperando que el vestido de baño se secara sobre el cuerpo y volviera á desempeñar el papel de traje diario." (Onelli 1904, p. 141) [el toldo] "... y frente al biombo, que desempeña el papel de fuera de la casa, humea el fuego cuyas brasas no se extinguen hasta la remoción del campamento. Ese punto es el hogar, la cocina, el comedor; un paso más hacia el interior, y donde en el suelo está extendidos cueros lanudos, es el salón para recibir visitas y boudoir donde las dueñas de casa hacen su toilette, cosen y preparan los quillangos de guanaco chico para el intercambio con los cristianos..." (Onelli 1904, p. 141) "Comimos y nos calentamos junto al fuego, y cabalgamos hacia la cueva..." (Claraz 1988, p. 130) “A: ¿hacían alguna ceremonia mientras se hacia el parto?; P: cuando estaba yo para tener el bebé, la mamá o alguna de mis tías, con los hombres u otras mujeres cantaban afuera...se hacía un fogón afuera del toldo, para que no tenga mayores dolores, y para que todo salga bien, se bailaba alrededor del fogón." (Aguerre 2000, p. 139)

"ese es un baile que se baila medio parecido...el "loncomeo" es de hombres y de mujeres...porque bailan los hombres y también salen las mujeres...claro, es similar al "loncomeo" del "nguillatun"...se baila, primero salían todos los varones y después corrían todos los varones, como el avestruz y después salían las mujeres hacia la ronda...corrían alrededor del fogón...se hacía un fogón afuera, donde se hacían los asados; todo eso...tipo ponen allí el fogón y allí hacen la ronda." (Aguerre 2000, p. 161)

"The natives continued abreast of the ship all night, making several great fires, and frequently shouting very loud." (Wallis 2004, p. 98)

"About half an hour after we had cast anchor, the natives made several large fires a-breast of the ship, and at break of day we saw about four hundred of them encamped in a fine green valley, between two hills, with their horses feeding beside them." (Wallis 2004, p. 102) 
"Festejaban los pehuenches, cn un huecu-ruca, baile de tres días alrededor de una damajuana durante el día, y de la hoguera durante la noche, la primera menstruación de una joven..." (Moreno 1997, p. 22)

"Encendieron grandes hogueras. Clavaron frente al ruca (toldo) del lonco (cabeza-jefe), dos hileras de lanzas perfectamente alineadas, colocáronse los jóvenes de un lado y los hombres de otro y principió la danza, marchando y haciendo mover la cabeza hacia los lados y cantando monótonamente para acompañar la música representada por el ralí, que tocaban las viejas sentadas cerca del escenario del baile, y por dos rutrucas, instrumento compuesto de una larga caña de coligüe, hueca, forrada con tripa, en a punto un cuerno de toro, y que llevan dos indios, uno el músico, que sopla con toda la fuerza de sus pulmones para producir solo un sonido seco y desagradable, y otro que conduce en sus hombros el instrumento. Algunos indios usaban pequeñas flautas de caña tierna de las que no obtenían sino silbidos..." (Moreno 1997, p. 130)

"Millares de fogones señalaban otros tantos toldos, y el alma del guerrero, dejando inerte su cuerpo, se unía a los corrillos formados por las almas de sus antepasados..." (Moreno 1997, p. 139)

[los perros] "En la furia del combate voltearon asado y puchero que fueron a caer entre los desperdicios que rodean el fogón. Según parece, esta escena debe repetirse con frecuencia..." (Moreno 1997, p. 248)

"Nuestro círculo alrededor del asado se compone, ademas de los dueños del toldo y de sus hijos, del viejo Kaikokelteish, del gigante Collohue, de su mujer..." (Moreno 1997, p. 248)

"Este día sucedió una desgracia a Lenglier; habiendo ido, según su costumbre a fumar una cachimba al círculo de chinas que cocinaban cerca del fuego, perdió su cuchillo." (Cox 2006, p. 155)

"A la entrada del sol, volvieron los indios, pero el viento violento que hacía no nos permitió conversar a la orilla del fuego como en la víspera." (Cox 2006, p. 186)

"Hicimos alto junto a un matorral, y en pocos minutos el fuego estuvo encendido. Mientras circulaba la pipa tuve oportunidad de observarlos detenidamente." (Musters 2005, p. 41)

"Me acerqué a una fogata donde algunos indios estaban reunidos comiendo avestruz y me disponía a desollar a los cachorros cuando Tankelow, que presidía la reunión, me detuvo diciendo que los desollaríamos en los toldos donde la sangre sería un regalo para las mujeres y las criaturas." (Musters 2005, p. 166)

"Durante esa noche nació una criatura cuyos padres eran ricos, y, en consecuencia, se llevó a cabo una gran matanza de yeguas, se erigió la tienda de mandiles y se anunció una siesta con baile...salimos junto con el a ver los danzarines, que estaban marchando vigorosamente alrededor de la fogata, delante de la tienda de mandiles." (Musters 2005, p. 224) 
"...mientras la mayor parte estábamos llevando los caballos al rodeo, y otros fumaban junto al fuego, aparecieron a lo lejos unos hombres..." (Musters 2005, p. 246)

"...cuando me llamaron a otro toldo, donde la tía de Casimiro, perteneciente a nuestro grupo doméstico y mi "compañera de pipa", estaba sentada junto al fuego bebiendo aguardiente, en cuya operación me invitó a ayudarla; sin repugnancia alguna, me senté y tomamos juntos dos o tres tragos..." (Musters 2005, p. 250)

"Se conversó otro poco sobre esto, y después volví a nuestro fuego acompañado por un mestizo..." (Musters 2005, p. 263)

"Estando sentados junto al fuego, un pájaro muy parecido a nuestro chotacabras común, pasó por sobre nuestras cabezas lanzando si chillido particular..." (Musters 2005, p. 269)

"...cuando estaba durmiendo junto al fuego, me despertó Gabriel..."(Musters 2005, p. 269)

"Las tres esposas del cacique presidían junto a las fogatas, y en el primer servicio se hicieron circular platos de madera cargados de grandes trozos de carne y la correspondiente ración de gordura." (Musters 2005, p. 277)

"... recibí un recado de Orkeke, cuyo fuego estaba a un centenar de pasos quizá del nuestro, diciéndome que deseaba verme cuando estuviera libre, y así que hube cenado fui allá y encontré al veterano sentado, cargando su pipa." (Musters 2005, p. 282)

"...oímos de pronto exclamaciones y gritos en los toldos de Foyel, y todos excepto Casimiro, que se quedó sentado junto al fuego, completamente inmóvil, salieron a tomar sus armas..." (Musters 2005, p. 284)

"Después de la comida, todos nos sentamos alrededor del fuego y tomamos un mate y un poco de torta india, una pasta amarilla hecha de algarroba machacada y mezclada con agua." (Musters 2005, p. 316)

"Después de una prolongada conversación junto al fuego, en la que se hizo saber que la ruta que seguíamos..." (Musters 2005, p. 318)

"La primera menstruación de las jóvenes (enake) es objeto de fiesta entre los indios, y ésta suele durar varios días consecutivos. En ella se baila al resplandor de la hoguera que arde en el centro del toldo, o se hacen grandes libaciones a Baco" (Lista 2006, p. 71)

Abandono: Siete referencias expresan elementos concernientes al apagado y abandono de los fogones:

"Un caballo muerto y los restos de fogatas y los fragmentos de pieles de guanacos y ovejas, nos indicaron que este lugar debia ser el campamento acostumbrado de las caravanas provenientes ó con destino á Bahía Gregorio." (Bove 1883, p. 75)

"Encontramos rastros de caballos y mucha bosta. En un lugar los restos de algunos toldos. Las mujeres habían estado buscando macachinas; la tierra estaba algo revuelta y había huesos 
machacados. Eran los tehuelches a quienes pertenecía el caballo. También excremento de vaca y alguna osamenta vacuna. Habían prendido fuego al campo en ambas orillas; por eso había pasto exuberante, sobre todo en el lado meridional." (Claraz 1988, p. 105)

"... but though we had seen no inhabitants, we saw places where they had made their fires, which however did not appear to be recent." (Byron 2004, p. 23)

"We fell in with a great number of the huts or wigwams of the Indians, which appeared to have been very lately deserted, for in some of them the fires which they had kindled were scarcely extinguished" (Byron 2004, p. 33)

"From the place where we stopped, the Indians had been gone so lately, that the wood, which lay half burnt, where they had made their fire, was still warm; and soon after our fire was kindled, we perceived that another was kindled directly opposite to it, on the Terra del Fuego shore; probably as a signal, which, if we had been Indians, we should have understood." (Byron 2004, p. 35)

"...aunque yendo siempre con mucha precaución, porque desde la víspera ibamos encontrando palos quemados, tizones, restos de fogones extinguidos, así como estiércol de caballo, manifestándonos que los indios habitaban estos parajes." (Cox 2006, p. 79)

"Marks of very recent fire, and numerous tracks of feet upon a soft muddy place at the side of the river, showed that a party of Indians had lately crossed over. A smoke rising on the southern shore, told where they were gone..." (Fitz Roy 1837, p. 119) 
ANEXO 2: BASE DE DATOS DE PIEZAS LíticAS TRATADAS

TÉRMICAMENTE DURANTE LAS EXPERIMENTACIONES

\begin{tabular}{|c|c|c|c|c|c|c|c|c|c|c|c|c|c|}
\hline Exp. & $\mathrm{T}^{\circ}$ & Pieza & $\mathrm{MP}$ & Lar. & Anc. & Esp. & Lust. & Color & Rug. & Hoy. & Agr. & Esc. & Pát. \\
\hline 1 & $333^{\circ}$ & 1 & MP5 & 4,7 & 4,7 & 2,2 & no & si & no & no & no & no & no \\
\hline 1 & $333^{\circ}$ & 2 & MP5 & 5,4 & 5 & 2 & no & si & no & no & si & no & no \\
\hline 1 & $333^{\circ}$ & 3 & MP5 & 4,5 & 4 & 1,8 & si & si & no & no & no & no & no \\
\hline 1 & $333^{\circ}$ & 4 & MP5 & 2,9 & 3,2 & 1,2 & si & si & no & no & no & no & no \\
\hline 1 & $333^{\circ}$ & 5 & MP5 & 5,5 & 2,9 & 1,5 & no & no & no & no & no & no & no \\
\hline 2 & $303^{\circ}$ & 6 & S. gris & 7,6 & 4 & 1,6 & si & si & no & si & no & si & no \\
\hline 2 & $303^{\circ}$ & 7 & S. gris & 2,5 & 5 & 0,5 & si & si & no & no & no & no & no \\
\hline 2 & $303^{\circ}$ & 8 & S. gris & 3,4 & 3,7 & 0,5 & si & si & no & no & no & no & no \\
\hline 2 & $303^{\circ}$ & 9 & MP5 & 5,3 & 3,5 & 2,9 & si & si & no & no & no & no & no \\
\hline 2 & $303^{\circ}$ & 10 & MP5 & 4,8 & 2,2 & 0,9 & si & si & no & no & no & no & no \\
\hline 2 & $303^{\circ}$ & 11 & MP5 & 3,6 & 2,3 & 0,7 & si & si & no & no & no & no & no \\
\hline 3 & $413^{\circ}$ & 12 & MP5 & 3,3 & 3,9 & 0,5 & si & si & no & no & no & no & no \\
\hline 3 & $413^{\circ}$ & 13 & MP5 & 4,6 & 2,7 & 0,9 & si & si & no & no & no & no & no \\
\hline 3 & $413^{\circ}$ & 14 & MP5 & 4,3 & 2,8 & 0,8 & no & no & si & si & no & no & no \\
\hline 3 & $413^{\circ}$ & 15 & MP5 & 3,7 & 4,3 & 0,5 & no & no & si & si & no & no & no \\
\hline 3 & $413^{\circ}$ & 16 & MP5 & 4,9 & 2,5 & 0,4 & no & si & si & si & si & no & no \\
\hline 3 & $413^{\circ}$ & 17 & MP5 & 4,1 & 2,4 & 0,6 & no & no & si & si & no & no & no \\
\hline 3 & $413^{\circ}$ & 18 & MP5 & 5,2 & 3,1 & 1,1 & no & si & si & si & no & no & no \\
\hline 3 & $413^{\circ}$ & 19 & MP5 & 5,1 & 3,7 & 1,3 & no & no & si & si & no & no & no \\
\hline 3 & $413^{\circ}$ & 20 & MP5 & 4,2 & 4,1 & 1,9 & no & si & si & no & no & si & no \\
\hline 4 & $340^{\circ}$ & 21 & MP5 & 3,9 & 4,5 & 1,7 & no & si & si & si & no & no & no \\
\hline 4 & $340^{\circ}$ & 22 & MP5 & 5 & 3,9 & 2 & no & si & si & no & no & no & no \\
\hline 4 & $340^{\circ}$ & 23 & MP5 & 4 & 2,1 & 0,6 & no & si & si & si & si & no & no \\
\hline 4 & $340^{\circ}$ & 24 & MP5 & 3,8 & 3,8 & 1,1 & no & si & si & si & no & si & no \\
\hline 4 & $340^{\circ}$ & 25 & MP5 & 6,5 & 6,3 & 2,2 & no & no & si & no & no & no & no \\
\hline 4 & $340^{\circ}$ & 26 & MP5 & 4,8 & 7,2 & 2,2 & no & no & si & no & no & no & no \\
\hline 4 & $340^{\circ}$ & 27 & MP5 & 5,5 & 6,8 & 2,2 & no & no & no & si & no & no & no \\
\hline 4 & $340^{\circ}$ & 28 & MP5 & 6,7 & 5,6 & 2,1 & no & no & no & si & no & no & no \\
\hline 4 & $340^{\circ}$ & 29 & MP5 & 3,4 & 5,1 & 1,2 & no & si & si & si & no & no & no \\
\hline 5 & $444^{\circ}$ & 30 & MP1 & 5,6 & 3,1 & 1,4 & no & si & si & si & no & si & no \\
\hline 5 & $444^{\circ}$ & 31 & MP1 & 4,2 & 2,3 & 0,6 & no & si & no & no & no & no & no \\
\hline 5 & $444^{\circ}$ & 32 & MP1 & 2 & 1,2 & 0,3 & no & si & no & no & no & no & no \\
\hline 5 & $444^{\circ}$ & 33 & MP2 & 5,8 & 4,7 & 1,3 & no & si & $\mathrm{si}$ & si & $\mathrm{si}$ & si & no \\
\hline 5 & $444^{\circ}$ & 34 & MP2 & 3,3 & 2,8 & 0,8 & no & si & si & si & si & si & no \\
\hline 5 & $444^{\circ}$ & 35 & MP2 & 1,4 & 1,3 & 0,4 & no & si & no & si & no & no & no \\
\hline 5 & $444^{\circ}$ & 36 & MP3 & 6,4 & 7,3 & 2,5 & no & si & no & no & no & no & si \\
\hline 5 & $444^{\circ}$ & 37 & MP3 & 2,6 & 3,6 & 0,6 & no & si & no & no & no & no & no \\
\hline 5 & $444^{\circ}$ & 38 & MP3 & 2 & 1,1 & 0,5 & no & si & no & no & si & no & no \\
\hline 5 & $444^{\circ}$ & 39 & MP4 & 3,8 & 3,2 & 1,8 & no & si & $\mathrm{si}$ & si & no & si & no \\
\hline 5 & $444^{\circ}$ & 40 & MP4 & 3,6 & 2,8 & 0,3 & no & si & si & si & no & si & no \\
\hline 5 & $444^{\circ}$ & 41 & MP4 & 1,3 & 1,6 & 0,3 & no & si & si & si & no & si & no \\
\hline
\end{tabular}




\begin{tabular}{|c|c|c|c|c|c|c|c|c|c|c|c|c|c|}
\hline 6 & - & 42 & MP1 & 4,8 & 5,7 & 1,5 & no & si & si & si & $\mathrm{si}$ & si & no \\
\hline 6 & - & 43 & MP1 & 4,7 & 2,6 & 1,4 & no & si & no & no & no & no & no \\
\hline 6 & - & 44 & MP1 & 1,8 & 1 & 0,2 & no & $\mathrm{si}$ & $\mathrm{si}$ & $\mathrm{si}$ & no & no & no \\
\hline 6 & - & 45 & MP1 & 1,1 & 1,6 & 0,2 & no & $\mathrm{si}$ & no & $\mathrm{n}$ & no & no & no \\
\hline 6 & - & 46 & MP2 & 4,1 & 6,1 & 0,8 & no & $\mathrm{si}$ & $\mathrm{si}$ & no & no & no & no \\
\hline 6 & - & 47 & MP2 & 4,5 & 4,2 & 0,9 & no & no & no & no & no & no & no \\
\hline 6 & - & 48 & MP2 & 1,8 & 1 & 0,1 & no & $\mathrm{si}$ & no & no & no & no & no \\
\hline 6 & - & 49 & MP2 & 1 & 1,5 & 0,2 & no & no & no & no & no & no & no \\
\hline 6 & - & 50 & MP3 & 1,8 & 4,9 & 1,2 & no & $\mathrm{si}$ & no & no & no & no & si \\
\hline 6 & - & 51 & MP3 & 5,5 & 2,6 & 1,1 & no & no & no & no & no & no & no \\
\hline 6 & - & 52 & MP3 & 1 & 1,5 & 0,2 & no & $\mathrm{si}$ & no & no & no & no & $\mathrm{si}$ \\
\hline 6 & - & 53 & MP3 & 1,5 & 1,1 & 0,2 & no & no & no & no & no & no & no \\
\hline 6 & - & 54 & MP4 & 4,3 & 2,6 & 1,6 & no & $\mathrm{si}$ & no & no & no & $\mathrm{si}$ & no \\
\hline 6 & - & 55 & MP4 & 2,6 & 3,6 & 0,9 & no & no & no & no & no & no & no \\
\hline 6 & - & 56 & MP4 & 1,2 & 2 & 0,3 & no & $\mathrm{si}$ & no & no & no & no & no \\
\hline 6 & - & 57 & MP4 & 1,1 & 1,9 & 0,3 & no & no & no & no & no & no & no \\
\hline 7 & $360^{\circ}$ & 58 & MP1 & 2,2 & 2,5 & 0,5 & no & $\mathrm{si}$ & no & no & no & no & no \\
\hline 7 & $360^{\circ}$ & 59 & MP1 & 2,1 & 1,8 & 0,4 & no & si & no & no & no & no & no \\
\hline 7 & $360^{\circ}$ & 60 & MP1 & 0,9 & 1,6 & 0,4 & no & si & no & no & no & no & no \\
\hline 7 & $360^{\circ}$ & 61 & MP1 & 1 & 1,4 & 0,3 & no & $\mathrm{si}$ & no & no & no & no & no \\
\hline 7 & $360^{\circ}$ & 62 & MP1 & 1,3 & 0,9 & 0,1 & no & $\mathrm{si}$ & no & no & no & no & no \\
\hline 7 & $360^{\circ}$ & 63 & MP1 & 1,1 & 0,6 & 0,2 & no & $\mathrm{si}$ & no & no & no & no & no \\
\hline 7 & $360^{\circ}$ & 64 & MP2 & 1,9 & 2,7 & 0,7 & si & $\mathrm{si}$ & no & no & no & no & no \\
\hline 7 & $360^{\circ}$ & 65 & MP2 & 1,9 & 2,2 & 0,3 & no & no & no & no & no & no & no \\
\hline 7 & $360^{\circ}$ & 66 & MP2 & 1,4 & 1,3 & 0,3 & no & no & no & no & no & no & no \\
\hline 7 & $360^{\circ}$ & 67 & MP2 & 1,6 & 1 & 0,3 & no & $\mathrm{si}$ & no & no & no & no & no \\
\hline 7 & $360^{\circ}$ & 68 & MP2 & 1,2 & 1 & 0,1 & no & no & no & no & no & no & no \\
\hline 7 & $360^{\circ}$ & 69 & MP2 & 1,4 & 0,6 & 0,4 & no & no & no & no & no & no & no \\
\hline 7 & $360^{\circ}$ & 70 & MP3 & 1,9 & 2,6 & 0,6 & si & $\mathrm{si}$ & no & no & no & no & no \\
\hline 7 & $360^{\circ}$ & 71 & MP3 & 1,6 & 2,6 & 0,4 & si & $\mathrm{si}$ & no & no & no & no & no \\
\hline 7 & $360^{\circ}$ & 72 & MP3 & 1,6 & 1 & 0,4 & si & $\mathrm{si}$ & no & no & no & no & no \\
\hline 7 & $360^{\circ}$ & 73 & MP3 & 1,4 & 0,9 & 0,3 & si & $\mathrm{si}$ & no & no & no & no & no \\
\hline 7 & $360^{\circ}$ & 74 & MP3 & 1 & 1,3 & 0,2 & si & $\mathrm{si}$ & no & no & no & no & no \\
\hline 7 & $360^{\circ}$ & 75 & MP3 & 0,8 & 1,3 & 0,4 & si & $\mathrm{si}$ & no & no & no & no & no \\
\hline 7 & $360^{\circ}$ & 76 & MP4 & 2,3 & 2,4 & 0,5 & no & $\mathrm{si}$ & $\mathrm{si}$ & si & no & no & no \\
\hline 7 & $360^{\circ}$ & 77 & MP4 & 1,5 & 2,4 & 0,4 & no & $\mathrm{si}$ & si & si & no & no & no \\
\hline 7 & $360^{\circ}$ & 78 & MP4 & 1,4 & 1,2 & 0,4 & no & $\mathrm{si}$ & $\mathrm{si}$ & si & no & no & no \\
\hline 7 & $360^{\circ}$ & 79 & MP4 & 1,3 & 1 & 0,2 & no & $\mathrm{si}$ & $\mathrm{si}$ & si & no & no & no \\
\hline 7 & $360^{\circ}$ & 80 & MP4 & 0,9 & 1,6 & 0,2 & no & $\mathrm{si}$ & $\mathrm{si}$ & si & no & no & no \\
\hline 7 & $360^{\circ}$ & 81 & MP4 & 1,4 & 0,6 & 0,3 & no & $\mathrm{si}$ & $\mathrm{si}$ & si & no & no & no \\
\hline 8 & $428^{\circ}$ & 82 & MP5 & 5,7 & 4,2 & 1,2 & si & no & no & no & no & $\mathrm{si}$ & no \\
\hline 8 & $428^{\circ}$ & 83 & MP5 & 5,4 & 4 & 0,6 & no & no & no & no & no & no & no \\
\hline 8 & $428^{\circ}$ & 84 & MP1 & 6,2 & 2,8 & 1,2 & no & $\mathrm{si}$ & no & si & no & $\mathrm{si}$ & no \\
\hline 8 & $428^{\circ}$ & 85 & MP1 & 4,4 & 3,7 & 0,9 & no & $\mathrm{si}$ & no & no & no & no & no \\
\hline 8 & $428^{\circ}$ & 86 & MP2 & 7,4 & 3,2 & 1,3 & si & no & no & no & no & no & no \\
\hline 8 & $428^{\circ}$ & 87 & MP2 & 4,5 & 4,4 & 1 & si & no & no & no & no & no & no \\
\hline
\end{tabular}




\begin{tabular}{|c|c|c|c|c|c|c|c|c|c|c|c|c|c|}
\hline 8 & $428^{\circ}$ & 88 & MP4 & 5,7 & 3,6 & 1,7 & no & si & no & no & no & no & no \\
\hline 8 & $428^{\circ}$ & 89 & MP4 & 4,9 & 3,1 & 1,4 & no & si & no & no & no & no & no \\
\hline 8 & $428^{\circ}$ & 90 & MP5 & 6,8 & 3,1 & 1,7 & no & si & no & no & no & no & no \\
\hline 8 & $428^{\circ}$ & 91 & MP5 & 4,2 & 3,1 & 1,2 & no & no & no & no & no & no & no \\
\hline 9 & $670^{\circ}$ & 92 & MP1 & 4,6 & 3,5 & 0,5 & no & si & $\mathrm{si}$ & no & $\mathrm{si}$ & no & no \\
\hline 9 & $670^{\circ}$ & 93 & MP1 & 3,5 & 4,4 & 1,2 & no & si & $\mathrm{si}$ & si & no & si & no \\
\hline 9 & $670^{\circ}$ & 94 & MP1 & 2,8 & 4,2 & 1,3 & no & si & $\mathrm{si}$ & no & $\mathrm{si}$ & si & no \\
\hline 9 & $670^{\circ}$ & 95 & MP1 & 3,8 & 2 & 0,9 & no & si & $\mathrm{si}$ & si & $\mathrm{si}$ & si & no \\
\hline 9 & $670^{\circ}$ & 96 & MP2 & 5 & 3,3 & 0,5 & no & si & no & no & no & no & no \\
\hline 9 & $670^{\circ}$ & 97 & MP2 & 3 & 4,2 & 0,7 & no & si & no & no & no & no & no \\
\hline 9 & $670^{\circ}$ & 98 & MP2 & 3,6 & 2,9 & 0,9 & no & si & no & no & no & no & no \\
\hline 9 & $670^{\circ}$ & 99 & MP2 & 4,7 & 2,1 & 0,7 & no & si & no & no & no & no & no \\
\hline 9 & $670^{\circ}$ & 100 & MP4 & 5 & 2,6 & 0,9 & no & si & $\mathrm{si}$ & si & no & no & no \\
\hline 9 & $670^{\circ}$ & 101 & MP4 & 3,6 & 3,8 & 1,2 & no & si & no & no & no & no & no \\
\hline 9 & $670^{\circ}$ & 102 & MP4 & 3,7 & 3,3 & 1,1 & no & si & no & no & no & no & no \\
\hline 9 & $670^{\circ}$ & 103 & MP4 & 2,3 & 4,7 & 0,7 & no & si & no & no & no & no & no \\
\hline 10 & $274^{\circ}$ & 104 & MP5 & 5,5 & 3,6 & 1,4 & no & si & no & no & no & no & no \\
\hline 10 & $274^{\circ}$ & 105 & MP2 & 8,2 & 3,7 & 2,9 & no & no & no & no & no & no & no \\
\hline 10 & $274^{\circ}$ & 106 & MP4 & 8,5 & 3,7 & 1,7 & no & no & no & no & no & no & no \\
\hline 10 & $274^{\circ}$ & 107 & MP5 & 5,6 & 6,5 & 1,6 & no & no & no & no & no & no & no \\
\hline 10 & $274^{\circ}$ & 108 & MP1 & 4,7 & 6,7 & 2 & no & no & no & no & no & no & no \\
\hline 11 & $310^{\circ}$ & 109 & MP5 & 4 & 5,1 & 1,1 & si & si & no & no & no & no & no \\
\hline 11 & $310^{\circ}$ & 110 & MP5 & 3,3 & 5,5 & 1,2 & no & si & no & no & no & no & no \\
\hline 11 & $310^{\circ}$ & 111 & MP5 & 5,2 & 4 & 1,5 & si & si & no & no & no & no & no \\
\hline 11 & $310^{\circ}$ & 112 & MP3 & 4,4 & 4,1 & 1,1 & si & no & $\mathrm{si}$ & si & $\mathrm{si}$ & no & no \\
\hline 11 & $310^{\circ}$ & 113 & MP3 & 4,3 & 3 & 1 & si & no & no & no & no & no & no \\
\hline 11 & $310^{\circ}$ & 114 & MP3 & 4,3 & 4,9 & 1,3 & no & no & $\mathrm{si}$ & si & $\mathrm{si}$ & si & no \\
\hline 11 & $310^{\circ}$ & 115 & MP3 & 5,4 & 6,5 & 2,4 & si & no & $\mathrm{si}$ & si & no & no & no \\
\hline 11 & $310^{\circ}$ & 116 & MP3 & 6,5 & 6,9 & 2,8 & no & no & $\mathrm{si}$ & si & $\mathrm{si}$ & si & no \\
\hline 11 & $310^{\circ}$ & 117 & MP3 & 6,5 & 6,4 & 1,2 & si & no & no & no & no & si & no \\
\hline 11 & $310^{\circ}$ & 118 & MP4 & 4,6 & 3,7 & 0,9 & no & si & $\mathrm{si}$ & si & no & si & no \\
\hline 11 & $310^{\circ}$ & 119 & MP4 & 5,3 & 5,7 & 1,3 & no & si & no & no & no & no & no \\
\hline 11 & $310^{\circ}$ & 120 & MP4 & 6,1 & 3,5 & 1,3 & no & si & no & no & no & no & no \\
\hline 12 & $312^{\circ}$ & 121 & MP5 & 6,2 & 3,9 & 1,7 & si & no & no & no & no & no & no \\
\hline 12 & $312^{\circ}$ & 122 & MP5 & 3,5 & 3,9 & 0,6 & si & no & no & no & no & no & no \\
\hline 12 & $312^{\circ}$ & 123 & MP5 & 2,7 & 3 & 1 & si & no & no & no & no & no & no \\
\hline 12 & $312^{\circ}$ & 124 & MP5 & 4,4 & 3,2 & 1,2 & si & si & no & no & no & no & no \\
\hline 12 & $312^{\circ}$ & 125 & MP5 & 4,7 & 2,6 & 1,7 & si & si & no & no & no & no & no \\
\hline
\end{tabular}

Referencias: $\mathrm{T}^{\circ}$ : Temperatura; Lar.: Largo; Anc.: Ancho; Esp.: Espesor; Lust.: Lustre; MP: Materia Prima; Rug.: Rugosidad; Hoy.: Hoyuelos; Agr.: Agrietamientos; Esc.: Escamaciones. Pat.: Pátina 